\title{
Secretos del Estante: Elementos para la descripción bibliográfica del Libro Antiguo
}

\section{Idalia García Aguilar}
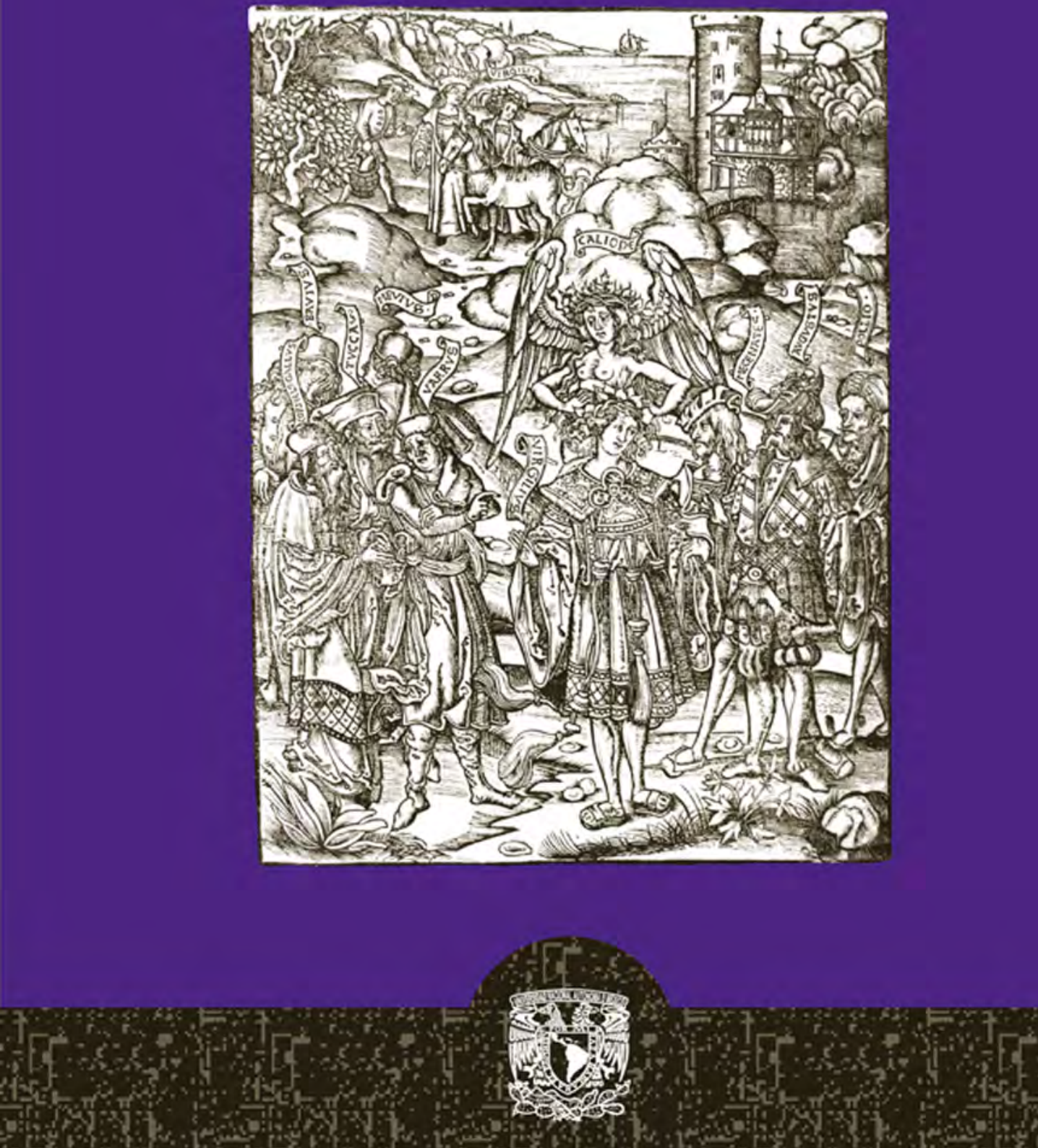


\section{La presente obra está bajo una licencia de:}

\section{http://creativecommons.org/licenses/by-nc-sa/3.0/deed.es MX}

\section{Atribución-No Comercial-Licenciamiento Reciproco 3.0 Unported}

Eres libre de:

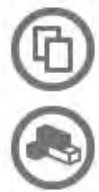

copiar, distribuir y comunicar públicamente la obra

hacer obras derivadas

Bajo las condiciones siguientes:

Atribución - Debes reconocer la autoría de la obra en los términos

especificados por el propio autor o licenciante.

No comercial - No puedes utilizar esta obra para fines comerciales.

Licenciamiento Reciproco - Si alteras, transformas o creas una obra a

partir de esta obra, solo podrás distribuir la obra resultante bajo una licencia

igual a ésta.

\section{Esto es un resumen fácilmente legible del: texto legal (de la licencia completa)}

\section{En los casos que sea usada la presente} obra, deben respetarse los términos especificados en esta licencia.

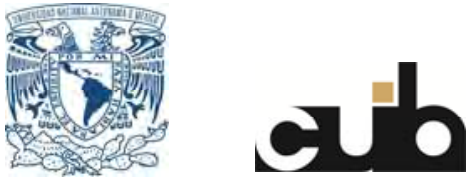


Secretos del estante: elementos para la descripción bibliográfica del libro antiguo 
COLECCIÓN

SISTEMAS BIBLIOTECARIOS DE INFORMACIÓN Y SOCIEDAD Centro Universitario de Investigaciones Bibliotecológicas 


\section{Secretos del estante: elementos para la descripción bibliográfica del libro antiguo}

\section{Idalia García Aguilar}

Universidad Nacional Autónoma de México 2011 


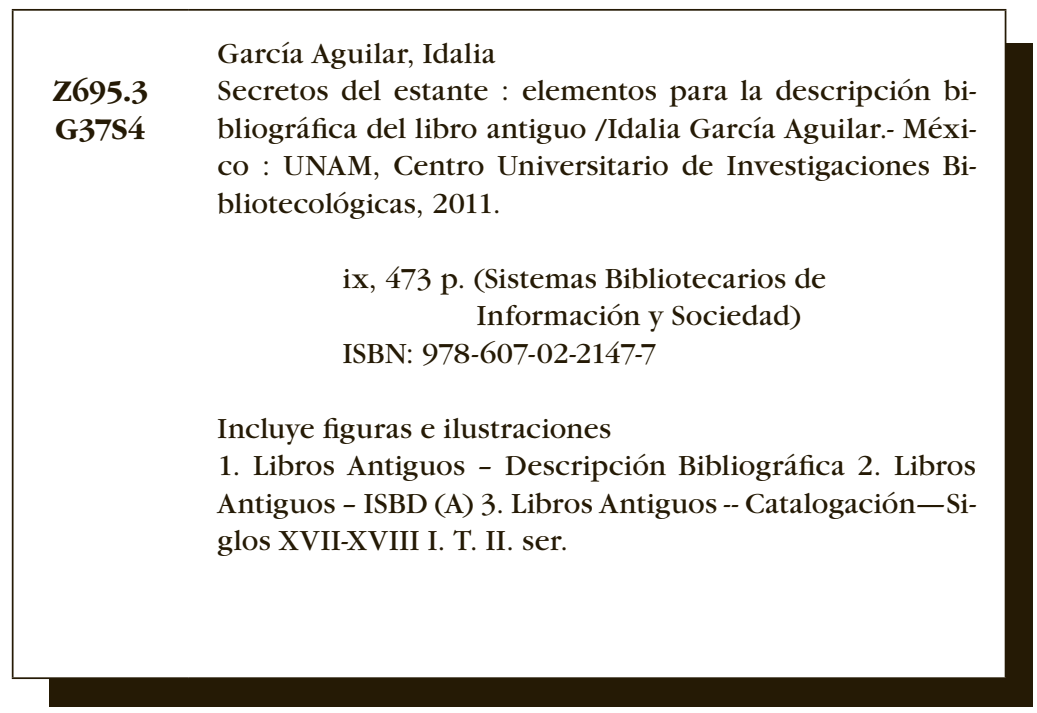

Diseño de portada: Mario Ocampo Chávez

Imagen de portada: Marón Plubio Virgilio. Opera Vergiliana docte \& familiariter exposita: docte quidem Bucolica: \& Georgica a Seruio Donato Mancinello: \& Probo nuper addito: cum adnotationibus Beroaldinis. Aeneis vero ab ijsdem praeter Mancinellum \& Probum \& ab Augustino Datbo in eius principio: opusculorum praeterea quaedam ab Domitio Calderino. Familiariter vero omnia tam opera quam opuscula ab Iodoco Badio Ascensio... Lugduni: ab Jacobo Sachon 1517. Grabado en h.2r. Biblbioteca Eusebio Francisco Kino 17134.

Primera Edición 2011

DR (C) Universidad Nacional Autónoma de México

Ciudad Universitaria, 04510, México D.F.

Impreso y hecho en México

ISBN: 978-607-02-2147-7 


\section{Índice}

\section{LIMINAR}

Pedro Ángeles . . . . . . . . . . . . . . . . . . . ix

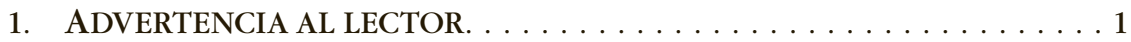

2. INTRODUCCIÓN A LA PROBLEMÁTICA

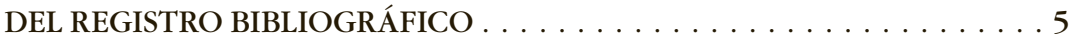

2.1 Las aportaciones de la Bibliografía Material . . . . . . . . 20

3. LA IMPORTANCIA DE LA DESCRIPCIÓN BIBLIOGRÁFICA

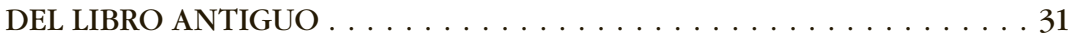

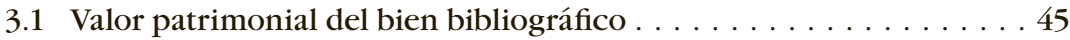

4. REPRESENTACIÓN BIBLIOGRÁFICA DEL LIBRO ANTIGUO EN MÉXICO . . . . . . . . . . . . . . . . . . . . . . . 57

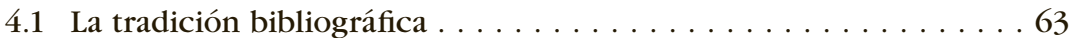

4.2 Análisis de modelos bibliográficos y catalográficos . . . . . . . . . 77

5. LA MANUFACTURA DE UN LIBRO ANTIGUO . . . . . . . . . . . . . 173

5.1 Un aspecto previo a considerar: edición, emisión y estado . . . . . 204

6. CONOCER PARA DESCRIBIR:

LA ESTRUCTURA MATERIAL DEL LIBRO ANTIGUO . . . . . . . . . 211

6.1 La descripción bibliográfica: el valor textual . . . . . . . . . . . . 214

a) La identificación previa: descripción breve de un material . . 217

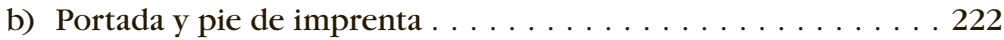

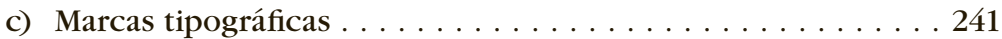

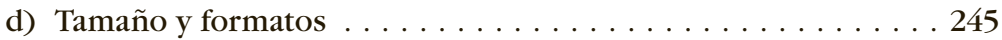

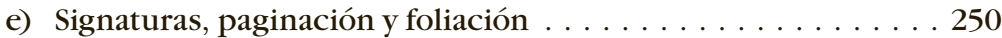

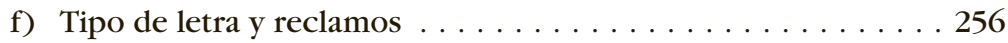

g) Los elementos decorativos . . . . . . . . . . . . . . 261

h) Relación del contenido de la obra: los preliminares y el texto . 271

6.2 La descripción bibliográfica del ejemplar: el valor patrimonial . . 291

i) Marcas de fuego, ex libris, y sellos . . . . . . . . . . . . . . 294

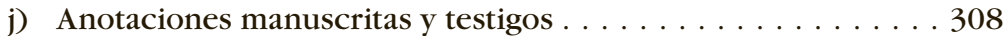

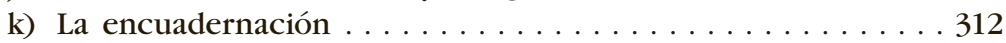


1) El estado de conservación . . . . . . . . . . . . . . . . . 319

m) Otros datos relevantes . . . . . . . . . . . . . . . . . 322

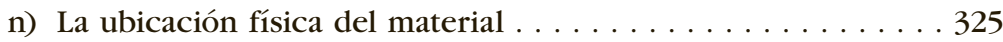

o) Referencias bibliográficas y otros ejemplares . . . . . . . 328

7. PROPUESTA PARA LA DESCRIPCIÓN BIBLIOGRÁFICA

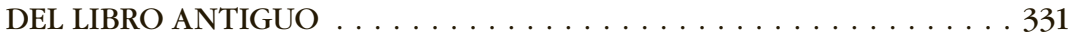

7.1 Modelos de descripción: Siglo XVII _ . . . . . . . . . . . . . . 337

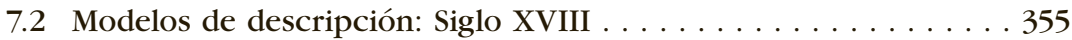

8. INTERPRETACIONES DE LA NORMA ISBD(A)

Cristina Herrero Pascual . . . . . . . . . . . . . . . . . . . . . . 375

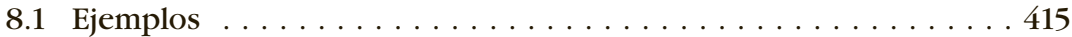

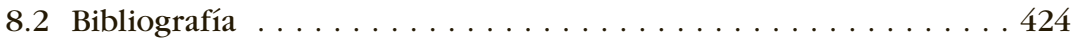

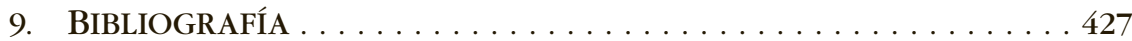

10. FigurAS E ILUSTRACIONES . . . . . . . . . . . . . . . . . . . . 473 


\section{Dedicatoria}

Para el Guisante, porque tu pérdida representó el más duro golpe que be recibido en la vida, pero me mostró el universo de posibilidades que comparto con Toni; especialmente porque sin tu pérdida boy no disfrutaríamos juntos de la sonrisa de la Aceitunica. Ella es lo mejor que bemos becho juntos. Este libro es especialmente para ti, mi pequeña Andrea.

Para todos esos viejos amigos que me ban enseñado que a pesar del polvo y el olvido, entre sus páginas existe todavía una batalla pendiente por librar.

Para el Padre Pancho López, S.I., y para Leticia Ruiz, por haberme dado la oportunidad de vivir y aprender en el laberinto de la Biblioteca Kino. Gracias también a todos los miembros de la Compañía de Jesús en México, por haber mostrado otro universo de conocimiento. Gracias a lo que me enseñaron puedo decir sin empacho que nunca se sabe lo suficiente.

Para Manuel de Santiago; sin tus ideas, "nuestra" cruzada perdería completamente el sentido. Ojalá pudiésemos contagiar de tu entusiasmo a todos.

Para Pedro Ángeles, Ramón Aureliano y Genaro Lamarca, sin vuestra lectura no bubiese sido fácil volver sobre mis pasos y no perderme.

Para Maricruz, Gina, Nacho, Ana Rita, José, Thalía, Alberto, Diego, Clive, Pedro, Teresita y Bolfy; porque sin ustedes es difícil seguir creyendo en un mundo mejor.

Para Dulce, no habría sido posible realizar este librito sin tu apoyo incondicional y tu permanente paciencia con el desastre de mi cabeza. Un caos reflejado siempre en el cubículo, al que más de una vez pusiste orden y concierto.

Para la Pulga, porque sigue ronroneando en mi barriga.

Gracias a todos por dejarme compartir este secreto. 



\section{Liminar}

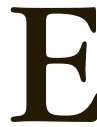

ntre las pinturas que se conservan en lo que fuera el Antiguo Convento de San Francisco de Cuernavaca existe una obra singular que seguramente se integró a su patrimonio en época relativamente reciente, pues ninguna relación directa guarda con la orden de los frailes menores, quienes fundaron dicho establecimiento entre los años 1525-1529: se trata de un lienzo con la efigie de Fray Juan de Grijalva ${ }^{i}$ (1580-1638), cronista novohispano, a quién se recuerda principalmente por su célebre Crónica de la orden de N.P.S. Agustín en las provincias de la Nueva España en cuatro edades, desde el año de 1533 basta el de 1592,ii obra que viera la imprenta por primera ocasión el año de 1624 y que resulta indispensable compendio del acontecer de la provincia del Santísimo Nombre de Jesús durante el siglo de la primera evangelización.

i Retrato de fray Juan de Grijalva, siglo XVII, óleo sobre tela, 184 x $107 \mathrm{~cm}$. Pinacoteca de la Catedral de Nuestra Señora de la Asunción, Cuernavaca

ii Fray Juan de Grijalva, Crónica de la orden de N. P. S. Agustín en las provincias de la Nueva España en cuatro edades, desde el año de 1533 hasta el de 1592, México, Porrúa, 1985. Biblioteca Porrúa, 85. 
El retrato del padre Grijalva llama la atención en más de un sentido: su factura construye una magnífica representación del célebre cronista agustino, impecable en su plástica, aunque recurre en su elaboración a muchas de las convenciones novohispanas del género del retrato.

La austera figura de Grijalva aparece de pie, portando el hábito negro tradicional a su Orden. Mira al espectador en posición de tres cuartos mientras frente a una mesa entinta su pluma disponiéndose a escribir los folios de lo que podría ser alguna de sus obras. Entre los objetos dispuestos sobre esa mesa descansan otros implementos de escritura y unos libros sobre los que halla un birrete que sin duda complementa el carácter de hombre letrado que caracterizó a quien se representa, completándose el mobiliario pintado en el lienzo con un atril y un librero cuyos estantes exhiben los becerros que encuadernan ejemplares de la Biblia y obras de los padres de la Iglesia.

Destaca al extremo inferior izquierdo una cartela, fiel testimonio que permite a lo escrito completar los efectos visuales de la representación, en donde se lee:

El R.P.F. Juan / de Grixalua, $\mathrm{M}^{\mathrm{r}}$. En $\mathrm{S}^{\mathrm{da}}$. / Teolg ${ }^{\mathrm{a}}$. Cronifta de / Nuestra Sagrada Reli/gion Confe for del Señor / Marques de Cadereita Virrey de efta Nueva / España, Colegial, Lector y Rector de efte Colegio

es decir, el Colegio Máximo de San Pedro y San Pablo, lo que permite considerar la hipótesis de que ese pudo ser el sitio al que originalmente perteneció el retrato, y donde sería exempla para la comunidad agustiniana al ser la efigie de Grijalva una fórmula simbólica del fraile letrado que se entrega a la sagrada sabiduría. Para ello, el anónimo pintor pudo plantear como campo natural de su representación una celda conventual, pero sugirió más bien un entorno de libros, que antes, como ahora, serían símbolos de saber y conocimiento.

Fue con ese prestigio que la sociedad novohispana, ya a título individual y sobre todo entre sus corporaciones religiosas, procuró con deliberado esmero la formación de bibliotecas que en más de una ocasión constituyeron fondos de alcances sorprendentes. Y esos libros eran lo mismo fruto del intenso tráfico comercial con ultramar, como 
se mira desde la perspectiva de algunos documentos entre los citados por Francisco Fernández del Castillo en su clásica obra, ${ }^{\text {iii }}$ o bien de la intensa actividad de las imprentas novohispanas que desde el siglo XVI iniciaron una tradición bibliográfica cuya labor sumó esfuerzos en la construcción de la riqueza patrimonial que constituyen las bibliotecas y el libro antiguo, formada en México desde tiempos novohispanos.

Más allá de las ciencias de la información, desde las otras disciplinas que conforman a las humanidades y las ciencias sociales, ¿cómo miramos la manera en que a lo largo de la historia de nuestro país esa riqueza ha sufrido de expolios, maltrato y olvido?, ¿qué tan conscientes somos de que los fondos bibliográficos antiguos constituyen un extraordinario patrimonio?, ¿cómo imaginamos un registro bibliográfico que sea mecanismo de control patrimonial y al mismo tiempo permita representar todo el valor cultural que subyace en cada volumen del fondo antiguo?

Pareciera que tras una tradición de abolengo, donde brillan nombres como los de Juan José de Eguiara y Eguren, Joaquín García Icazbalceta o Toribio Medina, Agustín Millares Carlo o Yhmoff Cabrera, o bien de instituciones como la Biblioteca Palafoxiana, que ya es museo y disfruta un nombramiento dentro del proyecto Memoria del Mundo, ${ }^{\text {iv }}$ tales preguntas no tendrían sentido, pero a la hora de leer el libro que el amable lector tiene entre las manos, sin duda se dará cuenta de que el esfuerzo realizado por Idalia García no sólo cobra sentido, sino que entraña inestimable valor.

Así lo creo porque quien ha estado cerca de procesos de catalogación de otro tipo de fondos patrimoniales, apreciará con claridad el valor derivado de esa encomiosa y aparentemente sencilla tarea, que entraña en su justa medida la manera como apreciamos el legado de nuestra herencia cultural.

En un mundo donde la catalogación mira al ámbito de las redes mundiales, ¿cómo deben ser nuestras aportaciones a la sociedad del conocimiento y qué problemáticas multidimensionales e interdisciplinarias

iii Francisco Fernández del Castillo, Libros y libreros del siglo XVI, México, Archivo General de la Nación, 1914.

iv Véase: http:/www.bpm.gob.mx. Consultada en febrero de 2007. 
encara esta inercia? Al adentrarse en este libro, también el lector apreciará una carta abierta y un llamado, no sólo a revisar las valiosas tradiciones formadas a partir de nuestra experiencia e historias institucionales, sino también a enfrentar las metodologías que, particularmente en el terreno del libro antiguo, pero que se pueden expandir al registro de toda obra con valor patrimonial, se desarrollan en el camino de modelos normalizados. Después de todo, nunca hay que olvidar que patrimonio es aquello que podemos responsablemente cuidar, procurar, organizar, describir, catalogar y estudiar, responsabilidad abierta para quienes tenemos parte, y habremos de esforzarnos en cumplir lo mejor posible esa compleja tarea.

En el prólogo a su Libra Astronómica y Filosófica, el sabio don Carlos de Sigüenza y Góngora escribía con tino sobre la fortuna de formar y escribir un libro:

No sé si es más veloz en idear y formar un libro que en olvidarlo. Encomiéndalo como mucho a la gaveta de un escritorio, y éste le parece bastante premio de su trabajo. Dichoso puede llamarse el papel suyo que esto consigue, porque otros, después de perfectos, o de sobre la mesa se los llevaron curiosos o murieron rotos en las manos a que debían el ser. ${ }^{\mathrm{v}}$

Con este libro que habla de libros, tenemos la oportunidad de reflexionar ampliamente desde la trinchera personal, y esperemos, desde la que forjan nuestras instituciones, ya no sólo sobre la importancia atribuible a nuestros libros antiguos y las bibliotecas depositarias de ellos, sino sobre todo, atendiendo más allá de descripciones "casi facsimilares", construir un registro que reconozca en estos objetos todo su valor patrimonial. La puerta está abierta, bienvenidos.

Pedro Ángeles Jiménez

v Carlos de Sigüenza y Góngora, Libra astronómica y filosófica, México, prólogo. 


\section{Advertencia al lector}

B enévolo lector, ponemos ante ti esta humilde obrita que no pretende ser exhaustiva ni mucho menos absoluta. Tampoco creemos que represente un círculo cerrado en el tema de la descripción del libro antiguo. Estas líneas representan nuestra opinión sobre un tema que estimamos importante en la salvaguarda de bienes culturales, y que refiere a la inevitable tarea del registro e inventario de la riqueza cultural de un país. Sin duda, existen múltiples modelos de registro para estos objetos, que se han desarrollado en diversos momentos de la historia y proceden de distintas disciplinas. Sin embargo, consideramos que para aquellos que son singulares o más representativos por alguna característica, se requiere de la elaboración de un registro que contenga prácticamente toda la información necesaria para distinguir a un objeto de otro similar.

Esta circunstancia se presentará siempre que se trate del registro de un libro antiguo. Sabemos con certeza que varias bibliotecas pueden tener la edición de alguno de ellos, pero el ejemplar de cada cual siempre es distinto por la historia que ha recorrido y la cual testimonia. Nuestra intención primordial es mostrar cómo un registro bibliográfico es un instrumento viable para representar correctamente el valor cultural de un libro antiguo y, por tanto, puede también ser empleado como mecanismo de control patrimonial. Una tarea que se favorecería 
si eliminamos el empeñoso afán de querer registrar un libro antiguo como uno moderno para comprender a ambos en su justa medida e historicidad.

Ciertamente este trabajo requiere del conocimiento de la naturaleza material del libro antiguo, derivada necesariamente del proceso de producción empleado en el periodo comprendido entre los siglos XVI y XVIII. Nuestra valoración y preocupación por estos libros ha evolucionado gradualmente a lo largo de los años, pero siempre ha estado presente la realidad de su custodia institucional y la falta de conocimiento sobre el objeto, que resulta evidente constituyen el principal problema para garantizar a las generaciones venideras el conocimiento de esta parte de su legado cultural.

Cada libro me ha mostrado un universo de posibilidades de estudio y ha dejado la sensación de falta de un guía más aventajado en este territorio de conocimiento, que estuviese ahí siempre que se le necesitara. A falta de esta dirección, los propios libros antiguos y las lecturas de otros que nos precedieron han sido la brújula que orienta estas líneas. Es aquí cuando debo ofrecer mi gratitud a los miembros de la Compañía de Jesús en México, quienes me permitieron trabajar libremente con los libros antiguos bajo su custodia en la Biblioteca Eusebio Francisco Kino. Sin esta oportunidad no hubiese sido posible concretar este texto en el que volcamos una reflexión que nos preocupa.

Los avatares y vicisitudes que estos libros han sufrido a lo largo del tiempo en México, nos conducen a una terrible constatación: si los que hoy conservamos son el resultado de una historia truculenta de tránsitos y saqueos, entonces solamente podemos imaginar el tesoro que hubo en nuestras bibliotecas. Por eso nos sumamos al objetivo de Julián Martín Abad, queremos

mostrar los aspectos sobre los que conviene que tenga alguna noticia quien tome en las manos un ejemplar de una edición antigua y sienta la necesidad de conocerlo. De su conocimiento derivará el disfrute de ese objeto manufacturado, ciertamente singular. Conociéndolo podrá sentir en las mejores condiciones de ese testimonio (que ocupa una situación precisa en la historia de la transmisión de un determinado texto) o de ese 
documento (que igualmente puede ser más o menos esencial para una investigación de carácter bibliográfico o histórico). ${ }^{1}$

Al igual que muchas otras peticiones existentes en los libros antiguos, apelamos a tu benevolencia en la lectura de las líneas que componen este texto. Con ello queremos motivar tu sensibilidad hacia los pequeños detalles que hacen de cada uno de estos libros un testigo irrepetible del pasado y, por tanto, una herencia cultural que debemos preservar para el futuro. La salvaguarda de bienes culturales es una tarea permanentemente inconclusa y con estas palabras queremos recuperar una tradición bibliográfica que nuestro país ha dejado en el camino.

La revisión de estos libros antiguos — nunca han sido suficientesha mostrado la dificultad de construir generalidades en su representación. La diversidad de los modelos bibliográficos utilizados obliga a construir una propuesta metodológica para la representación del valor cultural de un libro antiguo. Confiamos en que su lectura logre recuperar esa tradición y vuelva a poner en la esfera de nuestras preocupaciones sociales la conservación de los libros antiguos.

Por ello, sólo esperamos que sea un trabajo digno de la investigación universitaria, y de una profunda convicción de que en cuanto más sepamos de estos materiales del pasado, más elementos tendremos para otorgarles su justo valor. De ello depende que podamos transmitir esta apreciación a otros, presentes y futuros. Los libros antiguos que hoy conservamos nos demandan esta atención y esta es nuestra manera de reconocerlos. Para cerrar, este texto se ha realizado con la localización y obtención de todos los que nos anteceden, para su lectura y análisis. Por eso también debe ser considerado un homenaje a todas aquellas personas, antiguas y modernas, que describieron, documentaron y analizaron el proceso de impresión de un libro antiguo.

Idalia García Ciudad de México (2010), Zaragoza y Sevilla (2006)

1 Julián Martín Abad. Los libros impresos antiguos. Valladolid: Universidad, 2004. p. 13. 



\title{
2. Introducción a la problemática del registro bibliográfico
}

\author{
Los libros deben tener dos cosas: \\ una que fuesen ciertos y otra que fuesen \\ polidos y muy bien bechos, y que el estudioso \\ se precie de tenellos tales. Pues de ser ciertos \\ le es gran provecho y ser polidos e muy bien \\ bechos da contento
}

Pedro de Medina, Regimiento de la navegación, fol. LVII v., Sevilla, $1563^{2}$

ctualmente, para la mayoría de los países, el mayor problema
de la salvaguarda del patrimonio cultural se encuentra en el
registro e inventario de los bienes conservados en numerosas instituciones, tanto públicas como privadas. Efectivamente, preservar para transmitir cualquier elemento del patrimonio cultural requiere como condición primordial el registro de sus características más esenciales. Sin embargo, el registro de un objeto cultural requiere también el conocimiento de la naturaleza de ese objeto. Esto es exactamente igual para cualquier objeto material al que se le reconozca un valor cultural específico, sea una escultura, un cuadro, un documento o un libro.

Todos estos objetos, que componen el universo del patrimonio cultural de cualquier sociedad, son registrados para protegerse jurídica e institucionalmente a largo plazo, pero también para poder ser transmitidos entre generaciones. No hay que olvidar que toda sociedad realiza en diferentes momentos de su historia procesos distintos

2 Citado por Manuel Rico y Sinobas. El arte del libro en España. Madrid: Editorial Escelicer, 1941. p. 262 
de valoración sobre su pasado. La premisa anterior significa que lo que nuestra generación considera valioso o relevante, podría no representar lo mismo para la generación siguiente.

Esta condición de la transmisión no elude en lo absoluto a la institución de custodia de la responsabilidad del registro de objetos de naturaleza cultural. Esta responsabilidad también conlleva formas de representación del objeto en instrumentos de control y de consulta, como lo son los catálogos bibliográficos. Para el caso concreto de los libros antiguos, sirve contextualizar esas formas de registro en los catálogos disponibles de las bibliotecas nacionales porque son estas instituciones, en la mayoría de los casos, las que deben marcar lineamientos de catalogación para las bibliotecas de un país.

De ahí que sea pertinente observar cómo se registran - y por tanto representan - los libros antiguos en las bibliotecas nacionales de la región latinoamericana. Para una revisión que nos permita definir las formas de representación, hemos seleccionado y buscado la obra de Nicolás Antonio, la Bibliotheca Hispana Vetus en cualquiera de sus ediciones y tomos. De esta obra encontramos registros de la edición de 1788 en Argentina, ${ }^{3}$ Colombia ${ }^{4}$ y Perú, $^{5}$ y en Chile ${ }^{6}$ encontramos registrada la de 1696. En Brasil, ${ }^{7}$ Panamá $^{8}$ y República Dominicana, ${ }^{9}$ no hemos encontrado esta obra en concreto, pero sí otros libros antiguos que sirven para esta reflexión. En la de Bolivia ${ }^{10}$ no hemos encontrado información de este tipo, pero indican que cuentan con una "Sección

3 Información disponible en http://www.bibnal.edu.ar/ [Consulta: marzo de 2006]

4 Información disponible en http://www.bibliotecanacional.gov.co/ [Consulta: marzo de 2006]

5 Información disponible en http://www.bnp.gob.pe/portalbnp/ [Consulta: marzo de 2006]

6 Información disponible en http://www.dibam.cl/biblioteca_nacional/home. asp Consulta: marzo de 2006]

7 Información disponible en http://www.bn.br/Script/index.asp [Consulta: marzo de 2006]

8 Información disponible en http://www.binal.ac.pa/ [Consulta: marzo de 2006]

9 Información disponible en http://www.bnrd.gov.do/ [Consulta: marzo de 2006]

10 Información disponible en http://www.archivoybibliotecanacionales.org.bo/ bibliotecanacional/ [Consulta: febrero de 2009] 
Boliviana de Libros y Folletos". La condición de la búsqueda han sido los catálogos en línea disponibles en los portales institucionales.

En las otras bibliotecas nacionales de esta región que no cuentan en su sitio con un catálogo bibliográfico formal, ${ }^{11}$ hemos lanzado la búsqueda simple por la palabra Bibliotbeca de forma semejante a la que realizaríamos en cualquier buscador de la red. La búsqueda no ha reportado registros en Cuba ${ }^{12}$ y en El Salvador. ${ }^{13}$ Las bibliotecas nacionales de Uruguay, ${ }^{14}$ Costa Rica,${ }^{15}$ Paraguay, ${ }^{16}$ Nicaragua, ${ }^{17}$ tienen portal pero no acceso a un catálogo. No hemos encontrado un portal propio para la Biblioteca Nacional de Ecuador, ${ }^{18}$ mientras que los portales de las bibliotecas de Guatemala, ${ }^{19}$ Honduras $^{20}$ a la fecha de nuestra revisión, se encontraban en desarrollo. El portal de la biblioteca de Venezuela no ha permitido realizar la consulta en línea.

Efectivamente hay que considerar la diferencia que existe entre la representación catalográfica y bibliográfica de un libro antiguo. Para

11 Es decir, que permita una búsqueda de la información por campos y áreas de la descripción, e incluso por operadores booleanos.

12 Información disponible en http://www.bnjm.cu/bnjm/espanol/index_e.asp [Consulta: marzo de 2006]. Hemos encontrado registros de libros antiguos relacionadas con el homenaje a Cervantes.

13 Información disponible en http://www.binaes.gob.sv/ [Consulta: marzo de 2006]

14 Información disponible en http://www.bibna.gub.uy/ [Consulta: marzo de 2006]

15 Información disponible en http://www.abinia.org/costarica/ [Consulta: marzo de 2006]

16 Información disponible en http://www.bibliotecanacional.org/Bienvenida.ht$\mathrm{ml}$ [Consulta: febrero de 2009]

17 Información disponible en http://www.abinia.org/nicaragua/ [Consulta: febrero de 2009]

18 Información disponible en http://cce.org.ec/index.php?action=seccion [Consulta: marzo de 2006]. La página se encuentra relacionada con la Casa de la Cultura Ecuatoriana Benjamín Carrión

19 Información disponible en http://www.biblionet.edu.gt/ [Consulta: marzo de 2006]. Este portal se encuentra relacionado con el del Ministerio de Cultura y Deportes.

20 Información disponible en http://www.binah.gob.hn/ [Consulta: febrero de 2009] 
la primera bastaría con identificar una edición antigua como parte de la colección de una biblioteca, mientras que para la segunda es importante identificar de cuál edición, emisión o estado se trata; así como qué valores textuales e históricos caracterizan a esa edición. Sobre estas consideraciones podemos identificar la representación catalográfica del libro antiguo en los registros recuperados.

Dado que nuestro interés no es analizar las particularidades del registro catalográfico — ni la normativa sobre la que se soporta-, nuestra mirada se enfocará sobre tres elementos concretos que consideramos son los de mayor interés para el trabajo bibliográfico con este tipo de impresos. Nos referimos al título y pie de imprenta (datos puntuales de las portadas), la forma de la descripción física (reflejo de la estructura del libro antiguo), y la consideración de los elementos históricos (aspectos que otorgan unicidad a cada objeto).

En los registros recuperados sobre libros antiguos primeramente observamos que la información se organiza como lo indican las modernas normas bibliotecarias. Por esa normativa (descripción internacional normalizada para libros antiguos: ISBD A), parte de los títulos se omitirá pero se mantendrá en el idioma del material catalogado, aun cuando no se indique siempre que parte del título ha sido omitido. ${ }^{21}$ Los pies de imprenta también se registran como suelen aparecer en las portadas de libros antiguos, en su forma e idioma original. De lo que corresponde a la descripción física solamente encontraremos un ejemplo de registro de signaturas en su forma abreviada para la obra de Nicolás Antonio en concreto, ${ }^{22}$ y en los demás registros se realiza esa descripción en la forma catalográfica que conocemos: por páginas.

21 Dos condiciones que son recomendadas por la norma internacional que permite el uso de los corchetes para este efecto. Cfr. International Federation of Library Association. ISBD (A). Descripción bibliográfica internacional normalizada para publicaciones monográficas antiguas. Madrid: ANABAD: Arco Libros, 1993. pp. 13-15, 23 y 36.

22 Hemos confirmado en esos mismos catálogos que hay registros de libros antiguos que si tienen indicadas las signaturas y otros que no lo tienen. Lo cual es indicativo de la ausencia de una política de catalogación en la biblioteca, ya que las normas internacionales han considerado la inclusión de este dato como opcional en la descripción catalográfica. 
El caso concreto de los resultados recuperados en la Biblioteca Nacional de Panamá nos conduce a pensar que en la catalogación algunos facsímiles podrían pasar por libros antiguos para un lector no muy avispado. Por ejemplo, encontramos la obra Cigarrales de Toledo de Tirso de Molina como una edición impresa en 1621, cuando corresponde a una edición transcrita del siglo $\mathrm{XX} .^{23} \mathrm{Si}$ consultamos el mismo título, por ejemplo en un catálogo especializado, ${ }^{24}$ podremos ver estas diferencias de representación.

Es precisamente por esta relevancia relacionada con la valoración patrimonial del libro antiguo que se hace todavía más importante considerar en el registro a los elementos históricos que caracterizan a cada libro antiguo conservado. En la información recuperada de las bibliotecas latinoamericanas, cuatro de los siete registros catalográficos de libros antiguos incluyen algún dato de carácter patrimonial como la encuadernación, el estado de conservación, ex libris o anotaciones manuscritas.

De esta consideración patrimonial también se desprende la diversidad en la comprensión de los objetos custodiados - como un conjunto- y la denominación que la biblioteca hace de los mismos. En Guatemala, Colombia, Panamá y República Dominicana, la colección es designada como "fondo antiguo"; en Argentina, "fondo bibliográfico del Tesoro"; en Brasil, "obras raras"; en Cuba, "Fondos raros y valiosos"; en Venezuela, "Libros raros y manuscritos"; en Chile son "fondos históricos" 25 y en Perú "Colecciones especiales"; en Bolivia se denomina "Libros antiguos, raros y curiosos",26 en Ecuador, "Museo del Libro".

23 Los datos de la misma biblioteca de Panamá así lo confirman.

24 Hemos realizado la confrontación de los datos en el Catálogo Colectivo del Patrimonio Bibliográfico Español, disponible en http://www.mcu.es/ccpb/ccpbesp.html [Consulta: marzo de 2006]

25 Así son definidos en el catálogo mientras que en el portal son denominados Tesoros bibliográficos. Cfr. http://www.dibam.cl/biblioteca_nacional/Tesoros_bibliograficos.htm [Consulta: marzo de 2006]

26 Joaquín Loayza Valda. "La Biblioteca Nacional de Bolivia: su misión y objetivos en la realidad nacional y en información”. Proceedings 2o. Congreso Internacional de Bibliotecología, Documentación y Archivística (CIBDA), La Paz (Bolivia, 2003). p. 3. Texto disponible en http://eprints.rclis.org/archive/00001104/01/lapaz25.pdf [Consulta: noviembre de 2007] 
Por su parte El Salvador define a la colección como "libro antiguo" aunque declaran no poseer todavía un criterio definido para este concepto. ${ }^{27}$ En los portales de la biblioteca de Costa Rica y de Guatemala no se hace mención a este tipo de colecciones, y como habíamos indicado, Honduras y Paraguay no tienen portales. Apuntemos aquí que en la Biblioteca Digital Andina ${ }^{28}$ se encuentran denominados como incunables $^{29}$ dos ediciones del siglo XIX.

Estas formas de registro para los libros antiguos reflejan una comprensión del problema patrimonial y en consecuencia la construcción de un valor cultural específico. Las búsquedas en los portales de las bibliotecas nacionales nos proporcionan una idea cercana del conocimiento que se tiene en la región sobre un tema tan específico como el libro antiguo. En esa realidad regional podemos distinguir como excepción a las bibliotecas nacionales de Argentina, ${ }^{30}$ Chile, ${ }^{31}$ y Brasil,${ }^{32}$ las que además de poseer una comprensión patrimonial más definida, permiten acceder a algunos libros antiguos que han sido digitalizados.

Sin embargo esa misma comprensión del problema, como se deduce, es completamente diversa en aspectos puntuales como el empleo de conceptos, que se verán directamente reflejados en la descripción

27 Poseen la Colección Lambruschini, integrada por 6,000 obras impresas entre 1417 y 1800. Información extraída de la página http://www.binaes.gob.sv/origines.html [Consulta: marzo de 2006]

28 Puede consultarse en http://www.comunidadandina.org/bda/incunables.asp [Consulta: marzo de 2006] La comunidad Andina está conformada por Bolivia, Colombia, Ecuador, Perú y Venezuela

29 Nota curiosa, porque una de las participantes en este proyecto es precisamente la Biblioteca Nacional de Venezuela, la que por su información tiene idea de qué es un incunable. $C f r$. http://www.bnv.bib.ve/boton12.htm [Consulta: marzo 2006]

30 Biblioteca Nacional de la República de Argentina. Información disponible en http://www.cervantesvirtual.com/portal/BNA/index.shtml [Consulta: Febrero de 2009]

31 Memoria Chilena. Información disponible en http://www.memoriachilena.cl/ index.asp [Consulta: febrero de 2009]

32 Biblioteca Nacional sin Fronteras. Información disponible en http://www. bn.br/site/pages/bibliotecaDigital/bibsemfronteiras/index.html [Consulta: Febrero de 2009] 
catalográfica y en consecuencia en los valores reconocidos para estos libros, situación que resulta muy peculiar porque desde $1991,{ }^{33}$ se inició el proyecto de catalogación colectiva iberoamericana para las obras antiguas de los siglos XVI al XIX, conocido como Novum Regestrum, ${ }^{34}$ impulsado por ABINIA (Asociación de Estados Iberoamericanos para el Desarrollo de las Bibliotecas Nacionales de los Países de Iberoamérica).

Esta condición de trabajo compartido debería corresponderse, por un lado, con un número mayor de libros antiguos registrados, y por otro, con una catalogación basada en lineamientos internacionales que lograse proporcionar una idea común de representación del objeto bibliográfico que se trata. Por lo que hemos podido observar, esto no es así. Por el contrario, cada biblioteca latinoamericana parece entender una cosa distinta de las otras.

Tal diversidad de representación resulta todavía más llamativa porque para realizar ese catálogo colectivo se realizaron cursos de capacitación específicos, cuyos resultados deberían mostrar una idea compartida sobre las ediciones que se describen y los ejemplares de las mismas. Una tarea necesaria como basamento que finalmente se reflejaría en una adecuada descripción directamente en la red (el acceso se desarrolló en 2002). ${ }^{35}$

El resultado más lógico de tal proyecto compartido sería que todas las bibliotecas participantes en este catálogo ofrecieran la misma información bajo los mismos instrumentos, o cuando menos que las descripciones catalográficas se asemejaran a las realizadas en España. No hay que olvidar que este país, como parte de la comunidad iberoamericana,

33 María Cristina Guillén Bermejo. "Novum Regestrum, Catálogo Colectivo de impresos de los siglos XVI-XIX en las bibliotecas de Iberoamérica, España y Portugal". World Library and Information Congress: 70th IFLA General Conference and Council (22-27 de agosto de 2004, Buenos Aires, Argentina). Texto disponible en http://www.ifla.org/IV/ifla70/papers/074s-Bermejo.pdf [Consulta: marzo de 2006]

34 Catálogo Colectivo de Fondo Antiguo, siglos XV-XIX de la Asociación de Bibliotecas Nacionales de Iberoamérica [CD-ROM]. Madrid: Biblioteca Nacional de España: ABINIA, 1995.

35 María Cristina Guillén Bermejo. Op. cit. p. 7. 
es el que más ha invertido y apostado por la obtención de los resultados. Lo que observamos es precisamente lo contrario.

Esta misma tendencia de colaboración e intercambio manifiesta más resultados visibles en Europa y en Estados Unidos. En las instituciones bibliotecarias de esos países, nacionales o universitarias, notaremos otra comprensión del libro antiguo, que no necesariamente se verá reflejada en los trabajos de catalogación. ${ }^{36}$ Lo que difiere notablemente de la realidad latinoamericana es que la mayor parte de estos libros pueden recuperarse en catálogos colectivos o específicos ${ }^{37}$ y que el discurso de valoración patrimonial se ve mayormente representado en proyectos de digitalización ${ }^{38}$ o en exposiciones bibliográficas.

También la realidad de conocimiento es diferente porque en estas regiones, para el tema del libro antiguo, existen grupos de trabajo, formación profesional, investigaciones, publicaciones especializadas donde el trabajo bibliográfico con esos materiales ha desarrollado su propio camino y sus aportaciones, si bien esta realidad cognitiva se asemeja al anhelo de Octavio Paz sobre la democracia: no es perfecta pero cuando menos es incluyente. Sobre estos aportes y tendencias europeas y norteamericanas volveremos más adelante, porque desde nuestra perspectiva, las reflexiones de carácter bibliográfico son las que más contribuyen a la comprensión patrimonial de la problemática del registro de los libros antiguos.

Desde esta perspectiva es que analizaremos la realidad mexicana, que se enorgullece de la riqueza y variedad de su patrimonio cultural. Por lo mismo, la conservación de ese patrimonio ha sido una preocupación constante a lo largo de todo el siglo xx y de la cual se han derivado

36 Lo cierto es que a pesar de los esfuerzos que se derivan de la normalización internacional para el libro antiguo, esta descripción no presenta diferencias muy notables con la catalogación tradicional para monografías.

37 Cfr. Jean-Daniel Candaux. "Un problème européen: la localisation des livres anciens". La bibliographie materièlle, Gilles Barber [... et. al]; table ronde organiseé por le CNRS pars Jacques Petit. Paris: Éditions du Centre National de la Recherche Sientifique, 1983. p. 75-86

38 Por ejemplo Octavo Digital (http://www.octavo.com/) o Gallica (http://gallica. bnf.fr/), sólo ésta última de acceso gratuito. 
leyes de protección - tanto federales como estatales-, e instituciones especiales dedicadas a la conservación, estudio y difusión de los diversos elementos que componen esta riqueza cultural. Sin duda, estas acciones nacionales han recorrido mucho terreno y han posibilitado la salvaguarda de numerosos bienes culturales.

Este es el caso de los innumerables libros antiguos existentes en las bibliotecas mexicanas, tanto públicas como privadas, pero también conservados en otro tipo de colecciones, como las de archivos y museos. No hay que olvidar que

el patrimonio manuscrito, bibliográfico y documental de México alcanzó cifras insospechadas al cerrarse el ciclo de la dominación española. Ocurre al instante preguntar por el paradero de toda esa riqueza histórica acumulada en el transcurso de los tres siglos virreinales, en los repositorios oficiales, en las bibliotecas y archivos de los monasterios, catedrales, de las parroquias, de los colegios y de los seminarios diocesanos. A esto hay que responder que la dilapidamos de la manera más bochornosa como resultado de nuestras convulsiones político-sociales, de nuestra ignorancia, de nuestra imprevisión y falta de patriotismo. ${ }^{39}$

En efecto, la responsabilidad institucional de la custodia de bienes culturales no puede realizarse cabalmente si la institución no tiene noticia puntual de los bienes que se encuentran bajo su tutela. El registro de un bien cultural es el principio de toda política de protección patrimonial, sin el cual todo esfuerzo se vuelve inutil con el tiempo, tanto para la institución de custodia como para el beneficiario más directo de ese esfuerzo: la sociedad que hereda una riqueza cultural determinada. Esto es así de simple porque es imposible determinar acciones sin conocer con precisión la problemática patrimonial que se pretende abordar.

La problemática del registro de bienes culturales no es nueva y por lo tanto es una cuestión en la que se ha avanzado mucho, tanto nacional como internacionalmente. En la actualidad existen modelos de

39 Joaquín Fernández de Córdoba. Tesoros bibliográficos de México en los Estados Unidos. México: Editorial Cultura, 1959. p. 3 
registro en prácticamente todas las especialidades que trabajan con bienes de naturaleza cultural. Dichos modelos han ido evolucionando en función de necesidades de control patrimonial, pero también en función del desarrollo del conocimiento de las disciplinas que tienen por objeto de estudio a esos bienes culturales.

La bibliotecología no está exenta de esta particularidad. Sin embargo y a diferencia de lo que ocurre en otras latitudes, en nuestro país el pensamiento bibliotecológico ha ido relegando poco a poco el problema del registro de bienes bibliográficos de naturaleza cultural hasta dejar prácticamente desierta la reflexión sobre el registro de impresos antiguos. Definimos así de forma exclusiva a los libros que han sido producidos desde mediados del siglo XV hasta el siglo XIX. Es decir, una vez que ha terminado el periodo de los manuscritos y hasta que los procesos de producción industrial pueden ser caracterizados como modernos.

Esta condición es así porque no debemos olvidar que la comprensión teórico-práctica del libro antiguo deja fuera de su esfera a los impresos decimonónicos. Como explica Pedraza Gracia,${ }^{40}$ la discusión sobre conceptos tan complejos que definen a los impresos producidos antes del siglo XIX no está del todo cerrada y puede generar todavía más de una controversia, especialmente considerando que esos conceptos son fundamentales para definir a los mismos objetos como categorías jurídicas en la protección patrimonial.

En dicha protección debemos promover el reconocimiento de valores culturales en los impresos, más que la comprensión cronológica del problema patrimonial que necesariamente será una problemática permanente en el tiempo. La historia continúa y por tanto las leyes de protección por necesidad deberán ampliar sus condiciones para estar en posibilidad de proteger de manera adecuada lo que una sociedad valora culturalmente. Recordemos que cada sociedad valorará de forma distinta su pasado y los objetos que de éste hereda. De esa apreciación la norma jurídica definirá sus alcances, pero también sus limitantes.

40 Manuel Pedraza Gracia, Yolanda Clemente y Fermín de los Reyes. El Libro Antiguo. Madrid: Síntesis, 2003. p. 12 
Ciertamente, los límites cronológicos pueden ayudar a caracterizar formas materiales relacionadas con procesos históricos. Como un buen ejemplo de lo anterior podemos mencionar a los incunables. Empero, los especialistas en este terreno reconocen también que si bien pueden ser identificados como libros producidos en el siglo XV, las características por las que se identifica esta producción pueden encontrarse en otros materiales que no corresponden estrictamente al mismo periodo, sino a otro inmediatamente posterior, asunto cuya explicación se encuentra en la evolución de la técnica de impresión. ${ }^{41}$

Lo anterior nos conduce a establecer principios prioritarios para el tratamiento de impresos antiguos. El primero es su condición de impreso, lo que deja a los libros manuscritos para otro tipo de análisis correspondiente, pues su naturaleza los hace siempre únicos e irrepetibles y, por tanto, con otro tipo de problemática en su registro. El segundo es la estructura material que caracteriza a ese impreso y que no necesariamente se corresponde con un periodo cronológico limitado, ${ }^{42}$ aunque por esas mismas características estructurales podamos ubicarlo como una producción libresca que abarca poco más de tres siglos.

Efectivamente, el impreso producido de forma manual difiere en su estructura de los impresos producidos de forma industrial. Esta estructura que poseen los impresos antiguos forma parte de un proceso de producción que tiene características propias y en las cuales se pueden observar pocas modificaciones. Dicha estructura también caracteriza y diferencia a un impreso de otro, y como cualquier otra cosa, cumple con ciertas cualidades genéricas que no deben ser obviadas en el registro de las colecciones. Por ejemplo, pese a que las leyes de imprenta de su tiempo establecían la necesaria inclusión de ciertos documentos legales en la impresión de un libro, lo cierto es que no todos cumplían con estos requisitos.

41 Cfr. Julián Martín Abad. "Incunables, post-incunables y libros antiguos". Exposición virtual Civitas Librorum. La ciudad de los libros. Alcalá de Henares: Centro Virtual Cisneros de la Universidad, 2002. Texto disponible en http:// www.centrocisneros.uah.es/civitas/texto4.htm [Consulta: Abril de 2005]

42 Giuseppina Zappella. Il libro antico: struttura, tecniche, tipologie, evoluzione. Parte prima. Milano: Editrice Bibliografica, 2001. p. 11 
Sin embargo, la elaboración de todo registro bibliográfico debe reconocer dos finalidades distintas para distinguir los valores culturales de los objetos bibliográficos en cuestión. La primera finalidad es la elaboración de un catálogo bibliográfico como responsabilidad de una biblioteca que custodia impresos antiguos. Dicha responsabilidad no es prioritaria de una biblioteca nacional, aunque es deseable que este tipo de biblioteca proponga o instrumente un modelo bibliográfico normalizado que permita a otras intercambiar información valiosa en la protección de patrimonio librario. Por tanto, este modelo forma parte sustancial de una política cultural en la materia y como muestra podemos observar ejemplos interesantes en bibliotecas nacionales del continente europeo. ${ }^{43}$

En este sentido, el caso español es más que idóneo en tanto que relaciona directamente el modelo bibliográfico con la protección del patrimonio cultural del Estado, ya que éste reconoce por ley la obligatoriedad de la elaboración de un catálogo colectivo del patrimonio bibliográfico. ${ }^{44}$ Este modelo se basa en los criterios emanados por las normas internacionales, pero se aplica intentando incluir otro tipo de datos que para las instituciones españolas son relevantes, como ciertos elementos históricos $-v$. gr. encuadernación o marcas de propiedad- y tipográficos $-v$. $g r$. signaturas o errores-. Dicha inclusión estaría considerando, la responsabilidad legal de las bibliotecas en la custodia del patrimonio bibliográfico. El caso español también nos ayuda a ejemplificar la otra finalidad a la que nos referimos: el conocimiento bibliográfico de ejemplares conservados de impresos antiguos.

La bibliografía española que se ha desarrollado especialmente durante el siglo XX (de acuerdo con los principios de la bibliografía material de origen anglosajón y la propia hispanoamericana) nos muestra la posibilidad de elaborar un modelo bibliográfico que permite conocer

43 Por citar ejemplos España (http://www.mcu.es/ccpb/ccpb-esp.html), Francia (http://www.bnf.fr/) e Italia (http://www.internetculturale.it/moduli/opac/ opac.jsp). [Fecha de consulta: marzo de 2006]

44 Artículo 51. 1 de la Ley 16/1985 del Patrimonio Histórico Español. Texto disponible en http://www.mcu.es/legislacion/patri/pdf/ley16-1985.pdf [Consulta: marzo de 2006] 
a detalle las características por las que un impreso antiguo puede ser valorado culturalmente de forma especial. Pero, la aplicación de dicho modelo requiere de mayor conocimiento histórico y cultural del que normalmente se ofrece en los programas de formación bibliotecaria, especialmente en lo que se refiere al territorio latinoamericano. ${ }^{45}$

Este conocimiento también debería contribuir a la construcción de nuestra apreciación jurídica en la protección del patrimonio libresco. En este sentido, debemos considerar las leyes vigentes de protección del patrimonio cultural que depositan la responsabilidad de este registro al Instituto Nacional de Antropología e Historia (INAH) y al Instituto Nacional de Bellas Artes (INBA). Dicho registro depende del tipo de bien patrimonial que se establece para cada uno de estos institutos; a saber, el INAH se responsabiliza de lo que corresponde a los bienes paleontológicos, arqueológicos e históricos, mientras que el INBA se encarga de lo que corresponde a los bienes artísticos. ${ }^{46}$ Con esta condición podríamos suponer que el registro de los bienes del patrimonio cultural de los mexicanos se realiza puntualmente conforme a modelos diseñados reconociendo la naturaleza cultural de cada uno de los objetos señalados en el propio texto de la ley.

Desde esta perspectiva y siguiendo la indicación de la ley, el universo de los bienes conservados en bibliotecas y archivos son considerados monumentos históricos y, por tanto, su registro es responsabilidad institucional del INAH. Esta condición resulta interesante, ya que en otras latitudes dicha responsabilidad se ha depositado en el Archivo y Biblioteca Nacionales. En nuestro país no se estableció así por las condiciones especiales de adscripción que poseen nuestras instituciones nacionales. El Archivo General de la Nación forma parte

45 Cfr. Stella Maris Fernández y Graciela Maria Giunti. Planes de estudio de las escuelas de bibliotecología, archivonomia y museología de Iberoamerica. Buenos Aires: Sociedad de Investigaciones Bibliotecológicas, 1999.

46 Artículo 21 de la Ley Federal sobre Monumentos y Zonas Arqueológicos, Artísticos e Históricos. Publicada en Diario Oficial de la Federación de 6 de mayo de 1972. Diario Oficial de la Federación, 6 de mayo de 1972. Texto disponible en http://www.diputados.gob.mx/leyinfo/pdf/131.pdf [Consulta: Enero de 2006] 
de la estructura organizacional de la Secretaría de Gobernación, y la Biblioteca Nacional a la correspondiente de la Universidad Nacional Autónoma de México.

A pesar de esta condición institucional, nada debería imposibilitar al Archivo y la Biblioteca para que establecieran modelos de descripción normalizados, de acuerdo con los desarrollos en esta materia en el terreno internacional y que fuesen aplicados por los institutos federales u otras instituciones interesadas. Sin embargo, esto solamente lo ha implementado el AGN mediante la creación de los

Lineamientos generales para la organización y la conservación de los archivos de las dependencias y entidades de la Administración Pública Federal $^{47}$

que se utilizan en varios archivos. Por su parte, la Biblioteca Nacional recientemente ha comenzado un proyecto de "Catálogo Colectivo de los Fondos Antiguos" en el que se pretende integrar a las bibliotecas que posean este tipo de colecciones. ${ }^{48}$ En nuestra opinión, para que esto sea una realidad viable - por tanto, posible - y debido a su condición institucional, es necesario que previamente se establezcan acuerdos de participación donde se definan las responsabilidades y obligaciones de las instituciones participantes.

Además no habría que olvidar que el proyecto de catalogación de fondos conventuales del INAH de 1994 es el primer registro de bienes bibliográficos antiguos a gran escala, en el cual se incluyeron numerosos impresos antiguos. Por supuesto, dicho registro solamente se realizó sobre las colecciones bibliográficas que se encuentran bajo la custodia del mismo instituto. Es decir a pesar del carácter de esta acción institucional no generó, desde el espacio de acción de la misma

47 La información se encuentra disponible en la página Web del Archivo. http:// www.agn.gob.mx [Consulta enero de 2005]

$48 C f r$. Rosa María Fernández de Zamora. "Hacia el catálogo colectivo nacional de fondos antiguos: patrimonio bibliográfico mexicano". Actas de XXXIV Jornadas Mexicanas de Biblioteconomía (2003): pp. 151-156. Texto disponible en http://eprints.rclis.org/archive/00003458/01/ROSAMARIAFERNANDEZ.pdf [Consulta: agosto de 2005] 
institución, un programa nacional de registro del patrimonio libresco. También habría que agregar que este modelo de registro utilizado por el INAH no respetó ni consideró - por desconocimiento o falta de interés- los lineamientos establecidos por normas internacionales ni específicas del campo bibliotecológico. Por el contrario, el análisis del modelo citado nos muestra una mezcla, por demás interesante, que no deja definida la relación metodológica existente entre el registro de manuscritos, incunables, impresos antiguos y decimonónicos.

Esta condición también estaría determinada por la ausencia de reflexión en la materia desde el campo bibliotecológico, lo que ha propiciado la falta de formación, y por ende, de investigación en la materia. Probablemente, si el pensamiento bibliotecológico mexicano y la formación profesional que se deriva del mismo, tuvieran entre sus puntos de interés a este tipo de registro bibliográfico, no se hubiese posibilitado que el INAH desarrollara tan importante tarea patrimonial desconociendo los criterios más elementales en el registro bibliográfico de impresos antiguos.

Con todo, este esfuerzo es loable y constituye un interesante antecedente tanto de lo que no se debe hacer en la aplicación de metodologías bibliográficas, como de las posibilidades que existen para elaborar los registros de impresos antiguos en el terreno institucional. Por fortuna la situación ha comenzado a cambiar, y con ello algunas bibliotecas interesadas en el registro de sus colecciones patrimoniales han comenzado a implementar los criterios internacionales catalográficos y bibliográficos que se han desarrollado para estos materiales. Lamentablemente la mayoría se deja seducir por la idea de una catalogación fácil y rápida, y no económica, que les permita proclamar que sus materiales han sido ya registrados.

Por esta condición "aséptica" del problema patrimonial es que la situación no ha dejado de ser preocupante en tanto que no hemos resuelto lo correspondiente a la responsabilidad del catálogo y la tarea necesaria de la bibliografía de los impresos antiguos, como factor relevante en la valoración cultural y por tanto en la protección patrimonial. Debemos entender que

un catálogo de este tipo de materiales es un conjunto de registros que representan e individualizan bibliográfica y bibliotecariamente unos ejemplares 
concretos (con sus personales lujos o deficiencias, y su particular historia de posesión y uso) dentro de un determinado depósito bibliotecario, permitiendo su localización, consulta y conservación. ${ }^{49}$

La bibliografía, por el contrario, debe ayudarnos a conocer minuciosamente los objetos conservados y así coadyuvar en ambas tareas.

Ahora bien, este tipo de catálogo no puede cubrir lo que corresponde a la bibliografía puesto que su finalidad es otra. La bibliografía del impreso antiguo, tipobibliografía como la denomina la escuela española, ${ }^{50}$ analiza minuciosa y rigurosamente el material que describe con objeto de identificar a cabalidad los detalles de la edición a la que corresponde un ejemplar. ${ }^{51}$ Este es el punto de mayor interés en términos patrimoniales: los ejemplares y sus historias particulares. De ahí que el bibliógrafo de un libro antiguo no se conforme, como lo hace el catalogador, con la información básica del ejemplar a describir.

Es también por esto que dicho registro bibliográfico también se denomina descriptivo, dado que no escatima en los datos que debe registrar, ya sean textuales o históricos. De esta manera se construye un instrumento de investigación valioso para diferentes disciplinas, pero también se compone un registro de bien cultural capaz de proporcionar toda la información relevante para la institución de custodia.

\subsection{Las aportaciones de la Bibliografía Material}

Nuestro registro bibliográfico de un impreso antiguo como una metodología particular tiene honorables antecedentes como los repertorios

49 Julián Martín Abad. "Incunables e impresos antiguos". Los materiales especiales en las bibliotecas, coord.. Carmen Díez Carrera. Gijón: Trea, 1998. p. 64

50 Cfr. Julián Martín Abad. La imprenta en Alcalá de Henares, 1502-1600. Madrid: Arco Libros, 1991.

51 Aunque se define como "Bibliografía dispuesta por orden de impresores o de imprentas, y éstas, por años, recogiendo su respectiva producción bibliográfica”. Como se observa no se hace referencia al problema metodológico. Luis García Ejarque. Diccionario del Archivero Bibliotecario. Gijón: Trea, 2000. p. 424 
bibliográficos de García Icazbalceta o Toribio Medina ${ }^{52}$, entre otros. Pero por diversas razones que todavía no están del todo claras, esa tradición bibliográfica que nos enorgullece se perdió en el tiempo, dando por resultado el deterioro actual del trabajo bibliográfico en esta materia tan puntual y útil para la protección del patrimonio cultural, situación que es todavía más lamentable si consideramos la invaluable aportación que representa el trabajo y la presencia de Agustín Millares Carlo en nuestro territorio. No hay que olvidar que

son destacables sus descripciones de ejemplares contenidos en diversas bibliotecas, como los de la primera formada en el continente americano, la del obispo Fr. Juan de Zumárraga (1544) y en especial, por la mayor profundidad y pluralidad de estudios los referidos a los atesorados en la Biblioteca Nacional de México. ${ }^{53}$

Por supuesto, mención más importante requiere su edición anotada, corregida y aumentada en 1954 al trabajo bibliográfico de García Icazbalceta que enriqueció notablemente un valioso instrumento de investigación, pero también de identificación patrimonial.

De esta rica herencia bibliográfica podemos suponer que se alimentó Jesús Yhmoff Cabrera, quien representa uno de los mejores ejemplos contemporáneos en la práctica del trabajo bibliográfico mexicano y al cual debemos reconocer un profundo conocimiento de los impresos antiguos. Sus catálogos bibliográficos ${ }^{54}$ y el recientemente publicado

52 Hay que aclarar que Toribio Medina fue chileno, pero su notable trabajo sobre la imprenta en México lo ha colocado siempre como un referente de nuestra historia cultural.

53 José Antonio Moreiro González. Agustín Millares Carlo: el bombre y el sabio. Gobierno de Canarias: Viceconsejería de Cultura y Deportes, 1989. p. 215

54 Sin duda estos trabajos están en correspondencia metodológica con los modelos de otros países y al igual que otros repertorios parece poco lo que puede agregarse. Nos referimos al Catálogo de Incunables de la Biblioteca Nacional de México. $2^{\mathrm{a}}$ ed. México: UNAM, 1987; Impresos mexicanos del Siglo XVI en la Biblioteca Nacional de México México: UNAM, 1990 y Catalogo de los impresos europeos del siglo XVI que custodia la Biblioteca Nacional de México México: UNAM, 1996. 
de Cid Carmona, ${ }^{55}$ representan unos casos aislados en el uso de una metodología bibliográfica de tradición hispanoamericana. El que dicha metodología bibliográfica para el impreso antiguo tenga interés práctico en otras latitudes, nos anima a recuperar nuestras tradiciones más acertadas en este campo del conocimiento.

Ciertamente, en esta recuperación debemos integrar las posturas contemporáneas más notables, que están posibilitando una plena identificación de los impresos antiguos con objeto de contribuir a su justa valoración cultural como objetos producidos por una sociedad específica con características culturales y sociales propias y definidas. Este es el caso de la inmensa producción libresca de la Nueva España, de la que bibliográficamente se conoce poco, lo que nos conduce a una compleja realidad de conocimiento patrimonial, pese al saqueo y deterioro al que ha estado expuesta y que afecta a una cantidad importante de impresos bajo la custodia de nuestras ricas bibliotecas.

Desde finales del siglo XIX, los trabajos desarrollados por A.W. Pollard, W.W. Greg y R.B. McKerrow van a comenzar a delinear una metodología de trabajo con impresos antiguos, que hoy conocemos como Bibliografía Material, y que se propagaron desde la Bibliographical Society en Inglaterra, ${ }^{56}$ si bien la intención de estas tres personalidades no era realizar aportaciones a la disciplina bibliográfica, sino al conocimiento de la literatura antigua. Pero no habría que olvidar que su preocupación estaba determinada por las formas de transmisión de los autores antiguos; es decir, cómo se transmite a lo largo

55 Empero, a pesar de que el modelo bibliográfico utilizado no se encuentra definida su procedencia metodológica, me parece que cumpliría en términos generales con los principios de la bibliografía material y las normas internacionales. Pero considerando la tradición bibliográfica no aporta ninguna novedad a este campo; es más sería deseable que se hubiese agregado algunos datos para identificar correctamente el objeto material considerando sus valores textuales he históricos y lo que corresponde a la identificación plena de los ejemplares conservados. Cfr. Victor Julián Cid Carmona. Repertorio de impresos mexicanos en la Biblioteca Nacional de España, siglos XVI-XVII. México: COLMEX, 2004.

56 David McKitterick. "Introducción". Roland B. McKerrow. Introducción a la bibliografía material. Madrid: Arco Libros, 1998. p. 12 
del tiempo el texto original de un autor literario, por lo que resulta importante estudiar detalladamente los impresos conservados para analizar las formas de dicha transmisión y de ahí derivó parte de la metodología bibliográfica a la que nos referimos.

Sin importar este detalle tan particular, lo cierto es que los principios y características que definen a esta metodología siguen actuales y se corresponden directamente con los trabajos bibliográficos desarrollados con anterioridad. Lo que ha permitido esta metodología es principalmente comprender que "la bibliografía es ante todo el estudio de los libros como objetos materiales". ${ }^{57}$ Como tales, en su estudio e interpretación es necesario comprender las formas de producción que transformarán un texto manuscrito en un impreso, y de ahí, en un objeto que se relacionará socialmente con sus lectores.

Efectivamente,

los autores no escriben libros: escriben textos que luego se convierten en objetos impresos. La diferencia, que es justamente el espacio en el cual se construye el sentido, fue olvidada no sólo por la historia literaria clásica que piensa la obra en sí misma, como un texto abstracto cuyas formas tipográficas no importan. ${ }^{58}$

Pero estas formas tipográficas son relevantes, y nos ayudan a comprender al impreso en su contexto cultural y social tal y como fue producido. Son estas formas las que más interesan para la Bibliografía Material, pero también para el pensamiento patrimonialista que requiere comprender a ese objeto material con características propias que pueden hacerlo diferente de otros similares, al paralelo de su comprensión como objeto de posesión particular e institucional.

El desarrollo de esta metodología bibliográfica, con una larga tradición, fue determinante para hacer comprender a los bibliotecarios la necesidad de una norma de descripción específica, más acorde con la

57 Phillip Gaskell. Nueva introducción a la bibliografía material. Gijón: Trea, 1999. p. 1

58 Roger Chartier. El mundo como representación. Estudios sobre bistoria cultural. $2^{\text {a }}$ ed. Barcelona: Gedisa, 1995. p. 111. 
naturaleza del impreso antiguo. Ciertamente, también contribuyó de modo notable el trabajo de los bibliotecarios en la catalogación de impresos antiguos y en particular las problemáticas que enfrentaron en el desarrollo de bases de datos cooperativas para dicha catalogación, de ahí que la norma ISBD (A) recupere a su manera ciertos postulados de la Bibliografía Material. ${ }^{59}$ Por ejemplo, el registro de las signaturas para cualquier bibliógrafo es la forma en que se ordena la estructura interna de un libro y no debería ser obviada. El mismo dato para la norma internacional es un asunto que debe ser registrado a discreción del catalogador. De ahí que podamos observar, en los catálogos colectivos que utilizan esta norma internacional, variaciones considerables en el registro de los elementos textuales, como lo es la signatura de un impreso antiguo.

Pero como ya habíamos mencionado, la función de un catálogo se cumple cabalmente si es capaz de informar de manera puntual sobre los libros que se custodian en una determinada biblioteca. Empero, considerando el valor cultural que estos objetos han adquirido y por ende su apreciación patrimonial, es deseable que el catalogador conozca y registre cuando menos aquellos datos que particularizan e identifican sin equivocación a un ejemplar conservado, especialmente si se trata de aquellos elementos que le otorgan un sentido histórico al libro y por el cual adquiere valor patrimonial, que también determina la responsabilidad de la custodia del objeto.

Ahora bien, es la metodología de la Bibliografía Material y sus principios la que nos permite elaborar un registro más conciso de un ejemplar conservado y así aportar elementos para la valoración cultural de ese objeto. En dicha valoración, tanto el bibliógrafo como el catalogador

deben identificar correctamente la pieza que tienen a la vista. Esta inevitable tarea es siempre previa a la construcción de cualquier tipo de registro

59 Beth M. Rusell. "Description and Access in Rare Books Cataloging: A Historical Survey”. Cataloging and Classification Quarterly. Vol. 35, nos. 3/4 (2003), p. 504-506. 
bibliográfico de un catálogo o de un repertorio bibliográfico retrospectivo. ${ }^{60}$

Esta es quizás la mayor cercanía que existe entre el trabajo de un catalogador y de un bibliógrafo en lo que se refiere a un impreso antiguo. Para ambos, en ningún caso se puede elaborar el registro bibliográfico sin tener el objeto material a la vista.

"Ver los libros con los propios ojos es un deber sagrado del bibliógrafo. No puede jamás fiarse, sin decirlo, de la descripción hecha por otro". 61 Pero describir a este objeto sin conocer lo que se está analizando es tanto más grave porque no se sabe lo que se está haciendo, y se puede incurrir en errores considerables ${ }^{62}$ en la identificación de un impreso. De ahí que la búsqueda de información y la comparación entre ejemplares conservados de una edición sea una tarea primordial en el registro de los impresos antiguos, especialmente para el trabajo bibliográfico.

Sin duda, la Bibliografía Material ha evolucionado e incorporado aspectos relevantes en la tarea de registro de impresos antiguos, pero los trabajos de McKerrow, Gaskell, Bowers, Esdaile, Tanselle, Martín Abad, Montaner, ${ }^{63}$ entre otros igualmente importantes, nos muestran que la seriedad en el trabajo de este tipo de bibliografía posibilita la transmisión de la información registrada, de tal forma que no es necesario

60 Julián Martín Abad. "La valoración del libro: el punto de vista del bibliotecario de fondo antiguo". Ciclo de Conferencias sobre Bibliofilia y Mercado del Libro. Biblioteca Histórica Marques de Valdecilla, 2004. Texto disponible en: http://www.ucm.es/BUCM/foa/Conferencias/conferencia2.pdf [Consulta: noviembre de 2004] p. 6

61 Fernando Huarte Morton. "La descripción de los libros raros". Primeras Jornadas de Bibliografía. Madrid: Fundación Universitaria Española, 1977. p. 69. Citado por Julián Martín Abad (1991). Op. Cit. p. 38, nota 76

62 Una relación de los casos más relevantes de esta problemática se encuentra en el trabajo de Julián Martín Abad. "La tipobibliografía complutense del Siglo XVI: tareas y posibilidades”. El Libro Antiguo Español: Actas del Segundo Coloquio Internacional (Madrid). Salamanca: Ediciones de la Universidad de Salamanca: Biblioteca Nacional de Madrid: Sociedad Española de Historia del Libro, 1993. T. 1, pp. 273-293

63 Todos se encuentran en la bibliografía de este trabajo. 
volver a hacer el mismo trabajo sino enriquecerlo. También, que el conocimiento del impreso antiguo se acerca al trabajo de la erudición histórica, entendiendo a ésta como un acto de investigación rigurosa del pasado. Desde esta apreciación metodológica, es factible utilizar la información compilada para la elaboración de registros bibliográficos, también como instrumentos de control patrimonial.

Pero no por esta razón olvidemos que

los bibliógrafos, al igual que otros estudiosos, tienen que ser capaces de pensar con lógica, de juzgar críticamente y de perseverar en monótonas tareas, pero además deben conocer la historia del libro. El estudio de los libros impresos como objetos materiales y la correcta interpretación de los documentos impresos del pasado se ha de fundamentar principalmente en el conocimiento de cómo se compusieron con caracteres tipográficos, se imprimieron, se distribuyeron y se vendieron los manuscritos de los autores. ${ }^{64}$

Ciertamente, un modelo bibliográfico basado en los principios de la Bibliografía Material, permite hacer una correcta identificación de un ejemplar conservado en cierta biblioteca. Con esta información y la que pueda recuperarse en la documentación histórica, se han hecho excelentes trabajos históricos que nos dan a conocer un aspecto del pasado como los libros y sus lectores. Del interés por este binomio, el objeto bibliográfico y la persona que lo posee, se han producido interesantes textos especialmente en España, Francia, Inglaterra y Estados Unidos. Todos ellos actualmente constituyen enfoques disciplinarios donde se dibuja un territorio común para la investigación y se construye un mismo objeto: el impreso antiguo como objeto material $^{65}$ dentro de la orientación de la historia cultural y de las mentalidades.

Empero, la tendencia de estas investigaciones ha defendido que la mejor fuente de información es el inventario post mortem para realizar el análisis de la relación directa entre el lector y su libro. Pero

64 Philip Gaskell. Op. Cit.p. 2

65 Roger Chartier. Op. Cit. p. 120 
también es sabido que este tipo de documento histórico ofrece una pobre información bibliográfica sobre los objetos de estudio, lo que complica, mas no imposibilita su adecuada identificación. ${ }^{66}$ En este sentido, podemos recuperar la importancia del objeto original para estos estudios, que también nos ofrece información relacionada con el poseedor, ya sea institucional o privado, a través de las ricas anotaciones manuscritas, sellos y marcas que han quedado como testimonio en el propio libro. Efectivamente, lo deseable siempre sería que la investigación pudiera relacionar la documentación histórica con los libros antiguos conservados actualmente en las bibliotecas.

En este campo de conocimiento, fecundo y prometedor, el trabajo bibliográfico adquiere mayor relevancia en tanto que posibilita una adecuada transmisión de los objetos de estudio, necesarios para definir una actividad investigadora y también la comprensión de nuestro pasado en sus complejas formas culturales. Dicha comprensión también es determinante para construir la valoración del impreso antiguo en el territorio del pensamiento patrimonial.

Por otra parte, el conocimiento histórico de los libros y sus relaciones con el mundo se enfrenta siempre a la abundancia o carencia de fuentes originales; pero sin duda, se requiere de instrumentos que compilen esas fuentes para realizar más completamente posible el trabajo emprendido. Cualquier historiador siempre agradecerá que una biblioteca o un archivo cuenten con instrumentos que describan las colecciones documentales y bibliográficas que custodian. Entre más y mejor sea la información proporcionada, más fácilmente el investigador identificará aquellas fuentes originales que se acercan a su tema de estudio. Pero este mismo tipo de información permite a la institución proporcionar algo concreto frente a las restricciones de acceso a las colecciones.

En efecto, no olvidemos que un registro bibliográfico es la representación de un objeto material y por esta condición estaría en posibilidad de informar detalladamente sobre su contenido textual y valor testimonial. De ahí que con este tipo de información la institución

66 Manuel José Pedraza Gracia. Lectores y lecturas en Zaragoza, 1501-1521. Zaragoza: Prensas Universitarias, 1998. p. 14. 
puede restringir el acceso al original siempre que lo considere conveniente por razones de preservación. La persona que consulta la información obtendría prácticamente todos los detalles necesarios para saber si ese objeto es el de su interés, con lo que se reduce la consulta innecesaria de un original, que siempre podrá en riesgo su integridad material.

La descripción anterior constituye un ideal. Es decir, es posible y viable que la información recuperada y descrita con los principios de la Bibliografía Material pueda servir perfectamente para el control patrimonial que toda institución tiene por responsabilidad cuando custodia objetos culturales, aun cuando es necesario que un registro con esta finalidad explícita requiera otro tipo de datos como los legales de la institución de custodia o los relacionados con la tasación. Información de este tipo no es de conocimiento general, sino particular para aquellos responsables de la custodia. Por supuesto, lo anterior no implica que no debamos fomentar el uso de cuando menos ciertos criterios fundamentados en la Bibliografía Material, tanto para los registros de control patrimonial como para los instrumentos de consulta. Al menos, los mismos que deben implementarse como lineamientos en la catalogación de impresos antiguos.

Estos criterios que podrían convertirse en lineamientos ayudan a comprender uno de los principios culturales más relevantes del impreso antiguo. Nos referimos al que establece y permite "la identificación del texto con un escrito fijado, estabilizado, manipulable gracias a su permanencia". ${ }^{67}$ Este es el contexto de la apreciación patrimonial del objeto librario, que identifica en éste un valor textual (todo aquello que fue impreso) y un valor histórico (todo aquello que un ejemplar posee para demostrar su paso por el tiempo). ${ }^{68}$ Ambos valores pueden perfectamente representarse en un registro bibliográfico descriptivo de un impreso antiguo, con lo cual se favorece el conocimiento de qué tipo de materiales tenemos bajo custodia en nuestras instituciones, y

67 Roger Chartier. Entre poder y placer: cultura escrita y literatura en la Edad Moderna. Madrid: Cátedra, 2000. p. 111.

68 Cfr. Lorenzo Baldacchini. Il libro antico. Roma: La Nuova Italia Scientifica, 1982. pp. 13-14. 
así diseñar políticas culturales más acordes a la realidad patrimonial. En suma, este tipo de metodología permite aportar datos relevantes para la valoración cultural de un impreso antiguo.

Pero a pesar de las ventajas que podamos ver en la relación entre la custodia de un objeto cultural y las metodologías que nos permiten representarlo, existe una idea previa que nos ayuda a comenzar:

Si es un axioma en bibliografía que no se puede tener la pretensión de haber agotado totalmente la materia con una sola obra, en lo que respecta a la tipobibliografía esta certeza se multiplica indefinidamente, puesto que el objeto de la misma son los impresos antiguos, que han sufrido los avatares del paso del tiempo que han determinado que una gran cantidad de los mismos hayan desaparecido sin dejar el más mínimo rastro de su existencia. El uso al que dichos impresos son destinados, los materiales en que se imprimen, sus propios usuarios, la acción del tiempo y muy en especial las múltiples y nunca acabadas inquisiciones, todas estas acciones juntas dan como resultado el que nunca lleguemos a conocer con precisión cuántos y cuáles han sido los impresos producidos en un lugar y un periodo de tiempo determinados. ${ }^{69}$

Estas consideraciones nos colocan frente a una realidad ineludible: A pesar del valor cultural que los trabajos históricos y bibliográficos han permitido otorgar al impreso antiguo, en reconocimiento de una parte del patrimonio escrito, lamentablemente la protección definitiva como bien patrimonial no siempre está asegurada por completo. Contribuir a la construcción de argumentos que consoliden esta consideración patrimonial y por tanto la garantía de protección, es en parte la intención que pretenden ofrecer estas líneas, aun sabiendo que todo lo que se escriba sobre impresos antiguos siempre será un asunto controversial.

Asumir la responsabilidad que implica una reflexión como la que emprendemos significa también reconocer la obligación permanente que queda para el futuro, ya que

69 Lorenzo Ruiz Fidalgo. La Imprenta en Salamanca, 1501-1600. Madrid: Arco Libros, 1994. p. 7 
un trabajo de investigación histórica, es siempre el punto de partida que otros han de continuar, y la aparición de nuevas ediciones o documentos, exigirá la revisión de las conclusiones. ${ }^{70}$

Esta es la tarea y la responsabilidad que comprendemos y asumimos en la defensa de un territorio patrimonial que nos demanda acciones concretas: el del libro antiguo.

70 María Marsá. La imprenta en la Rioja, siglos XVI-XVII. Madrid: Arco Libros, 2002. p. 10 


\section{La importancia de la descripción bibliográfica del libro antiguo}

Adentrarse en la bistoria del libro es, sin duda, una aventura apasionante y, a un tiempo, gratificante, entre otras razones, por la multiplicidad de aspectos a considerar

María Carmen Álvarez Márquez

$\mathbf{P}$ ara comenzar esta parte de la reflexión es necesario puntualizar sobre nuestra comprensión del objeto de estudio, es decir, cómo podemos definir al libro antiguo para acercarnos a la problemática de su descripción. Como ya hemos anotado en líneas anteriores, la definición de este objeto presenta varias complejidades determinadas por su naturaleza cultural, pero también por la forma de la comprensión disciplinaria de una tradición específica. Aquí solamente distinguiremos dos complicaciones que constituyen el soporte de nuestra propuesta metodológica para la descripción de un libro antiguo.

La primera de estas es estrictamente bibliográfica y busca comprender al objeto que será representado mediante un registro que se elabora para una finalidad específica. Lo que significa que debemos acercarnos al objeto de la descripción desde las características materiales que lo distinguen y que representamos según una metodología bibliográfica. La segunda complicación se refiere al conjunto de valores que distinguimos en ese objeto material y por el cual lo reconocemos como un elemento patrimonial.

Para comprender al objeto "libro antiguo", se han propuesto diferentes definiciones que podemos ubicar en dos tendencias: una en la 
que predomina el elemento de la datación, y otra, que distingue las características materiales $^{71}$ de esos libros. En la primera tendencia encontramos la definición de la propia norma internacional ISBD (A), ${ }^{72}$ así como algunas de las categorías jurídicas de protección elaboradas por los Estados nacionales durante el siglo XX.

Por eso podemos encontrar a autores como Martínez de Sousa quien comprende que la definición del libro antiguo también estaría determinada por estipulación de una ley, es decir, reconoce por libro antiguo a todo impreso "producido desde la invención de la imprenta hasta una fecha que el uso o la ley determinan". ${ }^{73}$ De esta manera la determinación de la antigüedad se estipula por ley y en consecuencia se establecen limitaciones para su venta, circulación, pero también para su uso.

En la segunda tendencia encontramos básicamente las aportaciones de la Bibliografía Material, que distingue las particularidades de los objetos librarios derivadas del proceso mismo de producción y que también nos permite representar los valores históricos del objeto que se describe. Esta comprensión del concepto, de la que somos partidarios, se acerca más a la problemática de los valores culturales que se reconocen en los libros antiguos y por los cuales se les estima como elementos patrimoniales, pues comprende y define al libro antiguo en relación directa con la materialidad del objeto y con el proceso cultural del que es resultado, incluso considerando su propia historicidad.

Es decir, estamos refiriéndonos a un objeto manufacturado por la imprenta tipográfica hasta el advenimiento de la producción industrial. Desde este punto de vista cronológico, encontramos dos grupos de objetos definidos claramente por sus características y por su tiempo histórico. El primer grupo está conformado por los incunables, es decir, aquellos impresos producidos desde la invención de la imprenta de tipos móviles hasta el año de 1501.

71 Giuseppina Zappella. Op cit. p. 11.

72 Las fechas comprendidas en esta definición cronológica comprenden la segunda mitad del siglo XV hasta el año de 1820. Cfr. ISBD (A). Op. cit. p. X

73 José Martínez de Sousa. Diccionario de Bibliología y ciencias afines. $3^{\mathrm{a}}$ ed. Madrid: Ediciones Trea, 2004. p. 583 
Se justifica esta particular denominación por el hecho de que estos primitivos impresos difieren notablemente en su presentación de los aparecidos en siglos posteriores y además porque su descripción bibliográfica plantea problemas específicos. ${ }^{74}$

Así, por sus características propias, los incunables se han separado como objeto de estudio de la incunabulística, que tiene a su mejor representante en Konrad Haebler. ${ }^{75}$ Estos impresos representan el primer periodo histórico de los libros antiguos y el primer momento de evolución de la impresión tipográfica. Por esta razón, es difícil establecer generalidades en lo que respecta a las características materiales del incunable, aunque suele encontrarse esta tendencia en cierta literatura producida en México.

Lo anterior significa que no se puede establecer categóricamente que todos los incunables carecen de portada o que todos poseen colofón. Lo pertinente es indicar que las características de los mismos deben comprenderse según el lugar y la técnica tipográfica de la que son resultado. Debemos apuntar que precisamente son los incunables los impresos que mejor muestran la complejidad material y estructural en la composición de un registro bibliográfico para el material antiguo.

El segundo grupo, al que dedicamos este texto, está conformado por el conjunto de impresos que se conoce genéricamente como libros antiguos, y que conceptualmente resulta más favorable que el de libros raros. ${ }^{76}$ Esta condición es así porque la rareza de un material estaría determinada por la conjunción, tanto de aspectos textuales como históricos, que podría poseer un solo objeto, por ejemplo, el proceso que ha determinado que solamente tengamos noticia de un ejemplar correspondiente a una edición, o que dentro de ésta se encuentren particularidades que hacen a un ejemplar ser considerado

74 Julián Martín Abad (1998). Op. cit. p. 65

75 Especialmente lo que corresponde a su trabajo Introducción al estudio de los incunables. Madrid: Ollero \& Ramos, 1995.

76 Julián Martín Abad (1998). Op. cit. p. 66 
"raro" ${ }^{77}$ Recuérdese también que por "libro raro", debe entenderse a aquel que es difícil de obtener de cualquier forma, y que esta denominación también se refiere a una estimación de belleza o de valor monetario que ha creado una confusión en el uso del término. ${ }^{78}$

Nuestro interés está básicamente determinado porque estos libros, producidos durante los siglos XVI al XVIII, son los más numerosos en las colecciones y representan un acervo patrimonial que en México resulta prácticamente desconocido para la sociedad, condición que no aplica para grupos de especialistas muy definidos como los historiadores, los literatos o los bibliógrafos, por mencionar tan sólo algunos, que tienen en este objeto un soporte de sus investigaciones. Por el contrario, son pocos los bibliotecarios mexicanos entendidos en estos materiales, debido a que durante mucho tiempo hemos carecido de formación específica para el tratamiento catalográfico y bibliográfico del libro antiguo.

Afortunadamente, hoy en día contamos con algunos espacios de formación especialmente dedicados al libro antiguo, pese a que podríamos decir sin temor a equivocarnos que no tenemos todavía una comprensión compartida del problema que el libro antiguo representa, tanto bibliográfica como patrimonialmente. Esta situación conlleva una falta de acuerdo en lo que entendemos por libro antiguo, y en consecuencia, de las metodologías bibliográficas y catalográficas más idóneas para su representación y tratamiento.

Como también ya habíamos aclarado, la definición estricta del libro antiguo basada en un criterio meramente cronológico no es capaz de abarcar todo el problema bibliográfico y patrimonial que representan estos objetos. Empero, ese mismo criterio nos permite ubicar la producción libresca en un tiempo específico, y en este, determinar las formas de la estructura material del objeto que buscamos representar

77 A pesar de esta apreciación es necesario apuntar que en la literatura anglosajona así definen al conjunto de libros antiguos (Rare Books). La condición de rareza en esta literatura, es analizada con detalle en el libro de Roderick Cave. Rare book Librarianship. 2n revised edition. London: Clive Bingley, 1982. p. 21

78 Des livres rares depuis de l'invention de l'imprimerie, sous la direction d'Antoine Coron. Paris: Bibliothèque Nationale de France, 1998. p. 14 
adecuadamente mediante un registro bibliográfico. Esta misma comprensión cronológica es la que también ha determinado su acotación legal en algunos países para la protección que el Estado debe promover, por lo que no debemos olvidarla.

Desde cierta perspectiva disciplinaria,

tal vez el criterio que más peso específico tiene en la distinción del libro antiguo es el de su elaboración material, propiciada por la corriente teórica de la Bibliografía Material, del ámbito anglosajón, que se ha dedicado al estudio de la técnica de la producción de los libros impresos en los primeros siglos con objeto de ayudar a aclarar el cambio que sufre un original tras su paso por la imprenta. ${ }^{79}$

De ahí que la estructura material y la composición de la misma nos ayuden a identificar las características de las ediciones y de los ejemplares que se corresponden con éstas. Información con la que sería posible establecer y definir los valores culturales que reconocemos en los libros antiguos y construir una protección jurídica para su protección más adecuada de la que actualmente existe. ${ }^{80}$

De esta manera nuestro problema de conocimiento quedaría limitado desde el término del periodo de producción del incunable, que corresponde al siglo XVI, sin que ello cierre totalmente la posibilidad en encontrar en este mismo periodo histórico libros que por su estructura son más cercanos a él y que han sido denominados como post incunables. ${ }^{81}$ Este es el límite, debido a que la introducción de la imprenta de tipos móviles no se realizó al mismo tiempo y de la misma forma en todos los territorios, dado por resultado ediciones con trabajo tipográfico de distinta evolución.

Este es el caso de los impresos mexicanos del siglo XVI que en una parte importante de la literatura son denominados como incunables

79 Manuel Gracia Pedraza, Yolanda Clemente y Fermín de los Reyes. Op. cit. p. 14

80 Cfr. Idalia García. Legislación sobre bienes culturales muebles: protección del libro antiguo. México: UNAM. CUIB: BUAP, 2002. p. 34

81 Julián Martín Abad (2002). Op. cit. 
americanos. ${ }^{82}$ En términos estrictamente materiales, estos impresos no se corresponden con las peculiaridades de los incunables europeos. Por el contrario, su estructura material es más cercana a la que se reconoce para el libro antiguo. El uso de la tipografía gótica en algunos de estos impresos es una cuestión que encuentra su explicación en términos históricos y económicos más que tratarse de una tendencia de formas de producción predominantes de la época.

Por esta razón la expresión corriente "incunable americano" es ilegítima, puesto que la imprenta fue introducida en el continente solo ya muy entrado el siglo XVI. ${ }^{83}$

Efectivamente, la producción de este impreso novohispano ya está sujeta a las formas tipográficas predominantes y especialmente a las normativas de control de la imprenta de la época, aspectos que no debemos soslayar porque serán determinantes en la estructura material de esta herencia bibliográfica, aunque para algunos los incunables americanos sí poseen "peculiaridades características" ${ }^{84}$ en tipos, grabados, y otros elementos. Sin que ello demerite su importancia, en lo personal prefiero usar la denominación "impresos mexicanos del

82 Según Alfonso Reyes, García Icazbalceta denomina "incunables mexicanos" a los impresos "anteriores al año 1550, impresos en caracteres góticos. Alfonso Reyes. Letras de la Nueva España. México: FCE, 1948. p. 37.

83 Jacques Lafaye. Albores de la imprenta: el libro en España y Portugal y sus posesiones de ultramar, siglos XVy XVI. México: FCE; 2002. p. 17

84 Demetrio S. García. "La imprenta en América". IV Centenario de la imprenta en México: conferencias sustentadas en su conmemoración. México: Asociación de Libreros de México, 1939. p. 81 
siglo XVI" ${ }^{85}$ como lo han hecho ya León, ${ }^{86}$ Wagner, ${ }^{87}$ y por supuesto Yhmoff Cabrera. ${ }^{88}$

Por su apreciación particular es necesario citar a Valton, aunque observaremos que se refiere a esta comprensión por analogía y que la única distinción que realiza entre esos impresos y los incunables es en relación a los tipos y los grabados que fueron realizados enteramente en México. ${ }^{89}$ Sin embargo, para poder determinar con plena

85 Iguíniz consideró en su tiempo que el uso de este término es erróneo, ya que como lo indica es impropio denominar como incunables americanos a los libros impresos en México y Lima durante el siglo XVI, e igualmente a los de otros lugares del continente americano de épocas posteriores. Juan B. Iguíniz. Léxico bibliográfico. México: UNAM. Instituto de Investigaciones Bibliográficas, 1987. p. 160

86 A pesar de las diferencias manifestadas por el mismo en relación al concepto, en varios de sus trabajos optó por denominarlos "impresos mexicanos del Siglo XVI".

87 Enrique W. Wagner. Nueva bibliografía mexicana del siglo XVI: suplemento a las bibliografías de Don Joaquín García Icazbalceta, Don José Toribio Medina y Don Nicolás León. México: Editorial Polis, 1940. En las palabras del editor, éste se refiere a estos libros como impresos mexicanos del siglo XVI (p. XXIV) el igualmente el autor a lo largo de la obra.

88 Jesús Yhmoff Cabrera (1990). Op. cit.

89 "Los impresos europeos del siglo XV llevan el nombre absoluto de <incunables $>$, por haber salido cuando el arte tipográfico se hallaba en su cuna, es decir durante el primer periodo, después de la invención de la imprenta, comprendido entre el año 1455 ... y el año de 1500, que señala el fin de este periodo. De una manera análoga, los impresos mexicanos del siglo XVI -y en el mismo caso están los primeros impresos del Perú- merecen ser llamados <incunables americanos $>$, por haber sido dados a la estampa cuando el arte tipográfico en el Nuevo Mundo se encontraba en sus albores, es decir durante el primer periodo, después de la introducción de la imprenta en América, comprendido entre el año 1539 ... y el año 1600, que marca la conclusión del referido periodo. Además, haremos observar que dichos impresos mexicanos del siglo XVI, aunque por lo general son un reflejo de los impresos españoles de la misma época, sin embargo, en muchos casos, presentan un carácter enteramente particular enteramente distinto de ellos, tanto en sus tipos como en sus grabados que fueron ejecutados en los talleres del Nuevo Mundo". Emilio Valton. Impresos mexicanos del siglo XVI (incunables americanos) en la Biblioteca Nacional de México, el Museo Nacional y el Archivo General de la Nación. México: UNAM, 1935. p. XIV. 
certeza la afirmación de Valton sería necesario contar, además de la información bibliográfica tan detallada como la que él mismo ofrecióo $^{90}$ o la de Yhmoff Cabrera, ${ }^{91}$ con estudios científicos (por ejemplo con análisis de la metodología PIXE, entre otros) realizados sobre los impresos originales que ayuden a corroborar dichas afirmaciones. Actualmente no existe más información sobre las familias tipográficas de la imprenta novohispana de la que se ha escrito, que ayude a identificar con mayor precisión los orígenes y destinos de los tipos ${ }^{92}$ empleados en la imprenta novohispana, información que además podría completarse con estudios científicos sobre la composición de las tintas empleadas en los distintos talleres del periodo.

Pese a que estos impresos mexicanos y los libros antiguos (novohispanos y europeos) constituyen una importante fuente de recursos históricos y una riqueza cultural de gran valor, es muy escaso el trabajo realizado en nuestro país para registrar e identificar conforme a metodologías conocidas o probadas los impresos conservados; especialmente en materia de investigación especializada sobre el conocimiento que

90 Emilio Valton. "Algunas particularidades tipográficas de los impresos mexicanos del siglo XVI". IV Centenario de la Imprenta en México: conferencias sustentadas en su conmemoración. México: Asociación de Libreros de México, 1939: pp. 239-277. En este texto al analizar los tipos empleados en los impresos mexicanos del siglo XVI, aparentemente utiliza la clasificación derivada del conocido como método Proctor-Haebler para la medición de la tipografía, según el cual la medición milimétrica del tipo debe ir acompañada de la letra $G$ para los caracteres góticos y de la letra R para los redondos. Cfr. Agustín Millares Carlo. Introducción a la bistoria del libro y de las bibliotecas. México: FCE, 1975. p. 131, nota 35; Konrad Haebler. Op cit., 1995. pp. 132-135; Frederick J. Norton. La imprenta en España, 1501-1520. Madrid: Ollero \& Ramos, 1997. pp. 29-30 y; Julián Martín Abad (2004a). Op. cit. p. 50

91 Jesús Yhmoff Cabrera (1990). Op. cit.

92 Un ejemplo interesante sobre un acercamiento a esta cuestión puede encontrarse en los trabajos de María Isabel Grañen Porrúa "El ámbito socio-laboral de las imprentas novohispanas: siglo XVI". Anuario de Estudios Americanos, Núm. 48 (1991), pp. 49-94 y "Los Orígenes de la imprenta en Oaxaca". La Historia de la imprenta en Oaxaca. Oaxaca, Oax.: Biblioteca Francisco de Burgoa, 1999: 7-23. También el trabajo de Cristóbal Henestrosa. Espinosa: rescate de una tipografía novobispana. México: Designio, 2005. 
pueden aportarnos de un mundo cultural tan rico y diverso como lo fue el periodo colonial. No hay que olvidar que la falta de registro imposibilita la identificación precisa de la fuente para el estudio, por lo que esta carencia de conocimiento en parte se explica por la realidad del inventario y registro patrimonial que existe de todos estos impresos antiguos a nivel nacional. ${ }^{93}$

Esto es sustancialmente notable en comparación con el trabajo realizado en otros países donde se puede observar, por un lado, la elaboración de catálogos colectivos y repertorios bibliográficos sobre colecciones específicas de instituciones o sobre colecciones significativamente relevantes y, por otro, la existencia de numerosos estudios históricos que tienen como fuente primordial de investigación a los libros antiguos.

Ciertamente ambos aspectos son las dos caras de un conocimiento patrimonial que puede coadyuvar de forma importante en la transmisión de los objetos y de los valores culturales que se les reconocen.

Porque la historia de una imprenta es, en definitiva, la historia de la cultura y de la economía de un lugar, el reflejo de los acontecimientos que ocupan y preocupan a una sociedad. ${ }^{94}$

Sin embargo esto tampoco significa, en lo absoluto, que algunas tareas emprendidas en México en materia de registro representen un acertado antecedente, importante para garantizar la adecuada salvaguarda de colecciones de libros antiguos y, por tanto, su transmisión para las generaciones venideras. Empero, dada la complejidad de su conservación y la diversidad de su riqueza, todas las acciones emprendidas no han resultado suficientes para lograr consolidar su valor cultural y en consecuencia la importancia de su adecuada salvaguarda;

93 Efectivamente los impresos mexicanos del XVI constituyen los libros más conocidos o difundidos en varios repertorios bibliográficos, pero la investigación sobre el mundo social y cultural de aquellos que los elaboraron, sigue siendo similar a la que expreso en su tiempo José Toribio Medina. La Imprenta en México, 1539-1821. México: UNAM, 1989. 8 tomos.

94 Fermín de los Reyes Gómez. La imprenta en Segovia, 1472-1900. Madrid: Arco Libros, 1997. Vol.1, p. 9. 
en suma, su plena ciudadanía en el territorio del patrimonio cultural mexicano.

Esta afirmación se basa en un punto principal: en México todavía no se puede hablar de un catálogo colectivo que pueda informar de manera puntual sobre los libros antiguos conservados y más concretamente sobre la ubicación exacta y el estado de conservación de una edición específica. La idea de realizar este tipo de catálogo representa un viejo anhelo manifestado por numerosas personas, ${ }^{95}$ pero no ha podido concretarse por diversos motivos, entre los que cabe distinguir la falta de recursos económicos y humanos necesarios para emprender una tarea de semejante envergadura, así como la ausencia de un programa específico nacional donde participen todas y cada una de las bibliotecas públicas y privadas que poseen importantes colecciones de libros antiguos, una labor que además no puede emprenderse sin las tareas necesarias para la toma de conciencia sobre el valor patrimonial de los libros antiguos conservados y de programas de formación necesarios para iniciar las tareas de registro a largo plazo.

En este sentido no debe resultarnos extraño encontrar publicaciones en nuestro país en las que el problema del tratamiento bibliográfico o documental del libro antiguo se plantea sobre supuestos generales derivados de una lectura particular de ciertos textos, y no de una sensata puntualización sobre las características textuales y materiales que se observan en estos impresos, las que necesariamente deberían contrastarse con la información proporcionada por especialistas en la materia y por la notificación de su existencia en otros repertorios o catálogos.

Lamentablemente, el escaso conocimiento de la fuente original en México, así como el olvido de una rica tradición bibliográfica que nos antecede, han propiciado y propician confusiones en el reconocimiento del valor cultural y por tanto patrimonial del libro antiguo. ${ }^{96}$

95 Cfr. Rosa María Fernández de Zamora (2003). Op. cit.

$96 C f r$. Ernesto de la Torre Villar. "Autógrafos desconocidos de Sor Juana Inés de la Cruz en un libro más de su biblioteca”. Les cultures ibériques en devenir: essais publiés en hommage à la mémoire de Marcel Bataillon, 1895-1977. Paris: Fondation Singer-Pollinac, 1977. p. 503 
Confusiones que se ven representadas básicamente en el planteamiento e implementación de técnicas de catalogaciones específicas (pero también bibliográficas) para registrar la existencia de los libros antiguos en las bibliotecas mexicanas.

Si a esto sumamos que la catalogación en México se ha realizado desde las propuestas anglosajonas representadas en las Reglas de Catalogación Angloamericanas ( $2^{\text {a }}$ edición) que no han integrado con precisión las propuestas de la Sección de Libros Raros y Manuscritos de la Association of College and Research Libraries, ${ }^{97}$ no resultará extraño encontrar que en los textos mexicanos hay una clara confusión entre este tipo de catalogación y la metodología de la Bibliografía Material.

Entendemos por Bibliografía Material a la metodología diseñada para interpretar al libro antiguo como un objeto material que se fundamenta en las formas de producción y composición, así como las formas de distribución y por ende en las formas de posesión que lo convierten en un objeto histórico. Es decir, se trata de representar los valores textuales e históricos del libro antiguo como un objeto material, así como las peculiaridades de cada ejemplar conservado para posibilitar el estudio y la adecuada protección del objeto descrito. ${ }^{98}$

Ahora bien, la propuesta anglosajona de catalogación descriptiva para estos materiales tan específicos deriva del texto Bibliographic Description of Rare Books publicado en 1981 y de su revisión titulada Descriptive Cataloging of Rare Books ( $2^{\mathrm{a}}$ ed.) de 1991, una propuesta que ha estado permanentemente en revisión y de la cual actualmente existe en la red un documento denominado DCRM (B): Descriptive Cataloging or Rare Materials (Books) elaborada por la sección citada conjuntamente con el Comité de Estándares Bibliográficos de la Library of Congress fechada en 2005 y con una última versión en 2007.99

97 Una de sus mayores aportaciones es la explicación metodológica de la catalogación descriptiva para los libros antiguos

98 Cfr. Gaskell. Op. cit. p. 2 y Roland B. McKerrow. Op. cit. p. 43.

99 Association of College and Research Libraries. Rare Books and Manuscripts Section. Bibliographic Standards Committee. Descriptive Cataloging of Rare Materials (Books). Washington: Library of Congress, Cataloging Distribution Service, 2007. 
Por su parte, como ya hemos visto, la Bibliografía Material tiene nobles antecedentes. Su aplicación ha dado por resultado una mejor representación del libro antiguo y, en consecuencia, ha contribuido a la construcción de una valoración cultural más cercana a su naturaleza material e histórica. Sin embargo en nuestro país el conocimiento de esta metodología y especialmente de sus aportaciones sigue manifestando su ausencia en el territorio de la bibliotecología (aunque no solamente allí). Para ejemplificar esta cuestión a la que nos referimos, podemos observar cómo en una publicación reciente, ${ }^{100}$ dedicada a fortalecer el conocimiento en la formación profesional del bibliotecario sobre el tratamiento bibliográfico y documental de diversos objetos, se dan estas omisiones a las que nos referimos, especialmente las relacionadas con la metodología de la Bibliografía Material, lo que en nuestra opinión genera dificultades para soportar académicamente nuestras aportaciones en la valoración cultural del libro antiguo, pero también permiten reproducir y mantener en la formación del bibliotecario las carencias sobre este tema a las que nos hemos referido en otros trabajos. $^{101}$

De esta tendencia disciplinaria se ha generado una equívoca interpretación entre la catalogación descriptiva y la Bibliografía Material que resulta deplorable, tanto más si procede del medio bibliotecológico que tiene una responsabilidad clara en la adecuada identificación del

$100 C f r$. Sofía Brito. "El libro antiguo, un mundo olvidado en nuestras bibliotecas: elementos indispensables para su catalogación descriptiva". Organización bibliográfica y documental, compiladores Hugo Alberto Figueroa Alcántara y Cesar Augusto Ramírez Velásquez. México: unAm. Facultad de Filosofía y Letras: Centro Universitario de Investigaciones Bibliotecológicas, 2004, pp. 253262.

$101 C f r$. Idalia García "El legado bibliográfico en México: un aspecto inconcluso de la investigación bibliotecológica". Memoria del XXI Coloquio de Investigación Bibliotecológica y de la Información: la Investigación bibliotecológica en la era de la información. México: UNAM. Centro Universitario de Investigaciones Bibliotecológicas, 2004, pp. 226-247 y "Ese eterno desconocido del patrimonio cultural: el libro antiguo en México". Primer coloquio internacional del patrimonio cultural tangible e intangible. Universidad Autónoma del Estado de Hidalgo, 2004. Texto disponible en http://eprints.rclis.org/archive/00005858/01/ Hidalgo2004.pdf [Consulta: marzo de 2006] 
conocimiento ya desarrollado. Este conocimiento, tanto de la catalogación descriptiva como de la Bibliografía Material, permite soportar de mejor manera nuestras aportaciones al conocimiento y valoración del libro antiguo. Su omisión entre nuestras reflexiones solamente contribuye a crear un mayor embrollo en la correcta identificación y registro de los libros antiguos conservados. Efectivamente, la correcta identificación de conceptos, definiciones, términos y metodologías en la formación profesional y en el desarrollo de la investigación contribuiría a mejorar nuestro conocimiento sobre la riqueza cultural custodiada en las instituciones, y también a soportar el desarrollo de conocimiento en esta materia.

Actualmente en México casi todo el conocimiento que se tiene sobre estos importantes testimonios materiales es sumamente parcial y lamentablemente esporádico, de forma tal que los resultados y las conclusiones ya no se acercan a una realidad que necesariamente ha cambiado con el tiempo. En efecto, los cambios institucionales han generado la posibilidad inherente de que la colección de libros antiguos sufra alguna o algunas pérdidas importantes, que sin un adecuado registro bibliográfico podrían pasar completamente desapercibidas.

Por fortuna esto no ocurre cuando se ha desarrollado una investigación (nacional o extranjera) sobre un libro antiguo específico y, por tanto, se cuenta con datos para su identificación si ha habido un saqueo. Pero en los casos más tristes de estas tragedias culturales de alcance nacional, ni siquiera se han documentado para que la narración de los hechos impida que vuelvan a suceder. ${ }^{102}$

Ciertamente este es un deseo romántico porque refiere al tema de la historia de las bibliotecas en México y también a la condición jurídica que debería proteger su valor patrimonial. Para resolver esta última se debe consolidar, por parte del Estado mexicano, un reconocimiento

102 Prácticamente todo lo que se sabe de éstas "pérdidas bibliográficas" está basado en anécdotas y comentarios de aquellas personas que han vivido personalmente en las instituciones la falta de valoración y aprecio sobre los libros antiguos. Quizás algún día estos acontecimientos puedan documentarse como resultado de un trabajo serio de investigación histórica. 
sobre los valores culturales que otorgamos a estos libros y que deseamos transmitir, condición que se ve afectada porque en nuestro país tampoco hemos logrado distinguir la importancia de definir a la biblioteca por su función social y no únicamente por los servicios que presta. $^{103}$

En lo que se refiere en particular a la historia de las bibliotecas en México, no se ha apuntalado como un tema de investigación importante que pueda darnos una idea precisa de las colecciones de libros antiguos que en algún momento estuvieron custodiados por una biblioteca específica. Para la mayor parte de las bibliotecas en México, antiguas y modernas, no se ha elaborado una historia documentada que permita comprender su origen y su destino, así como las razones de este devenir. Lo anterior sin duda se relaciona con el estudio de la procedencia de libros antiguos que sigue siendo a la fecha una asignatura pendiente de conocimiento histórico, pese a la existencia de trabajos que constituyen las siempre honrosas excepciones.

A pesar de que todas las comparaciones son odiosas, las investigaciones y los resultados que se han obtenido en otros países han contribuido a la recuperación de los libros antiguos como objetos patrimoniales, y por esto se ha podido colocarlos en un lugar prioritario en las políticas culturales. Frente a este panorama y el trabajo que lo sustenta, la situación de los fondos antiguos de las bibliotecas mexicanas y, por ende, de los libros antiguos que en éstas se conservan parece sumamente desfavorable.

En efecto lo es, ya que todos los proyectos e iniciativas internacionales sobre libros antiguos han tenido como base sustancial el conocimiento de la riqueza cultural que se conserva en los acervos bibliográficos a los que se dedican. Lo que significa que han tenido conocimiento de su valor, porque se han realizado previamente registros e inventarios que informan puntualmente sobre la existencia de una edición, o de un ejemplar de la misma en una biblioteca específica.

Esta es la principal problemática que no se ha abordado plenamente en nuestro país. De ahí que no sea erróneo afirmar que la falta de conocimiento de estas colecciones y de las piezas que las conforman

103 Cfr. Idalia García (2002). Op. cit. pp. 43-52 
sea uno de los principales impedimentos para consolidar su importante lugar en el marco del patrimonio cultural mexicano. Afortunadamente en los últimos años esta situación ha comenzado a cambiar y con ello algunas instituciones comienzan a preocuparse por el futuro de sus fondos antiguos. Dicha preocupación ha posibilitado desarrollar proyectos de distinta naturaleza y finalidad que buscan recuperar y poner a disposición tanto las colecciones como la riqueza cultural que contienen. Sin embargo todavía no es suficiente, en la medida que la preocupación no ha alcanzado esferas importantes de trabajo y de acción política, sobre lo que es prioritario trabajar y que darían por resultado una garantía de salvaguarda para estos libros antiguos capaz de resistir el paso del tiempo y sus avatares.

\subsection{Valor patrimonial del bien bibliográfico}

La comprensión del libro antiguo como un bien bibliográfico ${ }^{104}$ reconoce que este objeto posee dos tipos de valores, los textuales e históricos a los que nos hemos referido. Por esta razón, para las instituciones que custodian este tipo de bienes se presenta una problemática específica de conservación, catalogación y valorización, ${ }^{105}$ que se corresponderá con el desarrollo de conocimiento especializado, con la protección jurídica y con el diseño e implementación de una política cultural.

Ciertamente, como cualquier objeto de naturaleza cultural, el bien bibliográfico presenta muchas problemáticas para su conservación y tratamiento que se complican aún más con el paso del tiempo, y que

104 Desde 1964, gracias a los trabajos de la Comissione d'indagine per la tulela e la valorizzacione del patrimonio storico, archaeologico, artistico e de paesaggio, mejor conocida como Comisión Franceschini, se establecieron cinco categorías de bienes: arqueológicos, artísticos e históricos, los ambientales, los archivísticos y los documentales, que por sus características propias requerían de formas de tratamiento distinto. Por esta razón, los libros forman parte de la comprensión jurídica del bien documental. $C f r$. Juan Manuel Alegre Ávila. Evolución y régimen jurídico del patrimonio bistórico. Madrid: Ministerio de Cultura, 1994. T. 1, p. 257

105 Lorenzo Baldacchini. Il libro antico: nuova edizione aggiornata. Roma: Carocci Editore, 2001. p. 11 
no podrán solventarse mientras existan carencias de ciertos conocimientos específicos y básicos como la condición material del objeto mismo. Es decir, toda acción administrativa, como la gestión cultural, debe estar precedida "por un previo acto puramente cognoscitivo". ${ }^{106}$

Es decir, entre más avancemos en informar y hacernos conscientes del nivel de la problemática que presentan los fondos antiguos en México, estaremos garantizando una preservación más efectiva y menos azarosa de la que han tenido en el pasado. Empero, las problemáticas sólo podrán resolverse si nos planteamos por principio la necesaria actividad de conocimiento sobre la composición de los fondos antiguos, su estado de conservación, y especialmente de las características singulares o representativas que permiten a ciertos elementos ser considerados como bienes culturales.

Para poder resolver las problemáticas de estos bienes, se hace necesario e imprescindible el pleno conocimiento del universo patrimonial que representan. Cualquier acción relacionada con estos bienes debe partir de conocer cuántos son, cuáles son, dónde están y cómo se conservan, para poder definir una política cultural diseñada especialmente para salvaguardar la riqueza que representan.

Si el objetivo final de toda tarea de conservación del patrimonio cultural es "proteger y transmitir la integridad física, cultural y funcional de los bienes culturales", ${ }^{107}$ debemos entonces propiciar el conocimiento de dichos bienes y esto sólo puede propiciarse a través de la elaboración de los registros e inventarios que permiten la identificación puntual de los objetos bibliográficos considerados patrimoniales. Sin dichos instrumentos, vitales toda tarea de protección y transmisión, se corre el permanente riesgo de que toda acción emprendida sea ineficaz a largo plazo.

106 Juan Manuel Alegre Ávila Op. cit. p. 255

107 Ignacio González-Varas. Conservación de bienes culturales.: teoría, bistoria, principios y normas. Madrid: Cátedra, 1999. p. 77 
En efecto, no es posible concebir ninguna acción de [...preservación y protección de bienes] del patrimonio cultural si no es partiendo del conocimiento previo, y lo más exhaustivo posible, de la realidad de bienes culturales que integran este patrimonio. ${ }^{108}$

Este registro de bienes culturales - cualquiera que sea su naturaleza- presupone a su vez un reconocimiento de que el objeto requiere tutela y protección por parte de instituciones especiales creadas para hacerse cargo de esa responsabilidad. Por norma general es el Estado quien crea, reconoce y deposita en las instituciones esta importante competencia patrimonial. Resulta evidente que para salvaguardar adecuadamente una herencia cultural se requiere antes de la elaboración de registros normalizados que permitan identificar a cada uno de los objetos del patrimonio cultural. Dicho registro debe considerar el reconocimiento de aquellas características que son singulares o especiales en cada uno de los objetos culturales.

Esta condición no parece haber sido considerada en la apreciación jurídica mexicana que incluye en la categoría de monumentos históricos a los libros antiguos. Dicha consideración solamente reconoce "rareza e importancia para la historia mexicana", lo que dificulta enormemente su protección. Por otra parte, la obligación de su registro e inventario queda bajo la responsabilidad institucional del INAH. Ahora bien, ciertamente bajo la custodia de este instituto se encuentran importantes colecciones de libros antiguos, pero no todas están bajo la custodia directa del INAH.

Por el contrario, existen numerosas bibliotecas en instituciones de educación superior, bibliotecas privadas, bibliotecas públicas de los estados, así como bajo la custodia de la Iglesia católica. Todos estos repositorios fuera de la acción del INAH poseen valiosos acervos, sin registros e inventarios de los materiales que los integran, por lo que la protección jurídica e institucional vigente en nuestro país se queda corta para asegurar la salvaguarda de la riqueza cultural que representan estos libros.

108 Ibídem. 
En verdad el INAH ha dedicado esfuerzos y actividades para registrar libros antiguos bajo su custodia como el de Fondos Conventuales ${ }^{109}$ que hemos citado, y a cuya metodología nos hemos referido someramente. No se puede decir mucho sobre esta metodología ya que el propio instituto no la ha explicado de modo puntual; solo podemos analizar la información proporcionada en las publicaciones, principalmente los catálogos impresos que se derivaron del mismo proyecto. Entre estos esfuerzos también habría que considerar que algunos proyectos en México han dado por resultado catálogos específicos de colecciones antiguas realizados por varias instituciones, ${ }^{110}$ catálogos de ciertas instituciones ${ }^{111}$ o derivados de investigaciones específicas $^{112}$ o incluso catálogos regionales como la iniciativa de la Asociación de Bibliotecas Nacionales de Iberoamérica (ABINIA), titulado Novum Regestrum ${ }^{113}$ y coordinado por la Biblioteca Nacional de España de acuerdo a la metodología internacional.

Sin embargo, la tónica general que puede apreciarse en todos estos instrumentos elaborados en México es la ausencia de un modelo único de registro bibliográfico, que es el principal problema para soportar

109 Fondos bibliográficos conventuales [CD-ROM]. México: INAH. Biblioteca Nacional de Antropología e Historia: Centro Nacional Editor de Discos Compactos, 1994.

110 ABIMEX. Antigua Bibliografía Mexicana [CD-ROM]. México: Fideicomiso para la Cultura México-Estado Unidos, 1996. La edición incluye información sobre instituciones como el Colegio de México, el Instituto Tecnológico Autónomo de México, el Instituto Tecnológico y de Estudios Superiores de Monterrey (Campus Estado de México), la Universidad de las Américas-Puebla y la Universidad Iberoamericana.

111 Pueden citarse aquí el Catálogo del Fondo reservado de la Biblioteca de México: una selección. México: CONACulTa. Dirección General de la Biblioteca de México, 1996, y el Catálogo Colonial Bibliográfico. Aguascalientes: Universidad Autónoma de Aguascalientes, 1999.

112 Podemos citar varios ejemplos interesantes, pero preferimos solamente mencionar aquí un texto que no será analizado con posterioridad: María Estela Muñoz Espinosa. Una muestra iconográfica de las estampas que guardan las obras que llegaron a la Nueva España. México: INAH, 2000.

113 Op. cit. en el capítulo 2, nota 35. Véase Fondos bibliográficos conventuales [CD-ROM]. México: INAH. Biblioteca Nacional de Antropología e Historia: Centro Nacional Editor de Discos Compactos, 1994. 
proyectos de colaboración e intercambio que a su vez redunden en la adecuada identificación de los libros antiguos conservados. Cada uno de los proyectos mexicanos mencionados ha decidido su forma de registro en función de una metodología de trabajo que no es muy clara - en tanto que no es explicada - y que da por resultado una confusión constante al localizar una edición o que incluso han creado ediciones fantasma. ${ }^{114}$

La cosa se complica todavía más si nos interesa localizar un solo ejemplar de esa edición por el valor de su procedencia. Por ejemplo, si queremos localizar los ejemplares de libros antiguos que pertenecieron a Carlos de Sigüenza y Góngora, o incluso al Colegio Apostólico de Pachuca en Hidalgo, nos encontraremos en serias dificultades. En estos proyectos los datos históricos de los ejemplares no fueron considerados de acuerdo a su relevancia o fueron registrados de manera inadecuada, por lo que no son plenamente comprensibles.

Estos resultados en el registro obligan a reflexionar sobre la importancia de la descripción bibliográfica del libro antiguo soportada por metodologías ya desarrolladas. Efectivamente,

supone también un reto ocuparse de ejemplares tan diversos como son un libro religioso del XVI, con sus particularidades, y un anuncio del servicio de diligencias del XIX. ${ }^{115}$

Sin embargo las diversas metodologías desarrolladas, tanto internacionalmente como aquellas derivadas de nuestra tradición, permiten augurar un futuro viable para el adecuado registro bibliográfico de libros antiguos, siempre y cuando se soporte sobre el conocimiento ya desarrollado y especialmente sobre sus resultados. Con esta condición estaríamos en posibilidad de eliminar el sombrío pasado que ha acechado a la custodia de libros antiguos en México.

Por otra parte, el olvido de la tradición bibliográfica tan notable de nuestro país, no ha contribuido de ninguna manera a mejorar nuestra comprensión del problema patrimonial que representan y representarán

114 Cfr. Julián Martín Abad (1993). Op. cit. pp. 286-287

115 Fermín de los Reyes Gómez. Op. cit. p. 9 
los libros antiguos. Efectivamente, este olvido no sólo ha afectado la valoración cultural y social de estos objetos, sino a todas las fuentes originales tanto bibliográficas como documentales. En la formación profesional de historiadores, bibliotecarios, archivistas, literatos y otras disciplinas de las humanidades, se ha devaluado la formación necesaria en metodologías bibliográficas y documentales que sin duda nos garantizaría "un ejército de cruzados" necesario para el registro de las fuentes originales, ${ }^{116}$ y en consecuencia, una mejor salvaguarda del pasado escrito para las generaciones futuras.

Dicha devaluación y olvido ${ }^{117}$ puede constatarse en la mera revisión bibliográfica sobre la que se soportan los proyectos institucionales y los textos de la literatura. En ambos se nota la ausencia tanto de los autores fundamentales de la Bibliografía Material, como los relacionados con la catalogación descriptiva. Ni mencionar lo relacionado a nuestra tradición bibliográfica y documental, que se encuentra referenciada para la localización de un libro, pero no en lo que corresponde a la metodología sobre la que se soportan dichos trabajos.

En este sentido pareciera que el desconocimiento de esas aportaciones disciplinaria, podría justificar los equívocos y primordialmente la falta de comprensión del valor cultural que representan los libros antiguos. Lo cierto es que esta situación respecto a las aportaciones del conocimiento bibliográfico sólo puede explicarse si lo denominamos como "negligencia de conocimiento", que significa meramente la omisión por desconocimiento o un mero desinterés hacia los textos que han sido considerados como medulares o más importantes en el desarrollo del conocimiento disciplinario en la materia $(v, g r$. Haebler, Gelder, Gaskell, McKerrow, Bowers, Tanselle, Simón Díaz, Moll, López

116 Rosa María Fernández de Zamora. "Sobre la bibliografía en México: reflexiones y comentarios. Jornadas Mexicanas de Biblioteconomía: Memorias (12: 1981: San Luis Potosí). p. 50. Especialmente lo relacionado a la elaboración de "tesis bibliográficas".

117 Aún cuando este fenómeno no puede documentarse puntualmente, porque no se ha desarrollado investigación sobre el tema, se puede observar en los programas de formación la falta sobre las metodologías mencionadas tanto de la tradición bibliográfica y documental que nos antecede como de los desarrollos en esta materia procedentes de otras latitudes. 
Huertas, Montaner, Abad, por tan sólo mencionar algunos). Efectivamente, estos textos y los desarrollos de la catalogación descriptiva, más las aportaciones contemporáneas derivadas de la comprensión de los bienes culturales, conforman un entramado de conocimiento que nadie debería soslayar. Sin embargo, la evidencia muestra que la mayor parte del trabajo realizado en nuestro país no solamente obvió esa información sino que la ha considerado de bajo nivel académico.

Esto resulta sumamente interesante considerando que desde 1980 (en que se publicó su primera edición) ${ }^{118}$ existe la norma internacional ISBD (A) para la descripción bibliográfica de libros antiguos, y que ésta es el resultado de las reflexiones conjuntas entre las aportaciones de la Bibliografía Material y de la catalogación descriptiva, lo que significa que los trabajos mexicanos más relevantes en esta materia se realizan cuando las aportaciones mencionadas, internacionales y disciplinaria, ya han sido objeto de reflexión y discusión especializada.

Para la década de los noventa, una parte importante de esta información ya circulaba en la red y podían observarse incluso parte de los resultados de los más relevantes catálogos colectivos de patrimonio bibliográfico. Entonces, ¿̇por qué no se consideró la pertinencia de introducir estas aportaciones metodológicas en los trabajos mexicanos? En realidad resulta difícil dar una respuesta a esta interrogante que pueda justificar el desatino de las acciones emprendidas en relación a la riqueza del bien bibliográfico conservado.

Pero lo que resulta más sugestivo en estos trabajos es la diversidad metodológica en la descripción bibliográfica de libros antiguos, frente a la existencia de una tradición bibliográfica notable que dio por resultado repertorios bibliográficos que aún se utilizan y consultan, como los de García Icazbalceta, Toribio Medina o Yhmoff Cabrera. Los repertorios realizados a la fecha nos dan una idea cercana sobre la falta de conocimiento que tienen varios autores sobre modelos bibliográficos, y más aún, de la tradición bibliográfica que los sustenta.

Esta ausencia de conocimiento no puede tener otro origen que la falta de formación profesional en materia de Bibliografía Material y los métodos que la caracterizan. Ciertamente existen muchas formas de 
hacer un registro bibliográfico, pero cuando se trata de materiales antiguos existen métodos y técnicas que no deben pasar desapercibidos por las personas que realizan esos registros debido a la importancia cultural involucrada.

Es decir, existe cierto tipo de datos que no deben ser obviados al realizar un registro de una edición antigua. Esto debe ser entendido de esta manera básicamente por dos razones: la primera, es la posibilidad de detectar con precisión las diferentes variantes existentes en la impresión de una sola obra; la segunda, es la identificación plena del ejemplar que pertenece a una colección específica y no a otra.

En relación a esto último, debido a que representa parte de la caracterización patrimonial, sabemos que de una sola obra impresa pueden existir varios ejemplares en distintas bibliotecas, pero por razones históricas un ejemplar de la misma obra se distingue de otro, y esta condición es la única forma de determinar que una obra pertenece a una colección específica. Esta información resulta crucial no sólo para el desarrollo del conocimiento de los libros antiguos que se custodian tanto en México como en otros países, sino para poder identificar plenamente el objeto en cuestión en caso de saqueo o pérdida.

De ahí que la descripción bibliográfica de un libro antiguo, independientemente de si se elabora para un catálogo de biblioteca como para un repertorio bibliográfico específico, requiera del conocimiento de las características materiales que distinguen a los libros antiguos pero también de aquellas que distinguen y diferencian a un ejemplar de otro. Nos referimos al estudio e identificación de la procedencia de un libro, en suma, a la identificación de los elementos que testimonian la historicidad de un objeto y que solamente puede realizarse con "la observación minuciosa de cada libro". 119

Resulta relevante la elaboración de un registro bibliográfico lo más completo posible y de acuerdo con las metodologías más idóneas, si se piensa en la necesidad de contar con un catálogo colectivo de libros

119 Esto se refiere a la descripción de ejemplares soportado sobre la descripción de ediciones y que resulta un elemento "esencial para libros antiguos". Cristina Herrero Pascual. "Metodología para un catálogo de libros del siglo XVI". Revista General de Información y Documentación. Vol. 6, no. 2 (1996). p. 12 
antiguos para México en algún futuro cercano, porque de esta manera un solo registro sirve para identificar todos los ejemplares existentes semejantes pero con la identificación de las diferencias no sólo en la impresión, sino también en lo que se refiere a la integridad y la autenticidad de un objeto. Pero también si queremos identificar en este los elementos históricos que hacen singular a un ejemplar, entre aquellos de naturaleza compartida, identificación de datos que servirán principalmente para fortalecer la comprensión patrimonial de los libros antiguos conservados en nuestro país.

Desde esta perspectiva, la patrimonial, es que se puede distinguir la importancia de la descripción bibliográfica de acuerdo a una metodología concreta o a una propuesta de descripción soportada sobre trabajos previos y, por tanto, los planteamientos en relación a esta no resultan una mera vanidad ociosa sino una consecuencia directa de la responsabilidad cultural que dicho trabajo implica a largo plazo. Efectivamente, la responsabilidad sobre este tipo de patrimonio también implica la transmisión correcta de las ediciones y de los ejemplares conservados.

Llegados a este punto, si convenimos creer, como es justo, en la existencia de 'fantasmas bibliográficos', es necesario, sin embargo, resistir a la tentación de creer en la existencia (real) de individuos bibliográficos sólo cuando estemos en contacto material con ellos. Si es cierto que en muchísimos trabajos de carácter bibliográfico [...] existe un deber moral y cultural de trabajar sobre las publicaciones; si es cierto que, en todo caso, sólo el examen directo del libro y un encuentro 'objetivo' pueden asegurar sin margen de duda su realidad bibliográfica y pueden confirmar de primera mano la exactitud de los elementos que han servido para unirse con él; también es cierto que en muchos otros casos (o mejor, en la generalidad de los casos) el testimonio de una fuente primaria, es decir de una bibliografía que haya registrado los datos extrayéndolos directamente del documento, puede bastar para garantizarnos su existencia y la descripción exacta de una edición. ${ }^{120}$

120 Rino Pensato. Curso de Bibliografía. Gijón: Trea, 1994. p. 68 
Además es necesario comprender que la elaboración de un repertorio bibliográfico o de una referencia bibliográfica destinada a la investigación también implica garantizar plenamente la identificación de un material particular en una colección específica, con objeto de que otros en el futuro puedan localizar ese mismo objeto para realizar su propia lectura histórica. Este punto es quizá un problema que en México se ha considerado muy a la ligera. Efectivamente, la notificación de la existencia de un libro antiguo (tanto de una edición como de un objeto histórico) conlleva otras responsabilidades más allá de las meramente históricas y culturales. Hablamos de que dicha existencia conlleva la tutela de un objeto patrimonial.

En un país como el nuestro, donde estos objetos no son valorados en su justa medida, dicha notificación lamentablemente abre una puerta al saqueo y la destrucción de un libro conservado durante siglos, porque la mayor parte de las instituciones no están preparadas adecuadamente para la custodia de bienes patrimoniales. La información puntual sobre un libro antiguo donde se registren tanto sus valores textuales como los elementos históricos proporciona la información más fiable y documentada para realizar la puesta en valor y en consecuencia también se posibilita la traducción de dichos valores en términos económicos.

Pero dicha información también implica que el objeto registrado se caracteriza de forma tal que solamente una institución específica puede tenerlo y cualquier cambio en esta situación de la custodia debe tener una explicación medianamente razonable. Desde nuestra forma de comprensión, este es el lugar donde las aportaciones bibliográficas coadyuvan a la salvaguarda institucional de un libro antiguo, y también contribuyen a la construcción de su valor cultural para la transmisión entre generaciones de su herencia patrimonial.

¿De qué otra manera podemos explicar que actualmente no se encuentren en nuestras colecciones objetos descritos en repertorios del pasado, mediatos e inmediatos? Sin duda este aspecto se refiere directamente a la responsabilidad de la custodia, pero también y lamentablemente nos habla de la falta de consideración de la importancia que conlleva la salvaguarda de bienes culturales y por tanto de su adecuado registro e inventario. 
Dicha tarea es prioritaria para la comprensión del problema que representa, y requiere de la aplicación de normas probadas como las internacionales. Pero esta tarea también implica comprender cabalmente que el registro

de libros antiguos presenta dificultades que ordinariamente los libros modernos no tienen. Requieren unos detalles de descripción más precisos para identificar características más significativas, como la disposición del papel o la distinción entre ediciones, emisiones y estados. Estos detalles son importantes porque permiten la identificación de las distintas copias de un libro y proporcionan una exacta descripción de él, ${ }^{121}$

y posibilitaría sin duda su recuperación en caso de saqueo. Los resultados de los grandes catálogos internacionales que se han elaborado y se elaboran bajo la norma ISBD (A) permiten observar que una gran parte de la información contenida en estos libros puede ser objeto de la normalización, aunque algunos no sean partidarios de esta idea.

Sin embargo en los libros antiguos, por la condición de producción manual, cualquier elemento puede alterar esa supuesta regularidad, ${ }^{122}$ que fortalece la normalización, y requerir soluciones especiales en la elaboración de un registro bibliográfico que permita identificar y precisar la particularidad existente. Una particularidad que no puede solucionarse desde una norma específica, ya que esta no puede ser la función exclusiva de la normalización. En suma, una norma no puede prever todos los diferentes casos que se presentarán, será tarea de la persona encargada de realizar los registros modificar o adecuarlas para dar lugar a ese material singular. Pero también debemos reconocer que normalizar coadyuva a mejorar la comprensión del problema patrimonial y, a diseñar mejores mecanismos para la adecuada salvaguarda.

De ahí que realizar cualquier descripción bibliográfica de un libro antiguo requiera conocer exactamente cómo se producían esos libros y cómo es la evolución gradual de los procesos de producción. De esta

121 Cristina Herrero Pascual. Op. cit. p. 11

122 Julián Martín Abad (2004a). Op. cit. p. 37 
manera se puede ubicar el periodo histórico de un material que carece de algunos datos para facilitar su identificación — de qué edición se trata-, ya sea porque así fue impreso o porque su propia historia lo ha mutilado.

Técnicamente la comprensión de un libro antiguo no resulta de gran complejidad, pero el conocimiento de los elementos estructurales de la forma material es sustancial para analizar y comprender al libro no sólo desde el aspecto literario de su contenido, sino también desde los puntos de vista de aquellos que compusieron, corrigieron, imprimieron y encuadernaron ese material. Sólo de esta manera el libro puede ser comprendido como una unidad compuesta de partes en las que se relacionan procesos distintos derivados de características, culturales, económicas, sociales y políticas claramente definidas.

Efectivamente, el conocimiento del libro antiguo como objeto histórico desde una disciplina como la bibliotecología, implica necesariamente la identificación de la estructura material, que podría singularizarlo, y también lo que corresponde a los elementos que testimonian su historicidad. La suma de estos datos compone el valor patrimonial que hace a estos objetos bienes bibliográficos, por lo que es nuestra responsabilidad profesional y cultural contribuir a su adecuada representación. De esta manera el valor patrimonial reconocido puede transmitirse a las generaciones venideras como parte de su legado.

De ahí que la valoración patrimonial y su correspondiente representación bibliográfica conformen nuestra manera de comprender ese legado cultural y en consecuencia nos informan sobre el lugar que tiene este patrimonio en nuestras preocupaciones disciplinaria aunque también sociales. La responsabilidad del adecuado registro de un libro antiguo es una tarea concreta que podemos abordar sin complicaciones para contribuir a la salvaguarda de unos materiales que han esperado pacientemente su reconocimiento patrimonial en nuestro país. 


\section{Representación bibliográfica del libro antiguo en México}

También podemos coincidir en que una descripción solo será inteligible y defendible en relación al conjunto de descripciones del que forma parte

Geoffrey Hawthorn (1995)

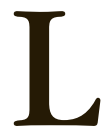
a intención primordial de estas líneas no es realizar una historia de la bibliografía y de sus prácticas, tarea que otros ya han emprendido de forma más que satisfactoria. Aquí pretendemos analizar, con los datos disponibles, los modelos bibliográficos que se han empleado en México desde Eguiara y Eguren hasta el año 2007, para fundamentar una propuesta de modelo de descripción del libro antiguo y la razón cultural que lo explica. Desde nuestra perspectiva, es necesario este análisis porque la rica tradición bibliográfica que distingue a este país debería ser de conocimiento tanto del bibliotecario que custodia estos objetos como del investigador que los emplea como fuente de conocimiento.

No obstante es conveniente hacer algunas precisiones importantes que nos ayudan a comprender las formas de representación bibliográfica de libros antiguos que se han empleado en México, como manifestación directa de la valoración cultural y patrimonial que representan. Especialmente porque esa comprensión incide de manera directa en la transmisión de esos valores a través de registros bibliográficos. Entre estas precisiones, una fundamental: la carencia de revisión histórica sobre una metodología bibliográfica que tuvo admirables protagonistas, cuyos trabajos siguen siendo utilizados hoy en el desarrollo 
de conocimiento ${ }^{123}$ y que observaremos al contrastar los textos históricos dedicados a la bibliografía que se han elaborado en otras latitudes, con los realizados en nuestro país.

Es más, estos repertorios a los que nos referimos todavía constituyen en México y en otros lugares, en las más de las ocasiones, el soporte principal de las aportaciones de conocimiento histórico orientadas a definir tendencias en la lectura de una época o incluso en las características de la producción bibliográfica, frente al empleo y análisis de fuentes primarias tanto bibliográficas como documentales. Dicha tendencia historiográfica también en gran parte determina la responsabilidad institucional y social de los acervos de custodia, como bibliotecas y archivos, que precisamente implica elaborar registros e inventarios de acuerdo a criterios internacionales, para garantizar la permanencia futura de las colecciones de libros antiguos y de documentos históricos como patrimonio documental.

De ahí que necesitemos partir de comprender el concepto que define a la bibliografía como una disciplina del conocimiento, el cual ha sido analizado numerosas veces en la búsqueda por definir una práctica y las metodologías que la han caracterizado desde el siglo XVI hasta la fecha, mediante las cuales se ha registrado y transmitido parte del conocimiento humano. En México, a pesar de esta relevancia histórica y cultural, actualmente la práctica bibliográfica no goza de toda la estimación académica que debiera, tal vez porque se le comprende como una actividad meramente instrumental donde se distinguen únicamente sus aspectos técnicos más que los motivos conceptuales que la propician y justifican, siendo crucial para el desarrollo del conocimiento. ${ }^{124}$

123 Los trabajos mexicanos que se distinguen de esta tendencia ya que hacen una revisión histórica de los personajes y de su tiempo serían: Alicia Perales Ojeda. La cultura bibliográfica en México. México: UNAM. Instituto de Investigaciones Bibliográficas, 2002 y Emma Rivas Mata. Bibliografías novobispanas o bistoria de varones eruditos. México: INAH, 2000. Sin embargo ninguno analiza la evolución y justificación de las metodologías bibliográficas.

124 Cfr. Luigi Balsamo. La bibliografía: historia de una tradición. Gijón: Trea, 1998. pp. 11-12 
La historia de esta práctica debemos insertarla en los procesos de difusión de la cultura que han existido en el pasado y que son necesarios en el presente, los cuales le otorgan una identidad disciplinar todavía vigente. Efectivamente, el concepto bibliografía puede ser comprendido desde dos posturas principales: aquella general que la define como una lista de publicaciones útil para la recuperación de información, y otra, que la comprende como el estudio de los libros desde su condición de objetos físicos. ${ }^{125}$

En ambas posturas, vertidas en diferentes publicaciones a lo largo de la historia, podemos encontrar un campo de conocimiento que entiende a los libros como entidades físicas y, por tanto, afecta al conocimiento de su historia, de los materiales y los métodos empleados en su fabricación, pero también a la evolución histórica en su descripción y compilación en listas o repertorios. Estos últimos, los repertorios bibliográficos, son los que han determinado el origen del término en su comprensión moderna, que también los designa como bibliografías aun cuando no hayan sido denominados de esta manera en la época de su elaboración: recordemos que algunos de los primeros repertorios de naturaleza bibliográfica solían denominarse "bibliothecas", "index", "repertorium", "inventarium", entre otros". 126

De ahí que sea necesario apuntar que existe una relación histórica directa entre la bibliografía y las primeras listas elaboradas para identificar las colecciones de las bibliotecas antiguas, o con los primeros listados de libros en circulación para venta. Por esta razón es que la historia de la bibliografía no puede realizarse basándose únicamente en el momento en que comienza a definirse con este término a las técnicas y métodos de descripción, que caracterizaron a una época determinada y que constituyeron un cierto canon bibliográfico empleado por los bibliógrafos o eruditos. Por ello no parece lo más correcto ubicar el nacimiento de esta práctica necesariamente con la aparición de la imprenta de tipos móviles, en tanto que ya se había manifestado

125 John Carter. ABC for book collector. New Castle, Delaware: The Oak Knoll Press, 1998. p. 37

126 Juan Delgado Casado. Introducción a la bibliografía: los repertorios bibliográficos y su elaboración. Madrid: Arco Libros, 2005. p. 15 
con anterioridad la necesidad de informar sobre la existencia de la información conservada. Sin duda esta tecnología contribuyó notablemente al desarrollo de la bibliografía y le permitió consolidarse como una disciplina propia.

Partiendo de este principio podemos comprender que el concepto bibliografía refleja una forma de describir objetos bibliográficos conforme a una metodología específica determinada por una finalidad concreta. Al fijar la atención en dichas metodologías el concepto inicial se va restringiendo para establecer divisiones del concepto original. Así comienzan a aparecer términos como bibliografía textual, descriptiva, analítica y otros más. Lo que se observa en esta subdivisión de términos es una aparente pérdida de la historicidad que posee cada una de las metodologías desarrolladas, así como las razones culturales que explican y fundamentan el trabajo bibliográfico. Dicha pérdida aparentemente se refiere a una carencia en la estimación o la valoración, y ve sus resultados como ajenos a las tareas intelectuales.

En México, dicha pérdida no es falta del concepto en sí ni de la subdivisión que se ha realizado sobre el mismo, sino la ausencia de cierta perspectiva histórica de la disciplina que cobija este conocimiento, y que por tanto, se traduce en una falta de recuperación de su propio pasado. Es decir, falta reflexión histórica sobre todo lo que compete a la bibliotecología contemporánea nacional, tanto en los aspectos que se relacionan con la investigación, la formación profesional y, por supuesto, las instituciones bibliotecarias, lo que significa que debemos preguntarnos sobre cómo comprendemos, explicamos y transmitimos tanto el devenir de la bibliotecología mexicana como el de sus productos y efectos sociales.

Si bien podemos encontrar excelentes trabajos sobre la historia de la bibliografía en otras latitudes, podremos observar en la mayoría de ellos una falta de análisis histórico sobre los métodos que la han soportado y cómo éstos han evolucionado. En suma, esa mayoría comprende la historicidad de la práctica bibliográfica como una serie de eventos relacionados, sin dar importancia a las razones que han justificado dicha evolución y que se verán reflejados en los registros elaborados y en las metodologías empleadas. ${ }^{127}$

127 Luigi Balsamo. Op. cit. 
En efecto la mayoría de este tipo de trabajos históricos (descontando las siempre notables excepciones como las caracterizaciones políticas e ideológicas del trabajo de Emma Rivas Mata) encontraremos la relación de aquellos personajes que contribuyeron al desarrollo de la bibliografía y una descripción general sobre los repertorios de su autoría. Pero lo que debemos distinguir es cómo el acercamiento a esta comprensión histórica de la bibliografía exclusivamente nos muestra la forma en que la práctica de registro ha sido relacionada con significados tales como lista de libros, conocimiento de manuscritos, ciencia del libro, ciencia de las bibliotecas, ciencia de los repertorios y también como parte de la documentación que se ocupa de los impresos. ${ }^{128}$

Pero esta apreciación no logra explicar puntualmente de qué forma la práctica bibliográfica y los modelos de descripción empleados van a definir una caracterización de los tipos de bibliografía según el material que se describe, más que en función del modelo bibliográfico empleado. Como indica McKenzie, la bibliografía es la disciplina que estudia los textos en tanto formas conservadas, así como sus procesos de transmisión, de la producción a la recepción. ${ }^{129}$ De esta manera, si nos acercamos a la evolución de las formas metodológicas de la bibliografía, encontraremos dos tendencias aparentemente definidas: la primera forma, que podríamos denominar "de tradición", que recupera los repertorios elaborados en un espacio geográfico definido y que se copian unos a otros sin argumentar su validez o fiabilidad y sin analizar la forma metodológica que los soporta; y la segunda que podríamos denominar "normalizada", que constituye una práctica de descripción bibliográfica contemporánea definida por formas de producción y evaluación del conocimiento, y que se enseña e implementa desde los centros de educación superior.

Desafortunadamente ambos tipos de metodologías no han logrado consolidarse como prácticas generalizadas en los distintos campos de conocimiento, y en consecuencia no siempre se transmiten en los centros

128 José Simón Díaz. La bibliografía: conceptos y aplicaciones. Barcelona: Planeta, 1971. pp. 13-18

129 D.F. McKenzie. La bibliographie et la sociologie des textes, préface de Roger Chartier. París: Éditions du Cercle de la Librairie, 1991. p. 30 
de formación, situación que se explica por el problema de valoración de la actividad y sus resultados al que nos hemos referido, que necesariamente genera diversas interpretaciones y prácticas sobre la descripción bibliográfica de las distintas fuentes de información. En este panorama podemos distinguir lo que corresponde a la Bibliografía Material y a las normas ISO, metodologías que gradualmente han logrado un lugar propio y que pese a las diferentes interpretaciones que de ellas se realicen, mantienen lineamientos comunes que posibilitan y favorecen el intercambio de información así como la adecuada recuperación de los objetos que se describen.

Sin embargo, no será sino hasta finales del siglo XIX y principios del XX, que se sentarán las bases primordiales del trabajo bibliográfico que actualmente reconocemos como una disciplina del conocimiento, al paralelo de las transformaciones científicas que transformaron las actividades intelectuales. Gracias a estos desarrollos los diversos tipos que se reconocen en la bibliografía también evolucionarán en relación directa con sus finalidades. Así se separarán dos campos en la práctica bibliográfica: una, general, que se caracteriza por una descripción breve y que será la tónica que caracteriza a los modelos normalizados, y otra descripción más erudita, la cual

precisará ser mucho más detallada que la que se requiere para la mayoría de las obras contemporáneas y [en la que] cada variante que se descubra debe ser debidamente registrada. ${ }^{130}$

Esta forma particular del trabajo bibliográfico es la que en lengua española identificamos como Bibliografía Material, nombre que ya había sido dado por Ebert — bibliógrafo alemán—, ${ }^{131}$ quien a pesar de esta consideración se acercará más a una definición de la bibliografía como la "ciencia de los libros". Pero no será hasta la traducción española

130 A.M. Lewin Robinson. Introducción a la bibliografía: guía práctica para trabajos de descripción y compilación. $4^{\mathrm{a}}$ ed. Madrid: Fundación Germán Sánchez Ruipérez, 1992. p.14

131 Citado por Georg Schneider. Theory and bistory of bibliography / translated by R.R. Shaw. New York: Columbia University, 1934. University Microfilms International 1987. p. 48. 
de las obras de McKerrow ${ }^{132}$ en 1998 y Gaskell ${ }^{133}$ al año siguiente, que este término se afiance en la literatura especializada de algunos países.

Pese a esta aparente evolución propiciada por la propia práctica de registro, especialmente de impresos producidos entre el siglo XVI y el XVIII,

tanto la bibliografía material como la enumerativa tienen diversas ramificaciones, lo que ha dado lugar a distintas acepciones de la palabra bibliografía, que se convierte en un término polisémico. ${ }^{134}$

En los diversos modos de comprensión será definida como especial, descriptiva, textual, catalográfica, histórica e incluso bibliofílica, ${ }^{135}$ pero siempre referirá a la construcción de un modelo de descripción donde el libro es el fin en sí mismo.

La complejidad de este aspecto requeriría de un espacio propio de reflexión, que sin duda otros han emprendido de forma más acertada. Aquí interesa comprender a la descripción bibliográfica de impresos antiguos como Sir Walter Greg definió a la bibliografía: simplemente el estudio de los libros como objetos materiales. ${ }^{136}$ Nos interesa partir de esta definición porque como hemos ya aclarado, esta finalidad es la que caracteriza a la Bibliografía Material y nos permite introducirnos en el desarrollo metodológico que se ha dado en nuestro país para registrar libros impresos de manufactura posterior al siglo XV y hasta el siglo XVIII.

\subsection{La tradición bibliográfica}

Pese al argumento anterior podemos comprender como una tradición propia a los repertorios bibliográficos realizados en México, que

132 Roland B. McKerrow. Op. cit. Publicada en 1927.

133 Phillip Gaskell. Op. cit. Publicada en 1949.

134 Juan Delgado Casado. Op. cit. p. 15

135 Georg Schneider. Op. cit. pp. 48-49.

136 Roy Stokes. A bibliographical companion. Metuche, N.J.: The Scarecrow Press, 1989. p. 18 
se pueden dividir en dos periodos precisos relacionados con la producción de repertorios y con una metodología que los caracterizó. El primero de estos periodos correspondería a la recuperación histórica de la producción bibliográfica del pasado que comienza con la obra de Eguiara y Eguren, seguida por los trabajos de José Mariano Beristáin de Souza,${ }^{137}$ Joaquín García Icazbalceta, ${ }^{138}$ Vicente de Paula Andrade, ${ }^{139}$ Nicolás León ${ }^{140}$ y los del chileno José Toribio Medina ${ }^{141}$ sobre la imprenta en diversas ciudades mexicanas. En efecto, este rico periodo histórico fue posible gracias a los esfuerzos por recuperar las fuentes antiguas de la época novohispana.

El segundo periodo estaría compuesto por los trabajos de revisión y adición a los repertorios del grupo arriba señalado. Esta parte de la tradición tuvo seguimiento, en cuanto al método descriptivo, en los trabajos de Valton, ${ }^{142}$ Zulaica Gárate, ${ }^{143}$ Wagner ${ }^{144}$ y González de Cossío, ${ }^{145}$ pero habría que aclarar que estos autores se enfocaron a enriquecer la información sobre los impresos mexicanos del siglo XVI debido a su importancia cultural, con excepción de González de Cossío que incluye información de impresos hasta el siglo XIX.

137 José Mariano Beristáin de Souza. Biblioteca Hispano Americana Setentrional. $2^{\text {a }}$ ed. Amecameca: Tipografía del Colegio Católico, 1883. 3 tomos.

138 Joaquín García Icazbalceta. Bibliografía mexicana del siglo XVI: catálogo razonado de libros impresos en México. México: Librería de Andrade y Morales, Sucesores, 1886.

139 Vicente de Paula Andrade. Ensayo bibliográfico mexicano del siglo XVII. $2^{\mathrm{a}}$ ed. México: Imprenta del Museo Nacional, 1899.

140 Nicolás León. Bibliografía mexicana del siglo XVIII. México: Imprenta de la Viuda de Francisco Díaz de León, 1902-1908.

141 José Toribio Medina. Op. cit.

142 Emilio Valton (1935). Op. cit.

143 Román Zulaica Gárate. Los franciscanos y la imprenta en México en el siglo XVI. México: Editorial Pedro Robredo, 1939 (Consulta sobre el facsimilar editado por el Instituto de Investigaciones Bibliográficas de UNAM en 1991)

144 Enrique W. Wagner. Op. cit.

145 Francisco González de Cossio. La imprenta en México 1594-1820: cien adiciones a la obra de don José Toribio Medina. México: Antigua Librería de Robredo de José Porrúa e Hijos, 1947 y La imprenta en México, 1153-1820: 510 adiciones a la obra de José Toribio Medina en homenaje al primer centenario de su nacimiento. México: Universidad Nacional de México, 1952. 
En este grupo podemos incluir la edición anotada del repertorio de García Icazbalceta realizada por Agustín Millares Carlo, ${ }^{146}$ quien ha hecho a este repertorio más valioso en términos documentales e históricos que original decimonónico, ya que como el propio Millares Carlo indica, se preocupó por "precisar en cada caso el paradero de los ejemplares que [García Icazbalceta] tuvo a la vista, con indicación de los Catálogos de Bibliotecas en que se les reseña o menciona”. ${ }^{147}$

Es preciso aclarar que esta tarea de continuidad sobre el trabajo bibliográfico se debe en gran parte a Genaro Estrada, quien organizó la serie de publicaciones conocida como Monografías Bibliográficas Mexicanas entre las que se encuentran los trabajos de Rafael Sala sobre marcas de fuego, el de Ramón Mena sobre filigranas, Felipe Teixidor sobre ex libris, o la de Ermilo Abreu Gómez sobre la biblioteca y bibliografía de Sor Juana. ${ }^{148}$

Este acercamiento histórico nos ayudará a comprender la tradición bibliográfica que nos antecede, y nos permite coincidir con Malclés en que una de las características primordiales de los primeros repertorios bibliográficos compilados por la gente del saber, es que informan "admirablemente sobre los autores y su pensamiento y también, aunque secundariamente, sobre sus libros". ${ }^{149}$ Pese a esta característica, que hoy nos hace identificarlos como biobibliografías, estos repertorios sentaron las bases de trabajo; que evolucionaron gradualmente de una somera descripción de libros, a una descripción detallada y precisa de los mismos.

Ahora bien, los trabajos de descripción bibliográfica que aquí analizamos pueden ser considerados como una forma de apreciación que testimonia el cambio de la valoración sobre el libro como objeto, tanto de arte como de conocimiento. Los modelos se presentan cronológicamente para analizar el registro mismo y no al objeto que se describe.

146 Agustín Millares Carlo. "Prólogo a la presente edición" en Joaquín García Icazbalceta. Bibliografía mexicana del siglo XVI: catálogo razonado de libros impresos en México de 1539 a 1600.México: FCE, 1954.

147 Ibíd.p. 9

148 Roberto Ramos. "Estado actual de la bibliografía en México". Boletín de la Biblioteca Nacional de México. T. 8, no. 1 (enero-marzo de 1957). pp. 17-19.

149 Louise Nöelle Malclés. La bibliografía. Buenos Aires: EUDEBA, 1960. p. 14 
Es decir, no trabajamos sobre el objeto material, sino sobre la representación de ese objeto y solamente observamos las diferencias más notorias en comparación con otras representaciones realizadas en bibliotecas o cuando el repertorio se acompaña de reproducciones de portadas. Sobre este punto hay que aclarar que la mayoría de los repertorios no incluyen las reproducciones fotográficas de los libros que describen, probablemente porque cualquier edición encarece su precio de producción si así ocurre. ${ }^{150}$

Una vez hecha esta aclaración podemos decir que nuestra propia tradición comienza con el repertorio de Juan José de Eguiara y Eguren, mejor conocido por el título corto de Bibliotbeca Mexicana ${ }^{151} \mathrm{e}$ impreso en 1755. Este trabajo resulta interesante por la decisión metodológica del autor registrar a los autores compilados por sus nombres y no por sus apellidos, ${ }^{152}$ así como dar noticia de los libros o textos producidos latinizados, decisión que ha sido analizada y juzgada de diferentes maneras. ${ }^{153}$ Esta decisión convierte al repertorio en una biobibliografía, desde nuestra comprensión moderna, y es una apuesta metodológica llamativa porque el trabajo fue elaborado en pleno periodo de la Ilustración y cuando la bibliofilia ha comenzado su plena expansión, por tanto, ya se han realizado cambios importantes en las metodologías bibliográficas. ${ }^{154}$

Las razones que justifican esta decisión fueron dadas a conocer por el propio autor en el texto que antecede a su obra (Anteloquia) y que fue traducido y publicado en un libro aparte por Agustín Millares Car10. ${ }^{155}$ No cabe duda de que las aportaciones de Eguiara y Eguren, no

150 Fredson Bowers. Principios de descripción bibliográfica. Madrid: Arco Libros, 2001. p. 179, nota 5.

151 Como se sabe los títulos de los impresos antiguos sueles ser bastante largos, e incluyen otra información adicional más allá del título propiamente dicho.

152 Alicia Perales Ojeda. Op. cit. p. 122

153 Cfr. Agustín Millares Carlo. Don Juan José de Eguiara y Eguren (1675-1763) y su Biblioteca Mexicana. México: UnAM, 1957.

154 Andrew Maunsell es el primero que organiza los registros bibliográficos según los apellidos de los autores en 1595. Cfr. Luigi Balsamo. Op. cit. p. 61

155 Juan José de Eguiara y Eguren. Prólogos a la Biblioteca Mexicana / versión española anotada, con un estudio biográfico y la bibliografía del autor por Agustín Millares Carlo. México: FCE, 1944. p. 245. 
solamente como bibliógrafo, sino como autor de varias obras y también por su actividad de censura manifiesta en los preliminares de numerosas ediciones de la época, constituyen el origen de una tradición bibliográfica que dará continuidad a la obra de Antonio de León Pinelo y Nicolás Antonio, ${ }^{156}$ aunque la obra de Eguiara debe asumirse como una particular comprensión y valoración del problema cultural que le ocupa, donde su prioridad será documentar que en "estas tierras" también se da el desarrollo de conocimiento y así contrastar las versiones adversas a la cultura americana existentes en Europa y manifestadas por numerosos autores.

De esta manera, en el repertorio de Eguiara la producción bibliográfica se verá reflejada a través de sus emisores, por lo que los manuscritos e impresos serán registrados brevemente y, en la mayoría de las ocasiones, sin pie de imprenta. Eguiara también proporciona información de referencias bibliográficas donde se ha registrado la producción que le interesa distinguir, pero especialmente las obras donde ha sido citado ese mismo objeto, lo que nos muestra la erudición y las lecturas del autor. Además indica, cuando se trata de manuscritos, el lugar en que se encuentra conservado el material. Para dar continuidad a esta tradición, Beristáin de Souza comienza en 1794 su propio repertorio bibliográfico con el ánimo de concluir la tarea emprendida por Eguiara.

Para esta labor Beristáin recupera los manuscritos del repertorio de Eguiara que localizó hasta la letra "J" en la biblioteca de la Iglesia de México y que consideró incompleta en los datos registrados. Si bien el propio Beristáin declara que realizará su propio repertorio bajo un plan distinto al de Eguiara, lo cierto es que revisó no solamente las fuentes compiladas por éste, sino que también empleó la misma forma de trabajo basada en la comunicación con otros intelectuales de la época para encontrar la producción bibliográfica, así como los autores que la produjeron.

Beristáin también declara en su "Discurso apologético", con el que inicia su repertorio, que ha considerado no escribir en latín porque ya es tiempo de no hacer agravios a la lengua castellana. A diferencia

156 Alicia Perales Ojeda. Op. cit. pp. 52-53 
de Eguiara, Beristáin organiza su obra por los apellidos de los autores y también decide abandonar el "estilo hinchado y modo difuso" 157 de la obra que le antecede. Su descripción incluye una breve noticia biográfica de los autores y el registro de sus obras, indicando el pie de imprenta correspondiente, el formato, lugares donde ha localizado los materiales y en ocasiones las citas o menciones de la obra.

Después de este meritorio trabajo se encuentra la obra sobre los impresos mexicanos del siglo XVI de García Icazbalceta. Este repertorio mostrará una evolución fundamental en el modelo bibliográfico, que lo convierte en el primero que se corresponde con los inicios de la propuesta bibliográfica de Pollard, McKerrow y Greg — como los tres pilares de la aportación anglosajona-. ${ }^{158}$ Dicha propuesta permitirá que la bibliografía adquiera

un nuevo significado y unos nuevos propósitos. En concreto iba a aplicarse no sólo a la catalogación de libros [...] sino también a la elaboración de la información que de esta manera se hace más asequible, completada con el análisis y la interpretación del proceso por el que los manuscritos originales se convirtieron en libros impresos. 159

Así el modelo descriptivo utilizado por García Icazbalceta se integra de una descripción línea a línea de la portada (separada cada una de éstas por una barra doble), formato, tipo de letra, presentación de caja de textos (i.e. columnas), signaturas, tipo de portada, características de la edición, descripción del contenido, colofón, características

157 José Mariano Beristáin de Souza. Op. cit. T. 1, p. III

158 Se sabe que García Icazbalceta conocía la obra de Brunet o Fuster, lo que explica su conocimiento bibliográfico. Cfr. Genaro Estrada. "Prólogo" a la Colección de documentos para la Historia de México I y II. México, 1858 y 1866. Citado por Liduska Cisarova. "Joaquín García Icazbalceta, iniciador de la bibliografía moderna en nuestro país”. Investigación Bibliotecológica. Vol. 18, no. 36 (junio de 2004). Texto disponible en http://www.ejournal.unam.mx/iibiblio/ vol18-36/IBI03603.pdf [Consulta: febrero de 2006] p. 28

159 David McKitterick. Op. cit. p. 16 
del ejemplar descrito, posesión en el momento de la revisión ${ }^{160}$ (generalmente de particulares); catálogos y costos de venta, también se incluyen acotaciones históricas sobre la obra, su autor y la noticia de las obras que han mencionado a la edición. En ocasiones se transcriben documentos preliminares u otros históricos relacionados que al autor le han parecido importantes.

La descripción bibliográfica que analizamos emplea una metodología que en parte fue descrita por el mismo García Icazbalceta de la siguiente manera:

he seguido la regla de copiar por entero las portadas...Como el mérito de este trabajo había de consistir principalmente en la exactitud, he conservado con todo rigor la ortografía de los originales, y aun las abreviaturas hoy desusadas. ${ }^{161}$

En efecto, García Icazbalceta es sumamente puntual en sus descripciones, lo que también explica su apreciación sobre el trabajo bibliográfico, en donde

señala los errores cometidos por los bibliógrafos anteriores, debido a su escasa técnica bibliográfica: la poca exactitud respecto a la descripción de los documentos; títulos mal copiados, y muy a menudo abreviados o traducidos con errores de impresión, todo lo cual en lugar de ayudar al estudioso únicamente le ha causado una gran confusión y ha originado muchas equivocaciones. ${ }^{162}$

Como observaremos, esta característica no se modificará, lo que en nuestra opinión ha contribuido a que el valor del libro antiguo, como objeto material y por tanto patrimonial, se haya ido poco a poco desvirtuando y por supuesto excluyendo. De ahí que las notas realizadas

160 Así como en ocasiones peculiaridades y notas históricas de los ejemplares revisados.

161 Joaquín García Icazbalceta. Apuntes para un catalogo de escritores en lenguas indígenas de América. México, 1886. p. 15

162 Liduska Cisarova. Op. cit. p. 35 
por Millares a esta edición incluyen la noticia de obras no conocidas por el autor, las que describe con "todo el rigor técnico". ${ }^{163}$ Son comentarios sobre las diferencias descritas para establecer variantes y las referencias bibliográficas de obras o catálogos donde el texto ha sido mencionado o registrado, la introducción de dos listados de libros, uno referido a aquellas obras de las que no se conoce ningún ejemplar, y el otro a ejemplares existentes de los cuales no se puede precisar fecha o impresor más que por conjetura, así como la existencia de reproducciones totales o parciales, y la elaboración de un índice alfabético.

Después del trabajo de García Icazbalceta encontramos los de Vicente de Paula Andrade y Nicolás León, quienes no realizarán aportaciones o modificaciones importantes a las metodologías bibliográficas de descripción ya empleadas. De Paula Andrade describirá la portada línea a línea, separadas por la barra recta ( () , en ocasiones mantendrá formas ortográficas y abreviaturas de la época, pero no indicará la presencia de altas y bajas en la tipografía, ni de las cursivas. Por el contrario, si indica la presencia de grabados de portada con una descripción breve de la iconografía presente. También integra el formato, el número de hojas, transcripción completa de finales de obra o colofones y, en ocasiones, indica preliminares y referencias bibliográficas de la edición que describe.

El repertorio de Nicolás León se integra por seis volúmenes que fueron publicados entre 1902 y 1908 . Este trabajo presenta un modelo de descripción que se compone de la entrada alfabética por el apellido de los autores, indicando la orden de procedencia de los mismos, la transcripción de la portada línea a línea, separadas por la barra recta (I), sin indicación de altas, bajas o cursivas de la tipografía. Inmediatamente después, en letra de menor tamaño indica el formato, el número de hojas, el tipo de preliminares genéricamente, los grabados relevantes y el lugar que ocupa el texto de la obra en la edición, ya sea en páginas o en folios.

Será Medina quién aporte más información sobre los impresos registrados, pero en cuanto al modelo bibliográfico realiza pocas innovaciones respecto al modelo empleado anteriormente por García

163 Agustín Millares Carlo (1954). Op. cit. p. 8 
Icazbalceta. El repertorio de Medina, ${ }^{164}$ organizado en primer lugar de forma cronológica y en segundo por los apellidos de los autores, describe la portada línea a línea, separadas por diagonales (/). Esta descripción respeta las formas ortográficas de la época, como el empleo de la "s" larga, o el de la "v" por la "u", pero no se indica la presencia de altas y bajas o cursivas en la tipografía. También introduce la presencia de los tacos xilográficos como la cruz (⿶) o el asterisco (*) que se emplearon de forma decorativa en algunas portadas; los elementos ilustrativos de las mismas se indican entre paréntesis y muy someramente.

Aunque el repertorio de Medina es uno de los más apreciados y consultados por la investigación especializada en nuestro país, hay que mirarlo como a otros y entender que

la poca fiabilidad bibliográfica de ciertos repertorios y catálogos no reviste una gravedad absoluta si esos instrumentos de información se examinan críticamente, no simplemente se citan y se citan y se citan. Consultados de ese modo se descubren fácilmente las erratas de imprenta y los inevitables y humanísimos descuidos. ${ }^{165}$

Posteriormente y en letra de menor tamaño, Medina indica el formato, el tipo de portada (orlada por ejemplo), brevemente el tipo de preliminares, y una descripción del texto de la obra y su posición en la edición que registra, ya sea en páginas o folios. También informa sobre las erratas y si el texto está apostillado, la institución de custodia y finalmente las referencias bibliográficas de los repertorios que han registrado la edición descrita, incluyendo ahí cuando existe una mención recuperada de otro repertorio o fuente. Al igual que otros trabajos de la misma talla, el de Medina se enriquece por la transcripción de documentos relevantes y especialmente por el trabajo histórico que antecede al repertorio.

En lo que corresponde al segundo periodo de nuestra tradición, debemos comenzar nuestra descripción con el trabajo de Valton. Su

164 José Toribio Medina. Op. cit.

165 Julián Martín Abad (2004a) Op. cit. p. 149. 
repertorio está organizado por cada uno de los impresores del siglo XVI de acuerdo al lugar que ocupa su producción en ese periodo. El autor nos proporciona previamente los datos biográficos de cada uno de estos impresores, para después comenzar a describir los impresos de cada uno. No debemos olvidar que Valton registra los impresos existentes en la Biblioteca Nacional de México, el Museo Nacional (hoy en la Biblioteca Nacional de Antropología e Historia) y el Archivo General de la Nación.

Los registros de los impresos se organizan alfabéticamente por el apellido de los autores. El modelo describe la portada línea a línea, separadas por una barra recta (I), respetando altas y bajas e indicando las cursivas de la tipografía. También respeta la "s" larga pero se reproduce como "f". Los grabados de la portada son indicados entre guiones (-) con una descripción de la representación iconográfica y de las leyendas que acompañan a éstos. Después describe el colofón con los mismos recursos empleados en la portada.

El registro sigue con la indicación del formato, el número de hojas que componen la edición, el número de líneas que hay en cada página, si existe renglón corrido o doble columna en la composición tipográfica, los reclamos y genéricamente otros grabados interiores. También Valton nos hace aclaraciones sobre las ediciones conocidas, nos indica como "registro" las signaturas y posteriormente nos da la referencia de la obra en otros repertorios como Icazbalceta o Medina. Finaliza su modelo de descripción con algunas consideraciones sobre el ejemplar que describe, entre las cuales se encuentra la ubicación en la colección donde se encuentra. Hay que aclarar que en algunos casos, si existen, indica someramente qué tipo de preliminares contiene la edición y también en qué parte de la misma se encuentra el texto de la obra respecto a páginas o folios. Como todo trabajo de esta naturaleza, el autor inicia su repertorio con una introducción a los orígenes de la imprenta en América y añade riqueza a su propio trabajo con acotaciones históricas que en este particular caso se ven reflejadas a pie de página.

Posteriormente, Zulaica Gárate indica que su trabajo

no puede menos que estar calcado en las diligentes y acabadas descripciones, que de los impresos del siglo XVI han hecho los maestros de la 
bibliografía mexicana, aunque he procurado, siempre que me ha sido posible, examinar directamente los libros descritos. Para ello he consultado la valiosa colección 'Icazbalceta' de la Universidad de Austin, y los pocos libros que se conservan en la Biblioteca Nacional. Cuando no he visto la obra, he copiado su descripción, sobre todo de Icazbalceta y Medina. ${ }^{166}$

Con esta consideración previa, es poco lo que podemos decir sobre el modelo de registro empleado en su trabajo. Sin embargo, haremos algunas anotaciones; en primer lugar, el trabajo se organiza cronológicamente, y dentro de este orden, alfabéticamente por los apellidos de los autores, de los cuales también incluye una noticia biográfica. Después se describe la portada del impreso línea a línea, separadas por diagonal (/), respetando la existencia de la "s" larga aunque también impresas como "f", indicando en qué parte de la tipografía son altas y bajas, o góticas y cursivas (denominado como bastardilla ${ }^{167}$ ) entre paréntesis. Cuando la portada presenta algún tipo de ilustración también lo indica entre paréntesis, pero lo que resulta relevante es la indicación que establece de si ese grabado fue empleado en otra edición anterior. También describe, si existen, los datos del colofón.

Una vez que ha finalizado esta información, Zulaica Gárate indica el formato del impreso, una descripción breve de las preliminares (sin olvidar personajes y fechas), cuál es la parte de la obra a que corresponde al texto en cuanto a páginas o folios, reporta la existencia detallada de ilustraciones relevante, y posteriormente registra el tipo de letra, cuántas líneas existen por página, qué tipo de capitulares se utilizaron, la existencia de reclamos y titulillos, y las signaturas. En esta información también hace aclaraciones sobre ciertos ejemplares analizados. Finalmente, el modelo bibliográfico cierra con la referencia a otros repertorios en donde el impreso ha sido registrado.

Por supuesto, también incluye información histórica relevante, la cual en este caso es un texto titulado "Introducción de la imprenta en

166 Ramón Zulaica Gárate. Op. cit. pp. 12-13

167 José Martínez de Souza. Diccionario de edición, tipografía y artes gráficas. Gijón: Trea, 2001. p. 249 
México" que aparece como apéndice y corresponde a los trabajos publicados por García Icazbalceta, Marcos Jiménez de la Espada y Henry Harrisse. En el mismo lugar presenta transcripción de documentación histórica, indicando la ubicación donde se encuentra. En esta información se distingue la transcripción del contrato celebrado en 1539 por Juan Cromberger y Juan Pablos, que posibilitó el inicio de la imprenta en México. La obra de Zulaica cierra con una noticia de las bibliotecas donde se localizan los impresos que ha registrado, relacionados con el número de orden dentro del propio repertorio. En dicha noticia se indica en cursivas qué instituciones poseen impresos incompletos.

Por su parte, la descripción realizada por Wagner está organizada cronológicamente, además proporciona un título general y el autor de la obra, el formato, el tipo de letra, una descripción de la estructura (portada, preliminares, páginas, grabados, entre otros elementos), las signaturas, los errores encontrados en los ejemplares analizados, las referencias a repertorios que los incluyen, la relación de los ejemplares con algunas peculiaridades de procedencia y un apartado titulado "Registros" donde se informa de algunas características que diferencian al ejemplar de una biblioteca y en ocasiones el costo de éste. ${ }^{168}$

En el repertorio realizado por Francisco González de Cossío, ${ }^{169}$ podemos observar que se mantienen las tendencias ya descritas de la descripción bibliográfica que le antecede: organización cronológica de la información, orden por apellido de los autores, descripción línea a línea de la portada, separadas éstas por diagonal pero seguidas las palabras con el latinismo "sic" entre paréntesis, no hay indicación de altas, bajas o cursivas de la tipografía, pero sí se indican los tacos xilográficos decorativos de portada y de las ilustraciones, entre paréntesis con una descripción breve o simplemente como "viñeta”.

Una modificación que pretende dar claridad es la descripción del pie de imprenta antecedido de "Al pie", igualmente entre paréntesis aunque no de forma regular, lo mismo ocurre con los colofones. El

168 Véase por ejemplo la referencia número 66. Enrique W. Wagner. Op. cit. pp. 289-290.

169 Nos refererimos aquí a la edición de 1952. 
autor también incluye, aunque no siempre, el formato, indicación del contenido de la obra en folios o páginas, y ocasionalmente menciona de forma breve los preliminares. Finalmente incluye noticias históricas y bibliográficas de la edición descrita y, lo que es meritorio, el lugar donde se encuentra la edición, pero desafortunadamente esta valiosa información no se encuentra en todos los casos.

Como otros trabajos similares, el autor reproduce partes del texto que le han parecido relevantes y también proporciona información histórica sobre las instituciones o personajes relacionados directamente con las ediciones que describe. En otros casos solamente identifica la obra mediante el registro breve, sin realizar descripción línea a línea de la portada ni otros datos sobre el ejemplar analizado, y sin precisar cuál es la razón que explica esta decisión. Pero aporta datos históricos sobre el autor así como sobre las fuentes bibliográficas donde han sido localizados, como puede verse en el ejemplo que se transcribe:

MENA, JERÓNIMO DE.

177. - Modo de rezar el Rosario. En México, por la viuda de Bernardo Calderón, 1645.

Así consta de la Memoria que esta impresora presento al Oficio de la Inquisición de México el 16 de noviembre de 1660, y que fue publicado como Documento XVI en el tomo X, Núm 4. del Boletín del Archivo General de la Nación.

No he podido encontrar dato alguno sobre el autor. ${ }^{170}$

En esta relación de los modelos, lamentablemente tan sucinta, es necesario, como decíamos, diferenciar las aportaciones de Agustín Millares Carlo, quien no solamente introdujo la relevancia del trabajo bibliográfico sino que nos heredó formas metodológicas magistrales que, en mi opinión, solamente han sido puestas en práctica en los

170 Francisco González de Cossío. Op. cit. p. 65 
trabajos de Yhmoff Cabrera. ${ }^{171}$ Ambos protagonistas se caracterizan, además de la metodología empleada en la descripción de impresos y manuscritos antiguos, por comprender que la introducción de conceptos a través de definiciones claras, precisas y completas, nos ayuda a entender la realidad y no a manipularla.

Efectivamente, la tradición bibliográfica que nos antecede y que tanto nos enorgullece, ha dejado definida una forma de trabajo para la descripción de impresos antiguos que en la actualidad con ciertas adaptaciones, podría constituir toda una visión metodológica moderna, descartando en esta categoría a Juan José de Eguiara y Eguren, quien realizó una biobibliografía y por tanto su interés se centró en los autores más que en los libros, que son los que nos interesan. De éstos, como hemos indicado, solamente encontraremos referencias someras que dificultan su localización contemporánea, de lo que concluimos que la identificación puntual de los impresos presenta la misma complejidad que aquella existente en el trabajo con documentos históricos, como podrían ser los inventarios de bibliotecas antiguas. Desafortunadamente, en nuestro país la bibliografía como práctica y con la noble tradición que le antecede ha ido perdiendo terreno con el tiempo, devaluándose así en las opiniones de los espacios académicos que la entienden como un mero problema técnico, de ahí que se considere que prácticamente no posee ningún valor intelectual. Esta postura no comprende que la Bibliografía Material ha contribuido a la transformación del estudio sobre el libro, por lo que

el rodeo por la erudición técnica no es sólo cuestión de especialista, sea coleccionista, librero o bibliotecario, sino fuente de conocimientos nuevos en cuanto a la edición y a la circulación de los productos de cultura, ${ }^{172}$

171 Además de las dos ediciones citadas (1990 y 1996), tambíen en su Catálogo de Incunables de la Biblioteca Nacional de México. $2^{a}$ ed. México: UnAM, 1987. Salvo un detalle, la clasificación o número de orden de algunos libros no se incluyó en el catálogo de libros europeos del siglo XVI.

172 Roger Chartier y Daniel Roche. "El libro. Un cambio de perspectiva". Hacer la bistoria, dirección de Jacques Le Goff y Pierre Nora. Barcelona: Laia, 1980. p. 120 
por lo que son escasos los trabajos de licenciatura dedicados a catalogar y registrar libros antiguos pertenecientes a colecciones específicas, que contribuyan a definir la dimensión de un problema patrimonial del cual se sabe su importancia, ${ }^{173}$ pero del que se desconocen las características y el número de ediciones conservadas.

De esta manera se ha propiciado una escasa comprensión del problema que representa el trabajo bibliográfico con impresos antiguos, no solamente para contribuir a la historia del libro como un campo de conocimiento rico y diverso que atañe a cada fase del proceso de producción de un libro y

al conjunto del proceso en el transcurso de sus variaciones en el espacio y en el tiempo y en todas sus relaciones con los otros sistemas, económico, social, político y cultural del mundo circundante. ${ }^{174}$

Esta devaluación de la bibliografía como lugar de conocimiento y como instrumento de control patrimonial también se corresponde con las formas historiográficas que predominan en nuestro país sobre el libro y la biblioteca, las cuales no han logrado contribuir notablemente al conocimiento del libro y su lugar en la cultura desde que se introdujo el pensamiento occidental en el siglo XVI. En nuestra opinión, ambos factores han influido notablemente en la comprensión nacional sobre las colecciones de libros antiguos conservados, las cuales por desgracia siguen esperando un cambio de apreciación que les permita consolidar su valor patrimonial y así garantizar su permanencia futura.

\subsection{Análisis de modelos bibliográficos y catalográficos}

La falta de apreciación histórica sobre los libros del pasado se advierte especialmente en la bibliotecología mexicana - aunque se comparte

173 Cfr. Idalia García. "El futuro incierto de una fuente histórica relevante: la situación de los fondos antiguos en México" Revista General de Información y Documentación. Vol. 14, No. 2 (2004). pp. 167-188.

174 Robert Darnton. “¿Qué es la historia del libro?”. Historias. No. 44 (1999). p. 6 
con otros países de la región latinoamericana-, en cuanto a la bibliografía y la bibliología. Respecto a la primera, se observa que esa apreciación se manifiesta en la forma de análisis y presentación de los libros antiguos como objetos materiales. En dicha forma se pueden distinguir dos peculiaridades; la primera es que el libro antiguo es registrado como si fuese un libro moderno, despojándolo de su historicidad; la segunda es que se emplea como fuente de información sin considerar su condición patrimonial y por tanto se relega la competencia institucional de custodia. ${ }^{175}$

Ambas peculiaridades también se observarán en los contenidos de la formación profesional, en el desarrollo de la investigación especializada, en la producción de conocimiento que se encuentra en las revistas especializadas de Latinoamérica, y especialmente en los espacios de reunión profesional como jornadas, reuniones o coloquios. El tema del libro antiguo y de la Bibliografía Material como forma de conocimiento de los mismos será el gran ausente de este desarrollo disciplinar, por lo cual tendrá sus correspondientes efectos en la realidad profesional e institucional relacionada. ${ }^{176}$

De esta manera no resulta extraño que el principal efecto, como ya indicábamos, sea la ausencia de un catálogo colectivo que pudiese integrar en sus registros tanto la normalización internacional como la tradición bibliográfica a la que nos hemos referido. No se puede descartar de entrada esta posibilidad sin haber analizado el problema a detalle, pero esto también requeriría reflexionar sobre el tipo de ciudadanía que tiene la bibliografía en el territorio del conocimiento especializado, particularmente en lo que corresponde a su aportación en el estudio del libro como objeto material, para dar a su vez cauce

175 Por condición patrimonial entendemos el proceso de valoración que se realiza sobre un objeto como bien cultural y por lo cual es protegido jurídicamente de forma especial. Por competencia institucional comprendemos la tarea de salvaguardar a ese objeto reconocido como bien cultural y que implica para la institución de custodia un tratamiento diferenciado, tanto del objeto como de la tarea de tutela.

$176 C f r$. Idalia García. "Para empezar, hay que recordar: la formación profesional y la investigación del libro antiguo en México", Revista Interamericana de Bibliotecología. Vol. 28, núm. 2 (julio-diciembre de 2005). pp. 157-175. 
y coherencia a otras disertaciones correspondientes a la historia del libro o de la historia cultural.

De ahí que no resulte peregrino el comentario sobre los espacios profesionales realizado por Fernández de Zamora, quien ya indicaba en la década de los ochenta que

revisando el contenido de las Jornadas celebradas a lo largo de estos 25 años, he encontrado que la bibliografía no ha sido un tema que inquiete a los bibliotecarios en sus reuniones nacionales. ${ }^{177}$

Hoy podemos decir que la situación no ha variado en lo absoluto, lo que nos debería conducir a reflexionar sobre el porqué de esta ausencia y cómo la misma afecta a la valoración y transmisión del valor cultural del libro antiguo.

Ciertamente estas tendencias descritas podrían explicar (aunque no de forma exclusiva) ${ }^{178}$, la diversidad metodológica que se encuentra presente en los registros bibliográficos elaborados hasta la fecha y que representan a estos libros antiguos. Efectivamente, la relación directa existente entre la valoración cultural del libro antiguo y el trabajo de los bibliotecarios como responsables de la custodia de esos mismos objetos patrimoniales, ha contribuido e incluso fortalecido esta situación, aun cuando es un tema sobre el cual en México no parece que se haya reflexionado mucho y por lo tanto tampoco se ha escrito sobre el mismo.

Una afirmación de esta naturaleza reconoce la influencia de ese trabajo en otros temas de la disciplina, como el de los sistemas de clasificación o el desarrollo de sistemas bibliotecarios como el de las universidades. En estos temas y otros se puede observar que la preocupación y el trabajo de los bibliotecarios en parte han modificado la realidad de la que se ocupan, aunque también debemos apuntar que

177 Rosa María Fernández de Zamora (1981). Op. cit. p. 41

178 Porque no explicaría ni justificaría el desconocimiento de modelos bibliográficos o catalográficos de reconocimiento internacional, que se observa en los productos de aquellas personas o instituciones que han registrado libros antiguos de colecciones mexicanas. 
esta participación disciplinar de la bibliotecología no ha alcanzado mayores esferas de actuación, como la sociedad misma o los poderes del Estado, de forma tal que se reconozca la importancia de las instituciones bibliotecarias en el desarrollo nacional, concretándose en leyes específicas, en programas nacionales de desarrollo o incluso en la asignación presupuestal para la cultura.

Para el caso concreto del libro antiguo en el trabajo bibliotecario no se observa la divulgación del conocimiento bibliográfico, ni de los aspectos que diferencian a los libros antiguos de la producción de libros modernos, como tampoco las tendencias internacionales que los reconocen con particularidades propias como para determinar un tipo de tratamiento específico. ¿Cómo entonces demandar a las instituciones y a la sociedad que valoren al libro antiguo como un bien cultural? ¿Cómo pedir a los historiadores e investigadores nacionales que conozcan las tendencias de la descripción bibliográfica de libros antiguos, cuando tampoco las conocen los bibliotecarios profesionales?

Si esta compleja realidad patrimonial a la que nos referimos pudiera dividirse en dos partes simples éstas serían, por un lado, la falta de valor del libro antiguo como fuente original en los temas de la investigación histórica nacional; y por otro, que ese mismo valor no se ha construido ni consolidado en el bibliotecario responsable de la custodia de libros antiguos como para justificar programas, planes, actividades específicas tendientes a preservar esos mismos libros en las instituciones que los custodian. Esa preservación a largo plazo requiere de forma ineludible realizar catálogos y bibliografías que permitan transmitir entre generaciones el valor cultural que los libros antiguos representan, y así favorecer el desarrollo de la investigación histórica con instrumentos fiables sobre el contenido de las colecciones bibliográficas conservadas.

No obstante, sin investigadores que demanden la elaboración de estos instrumentos a las instituciones de custodia, seguiremos posibilitando un escaso control patrimonial por parte de los bibliotecarios responsables. Por esta razón y para apuntalar nuestras consideraciones sobre el valor cultural del libro antiguo y la importancia del conocimiento bibliográfico para su adecuada transmisión, hemos considerado pertinente analizar aquí en lo que corresponde a sus características de registro, diversos repertorios y catálogos bibliográficos realizados 
en nuestro país. Si bien no son todos los que se han publicado, lo cierto es que no suelen realizarse, por lo que esta muestra no solamente es representativa sino también indicativa. Con el análisis buscamos determinar las tendencias metodológicas utilizadas sobre las que se soportan esos instrumentos, así como identificar la tradición bibliográfica que les antecede.

La intención es mostrar cómo estas formas de registrar bibliográficamente los libros antiguos, no contribuyen a fortalecer la condición del libro antiguo como bien cultural dentro del conjunto general de nuestro patrimonio heredado, aun considerando que estos registros, finalmente, son las representaciones del objeto material conservado en algún lugar específico. Hemos compilado, con esta intención, cuarenta y dos ejemplos de modelos de registro que se elaboraron en un periodo comprendido entre 1944 y 2007 , lo que representa una muestra bibliográfica de sesenta y tres años que nos permitirá determinar tendencias y formas metodológicas en el registro de libros antiguos, así como formas de valoración cultural de los mismos. Así podremos mostrar cómo se ha representado históricamente a los libros antiguos y qué tipo de información se considera relevante en dicha representación.

En términos generales, en el conjunto de estos ejemplos podemos encontrar una sola característica procedente de la tradición bibliográfica que nos enorgullece: la transcripción de la portada de forma "casi facsimilar", como la ha definido Fredson Bowers, ${ }^{179}$ y que es una peculiaridad de los más importantes trabajos bibliográficos que apuntalan nuestra tradición, ${ }^{180}$ (desde Beristáin hasta Yhmoff). Sin embargo, hay que hacer una precisión en relación a esta peculiaridad de la descripción bibliográfica; estrictamente, la forma "casi facsimilar"181,

179 Fredson Bowers. Op. cit. pp. 176-183.

180 Francisco González de Cossío. Op. cit. pp. IX-XVII.

181 La condición facsimilar se entiende como la una reproducción exacta de un texto, manuscrito, impreso, o grabado mediante la fotografía o cualquier otro procedimiento. Sin embargo cuando se aplica a la descripción bibliográfica, se refiere a la transcripción exacta de la información tal y como se presenta en el original. Del ahí el empleo del "casi", porque el facsimilar se referirá entonces a la edición de este tipo y no a su representación bibliográfica que es la que nos ocupa. 
que en páginas anteriores hemos denominado "transcripción línea a línea”, reproduce el tipo de carácter empleado en el diseño de una portada (altas, bajas, redondas, cursivas, góticas), y por tanto requiere una descripción más detallada que otras y constituye

el único método preciso de transcripción inventado hasta ahora por el cual una portada puede ser comparada para detectar variaciones con razonables esperanzas de éxito. ${ }^{182}$

Por otra parte, lo que corresponde a la descripción física de la materialidad del objeto (su estructura), los valores textuales (entre ellos el que representa la ilustración) y los valores históricos (los que testimonian el devenir en el tiempo del objeto) presenta variaciones que nos pueden ayudar a explicar el escaso valor cultural del libro antiguo que ha predominado en nuestro país.

El primer trabajo seleccionado para este análisis corresponde al modelo empleado por Agustín Millares Carlo, ${ }^{183}$ quien como hemos visto siempre se destacó por sus descripciones de ejemplares antiguos. Este ejemplo ha sido tomado de la bibliografía elaborada sobre las obras de Eguiara y Eguren, y en éste el bibliógrafo y humanista canario nos muestra una metodología impecable que se corresponde con la más pura tradición hispánica. En su noticia bibliográfica, como podemos apreciar, encontraremos la transcripción "casi facsimilar" de la portada, y por tanto respeta la presentación tipográfica de altas y bajas, la redonda y la cursiva, así como los elementos de ilustración tipográfica cuando dispone de la posibilidad técnica. En su defecto, nos marcará la presencia de este tipo de elemento entre paréntesis. Posteriormente, el modelo de Millares Carlo indica el tamaño en centímetros, así como una descripción física del ejemplar y las signaturas que le corresponden.

182 Fredson Bowers. Op. cit. p. 180

183 Juan José de Eguiara y Eguren (1944). Op. cit. p. 245. 
61. EL LADRON MAS DIESTRO DE EL ESPIRITU RELIGIOSO, EL GRAN PATRIARCA | SAN FELIPE NERI.|PANEGYRICO, | QUE SU PROPRIO DIA, Y TERCERO|de la Fiesta de Pentecostes, año de 1733. PATENTE EL SANTISSIMO SACRAMENTO, En la Iglesia de la Congregacion del Oratorio / de Mexico,|PREDICÓ|EL DOC. D. JVAN JOSEPH DE EGVIARA, Y EGVREN, | Cathedratico, que fue de Philosophia, y actual Proprietario|de Visperas de Sagrada Theologia, de la Real Vniversidad de $\mid$ Mexico, su Diputado de Hazienda, y Exaniinador Synodal $\mid$ de este Arzobispado. | SACALO A LUZ | La misma Congregacion de el Oratorio, | Y LO DEDICA |A los Santissimos Patriarcas de las Sacratissimas |Religiones. | (Linea de adorno) |CON LICENCIA EN MEXICO. | En la Imprenta Real del Superior Govierno, de Doña| Maria de Rivera, en el Empedradillo. Año de 1733.

$19 \mathrm{cms}$. $-\mathrm{t}$ hoj. de Port. +9 s. n. +29 pp.-Signs. $q^{i k}-q q^{2} \cdot q^{1} \cdot \AA^{2} \cdot F^{2} \cdot G^{1}$. Port orlV. en bl-A los Santissimos Patriarcas de las Santissimas Religiones. La Congregación de el Oratorio de México-Aprobación del Rmo. P. Fr. Antonio Joseph Pérez, Predicador General Jubilado, Notario del Santo Oficio, ex-Secretario de la Provincia del Santo Evangelio, y Guardián del Convento Grande de N. P. S. Franciscò de México: Convento de N. P. S. Francisco de México, 17 de Junio de 1733.-Parecer del R. P. Nicolás Zamudio, Professo de Quarto Voto de la Compañía de Jesús, y Prefecto de la Venerable Congregación de la Buena Muerte, en la Casa Professa de México: Professa de México, y Junio 25 de 1733.-Licencia del Seńor Virtey: 20 de Junio de 1733.Licencia del Señor Provisor: 27 de Junio de 1733.-Texto.-Pág. en bl.-Hoj. en b. México, Bibl. Nac., S-I-3-t8.-Medina $I M$, V, núm. 3282 .

62. Platicas en el Oratorio [de 1733 y 1734 ].

$23 \mathrm{cms}$.

Ibid., Sección de Manuscritos, 8-66. .

Podemos observar cómo posteriormente se presenta una descripción de los preliminares de forma breve pero indicando qué tipo de documento es y quién es el responsable de su elaboración, así como la fecha del documento. Igualmente incluye una parte dedicada al texto e incluso menciona en ésta las hojas en blanco existentes. Finaliza la noticia bibliográfica con la indicación del lugar donde se encontró el ejemplar que describió. Sobre esto es pertinente mencionar que Millares Carlo se refiere a una forma de organización antigua (México, Bibl. Nac., S-I-3-18) y que actualmente corresponde a la clasificación RSM 1735a M4EGU, del mismo acervo. ${ }^{184}$ Finaliza su noticia con la indicación

184 Catálogo Nautilo de la Biblioteca Nacional de México. Se puede consultar en la página http://132.248.77.3:8991/F [Consulta: 11 de octubre de 2005, 10:33] 
de la referencia bibliográfica correspondiente al trabajo de Medina, ${ }^{185}$ del que si se compara la transcripción de la portada con este ejemplo, observaremos que existen diferencias: Medina transcribe toda la información en minúsculas y sin cursivas, mientras que Millares Carlo sí hace este tipo de indicaciones.

Cuando existe una descripción previa de un ejemplar antiguo, resulta sumamente interesante observar cómo se han modificado los datos registrados en una versión moderna, como el catálogo electrónico de la Biblioteca Nacional; por ejemplo, en el caso que analizamos, lo que corresponde a las signaturas y al tamaño del libro. Observemos que el ejemplar aumenta de tamaño un centímetro y que la información de las signaturas no coincide entre la información proporcionada por Millares Carlo y la realizada por la misma biblioteca. ¿Qué fue lo que pasó? No se puede dar una respuesta concreta, lo único cierto es que el investigador interesado deberá verificar esas informaciones directamente con el ejemplar original.

En este sentido es pertinente indicar aquí la responsabilidad inherente al trabajo de la descripción bibliográfica de un impreso antiguo, que necesariamente requiere de la recuperación de los registros elaborados con anterioridad - particulares o institucionales- para que la identificación del ejemplar con que se trabaja sea lo más correcta posible o, en su defecto, se pueda hablar de una posible variante. En este punto en particular conviene ser cauteloso porque una afirmación de esta naturaleza requerirá obligatoriamente la revisión directa del original, ya que la información del registro bibliográfico puede ser incompleta, equívoca o simplemente estar mal transcrita.

En la obra de Fernández de Córdoba ${ }^{186}$ realizada en 1959 , se mencionan someramente como datos de libros antiguos el título abreviado, el autor, el lugar de edición y año (sin el impresor), así como una

185 Millares Carlo cita el Tomo v, número 3282. En la edición de 1989 consultada para este trabajo, la noticia bibliográfica se encuentra en el tomo 4. José Toribio Medina. Op. cit. p. 365, quien además indica que fue registrado por Beristain, t. 1, p. 399.

186 Fernández de Córdoba. Op. cit. p. 116 
identificación mínima de procedencia del ejemplar conservado, como se puede observar a continuación:

Doctrina breve muy provechosa de las cosas que pertenecen a la fe catholica, por Fray Juan de Zumárraga, México, 1543 (Ejemplar Ágreda); Tripartito ... de doctrina cristiana... traducido del latín en lengua castellana... por Juan Gersón, México, 1544 (Ejemplar Church); Este es un compendio breve que tracta de la manera como se ban de hazer procesiones, compuesto por Dionisio Richel, México, 1544 (ejemplar Church);

La información así presentada nos hace suponer que el autor de este repertorio pudo verificar ciertos ejemplares concretos de libros antiguos, pero a falta de la indicación sobre un elemento específico de esa procedencia, no podremos actualmente relacionar esta información con un objeto concreto conservado en la institución moderna citada a través de sus catálogos.

El siguiente trabajo, realizado unos años después, ${ }^{187}$ nos muestra que en la trascripción de la portada se cambió la "s" larga por la normal, que se deshicieron las abreviaturas, y que se indica entre corchetes la información añadida por el autor. También podemos observar que la transcripción del colofón se ha realizado de forma "casi facsimilar" 188 y que se indica brevemente el contenido de la obra y la fuente donde ha sido incluido.

187 Robert Duclas. Catálogo descriptivo de los libros impresos en la ciudad de Salamanca en el siglo XVI existentes en la Biblioteca Pública de Guadalajara. México: UNAM, 1961. p. 61

188 Podemos decir también que la falta de acuerdo general en el empleo de la forma "casi facsimilar" puede dar por resultado maneras distintas en la transcripción de la portada. Cfr. Fredson Bowers. Op. cit. p. 181. 


$$
12 a-1553
$$

Domingo Soro.

De Iustitia \& Iure libri decem.

FRATRIS DOMINICI / Soto Segouiensis, Theologi, ordinis / Praedicatorum, Caesareae Maiestati a sacris / confessionibus, Salmantini Profes/ soris, De Iustitia \& Iure / Libri decem. [Marca del impresor, No 2.] Cum Privilegio / SALMANTICAE, / Excudebat Andreas a Portonariis. / M. D. LIII. [Colofôn:] Salmanticae in Officina / Literaria Andreae a Portonarijs, Typogra- / phi multo accuratissimi: Anno ab orbe redempto Quarto \& Quinqua / gesimo supra Mille Quingen- / tos. Quinto Idus Maias.

Descripción: 1) reverso de portada: extracto del privilegio en latín; 2) "El autor a Felipe II", p. 3; 3) la obra, p. 5; 4) "Index summarius" e "Index Alphabeticus" (son los mismos que se pusieron por èror en lá obra anterior de Medina) ; 5) colofón y grabado.

Lo demás de la descripción es igual a lo del libro anterior que viene en la misma encuadernación, excepto que la numeración es por página.

$13-1553$

Otro ejemplar de la obra anterior. Le falta el colofón; la marca de fuego es de la Merced; acotaciones marginales en latín y una en español en p. 640.

\section{$14-1553$}

Otro ejemplar de la obra anterior, con marca de fuego de San Joseph.

El folio 477-478 fue reemplazado por una copia del mismo escrita a mano. En la hoja-guarda al frente viene manuscrito: "Sepan todos los vecinos de la ciudad que se vende a como me costó estoy enferma sin tener quien me socorra."

61

Este modelo resulta sumamente interesante porque hace puntualizaciones sobre los ejemplares de la misma edición y considera la noticia de los elementos históricos de cada uno de ellos, como marcas de fuego y anotaciones manuscritas que se transcriben entre comillas. Para que este modelo nos proporcionara una idea de la materialidad del libro descrito, únicamente le faltaría registrar lo correspondiente al formato y la estructura de la obra identificada. 
Veintidós años después encontramos un modelo bibliográfico en el que su autor, Quiñónez, aclara antes de iniciar:

ante todo me sentí obligado a respetar mi papel de mero informador y abstenerme de jugar al bibliógrafo; puesto que considero que a nivel de información no es ningún desdoro para la ficha de un libro antiguo ser presentada sin las complicaciones tipográficas de la historiobibliografía. ${ }^{189}$

Esta consideración podría eximir al autor del cumplimiento de unas normas básicas de la bibliografía, siempre que el trabajo se hubiese realizado con anterioridad a la publicación de la norma ISBD (A) y que el mismo autor no hubiese incluido en sus descripciones elementos bibliográficos importantes como los preliminares o las signaturas tipográficas que se relacionan directamente con la tradición bibliográfica.

Por ello resulta interesante el comentario del autor sobre el desdoro de la ficha que ha elaborado, quizá previendo la posterior crítica bibliográfica. Consideramos que de haberse querido, se pudo haber realizado un registro integrando la propuesta de la ISBD (A), rescatando los elementos de la tradición bibliográfica que él mismo reconoce en su registro, una tarea que no representaría mayor problema si reconociéramos el lugar que tienen en el la bibliografía y, por tanto, sin descartar del todo sus aportaciones.

La crítica a este modelo todavía es más puntual si comprendemos que procede del mundo de la literatura clásica y es por ello más cercana a las aportaciones de los bibliógrafos anglosajones, pero también porque ya se había publicado el artículo de Jaime Moll, ${ }^{190}$ considerado como el trabajo que introdujo la Bibliografía Material en la investigación literaria.

189 José Quiñónez Melgoza. Catálogo de obras de autores latinos en servicio en la Biblioteca Nacional de México. México: UNAM, 1983. p. 12

190 Jaime Moll. "Problemas bibliográficos del libro del Siglo de Oro". Boletín de la Real Academia Española. Vol. 59 (1979). pp. 49-107 
Secretos del estante: elementos para la descripción bibliográfica...

11. Publii Virgilii Maronis Opera. Argumentis et animadversionibus illustrata. Valentiae, 1677 .

$15 \mathrm{~cm}$. port, $v$. en bl. con una nota manuscrita que certifica la pertenencia al Convento de San José de Tacubaya. 3 hh. $s$. n. que contienen: Licencia, Madrid, 12 de marzo de 1563. Fe de erratas, Madrid, 16 de julio de 1653. Tasa, Madrid, 19 de julio de 1653. Vida de Virgilio, +198 hh. Texto, Maphaei Vegii Laudensis XXII [i. e. XII] librorum Aencidos supplementum, que comienza en la h. 190. Signs.: $\mathrm{q}^{4}, \mathrm{~A}^{8}-\mathrm{Z}^{5}, \mathrm{Aa}^{8}-\mathrm{Bb}^{8}$.

Como observé, comparando, son los mismos preliminares que lleva la edición de 1653 , puesta en el número 6 , con la que coincide también en paginación. Respecto a la edición, Palau ${ }^{10}$ señala: "en nota, sin más, de un catálogo de libreria."

Este catálogo al que nos referimos presenta a los autores por año de nacimiento, para posteriormente describir en un encabezado breve al autor, el título abreviado y el pie de imprenta, en ocasiones sin impresor como el ejemplo que presentamos. ${ }^{191}$ En las noticias suele desatar las abreviaturas, lo que se indica en cursivas. También presenta el tamaño de la obra en centímetros, indica la presencia de portada y, al mismo tiempo, la existencia de anotaciones manuscritas. Posteriormente relaciona los preliminares, indicando genéricamente el tipo y la fecha, asimismo nos informa cuántas hojas ocupa el texto de la obra y después las signaturas. Finaliza su noticia con anotaciones personales sobre los libros que ha trabajado y que ha podido comparar, a las que agrega una somera referencia bibliográfica como la que se observa de Palau. ${ }^{192}$ El catálogo contiene también comentarios del propio autor, la bibliografía empleada y un índice analítico.

Aquí cabe hacer una precisión: la norma internacional ISBD (A) no debe considerarse perfecta o completamente acabada. ${ }^{193}$ Como toda norma, sirve para normalizar ciertos criterios básicos, como una descripción

191 José Quiñónez Melgoza. Op. cit. p. 19

192 Antonio Palau y Dulcet. Manual del librero bispanoamericano. $2^{\mathrm{a}}$ ed. Barcelona: Librería Anticuaria de A. Palau, 1948-1977.

193 En el 2006, se realizó una revisión internacional de dicha norma, de la que se ha presentado una propuesta. $C f r$. http://www.ifla.org/en/news/worldwide-review-of-isbd [Consulta: enero de 2011]. La edición en español de esta versión se encuentra disponible en http://www.bne.es/es/Servicios/NormasEstandares/ ISBDconsolidada/ [Consulta: enero de 2011] 
breve para la identificación de un libro antiguo, pero ello no implica que no puedan adaptarse otros criterios bibliográficos de carácter básico que permitan representar mejor a este tipo de libros. Precisamente por la existencia de dicha norma y por la tradición bibliográfica, resulta todavía más interesante la diversidad metodológica presente en los instrumentos de descripción elaborados en México que han sido dedicados a los impresos antiguos.

El modelo siguiente para este análisis procede de una edición conmemorativa del cuarto centenario de la introducción de la imprenta en tierras mexicanas ${ }^{194}$ y fue realizado tres años después del anteriormente analizado. En esta edición encontramos registros de libros impresos entre los siglos XVI y el XIX, elaborados por Francisco Ziga Espinosa, Octavio Gordillo Ortiz, Irma Lombardo García y Guadalupe Curiel Defossé. Transcribimos una noticia para poder analizar los datos considerados:

Sigüenza y Góngora, Carlos de, 1545-1700.

Libra astronómica, y philosophica en que d. Carlos de Sigüenza y Góngora, cosmographo, y matemático regio en la Academia mexicana, examina no solo lo que a su manifiesto philosofico contra los cometas opuso el R. P. Eusebio Francisco Kino de la Compañía de Jesús; sino lo que el mismo R. P. opinó, y pretendió haber demostrado en su exposición astronómica del cometa del año de 1681. Sacala a luz d. Sebastián de Guzmán y Córdova. México: por los Herederos de la viuda de Bernardo Calderón 1690.

$1 \mathrm{v}$.

Procedencia: Fondo Reservado de la BNM

Como se observa, esta es una descripción catalográfica elaborada ya con posterioridad a la norma ISBD (A) en la que no se observan datos relacionados con los valores textuales o históricos que distinguen

1944 Siglos de imprenta en México: una muestra tipográfica mexicana. México: UNAM. Instituto de Investigaciones Bibliográficas, 1986. p. 21 
al ejemplar de libro antiguo que se describe, estos nos parecen importantes porque el catálogo debe servir para identificar puntualmente un objeto dentro de una colección. Sin embargo, los autores no han abreviado el título y respetan la forma bibliográfica para describir el pie de imprenta. Lo que sorprende es la condición material " 1 v." para un libro antiguo del que se sabe no se imprimieron más volúmenes.

Por la escueta información que se proporciona en este catálogo no se puede analizar mucho más de lo que se observa, pero nos ayuda a comprender el valor cultural que se otorga al libro antiguo en nuestro país, especialmente considerando que procede de una edición conmemorativa que por esa condición debería dar lugar a una comprensión mejor del objeto cuando el interés era distinguir a la tipografía mexicana, a la que no se hace prácticamente referencia.

Para esta selección encontramos también un trabajo dedicado exclusivamente a obras latinas, ${ }^{195}$ que también se elabora cuando la norma internacional no sólo ha sido discutida sino aprobada. En éste veremos que el modelo de descripción presenta una descripción de la portada, que por su forma no puede considerarse "casi facsimilar". Inmediatamente después se proporciona información sobre la estructura, el formato y el tipo de letra. También la autora realiza comentarios personales, se relaciona la información con otros registros del mismo catálogo y se ha transcrito brevemente el contenido de la obra, aunque no se indica qué parte de la edición ocupa. El registro finaliza con las referencias bibliográficas donde se ha compilado la obra y las instituciones en donde que se encuentran ejemplares de ella, ${ }^{196}$ incluso si son facsimilares o si están incompletos.

195 Silvia Vargas Alquicira. Catálogo de obras latinas impresas en México durante el siglo XVI. México: UNAM. Instituto de Investigaciones Filológicas, 1986. p. 81

196 El único ejemplar completo de este libro se encuentra en la Benemérita Universidad Autónoma de Puebla. Por esta relevancia y por la truculenta historia de robos y recuperaciones de la edición, hubiese sido conveniente que la autora registrara los valores históricos del objeto en cuestión. 


\title{
CIENCIAS APLICADAS
}

\author{
MEDICINA
}

\section{BRAVO, FrANCISCO}

Opera medicinalia, in quibus quam plurima extant scitu medico necessaria in 4 libros digesta, quae pagina versa continentur. Authore Francisco Bravo Orsunensi doctore, ac Mexicano medico. Mexici, apud Petrum Ocharte. Cum privilegio, 1570.

316 hs., en 8o., letra gótica. Vid. núms. 124, 127, 170, 171. *Esta fue la primera obra médica editada en la Nueva España. Actualmente Luz María Velázquez realiza su traducción.

A la vuelta de la portada se expresa el contenido de la obra y es el siguiente:

1. liber continet universam doctrinam immanis morbi (tavardete vulgo dicti) qui per hanc Mexicanam provinciam populariter grassatur, in quo libro natura eius exprimitur, causae, signa, simptomata, et debita eius medella proponuntur. 2. liber habet in se dialogum de venae sectione in pleuritide ac omnibus alijis corporis inflammationibus, in quo cuiusdam medici hispalensis placita de hac sententia obliterantur, et vera Galeni aliorumque graecorum doctrina exponitur, et multa ad pleuritidis medellam attinentia enodantur. In 3 . libro universa de diebus decretoriis doctrina, ad Hippocratis et Galeni mentem exponitur ac de eorum causis nova quaedam et verissima, hactenusque a nullo agitata opinio traditur. In ultimo et 4 . libro de radiculae quae vulgo sarsaparrilla dicitur temperie innata, et propriis effectibus succincto sermone agitur, et quibus morbis commode ea uti expediat, tractatur.

García BMS $X V I$, p. 221/Medina $I M, I$, p. 177/Wagner NBMS $X V I$, p. 248.

- Biblioteca del Congreso Americano (ejemplar facsimilar).

- Biblioteca de la Universidad de Puebla.

- Biblioteca Nacional de México (ejemplar facsimilar), clasif. R/082.1/GUE2.

- Biblioteca Pública de New York (ejemplar incompleto).

El siguiente modelo procede de un proyecto dedicado a los grabados existentes en libros europeos conservados en la Biblioteca Nacional de 
México y fue elaborado en la misma fecha que el anterior. ${ }^{197}$ Debido a su naturaleza e intención, los autores otorgan más interés a la descripción iconográfica que a la edición, de la que se ha extraído el grabado en cuestión. Como se observa la descripción del impreso antiguo es muy somera, pero no se indica en qué parte de la obra se encuentra el grabado que se describe y en cuanto a éste, es interesante observar que el tamaño se indica en centímetros y no en milímetros como correspondería. Lo llamativo de este modelo es que, frente a otros, se ha registrado un elemento histórico relevante: como se puede observar, los autores indican la anotación manuscrita de propiedad.

Lámina 52. Juan de Canova. Salamanca, 1557.

Palacio, Michael de. In tres libros Aristotelis de Anima Commentarii... Salmanticae Excudebat Ioannes a Canova, MVLVII. (1557).

Lámina plateresca; en la parte superior medallón con Belerofonte, en la inferior mascarón y pequeño sello con el logotipo de Ioannes de Canova. Todo el conjunto $16.5 \times 23.7 \mathrm{cms}$.

En la vuelta del colofón: Sello de Canova, medallón con Belerofonte; a los lados sátiros, $7.5 \times 8 \mathrm{cms}$. Manuscrito en la portada: "Es del convento de Toluca".

Posteriormente encontramos otro modelo, elaborado de nuevo con intenciones conmemorativas pero de mayor repercusión y realizado el mismo año que el anterior: se trata de una edición con motivo del centenario de la Biblioteca Nacional de Antropología e Historia. El primero de estos catálogos dará inicio a la serie identificada como "Fondos Bibliográficos Conventuales" a la que hemos hecho referencia con anterioridad. En este catálogo ${ }^{198}$ se explican someramente las decisiones

197 Eduardo Báez Macías, Jorge Guerra Ruiz y Judith Puente León. Libros y grabados en el Fondo de Origen de la Biblioteca Nacional. México: UNAM. IIE, 1988. p. 31

198 Salvia Segura Martínez y Alejandro Flores Barrón. Catálogo de las bibliotecas de San Agustín de Puebla y del Colegio de San Pablo de México. México: INAH, 1988. 
tomadas por el grupo de trabajo sobre la catalogación de impresos antiguos para definir como datos mínimos los siguientes:

autor, título, lugar de impresión, fecha, encuadernación, medidas (largo por ancho), signaturas, foliación o paginación, reclamos, tipo de letra, incipit opus, explicit opus, colofón, tres muestras de incipit y explicit folia, proveniencia [sic] según la marca de fuego o ex libris, condición física, observaciones, materia e idioma. 199

Aquí es donde encontraremos la explicación sobre el empleo de los incipit (del latín incipere) y explicit (del latín explicitus) en la transcripción de los datos bibliográficos de libros antiguos que ha caracterizado a los otros publicados por el INAH. Sobre este punto tan particular la explicación de los propios autores resulta confusa, ya que reconocen la existencia de variantes en las ediciones antiguas y la necesidad de identificarlas para la investigación, pero establecen que esta forma de descripción es la más adecuada para incunables y manuscritos.

Como sabemos, ambas palabras son frases latinas utilizadas prioritariamente para la descripción de libros manuscritos: la primera, utilizada como palabra de apertura a la primera sección del texto, ${ }^{200}$ y la segunda, para denotar el final del texto principal. Los estudiosos de los libros manuscritos han usado ambas frases para identificar a un tipo de texto cuando no se tiene constancia de alguna clase de numeración para las páginas o folios; según la apreciación de estos autores, las variantes de la edición sólo podían detectarse con los ejemplos de principios y finales de algunas hojas, pero pese a esta consideración solamente decidieron mantener en el modelo descriptivo los principios y finales de la obra.

Estas decisiones metodológicas resultarán muy importantes a largo plazo, porque los demás catálogos bibliográficos producidos por el INAH no volverán a recuperar una explicación sobre el modelo empleado.

199 Ibíd. p. 5. Los subrayados en el original.

200 Stan Knight. Historical Scripts: from classical times to the Renaissance. New Castle, Delaware: Oak Knoll Press, 1998. p. 106 
También son importantes porque fueron tomadas en el interior de la institución jurídicamente responsable de los impresos antiguos en su consideración de monumentos históricos, ${ }^{201}$ cuando ya se habían publicado las obras clásicas de la Bibliografía Material y especialmente la norma ISBD (A).

Lo anterior significa que la relevancia institucional del INAH y su responsabilidad jurídica, de cara a la envergadura de la tarea emprendida con el registro de libros antiguos, en principio, obligaba a los participantes a conocer las tendencias internacionales en la materia y, por tanto, a realizar una búsqueda bibliográfica mínima que sirviera de soporte de sus argumentaciones metodológicas. Como hemos dicho ya, se trata de una negligencia de conocimiento que fortalece una batalla de tradiciones y saberes donde se confunden y contraponen los intereses personales, que no contribuyen a conseguir un desarrollo armónico y constructivo de la práctica bibliográfica. La creación de nuevos paradigmas no puede hacerse sin contextualizar toda la dimensión del problema disciplinal mediando los factores sociales e históricos.

Con certeza no podemos determinar una respuesta al desconocimiento de esa información básica tanto de quienes elaboraron el trabajo como de quienes lo avalaron. Lo cierto es que no encontramos referencia puntual al conocimiento de esta información, ya que no se registra en la bibliografía ni existe una explicación metodológica razonada que justifique las decisiones tomadas para ese tipo de registro bibliográfico. La única fuente con que contamos para realizar estas consideraciones son los catálogos mismos y el análisis de la información ahí representada.

201 Artículo 36 inciso III de la Ley Federal sobre Monumentos y Zonas (1972). Op. cit. 
16. OLVIA, Juan Paulo de. Platicas domesticas espirituales.

[12], 486 pp. Sign.: 6, A8-Z8, Aa8-Ff8, Gg2. Reclamos en recto y verso, $204 \times 150 \mathrm{~mm}$, Pergamino.

Españo1. Letra romana. Con notas marginales.

Portada: PLATICAS / DOMESTICAS ESPIRITUALES, / HECHAS / Por el Reverendissimo Padre / JUAN PAULO OLIVA, / Preposito General de la compañia de JESUS, / A las comunidades de su Casa Professa, y demas Cole-/gios de Roma, Traducidas de Toscano en Español. / Por el HERMANO / LORENZO ORTIZ, / De la compañia de Jesus, I Y LAS OFRECE / A la muy Religiosa, y muy Apostolica Provincia del / Piru de la misma compañia de Iesus. [grabado de un cesto con flores] EN BRUSSELAS, / Por Francisco Tserstevens, Mercader de Libros. $1680 /$ Incipit op. p. 1; [curs.] Todas las demas Religiones en la observancia de sus Vo-/tos sigan los vsos, y las costumbres que han admitido / Explicit op. p. 371: [red.] Esto basta para renovar con fervor / los santos Votos, y para vivir en la Cruz abrazada / con creditos, y con merecimientos de Santidad. / Sin colofón,

Materia: Ascética. Observaciones: Al inicio tiene una dedicatoria, 1icencias, censuras, fe de erratas y una advertencia al lector. En la página [10] hay notas manuscritas en latín; la página 341 está numerada como 14l. Tiene notas en latín; al final de la obra se encuentra una Tabla de las cosas mas notables. Condición física: Presenta manchas de humedad $y$ hongo plano.

En el modelo que ahora presentamos (arriba) observamos una descripción breve sin pie de imprenta, que como se ve está claramente indicado en la portada. También integra una descripción física que incluye las signaturas tipográficas que indican el formato en la primera y en la última. También indica la existencia de los reclamos, que en esa época ya resultaban normales y no excepcionales. Se describe someramente el tipo de encuadernación "Pergamino", el idioma, el tipo de letra, y la existencia de anotaciones marginales.

El registro de la portada se realiza de forma "casi facsimilar" y en el mismo espacio dedicado a ésta se incluye el incipit y el explicit, así como si existe el colofón; no es el caso del registro que analizamos. También podemos observar en la descripción de la portada que 
los florones no se identifican como tales pese a que es el elemento de ilustración más conocido e identificado desde el siglo XIX. Finaliza el registro con la asignación de una materia, con observaciones de la edición en sus valores textual e histórico y también se realiza una descripción de la condición física del ejemplar descrito.

Dicha descripción en este catálogo es puntual ("humedad y hongo plano"), mientras que esta información pasará a ser subjetiva y genérica ("bueno, malo, regular") en los que se publican posteriormente. El modelo mezcla de un lado a otro los datos relacionados con los valores textuales e históricos, tendencia que se mantendrá en los catálogos posteriores, ${ }^{202}$ ocurre lo mismo con la forma de descripción de la portada y de los comienzos y finales. Pese a todo, este esfuerzo no sirvió para crear una línea institucional que dejara abierto el camino y la posibilidad para un catálogo colectivo de libros antiguos.

Como se puede desprender ya de este análisis, en México el valor cultural del libro antiguo no es completamente claro, definido ni constante. De ahí que no extraña la presencia de tantos repertorios y catálogos dedicados a libros antiguos en un mismo año, y que después pasen décadas sin encontrar ninguna publicación de cualquiera de sus tipos. El siguiente modelo deriva del interés por el conocimiento de la producción bibliográfica novohispana, que ha producido bibliografías especializadas de corte temático como la dedicada al arte 203 que ahora analizamos. En los documentos que anteceden a esta obra (prólogo y proemio) dividida en dos partes, no se hace ninguna referencia concreta a la metodología empleada para la descripción de impresos antiguos más que la indicación siguiente en el proemio de la segunda parte:

202 Se publicaron aproximadamente 18 catálogos de conventos, colegios y seminarios. Sin embargo la propia información del INAH no es muy clara respecto a estas ediciones.

203 Guillermo Tovar de Teresa. Bibliografía novobispana de arte. Primera parte: impresos mexicanos relativos al arte de los siglos XVI y XVIII / prólogo de José Pascual Buxo. México: FCE, 1988. p. 171. 
la presentación de cada uno es la misma que hicimos en el primer volumen: facsímil de la portada y grabados si es que los tienen, ficha bibliográfica, selección de textos, comentarios, notas y documentos relativos a los impresos. 204

\section{CIFUENTES (Fr. Luis de)}

46. ORACION\|ENGRANDECIDA\|CON LA ASSITENCIA\|De los Exmos, Señores\| DVQVES DE ALBVRQVERQVE, VIR-REYES |DESTA NVEVA ESPANA: de la dedicacion del sumptuoso, $\| y$ magnifico Templo, que el Capitan Simon de Haro, confagról|á la Purifsima Concepcion de Nueftra Señora; ||PREDICOLA\|EL Rmo. P. M. Fr. Lvis de Cifventes, \|de la Orden de Predicadores; Confeffor de fu Excellencia, , y Rector defta Real Vniverfidad de Mexico. \|OFRECELA $\|$ a nvestro M. R. P.M. Fr. Ivan Davila, ||Prouincial de la Religiofifsima Prouincia de San Hypolito\|Martir de Oaxac.\|sv ministro||Fr, Roque de la Serna, del mifmo Orden.\|(Un filete. $\|$ Con licencia. En Mexico, en la Imprenta de la Viuda de Bernardo\|Calderon, Año de 1656.

40. Port. orl. v. en bl. 2 hojas prels. s. f. 7 hojas de texto, casi todas a 2 cols. Apostillado.

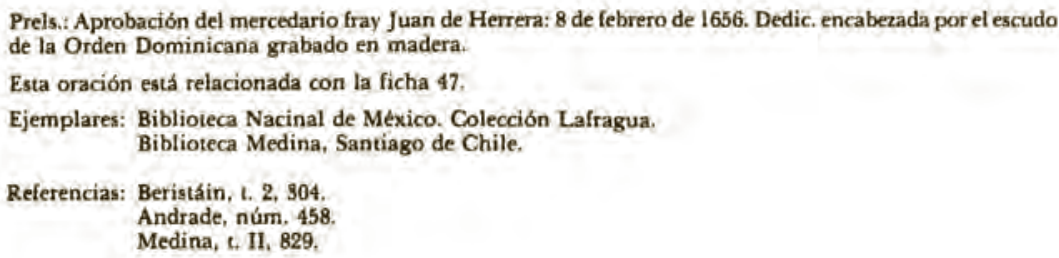

Continuando con la tradición bibliográfica que le antecede, el registro que analizamos integra la transcripción de algunos textos como sonetos y octavillas, ${ }^{205}$ pero no indica nada relacionado con el valor histórico del objeto descrito como las encuadernaciones, signos de posesión, censura o estado de la conservación, pese a que algunas de las portadas reproducidas en la bibliografía sí muestran anotaciones manuscritas de propiedad. ${ }^{206}$

204 Guillermo Tovar de Teresa. Bibliografía novobispana de arte. Segunda parte: impresos mexicanos relativos al arte del siglo XVIII. México: FCE, 1988. p. 7

205 Guillermo Tovar de Teresa. Primera parte, véase por ejemplo p. 217

206 Ibíd. Véase por ejemplo p. 195 
En el modelo que aquí presentamos se inicia la descripción con el autor o el título del impreso como punto de acceso, posteriormente observamos una descripción "casi facsimilar" de la portada, separando las líneas del texto con la doble línea (II), marcando altas y bajas de la tipografía, cursivas, algunos tacos xilográficos (como cruces, calderones o parágrafos) así como entre paréntesis el lugar de las viñetas (aunque no indica de qué tipo) y de los filetes; en éstos cuando son decorados se indica "línea de orla". ${ }^{207}$

Seguidamente se apunta el formato, el tipo de portada, hojas en blanco, preliminares, folios de texto (incluso si están a dos columnas), apostillado, una breve descripción de los preliminares (aunque no siempre, se incluye de quién son y la fecha de elaboración), así como grabados internos que considera relevantes, los ejemplares conservados y las correspondientes referencias bibliográficas de los repertorios en los que se ha descrito con anterioridad esta obra.

El autor de esta bibliografía también ha considerado la pertinencia de incluir información histórica relacionada no sólo con la obra que describe, sino con el asunto del que trata. Así también presenta información sobre personajes e instituciones del pasado, la cual es sumamente interesante porque en ella también nos aporta la noticia de otros textos que tienen relación directa con el tema artístico por el que ha seleccionado un impreso para este repertorio. Esta información la introduce, cuando es el caso, entre el registro de la información del impreso y la notificación correspondiente a los ejemplares conservados y las referencias.

Pese a la abundante información que proporciona este repertorio, en los casos en que se incluye la reproducción de la portada puede observarse que en ocasiones la descripción elaborada no puede considerarse formalmente "casi facsimilar", ya que existen diferencias en las mayúsculas y minúsculas empleadas en la composición tipográfica original y las que el autor emplea en su modelo descriptivo. Es decir, la información no coincide ya que en la portada reproducida se observa el uso de mayúsculas y en la transcripción de la información se han utilizado minúsculas, lo cual resulta interesante ya que sí se transcribe el empleo de la "s" larga como "f" y se respeta el uso de la "v" como

207 Guillermo Tovar de Teresa. Segunda parte, véase por ejemplo p. 19 
la "u" de la época. En este sentido también se observa la introducción del "[sic]" para justificar una ausencia en los datos de la portada. ${ }^{208}$ Finalmente, podemos indicar que existen registros de impresos en los cuales no se señala ninguna referencia bibliográfica ni lugar de custodia, lo que parece ser ya una tónica en lo que respecta a las descripciones de los impresos producidos en el siglo XVIII y recogidos en su mayoría en la segunda parte de esta bibliografía. ${ }^{209}$

A partir de este momento también debemos recordar que ya se ha publicado otro texto de Moll, ${ }^{210}$ que adiciona su trabajo anteriormente citado, donde presenta de forma más esquemática y puntual una propuesta de descripción bibliográfica pormenorizada. Dicha propuesta ${ }^{211}$ permite identificar y diferenciar una edición concreta de un libro antiguo como paso previo a la crítica textual, pero además en este texto Moll reconoce que

no se puede enfrentar - o despreciar- la descripción breve, bien hecha y con el suficiente número de datos, a la extensa y sofisticada, muchas veces de nula efectividad. ${ }^{212}$

Un comentario, sin duda, que debería obligarnos a reflexionar seriamente.

En 1989, encontramos la segunda edición de una bibliografía ${ }^{213}$ dedicada a la Colonia en México. El libro compila información sobre 2,424 obras, entre las que escasamente se incluyen manuscritos y libros antiguos. El registro de uno de estos últimos es el siguiente: ${ }^{214}$

208 Ibíd. Véase por ejemplo p. 82

209 Guillermo Tovar de Teresa. Primera parte, véase por ejemplo p. 193 y en Segunda parte, véase por ejemplo p. 219

210 Jaime Moll. "La bibliografía en la investigación literaria”. Métodos de estudio de la obra literaria / coordinación de José María Diéz Borque. $1^{a}$ reimp. Madrid: Taurus, 1989. pp. 145-182.

211 Ibíd. pp. 177-178

212 Ibíd.p. 176

213 Gonzalo López Cervantes y Rosa García García. Ensayo bibliográfico del periodo colonial mexicano. México: INAH, 1989.

214 Ibid. p. 17 
Secretos del estante: elementos para la descripción bibliográfica...

102. BELEÑA, Eusebio Buenaventura. Recopilación sumaria de todos los autos acordados de la Real Audiencia y sala de origen de esta Nueva España y Providencias de su superior gobierno; de varias reales cédulas y órdenes que después de publicada la Recopilación de Indias han podido recogerse así de las dirigidas en la misma audiencia o gobierno, como de algunos otros que por sus notables decisiones convendrá no ignorar”, Imprenta de Zuñiga y Ontiveros, 2 v., México, 1787.

Como se puede observar es un registro bibliográfico simplificado en el que en este caso concreto se ha decidido transcribir todo el título de la obra aunque existen diferencias en el uso de las altas y bajas, al igual que en los acentos de la época. Otras obras de libros antiguos han sido registradas como si fuesen obras modernas: es el caso de las obras Paraíso occidental ${ }^{215}$ y la Libra Astronómica ${ }^{216}$ de Carlos de Sigüenza y Góngora. La única característica distintiva que encontramos en esta bibliografía es la forma de realizar los registros, asociada con la disciplina histórica que coloca primero al impresor y posteriormente al lugar de impresión, justamente al revés de las formas bibliotecarias más comunes y normalizadas.

215 Parayso occidental, plantado, y cultivado por la liberal benefica mano de los muy catholicos, y poderosos reyes de España nuestros señores en su magnifico Real Convento de Jesus Maria de México: de cuya fundación, y progresos, $y$ de las prodigiosas maravillas, y virtudes, con que exalando olor suave de perfeccion, florecieron en su clausura la V.M. Marina de la Crvz, y otras exemplarissimas religiosas / da noticia en este volumen D. Carlos de Siguenza, y Gongora Presbytero Mexicano. México: Juan de Ribera, Impressor, y Mercader de libros, 1684. Registro extraído del catálogo de la Biblioteca Nacional de México (RSM 1684 M4SIG).

216 Libra astronomica, y philosopbica en que D. Carlos de Sigüenza y Gongora... examina no solo lo que à su Manifiesto philosophico contra los cometas opuso el R.P. Eusebio Francisco Kino... sino lo que el mismo R.P. opinò, y pretendio haver demostrado en su Exposicion astronomica del cometa del año de 1681 / sacala à luz D. Sebastian de Gvzman y Cordova. México: por los Herederos de la Viuda de Bernardo Calderón, 1690. Registro extraído del catálogo de la Biblioteca Nacional de México (RSM 1690 M4SIG). 
El modelo siguiente es el resultado de la publicación de una exposición bibliográfica ${ }^{217}$, celebrada por el décimo aniversario del Instituto de Investigaciones Dr. José María Luis Mora; es posible que esa razón explique la carencia de una explicación metodológica en la edición. De cualquier manera se puede encontrar la tónica marcada por el INAH, y en el registro vamos a encontrar mezclas de normas catalográficas y bibliográficas: primero encontraremos la clasificación de la biblioteca institucional que adquiere los libros, después el número de relación del impreso dentro del catálogo, y posteriormente en una forma particular los datos de la edición, ya que funciona como encabezamiento del registro y como la descripción misma.

217 Cien impresos coloniales poblanos. México: Instituto Mora, 1991. pp. 99-100 
R

252.1

DIA.S
26. Díaz Chamorro, Joseph. Sermon

Funeral en las honrras que celebro la muy Venerable Concordia Ecclesiástica del S. Phelipe Neri de la ciudad de la Puebla de los Angeles, al Illmo. y Excmo. señor doctor don Manuel Fernandez de Santa Cmuz, dignissimo obispo de esta Santa Iglesia de la Puebla / que predicó el bachiller don Joseph Dias Chamorro, consultor antiguo de la Venerable Concordia, y capellan de el Convento de Señoras Religiosas de la Purissima Concepción de Nuestra Señora, el día veinte y siète de febrero, de este año de 1699 ; sácalo a luz el doctor don Diego de Perea, prebendado de esta Santa Iglesia Catedral, $y$ actual preposito de la misma Concordia, quien lo dedica al Illmo, y Venerable señor dean y cabildo sede vacante, de esta Santa Iglesia Cathedral de la Puebla.-Puebla de los Angeles: Herederos de Juan de Villa Real, [1699].

$4 \%$.-Port. orl.-Vuelta en blanco. -5 hojas prels. s. f. -24 pp.-Apostillado.

Prels:- Dedicatoria (orlada).-Parecer del doctor don Francisco Díaz de Olivares: Ángeles, 18 de mayo de 1699.Lic. del Ord.: Puebla, 19 de íd-Aprob, del doctor don Miguel González de Valdeosera: México, 7 de julio de I699.-Lic. del virrey, 2 de íd.

[Medina, 193]

10 pp. s.f., 24 pp.; $200 \times 147 \mathrm{~mm}$, piel orlada en dorado.

El ejemplar que posee la Biblioteca presenta una inscripción manuscrita en tinta sepia en el margen derecho que dice "horrores" y sustituye a la palabra

"honras" tachada en el texto impreso; letras capitulares; apostillado; exlibris de José Ignacio Conde. 
En dicha descripción se observa el empleo de altas y bajas, así como el respeto aparente de las formas ortográficas de la época. El pie de imprenta se indicará de forma catalográfica sin conocimiento de la ISBD (A), sino de acuerdo a las Reglas de Catalogación Angloamericanas (RCA2), que poseen una particularidad a la que nos hemos referido y que aquí se manifiesta. Después se indica el formato, el tipo de portada, las características del verso de la misma, el número de hojas preliminares y el número de folios que componen la edición. A continuación se indican someramente los preliminares, con el tipo, responsable del documento y fecha de elaboración, y en algunos casos proporciona consideraciones tipográficas. Posteriormente se indica la referencia de un repertorio anterior, que en este caso es el de Medina; finaliza el registro con datos particulares del ejemplar que se describe, tales como anotaciones manuscritas y ex libris.

Mostramos ahora un registro que procede del Proyecto Fondos Conventuales del INAH, ${ }^{218}$ elaborado con posterioridad al presentado en páginas anteriores y en la misma fecha que el inmediato anterior. Como decíamos, se observa la misma metodología utilizada anteriormente, donde resalta nuevamente el empleo del incipit y el explicit para la descripción de libros elaborados en el siglo XVIII, por citar el ejemplo más llamativo.

218 María de los Ángeles Martínez. Catálogo de la Biblioteca de la catedral de la Ciudad de México. México: UnAM: INAH, 1991. p. 19 
4. BOSSUET, Jacobo Benigno. Oeuvres, t.II, ed. Juan Bautista Albrizzi, Estrasburgo, s. i., 1738.

[44], 514, [54] pp. Signs,: $[\mathrm{a}]^{6}, \mathrm{~b}^{4}-\mathrm{e}^{4}, \mathrm{~A}^{8}-\mathrm{Z}^{8}, \mathrm{Aa}^{8}-\mathrm{Mm}^{8}, \mathrm{Nn}^{4}$. Sin reclamos. $280 \mathrm{x}$ $205 \mathrm{~mm}$. Pergamino.

Francés. Letra romana. Apostillas.

Portada: OEUVRES / DE MESSIRE / JACQUES BENIGNE BOSSUET / EVEQUE DE MEAUX, / CONTENANT TOUT CE QUIL A ECRIT / SUR DIFFERENTES MATIERES. / VOLUME SECOND / DEDIÉ / A' SA MAJESTE / L'IMPERATRICE AMALIE. / [grabado que presenta una águila sobre la cual posan dos querubines; uno de ellos sostiene en la diestra un laurel] / ARGENTINA AUX DÉPENS DE IEAN BAPTISTE ALBRIZZI / MARCHAND LIBRAIRE A' VENISE. / M.DCCXXXVIII.

Incipit opus: [p. 1] [cap. 2] [curs.] LE commencement des disputes de Luthèr. Ses agita - tions. Ses soûmissions envers l'Eglise et envers le / Pape. Les fondemens de sa réforme dans la justice im- / putée; ses propositions inoüies; sa condamnation. / Explicit opus: [p. 514] ... \& que plusieurs / Protestans leur font tant d'honneur, qu'ils assûrent / mễme que l'Eglise persécutée par le Pape a conseré sa / succession dans cette société: erreur si grossiére \& si ma- / nifeste, qu'il faut tâcher une bonne fois de les en guerir. / Sin colofón.

Materia: Historia eclesíastica. Observaciones: La guarda anterior muestra ex libris impreso y adherido de la BIBLIOTHECA TURRIANA. La obra versa sobre l'histoire des variations des eglises protestantes. Condición física: Buena.

Como se puede apreciar, el registro se encuentra estructurado de la misma forma que el antes analizado, salvo que aquí sí se ha introducido el pie de imprenta en la descripción breve, aunque modernizado y por tanto contrario a los criterios internacionales y bibliográficos correspondientes. Después se realiza la descripción física del ejemplar, sin formato pero marcando la estructura básica del libro (hojas, folios o páginas). También aquí se registran las signaturas indicando el número de hojas del cuadernillo en la primera y en la última letra, a pesar de que son continuas como se aprecia.

Se anota posteriormente que el libro no tiene reclamos y en esta ocasión el tamaño del objeto está expresado en milímetros; sigue el idioma, el tipo de letra y el apostillado, a continuación la descripción "casi facsimilar" de la portada con una descripción detallada y no abusiva del 
grabado de portada entre corchetes. En esta aplicación del modelo se ha separado lo correspondiente al incipit y al explicit, una decisión que no ha considerado que en "el libro impreso el explicit se transforma definitivamente en colofón". ${ }^{219}$ Finaliza el registro con la asignación de materia, las observaciones dedicadas a los valores históricos y particularidades de la edición, así como esta forma genérica de apreciar el estado de la conservación. No se observa en este trabajo ninguna referencia bibliográfica ni tampoco alguna alusión al orden de la colección en la que se encuentra el objeto descrito.

El siguiente modelo procede de un texto dedicado a un solo libro, ${ }^{20}$ en el que vamos a encontrar formas interesantes de registrar y manejar una fuente antigua. En este registro observaremos una descripción detallada, aparentemente más cercana a aquellas elaboradas por los autores que componen nuestra tradición bibliográfica. En efecto, como corresponde a este tipo de trabajos, se han analizado distintas ediciones de una misma obra, la que aquí presentamos corresponde a 1792 .

219 Julián Martín Abad (2004a). Op. cit. p. 67

220 Fr. Joaquín Bolaños. La portentosa vida de la muerte, Emperatriz de los Sepulcros, Vengadora de los Agravios del Altísimo y muy Señora de la Humana Naturaleza (México, Joseph de Jáuregui, 1792) / Edición crítica, introducción y notas de Blanca López de Mariscal. México: COLMEX, 1992. pp. 61-64 
6.4. La edición de 1792

Portada

LA PORTENTOSA VIDA/ DE LA MUERTE,/ EMPERATRIZ DE LOS SEPULCROS,/ VENGADORA DE LOS AGRAVIOS/ DEL ALTÍSIMO,/ Y MUY SEÑORA/ DE LA HUMANA NATURALEZA,/ cuya célebre Historia encomienda a los Hombres/ de buen gusto/ FRAY JOAQUín BOLAÑOS,/ Predicador Apostólico del Colegio Seminario de Propa-/ ganda Fide de MARÍA Santísima de Guadalupe extra-/muros de la muy Noble y Leal Ciudad de Zacatecas/ en la Nueva Galicia, Examinador Sinodal del/ Obispado del Nuevo Reyno de León.

Colofón:

Impreso en México/ en la oficina de los herederos del Licenciado Don Joseph de Jáuregui,/ Calle de San Bernardo. Año 1792.

Formato:

Un volumen en $4^{\circ}(150 \times 205 \mathrm{~mm})$. Signatas de los pliegos: 4

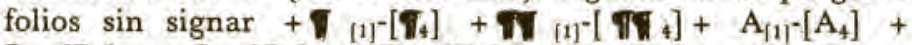
$B_{[1]^{-}}\left[B_{4}\right]+C_{[1]^{-}}\left[\mathrm{C}_{4}\right]+\mathrm{D}_{[1]^{-}}\left[\mathrm{D}_{4}\right]+\mathrm{E}_{[1]^{-}}\left[\mathrm{E}_{4}\right]+\mathrm{F}_{[1]^{-}}\left[\mathrm{F}_{4}\right]+$

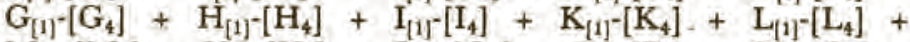

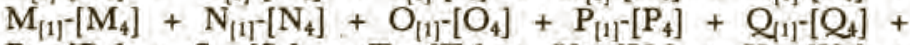
$\mathrm{R}_{[1]^{-}}\left[\mathrm{R}_{4}\right]+\mathrm{S}_{[1]^{-}}\left[\mathrm{S}_{4}\right]+\mathrm{T}_{[1)^{-}}\left[\mathrm{T}_{4}\right]+\mathrm{U}_{[1)^{-}}\left[\mathrm{U}_{4}\right]+\mathrm{X}_{[1]^{-}}\left[\mathrm{X}_{4}\right]+$ $\mathrm{Y}_{[1]^{-}}\left[\mathrm{Y}_{4}\right]+\mathrm{Z}_{[1]^{-}}\left[\mathrm{Z}_{4}\right]+\mathrm{Aa}_{[1]^{-}}\left[\mathrm{Aa}_{4}\right]+\mathrm{Bb}_{[1]^{-}}\left[\mathrm{Bb}_{4}\right]+\mathrm{Cc}_{[1]^{-}}\left[\mathrm{Cc}_{4}\right]$ $+\mathrm{Dd}_{[1]^{-}}\left[\mathrm{Dd}_{4}\right]+\mathrm{Ee}_{[1]^{-}}\left[\mathrm{Ee}_{4}\right]+\mathrm{Ff}_{[1]^{-}}\left[\mathrm{Ff}_{4}\right]+\mathrm{Gg}_{[1]}\left[\mathrm{Gg}_{4}\right]+$ $\mathrm{Hh}_{[1]}-\left[\mathrm{Hh}_{4}\right]+\mathrm{Ii}_{[1]}-\left[\mathrm{Ii}_{4}\right]+\mathrm{Kk}_{[1]^{-}}\left[\mathrm{Kk}_{4}\right]+\mathrm{Lu}_{[1]^{-}}\left[\mathrm{Li}_{4}\right]+\mathrm{Mm}_{[1]^{-}}$ $\left[\mathrm{Mm}_{4}\right]$

Contenido:

Portada (fol. 1r.s.n.) + Dedícala a Fray Manuel María Trujillo (fols. 3r.s.n. a 6v.s.n.) + Parecer de Fray Tomás Mercado (fol. 7r.s.n.) + Censura de Fray Ignacio Gentil (fols. 8v.s.n. a $11 r, s . n$.) + Licencia del Superior gobierno y Licencia del Ordinario (fol. 12v.s.n.) + Licencia de la Orden (fol. 13r.s.n.) + Fe de erratas (fol. 14y.s.n.) + Prólogo al lector (fols. 15r.s.n. a 
16v.s.n.) + Índice de los capítulos (fols. 17r,s.n. a 20v.s.n.) + Preámbulo (fols. 21r.s.n. a 24v.s.n.) + Texto (fols. núms. 1r. a $259 \mathrm{r}$.) + Conclusión (fols. 260v. a 268v ) + Testamento (fols. 268v. a $276 v$.)

Esta edición de La portentosa vida de la Muerte ha sido citada por Alzate, ${ }^{102}$ Beristáin de Souza, ${ }^{103}$ Medina, ${ }^{104}$ Nicolás León ${ }_{x}^{105} \mathrm{Re}$ yes, ${ }^{106}$ Iguíniz, ${ }^{107}$ Lazo $^{108}$ y Porrúa. ${ }^{109}$

Fue reproducida parcialmente por Agustín Yáñez con un prólogo introductorio y aparece en el mismo volumen con Los sirgueros de la Virgen, publicado por la Biblioteca del Estudiante Universitario en México, UNAM 1944. Y en edición facsimilar por el Instituto Nacional de Bellas Artes, serie La Matraca, México, 1983.

Grabados:

La obra contiene 18 láminas que representan pasajes de la vida de la Muerte, grabados en cobre en hojas sueltas sin foliar y firmadas por Aguera Fc. (o Sc.).

Toribio de Medina, en La imprenta en México, en su capítulo sobre grabadores, menciona a un Francisco Aguera Bustamante, que "inicia sus labores en 1784, grabando las dos alegorías o geroglíficos de Quirós y trabaja hasta 1805, en cuyo año graba con gran finura de buril, un frontis y nueve láminas para ilustrar la Novena de la Virgen de Loreto del Padre Croiset. Él fue también el que abrió las láminas para la desc[ripción], de las dos piedras de León y Gama y el retrato del P. San Cirilo ambas de 1792"'.110 Este mismo Aguera es el grabador que ilustra El Año Josefino del padre Bolaños, publicado un año después.

La crítica ha despreciado los grabados de Aguera tanto como a la Vida de la Muerte; Nicolás León los ha calificado de extrava-

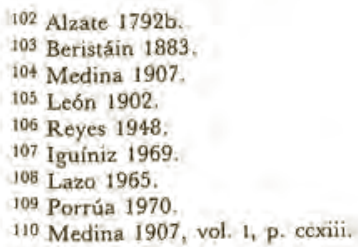


gantes ${ }^{115}$ y Gómez Canedo los considera horripilantes; ${ }^{112}$ Alzate dice de la estampa del capítulo IV que: "choca y chocará, no a los de buen gusto, sino también a los que tienen ojos con lagañas. .." Sinceramente creemos que el trabajo del grabador merece una revaloración por parte de los críticos de la obra gráfica, ya que posiblemente nos encontramos ante un interesantísimo antecedente del género en que sobresalió José Guadalupe Posada.

Comienza este registro directamente con la portada de forma "casi facsimilar", indicando altas y bajas pero no cursivas; después se indica el colofón con las mismas características que la portada, posteriormente el formato, el tamaño en milímetros y las signaturas (llamadas signatas $^{221}$ ) de manera muy desglosada, cuadernillo por cuadernillo. En éstas se observa una forma peculiar de comprender la colación, ya que se marca el número uno entre corchetes para el inicio, el número cuatro, también entre corchetes y con la letra correspondiente para el final de los cuadernillos compuestos por cuatro hojas y por ello de ocho páginas.

Después la autora apunta el contenido de la obra estableciendo el número de hoja (con indicación folio ${ }^{222}$ ), el recto o verso y cuál de éstos está numerado o sin numerar con las abreviaturas "r.s.n." o "v.s.n" que significan recto o verso sin numerar. ${ }^{223}$ Se puede ver que en el registro de los preliminares solamente se marca el tipo y en ocasiones el personaje responsable del documento, pero no se menciona ninguna fecha de éstos. Después de esta información, la autora informa en qué repertorios o trabajos ha sido registrada la edición que describe.

Una vez que ha descrito la edición, la autora dedica su atención a los dieciocho grabados que caracterizan esta obra, explicando cómo han

221 Palabra no reconocida en el Diccionario de la Lengua Española en su versión electrónica, disponible en http://buscon.rae.es/draeI/ [Consulta: enero 2008]

222 Cabe aclarar aquí que la hoja nunca está numerada, el folio lo está en la parte superior derecha y la página numera las dos caras de una hoja. Cfr. Fredson Bowers. Op. cit. p. 299

223 Condición que implica la existencia de hojas que podrían ser contadas. 
sido analizados o apreciados a lo largo de la historia. En este punto resulta todavía más interesante la ausencia de la Bibliografía Material en el campo de los estudiosos mexicanos de la literatura, especialmente sobre las ediciones antiguas. Esta bibliografía ayuda a comprender las descripciones de los ejemplares existentes de la edición, ${ }^{224}$ y especialmente a analizar si todos los libros conservados presentan los mismos grabados o se puede hablar de una variante de la edición. Sin duda este acercamiento disciplinal implica mayor trabajo y detalle en la información, pero también proporciona a otros la posibilidad de recuperar, comparar o relacionar esta edición (o variante de la misma) con otras igualmente relevantes.

Un año después, en un libro que identifica ejemplares novohispanos conservados en los Estados Unidos, ${ }^{225}$ encontramos que la

224 La autora aclara haber trabajado el ejemplar conservado en la Biblioteca Cervantina del Instituto Tecnológico y de Estudios Superiores de Monterrey, cuyo catálogo electrónico no proporciona demasiada información. Además nos informa que "existen cinco ejemplares: uno de ellos se encuentra en el Fondo Reservado de la Biblioteca Nacional de México, el segundo está en el Fondo Comermex, existe uno más en una biblioteca particular en el Distrito Federal y dos volúmenes en la ciudad de Monterrey, uno en la Capilla Alfonsina de la UANL y el [que existe] de la edición de 1792 en The Latin American Collection de la Universidad de Texas". Bolaños. Op. cit. p. 55; Hemos encontrado noticia de dos ejemplares más: uno en la biblioteca Luis González del Colegio de Michoacán y otro en la Biblioteca Elías Amador de Zacatecas. Cfr. Maria Isabel Terán Elizondo. Los recursos de la persuasión: la portentosa vida de la Muerte de fray Joaquín Bolaños. Michoacán: El Colegio de Michoacán: Universidad Autónoma de Zacatecas, 1997. También existe información sobre esta edición "Fray Joaquín Bolaños La portentosa Vida de la Muerte 1792. Libro novohispano impreso sobre papel de algodón. Estampas calcográficas. Reencuadernado en piel con grabados dorados hechos con carretilla, lomo con cuatro costillas y tejuelos verdes. 276 fojas más ilustraciones. 20.9 x $15.5 \mathrm{~cm}$ Col. Centro de Estudios de Historia de México Condumex". http://www.soumaya.com.mx/navegar/anteriores/anteriores03/rep.html [Consulta: marzo de 2006] Actualmente se trata del grupo CARSO. Por otra parte, una edición con estos datos no se localiza en la Biblioteca Palafoxiana, ni tampoco en las colecciones europeas, exceptuando la British Library (http://www.catalogue.bl.uk). [Consulta: marzo de 2006]

225 José Pascual Buxo. Impresos novobispanos en las bibliotecas públicas de los Estados Unidos de América, 1543-1800. México: UNAM. Instituto de Investigaciones Bibliográficas, 1994. p. 83 
mención del ejemplar es somera y por sus características parece reproducir la información de un catálogo de biblioteca, obsérvense los ejemplos:

GÁRATE, Juan de. Niño de cien años bien vividos... Sermón... a glorias de san Bernardo... México: Her. Vda. Bernardo Calderón, 1691. En Sermones varios. banc (F1207 S42 v.57:13 x), bnme.

MARTÍNEZ DE LA PARRA, José. Luz de verdades católicas, y explicación de la doctrina cristiana... México: Diego Fernández de León, 1691-96.

rpb (mf 230.2; A49-775), txu, dlc,jcb,bnme.

Como se aprecia no existe ninguna referencia relacionada con el formato o la descripción física del ejemplar que se describe, y solamente se indica el ordenamiento de la colección en algunas de las instituciones que se citan. Aquí no se relaciona el volumen facticio ${ }^{226}$ (al que se refiere el primero de estos registros) con las otras ediciones que lo componen y que necesariamente se deberían ver reflejadas en la obra que analizamos.

Publicado en el mismo año encontramos otro catálogo sobre impresos antiguos, los conservados en la Biblioteca del Congreso de la Unión. ${ }^{227}$ Como corresponde, se realiza una descripción catalográfica, pero como podemos observar no corresponde al modelo internacional de las ISBD (A).

226 Este tipo de volumen es el resultado de un agrupamiento bibliográfico artificial, que integra varias obras en una sola unidad. Nos referimos a este tipo de volumen con mayor detalle en el capítulo 6.

227 Catálogo de documentos antiguos: selección de impresos del siglo XVI al XIX. México: Cámara de Diputados. Comité de Biblioteca e Informática, 1994. Vol. 1, p. 26 


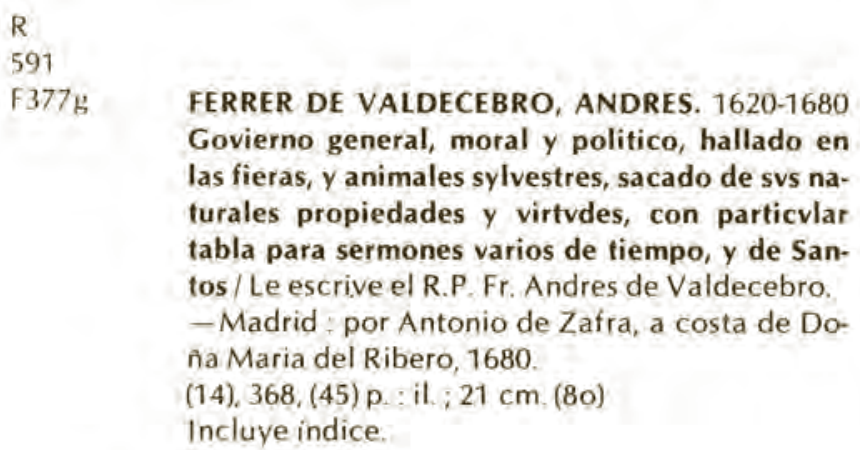

Vemos cómo se transcriben las formas ortográficas de época, especialmente lo que corresponde a la "v" por la "u", pero anota no se que parte de la información de la portada se ha omitido. La forma misma de la presentación de los datos nos remite a la idea de la ficha de un catálogo tradicional - en cuanto a márgenes y formas de puntuación-. La parte referida a la descripción física del ejemplar nos acerca a esta misma idea incluso en el reconocimiento de la estructura básica, a la que ya nos hemos referido.

Por ello sorprende la indicación del formato, todavía más cuando se observa que la intención del catálogo no es coherente con la historicidad del objeto conservado, sobre la que no encontraremos ninguna referencia. ${ }^{228}$ Es necesario aclarar que esta biblioteca es considerada tan importante como la Biblioteca Nacional de México, ya que la de los Diputados también recibe el depósito legal de la producción bibliográfica del país en igualdad de condiciones jurídicas que la nacional. $^{229}$

Frente a la información anterior, escueta y que nos refiere a la valoración cultural del objeto, nos encontramos otra muy distinta, elaborada al año siguiente. Nos referimos a los registros bibliográficos

228 En esta edición se incluyen algunas reproducciones de portadas pero son fotografías meramente decorativas, ya que el tamaño es sumamente reducido como para apreciar detalles tipográficos. Por esta condición no podrían ni siquiera considerarse informativas sino meramente decorativas.

229 Cfr. El depósito legal en México: órdenes y decretos expedidos de 1812 a 1991. México: Congreso de la Unión. Cámara de Diputados, 2001. 


\title{
que acompañan la edición realizada por el Museo Amparo $^{230}$ sobre el grabado barroco. En estos registros veremos un modelo que emplea metodología descriptiva semejante a la tradición bibliográfica que, por tanto, intenta ofrecer información puntual sobre el ejemplar de la edición que se describe.
}

\author{
6.- RAMIREZ DE VARGAS, Alonso.
}

Sagrado / Padrón / y / Panegyricos Sermones / A la Memoria Debida al Svmptvoso / Magnífico Templo, y curiosa Basilica del Convento / de Religiosas del Glorioso Abad / San Bernardo, / que edificó en su mayor parte el Capitán D. Ioseph de Retes Largache, difúto / Cavallero del Orden de Santiago, y consumaron en su / cabal perfección su Sobrino / Don Domingo de Retes y Doña / Teresa de Retes y Paz, / su hija, en esta dos vezes Imperial y siempre leal Ciudad de / México, con la Pómpa Fûnebre de la Translación / de sus Huessos, / que erige en descripción históricá / Panegyrica, / Don Alonso Ramírez de Vargas, natural de esta ciudad. / Dedicado, / a el muy Illustre Sr. D. Gariel Melen- / dez de Avilés Caballero del Orden de Alcantara, / Conde de Canalejas \&c. / (filete lineal tipográfico) / Con Iicencia, En México por la Viuda de Francisco Rodriguez Lu- / percio en la Puente de Palacio. Año de 1691. / (orla tipográfica).

$8^{\circ}$, m.- Port., vuelta blanca - 7 hojas Prels- Dedicatoria al Muy Ilustre Señor Don Gabriel Melendez de Aviles de Don DOmingo de Retes, con comisa al inicio de tipografía y capitular grabada en madera- Parecer del R. P. Mo. Francisco de Florencia, de la Compania de Jesus, apostillado con capitular graada en madera- Licencia del Exmo. Señor Don Gaspar de la Cerda, Sandoval Sylva y Mendoza, Virrey de esta Nueva España.- Sentir del R. P. Mo. Fr. Miguel de Aguilera, apostillado con capitular grabada en madera.- Licencia del Ordinario, el Doctor Don Diego de la Sierra, Vicario General del Arzobispadó- Los R. R. P. P. Prelados de las Sagradas Rellgiones, cada uno por lo que a su orden tocó, dieron Licenca para la Impresión de estos Sermones,- Portada del Sermón de Don loseph Vidal de Figueroa con orla tipográfica, vuelta blanca - Fojas 1-6 apostilladas con comisa tipográfica y capitular grabada en madera al inicio y fínal tipográfico-- Portada Sermón Panegyrico de Fr. Pedro Manso con orla tipográfica, vuelta blanca-11 fojas apostilladas con capitular y final grabados en madera, vuelta blanca - Portada del Sermón Panegyrico de Fr. Manuel de Arguello con orla tipográfica, vuelta blanca.- 15 fojas apostilladas con capitular y final grabados en madera, vuelta blanca.- Sermón Panegyrico de Fr. Ivan de Rueda con orla tipográfica, vuelta blanca - 8 Fojas apostilladas con comisa tipográfica al inicio y capitular y final grabados en madera - Portada del Sermón en la dedicación de el Templo de San Bernardo de el P. Fr. Mathias de San Juan Bautista, vuelta blanca.- 17 fojas apostilladas con capitular y final grabados en madera.-Portada del Sermón Panegyrico de Fr. Lus Méndez con orla típogrática, vuelta blanca, - 10 fojas apostilladas con comisa de tipografia y capitular grabada en madera al inicio, vuelta blanca- Portada del Sermón Panegyrico del M. R. P. Antonio Nuñez con orla tipográfica, vuelta blanca.- 24 fojas apostilladas con comisa de tipografía y capitular y final grabado en madera.- Portada del Sermón Panegyrico del el Dr. D. Iban de Narbaez con orla tipográfica, vuelta blanca- 14 fojas apostilladas con cornisa tipográfica y capitular y tinal grababdo en madera.- Portada de la Pompa Fúnebre en la Translación de los Huessos de el Capitán Don Joseph de Retes Largache Sálazar con prla tipográfica, vuelta blanca -5 fojas apostilladas con capitular grabada en madera, vuelta blanca.- Portada del Sermón Fúnebre de el T, Br. Fr. Diego de las Casas Zeinos.- 9 fojas apostilladas con grabado en madera al inicio escudo heráldico de la familia Retes. Anónimo, (91 X $96 \mathrm{~mm}$ ). con capilular y finál grabado en madera - 2 fojas con poema apostillado.- Unà foja Erratas.

16 pp. 5.f., 135 fojas, 2 pp. 5 . f; $203 \times 148$ mm., pergarnino.

230 Imprentas, ediciones y grabados de México Barroco. México: Museo Amparo, 1995. p. 140. 
Si bien como se observa existe toda una intención por distinguir los grabados de la edición, incluso los menores, veremos cómo el registro inicia con el autor para posteriormente describir línea a línea la portada. No decimos que sea de forma "casi facsimilar", pues como se observa no hay indicación de altas, bajas o cursivas, que son sumamente empleadas en las impresiones barrocas. Esta condición estética se indica al final de la transcripción de la portada como orla tipográfica. Por la misma razón no extraña que en algunos casos se respeten las formas antiguas (v.gr. "Panegyrica") y en otras se modernice la ortografía de las palabras (v.gr. "descripción histórica”).

Posteriormente, en lo correspondiente a la información sobre el contenido de la obra, veremos cómo ésta se presenta como ya se ha hecho anteriormente: primero el formato, después la portada, el número de hojas preliminares y la descripción de éstas. Aquí es donde se observa especialmente el interés por los grabados. En cada preliminar se indicará el tipo y la persona que lo elabora, pero en lugar de marcar la fecha y el lugar se señala de forma somera el tipo de grabado menor que existe (capitular, cornisas, escudos, etcétera).

Esta edición corresponde con una colección de sermones, que representan un número importante de las obras de la oratoria impresa novohispana. ${ }^{231}$ Pero por los datos proporcionados podría tratarse solamente de una edición compuesta o contrahecha $^{232}$ de partes anteriormente impresas. Esta suposición se basa en dos consideraciones, la primera es que el ejemplar descrito presenta portadas en lugar de portadillas por cada sermón incluido en esta colección y que además existen finales tipográficos (que bien pueden ser florones) para cada unidad de texto. Lamentablemente la ausencia de signaturas en la representación del objeto no ayuda a confirmar nuestra sospecha, ${ }^{233}$ pero al buscar

231 Cfr. Carlos Herrejón Peredo. "La oratoria en Nueva España". Relaciones. No. 57 (1997). p. 59

232 Fredson Bowers. Op. cit. p. 144, (Agradezco a Guadalupe Rodríguez la precisión).

233 La edición se encuentra en la Biblioteca Palafoxiana, "Números de localización 16777 16732-K Encuadernado con 21 obras". (http://www.bpm.gob.mx/) [Consulta: marzo de 2006]. 
ediciones semejantes conservadas con estos datos, hemos encontrado un ejemplar que así podría denotarlo. ${ }^{234}$

Como se sabe, este tipo de afirmaciones no deberían realizarse sin la revisión del original y contrastando directamente la información de la noticia bibliográfica, de ahí que consideremos que el registro de las signaturas en los catálogos de libros antiguos deba ser un dato obligatorio en los catálogos y no opcional como se promueve actualmente. En este registro además podemos observar que, en lo que corresponde a la descripción física, se indican "fojas" como en la descripción de documentos de archivo y no "folios" como correspondería a un impreso. El registro finaliza con la descripción física del objeto, advirtiendo las páginas sin foliar (que deben ser hojas), el tamaño en milímetros y una breve mención de la encuadernación. Tampoco se indica el lugar de custodia del ejemplar descrito.

El siguiente registro, también del mismo año, procede de la edición que se realizó con motivo de una exposición sobre impresos mexicanos del siglo XVI que se conservan en el Centro de Estudios de Historia de México CONDUMEX. ${ }^{235}$ El registro que aquí analizamos inicia con el nombre del autor al que sigue la transcripción "cuasi facsimilar" de la portada, empleando la diagonal (/). En ésta resalta la descripción detallada del grabado de la portada y la inclusión "[debajo del grabado]".

234 Nos referimos al registro correspondiente de la Biblioteca Nacional de México, cuya localización es RSM 1691 M4RAM. Obsérvense las signaturas correspondientes. Catálogo Nautilo http://132.248.77.3:8991/F [Consulta: febrero de 2007]

235 Actualmente con el nombre de Centro de Estudios de Historia de México CARSO 


\section{FRAY ALONSO DE MOLINA}

Confefsionario breue, en lengua/ Mexicana y Caftellana: compuefto por el muy reuerēdo/ padre fray Alonfo de Molina, dela ordē del fera=/ phico padre Sant Francifco,/ [Sigue un grabado en madera en rojo y negro entre filetes con una corona de flores y al centro el escudo de las cinco llagas. Alrededor:] Accipite Spiritum fanctum, quorum remi=/ feritis peccata: remittuntur eis. Et/ quorum retinueritis, retenta funt. Joānis. 20./ [Debajo del grabado:] En Mexico en cafa de Antonio de Efpinofa, Ympffor./ I565/

[Colofón castellano:] Acabofe de imprimir efte/ confefsionario en XXVJ./ de Henero Año de./ 1565./

Tamaño $4^{2}, 15.5 \times 21 \mathrm{~cm}$. Portada a dos tintas en rojo y negro. Al reverso aparece la licencia de la audiencia fechada el 24 de noviembre de 1564 .

Texto a dos columnas, cada una en un idioma. Fojas numeradas de la 2 a la 20 y al pie de esta última el colofón en mexicano y castellano.

Algunos grabados en madera, letra gótica, signaturas y reclamos y títuloś en las fojas.

Encuadernado con el "Confesionario mayor en lengua mexicana y castellana, Méxìco $1565 "$ ", en encuadernación mestiza.

Adquirido a José Porrúa Turanzas en 1989.

Posteriormente se anota, como tamaño, el formato y las medidas en centímetros, el tipo de portada y el documento preliminar que va al verso de la misma. También se señala la forma de la impresión del texto ("en columnas"), cuántas hojas están numeradas y el lugar que ocupa el colofón dentro de la impresión. A continuación se ofrece información sobre los grabados, el tipo de letra, y la presencia de signaturas sin indicar ninguna fórmula de colación. El registro cierra con información sobre la encuadernación y la inclusión de otra obra en el mismo volumen, así como datos relacionados con la procedencia del ejemplar descrito.

No es mucho lo que pueda decirse de este modelo; como otros, parece ser el resultado de una interpretación bibliográfica más que de la aplicación de una propuesta metodológica o el seguimiento a una tradición específica. Lo que sí nos parece pertinente precisar es la diversidad de 
formas en que los impresos del siglo XVI se han descrito. Sería interesante, en algún momento, contrastar cada uno de estos registros en sus coincidencias y divergencias frente a los originales conservados, para determinar cuál es el que representa mejor al objeto bibliográfico.

Encontramos otra edición de 1995, conmemorativa sobre la imprenta en México. ${ }^{236}$ El registro que hemos escogido para este análisis es un ejemplo interesante de combinación entre las formas bibliográficas y catalográficas. Vemos en primer lugar una ficha de catálogo en toda forma - sangrías y puntuación-; pese a que la transcripción del título ha respetado la lengua y las formas tipográficas, la descripción física es somera y común en un catálogo de biblioteca. Posteriormente se introducen ciertos elementos bibliográficos al describir la portada, en cuanto al grabado y la condición del ejemplar descrito, el tipo y color de la letra y las signaturas.

236 Tesoros bibliográficos mexicanos. México: primera imprenta de América, investigación, selección de material y textos Margarita Bosque Lastra; catalogación bibliográfica Aurora Serrano Cruz. México: UNAM, 1995 p. 102. 
Alonso de la Veracruz, c. 1504-1584.

Recognitio, svmmularum Reuerendi Patris Ildephonsi a Vera Crvce Avgvstiniani artivm ac sacrae Theologiae Doctoris apud indorum inclytam Mexicum primarij in Academia Theologiae Moderatoris. - Mexici : excudebat Ioannes Paulus Brissensis, 1554.

88 [8] h. : $30 \mathrm{~cm}$.

En la portada: Un pequeño corazón en el mar, atravesado por las flechas, $y$ a los lados: "Sagitaueras tu domine cor meum charitate tua." Más abajo [mutilado en el ejemplar de la Biblioteca Nacional de México] un grabado grande de $\mathbf{S}$. Agustín.

Portada en rojo y negro; letra romana it 2 columnas. Signaturas: A2, B8-L8, +8 .

Errores en la foliaciôn : h, 33 debe ser 85.

En las h. $30,34 b, 36,37,48 b$ y 49 hay figuras grabadas en madera para explicar la oposición y contrariedad de las proposiciones. Ademâs. en la h, 57 hay otro grabado que la ocupa toda, intitulado Pons asinorum.

A la vuelta de la portada un aviso del impresor, Mexici, Anno Domini, 1554, pridie Kalendas Maias, y dos composiciones latinas en elogio del autor.

En la h. 2, una epistola latina al autor, de Fr. Esteban de Salazar, su discípulo.

Dedicatoria del autor a su provincia: "Cum per annos plurimos in hac Nova Hispania, Patres gravissimi, discipulos a primis Dialecticae rudimentís susciperem instituendos, fuit mihi curae quam maxime sic eis viam ad Sacram Theologiam, veluti digito, demostrare, ut non solum consenescerent ad scopulos. Syreneos, verum ut ne difficultatis magnitudine perterriti retro cederent ... Kalendis Maii M.D.LII"

Sigue el texto de la obra, de h. 9 a $87,-88^{\circ}$, un Epigrama y un Apostrophe latinos de Fr. Esteban de Salazar, discípulo del autor, religioso agustino, como él, y después monje cartujo, autor de la obra intitulada Veinte discursos sobre el Credo, de la que hicieron to menos cinco ediciones, y en la cual se tratan varias cosas de México.- A la vuelta la fe de erratas.

Siguen $8 \mathrm{~h}$. sin numerar, que contienen un Epithome Summularum, que sirve al mismo tiempo de indice; $y$ en el fin, en la h. 8 a se lee: Ad dei magni gloriam explicitum fuit opus tertio idus lulîi Anno. 1554 .

Impreso en papel de trapo hecho a mano; encuadernación española: marroquinado en oro.

Uno de los primeros textos universitarios escritos en México.

Procedencia: Biblioteca Nacional de México. 
También se indican los errores en la foliación, y se describe el contenido de la obra a través de textos presentes en el ejemplar, como avisos del impresor, dedicatoria y otros. Por la descripción no parecen existir más preliminares que los ya descritos, pero la información proporcionada no se corresponde con la descripción física: se indican 88 hojas de texto y 8 más "sin numerar", lo que indicaría que las primeras están numeradas y por tanto serían folios. Especialmente si relacionamos y contrastamos esta información con la correspondiente a las signaturas, veremos que hay 2 hojas (A2) y 88 (B8-L8); estas últimas corresponden al texto y por tanto faltan en la descripción física inicial las dos hojas de los preliminares.

Pese al esfuerzo y al detalle, el registro no consigue darnos una idea específica de la condición material del objeto descrito, pero a diferencia de otros modelos presentados considera el valor cultural del objeto al informar sobre las características externas (papel y encuadernación) y sobre el valor cultural del objeto representado (uno de los primeros textos universitarios). Llama la atención que este registro haya sido elaborado por el Instituto de Investigaciones Bibliográficas de la UNAM, institución universitaria que tiene a su cargo la Biblioteca Nacional de México desde 1967, y donde suponemos debería existir un mejor conocimiento del libro antiguo.

Esta condición institucional nos confronta con la gravedad del caso que nos ocupa: el valor patrimonial del libro antiguo. En efecto, no puede explicarse cómo en estas instituciones no se consideró la relevancia de analizar descripciones bibliográficas de material antiguo realizadas con anterioridad (nacionales e internacionales) para diseñar o implementar un modelo más cercano a la naturaleza cultural del libro antiguo y relacionado con la evolución del conocimiento bibliográfico. De ahí que no nos resulten extrañas las "particulares" formas de registro ${ }^{237}$ que se observan en el propio catálogo de la Biblioteca Nacional, y cómo desde la esfera de actuación de esta institución no se haya podido consolidar ese valor patrimonial al que hacemos referencia.

237 Actualmente el registro en línea de estos materiales es más completo y responde a la naturaleza de la ISBD(A), sin embargo siguen manteniendo confusiones en conceptos importantes de la Bibliografía Material. 
Esta misma condición patrimonial que refleja la valoración cultural podemos observarla de nuevo en un catálogo sobre el fondo antiguo $^{238}$ que custodia la Biblioteca de México y que fue publicado al año siguiente. En este catálogo también se emplea metodología catalográfica pero, como podemos observar, tampoco coincide formalmente con la norma internacional ISBD (A).

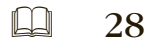

Manuel, Juan (Infante de Castilla)

El Conde Lvcanor. Compuesto por el excelentíssimo principe don Iuan Manuel, hijo del Infante don Manuel, y nieto del sancto rey don Fernando. -- Sevilla : En Casa de Hernándo Díaz, 1575

316 pp. ; $19 \mathrm{~cm}$

Particularidades: Texto a 1 columna. Exlibris: Etiqueta, en el interior de la tapa superior, "Joaquín García Icazbalceta". Reencuadernación en papel. Primera edición. Apostillas impresas. Reclamos en recto y verso

Palau señala: "Libro precioso para la literatura castellana, calificado de monumento del lenguaje más puro y culto del siglo XIV.” Edición príncipe

REFERENCIAS:

C.L.M. t. 2, p. 161, no. 9055

PALAU M.L.H. t. 8, p. 152, no 150122

Estado físico: Bueno

Colección: Joaquín García Icazbalceta/ no. 23

238 Catálogo del fondo reservado de la Biblioteca de México: una selección. México: ConaCulTa, 1996. p. 53 
Se observa que el desconocimiento de la norma internacional se enfatiza casi siempre en las omisiones del título, pese a que se mantienen las formas ortográficas ("v" por "u"), la forma de registro del pie de imprenta y especialmente en la forma de la descripción física. La falta de conocimiento sobre la naturaleza estructural del libro antiguo suele manifestarse en la inclusión del formato y las signaturas, así como en las formas en que se registran esos datos. Por otra parte, sí se consideran los valores textuales e históricos del ejemplar descrito, pero en cuanto a los primeros, llama la atención sobre la condición de "una columna" para una obra que no es poética sino literaria, también las apostillas y los reclamos que para los libros impresos desde el siglo XVI suelen ser características que se generalizan durante la Reforma. ${ }^{239}$ El registro finaliza con las referencias bibliográficas, el estado de la conservación de forma subjetiva y la colección a la que pertenece dentro de la biblioteca de custodia.

En el mismo año que el anterior, fue publicado otro catálogo sobre los libros antiguos conservados en la Biblioteca Nicolás León de la Facultad de Medicina de la UNAM. ${ }^{240}$ Estos registros también son una muestra del desconocimiento de la norma internacional y del trabajo bibliográfico con estos impresos; especialmente es notorio porque los autores declaran haber contado con la asesoría de Gloria Escamilla, quien elaboró la traducción al español de las Reglas Angloamericanas de Catalogación y fue una gran impulsora del trabajo bibliográfico y catalográfico en varias instituciones. Actualmente su manual ${ }^{241}$ sigue siendo una referencia constante en la investigación bibliográfica, pero lo que puede observarse en éste es la falta de mención de la norma internacional que nos ocupa y de los trabajos desarrollados por la catalogación descriptiva norteamericana.

239 Giuseppina Zapella. Op. cit. p. 405

240 Ana Cecilia Rodriguez de Romo, Arnulfo Irigoyen y María Teresa Hernández Sánchez. Tesoros de la Biblioteca Histórica Doctor Nicolás León: libros de medicina de los siglos XVI, XVII y XVIII. México: UNAM, Facultad de Medicina. Departamento de Historia y Filosofía de la Medicina, 1996. p. 43

241 Cfr. Gloria Escamilla. Manual de metodología y técnica bibliográficas. México: UNAM, 1988. 
79 DIEMERBROECK, YSBRAND VAN (1609-1674)

QM34 OPERA OMNIA MEDICA, ET ANATOMICA

D54 Partim jam antea excusa, sed Plurims locis ab ipso autore, emendata, E auctua, partim nondum edita... Patavii: Typographia Petri Mariae Frambotti, 1688 [12], 746, [6] p. Il. $20 \mathrm{~cm}$.

\section{Anatomía humana. 2. Disección}

El registro que presentamos es somero, más tendiente a la catalogación que a la bibliografía, y por ello no debería extrañarnos la ausencia de registro de los valores textuales o históricos. En lo particular pudimos observar este mismo ejemplar descrito ${ }^{242}$ y contrastar la información de este registro con el objeto original. Nuestra revisión mostró una forma diferente en la estructura física, ya que anteceden 6 hojas que corresponden a los preliminares, siguen las 746 páginas y finalizan 3 hojas más. Las primeras y segundas presentan cuadernillos de cuatro hojas indicados con signaturas A-Z hasta de cuatro letras y dos cuadernos más de cinco letras A-B. Las últimas hojas no presentan signaturas.

Lo más interesante de este libro original son sus valores históricos y textuales: ex libris, anotaciones manuscritas, grabados y otros; valores que aquí no son representados pese a que la intención de la edición es distinguir su valor cultural, de ahí el nombre de "Tesoros". En algunas ocasiones este catálogo describió fotocopias como originales sin indicar esta condición material, lo que nos conduce nuevamente a reflexionar sobre el valor que estos libros tienen en nuestra idea de pasado cultural.

También corresponde a este año la publicación de la Biblioteca Francisco de Burgoa; de esta tomamos como ejemplo el registro de un impreso mexicano del siglo XVI. ${ }^{243} \mathrm{Al}$ igual que otros trabajos ya

242 Biblioteca Histórica Nicolás León HBM-13373

243 Las joyas bibliográficas de la Universidad Autónoma Benito Juárez de Oaxaca: la Biblioteca Francisco de Burgoa, María Isabel Grañen Porrúa... [et. al.]. México: Fomento Cultural Banamex, 1996. p. 27 
presentados y elaborados por el INAH, en este catálogo se entiende como metodología la explicación detallada de los datos contenidos en la descripción bibliográfica, ${ }^{244}$ pero en este caso llama todavía más la atención el registro que analizamos por la edición de que se trata, ya que parece ser el único ejemplar que se conserva de la misma.

244 El modelo y la presentaciòn de la información es muy similar en el catàlogo de obras de Jalisco. 

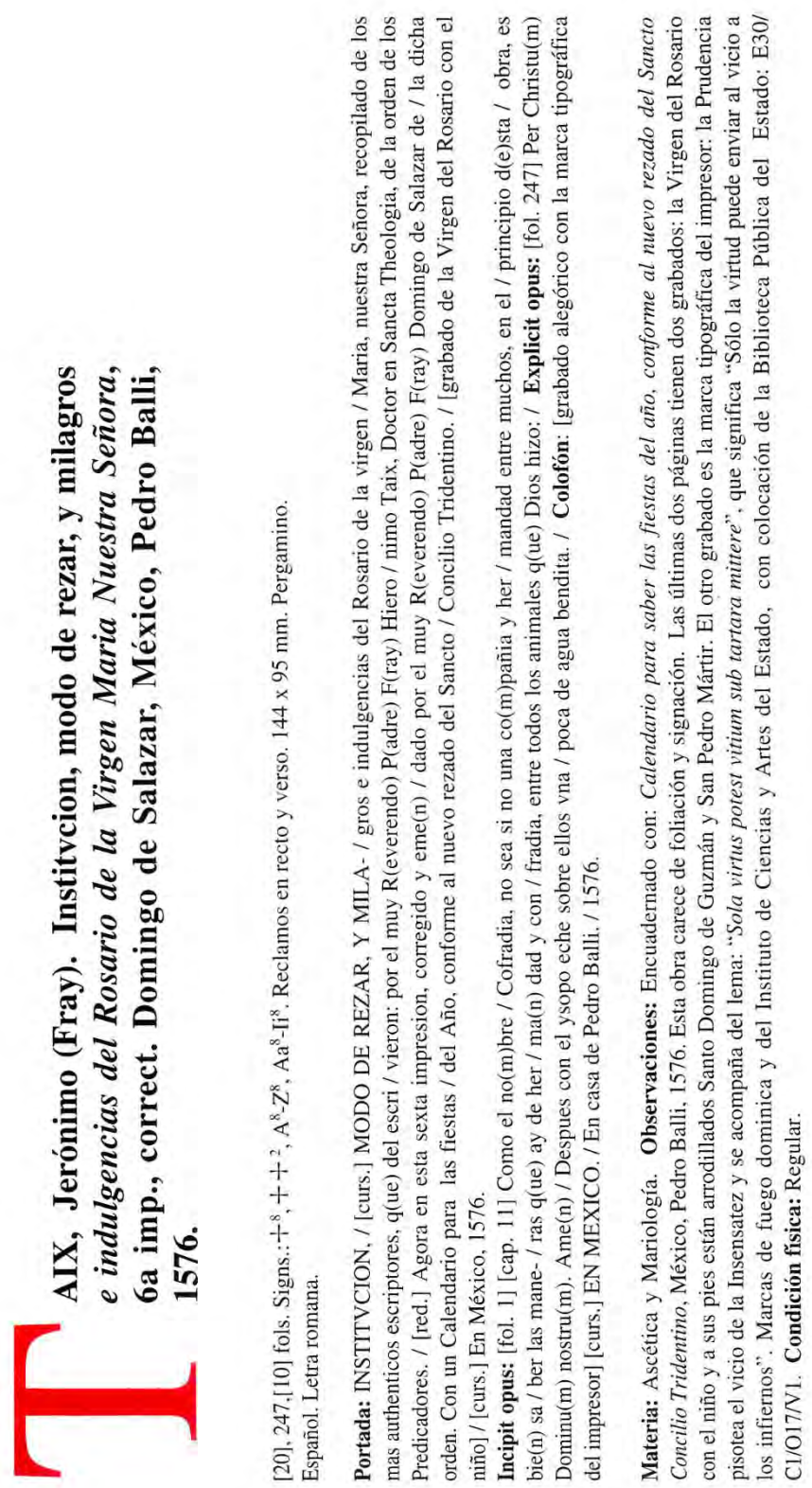
En efecto, uno de los datos que resalta de forma inmediata en el registro es el dato " $6 \mathrm{a}$ imp. correct" que aparece en el registro breve, aunque dicha información se extrae de la propia portada. Incluso al buscar el libro en la obra de Medina, ${ }^{245}$ encontramos que su mención refiere a la segunda edición mexicana, porque así se encuentra en la dedicatoria del impresor: "que este Libro del Rosario ha sido impreso en esta insigne ciudad y dedicado á la persona que entonces á su costa lo mandó imprimir". ${ }^{246}$ Medina también nos dice que la edición era desconocida para Icazbalceta, pero fue registrada en la edición anotada de su obra de $1954 .^{247}$

En esta obra, al igual que en la de Medina, la autoría ha sido adjudicada a Fr. Domingo de Salazar, pero González de Cossío dice en su propia noticia "he puesto el nombre de fray Jerónimo de Taix por ser en realidad éste el autor". ${ }^{248}$ En efecto, en la transcripción de la portada de estos registros mencionados y en el registro de Wagner ${ }^{249}$, observamos que el texto elaborado por Jerónimo Taix ha sido corregido por Salazar para esta edición de $1576,{ }^{250}$ que no se encuentra registrada en Valton. ${ }^{251}$

A dicha edición y como el impresor lo expresó, le corresponde una primera realizada en 1574 y de la que consta su existencia por estar registrada en una memoria de libros presentada ante la Inquisición por

245 José Toribio Medina. Op. cit. p. 208, registro 75.

246 Ibíd. p. 209

247 Joaquín García Icazbalceta. Op. cit. p. 278, no. 81

248 Francisco González de Cossío. Op. cit. p. 6, no. 106

249 Enrique R. Wagner. Op. cit. p. 306 y 307, no. 70b. Aquí se reproduce una portada que no corresponde a esta edición, sino que el autor supone posterior. Dicha edición, Millares Carlo la supone anterior “156...”. Joaquín García Icazbalceta. Op. cit. Apéndice, lista II, p. 509, no. 47

250 También existe noticia de esta edición en "Arte iberoamericano desde la Colonización a la Independencia”, Primera parte, Summa Artis. Historia General del Arte. Madrid: Espasa-Calpe, 1996. Volumen XXVIII, p. 500

251 Emilio Valton. Op. cit. 
el librero Juan de Ribera en 1660.252 Millares Carlo considera que es esta la edición a la que se refiere Balli, ya que las licencias y el privilegio que se reproducen en la edición de 1576 están fechados en $\mathbf{1 5 7 4}$, por lo que también considera que ambas fueron impresas por éste. ${ }^{253}$ Sin embargo, González de Cossío escribe que la edición de 1576, aunque no la registra, no debe ser considerada segunda sino tercera mexicana, porque encontró noticia de otra impresa en $1559 .{ }^{254}$

Ahora bien, siguiendo esta misma información, para que la edición que se corresponde con el registro que analizamos sea una sexta "impresión”, es necesario suponer que existieron tres más fechadas con anterioridad a 1559. González de Cossío cita como más antigua una edición de Barcelona en 1597 y otra de la misma ciudad en 1602, citada por Nicolás Antonio. ${ }^{255}$ En cuanto a éstas, en el Catálogo Colectivo del Patrimonio Bibliográfico Español encontramos sólo dos obras en catalán de Fr. Jerónimo Taix, ${ }^{256}$ anteriores a las ediciones mexicanas: ${ }^{257}$

252 "Memoria de los libros que presentó Juan de Ribera". AGN. Ramo Inquisición, t 585. Ha sido trascrita por Edmundo O'Gorman. "Bibliotecas y librerías coloniales”. Boletín del Archivo General de la Nación, T. 10, no 4 (1939). A la edición en cuestión le corresponde el número 191, en la página 812. Aquí también se atribuye la autoría a Fr. Domingo de Salazar.

253 Joaquín García Icazbalceta. Op. cit. p. 489 y 490, no. 68

254 Francisco González de Cossío. Op. cit. p. 4, no. 103

255 Ibidem.

256 Aparentemente existe una más anterior: "El autor de este libro fue un fraile dominico del convento de Barcelona nacido en 1503. El texto en cuestión apareció por primera vez en 1540 y en el transcurso de los siglos XVI y XVII tuvo varias ediciones". Martin Gelaberto Vilagran. La palabra del predicador. Contrarreforma y superstición en Cataluña (siglos XVII y XVIII). Barcelona: El autor, 2003 (Tesis de doctorado en Historia moderna y Contemporánea. Universidad de Barcelona). Texto disponible en http://www.tesisenxarxa.net/TESIS_UAB/AVAILABLE/TDX-0621104-164655//mgv1de1.pdf [Consulta: Noviembre de 2007]. p. 181, nota 103.

257 No obstante Palau indica una edición perdida para la bibliografía, fechada en 1570 . Reconoce esta de 1576 como segunda en castellano, también en octavo y con 247 folios. Antonio Palau y Dulcet. Manual del librero bispano-americano: inventario bibliográfico de la producción científica y literaria de España y de la América Latina desde la invención de la imprenta hasta nuestros días, con el valor comercial de todos los artículos descritos. Madrid: Luio Ollero Editor, 1990. t. 7 p. 7. 
Libre d[e]la institucio, manera de dir, miracles e indulgencies del Roser dela Verge Maria, señora n[ost]ra / co[m]post per ... Hieronim Taix ... ; ara nouament fet per lo dit auctor en lengua catalana, enlo qual hi ha afegides moltes coses les quals en les primeres jmpressio[n]s no hi eren, com es la segona part d[e]ls miracles y la taula de tot lo llibre ... [Barcelona]: estampat en casa de Pere Mo[n] pezat..., [1556] ${ }^{258}$

[Libro del Rosario...] [S.1. : s.n., s.a.] ${ }^{259}$

En el texto que acompaña este registro de Taix se informa que la edición fue reportada por primera vez en 1888 por Nicolás León, y que fue Felipe Teixidor quien documentó la permanencia de la obra en Oaxaca en $1937 .^{260}$ Los bibliógrafos Medina, Wagner y García Icazbalceta se refieren a este ejemplar conservado en Oaxaca, ${ }^{261}$ que como ya decíamos, a la fecha sería el único conservado o del que se tiene noticia. ${ }^{262}$

258 Fecha tomada del colofón. Existe un ejemplar en la Biblioteca Pública Lambert Mata (Ripoll, Girona). R. 248. Datos proporcionados en el mismo registro del Catálogo.

259 Fecha tomada de la página 8, y recuperada de la Historia ilustrada del libro español. Madrid: Fundación Germán Sánchez Ruipérez: Pirámide, 1994. p. 171. Existe un ejemplar en el Museo del Traje. Centro de Investigación del Patrimonio Etnológico (CIPE), Madrid. FA-816. Datos proporcionados en el mismo registro del Catálogo.

260 Las joyas bibliográficas de la Universidad Autónoma Benito Juárez de Oaxaca. Op. cit. p. 27

261 En la obra de Enrique R. Wagner. Op. cit. p. 306, en referencia a este ejemplar escribe: "León al describirlo dice que la portada y los preliminares ocupaban veinte hojas sin numerar, éstas con 256 hojas de texto y tabla, etc. Hacen un total de 276". Aún así, esta información también es distinta.

262 Rosa María Fernández Esquivel, en su tesis también registra este ejemplar de la edición de 1576, e indica la presencia de 296 h. que también difieren de las anteriores. Los impresos mexicanos del siglo XVI: su presencia en el patrimonio cultural del nuevo siglo. México: La autora, 2006. (Tesis de doctorado. Doctor en Bibliotecología y Estudios de la Información. UNAM. Facultad de Filosofía y Letras. División de Estudios de Posgrado). p. 74, no. 76. La autora no registra ninguna de las otras ediciones anteriores a esta fecha que hemos mencionado. 
Ahora bien, volviendo al ejemplo en cuestión, podemos observar que este se compone de un registro breve, al que ya nos hemos referido. En el siguiente bloque de información se da una descripción física que también considera las signaturas, la existencia de reclamos, el tamaño en milímetros y la palabra "Pergamino" que suponemos se refiere al tipo de encuadernación. No se ha notificado el formato. Sin embargo, la información de la descripción física no parece corresponder con la indicada por Medina, Wagner y García Icazbalceta, que tan sólo difieren en el número de hojas que contienen el texto de la obra; el primero y el segundo registran 247 y el tercero 277.

Como se observa, en el registro que analizamos, más que mencionar hojas, se hace referencia a folios, ${ }^{263}$ pero aún suponiendo que ambas categorías reconocen un recto y de un verso, en los registros de los bibliógrafos citados se registra la hoja de portada más $10 \mathrm{sin}$ numerar de preliminares que van antecediendo a las del texto de la obra que mencionamos en el párrafo anterior. También se indica que al final existen 9 hojas posteriores, -8 de tabla y una de colofón-. En el registro que analizamos se informa de 10 más anteriores y una más posterior.

Otro aspecto interesante a distinguir en dicho registro se refiere a la forma de transcripción de las signaturas, que no se corresponde con las metodologías modernas de la Bibliografía Material mencionadas. Sin embargo, aquí importa anotar que el primer alfabeto se corresponde con la información citada de los bibliógrafos (A-Z $\mathrm{Z}^{8}$ ), pero no el segundo alfabeto. En éste indican que el último cuadernillo (Ii) está compuesto de 4 hojas, y no de ocho como nos lo muestra el registro analizado. Si transcribimos la información de los bibliógrafos, suponemos que la signatura correcta debería ser: $\mathrm{Aa}-\mathrm{Hh}^{8}$, Ii4.

En lo que corresponde a la transcripción de la portada, existen ligeras diferencias con los registros de Medina e Icazbalceta en lo que corresponde a la separación de las líneas, y también que se han deshecho las abreviaturas: R.P.F. Igualmente incluye este bloque de información el incipit y el explicit que se corresponde con las formas de

263 Sobre esta compresión, tenemos una opinión que se justifica en el capítulo sexto de este libro. 
trabajos anteriores, realizados bajo la responsabilidad del INAH y que también hemos precisado.

La información que debemos analizar con cierto detalle es la proporcionada en las observaciones. Los datos relacionados con la historicidad del ejemplar conservado, como el tipo de encuadernación o las marcas de fuego, no son datos que puedan contrastarse con la información de los bibliógrafos de nuestra tradición, porque debemos recordar que éstos pusieron escaso interés en los valores históricos de los ejemplares descritos. Sobre la marca de fuego, resulta interesante que se diga "dominica y del Instituto de Ciencias y Artes del Estado". Suponemos que esto último es un error y se refiere a un sello, pero en ambos casos no indican el lugar donde se encuentran. También es conveniente observar que si se informa que está encuadernado con otro impreso, se supondría la existencia de una unidad bibliográfica distinta, de la que se precisa "carece de foliación y signación". Sin duda, para Medina y García Icazbalceta se trata de una sola unidad.

Por haberse publicado este mismo año, hemos seleccionado este ejemplo $^{264}$ de entre los catálogos elaborados por Yhmoff Cabrera. Si bien una gran parte de estos trabajos nos han mostrado la puntualidad y el rigor metodológico que caracterizaran al autor, sorprende que en éste no haya incluido la información correspondiente a las signaturas así como la clasificación del libro en la biblioteca de custodia. En sus trabajos anteriores sobre incunables e impresos mexicanos sí se puede encontrar este tipo de información, lo que permite verificar que el autor conocía las formas más idóneas de registrar tan particular dato. Sin embargo, en su introducción a esta edición de impresos europeos no hace ninguna explicación sobre la metodología empleada para la descripción y es extraña la omisión de ciertos datos siendo este trabajo el último de los que realizó, por lo que podría esperarse una síntesis de experiencia. ${ }^{265}$

264 Jesús Yhmoff Cabrera (1996). Op. cit. t. 1, p. 70

265 Quizá podría explicarse esta característica, porque es una obra que se publicó cuando Yhmoff había fallecido, por lo que el resultado no es un texto cuidado "hasta el final por su autor". Véase la advertencia a la edición. 
69. ÁlVAREZ GUERRERO, Alfonso, obispo de Minopoli, m. 1577. Thesaurus christianae religionis et Speculum Romanorum Pontificum, Imperatorum, Regum ac Episcoporum. Florencia, Hijos de Laurentius Torrentinus, 1563.

THESAVRVS / CHRISTIANAE / Religionis, / Et Speculum Sacrorum Summorum Romanorum Pon- / tificum, Imperatorum, ac Regum, \& San / ctissimorum Episcoporum. / Ubi multa de CONCILIO Generali indicendo traduntur. / PER CLARISSIMVM, AC PRAESTANTISSIMVM / I. V. D. Dominum Alphonsum Aharez Guerrero, Consiliarium Regium / Necnon Regiae Camerae Summariae in Regno Neapolis Praesidem, / Nunc noniter in lucem editum. / (Adorno tipográfico) / Ad Serenissimum, Sacrum, Catholicum, Inuictissimum, potentissimum / Augustum, PHILIPPVM, Regem Hispaniarum \&c. / Religionis Christianae seruatorem, ac / defensorem. / CVM GRATIA ET PRIVILEGIO. / (Marca tipográfica) / FLORENTIAE / Apud Filios Laurentii Torrentini Typographi / Ducalis, MDLXIII. En la página 512: Florcntiae, apud filios Laurentij Torrentini Typographi Ducalis. / MDLXIII.

Hojas: $4 \sin$ numerar y paginadas I-SI2. Signaturas, reclamos, título corriente. Líneas enteras. Letra romana y cursiva. Dos iniciales orladas, simples las demás. Encuadernación de pergamino. $31.5 \mathrm{~cm}$.

Las hojas no numeradas contienen: Dedicatorias del autor a Felípe If de España. Tabla de capítulos. Erratas.

Nota manuscrita en la portada: "attinet ad hanc blibiotecam (sic) Sancti dominici de mexico." Marca de fuego de este convento en el canto inferior.

Ejemplar 2. Dos notas manuscricas en la portada; la primera bajo tuchaduras dice "es del doctor Joan de Salzedo clerigo" y la segunda, "es de la libreria de san diego de mexico 1636." Marca de fuego de este convento en el canto superior. Encuadernación de pergamino. $31.5 \mathrm{~cm}$.

Los datos que proporciona Yhmoff nos muestran una descripción breve y adecuada, aunque no haya indicado donde omite información, porque al paralelo nos está proporcionando una descripción de la portada de forma "casi facsimilar", registrando altas, bajas, cursivas, redondas, adornos tipográficos y sin deshacer las abreviaturas, aunque es interesante observar que en el mismo espacio y con la misma forma transcribe la información del colofón. 
Posteriormente nos proporciona información sobre las hojas, paginación, tipo de letra, capitulares, encuadernación y algunos de los preliminares. Finaliza el registro con elementos históricos de dos ejemplares, el que describe y uno más: elementos como anotaciones manuscritas, marcas de fuego y encuadernación (del segundo ejemplar). Lamentablemente no indica si entre estos ejemplares de la edición encontró alguna diferencia textual que sea relevante, ${ }^{266}$ así como tampoco de dónde procede su información sobre la marca tipográfica que se ha relacionado con el impreso.

Al año siguiente encontramos trabajos históricos dedicados a la recuperación de bibliotecas particulares, como las de los obispos, ${ }^{267}$ basados en inventarios de bienes. A partir de esta información documental los autores recuperan la información de los impresos mencionados y nos proporcionan un modelo de descripción interesante que se presenta en la edición solamente en las notas, en relación directa con el inventario que se transcribe. Presentamos aquí dos modelos que aun cuando no aportan datos sobre ejemplares concretos, sí se indica dónde se encuentran algunos de éstos.

266 El catálogo de la Biblioteca Nacional de México no reporta ninguna edición impresa en Florencia en 1563, sino una impresa en Colonia en 1581. De esta se encuentran aparentemente ejemplares de la edición en varias bibliotecas universitarias y nacionales europeas .También encontramos otras ediciones del mismo titulo y autor impresas en Venecia de 1559 y en Nápoles de 1571, también en varias bibliotecas. Solamente en Bavaria (http://www.ubka.uni-karlsruhe.de/kvk/kvk/kvk_span.html) y en el Catálogo Colectivo del patrimonio Bibliográfico Español (http://www.mcu.es/bibliotecas/MC/CCPB/index.html) hemos encontrado descripciones que coinciden con los datos proporcionados por Yhmoff [Consultas: 29 de marzo de 2006] No es la primera vez que buscando los registros de Yhmoff, se descubre que no coinciden en lo absoluto con los registros del catálogo Nautilo de la Biblioteca Nacional. Esta situación genera una duda razonable sobre el trabajo de catalogación en la institución, ya que las descripciones de Yhmoff normalmente incluyen los valores históricos de los ejemplares y sus ediciones algunas reproducciones.

267 Cristina Gómez Álvarez y Francisco Téllez Guerrero. Una biblioteca obispal Antonio Bergosa Jordán 1802. Puebla: BUAP. Instituto de Ciencias y Sociales y Humanidades, 1997. p. 59 y de los mismos autores el trabajo Un bombre de Estado y sus libros: el Obispo Campillo, 1740-1813. Puebla. BUAP. Instituto de Ciencias y Sociales y Humanidades, 1997. p. 92 
4* Jacobi / Pignatelli / Ex Cryptaleis in Salentinis / S. Theolog. ac J. U. Doctoris / Novissimae / Consultationes / Canonicae. / Praecipuas controversias, / Quae ad Fiem, Erusque Regulam spectant, in quibus Errores Atheorum, / Infedelium, Schismaticorum, Haereticorum, \& aliorum Ecclcesiae Catholicae hostium / referuntur \& refelluntur praesertimque illas quae circa S. Inquisitionis / Tribunal versantur, ubi de Inquisitioribus, corumque Officialibus \& Ministris, / de Reis in quos jus \& potestatem habent, denque Poenis pro Casum varietate istis / infligendis, \& quam plurima alia ad hoc Argumentum facientia, complectentes. / Opus Juris Utriusque consultis non modo, / verùm etiam Theologis, imò \& omnibus Fidem Christianam profitentibus plane / necessarium ac utile. / Cum Indice Consultationum singulis Tomis praefijo. / Altera editio emendatior, cui accessit Index Rerum \& Materiarum locupleissimus. / Tomus Prior. / [viñeta] / Coloniae Allobrogum. / Apud Fratres de Tournes. / [filete] / M. DCCXIX. / Cum Privilegio Sacrae Caesareae Majestatis. [5 t., $36 \mathrm{~cm}$., perg.] (BNM: RFO 94-43878). Otras ediciones en (CP: 5955-5957); (BP: casilla 479, libros 14-17, piso 3\}; \{BNM: RFO 93-41612\}.

${ }_{195}$ Martin de TORRECiLLA, Examen / de la Potestad / y jutisdiccion / de los señores / obispos, / assi en comun, como / de los obispos regulares, y titulares, / con algunas Consultas concernientes á la materia. Su autor/el R. P. Fr. Martin de Torrecilla, lector de / teologia, Calificador de el Santo Oficio, Ex-Provincial de la / Provincia de Castilla, y Ex-Difinidor General de toda la / Orden de Menores Capuchinos. / Nuevamente corregida, y añadida mucho por el mesmo-Autor en esta Impression Segunda, con un indise copiosissimo de las cosas. Lo añadido comienza con esta senal + y acaba con esta. * / Dedicale al Ilustrissimo, y reverendissimo / Señor D. Fray Joseph de Leucaster, Obis. po un tiempo de Miranda, $y$ al pre - / sente Obispo de Leyria, del Consejo de su Alteza, \&c. / Año de / [viñeta] / 1693 / [filete] / Con privilegio. En Madrid: Por Antonio Gonzalez de Reyes. / A costa de los Herederos de Gabriel de Leon $[12 \mathrm{~h} .+420$ p. +11 h., folio, perg.] \{BN-Mx: 94-41689. BP: casilla 10, libro 12, piso 2\}.

Podemos observar en ambos casos que se trata de una transcripción línea a línea aunque no se hace distinción entre las altas, bajas, redondas o cursivas, pero sí se indica la presencia de filetes y viñetas. $^{268}$ También incluye una somera descripción física y una mención sobre la encuadernación ("perg”.). Finaliza el registro con la información y ubicación sobre otros ejemplares existentes de la edición.

Esta información nos sirve para hacer una precisión que consideramos importante y que se refiere a la limitación del territorio patrimonial.

268 Como se puede notar es la primera vez que en los ejemplos seleccionados para este análisis, se emplea el término filete y viñeta para indicar la decoración que forma parte de los datos de una portada. 
La indicación sobre la existencia de otros ejemplares nos parece conveniente porque nos da una idea sobre qué tantos libros se conservan de una edición, pero ello no implica que tal información deba ser considerada con mesura y cautela, porque esa condición como ejemplares de una misma edición no podría determinarse con plena certeza hasta que los ejemplares sean cotejados en sus semejanzas y en sus diferencias.

Sin embargo, como ya hemos dicho, debido a que la realidad sobre este patrimonio es que se sabe poco de él en términos de cualidad y cantidad, se agradecería siempre la información sobre "otros" libros conservados, porque permite que las generaciones venideras puedan recuperar los objetos y hacer sus propias lecturas tanto del objeto material como del texto que transmite. De otra manera no podríamos ni siquiera saber cuántos libros pudieron haberse conservado, pese a las dificultades que ha presentado la preservación de este patrimonio.

En 1997 encontramos otro trabajo dedicado a la revisión de la obra de José Toribio Medina. ${ }^{269}$ Los autores del mismo indican que respetaron

las normas y orden seguido por Toribio Medina y los maestros de la Bibliografía Mexicana que han dedicado buena parte de su existencia a registrar la producción bibliográfica de la Colonia. ${ }^{270}$

Después de esta consideración propia poco podemos decir sobre el modelo bibliográfico, pero sí acerca de la presentación de los datos, que difiere de la tradición bibliográfica a la que se acoge.

269 Francisco Ziga y Susano Espinosa. Adiciones a la Imprenta en México de José Toribio Medina, Puebla, Oaxaca, Guadalajara, Veracruz y de la Insurgencia, 1706-1801. México: UNAM. Instituto de Investigaciones Bibliográficas, 1997. p. 3

270 Ibíd.h.4v. 
SAN JOSEPH, ANTonta DAMtaNA.

1.-DEVOCION / TIERNA Y MVY PROVECHOSA / PRINCIPALMENTE PARA LA QVARESMA / A CHRISTO / SEFTOR NVESTRO CRVCIFICADO Y A / Matia Santissima de los Dolores al pie de la Cruz / que ha de durar, sinco dias comenzando en Lunes / Sacala à luz la devocion de la Madre ANTONIA / DAMIANA DE S. IOSEPH Religiosa del Cóvento [sic] de / Sr. S. Joseph de Gracia. / /grabado en madera de Jesús Crucificado, a sus pies la Virgen y San José. En recuadro orlado, con viñetas a los lados del grabado./ / Y LO DEDICA, Y OFRECE A LAS SENORAS RELIGIO- / SAS DE TODOS LOS CONVENTOS DE MEXICO / [CON LICENCIA DE LOS SUPERIORES, / En México, por los Herederos de la Viuda de / Francisco Rodriguez Lupercio. En la Puente [sic] de / Palacio, año de 1706.]

$14.5 \mathrm{~cm} .[22] \mathrm{p}$.

Signs, $\mathrm{A}^{2} 14, \mathrm{B8}$. Apostillas. Reclamos.

Port, fileteada.-v. en bl--Dedicatorias. Antonia Damiana de San Joscph. 2p.s.n.Motivos, que obligan a la Devocion de Christo Crucificado. Y las cosa que se Than de observar en fos cinco dias de esta devocion. 4p.s.n.-Acto de Contricion, Y oracion preparatoria, Y oracion de S. Agvstin. Vn Padre Nuestro... Antiphona. Segundo dia que es Martes. Oracion de S. Agustin. Oracion. 8p.s.n-Tetcer dia, que es el Miercoles, Oracion de S. Bernatdo. Oracion. Y Quarto dia, que es Jueves. Oracion de S. Bernardo. Y Qutinto, y ultimo dia, que es Viernes. Oracion de San Buenaventura. Oración. 8p.s.n.

1.jemplar en tucass condiciones, sin enctiadernat. Follcto.

Efectivamente podemos observar que inicia el registro con el año de publicación al igual que en su tiempo lo hizo Medina, después registran el autor y sigue la portada transcrita de forma "casi facsimilar", respetando altas, bajas, cursivas, redondas, formas ortográficas de época, pero cuando las encuentra es notorio el empleo de "[sic]" que no utilizaron los bibliógrafos de la tradición (García Icazbalceta o Medina). Posteriormente indica el tamaño en centímetros y el número de páginas que por la indicación del corchete no deben estar numeradas. Por su parte el registro de las signaturas es raro y poco comprensible, porque si tenemos 11 hojas (las 22 páginas), lo más comprensible sería un cuadernillo de cuatro hojas con signatura A y un cuaderno de ocho hojas con signatura B pero que nos darían un total de 12 hojas y por tanto 24 páginas.

Lo anterior es todavía más notorio si se contrasta y relaciona la información de las signaturas con las indicaciones que siguen sobre el contenido de la obra: portada, preliminares y texto de la obra. La suma 
total de esas partes (p.s.n.) es de 12 folios y por tanto de 24 páginas. La lectura de la información de las signaturas en relación con el contenido sería más fácil de leer si no existiese el criterio de establecer páginas donde no existen. En este caso, mencionar hojas sería lo más adecuado, de tal manera que ese 14 que existe reportado en signaturas, o es un error o es incomprensible respecto al objeto representado.

Vemos cómo según el registro, la edición solamente consta de una dedicatoria y no existen aprobaciones ni licencias, a pesar de que la información de la portada así lo indica. Este registro finaliza indicando el estado de la conservación del ejemplar que se describe, así como le atribuye una categoría tipológica por el número de páginas y no por el género editorial al que se debería adscribir. No se observa ninguna consideración respecto a los valores históricos ni al orden de la colección en la que se custodia.

En un texto dedicado al estudio de libros científicos ${ }^{271}$ encontramos descripciones de libros antiguos que podríamos esperar bibliográficamente más detallada. Sin embargo no es así, se trata de una representación catalográfica en la que se observa la transcripción aparentemente completa de la portada si no fuese por el detalle de la traducción del título original, como puede observarse.

Juanis Bautista MORANDI. Historia botánica practica, seu plantarum, quae ad usum medicinae pertinent. Nomenclatura descriptio, et virtutes, cum ab antiques, tum a recentibus celebrium auctorum screptis desumtae, ac aeries fabulis delineatae, atque ad vivum exprototypo expressae, nec non in classes xxxv. Distributae, ut facilius cujusque simplicis genus, ac species dignoscantur. Mediolani: Ex Topographia Petri Francisci Malatestae, 1744, 164 pp., otra edición de 1761 [BP]

La descripción física es somera e igualmente lo es en lo correspondiente a otra edición localizada en una biblioteca, pero como se puede

271 Alberto Saladino García. Libros científicos del siglo XVIII Latinoamericano. México: Universidad Autónoma del Estado de México, 1998. p. 152 
ver no indica orden alguno que nos remita a las colecciones de custodia, ni tampoco nada relacionado con el valor histórico del objeto que describe. Por esta condición parece que los registros no se hicieron con los originales correspondientes.

Encontramos otro registro en un catálogo publicado en Aguascalientes $^{272}$ que en el apartado de metodología reseña meramente los datos que se registran en la ficha, es decir, no se realiza ninguna alusión al problema de conocimiento y de patrimonio del que se trata. Lo triste de este caso concreto es que la edición no menciona en absoluto la fascinante historia que hay detrás de estos libros. Aparentemente fueron encontrados la década anterior, emparedados en un muro del convento franciscano de la ciudad, cuando la Universidad del estado realizó obras de rehabilitación en la parte del inmueble que le pertenece. Los libros fueron trasladados y depositados en la biblioteca central de la universidad y la mala fortuna quiso que ese verano lloviera con tal intensidad que las instalaciones se inundaron. Como era de esperarse, algunos libros se humedecieron de tal forma que fue prácticamente imposible salvarlos, otros - como tantos en la historiasobrevivieron al desastre. Esta historia, como numerosas "tragedias bibliográficas" en el país, nunca ha sido documentada y solamente se conoce por las versiones de algunos testigos. ${ }^{273}$

Debido a esto, la información proporcionada resulta sumamente básica, además habría que reflexionar sobre el apoyo que el INAH dio a este proyecto. El catálogo está ordenado por siglos y alfabéticamente por los autores. Como se observa, es también una descripción catalográfica que no ha considerado los desarrollos de la normativa internacional. Veamos un ejemplo:

272 Catálogo Colonial Bibliográfico de la Universidad Autónoma de Aguascalientes, integrado por Elvia Carreño Velásquez. Aguascalientes: Universidad Autónoma de Aguascalientes, 1999. p. 25

273 Personalmente tuve conocimiento de esta historia al impartir un curso en la Universidad de Aguascalientes, sobre metodologías bibliográficas para la descripción del libro antiguo, en agosto del año 2000. Pude documentar fotográficamente algunos de los daños más notorios del desastre, así como de algunos ejemplares sobrevivientes. 
7. Aguirre Antonio de

[Sermón sobre el glorioso tránsito de la Virgen María / Antonio de Aguirre. - México: s.i., 1698]

[7], 8h.; $19.5 \mathrm{~cm}$.

Falta portada. Datos tomados de las licencias.

Encuadernado con tres obras más. Libro desencuadernado.

Colección: Convento de la Purísima Concepción.

Número de control: 00153C

El registro que aquí presentamos es todavía más interesante porque lo podemos calificar como un trabajo apresurado y poco consciente del valor cultural del libro antiguo, incluyendo la propia historia de la recuperación de estos libros. Como vemos se trata de un sermón y como tal, parte de la producción bibliográfica de la oratoria novohispana, ${ }^{274}$ descrito ya por otros. ${ }^{275}$ Los autores de este catálogo declaran emplear como metodología una descripción de acuerdo a la naturaleza de los libros, aunque no explican a qué se refieren. Podemos ver que es precisamente esa naturaleza propia del libro antiguo, la que no está representada. ${ }^{276}$

Al final del milenio volvemos a encontrar otro catálogo ${ }^{277}$ derivado del proyecto Fondos conventuales, anteriormente citado, por lo que podemos observar las mismas características a las que ya nos hemos referido. La razón de esta nueva inclusión es para que pueda observarse la

274 Carlos Herrejón Peredo. Op. cit.

275 No hemos encontrado una obra con los datos proporcionados en el repertorio de José Toribio Medina. Op. cit. y Vicente de Paula Andrade. Op. cit. Tampoco se encuentra información en la Biblioteca Nacional de México, ni en la Palafoxiana, ni tampoco en el Instituto Mora. Existe una edición del autor y aparentemente con el mismo título en la British Library, pero fechado en 1694.

276 Véase el registro número 50 de Pedro Maldonado. Catálogo Colonial Bibliográfico. Op. cit. p. 41

277 Elvia Carreño Velásquez. Fondo Conventual de la Biblioteca Nacional de Antropología e Historia: Catálogo de la Biblioteca del Convento Grande de San Francisco de la Ciudad de México, V. México: INAH, 2000. p. 13. 
escasa reflexión que se realiza en nuestro país sobre el valor cultural de los libros antiguos, y cómo dicha valoración influye notablemente en la representación bibliográfica y catalográfica, ${ }^{278}$ sobre la cual tampoco existe una reflexión acerca de sus antecedentes en el país y las metodologías que la soportan.

Así, el registro comienza con una descripción breve del libro sin indicar qué parte se ha omitido. Posteriormente se realiza la descripción física del ejemplar acompañada de las signaturas, donde se observa la mención del número de hojas al principio y al final de cada símbolo o letra empleada. Si se relaciona y contrasta la información de las signaturas con la descripción física elaborada, no perdamos de vista que no coinciden. Como se puede constatar, también se indica la presencia de reclamos, el tamaño en milímetros, el tipo de encuadernación, el idioma, el tipo de letra y una particularidad: la presencia de anotaciones marginales y de apostillas como elementos diferenciales.

278 Sobre estos trabajos de catalogación promocionados por el INAH, se puede leer el siguiente comentario: "resulta un trabajo elaborado y eficiente [...con una] metodología que le permite al usuario conocer el por qué y para qué de cada uno de los elementos de la ficha" y también que "algo característico de estos catálogos es que fueron pensados y elaborados con una finalidad, que a mi parecer es la de una buena bibliotecología: calidad y cantidad de la información al usuario". Cfr. Daniel Moreno Jiménez. "La función del bibliotecólogo en el rescate de los testimonios bibliográficos históricos de nuestro país, siglos XVIXVIII". Memorias de las XXV Jornadas Mexicanas de Biblioteconomía (Puerto Vallarta, 1994). Texto disponible en http://www.ambac.org.mx/publicaciones/memorias/25jornadas.pdf [Consulta: marzo de 2006] pp. 92-93. 
Secretos del estante: elementos para la descripción bibliográfica...

1. ADAME Arriaga, José. Imperialis mexicana universitas illustrata ipsizs per constitutionum scholia, Sevilla, herederos de Tomás López Haro, 1698

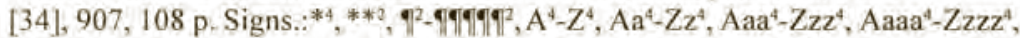
Aaaaa $-\mathrm{Tttt}^{4}, \mathrm{a}^{2}-\mathrm{z}^{2}, \mathrm{aa}^{2}-\mathrm{dd}^{2}$. Reclamos en recto y verso. $285 \times 200 \mathrm{~mm}$. Pergamino. Latín. Letra romana. Indicaciones marginales. Apostillas.

Portada: IMPERIALIS/ MEXICANA VNIVERSITAS/ ILLVSTRATA IPSIUS PER/ CONSTITVTIONVM SCHOLIA,/ ACADEMICO GENERALI/ COMMENTARIO, THEORICOPRACTICO,/FVNDATIONIS, PATRONATVS, INSTITVTI,/EXEMPTIONUM, CONSUETVDINVM,/ PONTIFICIJ, AC CAESAREJ UNIVERSI IVRIS STUDIA/ CONCERNENTIS, ET RERVM EIVS/INSIGNIVM./ AVTHORE/D[OMINO] IOSEPHO ADAME/ ET ARRIAGA,/ [curs.] IN EA VTRIVQVE IURIS DOCTORE PROPRIMARIO/ iuris Canonici, ac proprietario Vesperali Iustinianei iuris ex antecessore,/ perpetuo emerito primariae leguni Cathedrae Moderatore, quondam./ Sanctae Angelopolitanae Cathedralis Ecclesiae Canonico Doctorali, illius/ Episcopatus Sanctae Cruciatae Commissario subdelegato, et Mexicae Metropoliticae Canonico, nunc Thesaurario, Commissario Apostolico/Subdelegato generali totius novi Occidii Orbis, Insularum/ Philipinarum, ac lucatanensis, Archiepiscopatus/generali Examinatore/ Synodali,/ [red.] CVM GEMINATO ELENCHO EORVM, QVAE/ in constitutionum textibus, \& quae in elucidario eorum/continentur/[pleca]/HISPALI:-EX-TYPOGRAPHIA HAEREDVM THOMAELOPEZ DE HARO ANNO. M.DC, XCVIII.

Incipit opus: [p. 1] [col. A] [cap. 5] DE Divino patronatu/ verba facit exodij co[n.]-/ stitutio h[a]ec antequam/de Regio humano/ agatur...l

Explicit opus: [p. 907] +..los puntos, que de las dichas Constituciones quedan pendientes, según lo acordado en el dicho Auto; he tambien los informes en la primera/ ocasión que se ofrezca, con su parecer distinto, y claro, de lo que acerca de ello/ se les ofreciera: para que con vista de todo se provea lo mas conveniente, $\mathrm{Fe}$-/ cha en Madrid á primero de Mayo de mil seiscientos y quarenta y nueve/ año YO EL REY. Por mandado del Rey nuestro Señor Ivan Baptista/ Sans Narvarrete/ Sin colofón.

Materia: Historia civil.

Condición física: Buena.

El registro también incluye la descripción "casi facsimilar" de la portada. En ésta se marcan las altas, bajas, cursivas y las redondas, pero también se deshacen las abreviaturas marcándolas con un corchete y se observan las formas ortográficas de la época como la doble "s". Sin embargo, a pesar del tiempo que ha pasado, vuelve a emplear el incipit y el explicit, a pesar de que el libro no tiene colofón. Se indica la materia y el comentario subjetivo sobre el estado de la conservación. Resulta interesante que este registro no presente ninguna referencia sobre el valor histórico, pese a que el catálogo está dedicado a 
una de las bibliotecas franciscanas más importantes de la Colonia, por esa razón no podemos saber qué elemento fue considerado para establecer la procedencia de los materiales registrados.

En el mismo año se realizó el catálogo de la Colección Arango, ${ }^{279}$ que se integró a las colecciones históricas de la Universidad Iberoamericana. En este se observa una ficha catalográfica como ya hemos visto, respetando incluso las sangrías y formas de puntuación de las normas conocidas. Esta misma tendencia se puede observar en lo que corresponde a la composición física del ejemplar, donde se nota la ausencia del criterio internacional y de los datos más cercanos a la naturaleza del objeto.

\section{R18 Valadés, Diego, m. 1580}

Rbetorica christiana ad condicionandi, et orandi usum accommodata, utriusq facultatis exemplis suo loco insertis; quae quidem, ex indorum maxime de peompta sunt bistoriis. Unde praeter doctrinam, suma quoque delectatio comparabitur / auctore Didaco Valades. -- Perusiae : Apud Petrumiacobum Petrutium, 1579.

$$
\text { 10, 1, 378, [16] p. : il., grab., planos ; } 23 \mathrm{~cm} \text {. }
$$

Incluye índice.

Encuadernación de pergamino unido a cuero.

Papel de pulpa de algodón hecho a máquina, marcas de fuego en los cantos.

Estado de conservación regular; con manchas de mugre y oxidación en las hojas y la encuadernación reseca.

\section{Clasificación: BV 4209 V34..1579}

Pese a lo anterior, sí se advierte un interés por distinguir valores históricos como la encuadernación, el tipo de papel, el estado de la conservación de manera más objetiva y lo que es más llamativo, la indicación sobre la presencia de marcas de fuego en los cantos sin especificar de

279 Catálogo de la colección Manuel Arango Arias. México: UIA, 2000. p. 34 
qué tipo de marca se trata. Esto es relevante, considerando que esas marcas representan un valor excepcional en los libros antiguos relacionados con el periodo novohispano.

En este mismo año, 2000, encontramos un registro sobre un libro antiguo elaborado con la intención de difundir la riqueza bibliográfica custodiada por la Universidad de las Américas-Puebla. ${ }^{280}$ Es conveniente indicar aquí que esta institución aumentó dicha riqueza con el comodato que la Orden Franciscana le ha otorgado mediante la creación de la "Biblioteca Franciscana", un proyecto que además de reunir todos los materiales antiguos conservados por esa orden mendicante en la Provincia del Santo Evangelio, ha incluido la rehabilitación del Convento de San Gabriel en Cholula para convertirlo en un centro de investigación y cultura. ${ }^{281}$

280 Elvia Morales. "De nuestra biblioteca". Todo es Historia: boletín de estudios bistóricos (julio-diciembre 2000). Puebla: UDLAP. p. 59.

281 La información sobre esta biblioteca se puede encontrar en la página http:// biblio.udlap.mx/franciscana/ [Consulta: marzo de 2006] 


\section{Rrp-MQ/BX1431/P8/R4.4/1646/ gmsa}

Regla de la Gloriosa Santa Clara, con las constituciones de las monjas Capuchinas del Santissimo Crucifixo de Roma, reconocidas, y reformadas por el Padre General de los Capuchinos y con las Adiciones de dicha regla, sacadas de las que el Ilustrissimo Señor D. Alonso de Coloma, Obispo de Barcelona dio a las Monjas Capuchinas de la misma Ciudad, en el principio de la Fundación el año de 1603, Que después la Santidad de Paulo V. de felice recordación por breve particular concedió a la Abadessa, y Monjas del Convento de Santa Clara de Valencia, en 22 de Agosto del año de 1617, Que es la que oy guardan las Monjas Capuchinas de Castilla. - México : Imprenta del Lic. Don Jofeph de Jauregui, 1646.

En la guarda con tinta sepia en manuscrito: Soy del uso de María de la Cruz, para mi hermana Sor María. - Exlibris de José Miguel Quintana. - Portada en negro con el escudo de la Orden de Sta. Clara, viñetas a los lados. - Vuelta en blanco. -3 hojas prels. s.f.-232 p.

Prels. :- Aprobación del Dr. D. Francisco de Miranda ẏ Paz: Toledo, y Septiembre 12, de 1646. - Licencia de Don Pedro de Zamora Hurtado, Canónigo Inquisidor y Vicario General de Toledo: En Toledo a 17 de Septiembre de 1646. - Aprobación de Don Pedro de Toledo y Guzmán: Madrid, a 18 de Marzo de 1619. - Licencia del Licenciado Juan de Gomara y Mexia, Canónigo de Toledo, Vicario General de la Audiencia Arzobispal de la Villa de Madrid: Madrid, a 21 de Marzo de 1619. Confirmación que el Papa Innocencio hizo a la Primera Regla de Santa Clara: Assís en 8 de Agosto, el año dezimo de nuestro Pontificado.

Encuadernación en pergamino.

254933. - ESPAÑOL

Colección José Miguel Quintana.

En este registro se observa la clasificación conque el ejemplar puede ser localizado en la colección, así como las siglas de quien ha elaborado 
el registro (gmsa), sigue la transcripción del título de la obra, donde volvemos a encontrar una mezcla de formas antiguas y modernas de escritura (v.gr. doble "s" conjuntamente con acentos diacríticos). Como se puede notar, todo el título está en cursivas y no se emplea ningún tipo de diagonal para indicar las líneas que componen la portada, y solamente es la información del pie de imprenta la que está en redondas.

No existe ninguna descripción física de acuerdo a normas catalográficas y tampoco se anotan las signaturas. Posterior a la información de la portada, se encuentran registrados elementos históricos y valores textuales. Es aquí donde se indican las hojas y páginas del texto, para después mencionar el tipo de preliminares que presenta el ejemplar descrito; de estos documentos se apunta el tipo, el responsable, el lugar y la fecha. Termina el registro con la indicación del tipo de encuadernación, el número de orden dentro de la biblioteca, el idioma y la colección a la que pertenece, que se corresponde con el ex libris que se ha señalado. Como otros registros que hemos analizado, se entremezclan los datos sin una coherencia lógica, lo que no refleja la naturaleza del objeto del que se trata.

Al año siguiente del registro anterior volvemos a encontrar una investigación sobre bibliotecas particulares del siglo XVIII. ${ }^{282}$ En esta ocasión se trata de la de Andrés de Arze y Miranda, alumno distinguido de Juan José de Eguiara y Eguren con quien compartió un interesante espacio de poder que se puede apreciar en las censuras y aprobaciones de los libros impresos producidos en la imprenta de la "Biblioteca Mexicana". ${ }^{283}$ En esta investigación se presentan los libros que pertenecieron a Arze y Miranda, que han sido localizados mediante la búsqueda de los ejemplares que presentan su ex dono.

282 Columba Salazar Ibargüen. Una biblioteca virreinal de Puebla, siglo XVIII: Fondo Andrés de Arze y Miranda. Puebla: Benemérita Universidad Autónoma de Puebla. Instituto de Ciencias Sociales y Humanidades, 2001. p. 56

283 Actualmente Rosa Margarita Guerrero Alonso desarrolla la tesis titulada "Los preliminares como versión de poder y de control en el impreso antiguo. Andrés de Arce y Miranda y Juan José de Eguiara y Eguren" en donde se analiza esta relación a través de los documentos preliminares. Tesis del Programa de Posgrado en Bibliotecología y Estudios de la Información. Facultad de Filosofía y Letras/ CUIB, UNAM. 
Esta marca de propiedad solamente se colocó en los ejemplares de la colección particular, cuando fue entregada en donación al convento franciscano de la ciudad de Puebla.

\begin{abstract}
ALEMÁN, Mateo
PRIMERA, Y SEGUNDA PARTE / DE GUZMAN / DE ALFARACHE, / POR MATHEO

ALEMAN, CRLADO/del Rey nuestro señor, natural, y ve-/ zino de Sevilla. / DEDICADO/ [a] licenciado] DON JOSEPH BERMUDEZ, / [abogado de los] Reales Consejos, \&c. / Plieg. [Viñeta] 61. / CON LICENCIA. / [Filete] / En Madrid, en la Imprenta de la Calle de la Enco- / mienda Ar̃o de 1723. / A costa de Joseph Antonio Pimentel, Mercader de Libros.

[Orlado.]

C. B. 021547
\end{abstract}

En los registros observaremos un modelo que solamente proporciona la información de la portada y que, como ya se ha visto, deshace las abreviaturas como si se tratara de la transcripción de un documento histórico. La autora declara en su introducción que

las fichas que componen el fondo inician con el apellido del autor, continuando con el nombre; posteriormente, se transcribe la portada, respetando la tipografía alta y baja y señalando las viñetas y filetes, entre corchetes. Por fin, con una tipografía más pequeña en los casos necesarios, se especifica el número de volúmenes que ha sido localizado en el acervo de la Biblioteca Lafragua. ${ }^{284}$

Resulta interesante una descripción que no indica cursivas o redondas en la portada, o una descripción física del ejemplar e incluso los valores históricos y textuales relevantes, cuando se trata de una investigación que se corresponde con la recuperación histórica de bibliotecas coloniales, ${ }^{285}$ de lo cual presentamos en líneas anteriores

284 Columba Salazar Ibargüen Op. cit. p. 8

285 El proyecto se inició en la Benemérita Universidad Autónoma de Puebla en el año de 1997. Cfr. Cristina Gómez. "Libros y lectores en México, 1750-1850". Boletín del AGN. 6a época, no. 1 (agosto/octubre 2003). p. 11, pero hasta la fecha solamente se elaboraron los trabajos que aquí se relacionan. 
dos registros de bibliotecas pertenecientes a obispos. Lo que es más notorio es que la investigación y el registro de estos libros se realizaron con los materiales originales, y que en realidad no se procuró recuperar la totalidad de los materiales que compusieron esa biblioteca particular. En el desarrollo de la investigación hemos encontrado materiales que se encuentran en otras bibliotecas del país y que pueden ser perfectamente identificados por el ex libris que los caracteriza.

En el mismo año de 2001 se presentó una tesis sobre folletos de la colección Lafragua que hoy se encuentran custodiados en la Benemérita Universidad Autónoma de Puebla. La tesis contiene la descripción de dichos impresos y presenta una breve explicación sobre las técnicas catalográficas, lo que según se declara es el resultado de "una ardua tarea de investigación para determinar los criterios metodológicos que se emplearían en la catalogación". ${ }^{286}$ Sin embargo, no se encuentra citado o referenciado en la bibliografía ninguno de los textos clásicos de la Bibliografía Material como McKerrow o Gaskell, pero sí el trabajo de Gloria Escamilla. De los textos clásicos de la bibliografía mexicana sólo encontramos a José Toribio Medina. En lo particular, la autora declara seguir la metodología empleada por Lucina Moreno Valle ${ }^{287}$ en 1975.

En páginas posteriores se encuentran unas "notas aclaratorias al catálogo", ${ }^{288}$ donde se indica que la información se organiza alfabéticamente por autores o títulos - cuando la obra carece de autor o no se ha identificado-, que en la transcripción de los títulos se ha respetado la ortografía original que se presenta en portada, que los demás datos (ciudad, año o número de páginas) se presentan en el orden común de las técnicas bibliográficas y, finalmente, que cada registro contiene una simple enunciación para conocer su contenido.

286 María Estela Graciela Tecocoatzi Hernández. Impresos de la colección Lafragua1680-1873 (Folletería) legada al Colegio del Estado de Puebla, boy BUAP. México: La autora, 2001 (Tesis de Licenciatura en Historia. Facultad de Filosofía y Letras. UNAM). pp. 95-96

287 Lucina Moreno Valle. Catalogo de la colección Lafragua de la Biblioteca Nacional de México, 1821-1853. México: UNAM, Instituto de Investigaciones Bibliograficas, 1975.

288 María Estela Graciela Tecocoatzi Hernández. Op. cit. pp. 102-103 
4.- Delgado y Buenrestro, Antonio. Fragancias de la mejor rosa de los primeros dias. Sermón, predicado por el Lic. D. Antonio Delgado y Buenrostro en la Iglesia de Religiosas de Santa Inés de Montepoliciano, en Puebla de los Angeles. Impreso en Sevilla (s.i), 1680.11 h.s/n., 21 p: $20 \mathrm{~cm}$.

Carece de portada. Antrecede al inicio de la obra dedicatoria, aprobación, licencia y salutación. Contiene párrafos y notas en latin impresas en los márgenes. Presenta manchas amarillentas. Se trata de uri sermón dedicado a Santa Rosa del Perú, en la fiesta celebrada por una comunidad religiosa en su honor. Se encuentra desprendido de su respectivo volumen (33575),

Para nuestro análisis hemos seleccionado un impreso sevillano del siglo XVII. ${ }^{289}$ Observamos que se trata de una obra sin portada y que en ninguna parte del registro la autora indica de dónde se han tomado los datos. En otros registros veremos que la transcripción de la portada se realiza línea a línea, separadas por una diagonal, pero todo el título se ha puesto en cursivas, sin las letras en altas y bajas que caracterizan a las portadas antiguas. En otros casos se observa la presencia de un paréntesis con tres puntos suspensivos que suponemos remite a la eliminación de parte del texto. Por estos detalles, no podemos decir que se trata de una descripción "cuasi" facsimilar.

En lo que corresponde a la descripción física de la obra, no se registran ni mencionan las signaturas. Resulta interesante la aclaración en el registro que analizamos de las once hojas sin numerar, porque como veremos, las hojas se caracterizan y se diferencian de los folios precisamente por la carencia del número. Los registros dan idea del tipo de preliminares que contiene un impreso, sin hacer distinciones entre éstos, pero no se proporcionan más detalles, como lo puede ser la fecha en que fueron elaborados. También se incluyen algunas consideraciones sobre la caja de texto y el estado de conservación. Finalmente se apunta el tema que aborda la obra y la condición que ésta tiene en relación a un volumen.

289 Ibíd.p. 106 
Dos años después encontramos un texto dedicado a libros jurídicos, ${ }^{290}$ que primordialmente analiza la cultura jurídica de la época colonial. Esta investigación se acompaña de registros de libros, en los que podemos observar una descripción detallada de la portada, "casi facsimilar" como corresponde a la metodología de la Bibliografía Material, por lo cual encontramos marcadas las altas, bajas, redondas y cursivas. También se indican entre paréntesis aquellas partes del texto que se han perdido pero no hace mención a ningún tipo de ilustración.

290 José Enciso Contreras Antiguos libros jurídicos en dos bibliotecas de Zacatecas. Zacatecas: Tribunal Superior de Justicia del Estado de Zacatecas, 2003. p. 146 
2. LOMBARDI, Petri. Sententiarum... libro IV. París. Poncetum Lepreux. 1553.

Petri Lombardi / EPISCOPI PARISIENSIS / SENTENTIARVM LIB III. / Quibus author ille divinis scriptoris exercitatissi / mus universae Theologiae summam ex oc orthodoxorum pa / trum (roto) cretis adque sentecitiis mirabili compendio \& arte / comple (roto) est: ut iure optimo MAGISTER SEN / TENTIARVM merverit cognominari. Per loan/nem Aleaume, Parisien Theologiae professorem pristino / suo nitori nunc primen vere restituti: \& indicibus acnu / meris authorum libros \& capita mostrantibus quam fi / delis absoluti. / Singulis libris Titula, quibus capita distinguuntur prae posiumus, / ex authoris seci sententia: vt quod quaeritur facilius ocurrat. / Al calcem operis subii siuntur Articuli erronei, Pari / siis iam olim damnati, adque ab eorum assertoribus reca / tati: Adicctis non nullis ipsius Magistri quibus commu- / niter non aprobatu. / Postremo Index copiosus in singula libros materias in singulares or-/dine literario continens. / PARISIIS, / Apud Puncetum Lepreux, in via s. lacobi, sub intersi- / gnio Lupi e regione Mathurianorum. / 1553.

Tiene un total de 453 páginas, las 8 finales sin numerar. Letra romana. Manuscrita en la portada: «Alonso de la Mota y Escobar». Sin marca de fuego. Encuadernado en pergamino.

El registro finaliza con un párrafo que incluye la descripción física del ejemplar, el tipo de letra y una descripción del ejemplar en términos históricos que es puntual y menciona las anotaciones manuscritas, las marcas de fuego y el tipo de encuadernación. A pesar de que el autor describe en su introducción las bibliotecas zacatecanas en las que trabajó para identificar los libros, no presenta en sus registros ninguna 
referencia de localización o una organización cronológica. Tampoco informa si estos libros han sido registrados en otros repertorios y catálogos, o si ha encontrado otras ediciones disponibles en bibliotecas nacionales o internacionales.

Del renovado proceso de valoración cultural sobre la Biblioteca Palafoxiana a raíz del terrible terremoto de 1999, se han derivado tres cosas puntuales: la catalogación del fondo completo de la biblioteca que no se había realizado y al que se podía acceder a través de Internet; ${ }^{291}$ el desarrollo de un proyecto de gran envergadura de recuperación de la biblioteca, cuyo elevado costo financiero se coronó con el reconocimiento de la biblioteca como Memoria del Mundo en 2005; y el desarrollo de actividades de socialización patrimonial como exposiciones bibliográficas. De la primera de estas exposiciones $^{292}$ extraemos el registro siguiente.

21. - Autor: Steuchus Eugubinus, Augustinus

Título: Diez libros acerca de la filosofía perene

Pie de imprenta: Basilea, Nicolás Bryling y Sebastián Francken, 1542

Procedencia: Colegio del Espíritu Santo de la Compañía de Jesús

En la portada de este libro se mostró la advertencia "este autor está prohibido en otras obras no en ésta” lo cual permitió su circulación y lectura, además de que el dueño se protegía de cualquier pena al poseerlo.

Como podemos observar se trata de una descripción básica del ejemplar que se describe, en la cual se distinguen los elementos históricos y la prohibición inquisitorial por la que la obra fue seleccionada para la exposición.

Lo lamentable de todo este esfuerzo y del recurso financiero invertido es que en el catálogo en línea de la Biblioteca Palafoxiana no se

291 El catálogo estaba disponible en la página http://www.bpm.gob.mx hasta el 2006. A la fecha (enero de 2011) no se ha podido acceder.

292 Libros probibidos: censura y expurgo en la Biblioteca Palafoxiana (Exposición temporal). Puebla: Secretaria de Cultura, [2003] 
encuentra mayor información que la ya disponible en los catálogos de las exposiciones realizadas. Es decir, se trata de información catalográfica ordenada de acuerdo a normas bibliotecarias que no introduce ni valora ningún elemento bibliográfico. Los datos que se encuentran son: autor nominal, título, editorial, ciudad, país, año, descripción física, nota general y materias. Lo único a resaltar en este instrumento de consulta es la transcripción de toda la información de la portada pero sin indicaciones de altas, bajas, redondas o cursivas. Además se trata de una edición latina, de la que no debió traducirse el título pues se da noticia de una edición que no existe.

El siguiente registro de nuestra revisión, y al que ya hemos dedicado algunos comentarios en capítulos anteriores, procede de un catálogo dedicado a los impresos del siglo XVI conservados en la Biblioteca Nacional de España. ${ }^{293}$ El autor explica que

cada uno de los registros incluye la descripción detallada de la portada y de las diversas partes que conforman cada obra. Además la descripción precisa las características propias de cada ejemplar, por ejemplo: ex libris, marcas de fuego, notas manuscritas, indicaciones sobre la presencia de grabados en el texto o la falta de partes del mismo y otras peculiaridades que hayan sido detectadas. ${ }^{294}$

293 Víctor Julián Cid Carmona (2004). Op. cit. p 37

294 Ibíd.p. 15 


\section{3}

15 García de Palacio, Diego

DIALOGOS || MILITARES, || DE LA FORMACION, || è informacion de Perfonas, Inftrumen $\|$ tos, y cofas nefceffarias para el || buen vfo de la Guerra. || Compuefto por el Doctor Diego Garcia de Palacio, del || Confejo de fu Mageftad, y fu Oydor en la || Real Audiencia de Mexico. || (Escudo de armas) || CON LICENCIA, || En Mexico, en cafa de Pedro Ocharte. || Año de 1583.

Portada, verso con el sumario de la obra, seguido de $3 \mathrm{ff}$. de preliminares. En los folios 1-6 un "Argumentó, y recomendación a los Diálogos militares desta obra, por Eugenio de Salazar..." Texto ff. 7-192 con el colofón al pie.

$4^{\circ}$; 1. romana.

Signatura BNE: ${ }^{8} \mathrm{R} / 8574$.

Icazbalceta: 103 .

Medina: tomo I, 95, por error 98.

En el registro del libro que aquí presentamos, la portada se describe con altas y bajas pero sin indicaciones de cursivas o redondas, el escudo de la portada tampoco se detalla ni se relaciona, y no se observa ningún elemento histórico relevante. Como el mismo autor lo declara en su texto, este trabajo se realizó directamente con los originales. Se extraña en el mismo la falta de mención a la tipobibliografía española, porque varios de los impresos fueron analizados directamente en la Biblioteca Nacional de España. Creemos que de haberse aplicado los principios de aquella en estas descripciones, los datos aportarían mayor información sobre los impresos, a los que ha dedicado más de un trabajo.

Por esta relación es todavía más llamativa la ausencia de una descripción física del ejemplar, que sí se encuentra presente en el Catálogo Colectivo del Patrimonio Bibliográfico Español ${ }^{295}$ y en el catálogo de la Biblioteca Nacional de México donde aparentemente se encuentra otro ejemplar. ${ }^{296}$ Como ya hemos dicho, uno de los aspectos que distinguen

295 Consulta disponible en http://www.mcu.es/bibliotecas/MC/CCPB/index.html [Consulta: enero de 2011]

296 Consulta disponible en http://132.248.77.3:8991/F [Consulta: marzo de 2006] 
al trabajo español es la relación que se realiza en el registro de impresos antiguos, entre los criterios catalográficos ( $v . g r$. aplicación de la norma internacional) y bibliográficos ( $v . g r$. registro de las signaturas).

Como ya también hemos explicado, los impresos mexicanos producidos en el siglo XVI han sido sumamente registrados prácticamente en todos sus detalles, de ahí que pese a la intención del autor, su registro no aporta mayor información a la ya conocida. Ciertamente intenta localizar las fuentes originales conservadas en la biblioteca española -indica la localización en el acervo-, y solamente incluye como referencia los repertorios de Medina, Icazbalceta y de Paula Andrade. Sin embargo consideramos que el trabajo previo y la literatura española especializada en la materia le habrán permitido hacer un trabajo bibliográficamente más rico como la localización de ediciones, emisiones o estados.

En este trabajo que analizamos no se explica la procedencia del modelo bibliográfico empleado, de modo que pudiéramos entender, por ejemplo, por qué se ha preferido emplear la doble barra ${ }^{297}$ para separar las líneas de la portada, o por qué no se consideró pertinente registrar las signaturas. ${ }^{298} \mathrm{Al}$ revisar la bibliografía no encontramos referencia a ningún trabajo de la Bibliografía Material, por lo que no podríamos hacer ninguna consideración al respecto, solamente indicar que se ha realizado un modelo formado de partes, como otros que hemos analizado precisamente en este capítulo.

297 Cfr. Roland Mckerrow. Op. cit. p. 176

298 Es necesario notar que el autor emplea en su registro la palabra signatura para referirse a la ubicación del ejemplar dentro de la colección, más que referirse a la signatura tipográfica que se emplea regularmente en las descripciones, tanto catalográficas como bibliográficas, y que se relaciona con el formato y la estructura material del libro antiguo. 


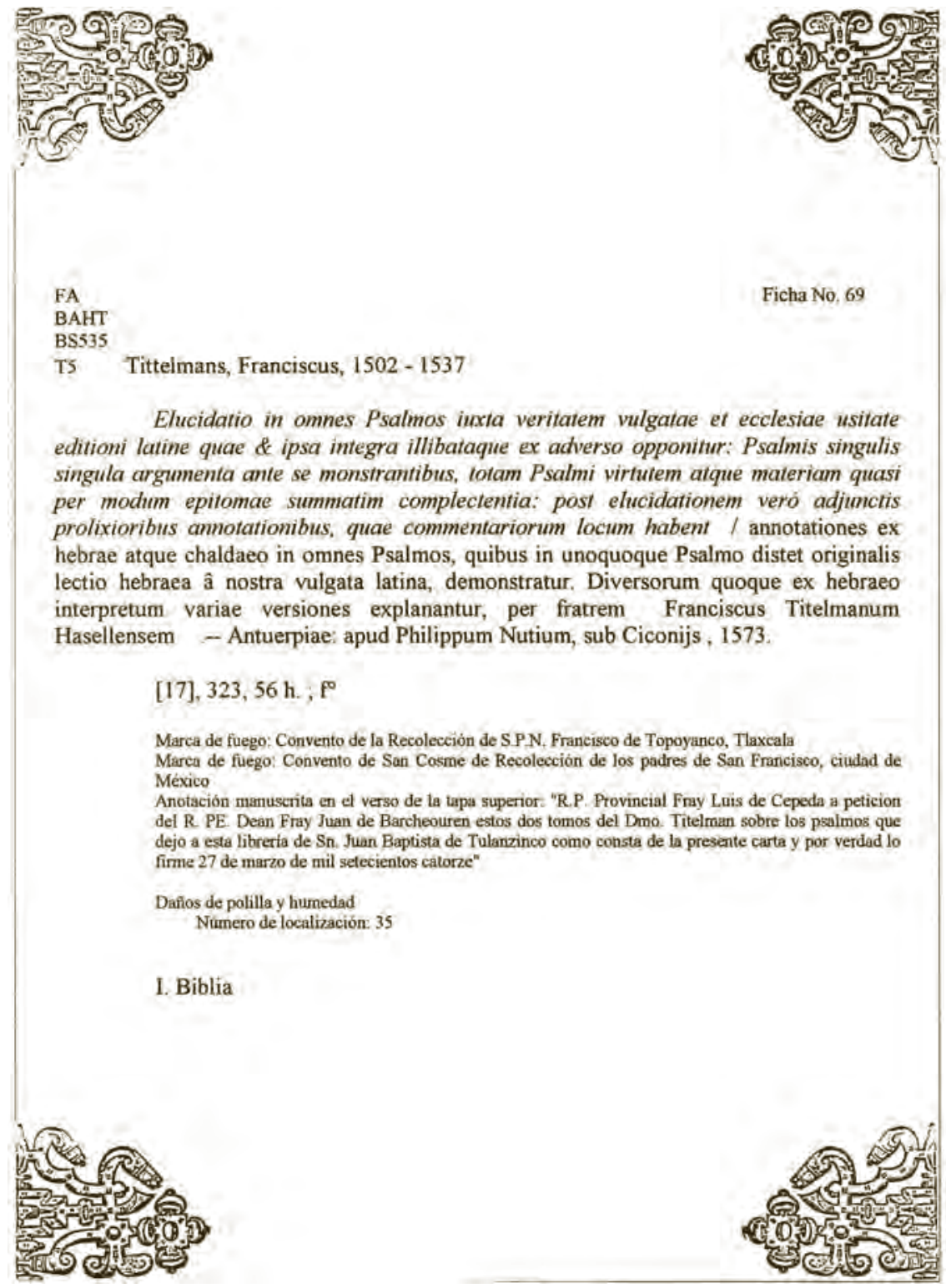


Extraemos otro modelo publicado en 2004 , de un catálogo de libros antiguos. ${ }^{299}$ Se trata de una ficha catalográfica que prácticamente no omite ningún dato de la portada. ${ }^{300}$ La cuestión a distinguir es la forma de la descripción bibliográfica que no se corresponde con el texto registrado en la Biblioteca Nacional de México en el que se registran 523 hojas, doscientas menos que en el modelo de la imagen. Ciertamente puede ser un error de número puesto que el otro dato relacionado con las hojas coincide. Tampoco se incluye el registro de las signaturas, aunque sí se indica el formato. Por otra parte, se pone más énfasis en el registro de los valores históricos como las marcas de fuego. Hay que poner atención ya que en esta ocasión se menciona una anotación manuscrita y es considerada como tal porque se trata de una donación, es decir de un "ex dono". 301

Otro ejemplo en esta selección procede de una edición electrónica de $2005,{ }^{302}$ sobre libros de procedencia conventual. En los registros de este trabajo se incluyen varios de los siguientes datos: número de registro, autor, título, mención de edición, ciudad, impresor o editor, año, paginación, ilustraciones, formato, serie, falta de datos, inclusiones (ilustraciones, marca de fuego, ex libris, sello, encuadernación, contenido, daños, mutilado, nota general, materia, número de secundarias, etcétera.

Como se puede ver en el registro que transcribimos, se trata de una forma catalográfica que elimina parte del título. No se ha incluido la signatura, aunque sí se informa del formato.

299 Catálogo de libros antiguos Archivo Histórico del Estado de Tlaxcala, Tlaxcala, Coordinadora Elvia Carreño Velázquez. México: Apoyo al Desarrollo de Archivos y Bibliotecas de México, A.C., 2004. p. 37.

300 Cuestión que resulta interesante porque se correspondería con la forma más completa de la aplicación de la norma $\operatorname{ISBD}(\mathrm{A})$, que ha sido gradualmente mejorada en los catálogos realizados por esta asociación.

301 "Indicación especial que llevan algunos libros en la que se hace constar que fueron donados". José Martínez de Sousa. Op. cit. p. 404. En este diccionario la palabra no se separa: exdono.

302 Catálogo Biblioteca Conventual Museo Virreinal de Zinacantepec. México: Apoyo al Desarrollo de Archivos y Bibliotecas de México, A.C.: Fundación Alberto Harp Helú, 2005 [CD-ROM] 
Madrigal, Juan Bautista

Discursos predicables, de las Dominicas de Adviento y fiestas de santos, hasta la... por el P. F. Juan Bautista de Madrigal Predicador, y guardian del Convento de San Bernardino de Madrid, de la provincia de S. Joseph. En Madrid por Miguel Serrano de Vargas, 1606. [26], $398 \mathrm{~h}$.

$4^{\circ}$

Daños de humedad y en la encuadernación

Portada con grabado central xilográfico. Encuadernación en pergamino

Homilética

Al año siguiente, en 2006, encontramos información bibliográfica procedente de dos tesis, una de licenciatura ${ }^{303}$ y otra de maestría. ${ }^{304}$ El primero de estos trabajos no es formalmente un repertorio, sino que está dedicado a registrar libros con marcas de fuego dentro de una colección específica. Sin embargo, contiene los registros de un conjunto de libros marcados que se han seleccionado previamente. Veamos un registro extraído de este trabajo de licenciatura:

Descartes, Rene, 1596-1650.

Geometría / a Renato Descartes ; anno 1637 Gallice edita; postea autem ; una cum notis Florimondi de Beavne, in Curia Blesensi Conciliarii Regii, Gallice conscriptis in latinan linguam versa, \& comentariis ilustrata opera atque Studio Francisci a Schooten. Amstelaedami : Apud Ludovicum \& Daliemen Elzeverios , 1659 520 p.:il.; $8^{\circ}(20 \mathrm{~cm})$

303 Cintia Elizabeth González Ordaz. Catálogo de marcas de fuego del Fondo Antiguo y Colecciones Especiales de la Biblioteca Central de la Dirección General de Bibliotecas de la UNAM. México: el autor, 2006 (Tesis licenciatura. Licenciado en Bibliotecología y Estudios de la Información. UNAM. Facultad de Filosofía y Letras).

304 Victor Julián Cid Carmona. Antonio Ricardo: impresor de dos ciudades, México y la Ciudad de los Reyes. México: el autor, 2006 (Tesis de maestría. Maestro en Bibliotecología y Estudios de la Información. UNAM. Posgrado en Bibliotecología y Estudios de la Información). 
n. p. $174^{305}$

Como se aprecia, se trata de la ficha de un catálogo que parece seguir la normativa internacional ya citada, en cuanto al respeto de la lengua. Pero si comparamos esta información con el registro del mismo libro en el Catálogo Colectivo del Patrimonio Bibliográfico Español, ${ }^{306}$ encontramos diferencias en el formato y en el tamaño, amén de otras discrepancias, que se aprecian en la consulta bajo la pestaña "ISBD" del catálogo citado. En especial nos interesa resaltar aquellas que corresponden a la inclusión de las hojas correspondientes a los preliminares, que la autora del trabajo sí ha indicado que se incluyen $^{307}$ en respeto a la norma ISBD (A).

En este modelo tampoco se ha realizado la transcripción de las signaturas, que nos parece importante para identificar de forma más correcta la edición que se describe. En el caso concreto del trabajo que analizamos, el ejemplo presentado nos permite apuntar una duda razonable sobre los formatos que se indican en el trabajo, ya que no contamos con otra información para verificar las diferencias respecto al el ejemplar original. Finalmente, este catálogo adolece de una cuestión importante como instrumento de consulta: la tesis cuenta con un índice de autores que remite al "número de procedencia" dentro de la colección donde se custodia la fuente, pero no remite a la página correspondiente del mismo catálogo, con lo cual, buscar los libros de un autor implica la revisión completa del instrumento elaborado.

El segundo trabajo al que nos hemos referido es la tesis de maestría, donde el autor dice atender a las indicaciones de Alberto Montaner, ${ }^{308}$ para la elaboración de las descripciones bibliográficas analíticas que se integran en su trabajo. Dichas pautas incluyen siete áreas para realizar esas descripciones, de las cuales el autor de esta tesis declara no emplear

305 Ibid. p. 123

306 Este catálogo como ya hemos indicado, aplica la norma internacional, de una manera más comprensible y adecuada a los impresos antiguos. Puede consultarse en la página http://www.mcu.es/bibliotecas/MC/CCPB/index.html [Consulta: enero de 2011]

307 Cintia Elizabeth González Ordaz. Op. cit. p. 83

308 Alberto Montaner Frutos. Op. cit. pp. 133-160 
las correspondientes a la descripción física (número 5) y a la valoración bibliográfica (número 6), en particular lo que corresponde a la descripción física, porque no se realizó el trabajo con las ediciones originales. ${ }^{309}$ A los datos de descripción el autor ha añadido un punto más, que corresponde a la reproducción de los elementos tipográficos de ornamentación (como capitulares, cenefas, viñetas y grabados).

309 Víctor Julián Cid Carmona (2006). Op. cit. pp. 31-33. Sin embargo, también se declara que se obtuvieron ejemplares de los diez impresos mexicanos salidos del taller de Antonio Ricardo, y de los impresos en Perú se trabajó con veintiocho reproducciones de las treinta y nueve obras de las que se conservan ejemplares. 
2 M. Ovidio Nason, Publio. Tristibus.

México: Antonio Ricardo, 1577.

P. OVIDII NASONIS || TAM DE TRISTIBVS || QVAM DE PONTO, || (Un IHS historiado, con la siguiente leyenda en rededor: DVLCE TVMM NOSTRO \|| FIGAS IN PECTORE NOMEN \| NAMQVE TVO CONSTAT \| NOMINE NOSTRA SALVS.) ॥ VNA CVM ELEGANTISSI- || mis quibuldam carminibus diui || Gregorij Nazianzeni. || MEXICl. || In Collegio Sanctorum Petri \& Pauli. || Apud Antonium Ricardum. || M. D. LXXVII.

$8^{\circ}$

Portada, verso en blanco. - Privilegio del virrey Enriquez, 16 de febrero de 1577. - Texto h. 5-64 Colofón."

Colofón:

MEXICI. ॥ Apud Antonium Ricardum. || ANNO. M. D. LXXVII.

Letra cursiva.

27 lineas por página.

Signaturas: $\mathrm{A}-\mathrm{H}$ de $\mathrm{S}$ hojas.

Faltan: las 2 primeras hojas de preliminares, sollo se conserva la ültima.

Contenido:

Preliminares

Privilegio del virrey Enriquez, h. [2r. - 4 v]

Texto:

II] Ovidio, h. $5 r-37 v$.

[ii] loannes Sulpicii Verulani carmen iuvenile, De moribus in mensa servandis, h. $38 \mathrm{r}$. $-40 \mathrm{~V}$.

[iii] Divi Gregorii Nazianzeni cognomento theologi: carmina panegirica, elegiae, epigrammata ac disticha, h. $41 \mathrm{r}-53 \mathrm{r}$.

[IV] Incipit Sedulii, praesbyten, in quo carmine reciproco dimidium versus primi finem complectitur versus secundi, h. $53 \mathrm{v},-55$

IV] Miracula Christi secundum Matheum versibus elegiacis, y otras poesias latinas, h. $56 r .-64 v$.

García lcazbalceta, 84 .

Toribio Medina, 80 .

Wagner. 72.

- El ejemplar aqui descrito procede de la Biblioteca Publica de Nueva York En la Bibliografía mexicana de lcazbalceta, se confirma que el ejemplar formó parte de la biblioteca de J. F. Ramirez, vendido, [no, 641], en $£ 14.10$ y que se conserva en dicha biblioteca, véase p. 280. 
Sin embargo, en el registro que aquí analizamos, ${ }^{310}$ se observan diferencias entre el modelo que se sigue y lo que finalmente se aplica; anotaremos aquí las que nos parecen más relevantes. En primer lugar el encabezamiento consta de una descripción breve en la que solamente en algunos casos se indica la supresión de parte del título, y los datos de imprenta tampoco se transcriben tal y como se encuentran. Se ha preferido simplemente indicar el lugar, el impresor por su nombre castellanizado — cuando difiere- y el año. Posteriormente, como se puede observar, el autor emplea la doble barra para indicar las líneas de la portada, mientras que Montaner recomienda el uso de sólo una.

Inmediatamente a continuación de la transcripción de la portada, se menciona solamente el formato. Debemos indicar aquí que el orden que tiene este dato en los registros de la tesis no es regular: en ocasiones se coloca de forma inmediata a la portada ${ }^{311}$ y en otras después de la transcripción del colofón. ${ }^{312}$ En el que aquí presentamos no se proporciona el formato ni las signaturas, lo que resulta extraño ya que es un impreso mexicano, por lo que suponemos que de éste no se obtuvo información original sino que se extrajo de alguna fuente secundaria que no se apunta.

Después del formato se encuentra una breve relación del contenido y si lo presenta, la transcripción del colofón. A éste le sigue una transcripción más detallada de ese contenido, indicando hojas y páginas correspondientes. En otros registros, antes de esta descripción se indica el tipo de letra, las líneas por página y las signaturas. Sobre éstas en particular no se sigue ninguna de las fórmulas de colación propuestas por Montaner. ${ }^{313}$ La que ha empleado el autor, tampoco se corresponde con ninguna de las propuestas en los textos específicos de la bibliografía material que ya hemos mencionado con anterioridad. A continuación en este modelo y en algunos registros se anotan los faltantes y los errores en la foliación o paginación.

310 Ibíd.pp. 93-94

311 Ibíd. p. 40

312 Ibíd.p. 97

313 Alberto Montaner Frutos. Op. cit. pp. 138-141 
En lo que corresponde a los preliminares no se indican de qué tipo son ni tampoco qué lugar del cuadernillo ocupan en el libro descrito, salvo en algunos casos en donde se advierte la consulta del impreso original. ${ }^{314}$ Si es este el caso se indica el orden dentro de la obra. La información bibliográfica cierra con las referencias bibliográficas, en donde ha sido citada la obra que se describe y, éstas no siguen las recomendaciones más conocidas. ${ }^{315}$

Finalmente el modelo empleado termina con la inclusión de elementos tipográficos de ornamentación (como capitulares, viñetas, adornos o grabados) que se reproducen. En este sentido es lamentable que no se especifique el tamaño de las mismas, como indica el citado Montaner. ${ }^{316}$ Particularidad todavía más notoria si recordamos el trabajo de Yhmoff Cabrera sobre impresos mexicanos del siglo XVI, ${ }^{317}$ en el cual se analizan y reproducen el tipo de letras y grabados que empleó cada uno de los impresores de esta época.

Yhmoff nos indica el tamaño de todas y cada una de las ornamentaciones que incluye para poder establecer consideraciones históricas sobre su empleo y transmisión. El autor del trabajo que analizamos considera en su bibliografía varios de los trabajos que Yhmoff realizó sobre este aspecto de los impresos, pero no parece que lo considerara importante. Sin duda, varios de los elementos ornamentales reproducidos en esta tesis, se asemejan a los empleados por otros impresores. Por esa razón, nos parece importante la inclusión del tamaño cuando se distingue esa información en los registros bibliográficos.

314 Cfr. Victor Julián Cid Carmona (2006). Op. cit. p. 42. Aunque en estos casos tampoco nos informa si las licencias son de la orden o del ordinario, pero sí cuando se trata de Virrey o de Arzobispo.

315 Nos referimos a Standard citation forms for published bibliographies and catalogs used in rare books cataloguing, prepared by Peter M. Van Wingen and Belinda D. Urquiza. 2nd ed. Washington: Library of Congress, 1996.

316 Alberto Montaner Frutos. Op. cit. pp. 151-153

317 Cfr. Jesús Yhmoff Cabrera (1990). Op. cit. 
El siguiente trabajo que analizamos, publicado en el mismo año, es el catálogo de una colección de sermones novohispanos. ${ }^{318}$ Se trata de un registro breve que no se corresponde con la normativa de la ISBD (A) ni con ninguno de los modelos de la Bibliografía Material. ${ }^{319}$ En este modelo se indica el autor, el título (aparentemente sin abreviaturas), el pie de imprenta sin los comunes "Por" o "En casa de", una descripción física acorde a normas de catalogación ${ }^{320}$ y, finalmente, la signatura topográfica de localización en la colección de la biblioteca.

121. Ramirez, Antonio, S.J. Sermón panegirico al immaculado libro y sagrada apologia de la gracia contra el infamatorio libelo de la culpa, en la purissima concepciōn de la soberana emperatriz de cielo y tierra, madre de Dios Maria Santísima. México: Imprenta de los Herederos de la viuda de Francisco Rodríguez Lupercio, 1709. 46 p.; ils., $19 \mathrm{~cm}$.

Sign.: AMC BX 1756 A2 R35 1709

122. Torrico Liaño, Joseph, Fray. Sagrada conjunción de luces en la concumencia de Sta. Rita y Sta. Quiteria, opuesta a las influencias de el can mayor y la canicula. Pónese a la protección de la sphera por todos títulos elevada, del cielo por todas partes lucido de el firmamento a todas luces brillante. México: Francisco de Rivera Calderón, 1709. 42 p.; ils., $19 \mathrm{~cm}$.

Sign.: AMC BX 1756 A2 O88 1709

123. Urtiaga Salazar y la Parra, Pedro Miguel de la Concepción, Fray. Piectra Philosophal que convierte en oro sus yerros nuestro sanclissimo padre Sr. San Pedro principe de los apóstoles. México: Imprenta de los Herederos de Juan Joseph Guillena Carrascoso, 1709. 34 p.; $18 \mathrm{~cm}$.

Sign:: AMC BX 1756 A2 U78 1709

318 Leticia Ruiz Rivera. Catálogo de sermones de la Biblioteca Eusebio F. Kino de la provincia mexicana de la Compañía de Jesús. Madrid: Fundación MAPFRE, 2006.

319 Ibid. p. 35

320 En la presentación del catálogo, se específica que se trata de las Reglas de Catalogación Angloamericanas. Ibid. p. 12 
En una fuente trascendental para el conocimiento de la cultura novohispana, como lo es el conjunto de la producción impresa de la oratoria, es deseable que se considerara el registro de aspectos significativos de los objetos materiales como las signaturas o los preliminares. Respecto a la importancia de estos últimos, en el propio catálogo se ha dado lugar a unos "ejemplos de licencias y pareceres", por desgracia no son tantos como desearíamos.

Incluimos aquí un modelo también de la autoría de Cid Carmona y otros. ${ }^{321}$ Se trata, como otros, de la descripción bibliográfica de ciertos impresos que son custodiados en una colección específica. En este caso se trata de la Biblioteca del Colegio de México, y el ejemplo que aquí recuperamos ya muestra una apropiación de las propuestas de la bibliografía material que no se observaba en los trabajos anteriores.

321 Víctor Cid Carmona...[et. al.] "Compendio de impresos mexicanos que se conservan en la Biblioteca Daniel Cosío Villegas, siglo XVIII”. Boletin Editorial del Colegio de México. No. 126 (marzo-abril 2007). pp. 9-21 
Portada orlada, texto en rojo y negro, verso en blanco. 9 ff. de preliminares sin foliar. Texto p, 1-200, "Indice de lo contenido en eftos quatro libros de la Gramática lapona" en $1 \mathrm{f}$, sin paginación, al final de ella "Se acabó este Arte de la lengua Japona a 12 de marzo de $1738^{*}$.

$4^{\circ}$.

Signatura: $94,594,{ }^{*}, \mathrm{~A}-\mathrm{ZA}_{4}, \mathrm{AA}-\mathrm{BB}_{4},{ }^{*}$,

Preliminares: Dedicatoria al Dr. D. Alonso Francisco Moreno y Castro, "Holpicio de S. Auguitin de las Cuebas" enero 6 de 1738, 8 p.: Parecer de Fr. Francisco Xavier. "Holpicio de S. Auguftin de las Cuebas" noviembre 10 de 1737, 2 p.; Aprobación de Fr. Francisco Xavier Pérez, "Holpicio. y cala de V. S. de San Auguftin de las Cuebas" noviembre 14 de 1737, 2 p.; Censura de Fr. Francisco Xayier, "Holpicio de San Auguftin de las Cuebas" octubre 16 de 1737,2 p.: Licencia del Superior gobierno, noviembre 22 de 1737; Licencia del Ordinario noviembre 23 de 1737, las dos en 1 p. Licencia del Orden. noviembre 7 de 1737, 1 p.; Preludio al lector; Fe de erratas y Advertencia al lector, todo en $2 \mathrm{p}$.

Beristáin, v. 2, p. 424.

Leon: Sección primeta, segunda parte, vol. 2, no. 441, p. 1169

Medina: v. 4, no. 3513.

Signatura BDCV: CE/495.65/Oy98a.

Melchor Oyanguren de Santa Inés nació en Salinas de Guipúzcoa en 1688, religioso franciscano destinado a las misiones de Filipinas, La enfermedad lo obligó a volver a España en 1721 y poco después paso a México, de donde salió al archipiélago filipino en 1724 para administrar los pueblos de los Baños y de Saryaha. Regresó a la Peninsula Ihérica en 1736 y por segunda vez se embarcó a México, donde desempeño el cargo de Prior del Hospicio de San Agustin de las Cuevas (Tlalpan) hasta su fallecimiento en enero de 1747.

Su deseo de ir a las misiones del Japón lo llevaron a estudiar la lengua japonesa, además de conocer el tagalo; muestra de ello se manifestó con la impresión de su Arte de la lengua japona y su Tagalysmo clucidado, y reducido (en to posible) a la latinidad de Lebrija... México, en la imprenta de D. Francisco Xavier Sánchez, 1742.'

\section{6}

\section{Cabrera y Quintero, Cayetano de}

Esciudo de armas de México... México, Viuda de José Bernardo de Hogal, 1746.

ESCUDO / DE ARMAS DE MEXICO; / CELESTIAL PROTECCION/DE ESTA NOBILISSIMA CIUDAD, DE

\footnotetext{
'Mod. v, 4. p. 313
}

LA NUEVA-ESPANAA, I $Y$ DE CASI TODO ELNUEVO MUNDO, / MARIA SANTISSIMA. / EN SU PORTENTOSA IMAGEN / DEL MEXTCANO GUADALUPE. / MILAGROSAMENTE APPARECIDA EN EL PALACIO ARZOBISPAL / EL AÑO DE $1531 . /$ Y JURADA SU PRINCIPAL PATRONA / EL PASSADODE 1737. / En la anguftia que

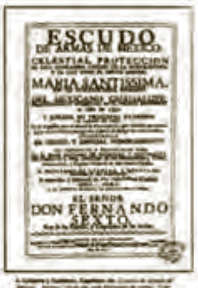
ocafionò là PESTLENCLA, que cebada con mayor / rigor en los Indios, mitigò fus ardores al abrigo de tanta lombra: / DESCRIBIALA / DE ORDEN, Y ESPECIAL NOMBRAMIENTO / DEL ILUSTRISSIMO, Y EXCELENTISSIMO SENOR / DR. D IUAN ANTONIO DE VIZARRON, Y EGUIARRETA, । Del Confejo de S. Mag. Arzobilpo de efta Metropolitana. Virrey, Gobernador, y Capitan General de efta NuevaEipana, / D. CAYETANO DE CABRERA, Y QUINTERO, / Presbytero de efte Arzobifpado: / A expenfas, y folicitud de efta Nobilitima Ciudad, / QUIEN LO DEDICA / A LA AUGUSTA MAGESTAD DE NUESTRO REY, Y SEÑOR, / EL SENOR / DON FERNANDO / SEXTO, / Rey de las Épañas, y Emperador de las Indias. / [Linea de adomo] / CON LICENCIA DE LOS SUPERIORES: / Imprefo en Mexico por la Viuda de D. JOSEPH BERNARDO DE HOGAL Imprefora / de Real, y Apoftolico Tribunal de la Santa Cruzada, en todo efte Reyno. / Año de 1746.

En hoja antes de la portada, grabado de la Virgen de Guadalupe signado: "Iosephus de Ibarra Inventor, Balthasar Troncoso delineavit et exculp. Mexice. a. 1743", con ocho versos latinos al pie. Portada fileteada, texto a dos tintas, negro y rojo, verso con epigrafe latino dentro de viñetas. $16 \mathrm{ff}$. de preliminares sin foliar. Texto p. 1-522. "Indice de cosas notables", 12 ff, sin foliar a dos columnas. $4^{\circ}$.

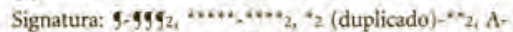
$\mathrm{Z} 2, \mathrm{Aa}_{2} \mathrm{Z}$ 27, Aaa-Z Z7z, Aaaa-Zmz2, Aaaaa-Zzzzz, AaaasaQqq9q42, 5. 59-5995992, 5959595.

Preliminares. Dedicatoria encabezada por un escudo de armas, 10 p.; Aprobación de /uan Antonio Fabrega Rubio. México, febrero 12 de 1743, 2 p.: Parecer de Joseph de Mercado, Puebla de los Angeles, enero 29 de 1744, 8 p. Juicio de la obra por Francisco Ximenez Caro, México, abril 12 de 1746,2 p.i Licencia del Superior gobiemo, septiembre 6 de 1742; Licencia del Ordinario. febrero 12 de 1743; erratas $y$ protesta, todo en $2 \mathrm{p}$; Prologo, $8 \mathrm{p}$.

Errores de signatura: Bbbbbbi por Bibbbbbz, falta Ooooooz; en indice, 52 por $\mathbf{5 9 5 9 5 9} 2$.

Errores de paginación: Los números de página 345-348 aparecen dos veces, la segunda vez corresponden a las páginas 344-352. 
El registro que analizamos comienza con una descripción breve como encabezamiento, en donde se indica la abreviatura del título con los puntos suspensivos (...). A continuación se encuentra la descripción de la portada "cuasi facsimilar", pero a diferencia de otras se ha empleado la diagonal (/) para indicar la separación línea a línea de la información. También se advierte un respeto a la tipografía impresa que incluye la "s" larga, los tipos de acento, las altas y bajas y los elementos decorativos.

Posteriormente se indica la presencia del grabado de la Virgen de Guadalupe que se encuentra en la hoja que antecede a la portada, el tipo de portada (fileteada), ${ }^{322}$ hojas de preliminares, lugar del texto de la obra y del índice. Sigue el formato, ${ }^{323}$ las signaturas, la descripción de los preliminares y el número de hojas que ocupan pero sin vinculación a la numeración de la propia obra, los errores en las signaturas y la paginación. También se indica un elemento de procedencia (sello) y, para cerrar, las referencias bibliográficas en donde ha sido incluida la obra, así como una breve noticia biográfica del autor.

El último modelo, aquí analizado, corresponde a un catálogo bibliográfico publicado en 2007 , en el que se describen impresos producidos desde el siglo XVII y hasta el siglo XIX custodiados en el Colegio de San Ignacio de Loyola, más conocido como el Colegio de las Vizcaínas. En los textos que le anteceden a este catálogo no se declara ninguna adscripción metodológica o normativa, por lo que extremos conclusiones sobre el registro que analizamos de un impreso novohispano. $^{324}$

322 El Diccionario de la Lengua Española, define fileteado como la "Artesanía que consiste en pintar filetes para ornamentación". Información disponible en http://www.rae.es/ [Consulta: enero de 2008]. Por su parte, Martínez de Sousa no reconoce como tal este tipo de portada. (2004). Op. cit. pp. 747-750.

323 En cuánto a éste, del que contamos con una descripción completa utilizada en otro trabajo en desarrollo, nuestra opinión sobre el formato difiere del que aquí se indica. Al igual que Medina, consideramos que se trata de un in folio.

324 Fondos bibliográficos del Archivo Histórico "José María Basagoiti" del Colegio de San Ignacio de Loyola, Vizcaínas. México: Apoyo al Desarrollo de Archivos y Bibliotecas de México, A.C. p. 45 
341

Torrubia, Pedro Tomás, S. J., fl, s. XVIII

Practica de los exercicios esprituales de San Ignacio de Loyola, fundador de la Compañia de lesus / por el P. Pedro Thomas Torrubia, de la Compañia de Jesus.- en Madrid: en la imprenta de la viuda Manuel Fernandez, 1761.

2 t. $; 8^{\circ}$

Notas

Lengua: español

Portada con monograma de la Sociedad de Jesús y pleca en grabado xilográfico. Encuademación en pergamino. Ex libris manuscrito en la guarda anterior: "Es del Colegio de S. S. Miguel de belen pa. la comunidad" (91). Sello en tinta del Colegio de la Paz, Biblioteca (Vizcainas). Daños en la encuadernación $(90,91)$.

Contenido: t. 1 Contiene las addiciones, annotaciones, meditaciones, oraciones vocales, lecciones esprituales, historiales, doctrinales, examenes, \&c, con methodo aplicable à exercicios, assi publicos, como privados.- t. 2 Contiene las meditaciones, oraciones vocales, lecciones espirituales, historiales, doctrinales, examenes, \&c, con methodo aplicable a exercicios, assi publicos, como privados.

Acervo: Colección Antigua, t. 1 (90), t. 2 (91)

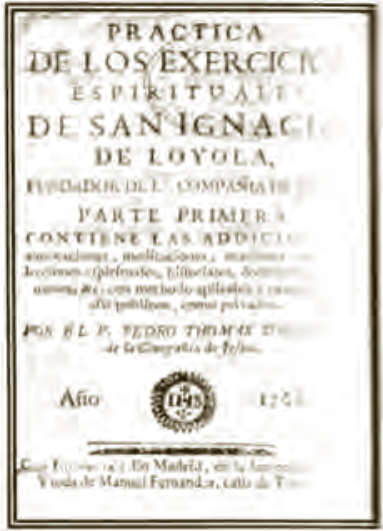

Tema: Ascética

Por la información presentada, se trata de una descripción catalográfica aparentemente en sintonía con la norma internacional ISBD (A), ${ }^{325}$ pues así se advierte en el registro del mismo libro en el Catálogo Colectivo del Patrimonio Bibliográfico Español. ${ }^{326}$ Sin embargo en la aplicación de esta misma norma en catálogos como el ICCU (Istituto Centrale per el Catalogo Unico delle Biblioteche Italiane e per le

$325 \operatorname{ISBD}(\mathrm{A})$. Op. cit.

326 La información se encuentra en el capítulo "Introducción a la problemática del Registro Bibliográfico" de este texto. 
Informazioni Bibliografiche), ${ }^{327}$ observaremos que en éste no emplean la diagonal para separar el autor del título de una obra. Así el registro se asemeje más a un bibliográfico, ya que se trata de los datos de la transcripción de una portada. El catálogo de Vizcaínas presenta acompañando al registro una fotografía pequeña de la portada, por lo que podemos analizar las diferencias entre lo que fue impreso y lo que fue registrado.

Por otra parte veremos en el registro que lo que corresponde a la descripción física del ejemplar solamente se indica el número de tomos y el formato, sin paginación, foliación o signaturas. Estos datos sí son incluidos en el catálogo español anteriormente citado, en el caso de los dos tomos. En la comparación con el registro italiano, en éste se incluyen además de las signaturas el dato de la identidad tipográfica, que permite relacionar prácticamente sin equívocos las cajas tipográficas de una edición en sus diferentes ejemplares. ${ }^{328}$

Ahora bien, en el espacio que corresponde a las notas del ejemplar conservado en Vizcaínas se encuentra información sobre el valor textual y la historicidad del objeto, como tipo de portada, sellos y anotaciones manuscritas. En particular estas últimas son denominadas como "ex libris manuscritos" de acuerdo a la forma española. Es un término que nos parece equívoco y que explicaremos más adelante con detalle. ${ }^{329}$ También se incluye el contenido de los dos tomos, el acervo y la temática sin precisar ninguna información correspondiente a los preliminares. Finalmente cabe decir que en prácticamente todos los registros, existen unos números (como se aprecia en la imagen) de los que

327 Este catálogo se encuentra disponible en la página http://www.sbn.it/opacsbn/ opac/iccu/informazioni.jsp [Consulta: enero de 2011]. Hemos utilizado para esta comparación otro impreso novohispano del mismo periodo y en éste registrado: Figueredo, Pedro Gonzales de. Oracion panegyrica en las bonras, que celebro el convento de S. Jacintbo, Orden de Predicadores A N. R.mo. P. M. Gl. Fr. Thomas Ripoll, dia 23. de Diciembre del ano de 1748. Dixola el R. P. Fr. Pedro Gonzalez. De Figueredo, doctor en sagrada theologia por la Universidad de Caracas,... Impressa en Mexico: por la Viuda de don Joseph Bernardo de Hogal: Calle de las Capuchinas, 1749.

328 Este dato corresponde al área $8^{\text {a }}$ de la norma y, por tanto, sería deseable su cumplimiento. Hasta donde tenemos noticia solamente se ha aplicado en Italia y en la Biblioteca Nacional de Cataluña.

329 En el capítulo "Conocer para describir:..." de este texto. 


\section{no queda muy claro su significado. Intentamos relacionarlos con los números del catálogo, pero no encontramos vinculación aparente.}

Nagera Yanguas, Diego de, Doctrina y enseñanca en la lengua Mapabua de cosas muy utiles, y provecbosas para los Ministros de Doctrina, y para los naturales que bablan la lengua Mafabua dirigida al ilustrisimo señor don Francisco Manso, y Cuniga, arzobispo de Mexico, del Consejo de su Magestad y de el Real de las Indias / por el licenciado Diego de Nagera Yanguas, beneficiado del partido de Xocotitlan: Comissario del Santo Oficio de la Inquisicion, y examinador en la dicha lengua maçahua, con liecncias. - Impressó en Mexico: por Iuan Ruyz, 1637. $[5], 177+[2]$ h. A-Y,$Z^{5} ; 8^{\circ}(15 \mathrm{~cm})$.

Contiene: Aprobacion del bachiller Andres de Ressa, Vicario y cura, Advertencias en lengua castellana muy necessarias para hablar con propiedad la lengua que llaman macahua, La confession en lengua castellana, y en lengua macahua, Inicia el cathecismo en lengua macahua, y en lengua castellana por preguntas y respuestas, Tabla de las cosas contenidas en este libro en lengua castellana y macahua.

Enc. en perg. - Marca de fuego: Convento de San Felipe Neri. - Texto a dos columnas, la primera en castellano y la segunda en macahua.

Deteriorado [mutilado en la parte superior, al igual que su hoja guarda y parte posterior, muestra desprendimiento del lomo y manchas de humedad].
Nota: En el facsimilar (Lenguas indigenas, 62) con título: Biblioteca Mexicana de obras raras y curiosas v. 1 , ejemplar núm. 51 , editada por el De. Roberto Valles Martinez en la ciudad de México, D. F. noviembré de 1952, da una referencia en el prólogo con el siguiente texto: "El Sr. Andrade en su "Ensayo Bibliográfico Mexicano del Siglo xvir", deseribe la obra bajo título de Doctrina y es de suponerse que no conoció, posiblemente, más ejemplar qué el de D. Joaquín, pues asi lo menciona como referencia, $y$ sin embargo le cambiỏ el título En cuanto al $\mathrm{St}_{\mathrm{f}}$ Medina en su obra "La Imprenta en México", la registra también como Doctrina y habla de un ejemplar existente en la Biblioteca de Guadalajara. Además menciona el hecho de que $\mathrm{Be}$ ristáin cita el Manual, $y$ declara no haberlo visto nunca. Hasta donde llegan mis informes sólo se han conocido cuatro ejemplares de esta importante y rarísima obra: el que perteneció al $\mathrm{S}$. Icazbalceta, el que cita el St. Medina como existente en la Biblioteca de Guadalajara; otro que pertenece a conocido bibliófilo michoacano $y$ por último el ejemplar que se usó para hacer la presente reedición y que es propiedad del Sr. D. Florencio Gavito, Vizconde de la Alborada y de Villarrubio..." Este es uno de los 4 ejemplares originales existentes a que en el texto anterior se hace mención.

Vitrina 2, núm. 63.

Lenguas indígenas núm. 61 
La descripción que se hemos seleccionado corresponde al catálogo publicado de la colección de impresos en lenguas indígenas, que custodia la Biblioteca Pública del Estado de Jalisco. ${ }^{330}$ Colección que fue registrada como Memoria del Mundo en el año 2007. Se trata sin duda, de impresos muy singulares y en el registro, ya se puede observar un cambio paradigmático que se correspondería con una formación más especializada que comenzó a impartirse en México a partir del año 2000.

Así observaremos, que la ficha inicia con el nombre del autor, seguido de una descripción bastante completa de los datos de la portada de un impreso novohispano del siglo XVII. Posteriormente se integra una descripción física del material, con todo y el tamaño en centímetros, que incluye el registro completo de las signaturas de una forma que se corresponde con el trabajo internacional. Igualmente se da noticia de cada uno de los preliminares que posee el impreso, pero sin indicar el lugar exacto que le corresponde en el original.

También se informa del tipo de encuadernación y las evidencias históricas que posee el objeto, así como características tipográficas de la composición ( $v$ gr . dos columnas). Posteriormente se notifica el estado de conservación. En este aspecto debemos anotar que ya se ha superado esa forma antigua tan básica de "bueno, regular o malo", que no aportaba mucha información por datos más precisos como desprendimiento del lomo o manchas de humedad.

El registro finaliza, aunque no en todos los casos del catálogo, con una nota bibliográfica que da cuenta de los diferentes repertorios u obras en las que esta impresión ha sido mencionada o documentada. Igualmente la nota presta atención a otros ejemplares que se han conservado o, de los que se tiene noticia. Este caso en particular, se distingue de los otros analizados porque ya cumple con lineamientos bibliográficos más acordes con la naturaleza patrimonial del objeto que se describe. Situación que no debe extrañar ya que el catálogo y la

330 Fondos del Tesoro. Colección de lenguas indígenas Biblioteca Pública del Estado de Jalisco "Juan José Arriola”, coord. Marina Mantilla Trolle y Nora Jiménez Hernández. Guadalajara: Universidad de Guadalajara: El Colegio de Michoacán, 2007, p. 256. 
identificación de los objetos se enmarcan en un reconocimiento internacional que sin duda influyó en la forma del registro.

Con este registro concluimos el análisis de cuarenta y tres modelos bibliográficos, podemos observar que la diversidad presente en las formas de registro del libro antiguo realizadas en México hace referencia a una valoración cambiante en la historia y poco consciente del valor cultural que ese objeto tiene y adquiere con el paso del tiempo. Ya habíamos apuntado en otro trabajo, ${ }^{331}$ que el valor cultural se compone a su vez de valoraciones estéticas, históricas y de conocimiento que se construyen y transmiten según las ideas culturales de una época determinada.

Lo que todos estos registros nos indican es un objeto multiforme, que puede ser moldeado según la interpretación de quienes lo representan, más que un objeto con particularidades propias que se derivan de un proceso histórico concreto por las cuales se distingue. Un objeto, que por su naturaleza y función social, ha adquirido con el tiempo una valoración concreta que debemos procurar reflejar mediante una descripción bibliográfica. En los modelos que hemos presentado la valoración predominante es la de conocimiento, es decir el contenido temático del libro que podría servir para hacer interpretaciones sobre la historia cultural de una época. ${ }^{332}$

Este valor, como lo muestran los datos registrados, favorece más la representación del objeto libro — en su compresión moderna— más que de su naturaleza material —en su comprensión histórica-. No está de más decir, que dicha valoración se contrapone a la idea contemporánea

$331 C f r$. Idalia García y Miguel Ángel Rendón. "El fondo antiguo: su estructura conceptual”. Binaria. Revista de Comunicación, Cultura y Tecnología. Vol. 1 (diciembre 2001). Texto disponible en http://www.uem.es/binaria/anteriores/n1/ introfl.html [Consulta: enero de 2006]

332 Las apreciaciones en este sentido siempre deben realizarse con prudencia, porque los documentos históricos que documentan la presencia de libros antiguos en el pasado, así como las referencias bibliográficas a esos libros no son en sí mismos pruebas de verdad absolutas. Por el contrario, los libros como objetos materiales y la relación con otros semejantes, debe considerarse en cualquier investigación antes de cualquier apreciación sobre la cultura escrita de una época. 
del valor cultural que reconocemos en los libros antiguos. Una idea que considera la relevancia de la valoración estética e histórica en el reconocimiento de un objeto patrimonial como lo es el libro antiguo. Es decir no sólo importa saber si son libros religiosos, literarios o científicos, importa saber cómo están hechos, en qué momento se introducen en el mundo social y cómo ha trascurrido su vida en ese mundo hasta la custodia moderna en una colección específica.

En nuestra opinión estos modelos no han sido concebidos como formas de representación material de impresos antiguos, sino como el ejercicio de una práctica bibliográfica tan devaluada que ha dejado de ser comprensible. Además

como bien sabemos, el dato escueto, considerado no más que en su exterior naturaleza documentaria, puede llegar a convertirse en una sigilosa forma del engaño: el dato tiene que ser necesariamente interpretado, es decir, puesto en relación no sólo con otros de su misma índole, sino en correlación con diversas noticias del mismo entorno cultural; de no hacerlo así podría seguir construyéndose la imagen histórica de nuestros siglos coloniales como quien compila un seco catálogo de obras y autores sólo capaz de atraer la atención de un aterrido positivista. 333

Por ello, la recuperación de una tradición bibliográfica, que aunque efímera ha estado presente en nuestro país, adquiere más relevancia en tanto relacionamos el conocimiento de un libro antiguo con su valor patrimonial. De ahí que para un adecuado conocimiento de las características del objeto y especialmente de la transmisión de su condición patrimonial, debamos comprender que

las normas de descripción deben ser, sin duda, más rigurosas y exhaustivas, ya que pretendemos crear un instrumento de control del libro y sus

333 José Pascual Buxo. "Prologo" a la obra de Guillermo Tovar de Teresa. Op. cit. Parte primera, p. 10 
partes, [en donde] el grado de detalle deberá ser el suficiente para permitirnos identificar posibles emisiones y estados. ${ }^{334}$

En efecto, al otorgar un lugar a la tarea de la descripción bibliográfica en el desarrollo del conocimiento sobre el libro antiguo, estaremos al mismo tiempo comprendiendo que, si bien esta tarea se fundamenta en una tradición, no discrimina todas las aportaciones metodológicas que hacen a su objeto de interés más inteligible para otros. Para ello es necesario que la recuperación de la tradición bibliográfica no sea meramente el "copiado" de un modelo de descripción, sino el análisis de sus características y de los elementos que se consideran relevantes para construir un registro que ayude a mejorar nuestra comprensión del bien librario - como lo denominan los italianos-.

Es la condición patrimonial el punto más substancial de nuestra reflexión, debido a la principal dificultad que presentan nuestras instituciones de custodia para ejercer una adecuada salvaguarda: el problema de la identificación de los objetos bibliográficos conservados y las razones que justifican el reconocimiento del valor cultural frente a otros objetos patrimoniales. Por esta razón podemos manifestar que en nuestro país, el conocimiento bibliográfico sobre los libros antiguos es más un "desorganizado inventario de omisiones, ausencias, ocultaciones, etc.," 335 que un profundo saber de las formas materiales de un objeto que forma parte y contribuye a la comprensión de la historia cultural que nos antecede.

Pero no solamente se trata del conocimiento sobre el objeto cultural que nos ocupa, sino de un profundo desconocimiento de la práctica bibliográfica y de la función social que adquiere con el tiempo. En efecto, no parece observarse una clara continuidad en el trabajo bibliográfico, especialmente en lo que corresponde a la herencia de Mantecón y Millares Carlo. Ambos en situación de exiliados habían

334 Paloma Alfaro Torres. La imprenta en Cuenca, 1528-1679. Madrid: Arco Libros, 2002. p. 20

335 Amedeo Quondam. "Mercancía de honor, mercancía de utilidad: producción del libro y trabajo intelectual en Venecia en el siglo XVI". Libros, Editores y Público en la Europa Moderna, comp. Armando Petrucci. Valencia: Edicions Alfons el Manànim. p. 73. 
trabajado fuentes antiguas y sus conocimientos en un país como México

les fue fácil reiniciar sus actividades profesionales. México en ese momento, no contaba con personal capacitado suficiente en este campo para acometer trabajos como los que hicieron Millares y Mantecón, por lo cual al llegar ellos, fueron inmediatamente aceptados por las instituciones oficiales de nuestro país, para investigar repositorios documentales que casi no habían sido tocados durante las primeras décadas del siglo Xx. 336

Millares Carlo y Mantecón fueron y son reconocidos, en nuestro país, como los continuadores de la tradición bibliográfica mexicana y como defensores de la bibliografía científica. Algo que resulta tan evidente, pero cuya relación directa no está presente en los trabajos que hemos analizado. De tal forma que no se comprende que una metodología no refiera a la construcción de un argumento sólido, que explique las razones por las que se describe un objeto de cierta manera y no de otra. Por el contrario en estos trabajos hemos encontrado que se entiende por metodología, una mera enumeración de datos que tampoco se explican por qué y para qué se han seleccionado.

Además, esos mismos datos se entremezclan de una forma desorganizada que no logra representar al objeto original como lo miraríamos en nuestra percepción más rudimentaria: de afuera hacia dentro y de dentro hacia fuera. La evolución bibliográfica que se corresponde con la evolución del mismo libro, explica porqué la descripción comienza con la portada y finaliza con las notas. Esa misma evolución es la que logra comprender al libro antiguo en su doble dimensión como objeto material y como objeto histórico para poder construir, y por tanto transmitir, un valor cultural concreto.

336 Estela Beatriz López Cervantes. Dos transterrados intelectuales y su aportación a la cultura mexicana: el Dr. Agustín Millares Carlo y el Dr. José Ignacio Mantecón. México: la autora, 2003. (Tesis Maestría. Maestro en Historia de México. UnAm. Facultad de Filosofía y Letras. División de Estudios de Posgrado). p. 70 
Es a través de este valor que el análisis de los modelos aquí presentados nos permite advertir tres aspectos distintivos en la representación del objeto: la transcripción de la portada, la descripción de las signaturas y la consideración de algún elemento que nos proporcione una idea de la historicidad del objeto descrito. En cuanto al primer aspecto veremos que prácticamente todos los registros que transcriben la portada de forma "casi facsimilar" emplean la diagonal (/) para separar las líneas del texto presentes. Solamente Cid Carmona emplea la doble barra (II) para el mismo procedimiento. Sin embargo prácticamente ninguno de los registros catalográficos aquí presentados, respeta las indicaciones de la norma internacional para el registro de los títulos o del pie de imprenta. Esta particularidad no solamente nos habla de la interpretación particular de la norma internacional y por tanto, también nos remite a la tarea institucional de la custodia y a la escasa reflexión que hacemos sobre la catalogación de libros antiguos en México como una tarea más relacionada con el control patrimonial de las colecciones. 


\section{La manufactura de un libro antiguo}

La historia es un lugar de experimentación, una manera de hacer salir las diferencias. Saber del otro, y por lo tanto de uno mismo

Roger Chartier (2000)

$\mathbf{P}$ ara acercarnos a la comprensión de la correcta representación bibliográfica de un libro antiguo, resulta inevitable introducirnos en las formas de producción que dieron por resultado a esos libros. De esta manera podremos entender cómo de un manuscrito o de un libro anterior se podía manufacturar un impreso con características propias y distintivas. Por eso, para describir un libro de tales características, es necesario no solamente conocer "la estructura material, sino el ámbito histórico, social, legal [...] que influyen claramente [...en el producto final]". 337

Como sabemos, se ha considerado "no sin cierta polémica entre los historiadores, que la invención de la imprenta fue consecuencia de la necesidad provocada por el desarrollo de la alfabetización desde el siglo XII. La intensa actividad intelectual que motivó el nacimiento de las primeras universidades supuso una mayor demanda de libros

337 María Milagros Ronco López. Nuevas aportaciones biobibliográficas y documentales en torno a la figura de Millares Carlo: la imprenta en Barcelona durante el periodo renacentista, 1590-1600. [Bilbao]: Universidad del País Vasco, [2001]. p. 29 
que los escritorios de los monjes no podían surtir". 338 De esta necesidad surgió la idea de aplicar una tecnología que ya se empleaba en la manufactura de otros productos. Recordemos que antes de los tiempos de Gutenberg, la prensa se usaba en los viñedos ${ }^{339}$ y, los punzones, en la fabricación de medallas y monedas.

La verdadera revolución tecnológica, que modificó los modos de producción de la cultura escrita, se dio con "el molde ajustable para fundir tipos de letras y la composición de una aleación metálica de estaño, plomo y antimonio para dicha fundición". ${ }^{340}$ Gracias a este procedimiento comenzó una forma nueva de transmisión de la cultura escrita, que pese a su mérito y alcance social, también se vería afectada por la regulación de las materias primas necesarias para la producción, entre ellas, el papel $^{341}$ y la tinta. No olvidemos que al final, sin romanticismo, se trata de un objeto manufacturado e introducido en circuitos comerciales como cualquier otro.

Ciertamente es difícil saber

de manera cierta ni precisa, cuál era verdaderamente el volumen de negocios de los talleres de la época moderna por la sencilla razón de que carecemos de dos datos imprescindibles: el número exacto de títulos publicados y, para cada uno de ellos, la tirada de ejemplares. ${ }^{342}$

338 Manuel Peña Díaz. "Libros y letras en tiempos de Isabel la Católica”. Domus Sapientae: fondos bibliográficos de la Universidad de Granada en la época de Isabel la Católica. Granada: Universidad 2004. p. 15

339 Cfr. Vicente Ros. "La máquina de prensar uvas". Infodiversidad. Num. 10 (2006). pp. 101-112. Texto disponible http://redalyc.uaemex.mx/redalyc/ pdf/277/27701005.pdf [Consulta: diciembre de 2007]

340 Ibíd. p.16

341 La historia de la fabricación de tan preciado ingrediente para la impresión de libros no es menos fascinante, pero precisamente por su importancia y su larga historia, debe ser abordada desde otra perspectiva. Cfr. Dard Hunter. Papermaking: The History and Technique of an Ancient Craft. New York: Dover Publications, 1978.

342 Philippe Berger. "La crisis de 1506-1509. Crónica de una quiebra anunciada". La memoria de los libros: estudios sobre la historia del escrito y de la lectura en Europa y América, bajo la dirección de Pedro M. Cátedra \& María Luisa López-Vidriero. Salamanca: Instituto de Historia del Libro y de la Lectura, 2004. T.1, Nota 3, p. 399. 
Partiendo de esto, solamente podemos tener una idea cercana del proceso de producción de los impresos tan acertadamente defendido como un arte, gracias a que se han conservado algunos documentos históricos y libros antiguos que nos ayudan a comprender cómo se fabricaban estos objetos.

Los más conocidos de estos textos son: el "Manual de tipografía" del obispo impresor Juan Caramuel, ${ }^{343}$ inserto dentro del libro Teología moralis fundamentalis... impreso en 1664, que puede ser considerado "el primer manual conscientemente técnico sobre el oficio de imprimir aparecido en Europa", ${ }^{344}$ y los libros de los impresores Alon-

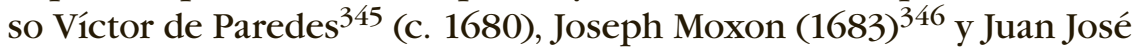
Sigüenza y Vera (1811). ${ }^{347}$ También son importantes las alabanzas al arte de la impresión contenidas en el discurso 111 del tratado de Cristóbal Suárez de Figueroa (en la edición de $1629^{348}$ ), la del dominico Jacinto de Parra $(1670)^{349}$ y la que forma parte del discurso de Melchor de Cabrera (1675). 350

343 Juan Caramuel. Syntagma de Arte Typographica, edición, traducción y glosa de Pablo Andrés Escapa. Salamanca: Instituto de Historia del Libro y de la Lectura, 2004 .

344 Pablo Andrés Escapa. "Juan Caramuel y Lobkowitz (1606-1682) \& Syntagma de Arte Typographica”. Ibíd. p. 24

345 Alonso Víctor de Paredes. Institución y origen del arte de la imprenta y reglas generales para los componedores, edición y prólogo de Jaime Moll. Madrid: Crotalón, 1984

346 Joseph Moxon. Mechanical Exercises or handy works. Applied to the e Art of Printing. The second volume... London: Printed for Joseph Moxon, 1683.

347 Juan Joseph Sigüenza y Vera. Mecanismo del arte de la imprenta para facilidad de los operarios que le exerzan. Madrid: Imprenta de la Compañía, 1811. Edición facsímil, Madrid: Tipus Almarabu, 1992.

348 Cristóbal Suárez de Figueroa. Plaza Universal de todas las cosas... Perpiñan: Luis Roure, 1629. (BGU de Sevilla 55 37).

349 Jacinto de Parra. Rosa Laureada entre los Santos... Madrid: Domingo García Morrás, 1670. (BGU de Sevilla 92 187)

350 Melchor de Cabrera Nuñez de Guzmán. Discurso legal, bistórico y político en prueba del origen, progressos, utilidad, nobleza y excelencias del arte de la imprenta... Madrid: En la Oficina de Lucas Antonio Bedmar, 1675. Edición facsimilar, Madrid: Sngular, 1993. 
Sin duda, la descripción de este noble proceso ha sido realizada con anterioridad de mejor manera por otros, entre los que distingo a Jaime Moll ${ }^{351}$ y a Julián Martín Abad. ${ }^{352}$ Pero debido a la naturaleza y finalidad de este trabajo debemos aventurarnos en esa complicada tarea. ${ }^{353}$ Aunque parezca repetitivo, y en efecto lo sea, comprender este proceso es relevante porque ayuda considerablemente a conocer la estructura y características del libro antiguo que deseamos representar en un registro bibliográfico. ${ }^{354}$

Ahora bien, en dicho proceso se involucran múltiples circunstancias que afectarán directamente al producto esperado. Dichas incidencias, estaban determinadas por las formas de producción y por un entramado de regulación legal que los poderes políticos y eclesiásticos establecieron, no sólo para controlar la producción del libro sino también para controlar su circulación en la sociedad. ${ }^{355}$ Dentro de ésta, "la actividad tipográfica estuvo fuertemente sometida al capital comercial, que hizo del libro un producto caro, que debía satisfacer las demandas del público, presentándolo de la mejor manera posible para hacer de él un objeto de deseo tanto por el contenido como por la forma".356

351 Jaime Moll. "La imprenta manual". Imprenta y crítica textual en el Siglo de Oro / estudios publicados bajo la dirección de Francisco Rico. Valladolid: Universidad. Centro para la Edición de los Clásicos Españoles, 2000. pp 13-27.

352 Julián Martín Abad. "La técnica impresora". José Manuel Lucía Mejías. Aquí se imprimen libros: la imprenta en la época del Quijote. Madrid: Imprenta Artesanal Ollero y Ramos, 2004. pp. 11-33.

353 Debo agradecer a Genaro Lamarca Langa estas líneas, porque sin su lectura y comentarios ni siquiera se me hubiese ocurrido intentar escribir esta parte del libro.

354 Lo anterior no es excusa para reconocer la permanente necesidad de acudir a la bibliografía especializada, siempre que se requiera profundizar en algún detalle concreto, tanto sobre los libros como sobre su proceso de impresión.

355 Para conocer mejor este tipo de normativas es sumamente recomendable consultar el libro de Fermín de los Reyes Gómez. El libro en España y América: legislación y censura (siglos XV-XVIII). Madrid: Arco Libros, 2000. 2 tomos.

356 Nicolás Bas Martín."Muestrarios de letras de la imprenta valenciana del siglo XVIII". La memoria de los libros: estudios sobre la bistoria del escrito y de la lectura en Europa y América, bajo la dirección de Pedro M. Cátedra \& María Luisa López-Vidriero. Salamanca: Instituto de Historia del Libro y de la Lectura, 2004. T.1, p. 336 
Sabemos que la resma (500 pliegos de papel) es la unidad de trabajo y de comercialización de un taller de imprenta, ${ }^{357}$ y que con este material comienza a desarrollarse la actividad que transformará el texto de un autor en un libro de circulación social. Ahora bien, decimos que el libro antiguo es un producto manual por

la fuerza requerida para empujar la prensa [...pero] ésta no era la única labor que había que realizar, ya que se precisaban diversos oficios en el arte de imprimir en los que no resultaba necesario emplear fuerza física. 358

También entendemos que el libro antiguo, al ser un objeto producido de forma manual, presenta una diversidad en la estructura de las partes que lo integran. Esta diversidad depende de la forma en que cada taller de impresión resolvió los problemas que le representó la elaboración de una obra específica. Es por lo cual que antes de proceder a describir el proceso de impresión, debemos indicar la importancia de la fundición de letras.

No en vano, la dotación material de un taller tipográfico fue fundamental para el buen desarrollo de la actividad cotidiana de los impresores, y sobre todo para el perfecto acabado de los libros. 359

Como bien escribió Paredes, estas letras servían para imprimir un pliego, después otro, y así "hasta que la letra se envejece o maltrata, y se derrite para fundirla de nuevo". ${ }^{360}$ Durante el periodo de impresión del libro antiguo se emplearon cuando menos 12 tipos distintos de letras según la naturaleza del material que se pretendía producir. Estás son: Grancanon, Petitcanon, Missal, Parangona, Texto, Atanasia, Letura

357 Philippe Berger. Op. cit. p. 395 y Juan Joseph Sigüenza y Vera. Op. cit. p. 38

358 María del Mar Fernández Vega. "Jerónima de Gales. Una impresora valenciana del siglo XVI". La memoria de los libros: estudios sobre la bistoria del escrito y de la lectura en Europa y América, bajo la dirección de Pedro M. Cátedra \& María Luisa López-Vidriero. Salamanca: Instituto de Historia del Libro y de la Lectura, 2004. T.1, p. 408

359 Nicolás Bas Martín. Op. cit. p. 327

360 Alonso Víctor de Paredes. Op. cit. p. 6 
o Cicero, Entredos, Breviario, Glossa, Miñona, Nomparilla o Piedemosca. ${ }^{361}$ Los estilos de presentación de estas letras eran básicamente tres: capital (mayúsculas), redonda y cursiva. ${ }^{362}$

La fundición de las letras - en conjunto denominadas letrería ${ }^{363}$ podía realizarse en el propio taller, pero también podían comprarse tipos en ciertos circuitos comerciales - como las ferias de libros- e incluso heredarse de un taller anterior. La descripción del proceso de fabricación de un tipo es aparentemente simple: ${ }^{364}$

El primer momento consiste en tallar, grabar o abrir en el extremo de un punzón de acero, de unos 45 milímetros de largo, el perfil de cada letra o signo. El segundo momento consistía en incrustar ese punzón en una pieza de cobre que, a su vez era golpeada para la obtención de una matriz. Esta pieza debidamente preparada [...] se fijaba en la base de un molde, en el que se vertía metal líquido, 365 consiguiéndose de ese modo un tipo, es decir, la representación tridimensional de una letra (o de otro signo cualquiera). ${ }^{366}$

361 Ibíd. h.7r.-8r. Se han transcrito tal y como se mencionan. Juan Caramuel. Op. cit. p. 67, menciona once tipos que son: Gran Canon, Peticano, Misal, Texto, Atanasia, Lectura o Cícero, Entredós, Breviario, Glosilla, Miñona, Monparella o Nonparell. Por su parte Sigüenza y Vera. Op. Cit. pp. 6-16, también muestra once tipos que son: De pradell o peticano, Misal, Parangona, Texto, Atanasia, Lectura Gorda, Lectura chica, Entredos, Breviario, Glosilla, y Nomparell de Espinosa. Estos nombres fueron dados en gran medida por las primeras obras que se compusieron o el tipo de obra que se editaba (cícero o breviario).

362 Juan Caramuel. Op. cit. p. 75

363 "Conjunto de letras que forman una póliza o fundición”. José Martínez de Sousa. Diccionario de edición, tipografía y artes gráficas. Gijón: Trea, 2001. p. 273. Como se aprecia a ese mismo conjunto de tipos se le denomina como fundición.

364 Aunque para otros es más complicado "cuesta indecible cuidado, y desvelo el ajustarla, para que corresponda con igual perfección à las demàs que se van fundiendo". Melchor de Cabrera. Op. cit. h.13v-14r.

365 Estaño y plomo según Cristóbal Suárez de Figueroa. Op. cit. p. 378r. El antimonio se empleaba para endurecer los tipos.

366 Julián Martín Abad (2005). Op. cit. p. 15. Otro texto que describe de forma bastante clara el proceso de producción de los tipos se encuentra en Ferdinand Geldner. Manual de incunables. Madrid: Arco Libros, 1998, pp. 65-67. 
Pero las matrices no pueden usarse si no se justifican. Es decir adaptar la matriz al molde y alinear para obtener una letrería perfecta en grosor, en espaciado y en verticalidad. ${ }^{367}$

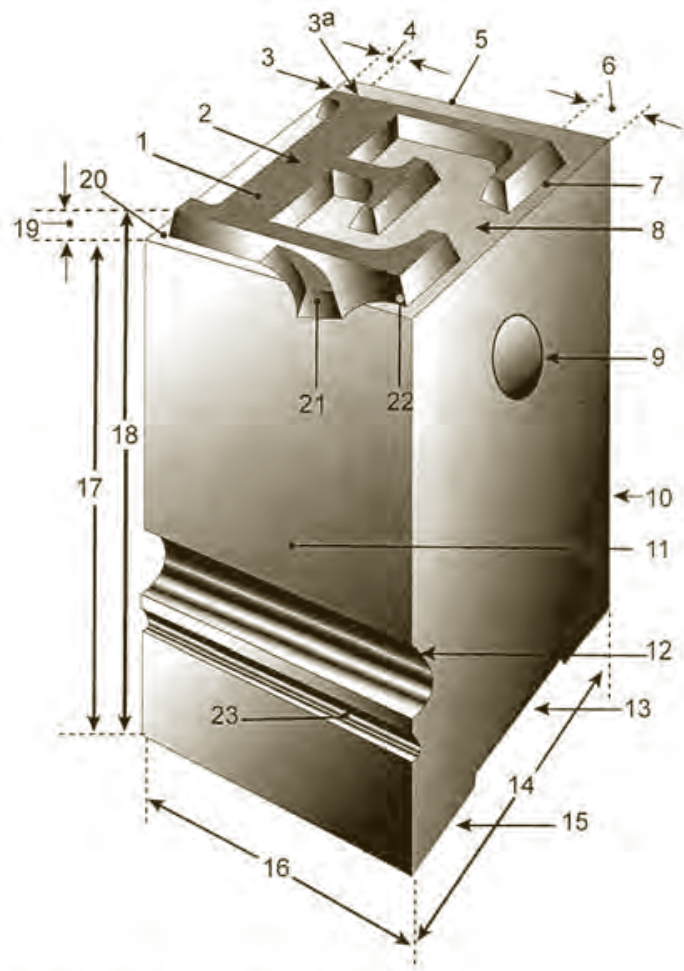

PARTES DE LA LETRA DE IMPRENTA:

1) asta; 2) ojo; 3) remate o terminal; 3a) línea estandar o base;

4) alineación izquierda; 5 ) hombro inferoir; 6 ) alineación derecha;

7)hombro derecho; 8) relieve interno; 9) marca del punzón;

10) cara posterior; 11) cara anterior; 12) cran principal; 13) canal;

14) cuerpo; 15) pie; 16) grueso o espesor; 17) árbol;

18) altura o alto real; 19) alzada; 20) hombro izquierdo;

21) acento (volado); 22) hombro superior; 23) cran secundario.

367 Jaime Moll. "La justificación de las matrices y el estudio de las letrerías". De la imprenta al lector: estudio sobre el libro español de los siglos XVI al XVIII. Madrid: Arco Libros, 1994. p. 110. 
Esta actividad de producción de tipos en un principio está relacionada con el trabajo de los orfebres, por el conocimiento que se requería para la aleación de metales. En breve tiempo esta tarea también formó parte de las actividades de los impresores y la subsiguiente división del trabajo. El número de tipos disponibles en cada taller dependía de los recursos de un impresor y regularmente del número de prensas que se tenían. Incluso algunos impresores podían contar con sus propias matrices ${ }^{368}$ o punzones, para hacer los tipos que necesitaran. 369

Toda vez que se contaba con el papel y la letrería para trabajar se podía proceder a diseñar el producto impreso. Debemos recordar que la base de trabajo en la imprenta manual es el pliego, en el cual se imprimirán las páginas que serán consecutivas, ya que éste haya sido doblado. Es decir, se contarán los pliegos que se necesitan para imprimir un libro y por tanto se debe decidir, previamente, el formato del mismo. En éste, el octavo será la guía de todos las demás. ${ }^{370}$ En el diseño de cada cuadernillo se considera que todas las planas "hacen una más de las que tienen: un cuarto tiene 16 y las de la forma tienen que ser $17 "{ }^{371}$

Tomada esta decisión se podía comenzar el proceso de impresión que se componía de tres fases: ${ }^{372}$ composición, casado, e imposición y tirada. La primera, labor del componedor, implicaba la distribución de las letras para lo cual se debe previamente

revisar el volumen que se va a imprimir y ver cómo se divide. Por ejemplo:

368 Como las que se conservan de Claude Garamond en el Museo Plantin-Moretus en Amberes. Pueden verse en el portal de la institución http://museum.antwerpen.be/plantin_Moretus/index_eng.html [Consulta: marzo de 2009]

369 Jaime Moll. "Las cursivas de Juan Mey, con algunas consideraciones previas sobre el estudio de las letrerías". El Libro Antiguo Español: Actas del primer Coloquio Internacional (Madrid, 18 al 20 de diciembre de 1986). Salamanca: Ediciones de la Universidad: Biblioteca Nacional de Madrid: Sociedad Española de Historia del Libro, 1993. p. 296.

370 Alonso Víctor de Paredes. Op. cit. h. 28r.

371 Ibíd.h.26v.

372 Jaime Moll (2000). Op. cit. p. 14 
el volumen se divide en partes, las partes en libros, los libros en capítulos, etc. ${ }^{373}$

Esta tarea también requería contar letras y palabras para distribuir el espacio del texto en páginas. Es un proceso que se realizaba marcando en el original, qué parte del texto correspondía a cada página y, para no cometer errores, se debían numerar los folios así como llevar una lista que relacionara a éstos con su correspondiente cuadernillo. ${ }^{374}$

Es ahí frente al manuscrito ${ }^{375}$ que se conoce la destreza del componedor, pues en su tarea va tomando decisiones sobre cuántos reglones tendrá cada hoja del impreso. Aquí irá marcando la forma de su plana para que se ajuste en la forma e igualmente decidirá — de forma acertada o no-, sobre la división, abreviaturas e incluso la eliminación de palabras. Para el trabajo de componedor se necesitaba conocer las letras y por supuesto, saber leer y escribir, porque son ellos quienes leían los originales de imprenta. Sin duda "las reglas de la buena tipografía establecían la utilización de los diferentes caracteres en función de los textos a imprimir". ${ }^{376}$

El trabajo de composición también requería de memoria porque tenían que retener parte del texto, ya que "no es posible que siempre aya tanta copia de letra en las fundiciones, que sea suficiente para poder componer sin contar". ${ }^{377}$ De esta manera, y con la habilidad necesaria, se puede ir formando las palabras con los tipos - que siempre deben que estar mojados - que estaban colocados uno a uno en los cajetines, ${ }^{378}$ incluidos los diptongos y las letras ligadas. ${ }^{379}$ En este

373 Juan Caramuel. Op. cit. p. 79

374 Alonso Víctor de Paredes. Op. cit. h. 37r-37v.

375 "En tipografía, al manuscrito original se le llama copia, a los libros impresos, ejemplares". Juan Caramuel. Op. cit. p. 133. Las cursivas en el original están entrecomilladas.

376 Nicolás Bas Martín. Op. cit. p. 332

377 Alonso Víctor de Paredes. Op. cit. h. 35v.

378 Nombre con el que se denomina la división de la caja, que era un mero cajón donde se colocaban en la parte superior (caja alta) las letras mayúsculas y en la parte inferior (caja baja) las letras minúsculas. Cfr. Cristóbal Suárez de Figueroa. Op. cit. p. 378r. Una descripción más detallada de las cajas y los tipos que integran cada una de éstas, se encuentra en Melchor de Cabrera. Op. cit. h.14v-15r.

379 Como ae, oe, fs, ff, entre otras. José Martínez de Sousa. Op. cit. p. 569 
proceso van componiendo la página que previamente han diseñado, considerando las líneas y también las separaciones, Sigüenza y Vera recomendaba componer deprisa y corregir despacio, ${ }^{380}$ para obtener un producto mejor hecho.

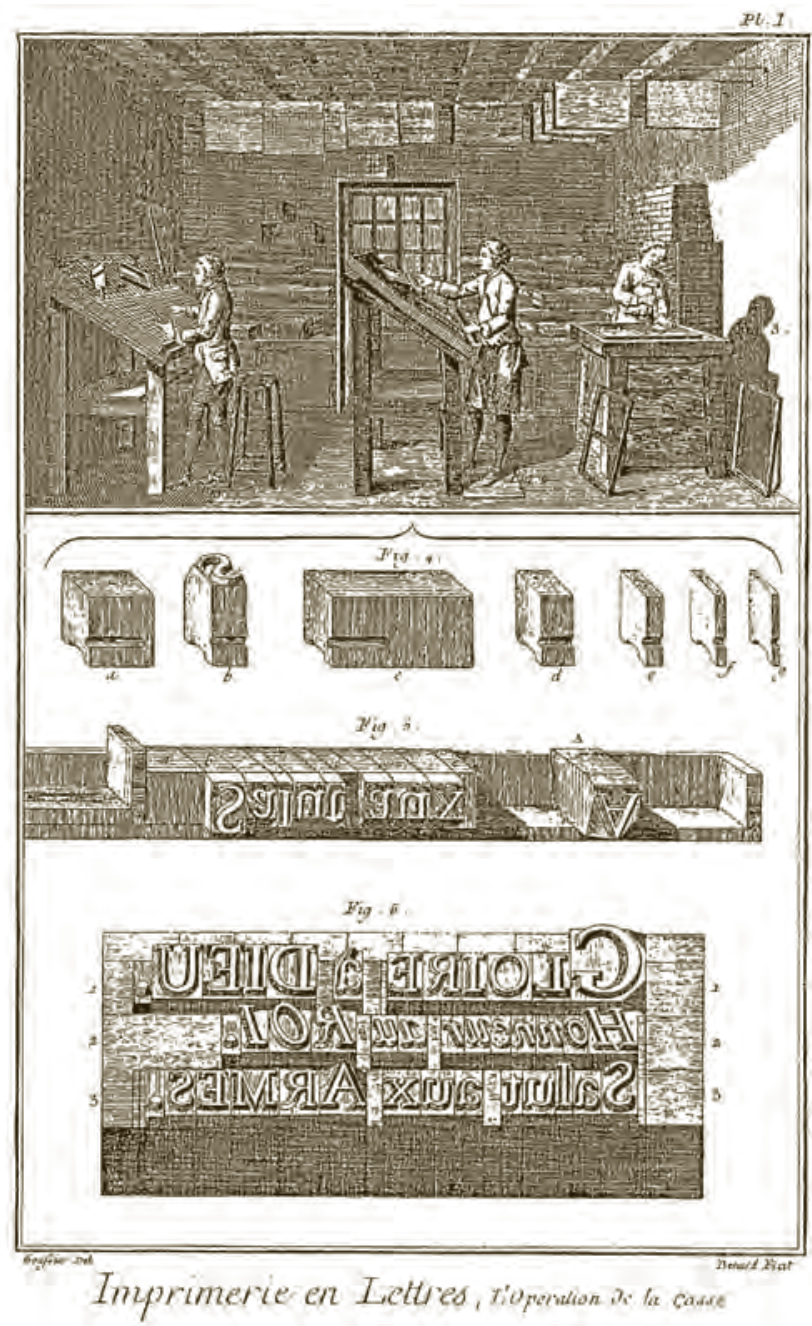

380 Juan Joseph Sigüenza y Vera. Op. cit. p. 28 
Los libros se imprimían por pliegos, primero por una cara y después por la otra. Por eso cada página debe formar un conjunto compacto que conocemos como el molde. ${ }^{381}$ Es aquí en donde son más útiles las signaturas porque servían para indicar la correspondencia de cada molde y su posición en el pliego. Las signaturas se ponen hasta la cuatro "porque las demás son ociosas y ellas se ponen para el gobierno de los encuadernadores". ${ }^{382}$ Por eso cada página, una vez compuesta en la galera, ${ }^{383}$ se ataba y reunía con otras para formar la cara de un pliego, considerando siempre la correcta posición y orientación. Debemos recordar que las páginas se contraponen unas con otras para que una vez impresas en el folio, puedan doblarse. Esta es la operación que se denomina como "casado".
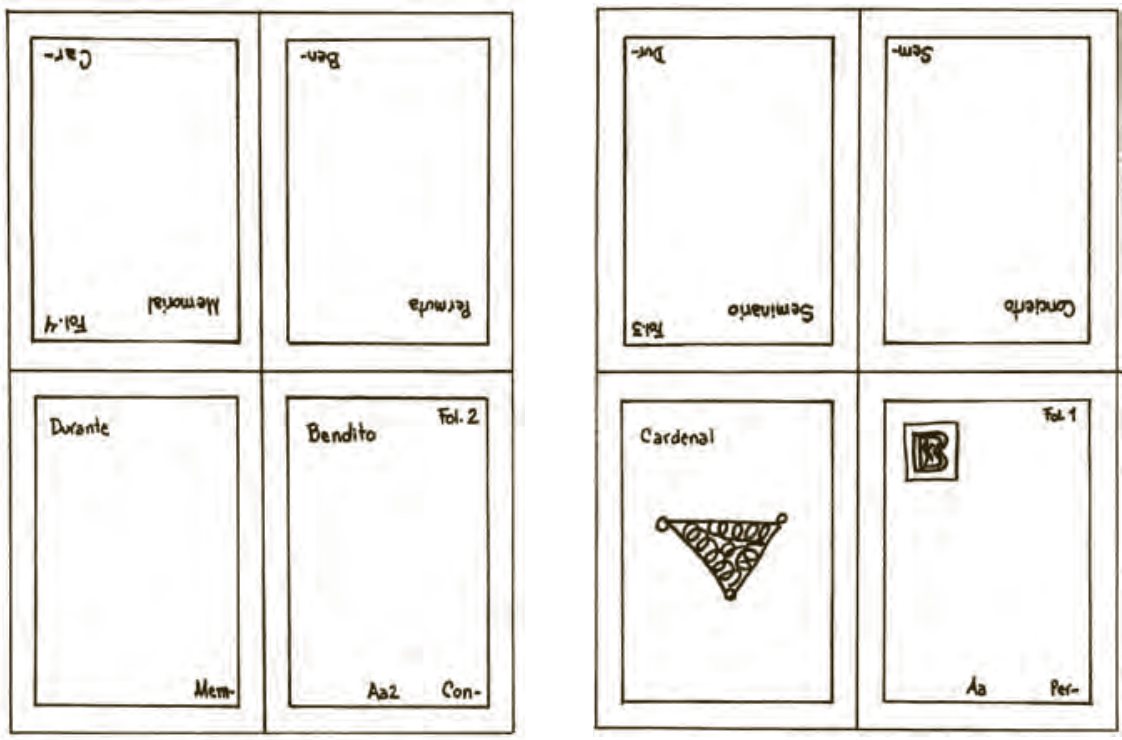

381 Este es "el conjunto de materiales tipográficos, ordenados y dispuestos según un original, que sirve para obtener un impreso”. José Martínez de Sousa. Op.cit. p. 670

382 Alonso Victor de Paredes. Op. cit. h.37v.

383 Es la "plancha de hierro o cinc guardada por tres de sus lados por listones", en donde se colocan y ordenan los tipos empleados en un molde. José Martínez de Sousa. Op. cit. p. 457 
Posteriormente a ésta, se procede a la imposición en donde los moldes se cercaran con un bastidor rectangular de metal, denominado rama. En este proceso,

se cuidará de que a la plana que se imprima le queden las márgenes necesarias [...], haciéndose cargo de las barbas del papel para el cortado: bien que muchas veces lo suelen desfigurar por poco cuidado al tiempo de cortarlo quitándole la hermosura. ${ }^{384}$

La rama con los moldes constituía la forma, que contenía la copia en metal de la cara de un pliego y que debía corresponderse con las hojas del cuadernillo.
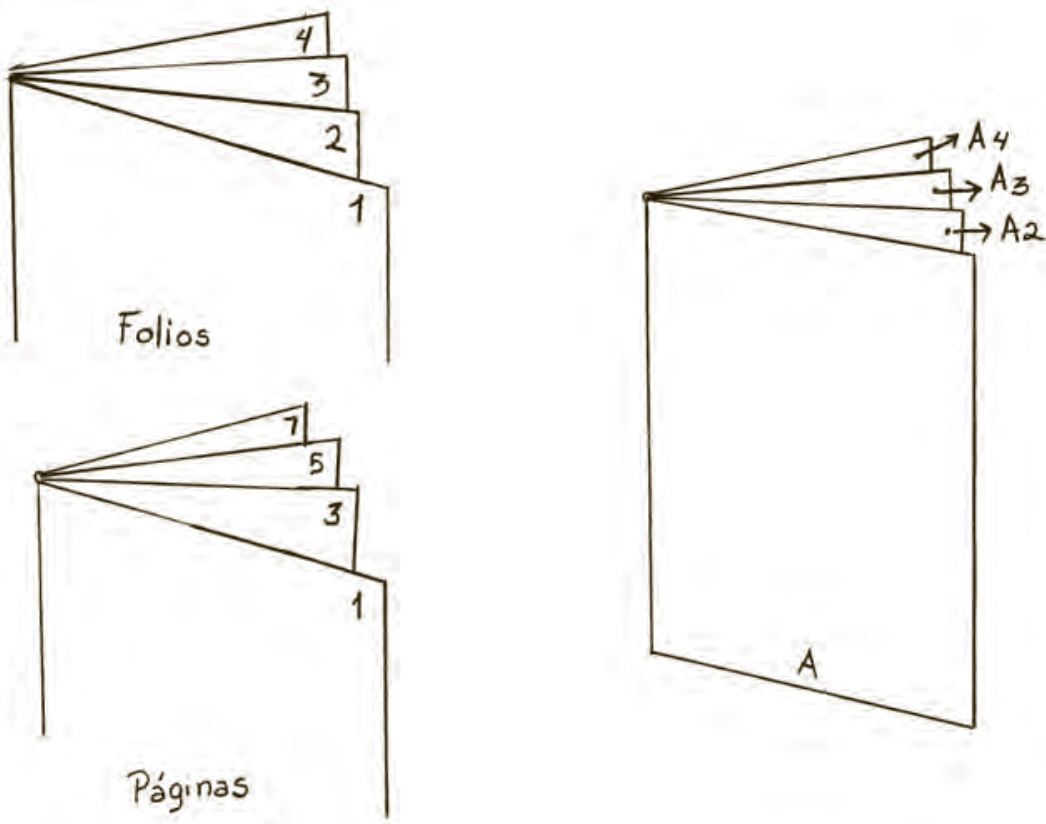

384 Juan Joseph Sigüenza y Vera. Op. cit. p. 34 
Terminado este proceso, de la forma se sacaba "la correspondiente prueba para que el corrector o el autor, señale las erratas que corregirá el componedor". ${ }^{385}$ De ahí que el trabajo del corrector sea trascendental dentro del propio taller de la imprenta, ya que puede revisar los pliegos conforme salen de la imprenta y corregir la forma que servirá para la tirada. ${ }^{386}$ Durante todas las tareas anteriormente descritas es que se cometían la mayor parte de los errores de transmisión de un texto. ${ }^{387}$ De ahí que sea la operación que debía hacerse con más cuidado, puesto que de ella dependía la transmisión adecuada del contenido de la obra.

Los constantes errores eran situación permanente que posibilitó la continuidad del libro manuscrito ${ }^{388}$ y, también generó más de una disputa y enfados entre los autores. Muchos de los cuales incluso se negarían a reconocer la responsabilidad de algunos impresos, ${ }^{389}$ por las graves faltas y abusos cometidos en los talleres de imprenta.

De hecho mientras se corrige una forma o se envía al autor una prueba, siguen imprimiendo muchos folios, dándose por contentos con que se incluyan las correcciones sólo en los últimos. Y así estafan al autor y desde la propia imprenta distribuyen la edición de un mismo libro con unos folios corregidos y otros sin corregir. 390

El proceso de corrección, como es sabido, también participa del ejercicio de la censura y control de la cultura escrita, ya que

385 Jaime Moll (2000). Op. cit. p. 16

386 Alonso Víctor de Paredes. Op. cit. h.42r.-23v.

387 En efecto "buscar libro sin error, es querer que todos sean Canónicos". Melchor de Cabrera. Op. cit. h.3r.

388 Cfr. Fernando Bouza. Corre manuscrito: una bistoria cultural del Siglo de Oro. Madrid: Marcial Pons, 2002. pp. 27-83.

389 Carmen Alvarez Márquez. "El escribano de letra de libros «versus» el cajista”. La memoria de los libros: estudios sobre la bistoria del escrito y de la lectura en Europa y América, bajo la dirección de Pedro M. Cátedra \& María Luisa LópezVidriero. Salamanca: Instituto de Historia del Libro y de la Lectura, 2004. T.1, p. 117

390 Juan Caramuel. Op. cit. p. 133 
... la ortografía de una obra impresa corresponde fundamentalmente a usos establecidos por la propia imprenta... por razones de oficio, los impresores eran los más impuestos en materia gráfica. ${ }^{391}$

Enmendada la prueba en metal se procedía a la tirada. En esta fase, el tirador "es el que gobierna la prensa". ${ }^{392}$

La prensa es una compleja maquinaria adaptada de otros usos y formada de numerosas partes. ${ }^{393}$ Su finalidad básica es que la forma sea impresa en el pliego mediante la presión. Podemos darnos una idea de la importancia dentro del circuito comercial que representa el conocimiento de un impresor tanto del proceso, la maquinaria, como de todos los elementos necesarios para la impresión de un libro antiguo por una noticia aparecida en la Gaceta de México:

Los días 10, 11, 12 y 13 se abrió la nueva imprenta, en la que se imprime esta Gaceta que ha venido en la presente flota y se compone de muy limpias y bien vaciadas letras, de las que consta una cabal imprenta; son caracteres de canto o música, gran canon, menor peticanon y respectivamente menores las de misal, parangona, atanasia, lectura, entredos, breviario, glosa, miñona, non parella, con griego y hebreo, y entre estas otras, como entre texto y atanasia, entre lectura y entredos, etc., con espacios, cuadrados, títulos de dos líneas y varias curiosidades para viñetas. Sus principales instrumentos son divisorios, mordante, galera, volandera, rama, cabeceras, cruceros, medianiles, llave, prensa, campeones, cofre, cigüeña, carro, tímpano, timpanillo, punteras, chavetas, frasqueta y balas; sus principales oficiales son: componedor, tirador y batidor, y a

391 Ramón Santiago. "Imprenta y ortografía en torno a Guillermo Foquel y Alonso Victor de Paredes". La memoria de los libros: estudios sobre la bistoria del escrito y de la lectura en Europa y América, bajo la dirección de Pedro M. Cátedra \& María Luisa López-Vidriero. Salamanca: Instituto de Historia del Libro y de la Lectura, 2004. T.1, p. 540

392 Melchor de Cabrera. Op. cit. h.16r.

393 Una excelente descripción sencilla y clara de la maquinaria en Jaime Moll (2000). Op. cit. pp. 16-24. 
éste último le toca fabricar y dar tinta, que se componen de pez, aceite y humo de tea, o si es colorada, bermellón 394

Dicha noticia también nos da cuenta de la permanencia de una técnica con escasas modificaciones durante casi tres siglos de historia. En efecto, no conocemos una descripción de la maquinaria anterior a la realizada por Moxon en el siglo XVII. ${ }^{395}$ En esta, además de proporcionarnos dos grabados de la prensa, nos dice de la existencia de dos tipos de prensa: una antigua y otra moderna. ${ }^{396}$ Describe la primera porque era la que más se emplea en Inglaterra, pero no deja de mencionar a Willem Fausen Blaew de Ámsterdam como el hombre que fabricó "la nueva prensa".

394 La Gazeta de Mexico, desde primero, hasta fines de febrero de 1733. Num. 63, p. 497. Integrada en Gacetas de México, estudio introd. por Francisco González de Cossío. México: Conductores Mexicanos, Centro de Estudios de Historia de México, 1986.

395 Joseph Moxon. Op. cit. pp. 37-58.

396 Innovación técnica de la que ya dispusieron los impresores en el periodo incunable, y que se refiere al cambio que se dio entre la prensa de un golpe para imprimir página a página, y la prensa de dos golpes que permitía imprimir varias páginas al mismo tiempo. Lotte Hellinga. Impresores, editores, correctores $y$ cajistas. Salamanca: instituto de Historia del Libro y de la Lectura, 2006. p. 33. 


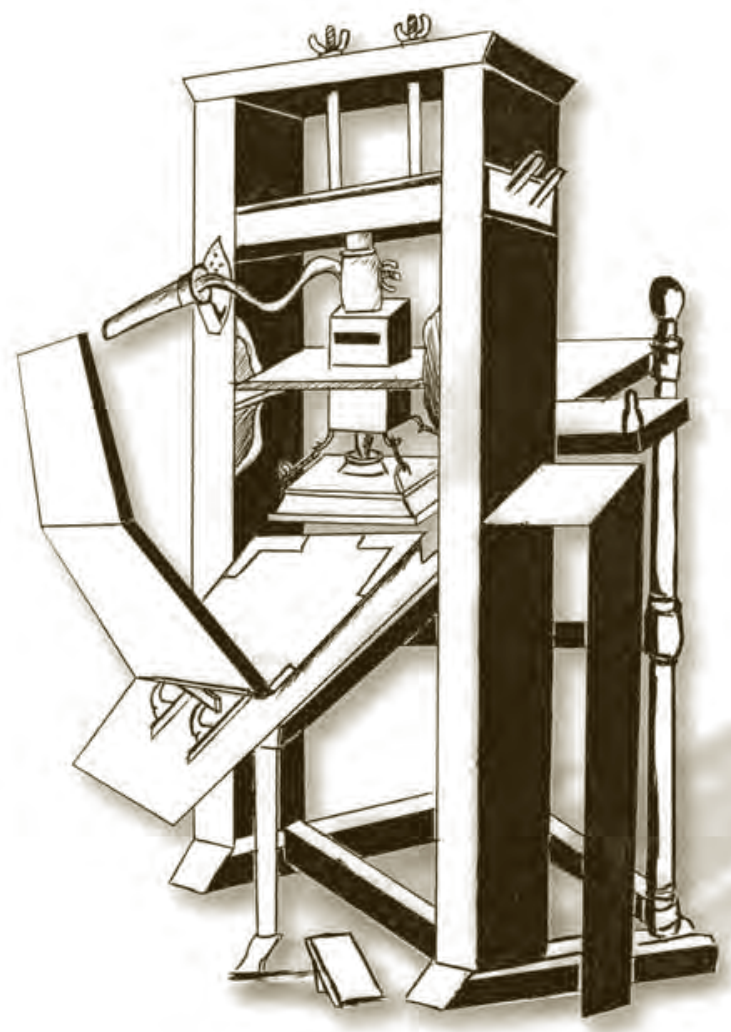

La descripción de la prensa realizada por Moxon, incluye treinta y dos elementos ${ }^{397}$ que dan idea de la complejidad de la maquinaria. Para relacionar las imágenes de ésta con el proceso de impresión, es conveniente consultar en orden cronológico a Sigüenza y Vera, ${ }^{398}$ Moll, ${ }^{399}$ y Martín Abad. ${ }^{400}$ Este último autor nos proporciona una síntesis de esta "máquina de hacer libros: "consta la prensa de dos partes

397 Joseph Moxon. Op. Cit. pp. 39-40

398 Juan Joseph Sigüenza y Vera. Op. cit. pp. 151-166

399 Jaime Moll (2000). Op. cit. pp. 16-24

400 Julián Martín Abad (2005). Op. cit. pp. 26-28 
fundamentales exigidas por el sistema utilizado al realizar la impresión de los pliegos, uno a uno, primero por un lado y luego por el otro. Una de esas partes fundamentales es el armazón, en el que se encuentra el cuadro como instrumento inmediato de presión, y la otra es la estructura que permite el desplazamiento de la forma hasta quedar colocada debajo de dicho cuadro y retornar a la posición previa que permite su cómodo entintado". 401

Es aquí cuando podemos introducirnos al proceso de "tirar", en el que trabajan tanto el batidor como el tirador. El primero de éstos estaba encargado de entintar los moldes de las formas previamente a la impresión. Una tarea que se realizaba con las balas, las cuales "son como unas almohadillas [que] se forran con piel de carnero [...y se colocan] en unas tablas torneadas con su manija" 402 y que posteriormente se rellenan de lana.

De esta manera, los batidores "toman tinta con las [balas y van dando golpes a la forma], y después de bien repartida (a quien llaman distribuir") ${ }^{403}$ se podía proceder a la impresión. Esta tarea era propiamente responsabilidad del tirador. Generalmente se cree que el proceso terminaba colocando el pliego de papel y prensando conjuntamente con la forma. Sin embargo, el tirador solamente imprime medio pliego la primera vez, después da vuelta a la manivela para introducir la otra mitad preparada para la impresión. ${ }^{404}$

La retiración, al revés exacto de la imposición, es tarea del tirador y procura que se ajusten los renglones en la impresión de cada cara del pliego. ${ }^{405}$ En este procedimiento de debía tener extremo cuidado, especialmente cuando se incluían capitulares, viñetas, o grabados. Tanto más si la impresión se realizaba a doble tinta. Para imprimir en rojo y negro se hacía la composición de la página entera, sin preocuparse por la diferencia. Posteriormente se ponían regletas por debajo de los tipos que se harían en rojo, con la finalidad de elevarlos. En seguida,

401 Ibíd. p. 26

402 Juan Joseph Sigüenza y Vera. Op. cit. p. 162.

403 Cristóbal Suárez de Figueroa. Op. cit. h. 379r.

404 Cfr. Jaime Moll (2000). Op. cit. p. 24

405 Cristóbal Suárez de Figueroa. Op. cit. fol. 379r. 
se entintan e imprimen. Finalmente para imprimir las negras se retiran las letras impresas en rojo y se sustituyen por tipos cuadrados, para volver a entintar e imprimir. Resultaba un trabajo complicado por lo que se podían cometer errores. ${ }^{406}$

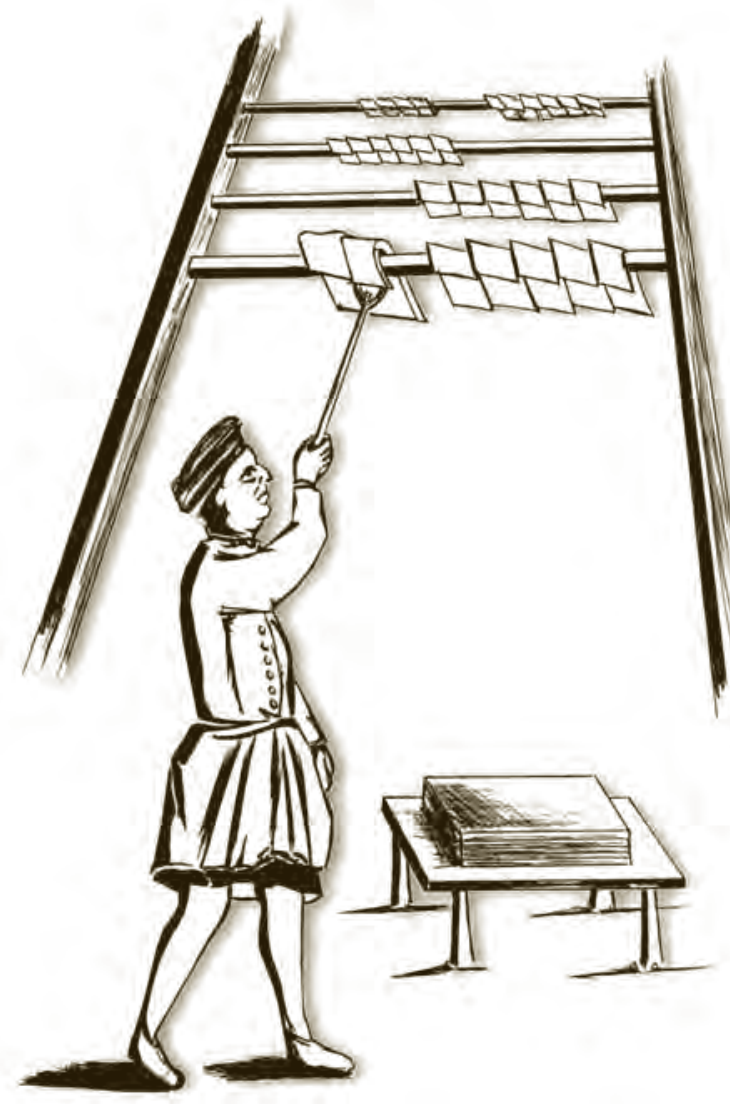

406 Juan Caramuel. Op. cit. p. 71. El mismo declara que para evitar los errores en su imprenta de Praga se fundieron tipos más altos para las rojas, de manera que sobresalían sobre las negras y se quitaban sin dificultad. Para Moxon, primero se deben imprimir las letras negras y posteriormente las rojas. Op. cit. pp. 328-329 
Una vez que el pliego había sido impreso por los dos lados se procedía a su secado, ya que para poder imprimir habían sido ligeramente humedecidos. Esto se hacía colgando los pliegos en una especie de tendedero, un "lugar de secado" lo denomima Moxon, ${ }^{407}$ en donde el proceso también implicaba cierto cuidado para no estropear los pliegos impresos y dar un orden que servirá después. Cuando los pliegos estaban secos, tiempo de espera que siempre variaba, se realizaba el alzado para construir cada ejemplar de una edición, tomando cada pliego en el orden que le correspondía. ${ }^{408}$ A continuación, y sin encuadernar, la producción era entregada al librero o editor, con lo que terminaban las labores de los talleres de imprenta y se ponían en marcha los mecanismos de distribución.

Como se puede advertir, el impresor y los operarios del taller también debían tener "ciertas habilidades para los negocios y la suficiente cultura y visión comercial para decidir que imprimirán”. ${ }^{409}$ Emprender y realizar una impresión es un negocio con riesgo económico que puede funcionar o fracasar. No son pocas las noticias sobre deudas, acreedores y quiebres en los talleres de impresión. Sin embargo, sabemos pocas cosas sobre estos hombres y mujeres como para retratarlos con cierta certeza. "Esta falta de datos concretos puede llevar a la tentación de generalizar sobre quienes produjeron los libros antiguos que manejamos diariamente", ${ }^{410}$ pero pese a esto no debemos olvidar que la imprenta era un negocio con provecho económico que requería una importante inversión. ${ }^{411}$

Hasta donde se sabe, en los talleres de imprenta se realizaban dos formas cada día con una tirada diaria — la jornada - de mil quinientos

407 Joseph Moxon. Op. cit. pp. 345-347

408 Es decir de acuerdo a las signaturas empleadas en la impresión de una obra.

409 María del Mar Fernández Vega. Op. cit. p. 408

410 Clive Griffin. "La carrera del impresor en la Edad Moderna: Pierre Regnier, peripecias da un impresor en la Barcelona del siglo XVI". La memoria de los libros: estudios sobre la bistoria del escrito y de la lectura en Europa y América, bajo la dirección de Pedro M. Cátedra \& María Luisa López-Vidriero. Salamanca: Instituto de Historia del Libro y de la Lectura, 2004. T.1, p. 383.

$411 C f r$. Lucien Febvre y Henri-Jean Martin. La aparición del libro. $3^{\text {a }}$ ed. México: FCE, 2005. pp. 119-141. 
pliegos. ${ }^{412}$ Este es el estimado para la producción de un taller normal, ya que de otra manera, "sólo empresas de envergadura podían afrontar los costos de grandes tiradas y realizarlos en talleres dotados de los elementos para una numerosa y rápida producción" ${ }^{413}$ Imprimir libros antiguos no era una empresa fácil, desde el establecimiento del taller, la obtención y mantenimiento de una clientela confiable, una producción estable y, por supuesto, que todo ese esfuerzo se pudiera transmitir a los herederos.

Ahora bien, la certeza que podemos tener sobre el número de ejemplares que conformaron una edición - aparentemente más de mil después del siglo $X V^{414}$-, está determinada por la localización del contrato de impresión entre un autor y el impresor, o la noticia puntual en un documento histórico. Lo indudable es que actualmente conservamos solamente restos de ese número de ediciones. En ocasiones, contamos con suficientes ejemplares como para analizar variantes y definir peculiaridades, pero en la gran mayoría de los casos sólo tenemos escasos testimonios de la edición de un libro antiguo.

Por esa razón, no debemos olvidar que

la comprobación directa de este tipo de material, ayuda a comprender determinados aspectos que no son fáciles de seguir dada nuestra percepción actual, tan diferente, de la estructura del libro. Se nos ha dicho desde diferentes ámbitos, que durante este [...periodo] es cuando adquiere la forma en la que le conocemos; pero eso es bastante relativo. ${ }^{415}$

Como veremos, la presentación final de los libros antiguos, tendrá transformaciones importantes entre el original manuscrito entregado

412 Jaime Moll (2000). Op. cit. p. 24 y Julián Martín Abad (2005). Op. cit. p. 30

413 Jaime Moll. "Plantino, los Junta y el privilegio del Nuevo Rezado". Simposio Internacional sobre Cristóbal Plantino, edición a cargo de Hans Tromp y Pedro Peira. Madrid: Universidad Complutense, 1990. p. 9

414 Lucien Febvre y Henri-Jean Martin. Op. cit. p. 253

415 Marías Milagros Ronco López. Op. cit. p. 29 
por el autor a un impresor, que son necesariamente atribuibles a los operarios del taller de imprenta. ${ }^{416}$

Ahora bien, las noticias específicas que tenemos sobre las prensas novohispanas - como maquinarias - son escasas y están dispersas en los numerosos estudios dedicados a la imprenta, los impresores y los impresos en la Nueva España. ${ }^{417}$ También contamos con algunas noticias bibliográficas y documentales que se han encontrado, como la que hemos presentado páginas atrás del siglo XVIII. Sin duda en su gran mayoría se trata de información relacionada con los primeros impresores del siglo XVI que llegaron al territorio americano, aunque no sea tan específica como para determinar qué tipo de prensas ${ }^{418}$ eran pero sí para darnos una idea cercana del tipo de material con el que contaban.

La primera prensa en la Nueva España y sus aparejos fueron proporcionados por Cromberger a Juan Pablos, como se puede deducir del contrato celebrado entre ambos en $1539 .{ }^{419}$ Los tipos traídos de España fueron góticos de Canon y Misal en diferentes tamaños ${ }^{420}$ hasta

416 Cfr. Sonia Garza Merino. "La cuenta del original". Imprenta y crítica textual en el Siglo de Oro, estudios publicados bajo la dirección de Francisco Rico. Valladolid: Universidad. Centro para la Edición de los Clásicos Españoles, 2000. p. 66

417 Una relación interesante de los documentos conservados o registrados, que están relacionados con los impresores del siglo XVI se encuentra en Joaquín García Icazbalceta. Op. cit. pp. 42-55.

418 Se sabe que desde el siglo XVI el tornillo de madera en la prensa fue sustituido por otro de metal. Los grabados antiguos han permitido identificar tres tipos de prensas: leonés, alemán del norte y flamenco. La lionesa fue la que se adoptó en España. Para el siglo XVII se introdujeron mejoras en la que se denominó como prensa holandesa, ya que fue elaborada en Holanda por Willem Janszoon Blaeu (el que ya nos había mencionado Joseph Moxon). En 1795 hay mejoras para una prensa prácticamente metálica, realizadas por Lord Stanhope en Londres. Lucien Febvre y Henri-Jean Martin. Op. cit. pp. 69-70.

419 La transcripción de este documento se encuentra en Agustín Millares Carlo y Julián Calvo. Juan Pablos: primer impresor que a esta tierra vino. México: Librería de Manuel Porrúa, [1953]. pp. 179-184. El costo de todo el taller estaba estimado en 100.000 maravedíes. Ibíd. p. 185

420 Valtón en su obra ya citada (1939) analizó los tipos de Juan Pablos, pero Millares Carlo en su texto dedicado a este impresor considera que no fue la forma más apropiada y mejora los datos para determinar tamaños más específicos de los tipos empleados en el taller del primer impresor novohispano. 
la llegada de Antonio de Espinosa como grabador y fundidor de tipos que permite a Juan Pablos introducir tipos romanos y cursivos de varios cuerpos. ${ }^{421}$ Este primer taller contaba con "dos imprentas de ymprimir con letras e ymagenes", ${ }^{422}$ y también hay noticia de una tercera prensa, que fue prestada a Antonio Álvarez ${ }^{423}$ por la viuda de Juan Pablos "con todos los demás aderezos del dicho oficio de impresor y un negro oficial". ${ }^{424}$

Antonio de Espinosa al terminar con el privilegio otorgado a Juan Pablos, que le permitía ser único impresor del territorio, ${ }^{425}$ se convirtió en el segundo impresor novohispano. Espinosa también trajo su prensa y aparejos, entre los cuales se encontraban "magníficos tipos góticos, romanos y cursivos y de notas de canto llano". ${ }^{426}$ El taller de este impresor a su muerte fue heredado a Maria Espinosa, su hija, que se casó con Diego López Dávalos por lo que este impresor adquirió todos los instrumentos y maquinaria del taller de Espinosa. María volvió a hacerse cargo del taller a la muerte de su esposo en 1612.

Todo el material del taller de Juan Pablos fue alquilado a su viuda por Pedro Ocharte entre 1562 y 1564, incluyendo las dos prensas, tipos, ramas viñetas y un esclavo negro. ${ }^{427}$ Entre los tipos había tres cuerpos góticos y quince de romano y cursivo. ${ }^{428}$ El matrimonio de Ocharte con María de Figueroa, la hija de Juan Pablos, lo convirtió

421 Agustín Millares Carlo y Julián Calvo. Op. cit. pp. 31-34.

422 Alexandre Stols. Antonio de Espinosa: el segundo impresor novobispano. México: UNAM. Instituto de Investigaciones Bibliográficas, 1989. pp. 7 y 21

423 Se conoce sólo un impreso de este impresor en 1563. Una persona con el mismo nombre es mencionada como oficial de imprenta, en la cédula real que autoriza a Antonio de Espinosa a ejercer el oficio de impresor en la Nueva España. Ibíd. p. 10

424 José Toribio Medina. Op. cit. T. 8, p. 387.

425 Hay que recordar que este tipo de privilegio no se le concedía a todos los impresores sino a algunos y en circunstancias muy especiales. El privilegio de impresión no se refiere al taller, se trata de una consideración especial y siempre por tiempo determinado que se da a un autor o impresor.

426 Alexandre Stols. Op. cit. p. 13

427 Alexander Stols. Pedro Ocharte: el tercer impresor mexicano. México: UNAM. Instituto de Investigaciones Bibliográficas, 1990. p . 7

428 Ibidem. 
aparentemente hacia 1565 en propietario del taller que alquilaba. ${ }^{429}$ Así se convirtió formalmente en el tercer impresor novohispano y, lamentablemente en el primero en ser juzgado y castigado por la Inquisición entre 1572 y $1574,{ }^{430}$ Ocharte vuelve a imprimir en 1584 y se cree que esta actividad duró hasta $1592,{ }^{431}$ fecha en que probablemente muere. Melchor Ocharte, ${ }^{432}$ que probablemente era su pariente, imprimió entre 1599 y 1601 en el Convento de Tlalelolco. La prensa de Ocharte ya estaba localizada ahí desde 1597,433 pues el taller había sido trasladado por su viuda María de Sansoric (segunda esposa, después de María de Figueroa). Su hijo Luis imprimió en esta ubicación hacia 1600.

No hay que olvidar que Cornelio Adriano César había sido confinado precisamente en Tlatelolco, después de ser juzgado por luterano hacia 1598 y sus bienes fueron confiscados por la Inquisición. ${ }^{434}$ Cornelio Adriano intentó abrir una imprenta en Coatitlán en 1597 con un socio flamenco de nombre Guillermo Enríquez, ${ }^{435}$ quién supuestamente lo delató. En la información inquisitorial que se conserva de Cornelio Adriano, este se declara como "impresor de libros" pero debido a su trágico destino sólo puedo ser operario de prensa - como cajista y prensista-. De su estancia y labor en Tlalelolco se conservan testimonios impresos, que han servido para documentar su relación con otros impresores como los Ocharte (Pedro, la viuda, Melchor y Luis) hasta 1602 que fue liberado. A partir de esta fecha se relaciona con otros impresores. ${ }^{436}$

429 Ibíd. p. 9

430 Ibíd. pp. 11-21

431 José Toribio Medina. Op. cit. T.1, p. LXXXIX

432 Se cree que Melchor vendió la imprenta a López Dávalos. Alexandre Stols (1989). Op. cit. p. 22

433 Emilio Valtón (1935). Op. cit. pp. 201-202.

434 José Toribio Medina. Op. cit. T. 1, p. CXIX

435 Emilio Valtón (1935). Op. cit. p. 195

436 Existe un trabajo dedicado a tan singular personaje de Juan Pascoe, Cornelio Adrián César, impresor en la Nueva España, 1597-1633. México: Redacta y el Taller Martín Pescador, 1992, que lamentablemente no hemos podido obtener. El libro está citado en la nota 8, de María Isabel Grañén Porrúa. "Francisca Flores y su imprenta". Texto disponible en http://www.adabi-ac.org/investigacion_libro_ant/articulos/paginas/04art_igp01.htm [Consulta: diciembre de 2010] 
El cuarto impresor, Pedro Balli, tuvo a cargo la prensa de Espinosa durante 25 años, ${ }^{437}$ y también compró parte del material de la imprenta de Pedro Ocharte. A pesar de esto, se cree que la prensa y el equipo no eran considerables por lo que los herederos se quedaron con un taller de poca monta. ${ }^{438}$ Medina considera que la prensa de Balli no vino de España sino que éste adquirió la de Ocharte cuando el taller estuvo parado. ${ }^{439}$ Como se sabe, cuando Ocharte fue encarcelado, su taller no paró totalmente pues tenía compromisos adquiridos: en 1572 uno de sus oficiales debía terminar un trabajo. Además Ocharte se asoció con Espinosa en 1576 y con Ricardo en 1578 para poder concluir otros trabajos. Balli comenzó a imprimir en 1574, el mismo año que terminaba el proceso de Ocharte, si adquirió la prensa de éste ¿con qué maquinaria e instrumentos trabajó Ocharte a partir de 1584? Pedro Balli sí se asocia con la viuda de Ocharte a partir de 1594.

El quinto impresor en el territorio novohispano, Antonio Ricardo, también debe haber contado con su propia imprenta e instrumentos, puesto que parece haber trabajado en la capital novohispana antes de dedicarse a las impresiones de los jesuitas entre 1577 y 1580 . Para Medina y Valton, este impresor no trajo prensa sino que debió llegar a petición de otros impresores. ${ }^{440}$ Si suponemos que tenía prensa propia, financiada o no por los jesuitas, es la que trasladará a Lima en 1579 cuando Antonio Ricardo decide mudarse a ese territorio a ejercer su actividad impresora. Sus obras se han caracterizado por unos tipos cursivos que se convirtieron en un estilo tipográfico que desapareció de las prensas novohispanas con su partida. ${ }^{441}$

El último impresor del siglo XVI, sexto de la relación, es Enrico Martínez, quién adquirió la prensa y los instrumentos de Cornelio

437 María Isabel Grañen Porrúa. "El ámbito socio-laboral de las imprentas novohispanas. Siglo XVI”. Anuario de Estudios Americanos, núm. 48 (1991). pp. 57-58

438 Alexandre Stols (1989). Op. cit. p. 21

439 José Toribio Medina. Op. cit. T. 1, p. XCI. Este autor también dice que el taller de Ocharte estuvo parado durante siete años, mientras que Stols opina que ocho.

440 José Toribio Medina. Op. cit. T. 1, p. XCIII y Enrique Valton (1935). Op. cit. pp. 187-188.

441 Alexander Stols (1990). Op. cit. p. 22 
Adriano César ${ }^{442}$ en 1599. También se ha escrito que Martínez debió contar con material de imprenta que sólo completó con el de Cornelio Adriano. ${ }^{443}$ Enrico Martínez no fue solamente impresor, también fue un hombre de ciencia que realizó el desagüe del valle de México, intérprete del Santo Oficio y autor de varias obras, algunas de las cuales imprimió en su taller. La continuidad de este taller se dio con su hijo Juan Ruiz entre 1613 y $1675,{ }^{444}$ y contaba con "una prensa, un buen número de matrices, moldes, punzones y herramientas diversas" ${ }^{445}$ Se tiene conocimiento que el taller de Juan Ruiz contaba con "dos prensas de madera con lo necesario, y la de una de ellas corriente y moliente, y la otra descompuesta que no se puede trabaxar en ella", por la transcripción que se realizó del inventario de sus bienes en $1675 .{ }^{446}$

Diego López Dávalos trasladó su taller temporalmente al Convento de Tlatelolco en 1605, se trata de la prensa y materiales de Antonio de Espinosa, que aumenta con parte de los de Juan Pablos y Pedro Ocharte. Puesto que parece haber comprado el taller de Ocharte que contaba con piezas de Pablos. ${ }^{447}$ Se cree que el taller de López Dávalos pasó a manos de Diego Garrido hacia $1620 .{ }^{448}$

Mas allá de las relaciones personales que se han podido comprobar entre estos impresores y sus familiares, se ha dicho que solían

442 Se tiene noticia de que era holandés y que trabajó como oficial en el taller de Cristobal Plantin,

443 Francisco de la Maza. Enrico Martínez. Cosmógrafo e Impresor de Nueva España. México: UNAM, 1991. pp. 13, 34-35.

444 José Toribio Medina. Op. cit. T. 1, p. CXXI.

445 Francisco de la Maza. Op. cit. p. 33

446 Francisco Pérez Salazar. Dos familias de impresores mexicanos del siglo XVII. Memorias de la Sociedad Científica Antonio Alzate, T. 43 (1925). México: Talleres Gráficos de la Nación, pp. 504-507. Grañen considera que esta es "la primera prensa tipográfica hecha en el Nuevo Mundo”. María Isabel Grañen Porrúa. "Los orígenes de la imprenta en Oaxaca". La Historia de la imprenta en Oaxaca. Oaxaca: Universidad Autónoma Benito Juárez de Oaxaca. Biblioteca Francisco de Burgoa, 1999, p. 11

447 Elvia Carreño Velásquez. "Diego López Dávalos y la tipografía mexicana del siglo XVI". Texto disponible en http://www.adabi-ac.org/investigacion_libro_ ant/articulos/paginas/05art_ecv04.htm [Consulta: marzo de 2009]

448 José Toribio Medina. Op.cit. T. 1, p. CXIII. 
intercambiar material de prensa pues "se puede observar que muchas planchas o grabados se pasaron de una casa a otra para decorar algún libro". ${ }^{449}$ Pese a lo anterior es más probable pensar que esa transferencia de material de imprenta se debiera a los lazos familiares establecidos, a las compras o alquiler de ese material y en ocasiones a las asociaciones comerciales ${ }^{450}$, más que a un préstamo. ${ }^{451}$

Sobre los operarios tenemos también pocas noticias. ${ }^{452}$ En la imprenta de Juan Pablos trabajaron Gil Barbero como oficial, ${ }^{453}$ Tomé Rico como prensista (o tirador), ${ }^{454}$ el componedor Juan Muñoz, ${ }^{455}$ y Antonio de Espinosa como fundidor y cortador de letras. ${ }^{456}$ En el taller de Ocharte, trabajaron Cornelio Adriano César como componedor, Pedro Balli como corrector y Juan Ortiz como grabador. ${ }^{457}$ En el taller de López Dávalos trabajaron nuevamente Cornelio Adriano y Juan Ruiz, ${ }^{458}$ también Cornelio trabajó con Jerónimo Balli entre 1608 y 1610, después con la viuda de Pedro Balli hasta 1614, y después con la

449 María Isabel Grañen Porrúa (1991). Op. cit. p. 66. Esta autora incluso afirma que intercambiaron letrerías y prensas. Ibíd. p. 69

450 Magdalena Chocano Mena. "Imprenta e impresores de Nueva España 15391700: límites económicos y condiciones políticas en la tipografía colonial americana”. Historia Social, núm. 23 (1995), p. 5.

451 Recordemos que entre los impresores se denunciaban entre ellos, situación que no puede explicar un ambiente tan amigable como para compartir material de la imprenta.

452 Para conocer la historia de otros operarios, es recomendable la lectura de Clive Griffin. Oficiales de imprenta, herejía e inquisición en la España del siglo XVI. Madrid: Imprenta Artesanal Ollero \& Ramos, 2009.

453 Agustín Millares Calvo y Julián Calvo. Op. cit. pp. 187-189 y María Isabel Grañen Porrúa. Op. cit. p. 69

454 Agustín Millares Calvo y Julián Calvo. Op. cit. pp. 195-198

455 Alexandre Stols (1989). Op. cit. p. 7 y 21, también María Isabel Grañen Porrúa. Op. cit. p. 56

456 Agustín Millares Calvo y Julián Calvo. Op. cit. p. 199. Hay noticia de otros dos oficiales tiradores de los que no se menciona su nombre para el año de 1560.

457 María Isabel Grañen Porrúa (1991). Op. cit. p. 70. Juan Ortiz también fue procesado por la Inquisición en 1572

458 Elvia Carreño. Op. cit. Podemos suponer que aquí aprendió el oficio antes de hacerse cargo del taller de su padre Enrico Martinez. 
viuda de López Dávalos hacia $1615 .{ }^{459}$ Pedro Gutiérrez fue cajista en el taller de López Dávalos en $1620,{ }^{460}$ y Diego Gutiérrez trabajó como cajista de Bernardo Calderón, junto a Pedro de Quiñones, ${ }^{461}$ y José de Pineda Ibarra como oficial de Paula de Benavidez (viuda de Calderón). ${ }^{462}$

Por otra parte Juan Francisco Fernández Orozco, Fulano Buitragueño y Lázaro Rodríguez de la Torre fueron oficiales de imprenta con Diego Fernández de León. ${ }^{463}$ El trabajo de tirador, como hemos visto uno de los más pesados en el proceso de impresión, también fue realizado por esclavos negros como Pedro, quién acompañó a Juan Pablos en su viaje a la Nueva España y los de Ocharte ${ }^{464}$ que trabajaban mientras estaba en prisión y que se negaron a realizar sus actividades con la esposa de Ocharte, María de Sansoric. ${ }^{465}$

También tenemos noticia de que el oficio de imprimir era trasmitido mediante aprendices en los talleres, pese a que no se conoce ninguna normativa gremial asociada a los impresores. Es el caso de Diego Alonso, quien a los catorce años entra como aprendiz con Juan Blanco de Alcázar en $1626,{ }^{466}$ y también el de Esteban Álvarez que fue aprendiz de José Bernardo de Hogal hacia $1730 .{ }^{467}$ Otro aspecto importante es el trabajo de las mujeres en la imprenta, un tema que ha generado

459 José Toribio Medina. Op. cit. t. 1, p. CXVIII

460 Ibíd. p. CXXV. Gutiérrez parece haber adquirido el taller de Garrido en 1632.

461 Ibid. p. CXXVI y CXXVIII.

462 José Toribio Medina. Historia de la imprenta en los antiguos dominios españoles de América y Oceanía. Santiago de Chile: Fondo Histórico y Bibliográfico José Toribio Medina, 1958.Tomo II, p. 171. Texto disponible en http://www. cervantesvirtual.com/portal/bnc/index.shtml [Consulta: marzo de 2009]

463 María Isabel Grañen Porrúa. Op. cit., p. 10

464 Alexandre Stols (1990). Op. cit. p. 13

465 Marina Garone "Impresoras novohispanas: un estado de la cuestión". Butlletí de la Reial Acadèmia de Bones Lletres, núm. LI, años 2007-2008 (en prensa). Existe una version preliminar disponible en https://bg.biograficas.com/secciones/docs_complementarios/Garone.pdf [Consulta: marzo de 2009], p. 6

466 Marina Garone. "Diseñadores de la lengua propia: calígrafos indígenas en la Nueva España”. Primer Coloquio Internacional de Lenguas y Culturas Coloniales (en prensa). p. 5 del documento original.

467 Noticia proporcionada por Ken Ward, quien calcula que en 1741 tendría unos 25 años. 
un notable interés en los últimos años, ${ }^{468}$ y del que todavía queda por determinar su participación, formas de aprendizaje, o si meramente fueron gestoras de una empresa familiar.

Sobre los procesos contamos con una información más organizada, ${ }^{469}$ pero referida al siglo XVI. En efecto, no tenemos a la fecha mayor información que pueda ilustrar si hubo cambios sustanciales en los procesos y en los instrumentos de las prensas novohispanas, lo que abre una enorme puerta para la investigación sobre la historia del libro en México. ${ }^{470}$ Ciertamente, los impresos mexicanos del siglo XVI merecen una valoración patrimonial, tanto de los que se conserva más de un ejemplar como de aquellos de los que queda un solo testimonio, pero, sin una comparación exhaustiva de los ejemplares conservados de una edición, será imposible determinar si se produjeron variantes en los procesos de impresión ${ }^{471} \mathrm{o}$ incluso determinar aspectos puntuales sobre los tipos empleados por cada taller. ${ }^{472}$

A la fecha, todo lo que se sabe de los impresores en la Nueva España a partir del siglo XVI es por Medina, que cuenta con una información más

468 Existe una publicación en prensa que compila varios trabajos dedicados a este aspecto: Las otras letras. Mujeres impresoras en la Biblioteca Palafoxiana. Puebla: Secretaría de Cultura. Véase también Marina Garone (2007-2008). Op. cit. y su trabajo "Mujeres y tipografía en la Nueva España". Hibris: Revista de bibliofilia. Núm. 43 (2008), pp. 13-25.

469 María Isabel Grañen Porrúa (1991). Op. cit. pp. 49-94.

470 Marina Garone realizó su investigación para la obtención del Doctorado en Historia del Arte, sobre los tipos empleados en los diversos impresos de lenguas indígenas. Cfr. Historia de la tipografía colonial para lenguas indígenas. México: la autora, 2009. (Tesis de doctorado. Doctor en Historia del Arte. UNAM. Facultad de Filosofía y Letras. División de Estudios de Posgrado)

471 Fernández de Zamora nos ha dejado una importante herramienta para la localización de los ejemplares conservados de los impresos mexicanos del siglo XVI. Pero aún queda por determinar si esas ediciones localizadas se corresponden puntualmente con sus diferentes descripciones bibliográficas elaboradas con anterioridad y por tanto corroborar si la estructura material de los impresos no ha sido alterada con el paso del tiempo. Cfr. Rosa María Fernández de Zamora Los impresos mexicanos del siglo XVI: su presencia en el patrimonio cultural del nuevo siglo. México: CUIB/UNAM, 2009

472 Cfr. Cristóbal Henestrosa. Espinosa: rescate de una tipografía novobispana. México: Designio, 2005, pp. 93-99. 
detallada o por trabajos más genéricos como el de Ernesto de la Torre Villar. ${ }^{473}$ No es un secreto que son pocos los impresores novohispanos, posteriores al XVI, que han atraído el interés de la investigación histórica como para generar trabajos dedicados exclusivamente a sus talleres que permita además contar con información más precisa sobre el funcionamiento de las prensas. Sin embargo, existen excepciones importantes de talleres de impresión novohispanos que debemos mencionar y de las que tenemos noticia: Juan Ruiz, ${ }^{474}$ los Calderón, ${ }^{475}$ la imprenta de la Biblioteca Mexicana ${ }^{476}$, Joseph de Jauregui ${ }^{477}$, la familia

473 Ernesto de la Torre Villar. Breve bistoria del libro en México. México: UnAm. Dirección General de Publicaciones y Fomento Editorial, 1999. pp. 141-1157. No citaremos aquí todos los trabajos que se han publicado sobre diversos aspectos de la imprenta e impresores en la Nueva España, en tanto que no proporcionan información sobre las prensas y los procesos de impresión.

474 Francisco Pérez Salazar. Op. cit.

475 Ken Ward de la John Carter Brown, realiza su tesis de doctorado sobre la dinastía Calderón.

476 La prensa fue traída a la Nueva España por Juan José de Eguiara y Eguren hacia 1753. Ernesto de la Torre Villar. Op. cit. p. 154. Eguiara consideraba que no se contaba en los talleres existentes con el material necesario para la edición de su Bibliotheca Mexicana. Se conoce el tipo de material con el que contaba la prensa de los hermanos Eguiara porque se ha conservado el remate que se hizo de esta en el Archivo General de la Nación de México. En este se mencionan cuatro prensas y luego tres, así como numerosos aparejos para la impresión, pero por esta característica habría que revisar el documento con mayor detalle. Dicho documento fue transcrito en Juan José de Eguiara y Eguren. Bibliotbeca mexicana: Monumenta eguiarense / pról y vers. Española Benjamín Fernández Valenzuela; estudio preliminar, notas, apéndices, índices y coord. gral. Ernesto de la Torre Villar; colab. Ramiro Navarro de Anda. México: UNAM. Coordinación de Humanidades, 1989. Vol. 5, p. 68. En la obra ya citada de Ernesto de la Torre Villar (1999) se dice que esta fue la prensa que adquirió Joseph de Jáuregui.

477 Parte de la historia de esta familia es trabajada por Ana Cecilia Montiel Ontiveros en la Universidad del Estado de México. También se ha dado noticia de otro trabajo relacionado con Jáuregui. Silvia Fernández, "El valor histórico del testamento del Bachiller Josef Fernández de Jáuregui”, Trabajo final del diplomado de Libro antiguo, 2006, inédito. Citado por Marina Garone (2007-2008) Op. cit. p. 13 
Hogal, ${ }^{478}$ la Imprenta del Colegio de San Ildefonso ${ }^{479}$ y los hermanos Zúñiga y Ontiveros. ${ }^{480}$

Los trabajos de Medina también ilustran y documentan asuntos relacionados con las prensas y los operarios de la imprenta en Puebla ${ }^{481}$ Oaxaca, ${ }^{482}$ Guadalajara ${ }^{483}$ y Veracruz. El caso particular de Oaxaca ha sido estudiado con mayor detalle por Isabel Grañén, ${ }^{484}$

478 Hemos encontrado en el Archivo General de la Nación de México el testamento y codicilos de Joseph Bernardo de Hogal en donde se registra una cotización de la prensa y aparejos. "Inventarios, aprecios y avalúos de los bienes que quedaron por la fin y muerte de D. Joseph Bernardo del Hogal, vecino y mercader de libros y dueño de imprenta que fue en esta ciudad de México". Archivo General de la Nación. Ramo Civil. Vol. 148, exp. 1 (1741), fol. 483r. y 489r.

479 Martha Ellen Whittaker. Jesuit Printing in Bourbon Mexico City. The Press of Colegio de San Ildefonso, 174-1767 (Dissertation for degree Doctor of Philosophy in Library and Information Studies. University of California. Berkeley)

480 Véase los trabajos de Arturo Soberón Mora. "Felipe de Zuñiga y Ontiveros, un impresor ilustrado en la Nueva España”. Tempus. Revista de Historia de la Facultad de Filosofía y Letras UNAM. Núm. 1 (otoño de 1993), pp. 51-75; Luis Cordoba Barradas. "La imprenta de Felipe de Zúñiga y Ontiveros en la ciudad de México”. Boletín del Museo Nacional del Virreinato. Nueva época, núm. 16 (enero-febrero 1995), pp. 1-5, Texto disponible en http://mx.geocities.com/ genealogiademexico/ [Consulta marzo de 2009], y Manuel Suárez Rivera. Felipe y Mariano de Zuñiga y Ontiveros: impresores ilustrados y empresarios culturales (1761-1825). México: el autor, 2005. (Tesis Licenciatura en Historia. UNAM, Facultad de Filosofía y Letras).

481 José Toribio Medina. La imprenta en la Puebla de los Ángeles (1640-1821). México: UNAM, Instituto de Investigaciones Bibliográficas, 1991.

482 José Toribio Medina: La imprenta en Oaxaca, Guadalajara, Veracruz, Mérida y varios lugares. (1720-1820). Santiago de Chile, Imprenta Elzeviriana, 1904. Reimpresión en México, UNAM, 1991.

483 El impresor Mariano Valdés contaba con privilegio exclusivo para su imprenta "en varios caxones de moldes de letras y utensilios de ymprenta". Carmen Castañeda García. "La imprenta en Guadalajara y su producción: 1793-1821”. Diccionario de Historia de la Educación en México / coord. Luz Elena Galván Lafarga. México: CIESAS: CONACYT, 2002. Texto disponible en http://biblioweb. dgsca.unam.mx/diccionario/htm/articulos/sec_2.htm [Consulta: marzo de 2009]

484 María Isabel Grañen Porrúa (1999). Op. cit. y también "Francisca Flores y su imprenta". Texto disponible en http://www.adabi-ac.org/investigacion_libro_ ant/articulos/paginas/04art_igp01.htm [Consulta: marzo de 2009] 
como para afirmar que la prensa de esta ciudad se inició con Francisca Flores en 1720 y que fue de Diego Fernández de León (impresor poblano). También nos dice que esta prensa fue la que trajo Juan Pablos de Sevilla, y que el taller se complementó con el material de Juan Ruiz. ${ }^{485}$ De esta manera algunos tipos del siglo XVI volvieron a emplearse en el siglo XVIII, e incluso hasta principios del siglo XIX. ${ }^{486}$

Esta brevísima relación - de tan compleja compilación- de lo que se sabe sobre las prensas novohispanas, muestra que la necesidad de la comparación tipográfica de los impresos de la Nueva España debe relacionarse con la documentación histórica conservada y la búsqueda de nuevas fuentes. Sólo así podremos determinar aspectos más puntuales sobre las prensas, operarios y procesos de impresión y características materiales de los impresos producidos ${ }^{487}$ durante el periodo novohispano.

De esta forma podríamos confirmar que las prensas se corresponden con los tamaños de papel y los formatos que se han establecido estaban en uso desde el siglo XVI, ${ }^{488}$ o también determinar con mayor certeza qué tipo de prensas y de aparejos fueron traídos desde la península ibérica para surtir a los impresores novohispanos. A la fecha no sabemos si en determinado momento existieron condiciones y posibilidades para construir una prensa en el territorio novohispano, o si el costo de la maquinaria y sus instrumentos justificaba tal inversión. Además, no debemos olvidar que todo el material necesario para

485 Ibíd. (1999), p. 8. La autora dice que esto lo ha declarado Juan Pascoe.

486 Por esta razón Isabel Grañen supone que las matrices y punzones de Enrico Martínez se encontraban en Oaxaca y que existió una persona que sabía utilizarlos para la producción de tipos. Ibíd. pp. 20 y 22.

487 Falta todavía por determinar la participación de los impresores novohispanos en la publicación de los bandos y ordenanzas, así como lo que se corresponde con los denominados impresos menores y las equivocadamente llamadas "tesis universitarias", que parecen ser más bien invitaciones a los eventos académicos. Cfr. Francisco de la Maza. Op. cit. p. 38

488 Se ha afirmado que estos eran: para folio $210 \mathrm{~mm}$. de ancho por 315 de alto, para cuarto $157 \mathrm{~mm}$. de ancho por 210 de alto y, para octavo $105 \mathrm{~mm}$. de ancho por 157 de alto. Cfr. Alexadre Stols (1990). Op. cit. p. [52] 
imprimir como el papel, ${ }^{489}$ prensas, tipos y otros materiales necesarios para la cultura escrita, fueron registrados en los navíos, ${ }^{490}$ y esta parte es un pendiente más que hace fascinante toda búsqueda sobre el arte de la imprenta en la Nueva España.

\subsection{Un aspecto previo a considerar: edición, emisión y estado}

Ahora bien, una vez que se ha concluido el proceso de impresión se ha terminado la edición de un libro que se entrega en "rama", es decir, sin encuadernar. La edición, por tanto, es el conjunto de ejemplares de una obra que ha sido impreso sustancialmente con la misma composición tipográfica. ${ }^{491}$ En este sentido existen casos de varias ediciones de una misma obra, en diferentes momentos históricos, que parecen hechas con la misma composición. Pero no siempre es así, por ejemplo, este impreso novohispano que aquí mostramos en dos de las ocho ediciones antiguas que se realizaron entre 1699 y 1820. Como se puede apreciar en las imágenes, los impresores conservan prácticamente la misma información tipográfica en líneas similares dando una idea de continuidad. ${ }^{492}$

489 Por ejemplo determinar quiénes eran los proveedores de papel de los impresores novohispanos y cuáles eran sus circuitos comerciales. A la fecha se conoce tres trabajos que aportan algunos datos, pero que no logran reflejar las circunstancias de aprovisionamiento de un elemento fundamental para el trabajo de las prensas. Estos son Ramón Mena. Filigranas o marcas transparentes en papeles de Nueva España, del siglo XVI. México: Secretaria de Relaciones Exteriores, 1925, Hans Lenz. Historia del papel en México y cosas relacionadas, 1525-1950. México: Miguel Ángel Porrúa, 1990 y, María Cristina Sánchez Bueno de Bonfil. El papel del papel en la Nueva España. México: INAH, 1993.

490 Pedro Rueda Ramírez. "La circulación de menudencias impresas en las redes atlánticas (siglos XVI-XVII)”. Cultura escrita E sociedad. Núm. 2 (2006), pp. 53-76.

491 E.W. Padwick Bibliographical metbod: an introductory survey. Cambridge: James Clarke \& Co., 1969. p. 21

492 Aunque la información anotada de portada indica que se trata de la edición de 1699, se trata de un error de indetificación, pues hemos confirmado que es un ejemplar de la edición de 1724. Cfr . Idalia García. "Entre plúteos y sombras: un recorrido por la materialidad de los impresos novohispanos". Simposio el libro en el mundo bispánico: nuevas tendencias y direcciones (En dictamen). 


\section{$45-$ \\ EXALTACION}

DE LA DIVINA MISERICORDIA

EN LA MILAGROSA RENOVACION

DE LA SOBERANA IMÁGEN

D焉 CIISTO

SEÑOR NUESTRO CRUCIFICADO,

Que se venera en la Iglesia del Convento de Señor San José de Religiosas Carmelitas Iescalzas de ia antigua fundacion de esta ciudad de Mexico,

QUE CONSAGRA

Á LA MADRE DE LA MISERICORDIA MARIA SANTISIMA DE LOS DOLORES, Of HISTORTICA

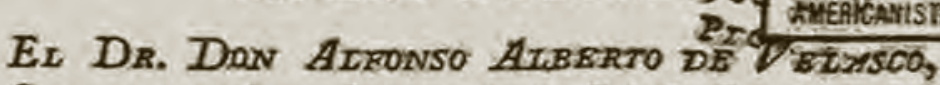
Car a mas antiguo de esta santa Iglesia Catedral Metropolitana, Abogado de la Real Audiencia y de presos del santo Oficio de la Inquisicion de esta Niveva España $y$ su Consultor, y del Colegio Semuinario de diabe santa Iglesia, Capellan del mismo Convento:

Se ballará en la portería de dicho Convento.

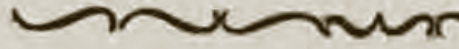

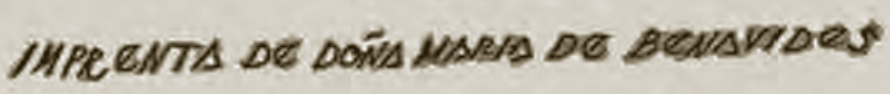




\section{EXALTACION}

DE LA DIVINA MISERICORDIA

EN LA MILAGROSA RENOVACFON

DE LA SOBERANA IMAGEN
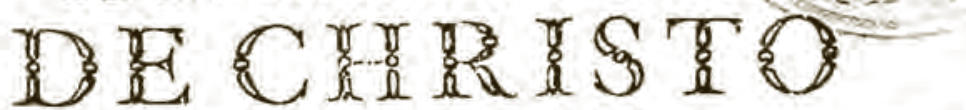

$$
\begin{aligned}
& \text { SENTOR NUESTRO } \\
& C R U C I F I C A D O \text {, }
\end{aligned}
$$

ASOCIRCION

HISTORIC.

AMEF, Lils:

QUE SE VENERA

En la Iglesia del Convento de Señor San JOSEPH de Religiosas Carmelitas Descalzas de la Antigua

Fundacion de esta Ciudad de México.

QUE CONSAGRA

A LA MADRE DE LA MISERICORDIA

MARIA SANTISIMA

DE LOS DOLORES,

ex Dr. D. Alfonso Alberto de Velasco, Cura mas Antiguo dz esta Santa Iglesia Catedral Metropólitana, Abogado de la Real Audiencia, y de Presos del Santo Oficio de la Inquisicion de esta Nueva España, $y$ su Consultor, $y$ del Colegio Seminario de dicha Santa Iglesia, Capellan del mismo Convento.

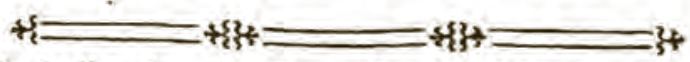

Se hallarí en la Porteria de dicho Comoento.

Reimpresa en Mérico, en la Oficina de los Herederos del Lic. D. Joseph de Jauregui, Callo de S. Bernardo. Año de I79o. 
Idealmente todos los ejemplares de una edición deberían ser idénticos, en realidad, lo son raramente ${ }^{493}$ porque existen variantes en la edición que conocemos como emisiones y estados. Estas variantes forman parte del conjunto de una edición antigua, pero son alteraciones producidas en la composición de la que son resultado, ya sea en los procesos de imposición o de tirada, modificando la forma primaria.

Así, se entiende por emisión un cambio intencional en la forma que afecta a un cierto número de ejemplares dentro de una edición. Ejemplos de estos casos pueden ser ejemplares de una misma edición que presentan distintas portadas, ya sea por decisión de venta, o porque se ha rejuvenecido una edición al modificar solamente la portada. Por su parte, el estado es una modificación improvisada posiblemente accidental que se ha dado en el proceso de producción, y que igualmente afecta a un cierto número de ejemplares de la edición. Estos casos pueden ejemplificarse con los ejemplares de una edición, a los que se les ha introducido alguna corrección sobre un error detectado cuando ya se ha realizado una parte de la edición o en los cuales se ha sustituido o agregado un elemento.

Las variantes representan uno de los problemas más puntuales de identificación en el trabajo bibliográfico y, por ello, se dificulta el establecimiento de una regla única para caracterizarlas. ${ }^{494}$ La principal diferencia que radica entre la emisión y el estado es la modificación del texto de la obra, ya

que en la primera el texto no sufre alteración. Las distintas emisiones de una edición presentan exactamente el mismo texto, si no concurren diferentes estados. Por el contrario la existencia de distintos estados revela variaciones textuales que pueden ser de gran importancia. 495

493 Lorenzo Baldacchini (1982). Op. cit. p. 77

494 Para acercarse a la complejidad de estas variantes puede revisarse las obras de Roland B. McKerrow. Op. cit. p. 198-246; Fredson Bowers. Op. cit. pp. 65-148. Phillip Gaskell. Op. cit. pp. 393-396; Giuseppina Zappella. Op. cit. pp. 271-280.

495 Jaime Moll (1989). Op. cit. p. 171 
Efectivamente tenemos conocimiento de estas particularidades en las ediciones antiguas, precisamente por la revisión y comparación de ejemplares conservados de una misma edición. ${ }^{496}$ Pero a pesar de la importancia que adquieren esas variantes, la mayor parte de las bibliografías o catálogos de libros antiguos no suelen hacer mención de su existencia. Por el contrario, solamente los estudiosos de la transmisión literaria y de la historia cultural consideran y reportan la existencia de emisiones y estados de una edición.

Debemos considerar que

el ejemplar que nosotros tenemos en las manos forma parte de la tirada de una edición y por ello nos ofrece el mismo texto que los restantes, pero tal igualdad no implica identidad absoluta, milímetro a milímetro, entre todos. Encontraremos siempre, prácticamente siempre, variantes como si fuese algo inevitable. ${ }^{497}$

De ahí que la comprobación entre ejemplares de una misma edición sea la forma más precisa para descubrir las variantes, pero esta tarea implica la revisión detallada de cada una las partes de un ejemplar.

También debemos recordar que por la existencia de las variantes, es relevante el concepto de copia ideal desarrollado por la bibliografía material de procedencia anglosajona. Por este concepto se define al "ejemplar idealmente perfecto de la edición original" ${ }^{498}$ que se construye precisamente a través de la descripción bibliográfica. Pero implica el conocimiento y revisión de todos y cada uno de los ejemplares conocidos de una edición, incluyendo las posibles emisiones y estados. 499

De ahí que podamos comprender cómo la descripción bibliográfica detallada se elabora progresivamente, porque la noción del ejemplar

496 Para precisar esta problemática es conveniente consultar a Giuseppina Zappella. Op. cit. pp. $277-279$.

497 Julián Martín Abad (2004a). Op. cit. p. 13

498 Fredson Bowers. Op. cit. p. 149. Para conocer mejor este concepto es recomendable la lectura de G. Thomas Tanselle. "The concept of ideal copy". Studies in bibliograpby, 33 (1980). pp. 18-53.

499 Cfr. Roland B. McKerrow. Op. cit. pp. 202-205 
teórico es un instrumento que permite analizar las anomalías propias en un sólo ejemplar examinado y sin las divergencias entre más ejemplares. Pero el examen de todos los ejemplares conocidos representa un ideal un poco mítico. ${ }^{500}$ En mi opinión es necesario realizar la descripción detallada de un ejemplar concreto, para estar en posibilidad de comparar éste con los otros semejantes y, entonces, poder interpretarlo como objeto histórico y teórico.

500 Jean-François Gilmont. Le livre E ses secrets. Gèneve: Université Catholique de Louvain: Librairie, 2003. pp. 388-389. 



\title{
6. Conocer para describir: la estructura material del libro antiguo
}

\author{
El carácter dual del libro exige, por ende, \\ un enfoque que tenga en cuenta tanto los \\ paradigmas socioculturales que ban \\ permeado la realidad y la valoración \\ social del libro, como también las \\ características que ba tenido en el pasado \\ la actividad editorial en su ciclo de \\ producción, distribución, circulación y
}

consumo

Bernardo Subercaseaux (1993)

\begin{abstract}
C omo hemos podido apreciar en capítulos anteriores, ha sido constante el desarrollo de la práctica bibliográfica como conocimiento material del libro antiguo, y ha contribuido con sus aportaciones a la construcción de la valoración cultural de ese mismo libro, tanto en su condición material como en su condición como elemento de la historia cultural. De esta manera, la identificación de un libro antiguo mediante la práctica de la bibliografía material se ha convertido en un puente de conocimiento necesario entre ese libro y otras disciplinas como la historia o la literatura.

Esta descripción no es un fin en sí mismo, sino una forma fiable para identificar la fuente original de estudio desde dos puntos de vista. El primero, diferencia a esa fuente de otras semejantes y, por tanto, permite relacionar los libros conservados de una misma edición. La segunda posibilita ubicar e identificar, como parte de una colección específica, a un libro antiguo para posteriores estudios. Por esta perspectiva la descripción puede coadyuvar al control patrimonial de la producción bibliográfica de una época del pasado, tanto para la investigación histórica como para la institución de custodia.
\end{abstract}


Sin embargo, como hemos apreciado, en México esta práctica de descripción para los libros antiguos no ha logrado consolidarse como un territorio propio en el conocimiento humanístico que permita dar continuidad a una tradición bibliográfica nada despreciable. Es decir una tarea que contribuya a soportar las necesidades de control patrimonial emprendidos por varias instituciones, al tiempo que se consolida el conocimiento sobre estos libros de la investigación especializada.

Frente a esta realidad palpable resulta interesante que la falta de interés en la Bibliografía Material se contraste, precisamente, con el ingente número de ejemplares que conforman el patrimonio bibliográfico conservado en las instituciones públicas y privadas del país. Un legado del pasado, superior al de otros territorios latinoamericanos, que no ha sido contabilizado ni caracterizado adecuadamente mediante el inventario y el registro de los libros antiguos.

Esta falta de interés mexicano podría explicarse en la devaluación de la práctica bibliográfica en el mundo académico y, por supuesto, en la valoración que se ha hecho sobre esos libros como parte de un legado histórico. Desde nuestro punto de vista esta comprensión, que involucra aspectos metodológicos y jurídicos, necesariamente afectará el desarrollo del conocimiento de la historia del libro y de las bibliotecas del periodo novohispano. Un desarrollo que también se verá reflejado en la historiografía de ese mismo periodo y en toda producción de conocimiento que tenga por protagonista a ese libro antiguo. ${ }^{501}$

Por otra parte también hemos apreciado que esa falta de conocimiento sobre el libro antiguo, como objeto material y como objeto

501 Actualmente esta pregunta de investigación no ha producido resultados concretos. Sin embargo es necesario considerar por qué la fuente original ha sido desplazada del conocimiento histórico, desde el cual se ha privilegiado el empleo de fuentes secundarias que han trascrito documentos históricos originales o registrado fuentes bibliográficas para determinar conclusiones sobre la lectura o la historia cultural del periodo novohispano. Cfr. Idalia García. "Cultura escrita en la Nueva España" [Investigación en desarrollo]. 
histórico, favorece el desarrollo de la bibliografía negativa ${ }^{502}$ y, por esta misma condición, no contribuye en nada a favorecer su lugar en el mundo académico, ni tampoco su utilidad para el control patrimonial del legado bibliográfico colonial. Estamos convencidos que los efectos nocivos de la práctica bibliográfica, provocadas por la desidia o desinterés, pueden contrarrestarse en gran medida con el conocimiento de la Bibliografía Material y de sus aportaciones metodológicas.

Ciertamente este conocimiento del objeto presupone también el de la misma producción de los libros y del mundo cultural del cual son resultado, por lo cual este tipo de conocimiento no debería estar ausente en la interpretación catalográfica de los elementos de un libro antiguo, ni tampoco en las contribuciones de la literatura y la crítica textual. El soporte de la Bibliografía Material permitiría a las instituciones de custodia que la catalogación de sus colecciones (desarrollada prioritariamente por bibliotecarios) sirva no solamente para identificar, sin equívocos, cada uno de los ejemplares conservados de las ediciones antiguas, sino también para garantizar la preservación de esos ejemplares a largo plazo.

Efectivamente

las bibliografías descriptivas son almacenes de información sobre las prácticas de la imprenta y las tendencias tipográficas del pasado, y la importancia de esa información para la historia de la lectura [del libro, y de las bibliotecas] está creando un nuevo público, ${ }^{503}$

que demanda instrumentos de control y consulta fiables a largo plazo que no requieran frecuentemente validar la información que contienen.

502 Así la denomina Julián Martín Abad (2004a). Op. cit. p. 142 y debe entenderse por ésta la práctica bibliográfica que se realiza sin considerar el trabajo precedente, tanto de los repertorios y catálogos como de las aportaciones metodológicas, que no favorece el conocimiento del libro antiguo descrito, porque no contribuye a mejorarlo sino por el contrario, solamente crea equívocos y confusiones.

503 G. Tomas Tanselle. "Introducción". Fredson Bowers. Op. cit. p. 19 
Por otro lado en la tarea de la investigación, desarrollada principalmente por investigadores y profesores universitarios, el conocimiento de la Bibliografía Material permitiría realizar una lectura más cercana a lo que representan los datos de los repertorios y catálogos anteriores, pero también les permitiría identificar en los catálogos modernos la fiabilidad y precisión del registro que se consulta. Estamos plenamente convencidos de que la correcta identificación de los libros antiguos, sea catalográfica o bibliográficamente, no tienen mayor sentido que apuntalar su condición patrimonial y, por tanto, garantizar al futuro su propia lectura y valoración sobre las fuentes originales.

Pero la tarea de registro bibliográfico, cuya mayor nobleza es asegurar la transmisión de ese legado entre generaciones, no puede realizarse sin una mínima formación básica que permita identificar los elementos que se registran para comprender por qué se describen de una manera o de otra. Describir bibliográficamente un libro antiguo puede ser complicado, tanto más enseñar cómo hacerlo. Nuestra intención aquí es mostrar un modelo de descripción bibliográfica, que hemos aplicado basándonos en las aportaciones de la Bibliografía Material, de la tipobibliografía española, en la tradición que nos antecede y en las consideraciones patrimoniales sobre el libro antiguo.

Por ello conviene indicar aquí que la intención no es reiterar información relevante sobre la estructura y características del libro antiguo, así como sus formas de producción, básicamente porque otros lo han hecho ya de mejor manera. Al contrario, pretendemos mostrar cómo algunos elementos de esos libros, en tanto particularidades de un objeto, se pueden (y deben) describir para construir un registro que ayude a identificar y diferenciar a ese mismo objeto de otros semejantes, en su condición de objeto material como en su condición de objeto histórico parte de un legado específico. Pero es imprescindible reiterar la necesidad del conocimiento de la bibliografía especializada en esta materia, para acudir a ésta siempre que se requiera profundizar en algún detalle concreto.

\subsection{La descripción bibliográfica: el valor textual}

Ahora bien, por estructura material entendemos el conjunto de partes que componen a estos libros y que lo distinguen de otro tipo de 
impresos. Dicha estructura está básicamente formada por las siguientes partes: la portada, los preliminares, el texto de la obra, las tablas e índices y el colofón. Esta forma material es el reflejo directo de las formas de producción de la época y del desarrollo técnico que la caracterizó.

Podemos también decir que el libro antiguo, al ser un objeto producido de forma manual, presenta una diversidad en la misma estructura de las partes que lo integran. Esta diversidad depende de la forma en que cada taller de impresión resolvió los problemas de producción de una obra específica. En la impresión de un libro se involucran múltiples circunstancias que afectarán directamente al producto esperado. Dichas incidencias estaban determinadas por las formas de producción y por un entramado de regulación legal que el poder político estableció no sólo para controlar la producción del libro, sino también para controlar su circulación en la sociedad. ${ }^{504}$ También la producción de libros se veía afectada por la regulación de las materias primas necesarias para la producción de las obras impresas entre otros factores como los sociales, culturales y políticos.

Por eso para describir un libro de tales características, es necesario no solamente conocer

la estructura material, sino el ámbito histórico, social, legal [...] que influyen claramente [...] No obstante, la comprobación directa de este tipo de material, ayuda a comprender determinados aspectos que no son fáciles de seguir dada nuestra percepción actual, tan diferente, de la estructura del libro. Se nos ha dicho desde diferentes ámbitos, que durante este [... periodo] es cuando adquiere la forma en la que le conocemos; pero eso es bastante relativo. 505

De igual forma es necesario considerar que en la descripción de libros antiguos suele ser común que el trabajo se realice sobre modelos ya desarrollados, por escuelas, por cierto bibliógrafo concreto, e

504 Para conocer mejor este tipo de normativas es sumamente recomendable consultar el libro de Fermín de los Reyes Gómez (2000). Op. cit.

505 Marías Milagros Ronco López. Op. cit. p. 29 
incluso siguiendo el modelo de descripción de algún repertorio específico. ${ }^{506}$ Como hemos visto, sin análisis metodológico y sin el conocimiento del objeto material que se describe, lo más probable sea que esa

descripción calcada de un modelo [no] sea impecable porque depende, claro está, de la bondad del modelo. Además una cosa es seguir algún modelo y otra hacerlo bien..$^{507}$

Efectivamente es esta tendencia la que más ha favorecido la vigencia de la bibliográfica negativa, y en gran parte, que elaborar una descripción sea considerado como una actividad fácil y económica que puede emprenderse en cualquier momento, con resultados rápidos, fiables y precisos. ${ }^{508}$

En nuestra perspectiva, el valor textual de un libro se refiere a todos los elementos de la estructura material que fueron impresos, y por esta razón, es fundamental el conocimiento de cada uno de esos elementos para la identificación del objeto que se describe. Ahora bien, por la importancia de esta tarea, no se puede pensar en un trabajo rápido para garantizar la correcta representación del objeto cultural que tratamos. Porque debemos recordar que desde este enfoque sí importa, y mucho, establecer si se trata de una edición, una emisión, un estado, si está completo, contrahecho, restaurado, manipulado, modificado, si es facsímile o una falsedad histórica que ha logrado prevalecer en el tiempo.

Por esta comprensión, bibliográfica y patrimonial, debemos aclarar que la información que hemos considerado relevante integrar en el modelo de la propuesta responde a esta división: primero los elementos que componen el valor textual y posteriormente los elementos que componen el valor histórico del libro antiguo que se describe.

506 Cfr. Juan Delgado Casado. Op. cit. p. 149

507 Ibídem.

508 Una tendencia que predomina en México, y que se ve promocionada por asociaciones civiles como Apoyo al Desarrollo de Archivos y Bibliotecas (ADABI). La información de esta entidad está disponible en http://www.adabi.org.mx/ [Consultado: abril de 2006] 
Sin duda reconocemos que la descripción bibliográfica debe estructurarse de una manera coherente y, por lo que aquí organizamos y explicamos la información de los valores textuales e históricos del libro antiguo, en relación directa al lugar que ocupa un determinado elemento en el modelo descriptivo de nuestra propuesta.

Esta propuesta busca realizar una descripción bibliográfica completamente detallada que incluye los siguientes elementos: encabezamiento (descripción sintética de la edición); transcripción facsímile de la portada; descripción física del ejemplar que incluye el formato, el tamaño, la fórmula de la colación, la paginación o foliación, el tipo de letra; descripción del contenido, incluyendo preliminares; y notas ${ }^{509}$ en el siguiente orden: marcas de fuego, ex libris, sellos y testigos; anotaciones manuscritas; encuadernación; estado de la conservación; otros datos relevantes - como errores en la signatura, paginación o foliación, grabados y ornamentación-; la ubicación del material; referencias bibliográficas y otros ejemplares.

Cada uno de estos elementos conforma un párrafo independiente en el modelo de descripción para construir una representación del objeto más inteligible, tanto para un lector ocasional como para un lector especializado de registros bibliográficos.

\section{a) La identificación previa: descripción breve de un material}

Antes que nada debemos precisar que todo trabajo de descripción bibliográfica, independientemente del modelo que se emplee, debe iniciar por constatar que se trata de un ejemplar completo de una edición antigua. Aunque parezca redundante debe verificarse que se trata de una edición original o de cualquier otro tipo de reproducción. Una tarea que solamente se puede realizar revisando la estructura material del ejemplar a describir.

509 Fredson Bowers. Op. cit. p. 161. También existen otro tipo de propuestas de descripción más detalladas que incluyen una descripción física más completa como el tipo de letra, la impaginación, la ornamentación, el soporte o sobre los ejemplares que sirven para la elaboración de la descripción. Cfr. Alberto Montaner Frutos. Op. cit. pp. 134-135. 
Ahora bien, la estructura material a la que nos hemos referido se refleja en la composición del objeto, que tiene por unidad básica al pliego y como unidad de estructura al cuadernillo. ${ }^{510}$ Es necesario también considerar que nuestra edición podría formar parte de un volumen, y que por tanto esas hojas que parecen formar parte de una unidad en realidad se trata de varias obras, que pueden estar completas o no.

Este tipo de agrupamiento bibliográfico se conoce como volumen facticio, y "es el construido al encuadernar juntos dos o más ejemplares pertenecientes a ediciones diferentes". ${ }^{511}$ En la descripción bibliográfica material, cada uno de las obras que integran un volumen facticio es un registro independiente y se relacionan unos con otros a través de las notas, como lo explicaremos más adelante.

Lo anterior nos permite apuntar aquí que una gran parte del conocimiento que se tiene sobre el libro antiguo como objeto material, procede de la casuística presente en toda colección de libros antiguos. De ahí que sea complicado detallar una a una, las posibilidades que se podrían encontrar al describir un libro antiguo. Quizá por ello la mejor recomendación para esta tarea sea la prudencia, la sensatez, la precisión, la uniformidad y coherencia y, sobre todo, documentar nuestras afirmaciones.

Así todo registro bibliográfico debe precederse por una entrada breve y directamente visible de la edición que se trata, que no sería fácilmente identificable sin una forma normalizada. ${ }^{512}$ Esta entrada se conoce como encabezamiento ${ }^{513}$ y sirve para identificar rápidamente la obra que se ha descrito. El encabezamiento puede tener varios elementos, lo ideal es emplear una forma de descripción breve que identifique claramente al autor, el título abreviado y el pie de imprenta de la forma siguiente:

510 Seguimos aquí el término empleado por Alberto Montaner Frutos. Op. cit. p. 130, ya que este elemento es denominado como cuaderno en otros textos de la bibliografía especializada.

511 Julián Martín Abad (2004a). Op. cit. p. 130

512 Jean-François Gilmont. Op. cit. p. 389

513 Alberto Montaner Frutos. Op. cit. p. 136 
PARDO, Francisco.

Vida y virtudes heroicas de la Madre María de Jesús... En México: por la Viuda de Bernardo Calderón, 1676.514

Como se puede observar seguimos las normas correspondientes para el registro del autor (en mayúsculas el apellido), pero es necesario indicar las siglas de la orden religiosa a la que pertenece el autor, cuando es un miembro del clero regular. Esta información puede ser relevante para el lector del registro bibliográfico y para su registro debe emplearse una forma normalizada. ${ }^{515} \mathrm{Si}$ bien no existe un lineamiento preciso para abreviar los títulos de los libros antiguos, por la complejidad de la información que presentan, ${ }^{516}$ lo más idóneo es omitir en el registro aquellas palabras que no aportan información relevante para la correcta identificación de la obra. Con todo se debe tener extremo cuidado cuando se trata de títulos genéricos como obra, opera, sumario, tratado, arte, recopilación, sermón, elogio, defensa, memorial y otros semejantes. ${ }^{517}$

Sin embargo hay que ser cauteloso cuando se trata de nombres propios, fechas o lugares, porque al omitirlos podríamos estar quitando información sustancial para la adecuada identificación de una edición

514 Biblioteca Eusebio Francisco Kino 016215

515 Aquí empleamos la que se recomienda en el apéndice VI de las Reglas de catalogación: edición refundida y revisada. Madrid: Ministerio de Cultura. Dirección General del Libro, Archivos y Bibliotecas, 1995. pp. 543-545. También es útil consultar el apéndice $\mathrm{V}$ para identificar las órdenes y congregaciones religiosas más comunes. pp. 539-542

516 Los títulos pueden parecer extremadamente largos y en la Nueva España fueron muestra de un barroco ornamental y complejo, en donde "no sólo se alargaba el título con las palabras rebuscadas y latinizantes, sino también con la cuidadosa identificación del mecenas, con sus títulos, cargos y dominios”. Magdalena Chocano Mena. La fortaleza... Op. cit. p. 213.

517 Un acercamiento a las diferentes formas del titulo se encuentra en José Simón Díaz. El libro español antiguo. Madrid: Ollero \& Ramos, 2000. pp. 81-114. y para introducirse a este complejo mundo, es conveniente consultar la obra de Giuseppina Zapella. Op. cit. pp. 529-538. En donde explica formas y tipos de construcción de títulos, que pueden resultar bastante útiles para la abreviatura de ese dato para el registro bibliográfico. 
antigua. En lo que corresponde al pie de imprenta, lo correcto es registrarlo tal y como se encuentra impreso y en algunos casos se puede omitir para la descripción breve, cierta información como la ubicación o la calle de la imprenta.

De igual manera y siguiendo las normas ya establecidas, cuando el año de la edición se encuentra en números romanos se transcribe con números arábigos y, cuando la fecha de la edición no corresponde a una forma de datación ${ }^{518}$ del calendario moderno, debería modernizarse, si no se puede es preferible transcribir tal y como se ha encontrado. ${ }^{519}$ Cuando esa fecha no ha sido extraída directamente de la portada debe escribirse entre corchetes e indicar en una nota al pie de dónde ha sido extraída esa información. Para ello es preferible tomar la data de algún documento preliminar que se corresponda con la legislación de época y el orden de la tramitación que corresponde.

En este sentido el último documento que establece la legislación es la tassa, por tanto el orden de la selección sería del último al primero. Sin embargo, nos parece pertinente anotar que es conveniente indicar con precisión el tipo de documento empleado para la datación. Es decir, en lugar de "Fecha tomada de la licencia", seríe preferible indicar "Fecha tomada de la licencia del Provincial", o "Fecha tomada de la licencia de impresión".

Como se sabe, algunos ejemplares conservados de libros antiguos por diversas razones han perdido las primeras y últimas hojas. Cuando el ejemplar que queremos describir presenta esta característica, lo más correcto es emplear la recomendación anterior: recuperar los datos de los documentos preliminares como las licencias, ya sea de la orden, del Consejo u otra, como la que aquí se presenta. Describimos los tipos y naturaleza de estos documentos más adelante.

518 Para ayudar en esta tarea se pueden emplear los cuadros del calendario romano antiguo y de la numeración según el alfabeto griego en Giuseppina Zappella. Op. cit. pp. 552-554.

$519 \operatorname{ISBD}(\mathrm{A})$. Op. cit. pp. $76-78$ 


\section{LICENCIA DE PUBLICAR, 广̀ VENDER.}

DON Juan Miguèl de Ocharan, Oficial mayor de la Escrivania de Camara, y de Govierno del Consejo, del cargo del Secretario Don Joseph Antonio de Yarza, cuyas ausencias, y enfermedades exerzo: Certifico, que por les Señores del Consejo se ha concedido licencia à Joaquín Ibarra, Impresor en esta Corte, para que pueda publicar, y vender la reimpresion, que en yirtud de otra Licencia de dichos Seńores tiene hecha del Libro Catjecirmo Romano, sacada principalmente de los Cathecismos de San Pio Quinto, y Clemente Oetavo, compuestos conforme al Decreto del Santo Concilio Tridentino por el Padre Juan Eusebio Niercmberg,de la Compañi., de Jesus; con tal, de que se ponga esta Certificacion al principio de cada librojy para que conste lo firmè en Madrid à diez $\boldsymbol{Y}$ siete de Febrero de mil setecientos sesenta.y tres.

\section{S. \\ Den Fuan Miguel de Ocbarint.}

Efectivamente, cuando se está elaborando un registro bibliográfico detallado, realizar la descripción breve no debe presentar mayores problemas que cuando se está realizando una interpretación catalográfica normalizada. Esto es así porque en la bibliografía, el encabezamiento va seguido de la transcripción de la portada línea a línea. Presentamos seguidamente la transcripción de la portada de la que hemos extraído la información para ejemplificar la descripción breve de un libro antiguo:

[taco xil.] VIDA Đ [taco xil.] / Y VIRTUDES HEROYCAS / de la Madre MARIA DE JESUS, / Religiofa profe $\iint a$ en el Convento de la LIMPIA / CONCEPCION de la Virgen Maria N. Señora / de la Ciudad de los Angeles. / DEDVCIDA DE LAS INFORMACIONES / autenticas,

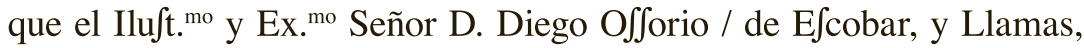
Obifpo de efta Dioce is hizo / [taco xil.] en efta mifma Cefarea Ciudad [taco xil.] / [taco xil.] CONSAGRASE [taco xil.] / A las aras puras, y mas favorables de la Emperatriz / Soberana del Cielo, y al decoro de $\mathrm{fu}$ candides original / en el inftante primero prefervada de la / primera culpa. / [taco xil.] ESCRIVESE [taco xil.] / A inftancias fervorofas del Señor Don Antonio del / Caftillo Camargo, Caballero del Orden de Santiago / del Confejo de fu Mageftad en el Real de Hazienda: / Gran Chanciller, y Regiftrador mayor en el de la / Santa Cruzada / [taco xil.] Y PROPONESE [taco xil.] / Con atenciones rendidas a el 
mas acertado examen, cientifica / dirección, y prudente arbitrio de las inteligencias superiores y / a la cenfura docta, y eftimable de otros claros ingenios, POR el / Bachiller FRANCISCO PARDO, Capellan de Choro / en el de la Igle fia Catedral de efta Angelica Republica. / [filete] / Con licencia. En México: Por la Uida de Bernardo Calderon, / en la calle de San Auguftin. Año de 1676.

\section{b) Portada y pie de imprenta}

La portada de un libro antiguo contiene los datos esenciales a considerar para la elaboración de cualquier tipo de descripción bibliográfica y de ahí que sea considerada como la primera fuente de información. Estos datos son el autor, el título y el pie de imprenta. Respecto a éste, recordemos que en las ediciones impresas en latín el nombre de la ciudad de impresión también se encuentra en esta lengua o se ha latinizado. Para identificar correctamente la ciudad de impresión que está impresa en latín, debe siempre consultarse bibliografía especializada. ${ }^{520}$ De otra manera corremos el riesgo de confundir los lugares de impresión por la coincidencia de los nombres y dificultar la identificación de las ediciones.

También debe considerarse que antecediendo el nombre del impresor o la casa de impresión, pueden encontrarse palabras latinas como apud, ${ }^{521}$

520 Cfr. José Ignacio Mantecón. Índice de nombres latinos de ciudades con imprenta, 1448-1825. México: UnAM, 1973, Tomaso Urso. Toponomastica bibliográfica: guida ai nomi dei luoghi di stampa fino al 1799. Firenze: Leo S. Olschki Editore, 1990, y el recientemente publicado de Isabel Moyano Andrés. Toponomástica. Madrid: Arco Libros, 2006. También puede consultarse el sitio que la Rare Books and Manuscripts Section de la ACRL tiene disponible en http://www.rbms.info/committees/bibliographic_standards/latin/index.html [Consultado: enero de 2011]

521 Es la palabra que se utiliza para designar que el libro se encuentra o se obtiene en la casa de un impresor, editor o vendedor de libros Geoffrey Ashall Glaister. Encyclopedia of the Book. London: Oak Knoll Press \& The British Library, c1996. p.13. En las portadas además de los datos más comunes, se pueden encontrar también mención de licencias o censuras, tasa, número de pliegos, la edición, citas y correcciones. Cfr. Fermín de los Reyes Gómez. "Estructura formal del libro antiguo". Manuel Pedraza Gracia, Yolanda Clemente y Fermín de los Reyes. Op. cit. pp. 211-225. 
sumptibus, excudebat, Ex Typographia y Ex Typis, ${ }^{522}$ y otras más como "En casa de", "Por los herederos de", "Por la Viuda de". Por otro lado también podría encontrarse formas diversas de indicar la fecha de impresión en número romanos, como aquella en que las letras parecen estar al revés ${ }^{523}$ como se observa en la imagen. Sin duda, la revisión de varias portadas permitirá identificar las diversas posibilidades.

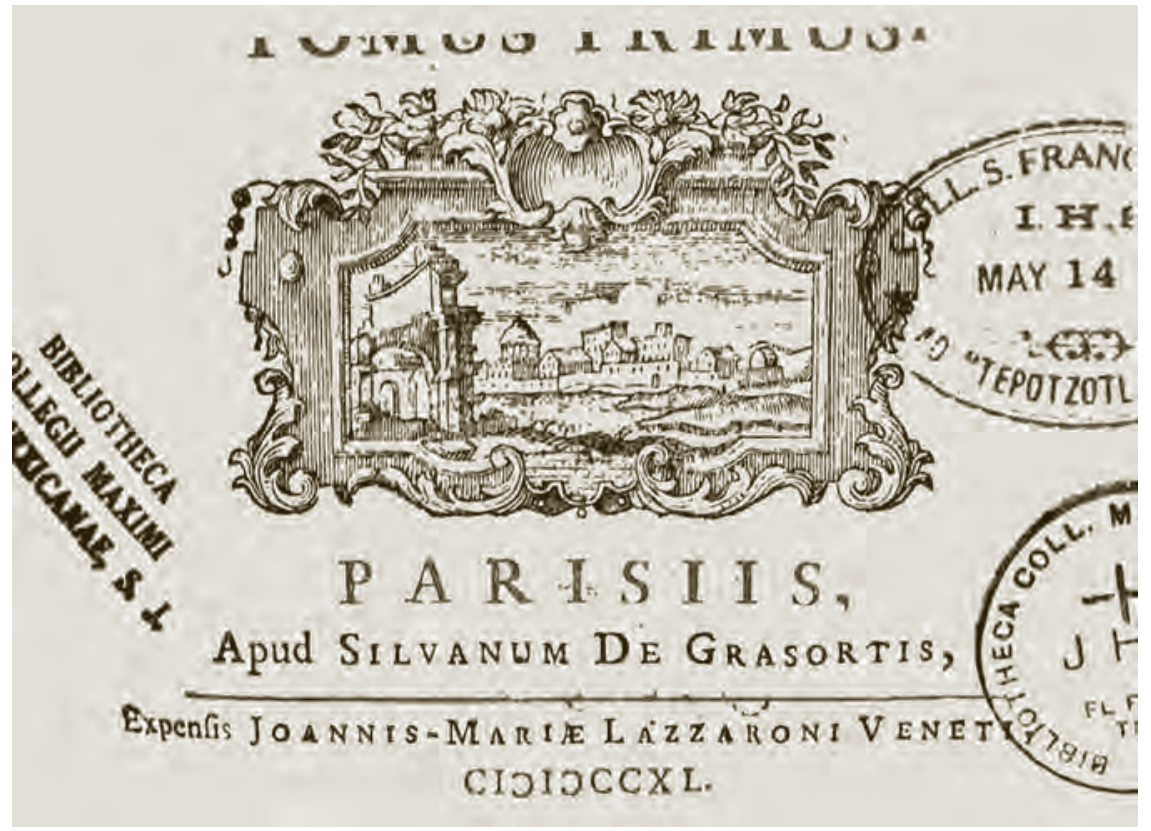

522 Puede entenderse por los siguientes términos: Sumptibus "a costa de", Excudebat "compuesto por"; Ex typografía "de la imprenta de", Ex typis "de los tipos de". Agradezco a Guillermo Morales, estas precisiones.

523 Para estos casos puede consultarse el apéndice II de Antiquarian books, a companion for booksellers, librarians and collectors, compiled and edited by Philippa Bernard with Leo Bernard and Angus O’Neill. Philadelphia: University of Pensilvania Press, 1994. p. 443, y en Alonso Víctor de Paredes. Institución y origen del arte de la imprenta y reglas generales para los componedores, edición y prólogo de Jaime Moll. Madrid: Crotalón, 1984. h. 23v. 
Los datos de la portada pueden dividirse en dos partes: la primera, estaría compuesta de los datos del autor, el título y otros más, como la mención de la dedicatoria o del mecenazgo, ubicándose en la parte superior. La segunda, estaría compuesta por la condición legal de la edición (i.e. "Con privilegio" o "Con las licencias necesarias") el pie de imprenta e incluso el costo del ejemplar. ${ }^{524}$ Estos datos se encuentran en la parte inferior de la portada, puestos inmediatamente después de algún elemento decorativo.

En una descripción detallada, como se indicaba, al encabezamiento del registro debe seguir la transcripción de la portada de forma casi facsimilar, es decir, línea a línea.

El principal propósito bibliográfico de esta transcripción es ofrecer toda la información práctica necesaria para una comparación minuciosa de cualquier ejemplar concreto con la transcripción publicada, de cara a confirmar su identidad precisa o establecer variaciones. 525

Por lo tanto, la transcripción implica registrar toda la información tal y como se presenta en el ejemplar que describimos. Es decir, las altas y bajas en donde corresponden, cursivas, color de la tinta, los elementos decorativos, e incluso los errores tipográficos y ortográficos. Para la indicación de la separación de cada línea de la portada, preferimos emplear la diagonal (/) siguiendo las indicaciones de Moll. ${ }^{526}$ No debe indicarse el principio del texto ni el final, sino únicamente las separaciones de las líneas que se describen.

524 Manuel Pedraza Gracia, Yolanda Clemente y Fermín de los Reyes. Op. cit. pp. 211-225

525 Fredson Bowers. Op. cit. p. 176

526 Jaime Moll (1989). Op. cit. p. 177. También indicada por Lorenzo Baldacchini (2001). Op. cit. p. 115, Connor Fahy. Saggi di bibliographia testuale. Padova: Editrice Antenore, 1988. pp. 266-267 y, por María José López-Huertas Pérez. Bibliografía de impresos granadinos de los siglos XVII y XVIII. Granada: Universidad: Diputación provincial, 1997. T. 1, p. 44. 
Aunque McKerrow, ${ }^{527}$ Bowers, ${ }^{528}$ y Montaner, ${ }^{529}$ prefieren utilizar la barra vertical (I) para la transcripción de los elementos de la portada, ${ }^{530}$ no empleamos ésta, porque en algunas ocasiones suele encontrarse como elemento decorativo en la portada, y no porque forme parte del teclado moderno aunque ciertamente simplifica la tarea. ${ }^{531}$ También debe indicarse entre corchetes la presencia de todos los elementos decorativos como grabados (con motivos iconográficos clásicos o cristianos), escudos (de ordenes religiosas, nobiliarios, de familia o episcopales), florones, tacos xilográficos (como § - ( $\mathrm{g}$ ), o marcas de impresor, como se observa en la imagen.

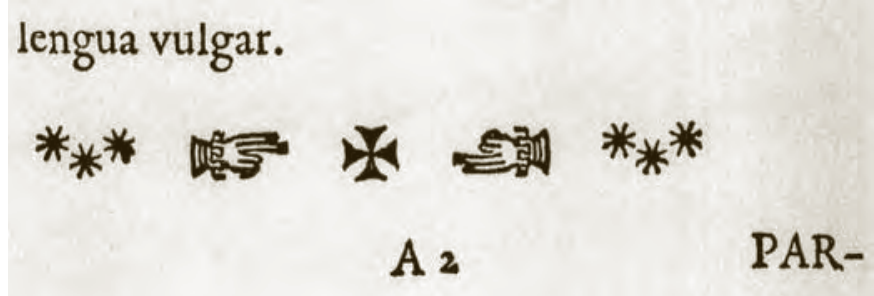

En cuanto a su registro existen dos tendencias. Una propone que en ese mismo espacio de la descripción de la portada, también deberían describirse las características del grabado que decora la portada de la siguiente manera: [Grabado calcográfico de la Inmaculada Concepción]. La otra, de la que somos partidarios, propone que se indique su presencia y tipo (grabado, escudo, marca de impresor, filete, florón o taco xilográfico) entre corchetes y en el lugar que corresponde, normalmente formando una línea aparte. Esto permite que cuando es relevante, las características del elemento decorativo de la portada, se registren con mayor detalle en una nota aparte, por su interés

527 Roland B. McKerrow. Op. cit. p. 176

528 Fredson Bowers. Op. cit. p. 194

529 Alberto Montaner Frutos. Op. cit. p. 135

530 En algunos modelos bibliográficos incluso puede encontrarse la doble barra (II), así lo recomienda Phillip Gaskell. Op. cit. p. 405

531 Fredson Bowers. Op. cit. p. 194 
cultural y la susceptibilidad que presenta para el saqueo. ${ }^{532}$ Un ejemplo de los cuales se observa en la imagen.

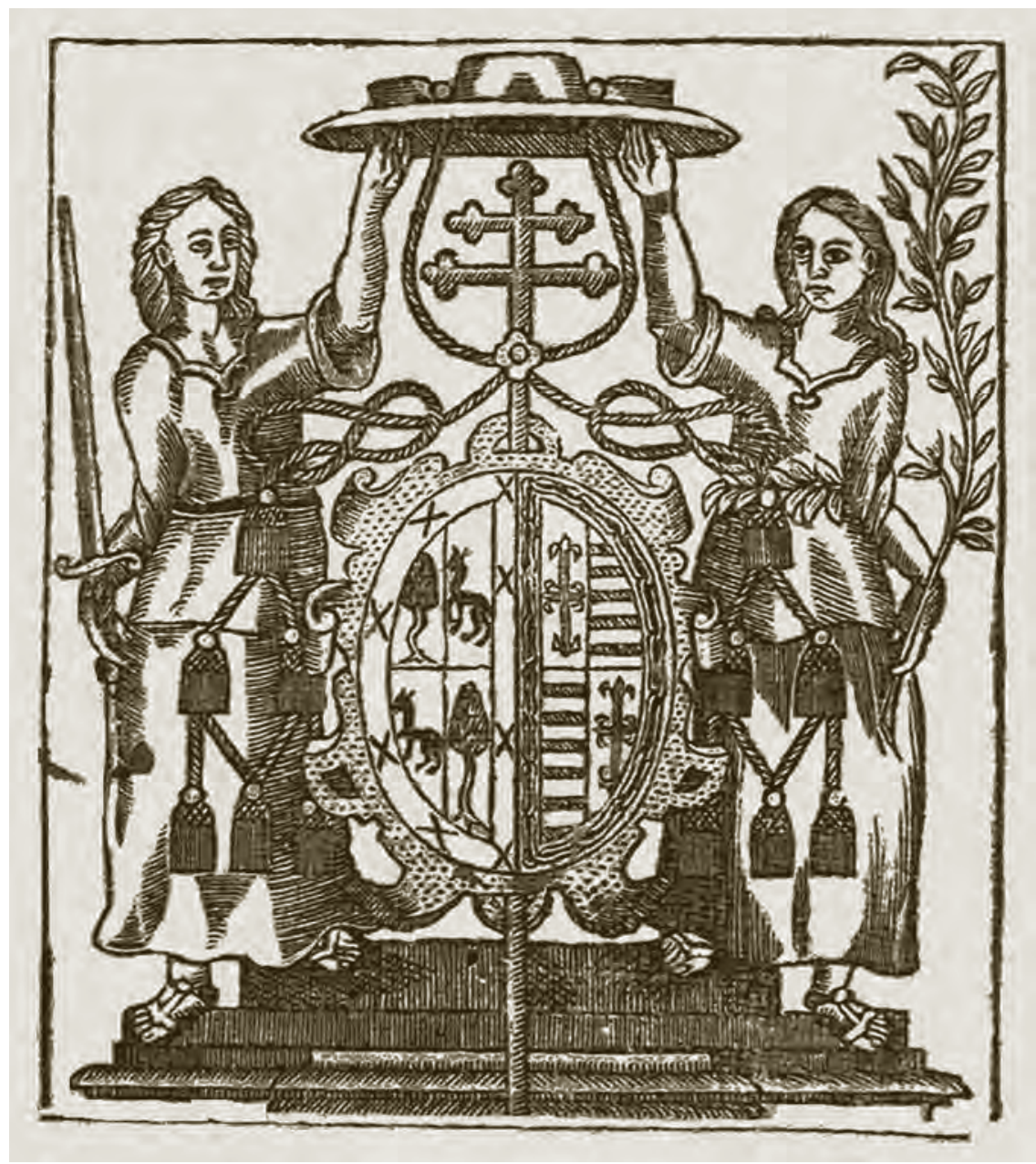

532 Para cualquiera que consulta material en el fondo antiguo, no será extraño recordar las numerosas ocasiones en las que al trabajar con un libro antiguo se encuentra con la desagradable sorpresa de un agujero en la portada, y aquellas otras en las que la restauración hace más evidente la pérdida. 
Ahora bien, cuando se trata de un grabado de portada y no de una marca tipográfica (del impresor), basta con indicar "grabado". 533 Lo mismo aplica para un escudo nobiliario o familiar, ${ }^{534}$ pero no para un escudo de una orden religiosa, que deberá indicarse en ese momento: [escudo jesuita] ${ }^{535}$ o [escudo franciscano]. ${ }^{536}$ Por otra parte si se trata de un "filete", que es una pleca horizontal, debe especificarse si se trata de uno doble (dos líneas), triple (tres líneas) o decorado (cuando la pleca se conforma de una composición de tacos xilográficos), de la siguiente forma: [filete decorado]. Si se trata de un taco xilográfico y se puede, es mejor representarlo, si no es así, debe indicarse de la siguiente manera: [taco xil.]. Si es un florón lo que decora la portada, se indica de forma simple [florón]. El florón es un ornamento tipográfico en la que principalmente se representa un jarrón, maceta o canasta con flores (y en ocasiones animales). ${ }^{537}$ Este último es uno de los elementos decorativos más comunes en las portadas antiguas y en la

533 Aunque también es recomendable describir el tipo de ilustración del que se trata. Para esta tarea es importante identificar el elemento iconográfico presente. Cfr. Juan Carmona Muela, Juan. Iconografía clásica: guía básica para estudiantes. Madrid: Istmo, 2000 e Iconografía cristiana: guía básica para estudiantes. Madrid: Istmo, 2001.

534 En cualquier caso debe consultarse bibliografía especializada de heráldica para identificar correctamente el escudo, aunque en algunos casos la propia información del libro puede aportar los datos necesarios. Para introducirse al este tema es recomendable consultar Fernando del Arco y García. Introducción a la Heráldica. Madrid: Ediciones. Iberoamericanas, 1996.

535 En este escudo en particular debe observase la presencia de los tres clavos bajo el anagrama de Cristo (IHS), pues, en el escudo de la Compañía representan los votos de la orden: pobreza, castidad, y obediencia.

536 Para esa tarea es necesario que cuando menos se conozcan los elementos iconográficos que están relacionados con las órdenes religiosas. Por ejemplo las cinco llagas de los Franciscanos o el monte coronado con una cruz de los Carmelitas.

537 Pese a esta apreciación, también se denomina florón a los numerosos tacos xilográficos empleados como ornamentos tipográficos en los libros antiguos que son representaciones de florecillas u hojas. Forma gráfica que también fue empleada para decorar las encuadernaciones. 
decoración interior de los libros. ${ }^{538}$ Un ejemplo de este elemento ornamental se puede observar en la imagen.

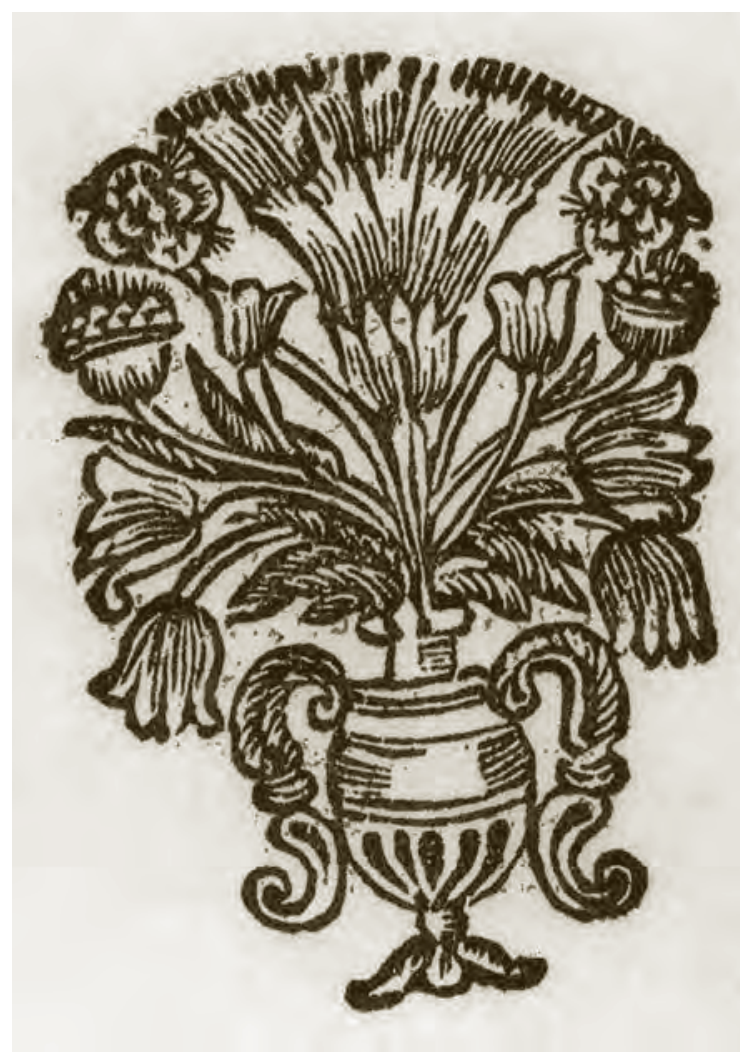

De esta manera, la descripción de una portada debería quedar como se observa a continuación:

538 Para observar la diversidad que se empleo de este tipo de ornamento se pueden consultar las bases de datos FLEURON: banque d'ornaments d'impremerie, disponible en la página http://dbserv1-bcu.unil.ch/ornements/scripts/index.html [Consulta: abril de 2009] y, Ornements typographiques de Pierre Mouriau de Meulenacker, disponible en la página http://www.ornements-typo-mouriau. be/index.php [Consulta: abril de 2009] 
[ ] OPUSCULOS / Y DOCTRINAS / PRACTICAS, / QUE PARA EL GOBIERNO INTERIOR / Y DIRECCION DE LAS ALMAS, Y PARA EL CONOCIMIENTO, / EXAMEN, Y PRUEBA DE VARIOS ESPIRITUS OFRECE / A SUS DIRECTORES, Y CONFESSORES, Y DA A LUZ / EL PADRE PEDRO DE CALATAYUD, \& de la Compañía de Jesvs, Maeftro de Teología, / Catedrático de Efcritura en el Colegio de San Am- / brofio de Valladolid, y Mifsionero Apoftolico / de la Provincia de Caftilla. / DEDICALOS / AL ILUSTRISSIMO SEÑOR / DON DIEGO DE ROXAS / Y CONTRERAS, CABALLERO DEL ORDEN DE / CALATRAVA, OBISPO QUE FUE DE CALAHORRA, Y LA / Calzada, y al prefente Obifpo de Cartagena, y Gobernador / del Confejo Supremo de Caftilla. / [comp. taco xil] [monograma de Jesús enmarcado en tipos] [comp. taco xil.] / [filete] / EN LOGROÑO: / EN LA IMPRENTA DE FRANCISCO DELGADO, IMPRESSOR / de la ciudad, y del Santo Tribunal. Año de MDCCLIV. ${ }^{539}$

Es conveniente aclarar que no somos partidarios del empleo de la abreviatura latina [sic.], ${ }^{540}$ porque en las descripciones casi facsimilares al emplear la metodología de la Bibliografía Material, se está admitiendo que la transcripción de los datos de la portada se dan tal y como aparecen. Ciertamente esta precisión debería incluirse en la explicación metodológica que antecede a todo trabajo de registro bibliográfico, incluso cuando se ha decidido copiar un modelo ya empleado con anterioridad.

También es importante tomar postura, hoy con más vigencia que nunca, sobre la reproducción fotográfica de las portadas frente a la descripción casi facsimilar. En realidad la una no debería confrontar a la otra, por el contrario deberían complementarse, y ciertamente la transcripción facsímile de la portada sigue siendo un método útil para comparar ediciones y detectar variantes. A pesar del desarrollo que

539 Pedro de Calatayud. Opusculos y doctrinas practicas que para el gobierno interior y dirección de las almas, y para el conocimiento, examen, y prueba de varios espiritus ofrece a sus directores y confesores... En Logroño: en la Imprenta de Francisco Delgado, 1754. Biblioteca Eusebio Francisco Kino 024565.

540 Lorenzo Baldacchini (2001). Op. cit. p. 116 
ha tenido la tecnología digital, que ha permitido abaratar notablemente el costo de producción y la reproducción de una fotografía, estas por sí mismas no son garantía de fiabilidad automática. ${ }^{541}$

Sin embargo, el verdadero problema de la descripción facsímile, sigue siendo el registro de la tipografía y el de la ornamentación de la portada. A la fecha no se ha encontrado una solución idónea para describir el tamaño de los tipos empleados en la composición de una portada y menos aún para indicar la medida de los espacios interlineales, sin que ello represente recargar de información adicional a la transcripción de la portada. ${ }^{52}$ Por eso creemos conveniente que

si por alguna razón, en casos especiales, es necesario indicar la disposición del texto en una portada, lo mejor es dar las medidas aproximadas (de arriba abajo) en milímetros. Pero por razones varias, no es nada fácil indicar la medida exacta. 543

Ahora bien, para transcribir la "s" larga, las letras conjugadas como "ae, st o ct" de forma semejante a la impresa, nos encontraremos con un problema porque no existe una sola tipografía contemporánea, para medios electrónicos, que contenga todos los tipos necesarios para describir lo más cercano posible al original. Debe buscarse entre las librerías de tipografías disponibles en la red una que cumpla con estas características, como Lucinda Sans Unicode y Hoefler Text Ornament, entre otras. Para nuestra propuesta hemos utilizado la tipografía digital $D I C E$, diseñada y desarrollada en la Universidad de Zaragoza (España). ${ }^{544}$

La tecnología no debe hacernos olvidar que cuando la transcripción se realiza de forma manual, porque no se cuenta con otra posibilidad,

541 Por otro lado los argumentos en contra del empleo de la fotografía para los repertorios bibliográficos por el encarecimiento de la edición, actualmente sólo son válidos si se trata de una edición impresa y no electrónica. A lo cual se suma el notable crecimiento de colecciones digitales de libros antiguos en numerosas instituciones.

542 Es decir, se trataría de un método semejante al Proctor empelando para la tipografía de los incunables.

543 Roland B. McKerrow. Op. cit. p. 175.

544 Utilizada con autorización de su creador (2005). 
las características del texto deben indicarse entre corchetes, por ejemplo, para indicar cursivas se debe escribir [curs.], antes de que inicie el texto con esta característica pero nunca cuando termina. Debido a que la mayor parte de los impresos emplean la letra redonda para el texto general de la portada y solamente la cursiva para distinguir una parte del mismo, solamente se indica redonda [red.], cuando ha terminado el texto en cursiva. Esta misma indicación se aplica para la descripción de las portadas a doble tinta, en donde proponemos describir en orden de color y tipo, es decir: [roj.] [red.] = rojo y redonda. Recordemos que todas estas indicaciones deben marcarse siempre el inicio de la característica y no el final de la misma.

Ahora bien, cuando se dispone de la posibilidad de realizar la transcripción directamente en un archivo de computadora, deberían emplearse directamente las cursivas, los cambios de color de la tinta o la presencia de tacos xilográficos. Aunque en algunos textos se recomienda que el cambio de color se indique en negritas. ${ }^{545}$ Esto podría representar una dificultad cuando la portada que se describe también presente una parte del texto en negritas. ${ }^{546}$ Cuando esto ocurre debe indicarse directamente o en su defecto con la indicación [negr.]. A continuación presentamos dos ejemplos de portadas a dos tintas que describimos considerando ambas opciones indicadas:

[roj.] SERMONES VARIOS / DEL DOCTOR / D. ANDRES / DE ARCE Y MIRANDA, / [neg.] Colegial Real de Oposicion en Sagrada Theologia del / Real y más Antiguo Colegio de S. Ildefonso de Mexi- / co, Abogado de la Real Audiencia, Cura Beneficiado, / que fue, por S.M. de la Parroquia de Santa Cruz de / la Puebla de los Angeles, Examinador Synodal de su / Obispado, al preferente Canonigo Magistral de su / Santa Iglesia, y Obispo electo de San Juan / de Puerto Rico. /

545 Alberto Montaner Frutos. Op. cit. p. 137

546 Si los registros elaborados dentro de una institución se realizan en computadora para servir como instrumento de consulta o de control, no hay mayor problema porque aún cuando no se cuente con una impresora de color, el resultado imprimirá los datos en tinta roja en la gama de los grises. Si el registro elaborado se emplea para una edición de un libro en papel, la decisión sobre el empleo o no de los corchetes dependerá del presupuesto de la edición proyectada. 
[curs.] TOMO SEGUNDO / [red.] DEDICADO / [roj.] / AL ILLMO. SR. Y RMO. P. MRO. / FRANCISCO DE RAVAGO / DE LA COMPAÑÍA DE JESUS, / [neg.] Confessor de la Magestad Catholica / de Nuestro Rey y Señor / [filete] / [roj.] CON LICENCIA DE LOS SUPERIORES / [neg.] En Mexico en la Imprenta nueva de la Bibliotheca Mex-/ xicana, enfrente del Convento de San Augustin. / [roj.] Año de $1755^{547}$

INSTRUCTORIO / ESPIRITUAL / DE LOS TERCEROS, TERCERAS, / Y BEATAS de Neuftra Señora del / CARMEN: / DISPUESTO / Por F. MANUEL DE SANTA TERESA, / Carmelita De fcalzo, Lector de Sagrada ES- / critura, ExDeffinidor, y Prior, que fue, de / los Conventos de Zelaya, y Toluca; y / Vicario del Santo Defierto: / QUIEN

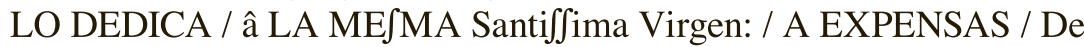
la me ma Venerable Tercera Orden de / Nra. Señora del Carmen de Sr. S. Joseph / de la Ciudad de Toluca / [taco] [escudo carmelita] [taco] / [filete decorado] / CON LICENCIA: En México por la Viuda de / Don Joseph Bernardo de Hogal, Calle de las Capuchinas, Año de 1742. ${ }^{548}$

En lo que respecta al tipo de portada, ${ }^{549}$ algunos prefieren registrar esta información directamente en la misma transcripción facsimilar. ${ }^{550}$ Por nuestra parte creemos pertinente que este dato se registre como primer elemento del contenido de un libro, lo que veremos más adelante. Empero es conveniente indicar aquí los tipos de portadas que podrían encontrarse, aunque no exista una tipología consensuada de las mismas. Por nuestra parte hemos identificado y caracterizado a las siguientes portadas:

547 Biblioteca Eusebio Francisco Kino 018113

548 Biblioteca Eusebio Francisco Kino 017949

549 Cfr. Giuseppina Zapella. Op. cit. pp. 421-499. Aquí se encontrara un análisis detallado de numerosas formas de composición tipográfica presentes en las portadas de libros antiguos. Para un acercamiento a la evolución histórica de la portada, es recomendable consultar la obra de Margaret S. Smith. The title page: its early development 1460-1510. London: The British Library: Oak Knoll Press, 2000.

550 Fredson Bowers. Op. cit. pp. 183-191 
- Portada simple es aquella que no presenta más que el texto y elementos decorativos como marcas de impresores o grabados de portada. Puede verse un ejemplo en la imagen.

\section{VIDA PRODIGIOSA}

DEL V. SIERVO DE DIOS

\section{FRAY SEBASTIAN \\ DE APARICIO,}

RELIGIOSO LEGO DE LA REGULAR Obfervancia de N. S. P. S. Francifco, è Hijo de la Provincia del Santo Evangelio de Mexico.

\section{SU AUTHOR}

EL R. P. FRAY JOSEPH MANUEL RODRIGUEZ, Ex-Lector de Sagrada Theologia, Predicador general, Notario Apoftólico, Chronifta general del Orden de N.S.P. S. Francifco en efla Nueva España, Comiffario Vifuador de fu Drdent Tercero de efta Cindad de México, y actual

Cistodio de dicha Santa Provincia.

DEDICANLA

LOS NATURALES, Y ORIUNDOS

DEL NOBILISSIMO REYNO DE GALICIA

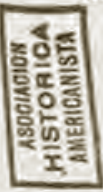

RESIDENTES EN ESTA CORTE,

$$
\text { AL ILLMO. SENंOR }
$$

D. MANUEL VENTURAys?

FIGUEROA.

EN MEXICO: En la Imprenta de D. Phelipe de Zuñiga,

y Ontiveros, Calle de la Palma, año de 1769. 
- Portada a dos tintas es aquella en donde se combinan el rojo y el negro para crear un espacio estético de composición. Puede verse un ejemplo en la imagen.

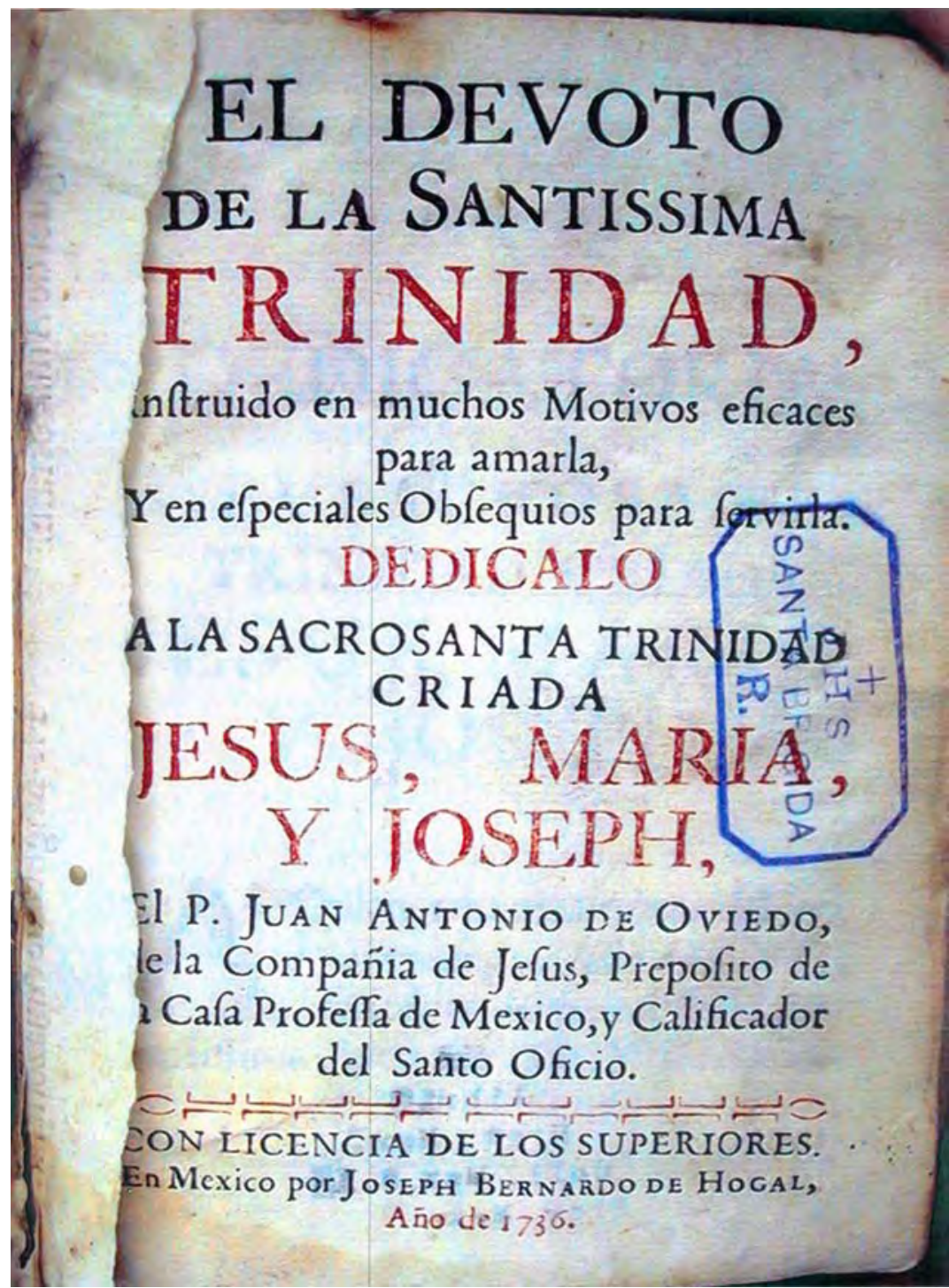


- Portada orlada es aquella cuyos datos están rodeados por una orla. Este adorno presenta una combinación geométrica (rectangular), en donde la orla está formada con una serie de piezas, iguales o distintas. ${ }^{551}$ Esta portada también puede encontrarse también a dos tintas como la que aquí mostramos.

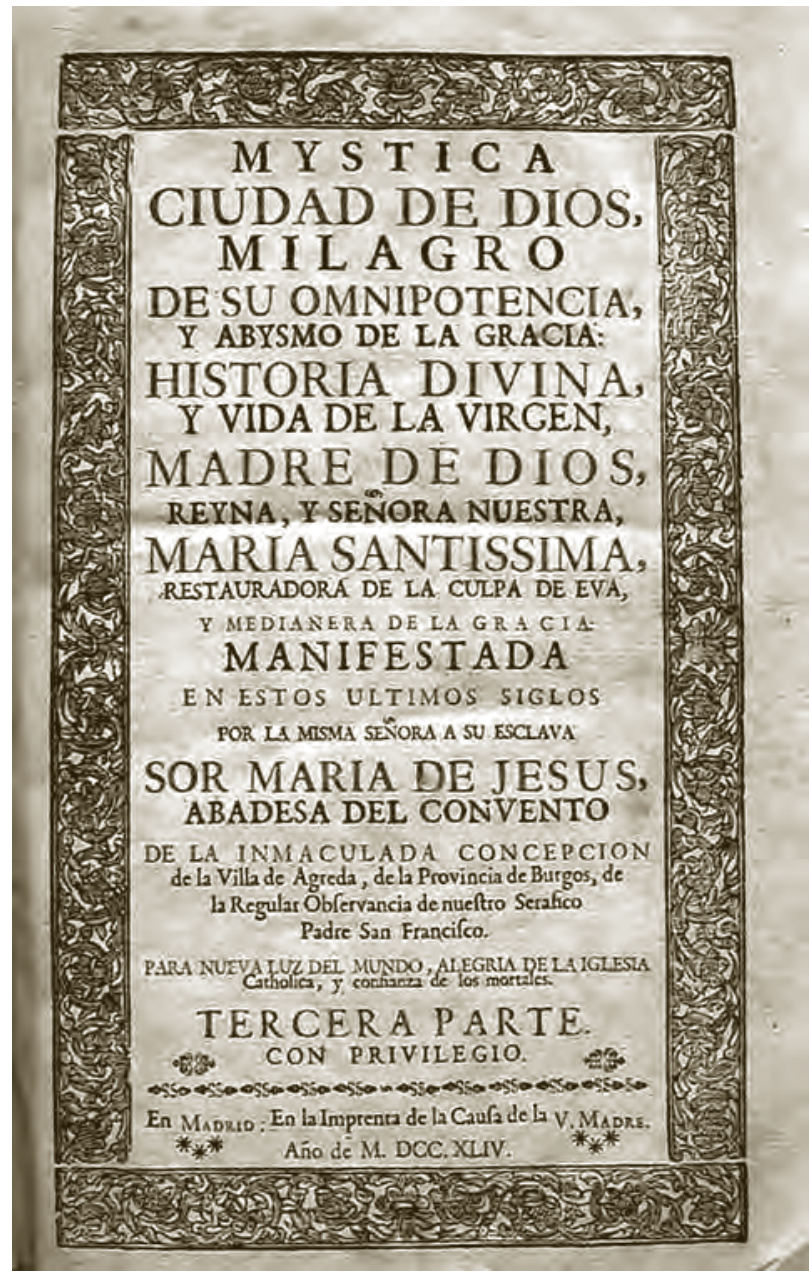

551 José Martínez de Sousa (1993). Op. cit. pp. 649-650 
Secretos del estante: elementos para la descripción bibliográfica...

- Portada con orla tipográfica, es aquella en donde la orla está compuesta de múltiples tipos, iguales o distintos, formando un cuadro alrededor del texto de la portada. Al igual que la anterior puede encontrarse a dos tintas.

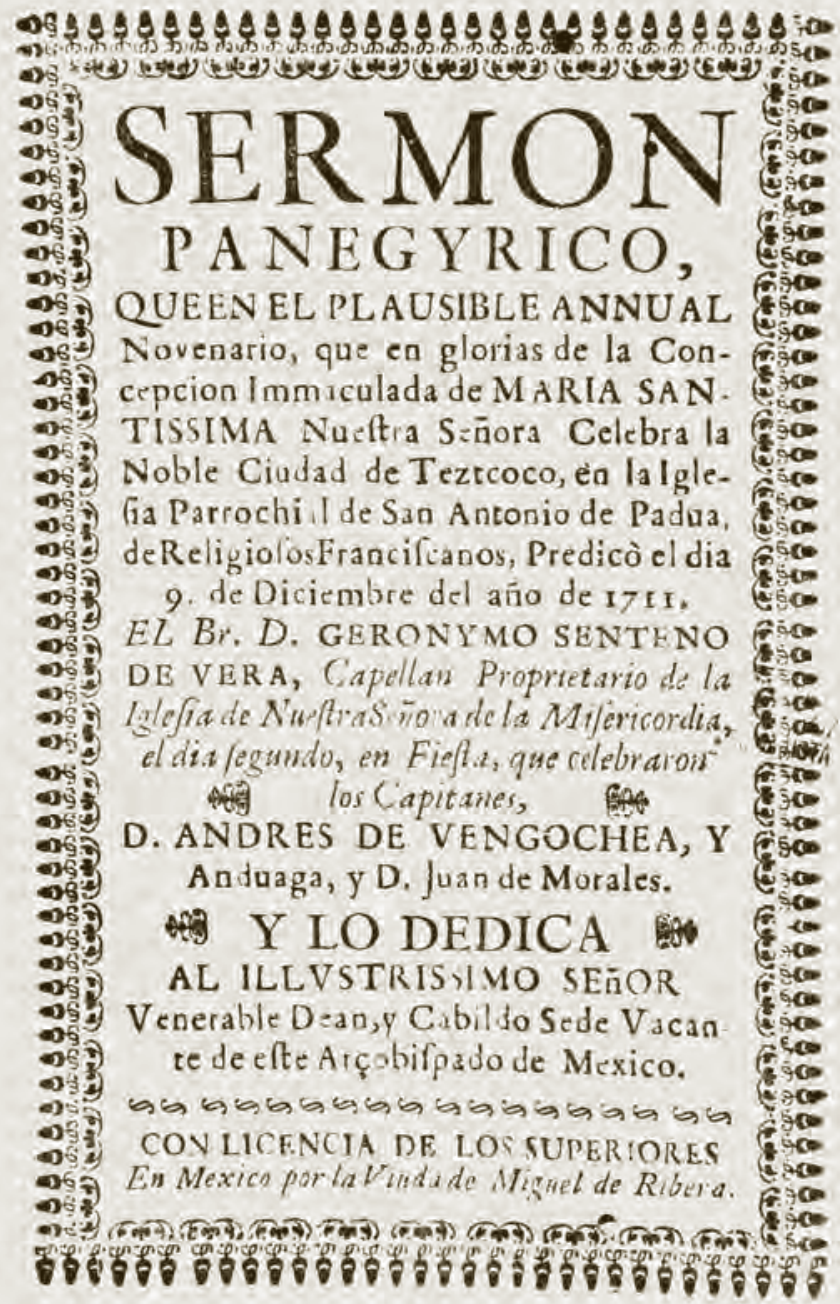


- Portada enmarcada es aquella en donde los datos se encuentran dentro de un marco simple o doble, y también puede presentar la combinación de dos tintas. ${ }^{552}$
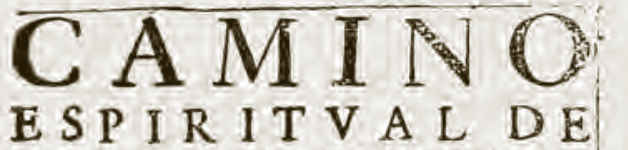

I. A A NERA QVE LO ENSENA

EL BIENAVENIVRADO PADRE Sap Igaacio, en fu libro de los

Exercicios.

P R I M E R A P A R T E.

POR ELPADRELDYSDELA

Palma, Proumcial de la Compañia de 1 ES VS en la Prouincia de Toledo, y natural de la mijma Cuudad.

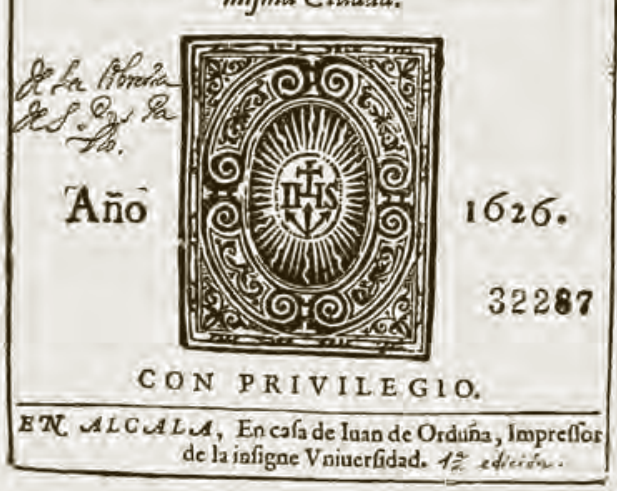

- Portada grabada, es aquella en donde la ilustración abarca toda la página, comprendiendo dentro de sí los datos (todos o algunos) de identificación de la obra. En realidad nunca sustituye totalmente a la portada sino que suele convivir con ésta, por lo que suele encontrarse otro tipo de portada ( $v . g r$. simple o con orla

552 Ioannis Lorini. Commentarivs in ecclesiasten editio novissima... Lugduni: Sumptibus Horati Cardon, 1619. Biblioteca Eusebio Francisco Kino s/n 
tipográfica ${ }^{553}$ siguiendo a la grabada. Aquí mostramos un bello ejemplo en la imagen.

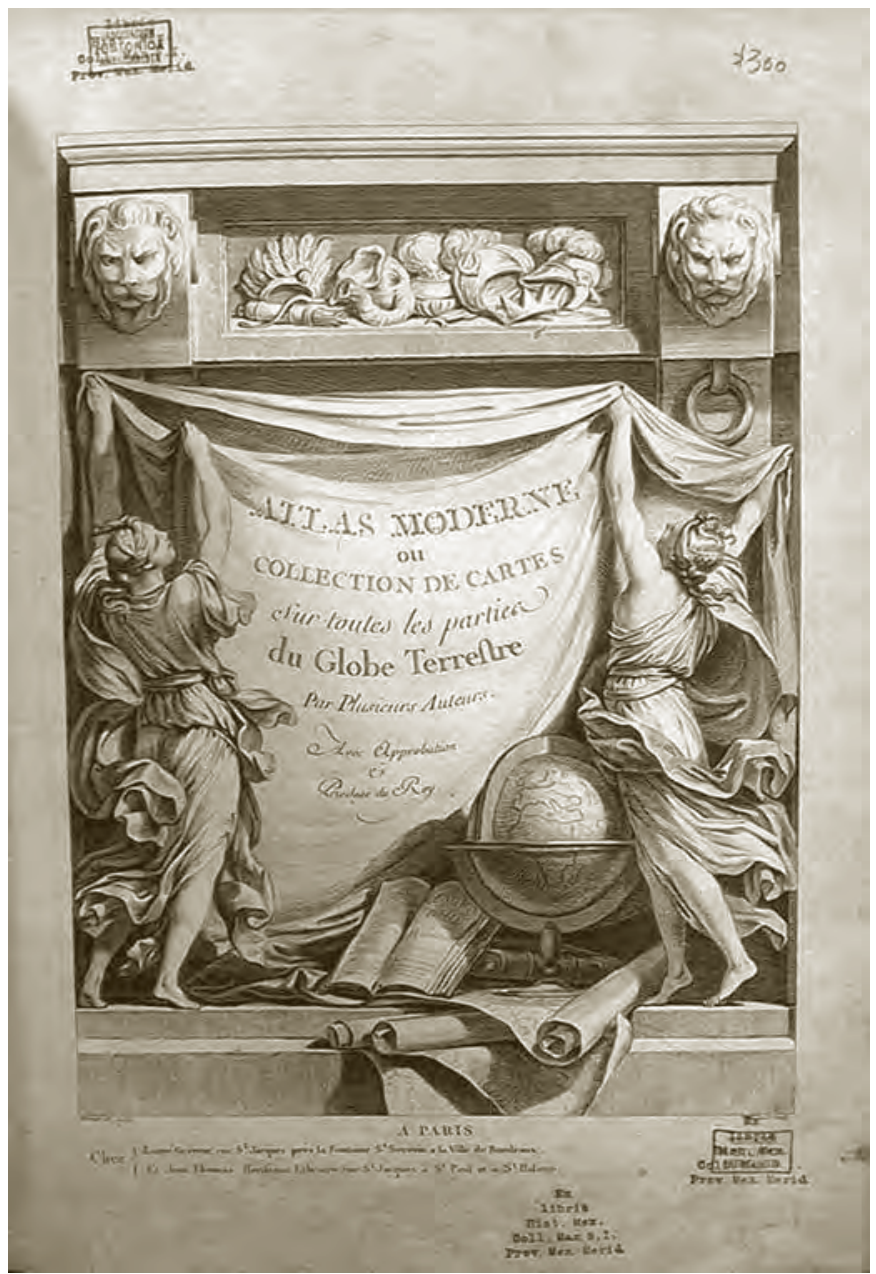

553 Por ejemplo, Antonii Francisi Aguado de Cordova, Alfonsi Antonii Aleman et Rosales et Domni Josephi Lopez Arguleta. Bullarium Equestris Ordinis S. Iacobi de Sphata...Matriti: Ex Typographia Ioannis de Ariztia, 1719. Biblioteca Eusebio Francisco Kino 016334 
Es preciso aclarar que suele emplearse de manera frecuente la palabra frontispicio ${ }^{554}$ para designar genéricamente a la portada, "pero conviene restringir su uso, como indica el DRAE, a la página de un libro anterior a la portada que suele contener el título y algún grabado o viñeta". 555 En lo particular preferimos emplear "portada con frontispicio" (que es una forma de portada grabada), ${ }^{556}$ para designar únicamente a aquella que tiene por elemento decorativo la representación de una fachada arquitectónica. ${ }^{557}$ Puede verse un ejemplo de lo anterior en la siguiente imagen que se presenta.

554 Lorenzo Baldacchini (2001). Op. cit. pp. 81-84.

555 Julián Martín Abad (2004a). Op. cit. p. 65

556 Algunos autores, como Eduardo Báez, denominan a esta portada como arquitectónica.

557 Giuseppina Zappela. Op. cit. p. 421. La autora dedica parte de su atención a diversas formas de estudio para las portadas que son: técnico-tipográfico, iconográfico-artístico, filológico-textual y editorial en las páginas 422 y 423. 
Secretos del estante: elementos para la descripción bibliográfica...

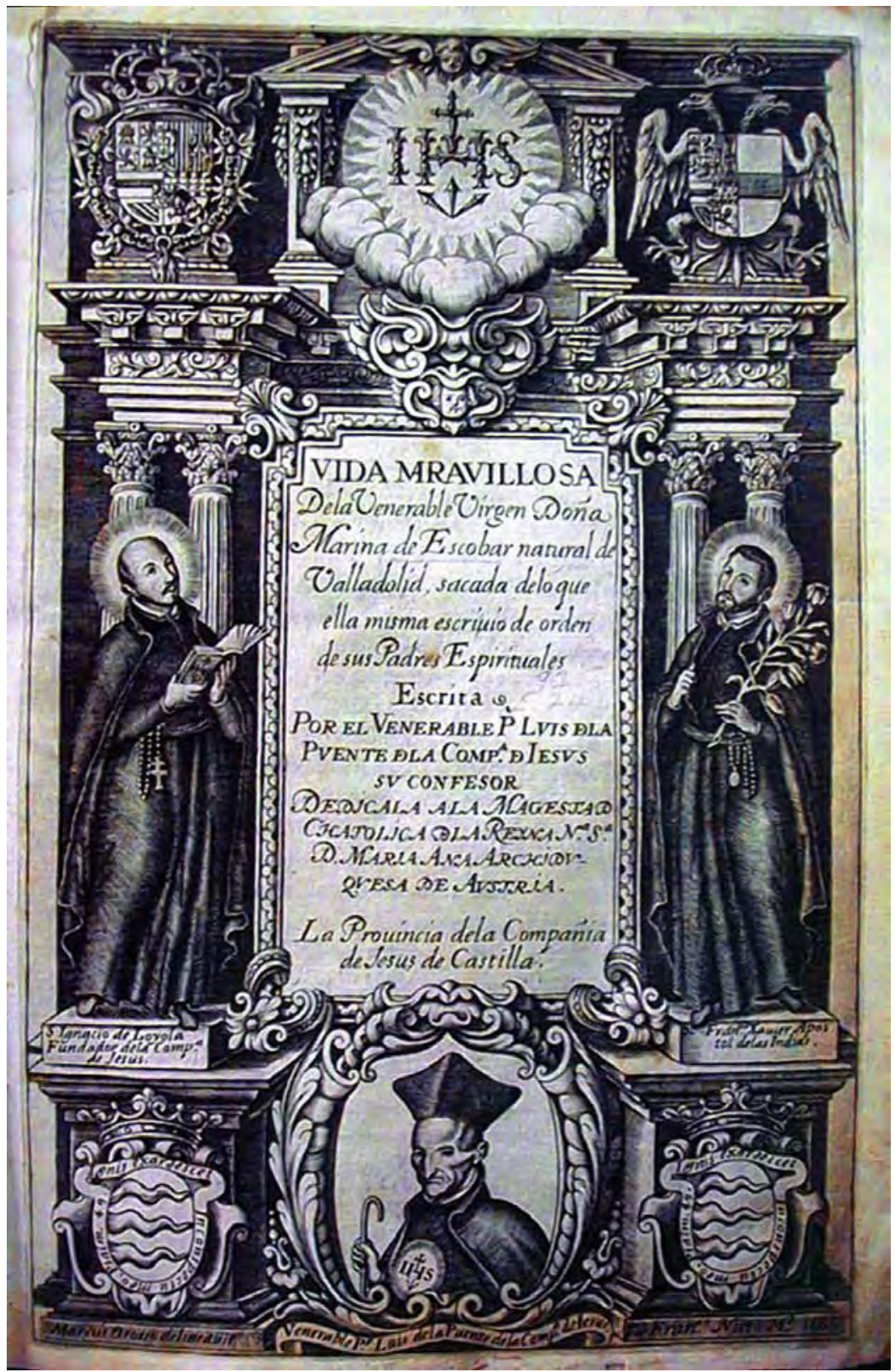


c) Marcas tipográficas 558

La marca tipográfica es un grabado que aparece regularmente en la portada de los libros antiguos y, por tanto, debería tratarse como un elemento de ornamentación. Debido a que forma parte de la descripción "casi facsimilar", hemos decidido explicarlo ahora. Este grabado puede ser una alegoría, monograma, ${ }^{559}$ anagrama $^{560}$ viñeta o signo convencional que distingue a un impresor y que puede incluso emplearse por otro impresor, al ser adquirido el taller o heredado por matrimonio. Un ejemplo de estas marcas se puede apreciar en la imagen.

I EOSDEM SALMANTI Primario Pontificij Anteceffore.

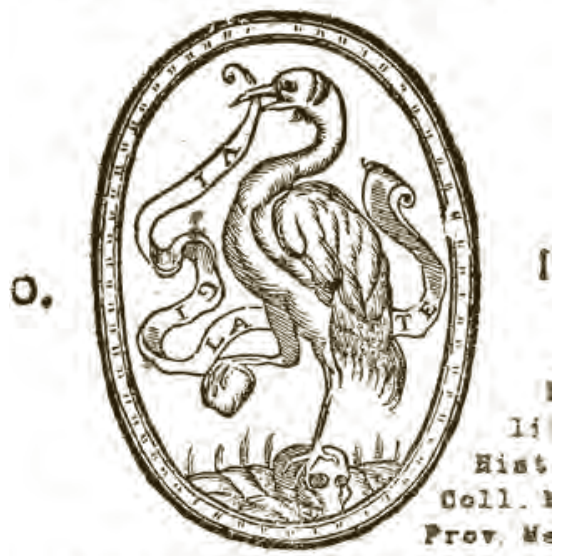

MAN TI CAE. EX Tiagographia Antonix R :

558 También son conocidas como "Escudos tipográficos" o "Marcas de impresor". Cfr. Emilio Torné. Tesauro de la cultura escrita en la Edad Moderna. Madrid: Calambur, 2005. p. 199.

559 "Cifra que como abreviatura se emplea en sellos, marcas, etc." Diccionario de la Real Academia Española. Disponible en la dirección http://www.rae.es/ [Consultado: abril de 2006]

560 "Símbolo o emblema, especialmente el constituido por letras". Diccionario de la Real Academia Española. Disponible en la dirección http://www.rae.es/ [Consultado: abril de 2006] 
Esta marca suele colocarse en la portada o en el colofón - en algunos casos en ambos espacios-, aunque también puede encontrarse en una hoja en blanco después del colofón. Indica de una manera el origen del libro y la calidad determinada por su procedencia. ${ }^{561}$ Es uno de los elementos iconográficos más antiguos presentes en el libro antiguo y puede servir para descubrir la manufactura de un impreso cuando éste no cuenta con un pie de imprenta o un colofón.

Pero como hemos dicho, en las portadas existen otro tipo de elementos decorativos, de ahí la conveniencia de analizar detalladamente el grabado que se presupone es una marca tipográfica, ${ }^{562}$ para poder atribuirla correctamente ya que algunos libros pueden presentar una marca de librero ${ }^{563}$ en lugar de impresor. Para facilitar esta identificación puede observarse que en algunos casos, como el de la imagen, el grabado se acompaña de las siglas de los impresores o de un monograma.

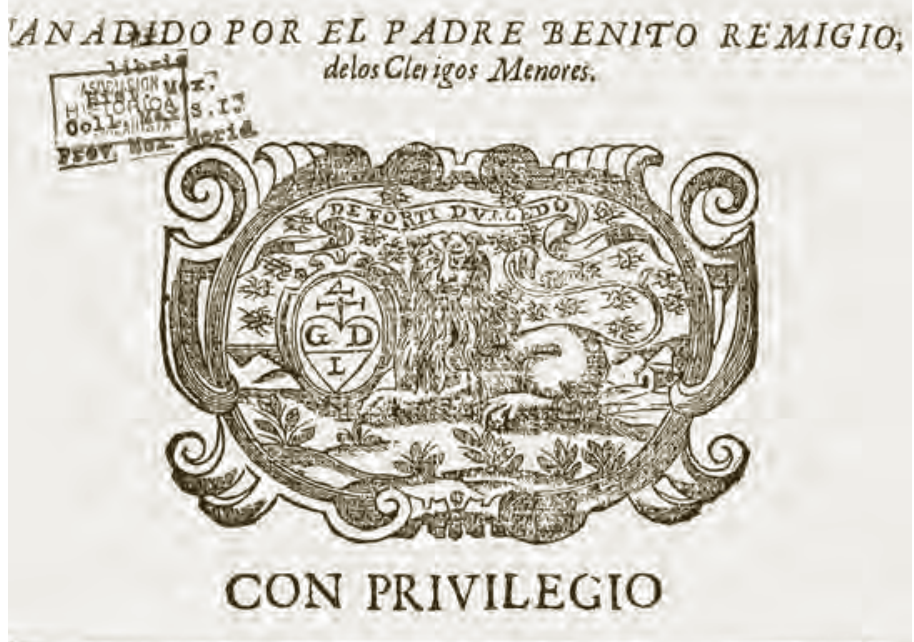

561 Roland B. McKerrow. Op. cit. p. 144.

562 El capítulo D.IV de la obra de Giuseppina Zapella. Op. cit. pp. 559-662, aporta datos relevantes para la correcta identificación.

563 También conocida como "Escudo de Librero". Cfr. Emilio Torné. Op. Cit. p. 199. 
Este elemento suele coincidir con los nombres de los impresores que aparecen en el pie de imprenta, ya sea en portada o en el colofón. En otros casos el grabado se acompaña de alguna frase alusiva a la casa del impresor, por ejemplo "Labore et Constantia" de la casa Plantino y que fue también empleada por sus sucesores que aquí se presenta.

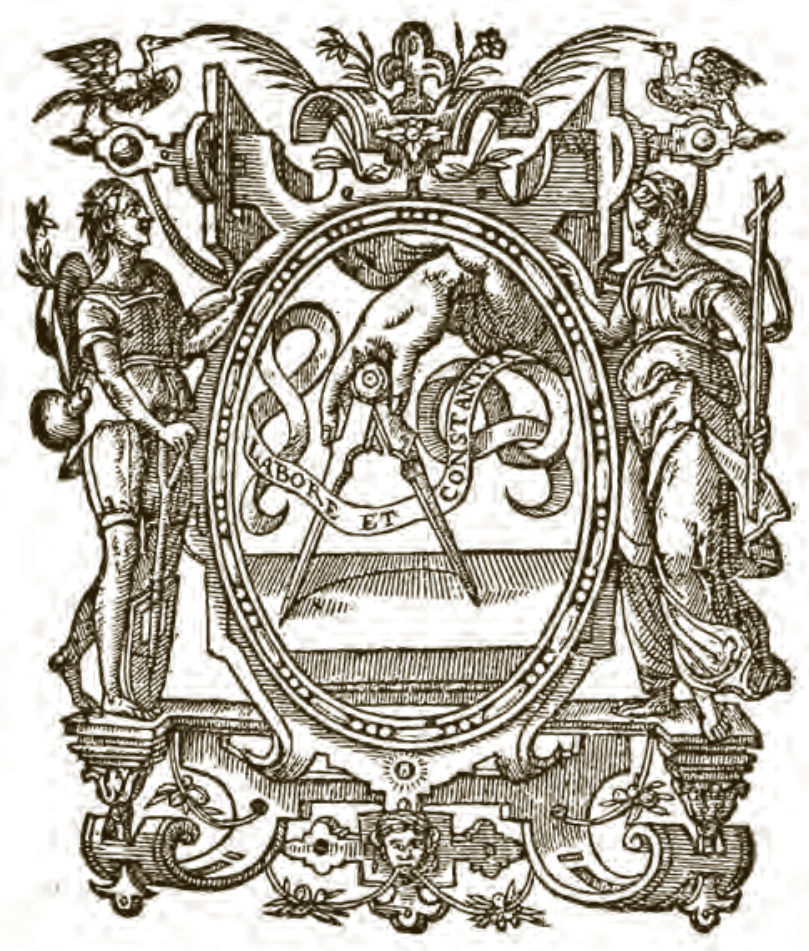

Una vez que el análisis nos permite determinar que ese elemento es una marca de impresor, porque ha sido identificada en trabajos anteriores y coincide en la forma e iconografía con la que describimos, su inclusión en la descripción de la portada se realiza genéricamente entre corchetes [marca tipográfica], como se observa en el ejemplo siguiente: 
TRACTATVS / DE / NVLLITATIBVS / PROCESSVVM AC SENTE- / TIARVM CAVSARVM PATRONIS CÆEETE- / risq; Legum Studiofis, $\&$ in foro præeertim Romano / uerfantibus non minùs utilis quám nece $\int$ arius, / inter alia oftendens quot, \& quibusmodis- / proce $\iint u s$, acfententiæ per modum / nullitatis impugnari, \& impu- / gnatæ ab eifdem nullita- / tibus defendi feu re- / parari pofsint à D. / SEBASTIANO VANTIO / Ariminenfi, pulchro / \& eleganti ordine etiam / cum fuo Indice Alphabetico compo/ieus / [marca tipográfica] / Lugduni, / Apud Mathiam Bonhomme. / [filete] / M. D. LII. / Cum Priuilegys Sumi Pontif. Iuly III. / Henrici II. Gall. Regis. \& Senatus Veneti. ${ }^{64}$

Posteriormente, si para identificar una marca tipográfica se ha empleado un recurso bibliográfico, debe indicarse la fuente como una referencia normalizada en las notas de los elementos decorativos. Si la marca no ha podido ser identificada pero presenta elementos que la caracterizan como tal, en las mismas notas debe realizarse una descripción breve de la iconografía que presenta. ${ }^{565}$

Debido a esta particularidad hay que tener cuidado para no confundir una decoración genérica y una marca tipográfica, por lo que debe consultarse bibliografía especializada ${ }^{566}$ para la correcta identificación. En esta tarea ayuda la consulta a las dos bases de datos, disponibles en la red, que recopilan información gráfica de marcas tipográficas. La primera de éstas es Marques d' impressors realizada por la Universitat de Barcelona, ${ }^{567}$ y la segunda es Printers Devices realizada en la Universidad de Florida. ${ }^{568}$

564 Biblioteca Eusebio Francisco Kino 023774

565 Para lo cual pueden consultarse diccionarios iconográficos, u obras especializadas, o cuando menos identificar claramente los elementos y atributos que distinguen a los elementos comunes de la iconografía clásica y cristiana.

566 Una lista relevante de ésta se incluye en el Vademécum bibliográfico de Julián Martín Abad (2004a). Op. cit. pp. 151-158.

567 Disponible en http://eclipsi.bib.ub.es/imp/impcat.htm [Consultado: abril de 2006]. Esta base de datos recopila todas las versiones identificadas de una marca de impresor, puesto que esta información compilada se relaciona con los libros del fondo antiguo de la biblioteca universitaria.

568 Disponible en http://web.uflib.ufl.edu/spec/rarebook/devices/device.htm [Consultado: abril de 2006] 


\section{d) Tamaño y Formatos}

Con estos datos damos inicio, en nuestra propuesta, a un párrafo independiente después de transcribir la portada, que corresponde a la descripción física del ejemplar. Este párrafo se conforma de los siguientes elementos: formato, tamaño, colación, hojas, páginas, folios, y tipo de letra. ${ }^{569}$ Procedemos a explicar cada uno de ellos y a presentar la forma de representación en el registro bibliográfico.

Un aspecto importante a considerar en la tarea de la descripción bibliográfica es el relativo al formato y tamaño del libro que se describe. A pesar de lo que muchos opinan, ya no refieren la misma cosa el formato y el tamaño cuando se trata de un libro antiguo. ${ }^{570}$ Ciertamente en el origen de estos libros se correspondían de forma exacta el formato y el tamaño, ${ }^{571}$ actualmente esta relación no es la mejor manera de comprender esos conceptos, porque los libros antiguos que hoy describimos son objetos históricos que han modificado especialmente su tamaño con el paso del tiempo por los procesos de encuadernación. Así, los diversos ejemplares de una edición antigua tendrán el mismo formato porque en ese fueron impresos, así cada ejemplar conservado variará su tamaño por la historia particular que haya tenido.

El formato es un dato indispensable en la descripción bibliográfica y catalográfica del libro antiguo, porque se refiere a la unidad básica de composición que dependía directamente del tamaño del pliego, ya que es éste, el que impreso por los dos lados y doblado, forma lo que hoy comprendemos por cuadernillos. Así, el formato refiere siempre "al número de veces en que se ha doblado un pliego para obtener las hojas de un libro". 572

El formato presenta como formas comunes los siguientes: en folio (al doblar el pliego una sola vez resultan dos hojas y cuatro páginas),

569 Todos estos elementos conforman las partes estructurales del libro. Emilio Torné. Op. cit. p. 207

570 Roland B. McKerrow. Op. cit. p. 188

571 Cfr. Giuseppina Zappella. Op. cit. pp. 326-327. Este trabajo contiene una completa explicación sobre el formato de un libro antiguo que se acompañan de un grupo de tablas que presentan varias opciones posibles, pp. 325-385.

572 Roland B. McKerrow. Op. cit. p. 189 
en cuarto (al doblar el pliego una vez más sobre el plegado anterior resultan cuatro hojas y ocho páginas) y en octavo (un plegado más sobre los anteriores del que resultan ocho hojas y dieciséis páginas), aunque por supuesto no son las únicas. ${ }^{573}$ Sin embargo, la compresión del formato se basa en el pliego entero sin considerar el resultado de la encuadernación. Véase la imagen siguiente para una mejor comprensión.

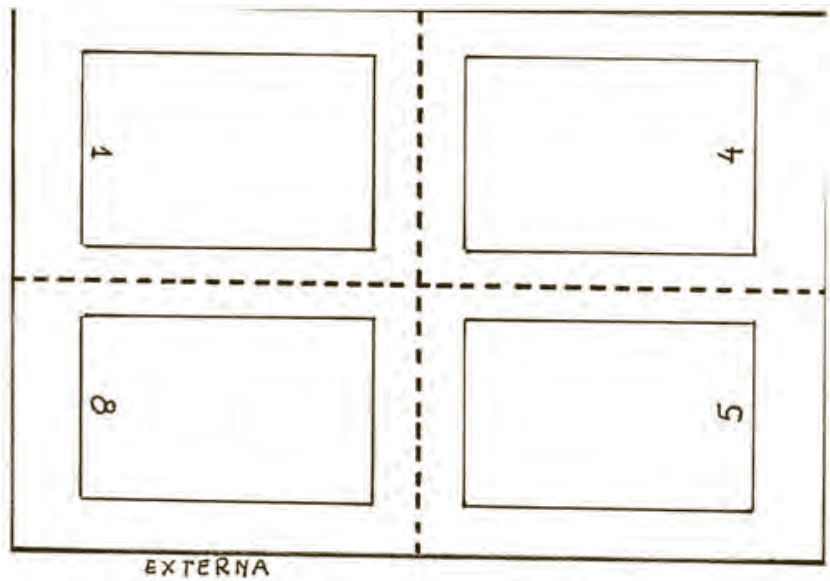

EXTERNA

INTERNA

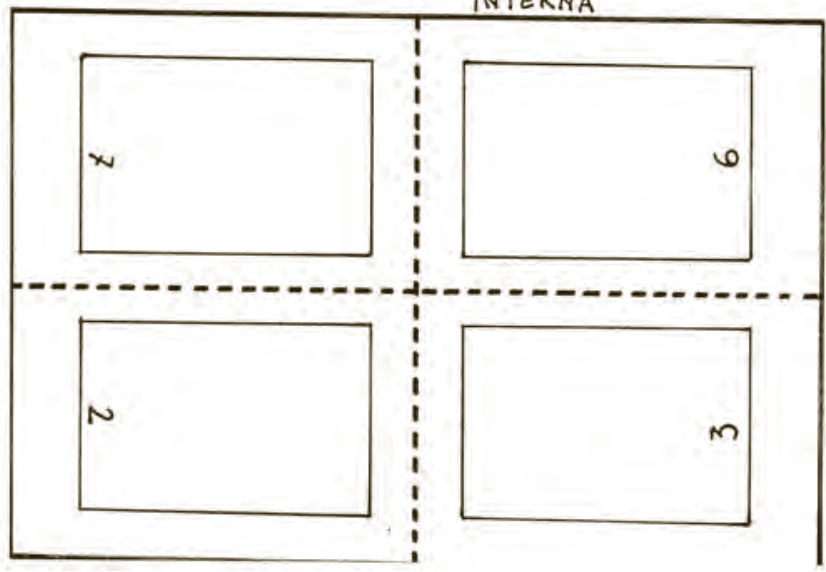

573 Para comprender mejor este punto de la descripción puede consultarse el cuadro elaborado por Alberto Montaner Frutos. Op. cit. p. 88 
Para determinar de forma correcta el formato de un libro debe revisarse la conjunción de la posición de la filigrana en relación directa con la dirección que presentan los corondeles del papel. ${ }^{574}$ Los corondeles son las líneas más separadas que se observan en el papel de trapo ${ }^{575}$ (también llamado de tina o verjurado) y que recorren la página verticalmente, mientras que los puntizones son las líneas más juntas que se encuentran en el mismo papel y que recorren la página horizontalmente. Sobre los puntizones se soportaba la filigrana que dejará como resultado la marca de agua ${ }^{576}$ que ayuda a identificar al productor del papel.

Esta forma tan aparentemente sencilla de determinar el formato en realidad no lo es, porque las variaciones que se pueden encontrar a este respecto imponen mesura en este dato, si se quiere ser extremadamente preciso, para indicar si el formato es regular y por tanto corresponde a los tamaños del papel ya establecidos. ${ }^{577}$ Además este criterio podría fallar porque no todos los papeles de la época pueden presentar los corondeles en la misma orientación.

Lo que está fuera de toda cuestión es que el problema del formato no puede resolverse sin la revisión completa de las signaturas de un

574 Roland B. McKerrow. Op. cit. pp. 189-191

575 Para una explicación del procedimiento de manufactura de este papel puede consultarse Phillip Gaskell. Op. cit. pp. 72-96, Alberto Montaner Frutos. Op. cit. pp. 83-87

576 Dibujo o figura realizado con alambre que se fija entre los puntizones para que deje su huella en el papel. Alberto Montaner Frutos. Op. cit. p. 86. Para información adicional al respecto puede consultarse Charles Möise Briquet. Les filigranes: dictionnaire bistorique des marques du papier dès leur apparition vers 1282 jisquéen 1600. Mansfield: Martino Publishing, 2000. 4 vol. (Facsímile de la edición original del 1923 publicada en Leipzig) y Puzzles in paper. Concepts in historical watermarks: essays from International Conference on the History, Function and Study of Watermarks (Roanoke, Virginia) / edited by Daniel W. Mosser, Michale Saffle y Ernest W. Sullivan II. Delaware: Oak Knoll Press: The British Library, 2000.

577 Por ejemplo si es mayor, menor o prolongado de aquél que se considera regular. Para este punto tan particular puede consultarse Roland B. McKerrow. Op. cit. pp. 188-197; Fredson Bowers. Op. cit. pp. 236-240; Phillip Gaskell. Op. cit. pp. 92-94; Alberto Montaner Frutos. Op. cit. pp. 88-90 y 138; Manuel Pedraza Gracia, Yolanda Clemente y Fermín de los Reyes. Op. cit. pp. 151-167; y especialmente Giuseppina Zapella. Op. cit. pp. 70-72 y 325-385. 
libro antiguo. Sólo a través de este simple procedimiento podremos determinar si las signaturas son secuencias continuas y homogéneas, y por lo tanto refieren a un formato regular. Pero si la secuencia es irregular y discontinua nos encontraremos ante un problema para establecer el formato más adecuado, porque se dificulta, más no se imposibilita, determinar cuántas veces ha sido doblado el pliego en un libro. ${ }^{578}$ Además podemos considerar la posibilidad de un error presente que se haya dado en la encuadernación original, que haya dado como resultado el cambio del orden de las signaturas y, por tanto, no sea un error derivado del proceso de impresión. También es posible que el ejemplar que se describe haya sido encuadernado más de una vez y que en algunos casos estas acciones hayan trastocado el orden de las signaturas.

Aunque para los fines de esta propuesta no somos partidarios de tanta exhaustividad podemos decir, brevemente, que si es regular, el formato en folio presentaría corondeles verticales, si es en cuarto presentaría corondeles horizontales y si es en octavo, presentaría corondeles verticales. ${ }^{579}$ Otra cosa muy distinta es si presenta marca de agua y en qué posición. ${ }^{580}$ No obstante tal detalle y apreciación en la información del formato, sí que debería ser considerada cuando el registro bibliográfico detallado forma parte de un estudio específico $y$, por tanto, se analizan varios ejemplares de una obra y las posibles variantes.

Para nosotros "estas explicaciones son redundantes cuando van seguidas de la [transcripción completa de las signaturas], e inexactas si existen variaciones internas". ${ }^{581}$ Es decir, cuando existen cuadernillos compuestos, que pueden ser encartados, plegados o alzados y que serían el resultado de añadidos o supresiones en una edición antigua. Pero también cuando se trata de casos poco frecuentes, en los que se

578 Edoardo Barbieri. Guida al libro antico: conoscere e descrivere il libro tipográfico. Firenze: Le Monnier Universitá, 2006, pp. 91-93.

579 Cfr. Julián Martín Abad (2004a). Op. cit. pp. 39-40.

580 Bowers indica que Greg nunca encontró en su trabajo, los corondeles y la marca de agua en cada cuadernillo. Fredson Bowers. Op. cit. p. 237. En nuestra propia revisión son escasas las coincidencias en este sentido.

581 Fredson Bowers. Op. cit. p. 240 
observa una decisión del impresor posiblemente motivada por la carencia de ciertos tipos en el proceso de la composición. ${ }^{52}$

Ahora bien, el formato puede representarse de diversas formas en la descripción bibliográfica: de forma completa (en cuarto o en folio), de forma abreviada (fol., 4to, 8vo.) y en numeral exponencial $\left(4^{\circ}, 8^{\circ}\right.$, $\left.12^{\circ}\right){ }^{583}$ Esta última es la que empleamos en esta propuesta para indicar el formato, considerando la regularidad o irregularidad en el número de hojas de cada cuaderno y la impresión de las signaturas que presenta.

Cuando la situación del formato es regular, el formato en cuarto estaría conformado por cuadernillos de cuatro hojas o en octavo por cuadernos de ocho hojas. Pero la situación se complica cuando existen irregularidades. Hemos resuelto esta problemática considerando siempre el número de hojas, homogéneas y continúas que existen mayoritariamente, en los cuadernillos del texto de la obra, nunca del cuadernillo de los preliminares. La razón que explica esta decisión es que este cuadernillo se imprime al final y por tanto responde a otra decisión de impresión distinta a la que se determinó para el texto de la obra.

De esta manera si al terminar la revisión de las signaturas obtenemos la siguiente colación: $† 4, \mathrm{~A}-\mathrm{D} 8, \mathrm{E} 2,{ }^{584}$ por tanto podemos establecer el formato en octavo. Esta forma, tal y como la declaramos,

582 Por ejemplo, existe un ejemplar de un impreso mexicano en el que el impresor resolvió de una manera muy diferente el orden de sus signaturas. Así, al terminar los cuadernos de un formato en cuarto, en el último tercer alfabeto de $\mathrm{Y}$ (Yyy), el impresor emplea unas signatura Ttt y Yyy por cada columna del texto, y así se mantiene en dos cuadernos, el sieguiente será Vvv y Zzz. A partir de aquí vuelve el uso de la signatura normal con el orden Xxx. Larraga, Francisco (O.P.), Promptuario de la Theologia Moral... que se ilustra con la explicacion de varias Constituciones de N. SS. P. Benedicto XIV... Con las licencias necessarias reimpresso en el Colegio Real de San Ignacio de la Puebla de los Angeles, 1766. Son los cuadernos correspondientes a las páginas 539-552. Centro de Documentación Histórica Rafael Montejano de la Universidad Autónoma de San Luis Potosí.

583 Giuseppina Zapella. Op. cit. p. 334

584 Aquavivae, Claudio (S.I.). Instructio pro superioribus ad augendum... Florentiae: Apud Iuntas, 1604. Biblioteca Eusebio Francisco Kino 017963. 
también presenta un inconveniente que debemos precisar: cuando se encuentran cuadernillos de seis hojas, nuestra propuesta podría llevar al equívoco de establecer como formato el $6^{\circ}$, que no existe. Según los especialistas, este doblez del pliego formalmente debería ser considerado como un cuarto encartado. ${ }^{585}$ Para nuestra finalidad, basta indicar que es en cuarto, porque este dato se complementa con la transcripción de la fórmula colacional.

Una vez establecido el formato, pese a las dificultades, debe indicarse entre paréntesis el tamaño del libro que se describe. No debemos olvidar que aquí nos referimos al tamaño de un ejemplar concreto. Por lo tanto este dato debe indicarse en milímetros y solamente en lo que corresponde al largo de la obra: $(215 \mathrm{~mm})$. Efectivamente en la actualidad el tamaño de un libro no parece ser un detalle importante en el registro bibliográfico o catalográfico, aunque es un elemento representado todavía. En general este dato se indica en centímetros y regularmente es una medida redondeada que, por esa razón, nunca es exacta.

\section{e) Signaturas, paginación y foliación}

Ahora bien, hemos dicho que una de las diferencias más relevantes entre los libros antiguos y los modernos es la forma de la composición de los mismos que da por resultado su estructura y que la unidad de la misma es el cuadernillo. De ahí que

la definición del formato y la fórmula de colación constituyen la prueba principal de la estructura del libro y de su método de impresión y de encuadernación. 586

Por ello la integridad de los cuadernillos remite a las signaturas tipográficas y de ahí el interés del bibliógrafo en su adecuado registro -y su inevitable revisión-, frente a la visión opcional que la norma internacional ofrece al catalogador.

585 Llamado conjugado por Roland B. Mckerrow. Op. cit. p. 65, pero considerado un $2^{\circ}$ en 6 , o un octavo $3 / 4$ por Giuseppina Zapella. Op. cit. p. 360.

586 Fredson Bowers. Op. cit. p. 163 
Las signaturas representan una información que nos permite identificar a los ejemplares de una edición y sus posibles variantes, por lo que su registro es "el corazón de cualquier descripción y, junto con el título, forma el bloque de información más importante de cualquier libro" ${ }^{587}$ La signatura es la letra o símbolo impreso que encontramos regularmente en la primera hoja de un cuadernillo (en el recto) y se localiza en la parte central inferior de la página y fuera de caja de texto. Este elemento sirve para indicar el orden progresivo del folio según fue impreso y plegado, ${ }^{588}$ véase en la imagen como ejemplo un calderón.
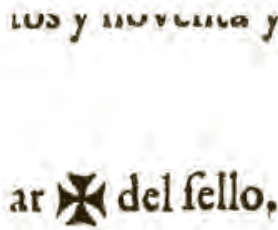

\section{Fr.Iuan de la Anunci Gener:}

\section{Fr.luan de la Madre de D Secreta}
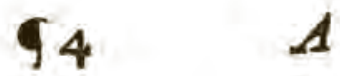

Recordemos que como los preliminares de un libro antiguo se imprimían posterior al texto de la obra, estos suelen presentar signaturas simbólicas (calderón $\uparrow^{589}$, asterisco *, cruz $\mathbf{t}$, parágrafo q, cristus $-),{ }^{590}$ o vocales. Para el texto de la obra se emplearon signaturas alfabéticas con un abecedario de 23 letras (sin contar la J, U o V y la W), tanto en altas (mayoritariamente) como en bajas. ${ }^{591}$

Las signaturas van siempre acompañadas de un número en arábigo o en romano y cuando se agotaba el alfabeto, los impresores duplicaban

587 Ibídem.

588 Roland B. McKerrow. Op. cit. p. 106 y Giuseppina Zappella. Op. cit. p. 399.

589 Ya denominado así desde la época de los primeros impresores. Alonso Víctor de Paredes. Op. cit. h.14v.

590 Alberto Montaner Frutos. Op. cit. pp. 138-139

591 Fredson Bowers. Op. cit. p. 243 
la letra y así sucesivamente. También pueden ser regulares $\left(\mathrm{A}-\mathrm{Z}^{8}\right)$ o irregulares $\left(A-\mathrm{M}^{8}, \mathrm{~N}^{6}, \mathrm{O}-\mathrm{Z}^{8}\right)$. Las primeras, representan sin problema al formato regular empleado en la impresión, mientras que las segundas podrían representar las otras variaciones del formato ${ }^{592} \mathrm{y}$, particularmente, las emisiones o estados de una edición.

Cuando se realiza la revisión de las signaturas no debe resultar extraño encontrar que sólo una parte de las hojas del cuadernillo presentan signaturas y otras no. ${ }^{593}$ De manera regular el cuadernillo tiene impresa la signatura en la primera hoja, y en las restantes pueden encontrarse peculiaridades como que todas las hojas tengan signatura, o solamente las primeras cuatro e incluso solamente los impares. Por esta peculiaridades se deben contar siempre las hojas que existen entre cada signatura impresa, por que nos ayudará a representar correctamente la estructura del libro.

El registro de las signaturas se conoce como colación ${ }^{594}$ o fórmula colacional $^{595}$ y es el dato que se indica en nuestra propuesta inmediatamente después del formato y el tamaño. Debe registrarse con rigurosidad indicando después de la signatura (símbolo o letra) o secuencia de las mismas, en superíndice el número de hojas que componen un cuadernillo. La secuencia continua debe indicarse con un guión (-): A-Z8 y, la secuencia discontinua con una coma (,): A-D4, E8.

Efectivamente, la portada también forma parte de las signaturas de un cuadernillo, pero no suele tener impresa una signatura aunque existen casos en que así fue; sin embargo puede deducirse. ${ }^{596}$ Lo mismo podría hacerse en otros cuadernillo que no presenten signaturas, pero consideramos mejor indicar la presencia del número de hojas del cuaderno dentro de un corchete. ${ }^{597}$ Obsérvense estos ejemplos:

592 Rolan B. McKerrow. Op. cit. p. 242

593 Ibíd. pp. 111-112

594 Ibíd. p. 180

595 Fredson Bowers. Op. cit. p. 236

596 Ibíd. p. 249

597 Roland B. McKerrow. Op. cit. p. 181 


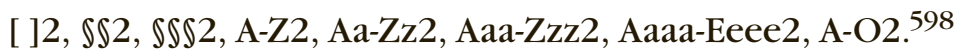

[ ]2, 『3, A-Z4, Aa-Zz4, Aaa-Ddd4599

Ahora bien para registrar las signaturas existen dos tendencias, una de forma larga y otra de forma breve. ${ }^{600}$ La primera indica todas las signaturas tal y como se han encontrado y se encuentran impresas en el libro, como el ejemplo siguiente:

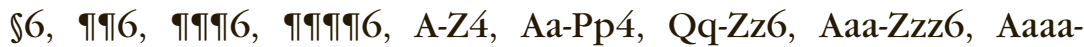
Zzzz6, Aaaaa-Mmmmm6, Nnnnn5, ๆ6, ๆๆ6, ๆ ๆा

La segunda tendencia propone que, para registrar esas mismas signaturas se abrevien indicando con un número a la izquierda de la signatura, las veces que ésta fue impresa. Así quedarían registradas las mismas signaturas anteriores:

§6, 2ף-4ๆ6, A-Z4, A-2P4, Qq-Zz6, A-4Z6, A-5M6, 5N5, ๆ6-5ा6, 5ा4

598 Agustin Betancourt. Chronica de la Provincia del Santo Evangelio de México... Con licencia de los Superiores en Mexico: por Doña María de Benavides, Viuda de Juan de Ribera, 1697. Biblioteca Eusebio Francisco Kino 016341. Incluye portadilla para el Menologio Franciscano, y Tratado de la ciudad de México.

599 Joseph Eugenio Valdez. Vida admirable y penitente de la V.M. Sor Sebastia$n a . .$. Impressa en México: en la Imprenta de la Biblioteca Mexicana, 1765. Biblioteca Eusebio Francisco Kino 018007.

600 Cfr. Giuseppina Zappella. Op. cit. p. 415. En este trabajo se presentan prácticamente la mayor parte de los casos posibles de signaturas. También la complejidad del tema puede revisarse en Roland B. McKerrow. Op. cit. pp. 180-186; Fredson Bowers. Op. cit. pp. 240-283; Phillip Gaskell. Op. cit. pp. 65-66 y 410416; E.W. Padwick. Op. cit. pp. 166-175; Conor Fahy. Op. cit. pp. 105-111; Alberto Montaner Frutos. Op. cit. pp. 138-141; y Lorenzo Baldacchini (2001). Op. cit. pp. 127-133

601 Pedro de Torres Excelencias de S. Joseph, varon divino, patriarca grande, esposo purissimo de la madre de Dios, y altísimo padre adoptivo del hijo de Dios... Con licencia en Sevilla: por los Herederos de Thomas Lopez de Haro, 1710. Biblioteca Eusebio Francisco Kino 017316 
El registro abreviado de las signaturas presenta una dificultad al simplificar las series alfabéticas homogéneas, de tal forma que no se puede distinguir si la forma 2A puede representar cuadernillos marcados con AA o Aa. ${ }^{602} \mathrm{Si}$ bien este método permite una lectura rápida de esa información cuando la letra se repite más de cuatro veces, pero consideramos que solamente es útil cuando se trata de símbolos, ${ }^{603}$ de otra manera podría crear confusiones.

Otros elementos que nos ayudan a conocer la forma física del objeto son la foliación y la paginación. Sobre este particular que testimonia las formas evolutivas de la composición de los libros, podemos decir que las hojas no suelen estar numeradas y tienen dos caras (son bidimensionales) que conocemos como recto ${ }^{604}$ y verso. Por su parte los folios están numerados únicamente en el recto y las páginas numeran el recto y el verso. Aparentemente estos métodos de organización interna del texto, fueron el uno precediendo al otro en la evolución histórica de la impresión. Así hasta quedar la paginación como la conocemos actualmente en los libros modernos, como se observa en la imagen.

602 Jean-François Gilmont. Op. cit. pp. 391-392.

603 Por ejemplo, algunos impresores emplearon una forma similar a este método para abreviar el número de veces que debían imprimir un símbolo en la signatura. En un texto del siglo XVIII, en formato In folio, el impresor empezó a indicar el número de veces que correspondía al calderón a partir del 12 y hasta el 16. La diferencia radica en que el número está impreso al lado derecho del símbolo. Cfr. Juan José de Eguiara y Eguren. Vida del venerable Padre Don Pedro de Arellano, y Sossa... México: En La Imprenta Real del Superior Gobierno y del nuevo Rezado, de Doña María de Rivera, 1735. Este libro se describe en el capítulo siguiente de este libro.

604 "Dicho de un folio o plana de un libro o cuaderno abierto: Que cae a la derecha de quien lee, en oposición al verso o vuelto". Diccionario de la Real Academia Española. Disponible en la dirección http://www.rae.es/ [Consultado: abril de 2006] 


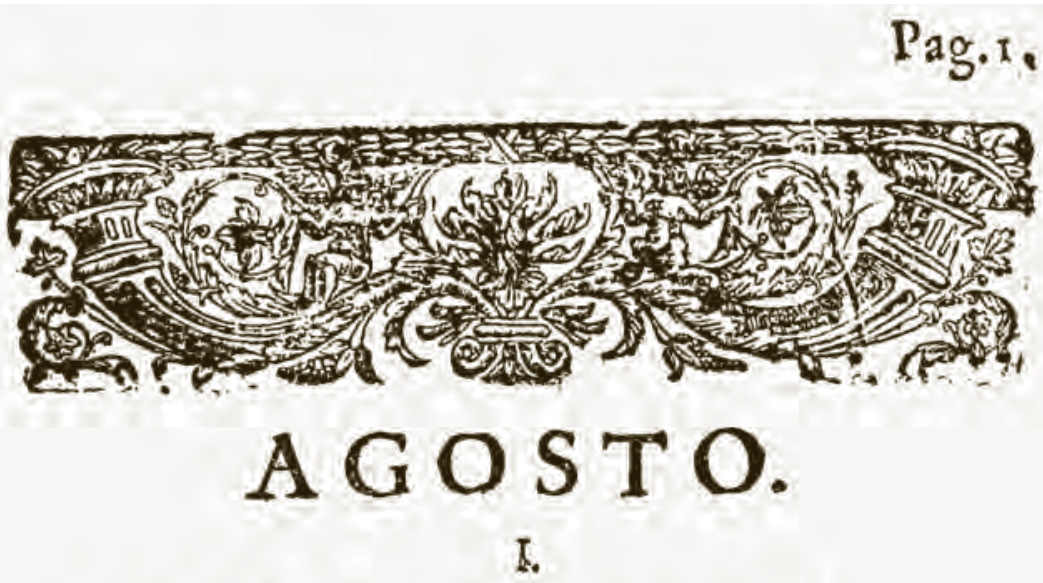

IAS CADENAS DE SAN PEDRO.

Lo que es cierto es que ni la foliación ni la paginación funcionaron como un instrumento

sustitutivo o alternativo de las signaturas tipográficas, es decir un elemento de interés referido a la estructura. El poco uso y la abundancia de erratas en las cifras [que presentan tanto la foliación como la paginación], en claro contraste con el cuidado puesto por el cajista en la composición de las signaturas tipográficas, es dato que merece tenerse muy en cuenta ${ }^{605}$,

y que debe registrarse en las notas relevantes.

Ahora bien, la misma estructura material que se refleja en cuadernillos y signaturas corresponde de forma general a hojas, folios o páginas, y hojas. Por lo que a la colación debe seguir el registro de estos elementos que deben indicarse considerando el nombre real de hojas, de folios o de páginas y, la última cifra efectivamente impresa. Es decir somos partidarios de que las hojas al no estar numeradas se registren dentro de un corchete, y que no se deduzcan los folios o páginas que no fueron impresos para evitar equívocos innecesarios.

605 Julián Martín Abad (2004a). Op. cit. p. 94 
Esto debe ser así porque servirá siempre para comparar esta información con las signaturas y por tanto debe corresponderse con exactitud. ${ }^{606}$ Para ejemplificar lo anteriormente dicho, puede observarse esta descripción que corresponde a los tres primeros ejemplos de signaturas que hemos presentado ordenadamente:

[4], 65 p., [2].

[6], 136p. [2], 156 p., 56 p.

[5], 396 p., [2].

También podemos decir sobre este punto particular, que en más de una ocasión, al iniciar el texto de la obra, veremos impreso en la primera hoja y en la parte superior "Fol." o "Pag.", como también veremos que esto no necesariamente se corresponde con lo que fue impreso. Es decir el impresor indica paginación y en realidad se imprimió foliación, o a la inversa. Este error y los que demás que aparezcan de la misma naturaleza, deben reportarse cuidadosamente en las notas correspondientes.

\section{f) Tipo de letra y reclamos}

El último elemento que consideramos en el párrafo correspondiente a la descripción física del ejemplar es el tipo de letra que presenta un libro antiguo. La descripción de este elemento es mucho más compleja de lo que aparenta, ${ }^{607}$ porque se trata de "una combinación que incluye entre las formas de sus ojos, los rasgos de identidad de cada familia y estilo, el tamaño de las letras y su relación de proporciones". ${ }^{608}$ En suma, es la identificación de la relación con la familia tipográfica (el

606 Fredson Bowers. Op. cit. p. 300

607 Cfr. Harry Carter Orígenes de la tipografía: Punzones, matrices y tipos de imprenta (siglos $X V y$ XVI). Madrid: Ollero y Ramos 1999 y Phillip Gaskell. Op. cit. pp. 12-50.

608 Marina Garone. "La tipografía en el libro antiguo, nociones generales para su estudio". Un impreso encantador: conservación, protección y difusión del libro antiguo / coordinación de Idalia García y Diego Navarro. [Edición en prensa. México, CUIB, 2010] 
conjunto de letras que comparten un diseño v. gr. garaldas por Garamond o didones de Bodoni), ${ }^{609}$ la letrería, que es un alfabeto con características específicas y, la fundición, que se refiere a las letrerías producidas en un mismo taller. ${ }^{610}$

La historia de los tipos de imprenta ${ }^{611}$ es igualmente compleja que la de los libros antiguos, pero la indicación del tipo presente en una edición antigua es un dato que se considera en la descripción bibliográfica porque puede "contribuir a fechar un libro u ofrecer pruebas de irregularidad en la impresión o en una variante de la edición". 612 En este sentido, resulta conveniente registrar esa información de acuerdo al cuerpo, la interlínea y la medida que presentan los tipos empleados. ${ }^{613}$

Ciertamente el conocimiento de la tipografía antigua es un campo para la investigación especializada, ${ }^{614}$ tanto histórica como gráfica, que lamentablemente no ha sido de gran interés para los bibliógrafos materiales. Debido a esto la especificación detallada sobre la tipografía empleada en libros antiguos solamente la consideramos necesaria cuando el registro bibliográfico se empleará para resultados vinculados con este tipo particular de estudios, como los tipos empleados

609 Alberto Montaner Frutos. Op. cit. p. 126

610 Ibíd. pp. 125-127.

611 Para acercarse al tema es recomendable la obra Geoffrey Dowding. An introduction to the History of Printing Types: An Ilustrated Summary of the Main Stages in the Development of Type Design from 1440 up to the Present Day an Aid to Type Face Identification. United Kingdom: The British Library \& Oak Knoll Press, 1998. También si existe interés es conveniente visitar la página Unos tipos duros disponible en http://www.unostiposduros.com/index.html [Consultado: abril de 2006]

612 Fredson Bowers. Op. cit. p. 328

613 Cfr. Alberto Montaner Frutos. Op. cit. pp. 149-153.

614 Un acercamiento a este tema y sus características se puede apreciar en Marina Garone Gravier. Breve introducción al estudio de la tipografía en el libro antiguo: panorama bistórico y nociones básicas para su reconocimiento. México: AMBIFA, 2009. 
por un determinado impresor y que distinguen a su producción. ${ }^{615}$ Si es así resultará conveniente, siempre que sea posible, identificar la designación original que le fue dada por el grabador o el catálogo, y las medidas de la imagen impresa en relación al tamaño de su cuerpo y ojo. ${ }^{616}$ Un muestrario de letras empleadas se ilustra en la imagen.

\title{
FEE DE ERRATAS.
}

Q Ap.r.fol.t. Jin.s g. Tecientos, lee feífcientos. Cap.r: fol, I7. lin.s.Ledefmas, lee Lede!ma.Cap . .fol.22, lin.18. hizief fen,lee hoyeffen. Cap. 2. fol.2 3. lin.2 5.matrimoni,lee matrimonio.Cap 6.fol.45.lin 9. avotes, lee favores. Cap.7. fol.sz. Jin.tz .baeha, lee hachaque. Cap.r4 fol.gt.lin.3. Prevenidos, lee Prevenida.Cap.16 fol. 106 , lin.2 s. vicios, lee viros. Cap. 16. fol. r ro.lin.7. Befo, lee Bosò.Cap.r 7. fol.11 4. Jin.17.vicics,lee viros. Cap.1 g.fol.124.lin.13, aunque, lee Ave que. Cap.21, fol:igt. lin.z, efto, lee efte.Cap.zz.fol. 4 ; i lin.2 s.lleuar, lee llenar, Cap. 43 , fol. 21 , lin, 30 , frente, lee fuente.

\section{Efte Libro intitulado: Vida de $S_{a n} P_{e}$} dro de Alcantara, fu Autor Don Fernando Camberos y Yegros; eftà fielmenteimpreffo, y correfponde à fu original. $\mathrm{Ma}$ drid, y Julio 9. de 1723.

\author{
Licenciado Don Benito del Rito \\ de Cordido. \\ Corrector General por fu Mageltad
}

615 Como es el caso de la obra citada de Henestrosa, quién emplea la forma de medición de tipos utilizadas por Valtón (1939). Op. cit. pp. 250-277 y Millares y Calvo (1953). Op. cit. pp. 24-34. Método que se basa en cuantificar los milímetros que ocupan los tipos en 20 líneas de la caja de texto, así 240R significa que las líneas de esa tipografía miden 240 milímetros y la $\mathrm{R}$ que es romana. $C f r$. Cristóbal Henestrosa. Op. cit. p. 105, nota 4.

616 Marina Garone [2010]. Op. cit. 
Para los fines de esta propuesta solamente interesa identificar si el texto de la obra en su conjunto presenta tipos de letra góticos, redondos (también llamados romanos), o cursivos, ${ }^{617}$ pero también si en el libro se encuentran caracteres griegos o hebreos. Este dato cierra el párrafo correspondiente a la descripción física del ejemplar y se emplean las siguientes abreviaturas: $\mathrm{R}=$ Romano, $\mathrm{C}=$ Cursivo, $\mathrm{G}=$ Gótico, $\mathrm{Gr}=\mathrm{Grie}$ go, y $\mathrm{Hb}=$ Hebreo. ${ }^{618}$ Como se puede apreciar, no estamos integrando ningún método de medición tipográfica por la complejidad que implica.

De esta manera todos los elementos descritos se integran en el párrafo correspondiente conformando una sola unidad. Los elementos se presentarán conjuntamente pero separados por un punto y coma (;) para quedar de la siguiente manera:

$$
8^{\circ} ;(210 \mathrm{~mm}) ; \mathrm{a} 8, \mathrm{~A}-\mathrm{M} 8, \mathrm{~N} ;[8], 194 \text { p.; RC. }{ }^{619}
$$

Creemos que la idea de registrar igualmente las signaturas y la paginación es una solución que satisface a la vez a la mayoría de lectores, porque unos privilegian la paginación y otros, como los especialistas, privilegian los datos que les permitan descubrir la estructura del libro. ${ }^{620}$

El último elemento que consideramos en esta explicación es el reclamo, porque como hemos visto ha estado presente en la representación bibliográfica del libro antiguo que se ha realizado en México. El reclamo, al igual que la signatura, tenía por función ayudar a la secuencia e integridad de las hojas impresas. Este elemento consiste en imprimir al final de la página, fuera de la caja de texto y a la derecha de las signaturas, las primeras letras de la palabra o la palabra completa

617 Lorenzo Baldacchini (2001). Op. cit. p. 134

618 Seguimos a Giuseppina Zappella. Op. cit. p. 179

619 Pedro Salquero. Vida del venerable padre y ejemplarisimo varón el maestro Fr. Diego Basalenque, provincial que fue de la provincia de San Nicolás de Mechoacan... En Roma: En la Imprenta de los Herederos de Barbielini, 1761. Biblioteca Eusebio Francisco Kino 016198.

620 Jean-François Gilmont. Op. cit. p. 393 
con que se inicia la página siguiente. En la imagen se encuentra un ejemplo del reclamo.

Alemania, ion ras mas uamauas de los Eftados. He procurado guardar el eftilo mas propio, concilo y hiftorico me ha fido porsible. En el fegundolibro teniaintento referir de te eipauic riciculauunay iayme Bleda, adonde los hombres doctos y curiolos vetan muy bien feguido efte intento.

(?)

\section{LA V S D O, \\ Et Beatæ Mariæ eius genitrici, \& Beato Dominico P.N.\&omnibus Sanctis.
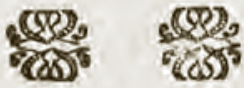 \\ TABLA}

El empleo presenta variaciones entre los distintos impresores, ${ }^{621}$ por lo cual podemos encontrar la presencia del reclamo en los libros antiguos, en todas las páginas, solamente impreso en las hojas que no tienen signatura, en el verso de todas las hojas, en el verso de la última hoja de cada cuadernillo, o no presentar ningún reclamo. ${ }^{622}$ Sin embargo, en la mayoría de los libros antiguos suele encontrarse tanto en el recto como en el verso de la hoja, ${ }^{623}$ por lo que solamente resulta conveniente indicar la presencia de este elemento cuando se encuentra una peculiaridad interesante o, en su defecto, si es relevante para la identificación del libro antiguo.

621 Lorenzo Baldacchini (2001). Op. cit. p. 93

622 Giuseppina Zapella. Op. cit. p. 405

623 De ahí que nos haya llamado la presencia de este elemento en el análisis de los modelos bibliográficos del capitulo anterior. 


\section{g) Los elementos decorativos}

Como parte del valor textual de los libros antiguos debemos distinguir a los elementos decorativos, que representan la cara más agradable de este objeto cultural y son los que aportan más visibilidad en la necesaria tarea de su socialización como bienes patrimoniales. Estos elementos que encontramos en los libros antiguos representan todo un universo gráfico de representación que, sin duda, requiere de un trabajo especializado. ${ }^{624}$ Sin embargo, es un elemento del que no debemos olvidarnos en la tarea de la descripción bibliográfica, precisamente porque es el más vulnerable al saqueo selectivo.

Antes de acercarnos a analizar los diferentes tipos de ornamentación de los libros debemos hacer tres precisiones que nos parecen importantes. La primera se refiere a la técnica del grabado, que puede ser en madera y que conocemos como xilografía, o en metal, que conocemos como calcografía. Entre ambas "hay diferencias no sólo de índole técnica, que son obvias, sino también en cuanto a la manera de concebir y de pensar el libro". ${ }^{625}$ Dichas diferencias se manifiestan directamente en el libro con una evidencia simple: si el grabado es en madera no deja huella sobre el papel, mientras que si es en metal, alrededor del elemento ornamental se puede observar una especie de marco que es la huella del metal sobre el papel. ${ }^{626}$ Un ejemplo de esta característica se puede apreciar en la imagen siguiente.

624 Para acercarse a este campo complejo y rico de estudio pueden consultarse, entre otros, a Blanca García Vega. El grabado del libro español, siglos XV, XVI y XVII: aportación a su estudio con los fondos de las bibliotecas de Valladolid. Valladolid: Diputación Provincial: Institución Cultural Simancas, 1984. 2 tomos; Francisco Esteve Botey. El grabado en la ilustración del libro: las gráficas artísticas y las fotomecánicas. Madrid: Ediciones Doce Calles, 1996, 2 tomos; James P. R. Lyell. La ilustración del libro antiguo en España. Madrid: Ollero \& Ramos, 1997.

625 Eduardo Báez Macías, Jorge Guerra Ruiz y Judith Puente León. Op. cit. p. 11.

626 Denominada como "marca de la plancha”. Cfr. Philip Gaskell. Op. cit. p. 193 


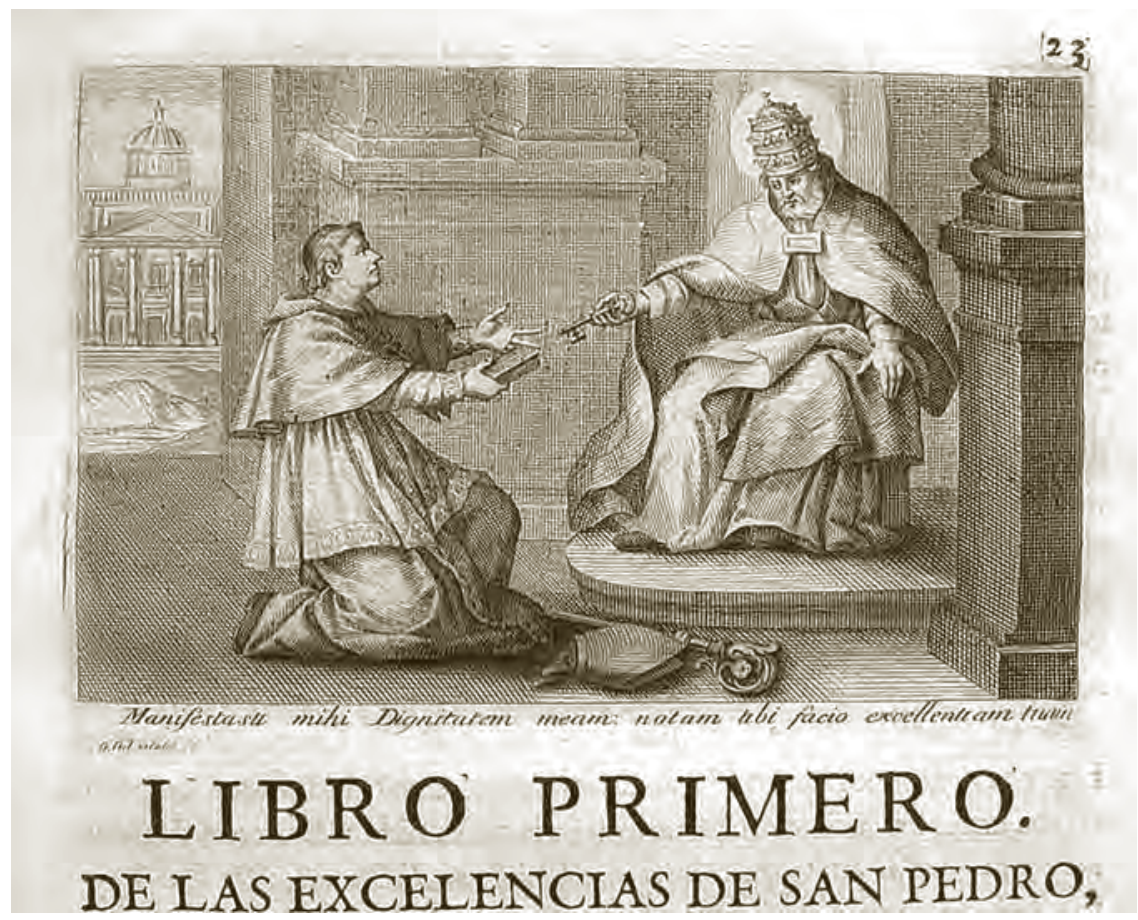

La segunda precisión se refiere a la función ${ }^{627}$ del elemento ornamental dentro del libro, que podemos distinguir entre decorativo e ilustrativo. El primero se compone de aquellos elementos que no tienen relación directa con el texto y solamente decoran, como las viñetas o los tacos, mientras que el segundo se integra con aquellos elementos que se relacionan directamente con el texto, como los grabados interiores o los retratos grabados. ${ }^{628}$

La tercera precisión se refiere a los elementos decorativos que ocupan una sola hoja y que no están considerados dentro de la unidad de composición (el pliego) ni en la unidad de estructura (el cuadernillo).

627 Cfr. Víctor Minguez. "Imágenes para leer: función del grabado en el libro del Siglo de Oro". Escribir y leer en el siglo de Cervantes, compilador Antonio Castillo Gómez. Barcelona: Gedisa, 1999. pp. 255-283.

628 Cfr. Roland B. Mckerrow. Op. cit. p. 137 
Por esta razón consideramos en nuestra propuesta que deben describirse como una hoja aparte, ya que la xilografía ilustra

de manera directa y franca el texto dentro de una misma composición, llevando así la ventaja, sobre el metal, de que permitía el formato en una sola plancha de texto e ilustraciones, mientras que el segundo requería de tiradas aparte

y por tanto constituyen piezas expresamente fabricadas para que ilustren ciertos libros que constituyen verdaderas muestras de la maestría que alcanzó el desarrollo del grabado, como lo representa la edición de Figures de la Biblie. ${ }^{629}$

Ahora bien, a falta de una tipología que nos permita representar los elementos decorativos presentes en los libros antiguos, hemos empleado una propia que nos parece identifica claramente a cada uno de los elementos que hemos encontrado: el primero de éstos es el grabado de portada, que como ya hemos precisado la decora y puede ser, en orden de importancia gráfica, la marca tipográfica o librero, un escudo de familia, ${ }^{630}$ de orden religiosa o episcopales ${ }^{631}$, entre otros; un florón, un taco, y finalmente un grabado representativo con iconografía clásica o religiosa, de los cuales presentamos un ejemplo.

629 Impreso en la Haya: Chez Pierre de Hondt, 1728. Biblioteca Eusebio Francisco Kino 024465.

630 Un texto de gran ayuda para la indentificación de los escudos Ampelio Alonso Cadenas y López y Vicente de Cadenas y Vicent. Heraldario Español Europeo y Americano. Madrid: CSIC. Instituto Salazar y Castro: Hidalguía, 1991-2000. 6 tomos.

631 Para acercarse a este tema es recomendable leer el libro de Vicente de Cadenas y Vicent. Vademecun beráldico: aplicación de la ciencia del blasón, con especial referencia a la beráldica eclesiástica. Madrid. CSIC. Instituto Salazar y Castro: Hidalguía, 1984. 


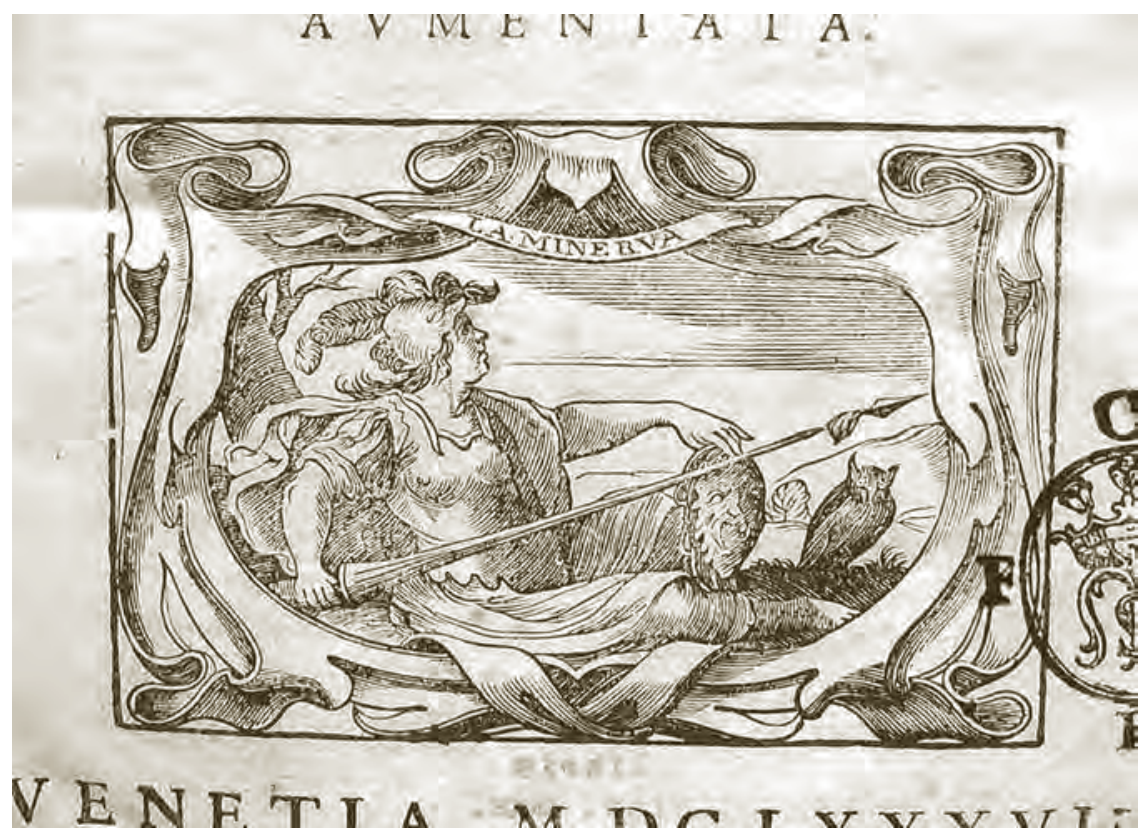

Posteriormente el siguiente elemento es el retrato grabado, ${ }^{632}$ que representa a personajes reales ${ }^{633}$ a los que se les ha dedicado el libro o son los mecenas, pero también puede tratarse de los autores de los libros. Este retrato presenta genéricamente dos formas que dependen de la época de elaboración y de las tendencias estéticas: ${ }^{634}$ en la primera el retrato puede estar dentro de un óvalo, mientras que en la segunda la forma de representación es dentro de un cuadrado. En ambas el

632 Cfr. Giuseppina Zapella. Il ritrato nel libro italiano del Cinquecento. Milano: Editrice Bibliográfica, 1988, Ruth Mortimer. "Author's image: Italian SixteenthCentury Printed Portraits", with an Introduction by G. Thomas Tanselle. Harvard Library Bulletin. Vo. 7, no. 2 (summer 1996).

633 Cfr. Verónica Mateo Ripoll. El clero y los libros. Alicante: Instituto Alicantino de Cultura, 2002. p. 193.

634 Cfr. Pedro Ángeles Jiménez. Imágenes y memoria: la pintura de retrato de los franciscanos en la Nueva España. Mécxico: el autor, 2010. (Tesis de doctorado. Doctor en Historia del Arte. UNAM. Facultad de Filosofía y Letras. División de Estudios de Posgrado). 
personaje puede estar representado, sentado o parado, junto a unos libros o biblioteca con instrumentos de escritura, pero también con otros elementos relacionados con su actividad. Aquí mostramos un ejemplo de lo anterior.

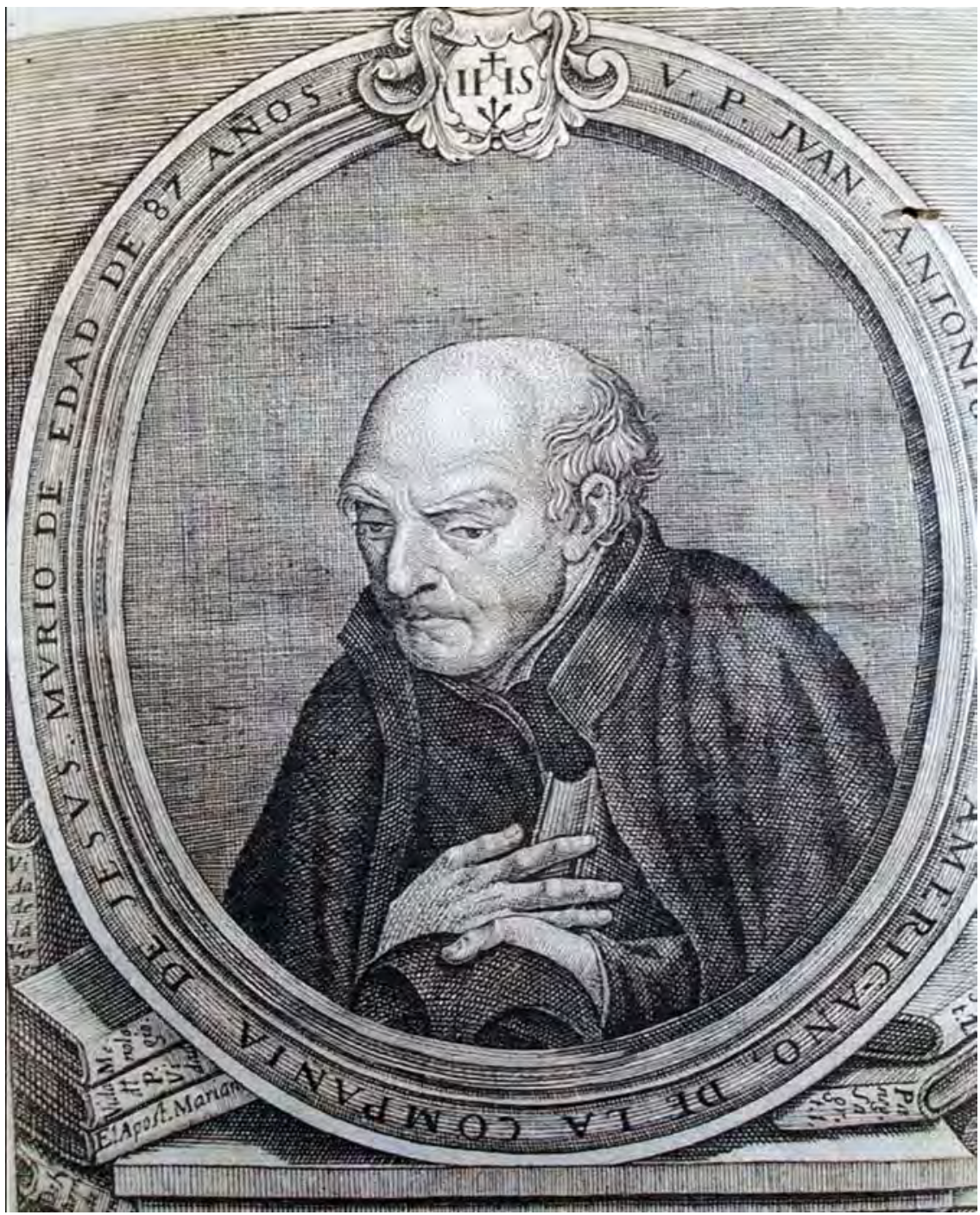


El tercer elemento es la capitular y la letra capital, que han sido tradicionalmente usadas para dar comienzo a un capítulo o parte de un libro. Ambas tienen como noble antecedente a los manuscritos iluminados, pero en éstos se les denomina inicial ${ }^{635}$ y son letras grandes y decoradas que introducen a una parte importante del texto. ${ }^{636}$ En los libros antiguos se denomina capital a la letra que solamente aumenta su tamaño (como la empleamos actualmente), y capitular 637 a la que generalmente contiene algún motivo representativo de decoración. ${ }^{638}$

Por la diversidad de estos motivos, podríamos subdividirlas genéricamente como decoradas e historiadas, aunque se ha determinado que el motivo historiado sólo se refiere al uso de esta letra en los códices e incunables. ${ }^{639}$ Las decoradas presentan como motivos más comunes el antropomorfo, ${ }^{640}$ el floral, ${ }^{641}$ el zoomórfico, ${ }^{642}$ y el zooantropomórfico, ${ }^{643}$ además suelen ser xilográficas. Por su parte, las capitulares historiadas están compuestas por escenas o figuras algunas veces relacionadas con el texto, donde se encuentra una escena narrativa,${ }^{644}$ y suelen ser calcográficas. Aquí presentamos un ejemplo de tipo vegetal.

635 Se llama así porque deriva de la palabra latina "initium", y significa la primera letra. Peter Beal. A Dictionary of English Manuscript Terminology, 14502000. Great Britain: Oxford University Press, 2008, p. 200.

636 Tienen niveles de importancia y significado en relación con un programa de decoración. Por esta característica pueden dividirse en mayores y menores, que pueden estar decoradas o simplemente remarcadas con la misma tinta del texto.

637 Aún cuando Emilio Torné prefiere que sean denominadas como Iniciales como descriptores. Cfr. Emilio Torné. Op. cit. p. 143.

638 José Martínez de Sousa (1993). Op. cit. p. 493

639 Ibíd. p. 501

640 Se representa a la figura humana total o en partes.

641 Se representan flores o también motivos vegetales.

642 Se representa de forma total o en parte a figuras animales.

643 Se representa de forma total o en parte, una composición de figuras humanas y animales como los símbolos evangelistas en donde la figura humana es rodeada por un animal simbólico que la identifica.

644 Michelle P Brown. Understanding illuminated manuscripts: a guide to technical terms. London: The J. Paul Getty Museum: The British Library, 1994. p. 73; y Stan Knight. Op. cit. p. 106 


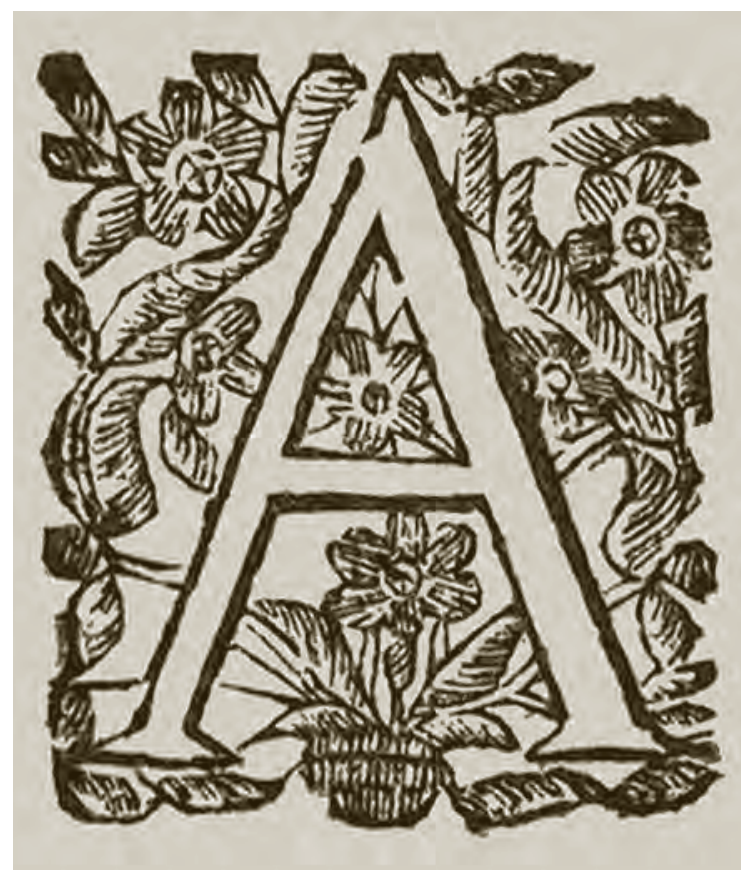

Los siguientes elementos son las orlas y las viñetas. Entendemos por las primeras a la composición formada exclusivamente de tacos xilográficos, a diferencia de la orlas de portada como hemos especificado. Por viñetas entendemos un grabado de orden simbólico como animales, seres fantásticos, máscaras, mascarones u otro, que se emplea para decorar el principio pero también el final de un capítulo o parte del libro. Aquí presentamos un ejemplo de esta ornamentación.

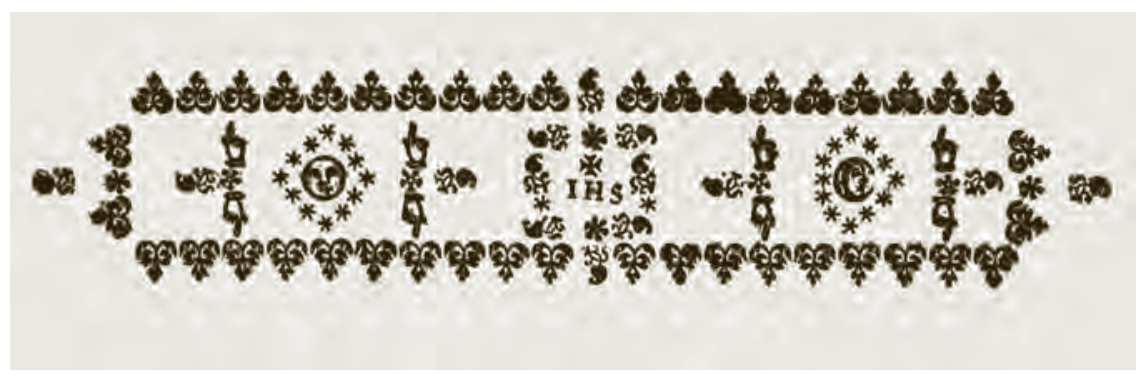


A las viñetas de principio las denominamos de cabecera y regularmente son de forma rectangular. A las viñetas que aparecen al final de un capítulo o de una parte del texto las denominamos de pie y regularmente presentan una forma de triángulo invertido, aunque se dan casos con otras formas geométricas.

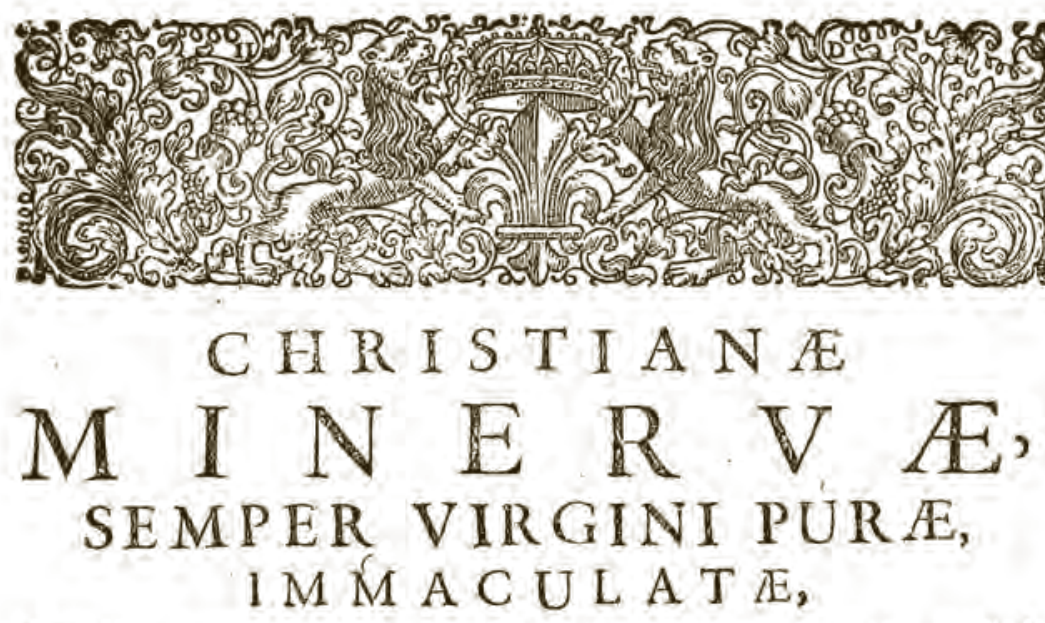

Nullo vnquam hæreditario nævo, aut aviti languinis infectła labeculâ;

Mulieri amicte Solc, coronata flcllis, calccatic Lunâ.

Estas viñetas suelen emplearse en la misma posición de cierre que los florones, aunque hemos visto que éstos también se emplearon como grabados de portada. Tanto en el caso de las viñetas (de pie y cabecera) como de los florones, también encontraremos orlas y viñetas decorando libros impresos en periodos diferentes y geográficamente distantes. Lo cual no resulta extraño, puesto que este tipo de material, junto con las letrerías y las prensas, se traslada entre generaciones de familias impresoras o por la compra del material de un taller tipográfico. Aquí mostramos un bello ejemplo empleado en las prensas novohispanas. 


\section{O. S. C. S. M. E. C. A. R.}

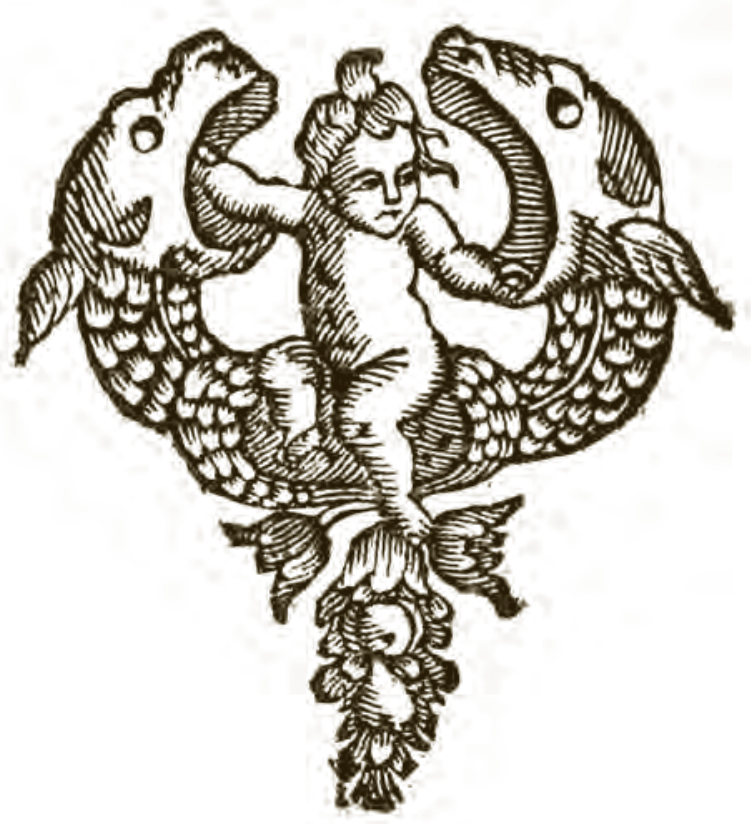

El último elemento son los grabados interiores, que regularmente suelen ilustrar el texto de una obra y pueden insertarse dentro de éste (xilográficos), o conformar una serie en hojas aparte (calcográficos) que se insertan donde corresponde. Este tipo de grabados suele ser común en los libros científicos en los que se explica un procedimiento, una máquina o instrumentos, aunque también se pueden encontrar en libros de emblemática o históricos, como el del ejemplo que presentamos. 
Secretos del estante: elementos para la descripción bibliográfica...

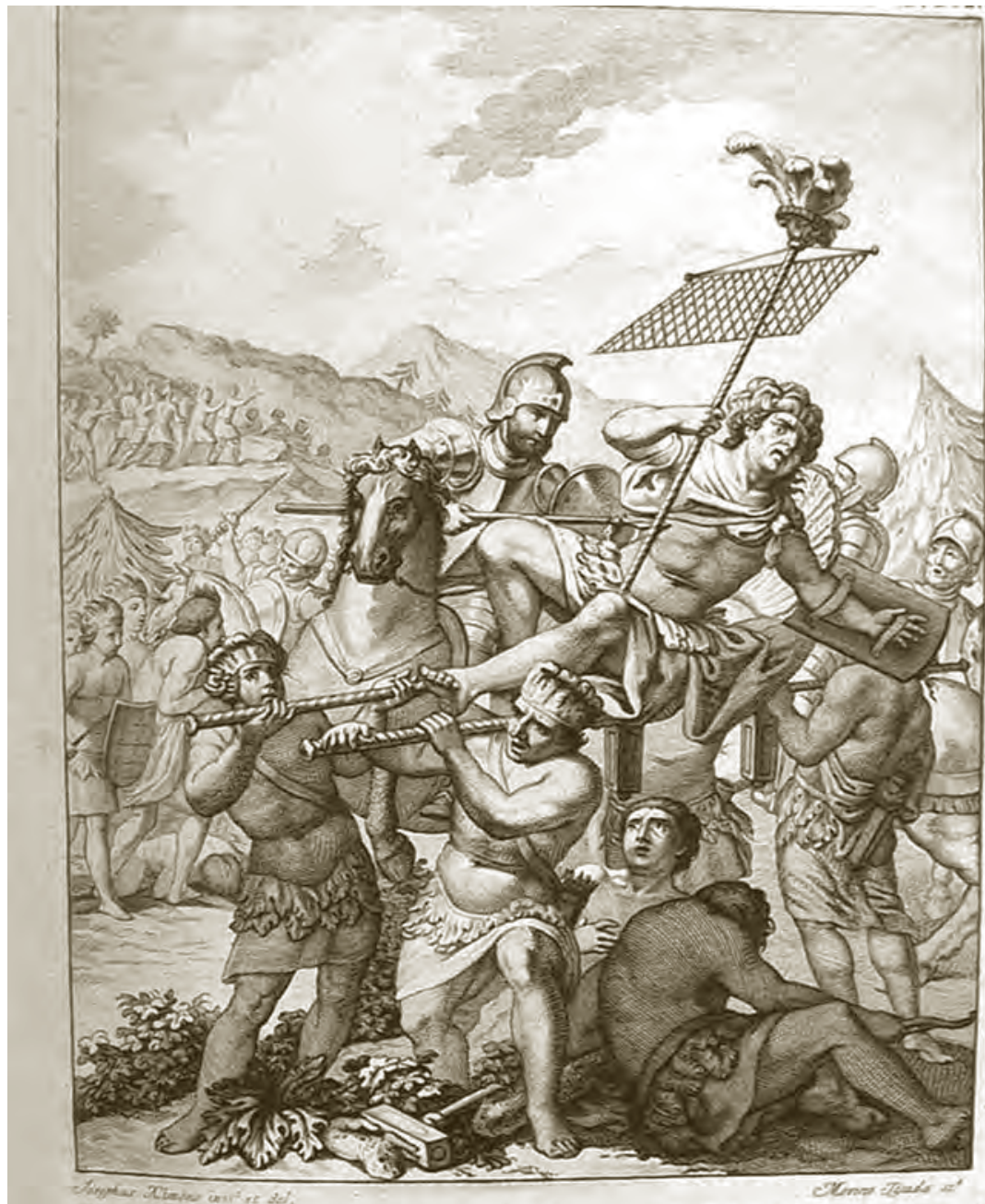

Pelea todo al poder de X (erico con el corto cxerito de CoRTÉs en el Valle de Otumba, donde quedan deshechos y destruidos los Xericanos.

En nuestra propuesta consideramos dos maneras correlacionadas para el registro, cuando se considera que el elemento es relevante. Se trata de describir la forma de ornamentación que es, dentro de la relación 
de contenido, de la siguiente manera: "Portada orlada", "Grabado calcográfico", "Escudo nobiliario", etcétera. Posteriormente y en notas debemos especificar las características del grabado y las medidas en milímetros que le corresponden (ancho por alto, ${ }^{645}$ por ejemplo: "Grabado en h.1v. de la Virgen de Guadalupe dentro de una orla tipográfica (151 x $113 \mathrm{~mm})$ ". 646

\section{b) Relación del contenido de la obra: los preliminares y el texto}

El siguiente párrafo de la descripción bibliográfica que sigue a la transcripción de la portada, el formato y la descripción física, es la relación del contenido de la obra, que forma otro párrafo independiente. Este párrafo se integra con la descripción detallada de cada uno de los preliminares que se encuentran en el libro y la parte que ocupan en la estructura del objeto. También se considera la ubicación del texto de la obra, en ocasiones si está dividido, el lugar de las tablas e índices, y si existe colofón.

Debido a la importancia de estos elementos, creemos conveniente hacer una explicación breve sobre su función e importancia antes de presentar la propuesta para su descripción. En principio debemos comprender que en los primeros tiempos de la imprenta, el libro no fue considerado como un enemigo ni del sistema político ni de las ideologías imperantes. ${ }^{647}$ Esta situación fue cambiando gradualmente conforme se fue constatando su influencia en el mundo social y cultural de la época. Así, se fue requiriendo de un control más preciso sobre el producto impreso mediante ciertas disposiciones legales de obligado cumplimiento.

645 Alberto Montaner Frutos. Op. cit. p. 151

646 Juan de Palafox y Mendoza. Constituciones para la contaduria de Iglesia Cathedral... Puebla: Imprenta de Miguel de Ortega y Bonilla, 1713. Biblioteca Eusebio Francisco Kino 016383

647 Para acercarnos a la cultura de la época de la imprenta en Europa, es recomendable el trabajo de Colin Clair. Historia de la imprenta en Europa. Madrid: Ollero \& Ramos, 1998. 
Por esa razón es necesario el conocimiento de las normas legales y de las características de un periodo histórico ${ }^{648}$, para analizar y describir a los libros antiguos. Si observamos el tipo de normas y disposiciones que debían cumplir los impresores antes de sacar una edición a la circulación, veremos cómo en cada una se cumplía con las mismas normas de formas muy diferentes; es decir, no en todos los libros antiguos se podrán encontrar todos los documentos requeridos por la normativa legal de la época. ${ }^{649}$ Aquí mostramos un tipo de licencia.

\section{Licencia del Superior Govierno.}

FL Excelenti/simo Señor Don foacbin de Monferrat, Calatayiur, Sans de la Llofa, Marques de Cruillas, Caba. llcro Gran.Cruz, Clavero, Comendador de Montroy, $y$ Burriana; y Bayllo de Sueca en el Orden de Montefa; Gentil Hombre de Camara de $S M$, con exercicio; Tbenien. te General de los Reals Exercitns; Theniente Corónel de fis Reales Guardias E.jpañulas de Infanteria; Virrey, Go. vernador, y Capitan General de Nueva E/paña, y Prefs. dente dé la Real Audiencia de ella, Éc. concedid Ju licen. cia para la imprelsion de elle Sermon, viflo el antecedente Parecer del Dr. y Mró. D. Antonio Lopez Portillo Ca. noinigo de efta Santa Iglefia Metropolitana, coma confla de fu Decreto de 6. de. Febrero de 1765 .

648 Para conocer cada una de estas normas es recomendable el libro de Fermín de los Reyes Gómez (2000). Op. cit. T. 2, apéndice legislativo y también José Simón Díaz. Op. cit. pp. 19-46.

649 Probablemente habría que revisar y cuantificar cuántos libros de un periodo específico, presentan todos los documentos requeridos según la legislación predominante en el momento de su producción, para comparar cuántos de esos libros no la cumplen. 
El conjunto de documentos que anteceden al texto de una obra son conocidos como preliminares. ${ }^{650}$ Como ya hemos aclarado, forman un cuadernillo que se imprime después de la obra y una parte de los mismos. Se trata de documentos que no tienen un orden regular de presentación y son, por una parte, prueba de la tramitación necesaria que las leyes establecían para la impresión de un libro, ${ }^{651}$ y por otra son documentos de naturaleza literaria.

Por esta condición se denomina a los primeros como preliminares legales, entre los que se encuentran el privilegio o cesión del mismo, las licencias (civiles y eclesiásticas), ${ }^{652}$ las aprobaciones (como manifestación directa de la censura y el control), que pueden ser civiles o religiosas, las erratas y la tasa. A los segundos los denominamos preliminares literarios y entre ellos se encuentran las dedicatorias, que pueden ser realizadas por el autor de la obra o por el mecenas, ${ }^{653} \mathrm{y}$ dirigirse a personas e instituciones importantes del contexto cultural

650 "Cuando se empieza a ver la modificación en la estructura de los libros es a partir de la Pragmática sobre los libros de Juana de Austria en 1558, en que se reitera la obligación de la censura previa, pero esta vez se obliga a la inclusión, al principio de los libros de la licencia, de la tasa y del privilegio si le hubiere (también el nombre del autor, lugar de impresión y nombre del impresor". Fermín de los Reyes Gómez. "Licencia y privilegio en el libro español antiguo: breves notas y aclaraciones". Pliegos de Bibliofilia. No. 15 (2001). p. 77.

651 Una descripción breve de esta tramitación y de los documentos que se derivan de la misma, puede encontrarse en Alberto Montaner Frutos. Op. cit. pp. 131133. También es recomendable la lectura de Amparo García Cuadrado. "Aproximación a los criterios legales en materia de imprenta durante la edad moderna en España”. Revista General de Información y Documentación. Vol. 6, no. 2 (1996). pp. 125-187

652 Los miembros de órdenes religiosas debían someter la publicación de sus obras a sus correspondientes superiores. También las licencias de tipo eclesiástico son necesarias y deseables, cuando el tema de la obra entraba en las esferas de la atención de la Inquisición.

653 En efecto, las dedicatorias también pueden ser consideradas como "testimonios inequívocos y directos de fidelidad que buscaban consolidar o proclamar un vínculo entre el autor (y/o su editor o quien auspiciaba la impresión de su obra y un determinado mecenas". De ahí que por ejemplo en el libro novohispano sean los virreyes quienes concentraron un porcentaje importante de dedicatorias. Magdalena Chocano Mena (2000), Op. cit. pp. 211-212 
de la época ${ }^{654}$ — pero también a Jesús, la Virgen y a los Santos-, los prólogos, los textos poéticos y laudatorios, ${ }^{655}$ y también la protesta de fe, de la cual mostramos un ejemplo.

\section{PROTEST A.}

Bedeciendo â los decretos Pontificios, protefto,
que en quanto efcribo en efta hiftoria, afsi de
las virtudes, y obras admirables de el Exemplar, y fer-
vorofo Hermano Juan Nicolas, como de otros fuge-
tos, que fe mencionan en ella, no es mi intencion fe
le dé mas credito, que el que merece vna fee pura-
mente humana: ni intento calificar Santidad, ô virtud
alguna : pues el juicio de efta folo toca â nueftra San-
ta Madre la Iglefia,y â fu Vicario, â quien como obe-
diente Hijo me fujeto: fin exceder los terminos de la
verdad de vná hiftoria por sí falible.

\section{Fuav Antonio de Mora.}

654 Sobre este punto nos dice Caramuel: "A reyes y príncipes se les dedican los libros para que los defiendan de la envidia. Eso es lo que dicen en la dedicatoria. Pero ¿qué rey, pregunto, ha preparado una expedición militar, qué príncipe ha empuñado la espada para proteger un libro que le había sido dedicado? ¿Qué envidioso ha contenido nunca su ira y se ha abstenido de murmurar por el hecho de que el libro hubiese surgido a la sombra de un gran príncipe? Ciertamente, si un libro es bueno, aunque no esté dedicado, será bueno; y si es malo, aunque esté dedicado a Julio César, terror del mundo, o a Tito, delicia del género humano, seguirá siendo malo. Entretanto, visto que el mundo es ya viejo, y que será más fácil lavar a un etíope que hacer que un viejo decrépito cambie de cara, confiémonos a la corriente y dediquemos nuestros libros a los amigos, o permitamos que el impresor se los dedique a los príncipes". Juan Caramuel. Op. cit. p. 89

655 Un grupo de estos textos pueden ser del propio autor, otros más son de amigos o conocidos del autor que alaban su inteligencia, trabajo o mérito. Cfr. José Simón Díaz (2000). Op. cit. pp. 175 y 195 
No debemos olvidar que el libro es un producto controlado y los preliminares legales constituyen un requisito para que el objeto pueda circular socialmente, de ahí que sea importante considerar su registro en la descripción bibliográfica detallada, especialmente porque se trata de control y censura en los libros antiguos y se refiere al ámbito de la Inquisición Española. ${ }^{656}$ A pesar de que esta institución perseguía la herejía, pronto se encargó de controlar

la doctrina y de todo escrito tangente a ella e incluso al de la práctica íntima de la espiritualidad individual; [...y así censurar] las expresiones de escritores y científicos que aun de lejos ofendieran la ortodoxia establecida, cuyo fiel guardián se consideraba. ${ }^{657}$

El más importante de los preliminares legales es el privilegio, que

se daba a la propiedad de la edición, y de esta forma se reconocía y se garantizaba para aquellos lugares donde fuera concedido. Si no se le concedía al autor - por no solicitarlo, simplemente-, sino al librero, o al impresor o al editor, el autor no tenía derechos de este tipo. ${ }^{658}$

Sin embargo, no cubría todo un territorio sino que abarcaba un solo reino o un conjunto de éstos: ${ }^{.69}$ tampoco se otorgaba de forma indefinida sino temporal.

Pero los libros con privilegio no son todos. Una gran parte simplemente posee una licencia de impresión que daría como resultado la revisión del manuscrito y en consecuencia la emisión de las aprobaciones

656 Esta institución fue creada en 1478 por el papa Sixto IV por la bula Exigit sincerae devotionis affectus y a petición de los Reyes Católicos, Isabel y Fernando. A pesar de que es una institución creada para perseguir la herejía, en España funcionó como uno más de los Consejos de la administración de Estado.

657 Ángel Alcalá. Literatura y ciencia ante la Inquisición Española. Madrid: Ediciones del Laberinto, 2001. pp. 12-13

658 María Milagros Ronco López. Op. cit. p. 88

659 Jaime Moll. "El impresor y el librero en el Siglo de Oro". El mundo del libro antiguo / dirigido por Francisco Asín Remírez de Esparza. Madrid: Editorial Complutense, 1996. p. 28 
(derivadas del Consejo, del Ordinario y de la Orden religiosa), en las cuales un conjunto de personas autorizadas emitían comentarios favorables para imprimir una obra siempre que ésta no tuviera nada contra la fe y las buenas costumbres. ${ }^{660}$ Este tipo de documentos también aparecen impresos como censuras, pareceres y sentires. ${ }^{661}$ Solamente después de haberse cumplido esta revisión, el Consejo emitía la licencia y con ello se podían comenzar los trabajos de impresión. El ejemplo ilustra un tipo de licencia.

660 José Simón Díaz. Op. cit. p. 130

661 Parecer y sentir, son formas comunes para denominar las aprobaciones en los impresos novohispanos. Ibíd. p. 151 
* Licencia

Del M. R. P. Thomas Altamirano,

Provincial de la Compañia. de Jesvs.

7 HOMAS ALTAMIRANO Provincial de la Compañia de JE S V S en efta Nueva-Elpaña. Por la prefente doy licencia al Padre Thomas de Elcalante, Sacerdore Religiofo Profeffo de la mifma Cōpañia, para que pueda imprimir efta relacion, que efcribió de la Vida del Venerable Padre Bartholome Caftańo de nueftra Compañia: porque haviendola vifto, y examinado perlonas doctas de la mifima Compañia, jufgan no hallarfe en ella cofa digna de cenfura, y que fe puede imprimir con licencia de los Superiores a cuyo cargo eftà dar facultad para la Impreffron. Dada en nueftro Colegio de S.Pedro,y S. Pablo de Mexico, en 26. de Agofto de 1679.

\section{Thomas Altamirano.}

\section{Pormandadode N. P. Provincial}

\section{Luis del Canto.} Sccretario 
Posteriormente un ejemplar de la edición debía ser entregado de nuevo al Consejo, junto con el manuscrito oficial (el que había sido objeto de revisión); así, un corrector verificaba la integridad entre el impreso y el manuscrito, para emitir la fe de erratas, con lo cual se certificaba que la obra coincidía con el manuscrito y que presentaba un cierto tipo de errores. Pero sobre este documento deberíamos considerar

que en estas listas pueden aparecer indicadas erratas que no existen en todos los ejemplares, porque en un determinado momento de la tirada se detectaron y se corrigió la forma. ${ }^{662}$

Con este trámite terminado, el Consejo puede emitir la tasa, ${ }^{663}$ fijando el precio al que debería venderse el libro sin encuadernar.

En el libro antiguo español y en los que se producen dentro de su esfera cultural,

estos documentos hacen sobremanera pesadas las preliminares, pues ordinariamente no van resumidos como en los de otros países, sino transcritos íntegros y en un lenguaje barroco muy recargado que alarga y dificulta su comprensión. 664

Ahora bien, por norma general, en los documentos preliminares que reflejan la valoración sobre el texto de la obra (v.gr. aprobaciones o pareceres), el inicio de cada documento del que se trate se encuentra en cursiva, indicando el nombre de la persona que lo elaboró y un breve "currículo" de su vida. De esta manera se distingue esta información del texto mismo a diferencia de otros documentos preliminares, como puede verse en el ejemplo que presentamos de una aprobación.

662 Julián Martín Abad (2004a). Op. cit. p. 102

663 Existe un interesante texto que es recomendable leer sobre este particular documento de Fermín de los Reyes Gómez. "La tasa en el libro español antiguo". Pliegos de Bibliofilia. No. 4 (1998). pp. 35-52. Recordemos que la tasa fue finalmente suprimida el 14 de noviembre de 1762 por Real Orden de Carlos III.

664 Jesús Yhmoff Cabrera (1996). Op. cit. T. 1, p. XVI. 


\section{APROBACION,}

DEL R. P. M. 7OACHIN ANTONIO deVillalobos, Professo de quarto voto, de la $S a-$ grada Compañia de 7 ESV S, Prefecto de la muy Iluftre Congregacion de Nueftra Señora la Sancti $/$ sima Virgen, $y$ de la Venerable de la Buena Muerte, en el Colegio de el Espiritu Sancto de efta Ciudad de la Puebla de los Angeles.

\section{Sen̄or Provifor.}

En nuestra propuesta preferimos indicar la presencia de cada tipo de preliminar en hoja, ya sea en el recto o en el verso; recordemos que la forma externa de la hoja es el recto, y la forma interna es el verso. Esto aplica siempre y cuando no exista foliación o paginación. Cuando existe se debe indicar, ya sea "p." para página y "fol." para folio. Este último, al igual que la hoja, requiere de la especificación de recto y verso. Ciertamente, en otras propuestas de descripción, ${ }^{665}$ se propone que la relación de contenido indique las signaturas que corresponden. No somos partidarios de esta postura porque la finalidad de nuestra propuesta es que la información proporcionada pueda ser legible tanto para un lector especializado como para uno que no lo es; de otra manera no se podría cumplir con la expectativa de que este registro sirva como instrumento de consulta y de control patrimonial.

De esta manera, el primer elemento que registramos es la portada, que es una página impar incluso si es grabada, y corresponde siempre a la hoja 1 recto, que escribimos "h.1r." y así sucesivamente. Esto sólo

665 Fredson Bowers. Op. cit. pp. 317-326; Jaime Moll (1989). Op. cit. pp. 177-178; Alberto Montaner Frutos. Op. cit. pp. 142-147. 
se modifica si el libro tiene portadilla, ${ }^{666}$ que es la hoja impresa donde sólo figura un título abreviado de la obra y que suele anteceder a la portada. Por esto, cuando se indica la presencia de la portada, también se específica el tipo de que se trata, según la relación que hemos presentado anteriormente. No debemos olvidar también la presencia de retratos grabados o grabados interiores que podrían encontrarse entre la portadilla y la portada, o solamente antecediendo a la portada y que debemos incluir en esta relación.

La forma en que debemos registrar la información de los preliminares literarios es mencionar el tipo de documento que se trata, por ejemplo dedicatoria, prólogo al lector, poesía laudatoria, soneto, epigrama, etcétera. Si se indica quién lo elabora es pertinente señalarlo. La forma de registrar a los preliminares legales es la siguiente: primero el tipo de documento, después el nombre del responsable de él y sus cargos distintivos (en algunos casos, de un secretario o notario encargado), y finalmente la fecha y lugar en que se elabora el documento preliminar.

En estos documentos es preferible registrar los cargos que se desempeñan en el momento de la elaboración y no los que se han desempeñado, que aparecen mencionados como "Ex lector", "lector jubilado", "rector que fue", "guardian que fue", entre otros. Al igual que en la descripción breve, si la fecha del documento preliminar está impresa en números romanos, debemos transcribirla en números arábigos.

Cuando se registran las aprobaciones, pareceres o sentires, debe transcribirse siempre el nombre de la persona, omitiendo los formalismos de tratamiento social de la época como "ilustrísimo", "excelentísimo" o "M.R.P.M.", ${ }^{667}$ pero respetando la abreviatura $F r$. de Fraile y $P$. de Padre, e indicando la orden religiosa a la que pertenece o el cargo eclesiástico. La inclusión de estos datos permite a los lectores especializados obtener información relevante para ubicar históricamente a las personas que participaron en el control y censura de los libros de una época. Un ejemplo de esto puede observarse en la imagen.

666 Puede verse un análisis interesante, documentado y amplio relacionado con esta temática en Giuseppina Zappella. Op. cit. pp. 501-527.

667 Siglas que significan: Muy Reverendo Padre Maestro 


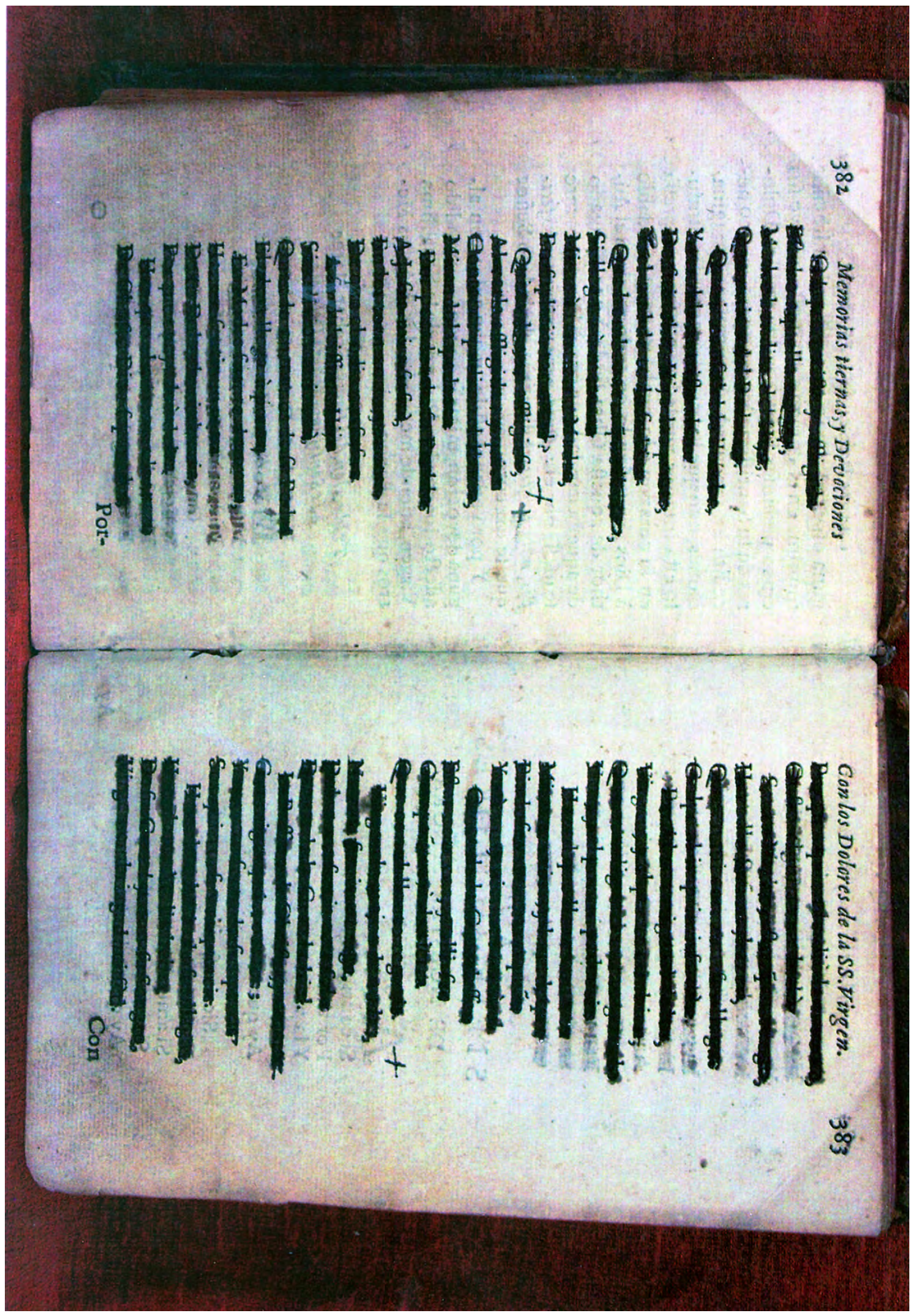


También hay que considerar que, en algunas ocasiones, el documento preliminar está fechado en un convento o establecimiento religioso que indica el lugar geográfico, por lo que si se registra así, no valdría la pena repetir esa información sino transcribir entre corchetes la región donde se ubicaba dicha entidad, si es que se considera necesario. Para comprender mejor estas recomendaciones pueden observarse los siguientes ejemplos:

Documento original:

PARECER DEL R.P.Fr. FRANCISCO LEAL, / Predicador General, Calificador del Santo Oficio / de la Inquisición, Notario Apostolico, Chronista de / esta Provincia del Santo Evangelio, de la Regular / Observancia de N.P.S. Francisco, y Cura-Minis- / tro por su Magd. de la Parroquia del Señor San / Joseph de esta Ciudad de Mexico: y del R.P.Fr. / Diego Ossorio, ex Lector de Theologia Moral, / Predicador General jubilado, Notario Apostolico, / y Cura-Ministro por su Magestad, de la / Doctrina de Chalco... Convento de V.P.M.R. de N. Seraphico Padre S. Francisco de México, y Febrero 16. de 1737. años ${ }^{668}$

Se debe registrar:

Parecer de Fr. Francisco Leal, franciscano, Calificador del Santo Oficio de la Inquisición. Convento de San Francisco de México, 16 de febrero de 1737.

Documento original:

DICTAMEN DEL M.R.P.DR.D. / JOSEPH PEREDA, Presbítero de la Congregación del Oratorio de S. Fe- / lipe Neri de esta Ciudad de México, / y Consultor del Santo Oficio de la Inquisición

668 Documento en h.4v.-5v. de la obra de Joseph de Castro. Directorio para informaciones de los pretendientes de el Santo Habito de N. Seraphico P. S. Francisco... Con licencia en México: en la Imprenta Real del Superior Gobierno, y del Nuevo Rezado: Por Doña María de Ribera, 1737. Biblioteca Eusebio Francisco Kino, encuadernado en 021601. 
...Real Casa del Oratorio de México, y Enero 24 de $1781^{669}$. Se registra:

Dictamen de Joseph Pereda, oratoriano, consultor del Santo Oficio de la Inquisición. Real Casa del Oratorio de México, 24 de enero de 1781.

Documento original:

APROBACIÓN DEL R.P.F. JOSEPH BATLLE, / Lector de Teología, Calificador del Santo Oficio, Guardian del / Colegio de S. Buenaventura, y Colegial que fue del mayor / de San Pedro, y San Pablo, Vniversidad de / Alcala de Henares... Barcelona en el Colegio de S. Buenaventura en 20 del mes de Agosto del año de $1688^{670}$

Se registra:

Aprobación de Fr. Joseph Batlle, jesuita, Calificador del Santo Oficio. Barcelona, Colegio de Buenaventura, 20 de agosto de 1688.

Documento original:

El Excmo, Señor D. Carlos Francisco / de Croix, Marquès de Croix, Ca- / vallero del Orden de Calatrava, Comen- / dador de Molinos, y Laguna Reta en la / misma Orden, Capitan General de los / Reales Exercitos de S. M. Virrey. Gover- / nador y Capitan General del Reyno de / Nueva España, Presidente de su Real Au- / diencia, Superintendente General de Real / Hacienda y Ramo del Tabaco, Juez Con- / servador de este, Presidente de su Junta, / y Subdelegado General de la Renta de / Correos en el missmo Reyno, \&¿c. Concedió / su licencia para la impresion de este Li- / bro,

669 Documento en h. 5r-v. de la obra de Pablo Antonio Peñuelas. Breve noticia de la prodigiosa imagen de Nuestra Señora de los Angeles... Impressa en México: por D. Felipe de Zuñiga y Ontiveros, 1781 Kino 021590

670 Documento en h. 4r de la obra de Miguel Mestre. Vida y milagros del glorioso S. Antonio de Padua... Madrid: A costa de Pedro del Castillo, 1724. Biblioteca Eusebio Francisco Kino 021652. 
visto el parecer del Dr. y Mrò. D. / Joseph Joachin Serruto, y Nava. Como / consta por su Decreto de 7. de Henero de / 1771 Rubricado de S. Excá. ${ }^{671}$

Se registra:

Licencia de impresión, Carlos Francisco de Croix, Virrey, Gobernador y Capitán General de la Nueva España. 7 de enero de 1771.

Documento original:

SUMMA DE LICENCIAS

EL EXmo. Señor D. Juan de Acuña, Mar- / qués de Casa-Fuerte, Cavallero del Orden de Santiago, Comendador de Adelfa, / en la de Alcantara, del Consejo de su Magestad / en el Real, y Supremo de Guerra, General de sus / Reales Exercitos, Virrey Governador, y Capitan / General de esta Nueva-España, \&c. concedió su licencia para la impression de este Compendio, / visto el Parecer de esta Real Vniversidad, \&c. / como consta en su Decreto de 20. de Diziem- / bre de $1727^{672}$

Se registra:

Summa de licencias, Juan de Acuña, Virrey, Gobernador y Capitán General de la Nueva España. 20 de diciembre de 1727.

Documento original:

PROTESTA DEL PREDICADOR

Obedeciendo à los Sagrados Decretos de los / Sumos Pontifices, singularmente, de N. Santissimo / Padre Vrbano VIII. protesto, y declaro, que, to- / cando en este Panegyrico, aunque de passo, las me- / morias de algunos Sujetos, respetables por sus vir- /

671 Documento en h.8.r de la obra de Luis Nepomuceno Gomez Galvan. El sacerdote instruido en los ministerios de predicar y confesar en dos cartas de $S$. Francisco de Sales... Impreso en México: en la Imprenta del Superior Gobierno, del Br. D. Joseph Antonio de Hogal, 1771. Biblioteca Eusebio Francisco Kino 024388.

672 Documento en h.13.r de la obra de Juan Antonio de Oviedo. Espejo de la juventud... vidas de... San Estanislao Koska y S. Luis Gonzaga... En México: por Joseph Bernardo de Hogal, 1727. Biblioteca Eusebio Francisco Kino 024986. 
tudes, y que no estàn colocados en el numero de / los Santos; no es mi intencion prevenir el juycio / de la Silla Apostolica: ni pretendo se les dè mas cre- / dito, que el que merece vna fee humana falible: / sujetandome en todo à las Santas, è infalibles de- / terminaciones de la Santa Madre Iglesia. ${ }^{673}$

Se registra:

Protesta del Predicador, Juan José de Eguiara y Eguren.

Sobre esta propuesta de registro, consideramos que todos los documentos legales deben registrarse tal y como aparecen impresos: "Licencia", "Licencia de impresión", "Licencia del Superior Gobierno", "Privilegio", "Summa del Privilegio", "Erratas", "fe de erratas", "Tassa", etcétera. Recordemos que la finalidad del registro bibliográfico es representar todos los datos de la forma más cercana al original, cuestión que es tanto más importante si se registra una obra en una lengua que no se conoce, como el latín.

Los documentos que pueden presentar falta de alguna información cronológica y geográfica son la tasa y las erratas. El primero nos aporta información sobre el precio del libro en su época y el segundo sobre los errores que se detectaron en la composición pero que no suponen una falta sobre el texto aprobado. De cualquier manera creemos conveniente registrar aunque sea su existencia en el texto, de la siguiente forma:

Documento original:

TASSA

Tassaron los Señores del Real Con $\int$ ejo este li- / bro intitulado: Juizio de los Sacerdotes, \& c. / à seis maravedis cada pliego,

673 Documento en p. 29 de la obra de Juan Joseph de Eguiara y Eguren. El ladron mas diestro de el espiritu religioso, el gran patriarca San Felipe Neri. Panegyrico... Con licencia en Mexico: en la Imprenta Real del Superior Gobierno de Doña María de Ribera, 1733. Biblioteca Eusebio Francisco Kino 18368, encuadernado en 016107. 
como consta en el original en el mismo Oficio. ${ }^{674}$

Se registra:

Tassa. 6 maravedís cada pliego. ${ }^{675}$

O, simplemente Tassa, pero anotando al igual que en otros documentos preliminares la fecha si se cuenta con esa información, el ejemplo anterior no lo tiene. Es preciso destacar aquí que el precio de la tasación, es un dato que puede contribuir a estudios posteriores sobre el mercado del libro, de ahí el interés por consignarlo.

En el caso de las erratas, debido a que se ofrece una información puntual de las palabras donde existen errores de impresión verificados frente al original, bastaría con indicar simplemente "Erratas" o "Fe de erratas", aunque existen documentos que no necesariamente cumplen con lo genérico de este preliminar, como puede observarse en el que se transcribe a continuación:

\section{ERRATAS}

No dexa de tener algunas: No es maravilla, es- / tando impresso por etxtrageros de la lengua, / quando los naturales las cometen. No hai alguna, / que necessite de notarse para la inteligencia: qual/ quiera, si quisiese, las podria enmendar, pues que / son ellas muy cognoscibles. Las que tiene de Ortho- / graphia tampoco le varian el sentido. Perdone el / Lector al Impressor por Extragero, y al Corrector, / que no ha podido conseguir mas: y solo el sabe / que no ha conseguido poco. ${ }^{676}$

Por lo que corresponde al texto de la obra, en la relación de contenido solamente debe indicarse cuáles hojas, folios o pliegos ocupa y

674 Documento en h.18v. de la obra de Pedro de Calatayud. Juizio de los sacerdotes, doctrina practica y anatomia de sus conciencias... En Valencia: en la oficina de Joseph Estevan Dolz, 1736. Biblioteca Eusebio Francisco Kino 023179.

675 Cuando menos así lo sugiere Alberto Montaner Frutos. Op. cit. p. 142

676 Documento en h.6v. de la obra de Joseph Languet. Tratado de la confianza en las misericordia de Dios...Sevilla: en la Imprenta de las Siete Revueltas, a costa de D. Juan Leonardo Malo Manrique, 1744. Biblioteca Eusebio Francisco Kino 024288 
si está dividido de alguna manera particular, por ejemplo en capítulos o en partes. La información sobre las características que presenta el texto (glosado o apostillado, entre otros) corresponde a las notas, pero las tablas o índices, estén al principio o al final del libro, también debe indicarse según corresponda al propio orden del ejemplar.

El colofón y el registrum son elementos más comunes en los incunables y en los primeros libros antiguos. El primero proporciona datos similares al pie de imprenta y pueden aportar información diferente a la portada, ${ }^{677}$ por esa razón, algunos emplean la información del colofón cuando se carece de portada. Nosotros no somos partidarios de esto, en nuestra propuesta si no existe portada se debe tomar la información de los preliminares, considerando siempre el orden de importancia de cada uno de los documentos, de ahí la necesidad de diferenciar un privilegio de una licencia de impresión. Pero si existen ambos elementos, y el colofón difiere de la información de portada, consideramos pertinente registrar esa información transcribiendo de forma casi facsimilar dentro de la relación de contenido y donde corresponde. Aquí presentamos un ejemplo de colofón.

677 Cfr. Giuseppina Zappela. Op. cit. pp. 538-551 
Secretos del estante: elementos para la descripción bibliográfica...

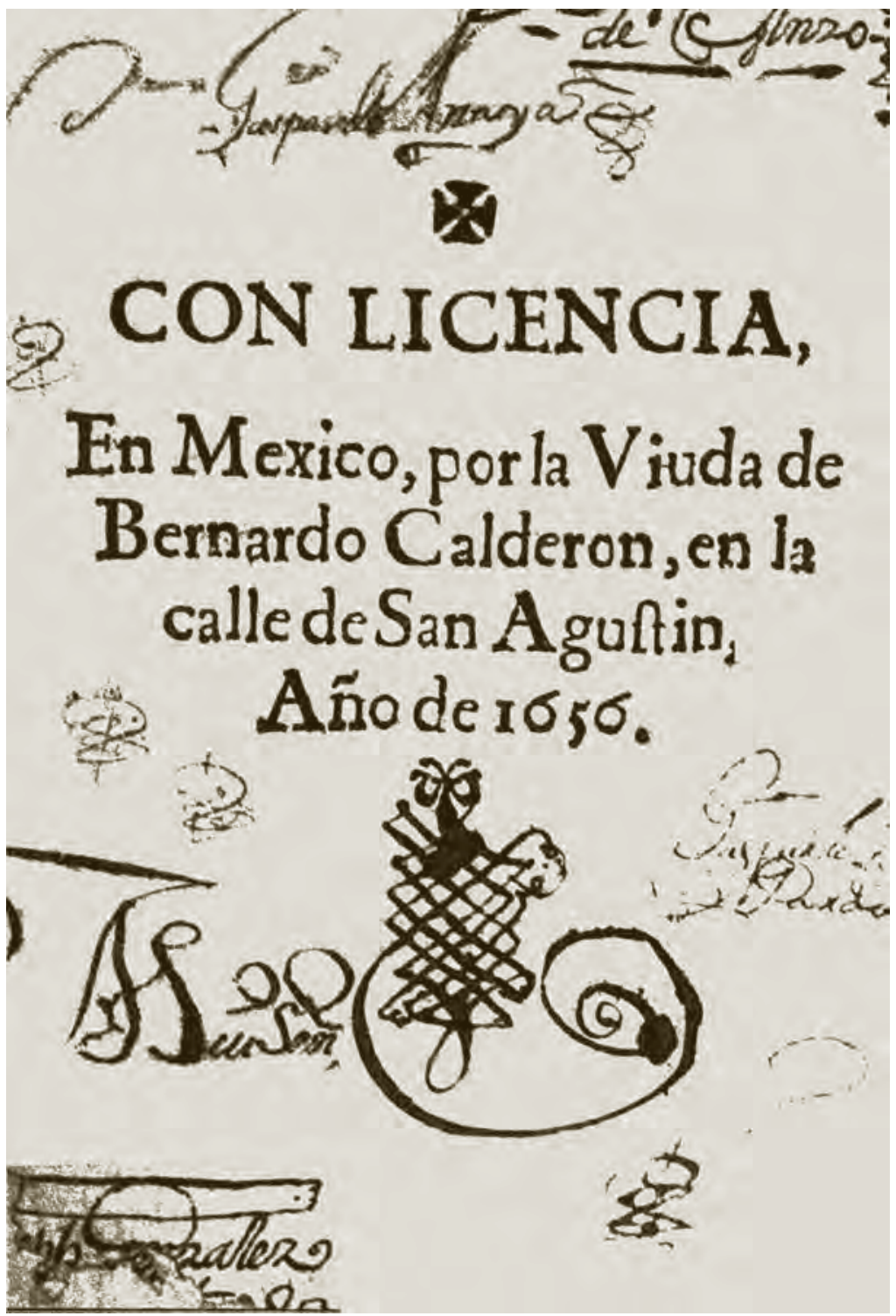

Por su parte el regestrum o registro aparece al final del libro y ofrece la información sobre las signaturas empleadas por el impresor para 
la correcta disposición de los cuadernillos. ${ }^{678}$ Es un dato que servía para el trabajo del encuadernador y para que el comprador del libro supiera si su ejemplar estaba completo. ${ }^{679}$ Tanto el registro como el colofón, van gradualmente dejando de usarse conforme el libro antiguo adquiere características más regulares. ${ }^{680}$ Presentamos en la imagen un caso que mezcla el colofón y el regístrum.

mA.B.C.D.E.F.G.H.I.K.L.M.N.OPQR.S.T.V.X.Y.Z. Aa Bb. Cc. Dd. Ee. Ff. Gg. Hh, li, Kk. Ll. Mns. Nn, Oo, Pp. Qq.Rr. Sf. Tt. Vv. Xx. Yy.Zz. Aaa. Bbb. Ccc, Ddd. Eee.Fff Ggg.

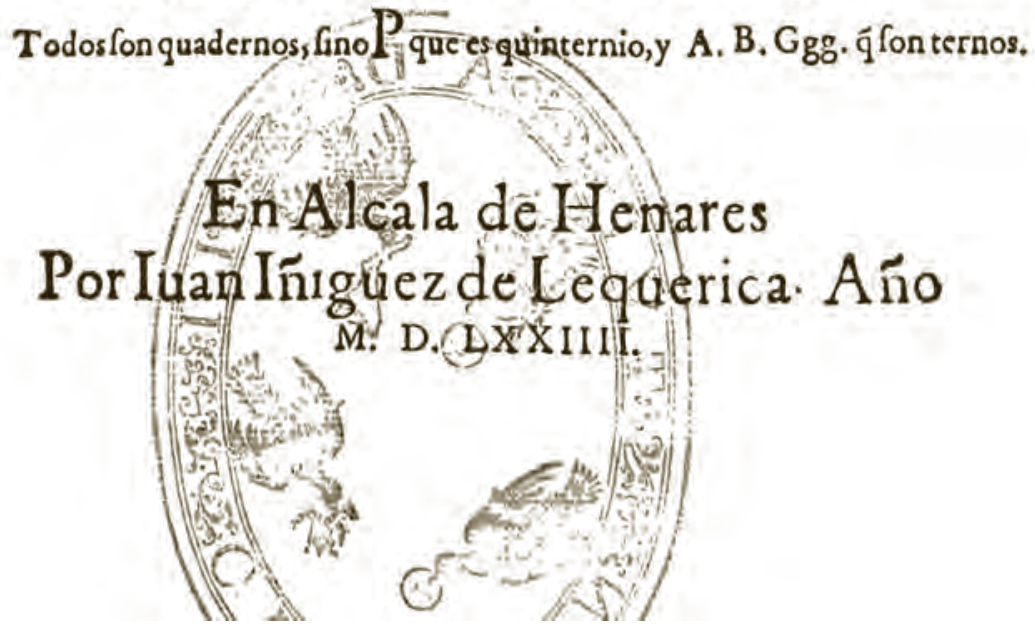

Sin embargo pueden encontrarse ejemplos incluso hasta el siglo XVII, como el que transcribimos que combina ambos datos:

678 Ibíd. p. 402

679 Julián Martín Abad (2004a). Op. cit. pp. 43-44.

680 Philip Gaskell. Op. cit. p. 66 
REGISTRUM. / †ABCDEFGHIKL. / Omnes sunt duerniones, prae / ter $\dagger$, quae sunt simplices. / [filete decorado] / FLORENTIAE / Apud IVNTAS. 1604. / Cum licentia Superiorum. ${ }^{681}$

De esta manera la relación de contenido de una obra, considerando los datos e información que hemos explicado, debe quedar estructurada de la siguiente manera indicando qué parte de la obra ocupa cada documento o parte que transcribimos:

\begin{tabular}{|l|l|}
\hline h.1r. & Portada con orla tipográfica \\
\hline h.1v. & En blanco \\
\hline h.2r. & $\begin{array}{l}\text { Aprobación del P. Francisco de Florencia, jesuita, Procurador } \\
\text { General de la Curia Romana y Calificador del Santo Oficio } \\
\text { de la Inquisición de la Nueva España. Colegio de San Pedro y } \\
\text { San Pablo, 30 de enero de 1688. }\end{array}$ \\
\hline h.2v. & $\begin{array}{l}\text { Licencia de impresión. 6 de febrero de 1688. } \\
\text { Aprobación por Francisco de Aguilar, Abogado de la Real } \\
\text { Audiencia y Provisor de los Naturales del Arzobispado de } \\
\text { México. 12 de febrero de 1688. }\end{array}$ \\
\hline h.3r. & Licencia del Arzobispo, 16 de febrero de 1688. \\
\hline Fol. 1r.-2v. & Dedicatoria \\
\hline Fol.3r-118r & Texto de la obra \\
\hline Fol. 118v & $\begin{array}{l}\text { Erratas } \\
\text { Nota: "Salio â luz â diligencias de la Madre / BERNARDA } \\
\text { MARIA DE LA CON- / CEPCION, Religiofa mas antigua / } \\
\text { del Convento, y actual Priora" }\end{array}$ \\
\hline h.1r-5v. & $\begin{array}{l}\text { Testimonio de sentencia sobre el principal milagro del cristo } \\
\text { de Ysmiquilpa }\end{array}$ \\
\hline h.5v-6v. & Júbilo de la ciudad y algunas circunstancias notables \\
\hline
\end{tabular}

681 Claudii Aquavivae. Industriae pro Superioribus eiusdem Societatis...Florentiae: Apun Iuntas, 1604. †4, A-K8, L4 (4h. 167 p.) error en paginación 105-147 coincide reclamos y signaturas. Biblioteca Eusebio Francisco Kino, sin número y encuadernado en 017963.

682 Alonso Alberto de Velasco. Renovacion por si misma de la soberana imagen de Christo Señor Nuestro Crvcificado... En Mexico: por la Viuda de Francisco Rodríguez Lupercio, 1688. Biblioteca Eusebio Francisco Kino 016180 
Como se observa, esta relación de contenido describe la información respetando la estructura material representada en hojas, folios o páginas, y hojas. ${ }^{683}$ Creemos que esta forma representa mejor la materialidad del objeto y, permite observar con mayor detalle las diferencias cuando se producen, además tanto el lector especializado como el lector ocasional puedan identificar sin equívoco el lugar de una información dentro del libro. Cuando se deducen números de páginas o se remite a las signaturas, se da lugar a confusiones buscando algo que no fue impreso.

\subsection{La descripción bibliográfica del ejemplar: el valor patrimonial}

Nuestra descripción bibliográfica no podría estar completa ni cumplir sus expectativas de control patrimonial si no considera la inclusión de aquellos elementos que otorgan historicidad al objeto. El devenir histórico de un libro antiguo es lo que proporciona la condición patrimonial al objeto, y por tanto es lo que distingue y caracteriza al mismo objeto de otros similares dentro de la misma colección de una institución como respecto de la de otras.

En nuestra propuesta el valor cultural y la condición patrimonial forman parte de las notas de la descripción bibliográfica. Por esta condición, hemos preferido organizar la información de las notas en relación a la importancia que otorgamos a cada elemento en la construcción de ese valor, de esta manera, organizamos los datos en cuatro grupos: el primero se refiere a las formas de posesión y uso del objeto, el segundo, a los valores textuales relevantes que no fueron representados en el propio cuerpo de la descripción, el tercero representa la materialidad del objeto cultural, comprendido desde nuestra visión moderna, y finalmente el cuarto indica todos aquellos datos que se consideren relevantes del ejemplar que se describe y también para las relaciones bibliográficas del mismo.

683 Método ya empleado por María José López-Huertas Pérez. Op. cit. pp. 40-41 
En cualquier caso, para intentar comprender

el complejo universo del libro antiguo es necesario incorporar la figura del lector. De este modo, junto a los conceptos de ejemplar ideal y edición (anteriores a la impresión), de emisión y estado (producidos durante la impresión), creemos necesario incluir el de ejemplar (con las marcas propias de su transmisión), el de ese ejemplar concreto que se ha conservado de un libro antiguo, y en cuyos márgenes, en cuya encuadernación o colocación en las librerías antiguas se esconden valiosas informaciones sobre la historia particular de cada uno de ellos, de los modos de recepción de un género o de los textos concretos a lo largo de la historia, por lo que los datos que aportan merecen una atención mayor de la que hasta ahora se le ha dispensado. ${ }^{684}$

De esta manera, la información histórica de un ejemplar antiguo puede resultar crucial para identificar no sólo la trayectoria del mismo ejemplar, ${ }^{685}$ sino también para obtener datos sobre los usos sociales de las lecturas de una época determinada, o incluso para permitir la identificación de colecciones completas pertenecientes a una persona o a una institución, y con ello favorecer la organización y la recuperación de los libros antiguos resguardados en una biblioteca contemporánea. Aquí presentamos un ejemplo de tejuelo ${ }^{686}$ interior.

684 José Manuel Lucía Megías. Imprenta y libros de caballerías. Madrid: Ollero \& Ramos, 2000. p. 95

685 Cuando el ejemplar de una edición se convierte en un producto histórico singularizado dentro de un fondo. Cfr. Julián Martín Abad (2004a). Op. cit. p. 109

686 Se entiende por éste, al "recuadro de pile, tela, papel, etcétera que se pega al lomo de los libros en las encuadernaciones", pero también al "trozo de papel u de otro material" que se pega a los materiales como portador de la signatura de localización, o cualquier otro tipo de información que permite localizar el ejemplar en una colección. José Martínez de Souza. Op. cit. pp. 828-829. 


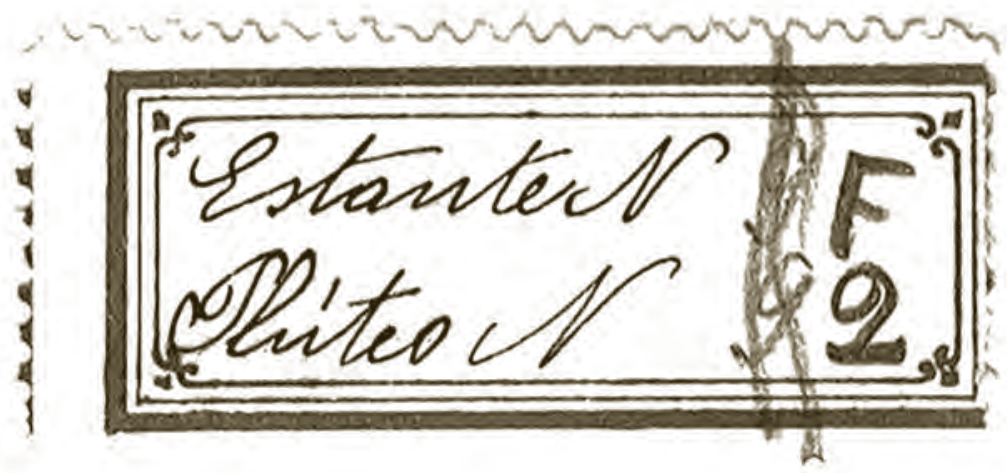

El conjunto de los elementos históricos son conocidos en el mundo bibliográfico anglosajón con el término "provenance", que se refiere al origen o la procedencia original de un libro, ${ }^{687}$ aunque resulta más adecuado el término "fortuna" empleado por estudiosos italianos para referirse al acontecer histórico de un manuscrito, tanto en su aspecto material como en su contenido. ${ }^{688}$ Sin embargo, parte de la riqueza histórica que puede encontrarse en los libros antiguos está determinada no solamente por un origen sino por varios, ya que cuando el ejemplar tiene signos de pertenencia o procedencia se trata de

una pieza de un fondo o de un conjunto de ejemplares unidos naturalmente: pertenecieron a una persona o a una institución histórica, previamente a su incorporación a la colección o conjunto de ejemplares unidos accidentalmente en una biblioteca pública actual. En esta unión física en ocasiones el bibliotecario ha perdido el sentido de lo histórico. ${ }^{689}$

687 Una buena información relacionada con proyectos destinados a la identificación de la procedencia de colecciones antiguas se encuentra en http://www. cerl.org/Provenance/provenance.htm [Consultado: abril de 2006]

688 Elisa Ruiz. Manual de codicología. Madrid: Fundación Germán Sánchez Ruipérez, 1988. p. 257

689 Julián Martín Abad. (2004a) Op. cit. p. 124 
Esta idea se asemeja a lo que la archivística determina como punto crucial en su desarrollo disciplinal y que determina la ordenación de los fondos archivísticos: el principio de procedencia, es decir, el origen natural de elaboración de los documentos. Pero para el caso particular de las colecciones de libros antiguos, la procedencia de los materiales resulta sustancial tanto para la investigación en la historia del libro, como para realizar la puesta en valor del objeto en su dimensión cultural y en parte debería servir para la organización de la colección en su conjunto. En efecto, con los materiales conservados, el modo más fácil de constatar la procedencia de los libros "consiste en examinar los ex libris, las notas manuscritas y las marcas de fuego que los mismos libros tienen". 690

\section{i) Marcas de fuego, ex libris, y sellos}

Los elementos históricos que nos ayudan a determinar la procedencia de un material son varios y responden a formas culturales de su apropiación. De entre estos elementos, el grupo más importante es el que denominamos genéricamente como marcas de propiedad. Estas marcas han existido siempre que el poseedor de un libro ha deseado identificar su propiedad y quizás la más común de esas marcas sea la firma del propietario en la portada. La muestra corresponde a un ejemplar propiedad de Carlos de Sigüenza y Góngora en 1674.

690 Jesús Yhmoff Cabrera (1996). Op. cit. T. 1, p. VI. 


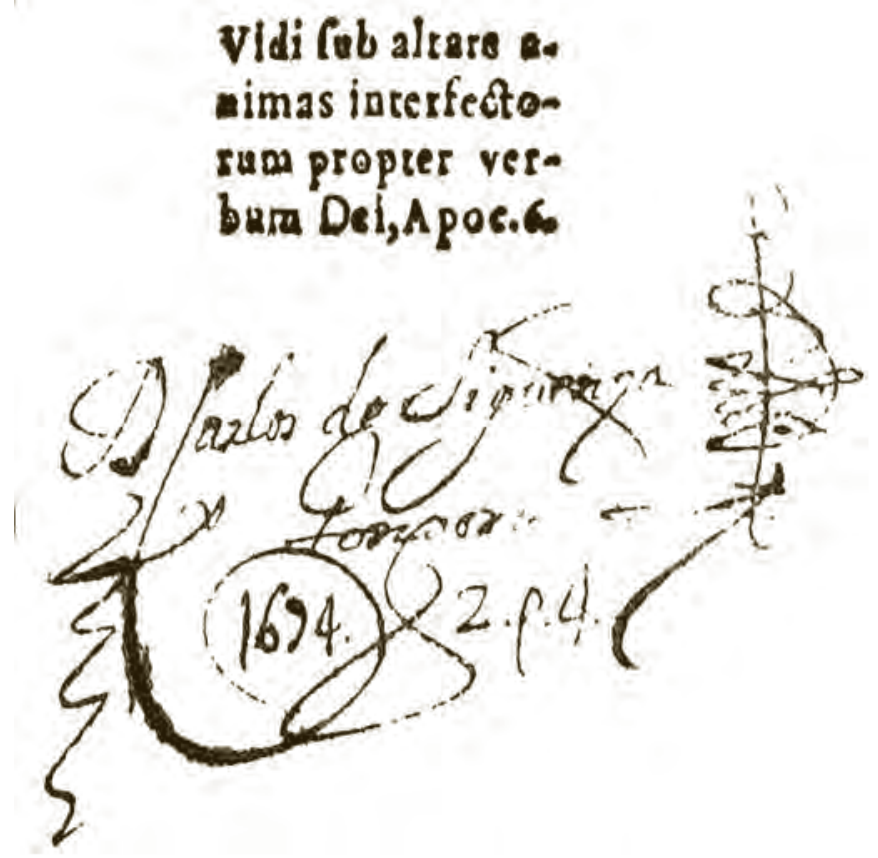

Sin embargo, por el interés patrimonial de esta propuesta bibliográfica, creemos conveniente distinguir en primer lugar una de las evidencias de procedencias más importantes e interesantes que existen en las colecciones de libros antiguos de las bibliotecas mexicanas, se trata de la marca de fuego. A pesar de que para algunos sea "un signo de propiedad de empleo comparativamente menor", 691 basta una simple mirada a cualquier fondo antiguo de bibliotecas mexicanas para darse cuenta de que no es así.

Si bien suele dársele cierta importancia a esta marca, a la fecha no se ha determinado con plena certeza cuándo se comenzó a utilizar y especialmente qué motivó su empleo; es decir, no se han encontrado testimonios documentales que acreditan su utilización en un momento específico de la historia. Esta marca parece haberse empleado únicamente en territorio novohispano, aunque algunos indican que se

691 Cfr. Julián Martín Abad (2003) y (2004a). Op. cit. p. 112 
gestó en España en pleno siglo XVI. ${ }^{692}$ A la fecha solamente tenemos noticia de una marca de fuego española, pero de ninguna de las otras colonias de la América española, frente a los numerosos ejemplos que se pueden encontrar en los libros antiguos conservados en México.

Esta marca es un signo, señal, anagrama, anátrofe, monograma, sigla o escudo estampado en los cantos - superior, delantero o inferior- de un libro antiguo, que se ponía con un hierro al rojo vivo. Se le ha definido como signo de propiedad, aunque la evidencia material de la casuística indica que no todos los libros que podemos adjudicar a una procedencia específica presentan la marca de fuego de los otros semejantes. ${ }^{693}$ En la página derecha presentamos un ejemplo del Convento de Santa Clara.

En México, hasta la fecha se han compilado cinco catálogos de estas marcas: de Rafael Sala, ${ }^{694}$ del INAH,${ }^{695}$ de David Saavedra, ${ }^{696}$ de Villagrán, ${ }^{697}$ y el reciente de la Biblioteca Lafragua. ${ }^{698}$ Sobre estas marcas se pueden encontrar trabajos presentados en eventos profesionales de México. Sin embargo, en toda esta información producida se hace escasa referencia a los libros marcados, por lo que todavía no se ha logrado identificar cuántos se conservan con una sola marca. De esta

692 Carlos Manuel Krausse Rodríguez. Marcas de Fuego: Catálogo. México: INAH, 1989. p. 1; y José Luis Checa Cremades. El libro antiguo. Madrid: Acento Editorial, 1999. p. 13

693 Sería interesante contrastar los libros marcados por una sola entidad, frente a un inventario de época conservado de la librería conventual para conocer mejor esta problemática sobre un signo considerado de propiedad.

694 Rafael Sala. Marcas de fuego de las antiguas bibliotecas mexicanas. México: Secretaría de Relaciones Exteriores, 1925.

695 Carlos Manuel Krausse Rodríguez. Op. cit.

696 David Saavedra. Marcas de fuego de la Biblioteca Conventual del Museo Regional de Querétaro del Instituto Nacional de Antropología e Historia. México: INAH,1994.

697 Manuel Villagrán Reyes. Marcas de fuego de las librerías conventuales en la Biblioteca "Elías Amador" de Zacatecas. Zacatecas: Museo Pedro Coronel, 1992.

698 Marcas de fuego de la Biblioteca José María Lafragua de la BUAP que se transformó en el año 2010 en el Catálogo Colectivo de Marcas de fuego. Información disponible en http://www.marcasdefuego.buap.mx:8180/xmLibris/projects/ firebrand/ [Consulta: junio de 2011] 
Conocer para describir: la estructura material del libro antiguo

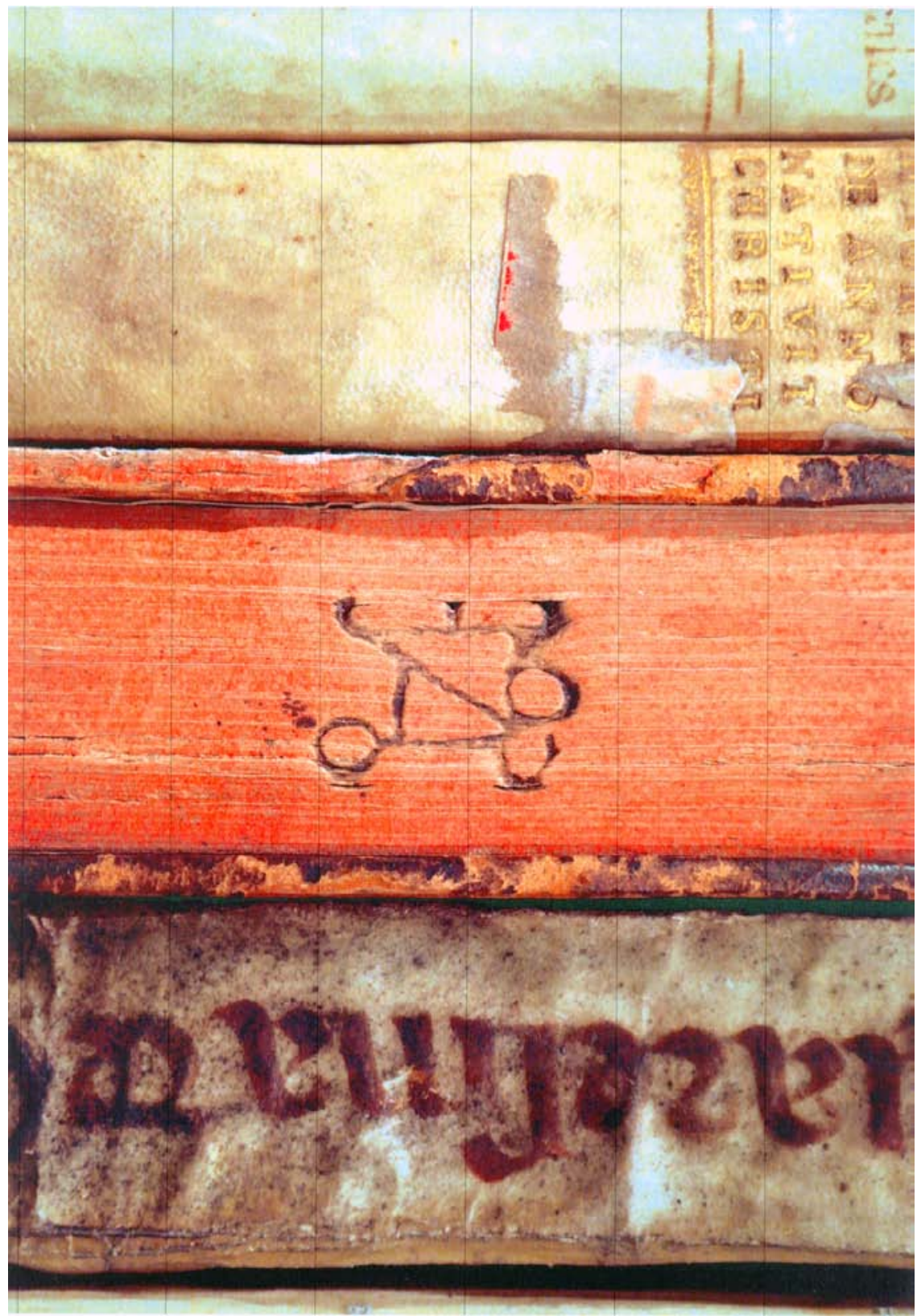


tendencia habría que exceptuar al catálogo de la Biblioteca Lafragua, que conjuntamente muestra las marcas y los libros que las presentan.

Por sus características, epigráficas y figurativas, se ha determinado que fue usada con mayor frecuencia por las órdenes religiosas que tuvieron instituciones durante el periodo novohispano, como franciscanos, carmelitas, mercedarios, dominicos, agustinos y jesuitas. De los ejemplares que hemos podido analizar y que relacionamos con otros elementos, una mayoría de las marcas corresponde a establecimientos religiosos. Pero también se encuentran marcas de fuego relacionadas con personajes poseedores de bibliotecas antiguas, y otros que parecen haber imitado con tinta a la de fuego en un periodo posterior. Aquí presentamos un ejemplo que no ha sido identificado.

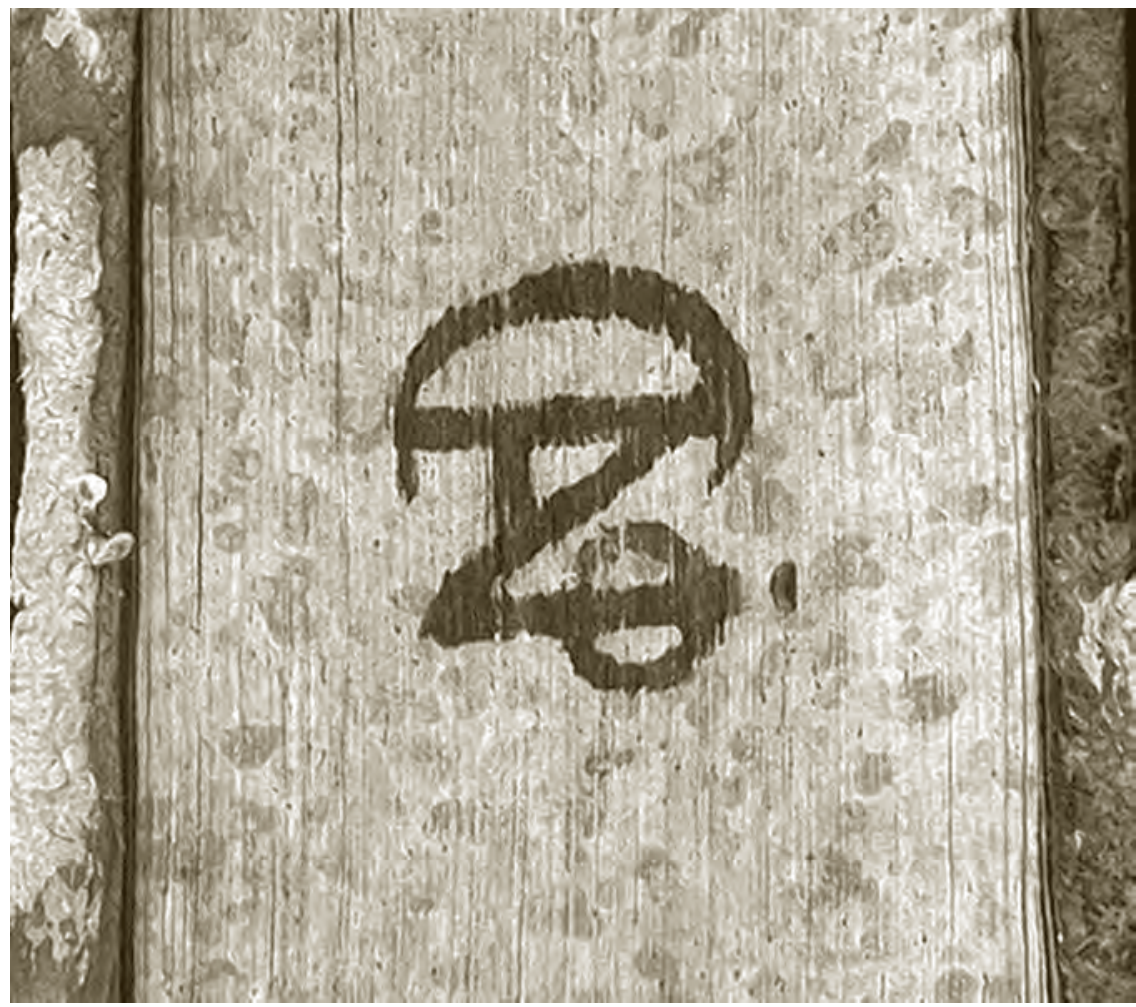


Las marcas de fuego son de varios tipos pero básicamente se trata de dos grandes grupos: epigráficas y figurativas, ${ }^{699}$ ejemplo del primer grupo es la letra "A" para los agustinos, y del segundo, las cinco llagas para los franciscanos. Sin embargo, numerosos libros antiguos poseen no sólo una, sino varias marcas de fuego en sus cantos. Esta conjunción de marcas también testimonia el movimiento que ciertos libros tuvieron entre las diferentes bibliotecas coloniales. Precisamente porque no todas las marcas pueden ser identificadas con claridad, la anotación manuscrita que puede encontrarse en la portada de los libros es una información que puede ayudar a atribuir una marca a una cierta institución colonial, incluso, la revisión de estas anotaciones ha mostrado que la información contenida en los catálogos anteriormente citados no es siempre correcta.

Indudablemente, el conocimiento y registro de la marca de fuego podría ayudar a identificar la colección de los diferentes establecimientos religiosos y por tanto constituye un dato fundamental para recuperar la procedencia de los libros que hoy conservamos. ${ }^{700}$ Por esa razón creemos conveniente que se indique su existencia, incluso si hay más de una, que se especifique el lugar donde se encuentra y si ya ha sido identificada en algún catálogo, incluso si difiere de la adscripción institucional. El registro debe hacerse de la siguiente forma:

699 La construcción de una tipología de las marcas de fuego ha sido extremadamente complicada, por lo que nos parece conveniente solamente establecer estas dos categorías, hasta que una compilación mayor de ejemplos conservados nos permita establecer tipos más acertados. Cfr. Idalia García. "Libros marcados con fuego". Emblemata: Revista Aragonesa de Emblemática. Vol. 13 (2007), pp. 271-299. Texto disponible en http://ifc.dpz.es/recursos/publicaciones/27/25/7.Garcia.pdf [Consulta: abril de 2009]

700 Por esa razón actualmente se ha desarrollado una metodología especial para identificar y describir estas marcas. Cfr. Mercedes Isabel Salomón Salazar y Andrew Green, "Las marcas de fuego: propuesta de una metodología para su identificación", en Leer en tiempos de la Colonia: imprenta, bibliotecas y lectores en la Nueva España, comp. Idalia García y Pedro Rueda, México: CUIB, 2010, pp. 341-367. 
Marca de fuego en canto superior e inferior del Convento de Santa Bárbara de Puebla. (Saavedra, p. 56) ${ }^{701}$

La otra marca de propiedad más conocida son los ex libris que es el término que

se utiliza para designar una etiqueta, elaborada por diferentes procedimientos, que se pega en los libros y en donde consta, por lo menos, el nombre de su propietario. ${ }^{702}$

Esta marca significa principalmente dos cosas: la acreditación de la propiedad y el señalamiento de la cultura libresca,${ }^{703}$ y se refiere a una marca de posesión impresa.

El uso del ex libris es tan antiguo como la imprenta misma, ${ }^{704} \mathrm{e}$ identifica la colección de un propietario, sin embargo no debe ser confundido con otras marcas de propiedad cuya naturaleza es distinta. La diferencia del ex libris con otras marcas, está determinada porque es una pieza de papel pegada al libro, lo cual constituye su característica principal.

Así pues, el ex libris es una hoja pequeña de papel, por regla general rectangular, cuadrada o alargada, raramente circular o elíptica, donde consta el nombre del propietario al que suele acompañar alguna fórmula para indicar la posesión - ex libris..., de la biblioteca de..., de... - y a veces una frase célebre, algún adorno - por ejemplo una orla-y, casi siempre, un

701 Carlos de Sigüenza y Góngora. Glorias de Queretaro... México: Viuda de Bernardo Calderon, 1680. Biblioteca Eusebio Francisco Kino. Fondo Mariano Cuevas: MC/G BT 660 G8 S53

702 Juan Delgado Casado. Los ex libris españoles. Valencia: Vicent García Editores, 1996. p. 5, y Juan B. Iguíniz. "Ex libris de bibliófilos mexicanos: colección formada por el Dr. Nicolás Léón”. Anales T. 5, 9, p. 67.

703 Ernesto de la Torre Villar. "Los ex libris y las marcas de fuego". Gaceta del Instituto de Investigaciones Bibliográficas. No. 5 (julio-septiembre 2000). Texto disponible en http://biblional.bibliog.unam.mx/ [Consultado: Mayo de 2006]

704 David Pearson. Provenance research in book bistory: a handbook. England: The British Library, 1994. p. 54 
dibujo más o menos relacionado de alguna manera también con el dueño del libro, que puede ser su escudo heráldico, su libro preferido, instrumentos de su profesión, etc. ${ }^{705}$

La imagen que presentamos ilustra esta condición.

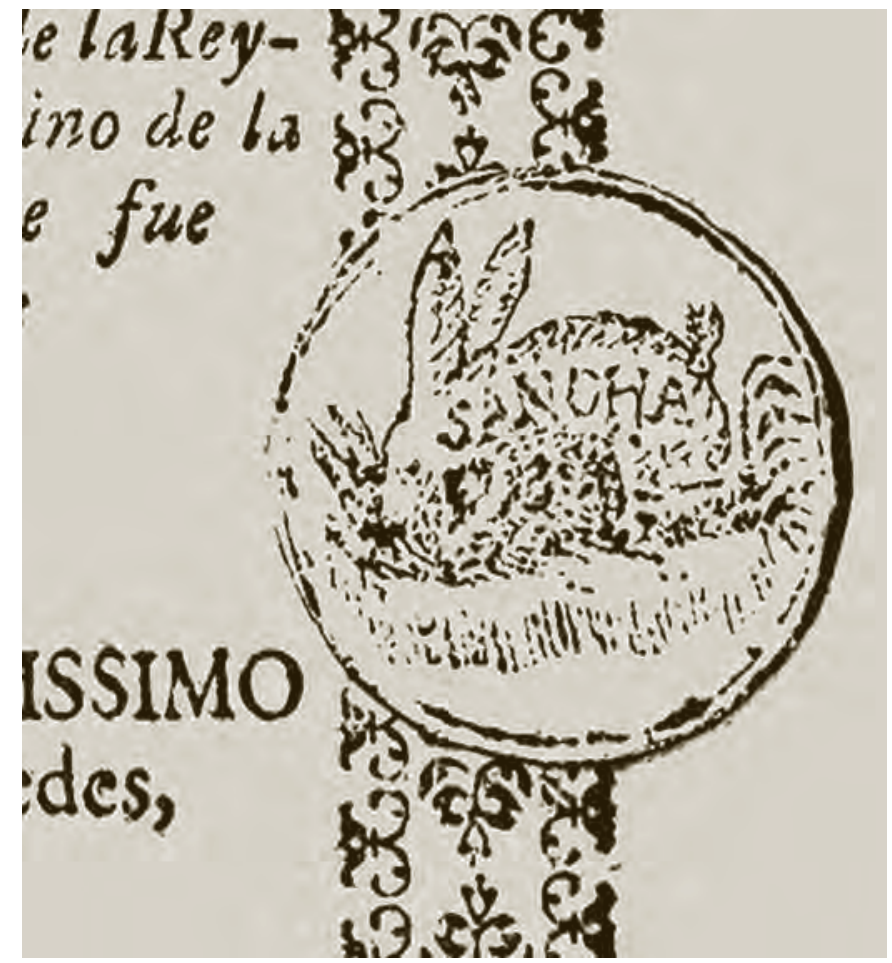

En efecto, el ex libris es confundido de forma general con cualquier elemento que indique la propiedad de un libro, por ejemplo las anotaciones

705 Ibíd.pp. 6-7 
manuscritas, en ocasiones descritas como ex libris manuscritos ${ }^{706} \mathrm{o}$ el "ex dono". ${ }^{707}$ Por esta razón, preferimos hacer la distinción entre estos elementos y el ex libris, ya que este último es el elemento histórico que se utiliza y se desarrolla con posterioridad a la imprenta; así, puede decirse que surge durante el siglo XVI. A este tipo de ex libris la literatura anglosajona lo denomina "bookplates" y se identifica de otros tipos de ex libris por ser una pieza de papel, impresa ya sea mediante madera o metal, donde se identifica al poseedor.

De ahí que sea relevante su identificación y estudio como documento histórico relacionado con la procedencia de los materiales bibliográficos, ${ }^{708}$ pero sin duda resultan cruciales para entender el coleccionismo y los intereses de diversos momentos históricos. Los ex libris más conocidos y habituales son los de tipo heráldico, donde aparece representado el escudo de la familia a la que pertenece el poseedor. Aquí presentamos un bello ejemplo de ex libris de Antonio Álvarez de Abreu.

706 Existen casos de etiquetas pegadas a los libros como elemento distintivo de propiedad que están efectivamente escritas a mano, por esta condición tan particular es el que puede llamarse apropiadamente como ex libris manuscrito. Puede verse un caso en el ejemplar de la obra de Valvoa Mogrovejo, Ioanne. Lectiones Salmanticenses sive aniversia relectio ad titvlum foro competenti in Libro 2. Decretalivm... Salmanticae: Ex Typographia Antoniae Ramirez, 1629. Biblioteca Eusebio Kino 17860.

707 Este elemento que puede ser impreso o manuscrito, indica la donación de material bibliográfico a una institución específica antigua o moderna. $C f r$. Albert Labarre. Historia del libro. México: Siglo XXI, 2002, p. 99.

708 Perla Chinchilla y Rubén Lozano Herrera. "El ex libris como documento histórico". Catálogo de la colección de Ex libris de Guillermo Tovar y de Teresa. México: Universidad Iberoamericana, 2002. p. 7 


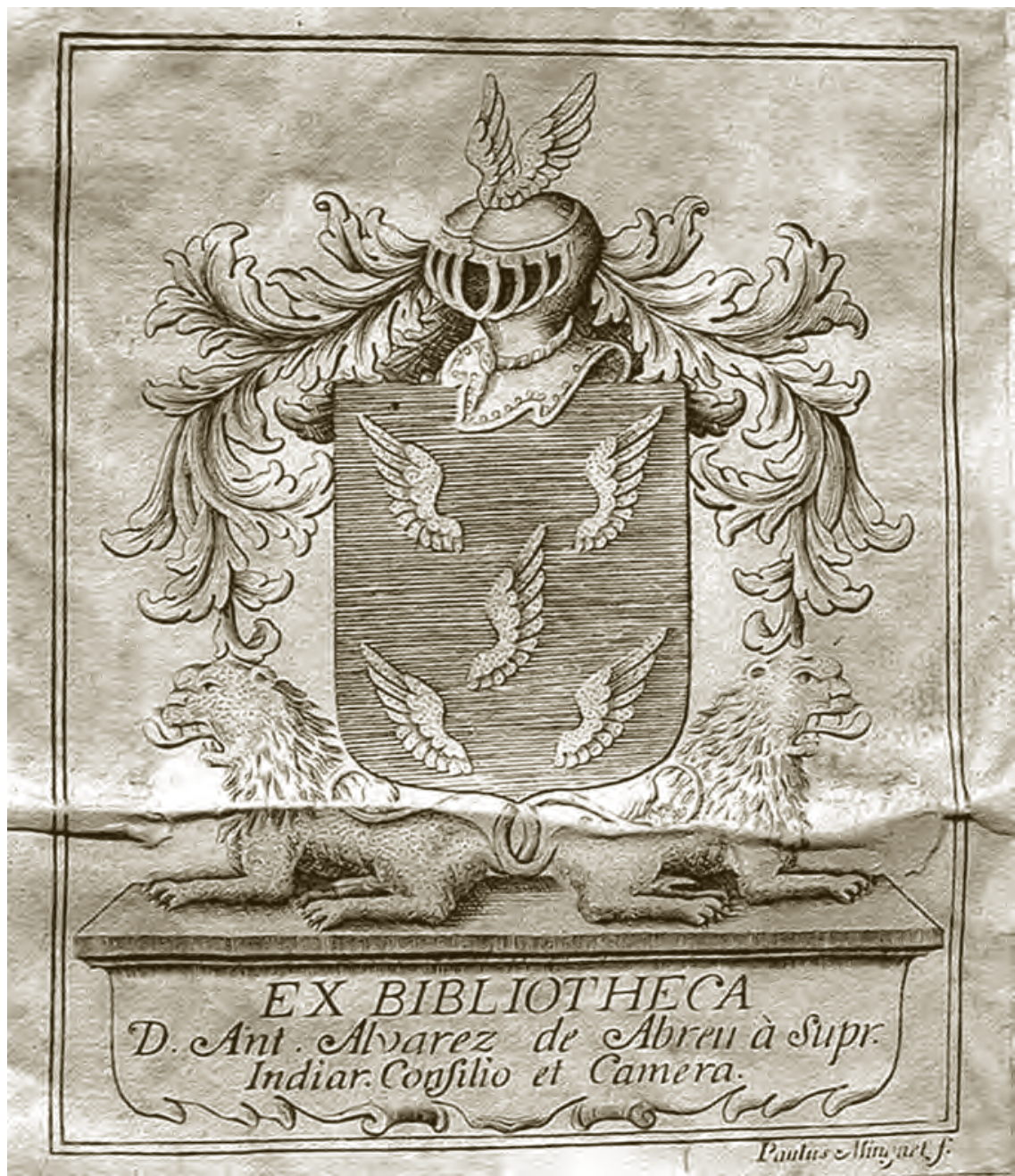

También se encuentran los ex libris "que Vindel denomina tipográficos", ${ }^{709}$ que se diferencian de los anteriores por contener una fórmula de propiedad y normalmente están rodeados de una orla sencilla (book label). También se conocen algunos que fueron impresos

709 Ibid. p. 9 
directamente sobre los libros. En otros puede encontrarse un texto que indica la transferencia de propiedad de los libros entre personas, instituciones ya sea por donación o herencia, y que se denominan ex donos. Aquí presentamos el de Andrés de Arce y Miranda.

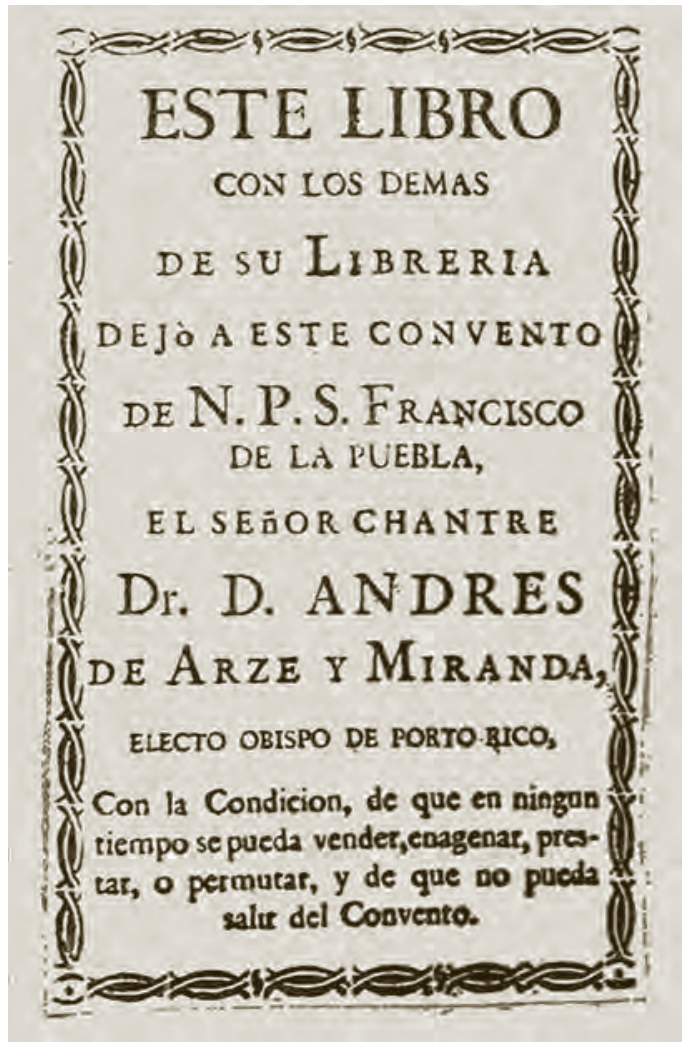

Otro tipo de ex libris que se conoce comenzó a utilizarse desde el siglo XIX y estaban hechos de caucho, pero también corresponde a este tipo el sello blanco o "en frío" que no necesita tinta (book stamp). Este tipo puede ser considerado como el antecesor de los sellos contemporáneos que se utilizan en bibliotecas. Por la variedad de tipos conocidos de ex libris que se conservan, han sido estudiados en su relación directa con artistas y con el coleccionismo de libros, pero puede 
observarse que en ninguno de esos trabajos (incluso en los catálogos de exposiciones que se han realizado) se ha considerado como ex libris a la anotación manuscrita de propiedad.

A los ex libris los distingue la presencia de cuando menos tres características: el nombre del propietario, una ilustración y la fórmula textual que indica la propiedad. No es necesaria la presencia de las tres partes, pero es difícil que se omitan todas. Ahora bien, la parte sustancial es el nombre del propietario que puede aparecer completo, sus siglas o incluso algún seudónimo. Entre los que pueden considerarse como ex libris modernos (desde el siglo XIX), es mucho más frecuente la presencia de la expresión "ex libris" y cuando es así prácticamente desaparece alguna otra fórmula de propiedad. Esto es así porque la expresión en sí misma ya ha adquirido un sentido y significado irrevocable: la propiedad de un libro.

Sin duda la riqueza cultural de este elemento histórico está más representada en el uso de las ilustraciones, que en algunas ocasiones del libro hacen una verdadera obra de arte. La orla es la ilustración más sencilla, pero también encontramos motivos geométricos, columnas, decoraciones en blanco y negro o en colores, uso de personas, profesiones, oficios o actividades, animales y plantas (a veces con significado simbólico, como la lechuza), paisajes y edificios de ciudades, edificios y elementos arquitectónicos, escudos heráldicos, temas religiosos, mitológicos o literarios (es muy frecuente encontrar a Don Quijote), instituciones como bibliotecas antiguas o modernas (utilizadas con más frecuencia cuando el propietario es una institución) y objetos de distinto tipo (el más numeroso, por supuesto, el libro).

El sello es otro de los elementos que nos ayudan a identificar la procedencia de las colecciones de libros antiguos. Este elemento tiene mayor relación con la diplomática, y su estudio específico es competencia de la sigilografía. ${ }^{710}$ Los sellos presentes en los libros antiguos no presentan mucha variedad, y sin duda el de tinta es el más usual aunque también encontraremos de placa (en papel y cera, y en

710 Para introducirse al tema es conveniente consultar la obra de Alberto Tamayo. Archivística, diplomática y sigilografía. Madrid: Cátedra, 1996. 
papel y oblea), en seco o de tinta grasa. ${ }^{711}$ De este último presentamos un ejemplo.

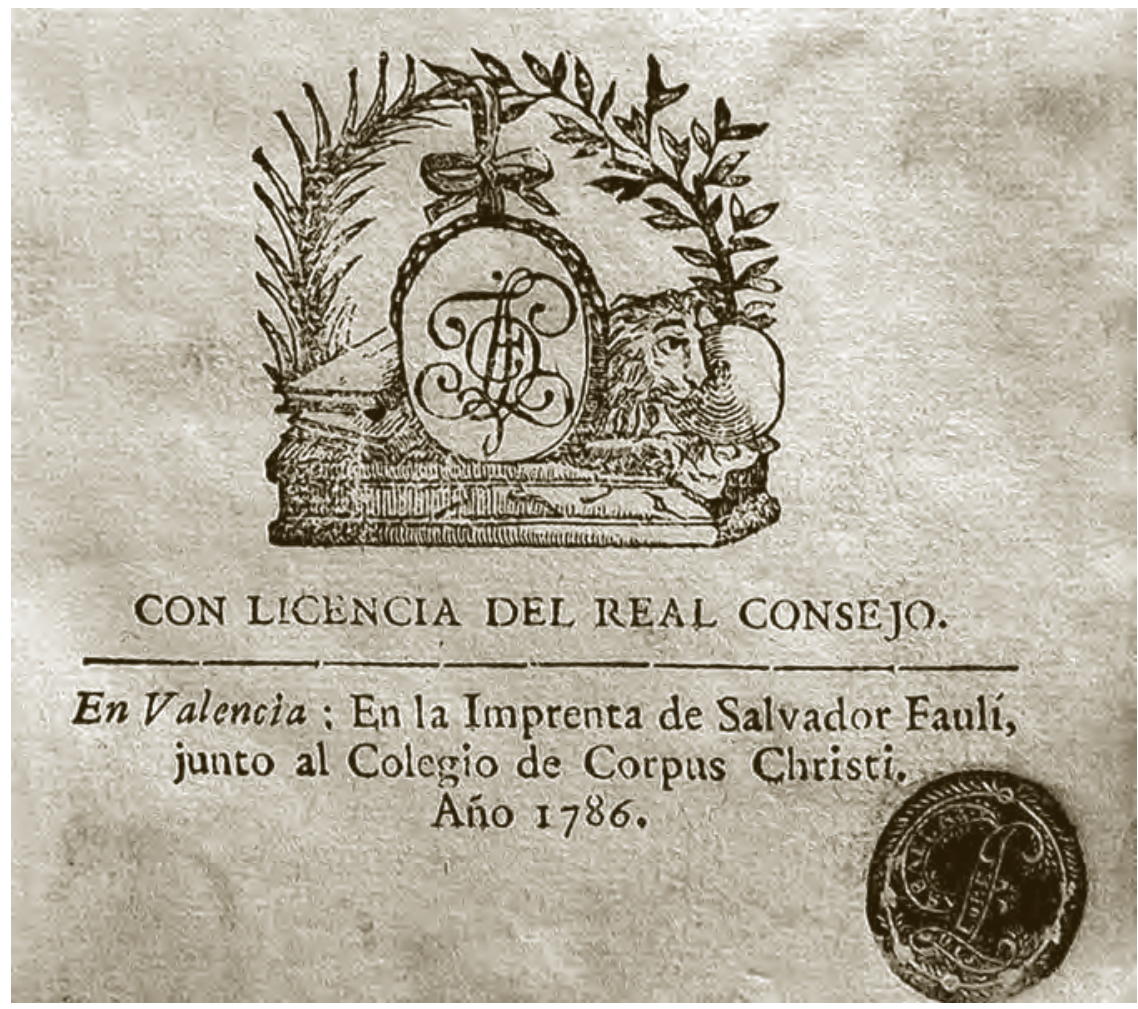

El sello de tinta lamentablemente nos muestra el poco aprecio que sobre el objeto material llegaron a tener ciertos custodios, puesto que en más de una ocasión veremos cómo la impronta de este sello se plasma de forma excesiva, cómo se coloca enfadosamente sobre un grabado o incluso cómo nos impide leer parte de la información de la obra. Aquí mostramos un sello de tinta cuya colocación respetó el grabado de la portada.

711 Elaborado con matrices grabadas en hueco. Para acercarse a este tema se recomienda consultar el María Carmona de los Santos. Manual de sigilografía. Madrid: Ministerio de Cultura. Subdirección General de Archivos Estatales, 1996. 
m.

tináex capitulorsm initio prafixus, ion alius in fine rerum granium rofis:illimus.
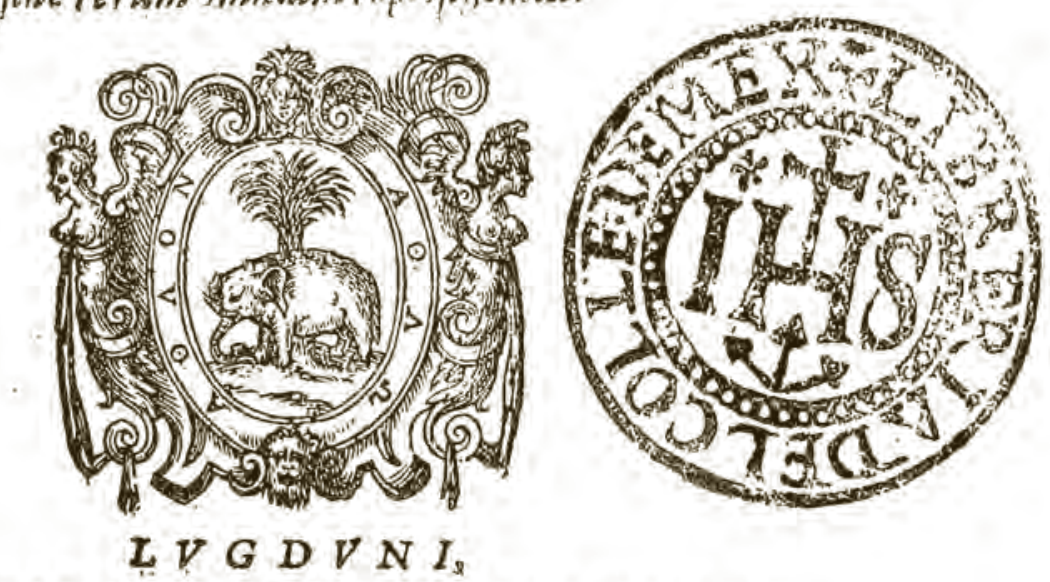

IOANNEM BAPTISTAM

M. D. XCIII.

Pese a lo anterior, los sellos de tinta representan la evidencia de la movilidad de los libros antiguos conservados en México en las distintas bibliotecas, desde el siglo XIX hasta su tutela contemporánea a lo largo y ancho del territorio nacional; sin embargo, tampoco se han registrado ni documentado para ayudar al conocimiento de la procedencia, ${ }^{712}$ por esta razón creemos que tanto el ex libris como los sellos deben registrarse transcribiendo la información y si se conoce una referencia documental también debe indicarse de la siguiente forma:

712 En este sentido un ejemplo interesante a seguir es el libro de Enriqueta Clemente García y Leonardo Blanco Lalinde. Los sellos municipales de tinta de la provincia de Teruel en el siglo XIX. Teruel: Instituto de Estudios Turolenses y Zaragoza Institución Fernando el Católico, 2002. 
Ex libris de Isidro García Carrasquedo en h.1v. ${ }^{713}$ Catálogo de la colección de Ex libris de Guillermo Tovar y de Teresa. México: Universidad Iberoamericana, 2002. p. 144.

Sellos de tinta en portada, h.16r. y h.33v.: "Asociación Histórica Americanista", "Ex libris Hist. Mex. Coll. Max. S.I. Prov. Mex. Merid."714

\section{j) Anotaciones manuscritas y testigos}

Las anotaciones manuscritas representan una de las evidencias históricas presentes en los libros antiguos más ricas e interesantes para la investigación histórica. Están presentes a lo largo del libro y pueden considerarse como tales incluso las líneas manuscritas que se encuentran en portadas, guardas o en el interior del texto de una obra. La más común de estas anotaciones es la que indica la propiedad de un objeto, ${ }^{715}$ ya sea personal o institucional.

Este tipo de anotaciones podrían ser consideradas como un antecedente del ex libris, y por tanto no pueden ser reconocidas como ese elemento, porque difieren en su naturaleza. En nuestra opinión, este tipo de anotación manuscrita no debería ser denominado "ex libris manuscrito" en los catálogos y bibliografías, porque se presta a confusiones en el uso de los conceptos y no ayuda a normalizar el conocimiento bibliográfico del libro antiguo. Aquí presentamos la del Colegio Apostólico de San Francisco de Pachuca (Hidalgo, México).

713 Antonio de Vieyra. El V. P....Todos sus sermones y obras diferentes...Tomo primero... Barcelona: En la Imprenta de María Martí, Viuda, 1734. Biblioteca Histórica Nicolás León de la Facultad de Medicina. UNAM

714 Petro Canisio. Summa doctrinae christianae per quaestione luculenter conscripta... Salmanticae: excudebat Mathias Gastius, 1570. Biblioteca Eusebio Francisco Kino 017215

715 David Pearson. Op. cit. p.12 


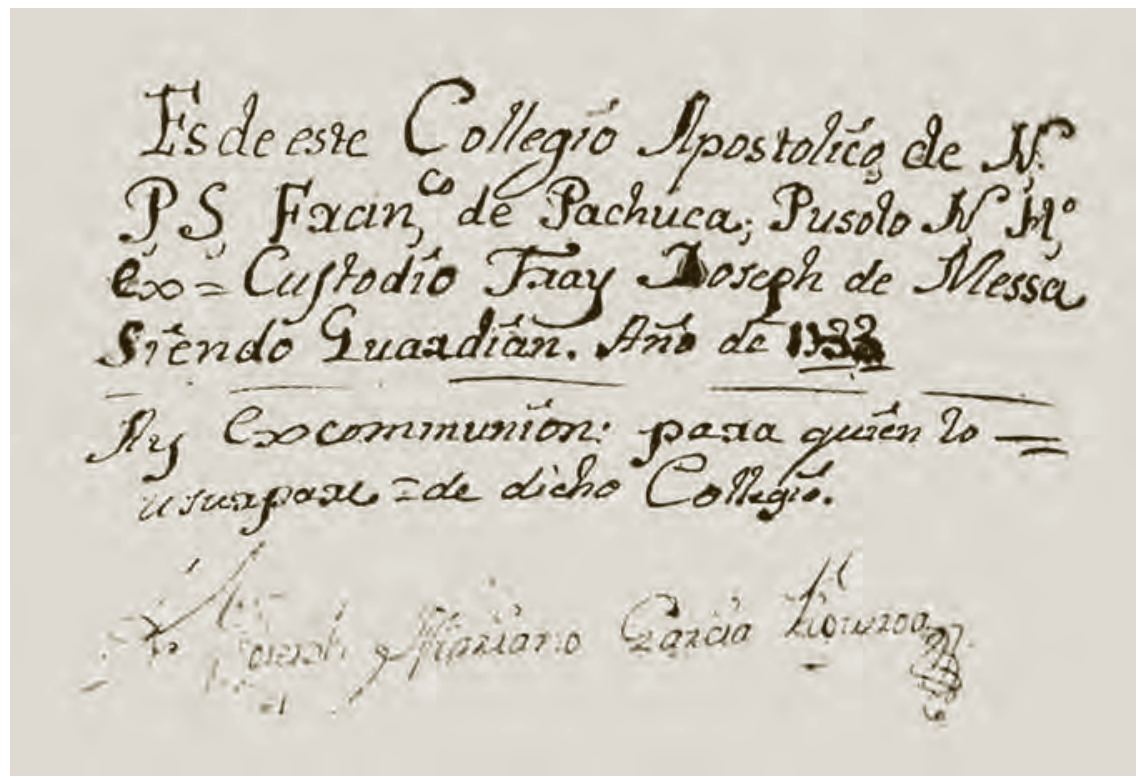

Desde luego, las anotaciones manuscritas no sólo se utilizan para señalar la procedencia y propiedad de un objeto, también nos sirven para identificar la lectura de los materiales que en algunas ocasiones pueden conjugarse armoniosamente para dotar de singularidad a un objeto específico. Por ejemplo, podemos pensar en las obras que constituyeron la biblioteca particular de un personaje destacado de la historia. En estos ejemplares encontramos anotaciones manuscritas de propiedad conjuntamente con marcas de lectura de los mismos. Estas últimas pueden ser manos (manitas), comentarios, críticas e incluso censura de parte de los textos realizada por el lector. Aquí presentamos un curioso ejemplo que parece derivado de una lectura. 


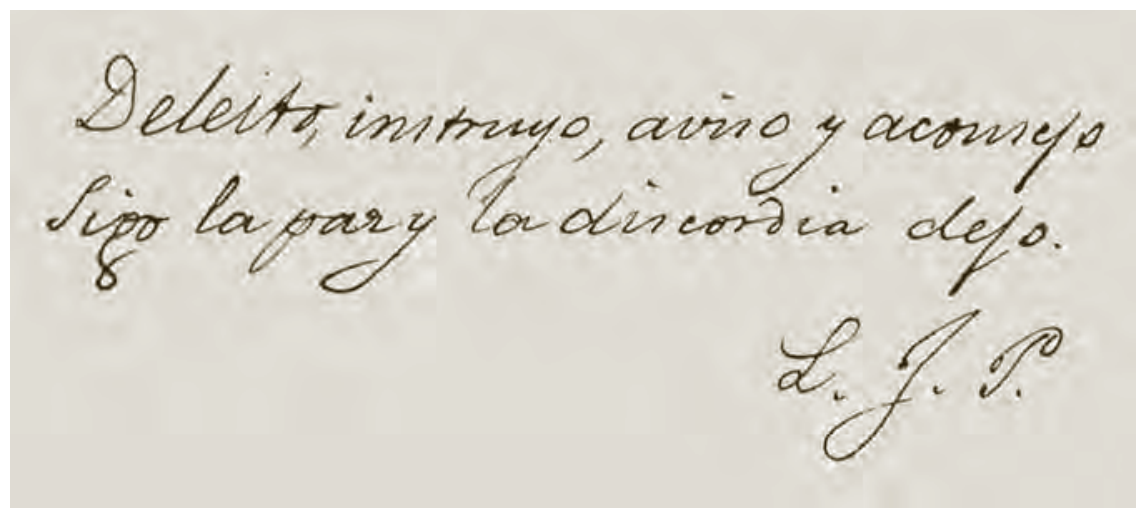

Pero también existe un tipo de anotación relevante en la identificación bibliográfica: la de expurgo. Para adjudicarla de forma correcta

debemos distinguir entre Índices probibitorios e Índices expurgatorios. Los probibitorios lo hacen en su totalidad, tanto si se trata de una obra concreta como de toda la producción de un determinado autor. Los expurgatorios, retiran u obligan a la modificación de aquella o aquellas partes que no pueden ser publicadas. Una vez expurgado el libro puede salir a la luz pública. ${ }^{716}$

Este tipo de anotación, como reflejo directo del control y la censura, deja una huella distintiva en los libros. El expurgo, como trámite administrativo realizado por los calificadores, deja como evidencia solamente la omisión de una parte del texto, ya que permitía la lectura de libros considerados aceptables en su conjunto pero en los que se había detectado algún comentario que debía suprimirse. Esta omisión se realizó "tachando con gruesa tinta palabras o frases o arrancando páginas estimadas inaceptables" ${ }^{717}$ pero también se indicó en portada que el libro había sido expurgado en una fecha precisa. Presentamos aquí una nota de expurgo del siglo XVII.

716 María Milagros Ronco López. Op. cit. p. 90

717 Ángel Alcalá. Op. cit. p. 16 


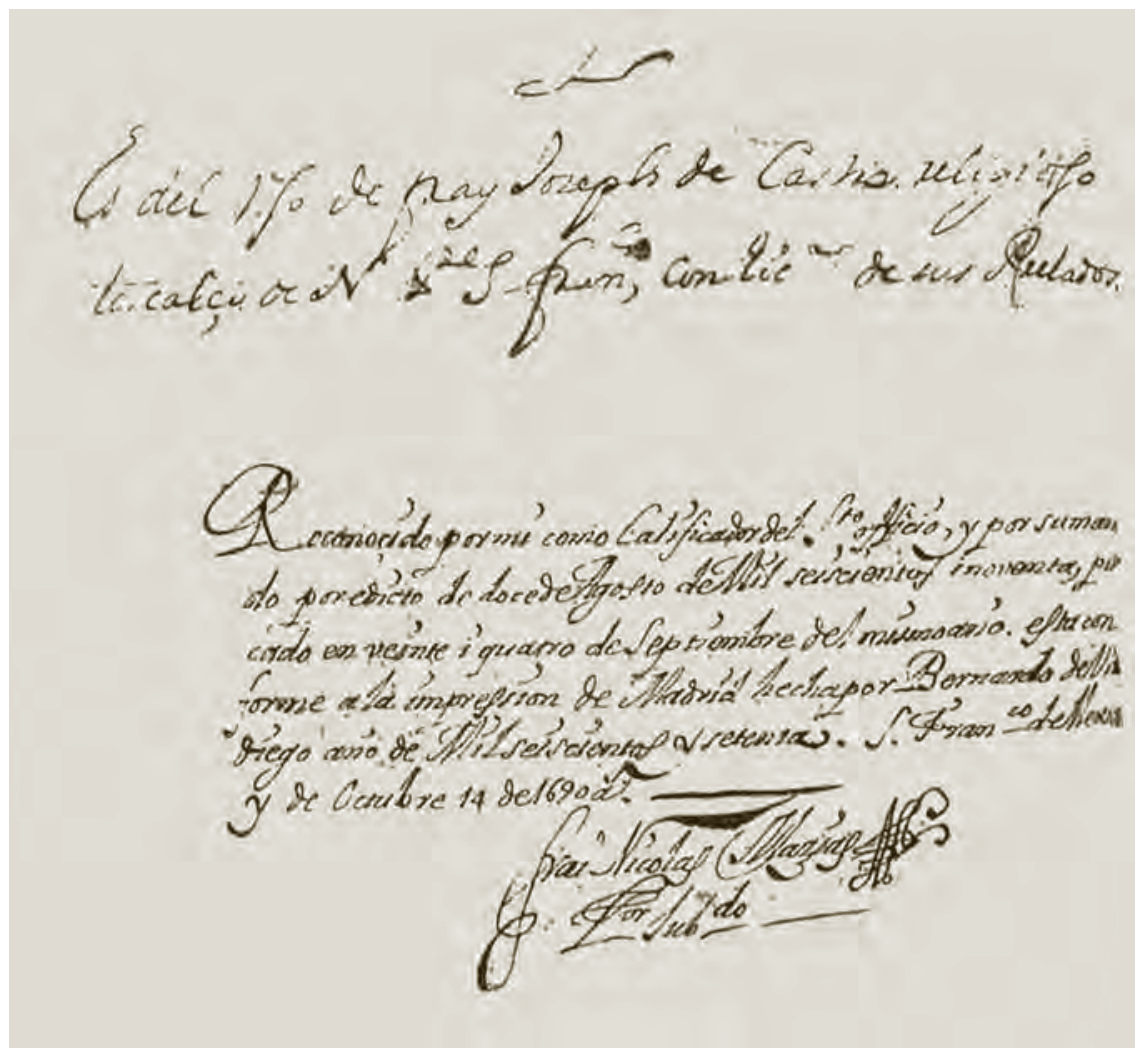

En efecto, la recuperación del legado bibliográfico de personas del pasado no es una tarea imposible: basta con reconocer la importancia de registrar en las descripciones bibliográficas o catalográficas tales anotaciones, no como una información opcional. Por eso consideramos pertinente que la inclusión de este dato en la descripción bibliográfica se mantenga como anotación manuscrita con la abreviatura "an. ms." o "ans. mss." si hay más de una, así como indicar si es de propiedad, de lectura o de expurgo y transcribir el texto siempre que sea posible, como lo muestra el ejemplo siguiente: 
Ans. mss. de propiedad en portada y en p. 110: "Pertenece este libro al Conv.to de el Carmen de Atlisco" y en p. [215]: "Este libro es del Carmen de Atlisco"; An. ms. de lectura en p. [135]: "O morir, o padecer, padecer, o morir, o las dos cosas" ${ }^{718}$

Finalmente los testigos son considerados piezas documentales o bibliográficas que se encuentran en el interior de los libros antiguos, y también pueden ser un testimonio de historicidad. Las razones de su presencia son tan complejas como la mente humana y de ahí su variedad. Efectivamente, podemos encontrar cartas, partes de documentos históricos, estampas, fotografías, ejercicios de escritura ${ }^{719}$ y todo un amplio espectro de posibilidades. Sin embargo, no todos los testigos son relevantes, aunque en algunas ocasiones podemos encontrar evidencia sobre la adquisición del libro o sobre su valor (económico o cultural). Cuando es relevante como información histórica, debe indicarse qué tipo de documento es y dónde se encontró, es decir, entre qué hojas, páginas o folios, siempre que sea posible aunque esto no puede considerarse más que como información indicativa.

Creemos que el conjunto de elementos a los que nos hemos referido testimonian el devenir histórico del libro, por eso consideramos pertinente indicar su existencia en las notas porque además proporcionan singularidad a cada ejemplar conservado. A lo que debemos prestar atención es a las hojas de tabaco y flores dentro de un libro, que no constituyen un testigo; por el contrario son elementos biológicos que pueden poner en riesgo la conservación de los materiales.

\section{k) La encuadernación}

Toda mirada exterior sobre el libro antiguo no debe olvidar a la encuadernación. No importa si ésta es vieja, llamativa, rara o singular; lo

718 Fernando Manrique de Lujan. Relacion de las fiestas de la civdad de Salamanca en la beatificación de la Sancta Madre Teresa de Jesús... En Salamanca: por Diego Cussio, 1615. este ejemplar presenta errores en paginación. Biblioteca Eusebio Francisco Kino 021566.

719 Denominados como probatio calami. Estos meramente son pruebas de escritura, dibujo o juegos con la pluma que alguna persona realizó sobre el libro. 
cierto es que forma parte indisoluble de la condición patrimonial del objeto y por esa simple razón no debemos dejarla fuera de la tarea de la descripción. Sin duda es otro elemento histórico, objeto de la mirada especializada de restauradores, conservadores, historiadores del arte y bibliófilos, para quienes seguramente

el libro bello exige una bella encuadernación; sin ceder a los caprichos de la moda, ha de ser perdurable técnica y estéticamente al margen de resistente al paso del tiempo. ${ }^{720}$

Por esta razón, para ciertos especialistas la encuadernación es el dato más valorado del libro antiguo y promueven un registro detallado de todos sus componentes, mientras que para la descripción bibliográfica el tipo de encuadernación que presenta un libro antiguo no ha sido uno de los datos más relevantes a distinguir. En México la encuadernación es un elemento histórico que prácticamente no se ha estudiado; es más, a la fecha no tenemos caracterizados los tipos de encuadernaciones que existen en nuestros fondos antiguos y que no correspondan a formas y estilos realizados en Europa. Mostramos un ejemplo común de encuadernación holandesa.

720 Juan Antonio Yeves. "Don José Lázaro: el bibliófilo y su biblioteca”. En La estética del libro español: manuscritos e impresos españoles hasta finales del siglo XVI en la Biblioteca Lázaro Galdiano. Madrid: Fundación Lázaro Galdiano, 1997. p. 38 


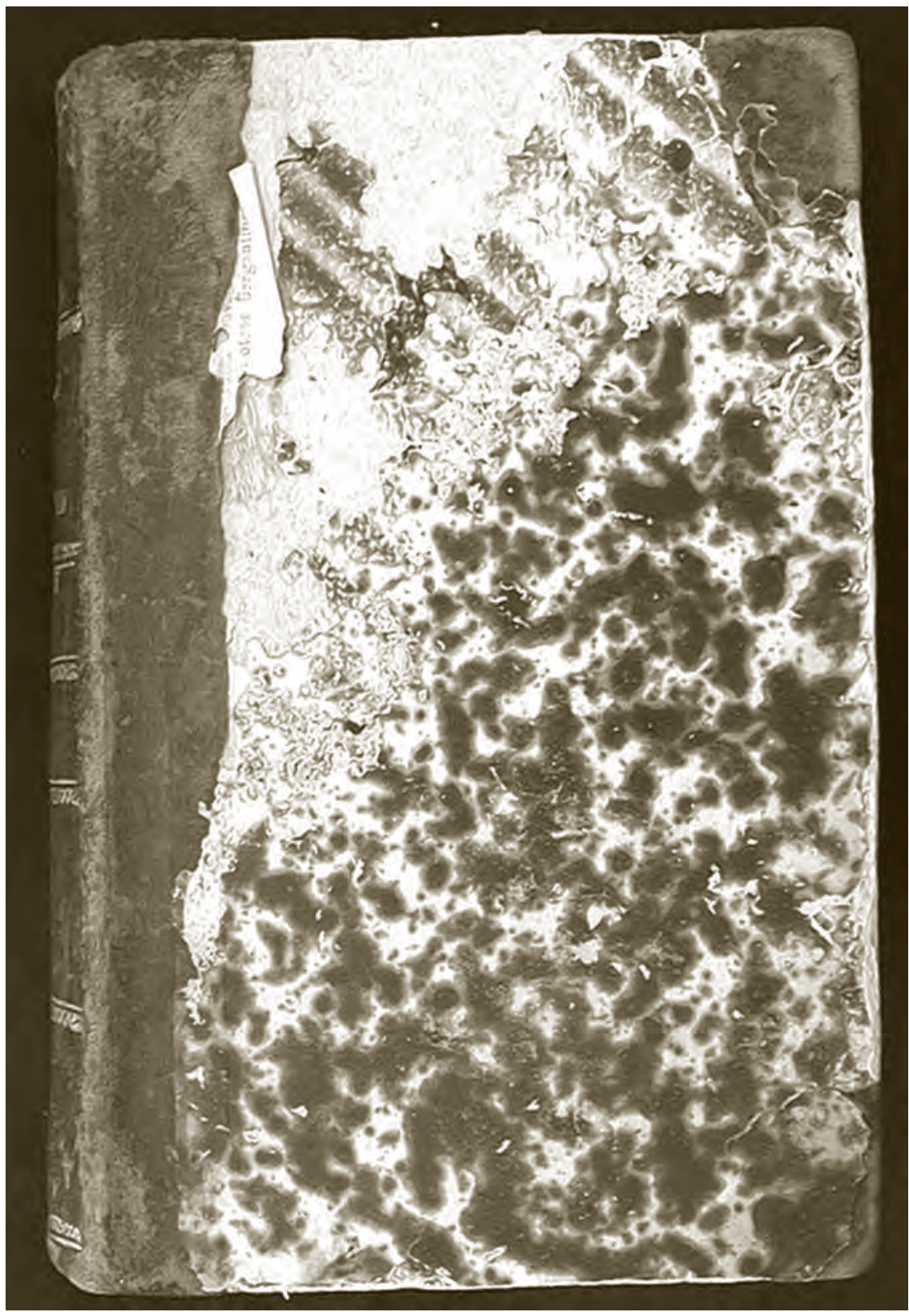


De ahí que no resulte extraño, como hemos visto, que en las descripciones bibliográficas realizadas en el pasado sea un dato ausente o, en su defecto, sea simplemente registrado como "encuadernación en pergamino". Tal denominación es incorrecta, por un lado, porque la encuadernación es de un tipo de soporte específico, y no pertenece a éste para justificar la preposición "de". Por otro lado, una descripción así, no proporciona mucha más información considerando que las de encuadernaciones en pergamino son denominadas genéricamente como "conventuales", así con ese dato no se ayuda a identificar con precisión la época de su elaboración y el lugar de procedencia, que significa tanto como indicar "encuadernación de época". ${ }^{721}$

Estas formas no logran definir si la encuadernación del libro antiguo posee un valor especial o si en su defecto es un dato histórico relevante, porque no se especifica si por época se refiere a la misma de la impresión o a otra muy diferente. Por ejemplo, sabemos que las encuadernaciones del siglo XVI se caracterizan por estar elaboradas con tablas gruesas forradas en piel curtida y ostentando broches metálicos, ${ }^{722}$ como las que conservan una parte importante de los incunables o ediciones del siglo XVI.

721 Además debemos considerar que entre las encuadernaciones en pergamino existen cuando menos tres tipos en nuestros fondos: uno que tiene escrito el título del libro en letra gótica; otra que lo tiene en letra redonda; y finalmente, una que tiene el título en letra gótica pero con doble tinta. Es posible que esta última sea una falsificación histórica que no proceda del periodo colonial, porque es más legible que la anterior y la tinta roja sólo se emplea para las iniciales de texto. Sin embargo, sin análisis más detallados esta es una mera suposición.

722 Manuel Romero de Terreros. Encuadernaciones Artísticas Mexicanas. $2^{\mathrm{a}}$ ed. México: Biblioteca de la II Feria del Libro y Exposición Nacional del Periodismo, 1943. p. 3 


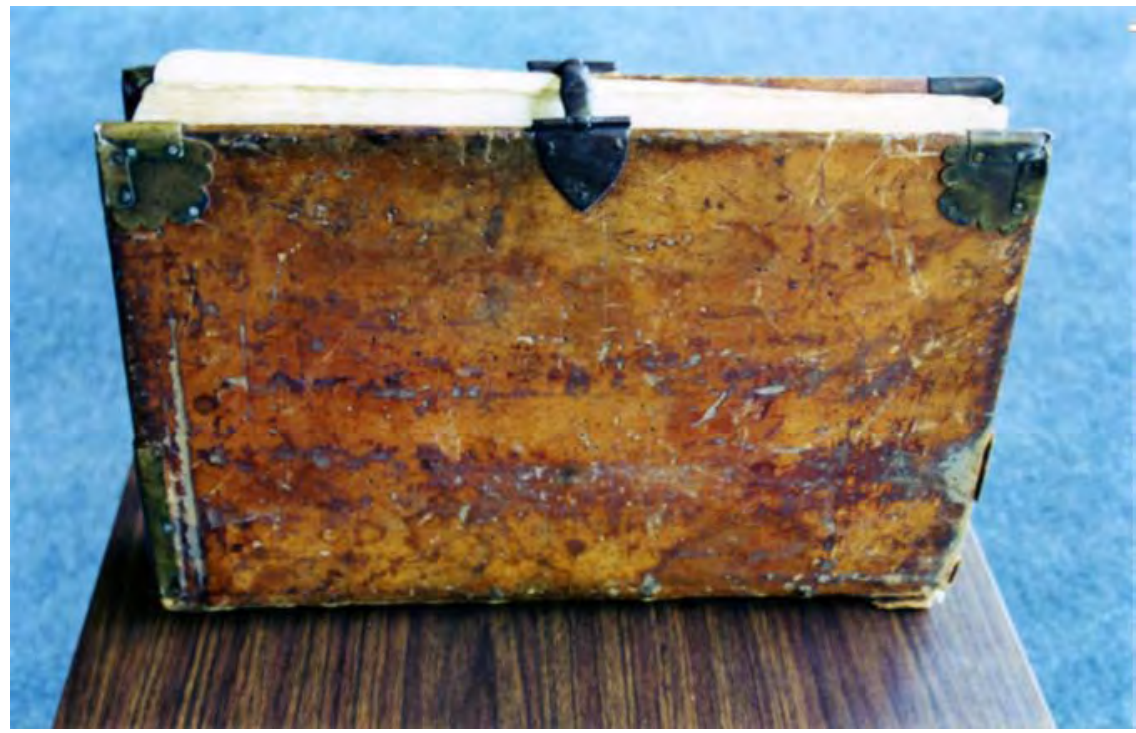

Pero este mismo tipo de encuadernación no se encuentra frecuentemente en los fondos antiguos mexicanos, en los cuales existen diversos tipos de encuadernaciones que deberían ser identificados y descritos para un mejor conocimiento patrimonial de los objetos conservados. La más común de las encuadernaciones que caracterizan a los impresos novohispanos es de pergamino con "correas o presillas de cuero", con el título pintado a lo largo del lomo con tinta, mientras que los impresos procedentes de Europa venían encuadernados en becerro. ${ }^{723}$

Lo cierto y lamentable es que la encuadernación es otro de los elementos, junto con la ilustración, más sensibles a la destrucción. Esta se realizó y se realiza mediante la reencuadernación, que sustituye encuadernaciones originales y representa un verdadero desastre bibliográfico en la medida en que da pie a la pérdida de importante información histórica; debido a que este proceso no solamente acaba con la encuadernación sino también con otros datos, como las firmas de los propietarios o las guardas originales, todo lo que en conjunto podría

723 Ibíd. p. 4 
testimoniar la dimensión de una biblioteca y los gustos estéticos de una persona.

Ciertamente

en las últimas décadas, la reencuadernación de libros antiguos se ha convertido en un asunto bastante polémico; coleccionistas y libreros tienen un punto de vista subjetivo, mientras que los que no son propietarios de los libros - los bibliotecarios y conservadores- se acercan a esta cuestión de forma más objetiva. ${ }^{724}$

El objeto de esta polémica es la razón por la cual consideramos que la encuadernación debe ser registrada en la descripción bibliográfica. $^{725}$

Por la relevancia histórica y estética de la encuadernación, "hemos de pertrecharnos en ciertos saberes. Al examinar por fuera los ejemplares nuestro propósito es precisar, con la terminología correcta, su singularidad". ${ }^{726}$ Creemos que al describirla hemos de referirnos básicamente al material de la encuadernación (es de pergamino, piel, papel o tela), si corresponde a un estilo ( $v$.gr. holandesa con esquinas), ${ }^{727}$ si presenta un tipo especial de decoración ${ }^{728}$ o marca de procedencia.

724 Ibíd. p. 205

725 Es un aspecto de interés que se observa en las obras de Philip Gaskell. Op. cit. pp. 178-187; Alberto Montaner Frutos. Op. cit. p. 155; Lorenzo Baldacchini. Op. cit. pp. 96-104.

726 Julián Martín Abad (2004a). Op. cit. 118

727 Para lo cual es importante documentar nuestra apreciación con algún libro especializado como la Enciclopedia de la encuadernación. Madrid: Ollero \& Ramos, 1998, entre otros o incluso la base de datos de la Biblioteca Británica, disponible en la página http://www.bl.uk/catalogues/bookbindings/welcome. htm [Consultado: Mayo de 2006]

728 Como puede serlo las guardas decoradas que conforman un universo fascinante de estilos artísticos y a las que no suele prestarse mucha atención. Cfr. Rosamond B. Loring Decorated Book Papers: being an account of their designs and fashions. 4a ed. Cambridge: Houghton Library: Harvard College Library, 2007. 
De estos dos últimos datos se trata de especificar si presenta cantos en color (en rojo, azul, amarillo, marmoleados, moteados y salpicados), ${ }^{729}$ si hay presencia o restos de broches o correas, si hay algún problema de conservación concreto (óxido, manchas, xilófagos, restaurada, conservada), ${ }^{730}$ si el lomo presenta título pintado (especificar de que tipo y color) o si existen tejuelos (en lomo o tapas) que testimonien un cierto sistema empleado en las bibliotecas para la ordenación de sus libros; también, por supuesto, si hay supralibros en las tapas (escudo, monograma, emblema, firma, inicial). ${ }^{731}$

Aun cuando reconocemos que el registro de este elemento histórico para ciertos especialistas podría requerir de mayor detalle, para nosotros es suficiente con registrar la información de la siguiente manera:

Encuadernación de pergamino con título redondo pintado en el lomo, cantos moteados en rojo, y evidencias de correas de cuero. ${ }^{732}$

Para otro tipo de trabajo más especializado en el que la encuadernación sea el objeto principal de atención, por supuesto que se requerirá de un mayor detalle en su registro e identificación, como pueden ser los procesos de restauración o conservación, que deben documentar puntualmente de qué encuadernación se trata y si debe sustituirse, así como la razón que motiva tal decisión.

En la finalidad de nuestra propuesta consideramos que si un registro elaborado en un periodo definido indica un tipo de encuadernación específica, y en la posterior consulta de ese mismo objeto la encuadernación ha cambiado, significa necesariamente que algo se ha perdido, pero también porque su inclusión en el registro puede

729 Cfr. Lucía Torner Morales. "El estudio material del libro antiguo: El análisis de guardas, cantos y planos decorados". XVIII Encuentro de Investigadores. Del pensamiento novobispano. Noviembre de 2005.

730 Antonio Carpallo Bautista. "La encuadernación y su descripción". Boletín de la ANABAD. Vol. 49, no. 1 (1999). p. 235

731 Julián Martín Abad (2004a). Op. cit. p. 114

732 Diego de Jesús. Nombres de Christo sacramentado... Reimpreso en México: en la Imprenta de los Herederos de Doña María de Rivera, 1766. Biblioteca Eusebio Francisco Kino 024183 
ayudar a seleccionar piezas importantes para las exposiciones bibliográficas.

\section{l) El estado de conservación}

El estado de conservación del ejemplar que se describe no parece ser un dato tan evidente a pesar de que "en muchos casos la pésima presentación tipográfica es debida a la mala calidad del papel". ${ }^{733}$ Este detalle parece trivial en cada caso, pero en conjunto toma dimensiones de gran importancia para el conocimiento y especialmente para la preservación a largo plazo del legado cultural que representan los libros antiguos. He aquí un lamentable caso de estado de conservación que tienen algunos ejemplares en los fondos antiguos de México.

733 Jaime Moll (1996). Op. cit. p. 31 


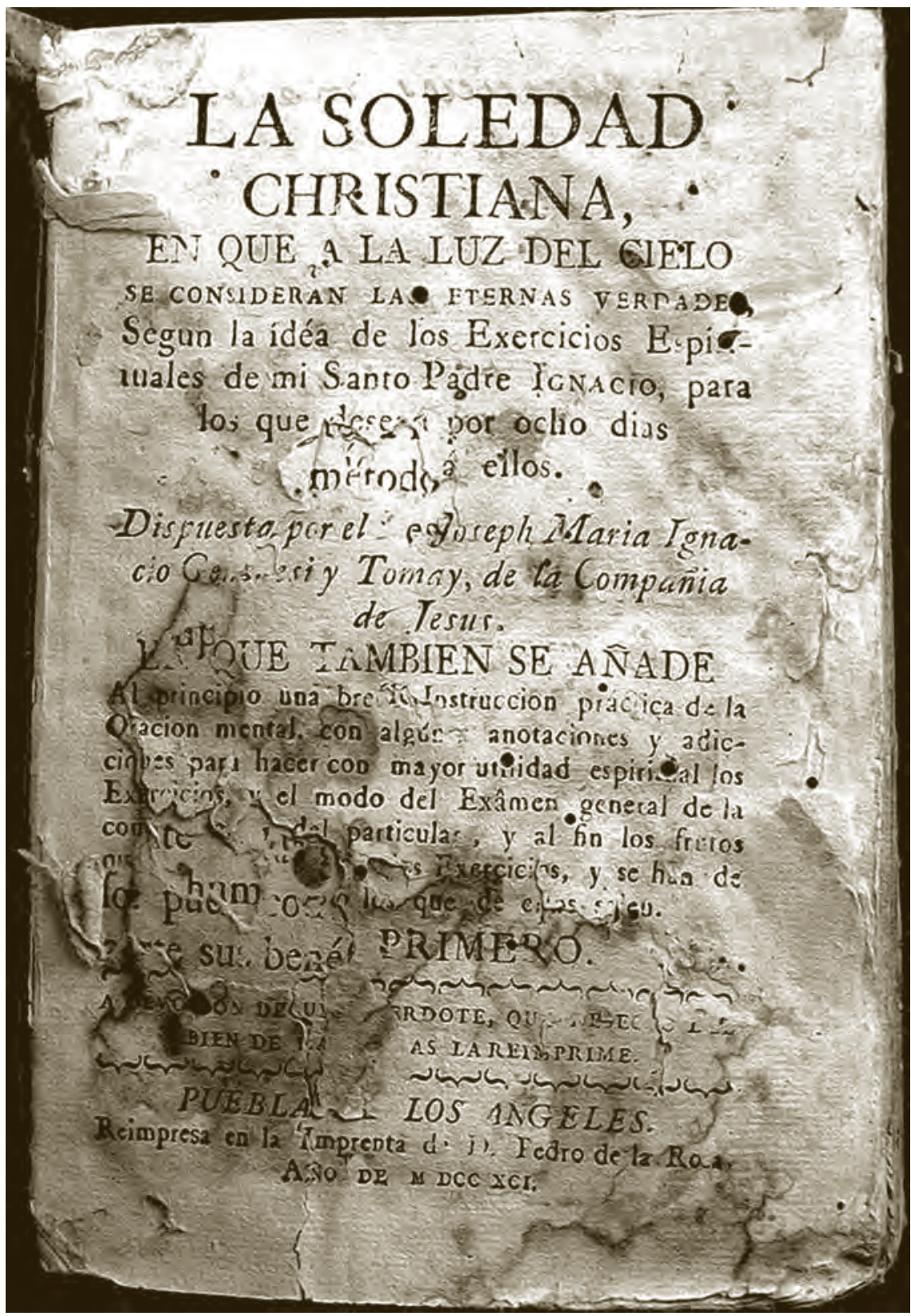


No considerar el estado de la conservación en el momento de la descripción en parte significa no estar consciente de que ese dato también nos aporta información importante sobre la historia particular de cada libro en el estante. No hay que olvidar que

las obras están en una biblioteca para ser usadas, evidentemente, pero no en menor medida es preciso comprender que el uso indiscriminado de ejemplares únicos no lleva sino a que se estropeen y posiblemente sufran daños irreparables. ${ }^{734}$

Al igual que ocurre con la relevancia de la encuadernación, el restaurador o un conservador deben considerar, antes de decidir cualquier intervención sobre un objeto original, la identificación precisa del estado de la misma tomando en cuenta la información del registro bibliográfico o catalográfico. Por esta particular condición tanto más debe considerarse la inclusión del estado de conservación en la descripción, aunque sea de forma somera para documentar los procesos de deterioro que el libro ha sufrido. ${ }^{735}$

Lo anterior no significa que debamos quedarnos en las calificaciones "bueno" o "malo", sino que podamos identificar el tipo de deterioro (xilófagos, ${ }^{736}$ oxidación, ${ }^{737}$ roturas, hongos, etcétera), así como dónde específicamente se presenta. Para nosotros la conservación se indica antecedida de la sigla "EC", de la siguiente forma:

734 Juan José Fuentes. Las bibliotecas nacionales: un estado de la cuestión. Gijón: Trea, 2003. p. 297

735 José Vergara Peris. Conservación y restauración de material cultural en archivos y bibliotecas. Valencia: Biblioteca Valenciana, 2002. p. 90

736 Especialmente cuando se ha formado una "galería" que afecta a la comprensión del texto. Por galería se entiende a los "pasillos formados por la suma de agujeros que presentan diferentes trayectos y ocasionan la pérdida de parte del material del soporte”. Carmen Bello Urguellès y Àngels Borrell Crehuet. El patrimonio bibliográfico y documental: claves para su conservación preventiva. Gijón: Trea, 2002. p. 68

737 Es el color marrón que presentan los libros y que constituye una reacción química de la humedad con el oxigeno. Ibíd. p. 72 
EC: Bueno pero presenta manchas de humedad y hojas oxidadas. El folio 200 más deteriorado y restaurado. ${ }^{738}$

\section{m) Otros datos relevantes}

La consideración de otros datos relevantes para el registro bibliográfico depende directamente de la valoración cultural que se tenga del libro antiguo. Para nosotros esos otros datos pueden ser la ornamentación, variaciones de la edición, errores presentes en el ejemplar que se describe y características de la composición, entre las cuales se incluirían las apostillas, el número de líneas en la caja de textos, los reclamos o la presencia de titulillos.

En lo que corresponde a la ornamentación, se debe identificar la relevancia del elemento en cuestión de acuerdo a la función que tiene en un libro y a la relevancia del trabajo gráfico. Estas dos consideraciones son prioritarias para definir si debe o no formar parte de las notas correspondientes en la descripción; por ejemplo, si las capitulares son todas historiadas y por tanto presentan una secuencia narrativa, si el libro tiene una secuencia de grabados, o incluso si dentro del texto existe un programa decorativo que se observa en todos los elementos ornamentales presentes.

Si el grabado tiene el nombre del grabador o de quien lo dibujó, lo más pertinente es proporcionar también esta información, ${ }^{739}$ por ejemplo:

Grabados calcográficos de Gaspar Bouttats (sculpit) al inicio de la obra, y entre p. 78 y 79, 128 y 129, 356 y 357, $\left(47\right.$ x 76). ${ }^{740}$

738 Carlos de Sigüenza y Góngora. Paraíso occidental, plantado, y cultivado... en su magnifico Real Convento de Jesús Maria de México de cuya fundación y progresos... Con licencia de los superiores en México: por Juan de Ribera, 1684. Biblioteca Eusebio Francisco Kino 016445.

739 Suelen aparecer la palabras latinas sculpit para quien graba y fecit para quien dibuja. A veces juntas y en otras ocasiones sólo una de éstas.

740 Joseph Vidal. Memorias tiernas dispertador afectuoso y devociones... de la Santissima Virgen... En Amberez: por Henrico y Cornelio Verdussen, 1695. Biblioteca Eusebio Francisco Kino 24010. 
Finalmente cuando la ornamentación no es relevante pero está presente a lo largo del libro, creemos pertinente indicar su existencia en las notas de forma general como se sugiere:

"capitulares a lo largo del texto", "orlas al iniciar cada capítulo", "viñetas de pie y cabecera en cada capítulo".

Por lo que compete a la composición, es claro que en la actualidad "estamos totalmente familiarizados con los detalles que encontramos en los márgenes superiores [e inferiores] de las páginas en los libros modernos" ${ }^{741}$ Sin embargo, en los libros antiguos ciertos elementos de la composición no son tan comunes y por eso consideramos que deben documentarse si se considera pertinente o relevante.

Por ejemplo, cuando aparece el título completo o abreviado de la obra en la parte superior de las páginas, o en los casos en que se imprimió en la página de la izquierda ese título y en el de la derecha el de un capítulo concreto. Esta línea de texto marginal recibe el nombre de titulillo y puede servir para identificar un libro cuando se carece de portada y de preliminares.

741 Julián Martín Abad (2004a). Op. cit. p. 97 


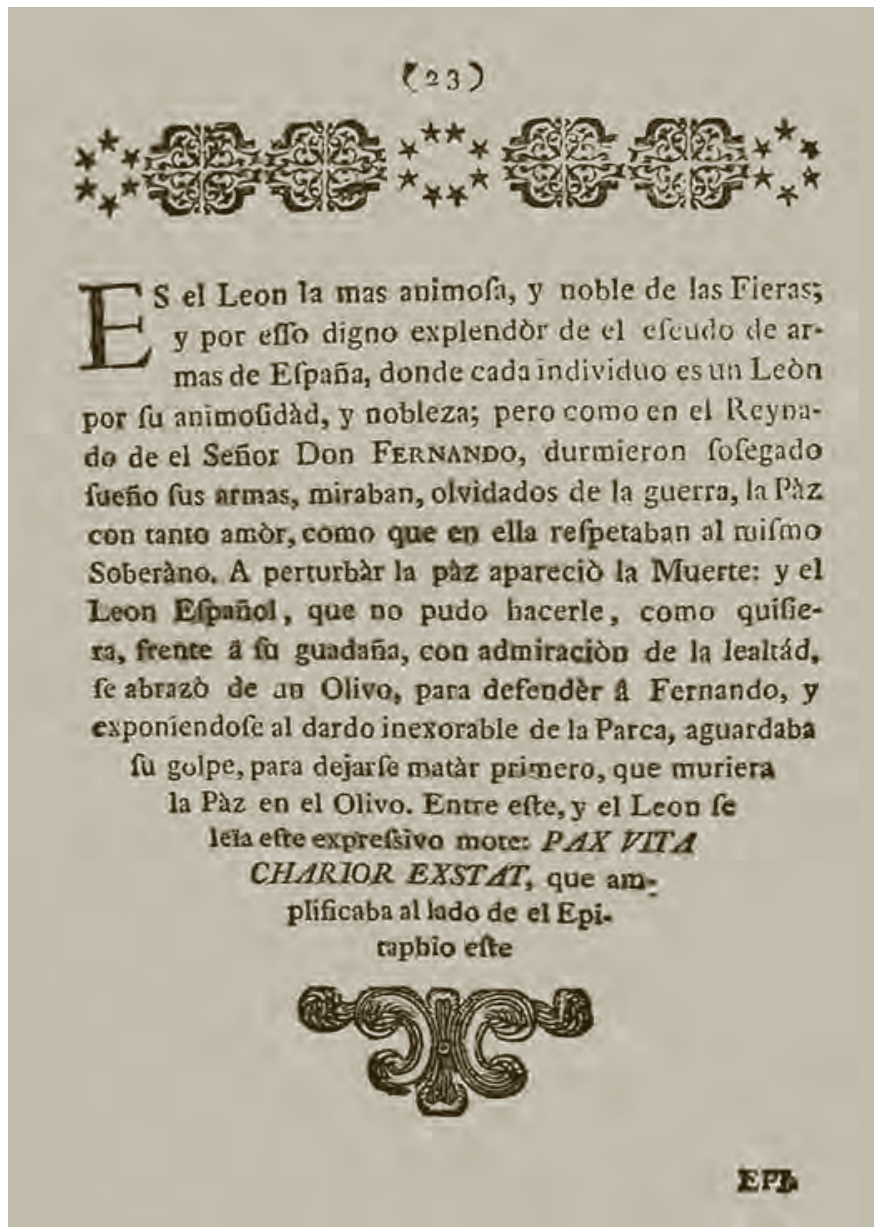

También puede resultar importante registrar la presencia de apostillas en los márgenes izquierdo y derecho, o si el texto está glosado o en columnas, la anotación completa de errores (de paginación o foliación) que puede constituir una información interesante de cierta utilidad, ${ }^{742}$ y finalmente informar de cuántas líneas se compone la caja de texto, con líneas, reclamos y signaturas. De esta manera la nota

742 Jean-François Gilmont. Op. cit. p. 391. 
correspondiente debería quedar como se muestra en los siguientes ejemplos:

Apostillas separadas del texto por una línea

El reclamo de la página 101 corresponde a la segunda palabra de la página 102, no existe reclamo en la página $180 .{ }^{743}$

Errores en paginación: de 245 pasa a 256; de 312 pasa a 314 y; de 448 a 455. Es y debe ser: 138 por 338, 141-341, 346-348. Todos los reclamos y las signaturas coinciden.

28 líneas de texto, 30 con reclamo y paginación. ${ }^{744}$

\section{n) La ubicación física del material}

La naturaleza patrimonial del libro antiguo condiciona el acceso a las colecciones donde se custodian, que suele de restringido a ciertas personas, por esa razón resulta conveniente indicar dónde se encuentra el material que se ha descrito o que es el soporte de alguna de nuestras argumentaciones. Este dato tiene mayor sentido si se considera que nuestras aportaciones dan a conocer la existencia de un material con un valor cultural específico, y que por tanto se coloca al libro antiguo en la mirada de intenciones "menos honrosas" que la del conocimiento mismo.

También es necesario considerar que la información que hemos registrado será útil para otros, en la medida en que varios intereses de investigación puedan corroborar o confrontar esa misma información, porque para el desarrollo del conocimiento resulta importante

conocer el lugar preciso de la biblioteca a donde se encuentra tal o cual libro, por lo que es necesario en las bibliografías, citar al final de cada ficha, la biblioteca que lo tiene en su acervo. ${ }^{745}$

743 Reglas de la Compañia de Jesús. Reimpresas en México: en la Imprenta Real de Doña María de Rivera, 1742. Biblioteca Eusebio Francisco Kino 017964

744 Juan Paulo Oliva. Platicas domesticas espirituales... En Bruselas: por Francisco Tserstevenes, 1680. Biblioteca Eusebio Francisco Kino 021784

745 Roberto Ramos. Op. cit. p. 22. 
Existe en este sentido un caso concreto que afecta a las colecciones mexicanas de libros antiguos; se trata de los sermones novohispanos, que suelen encontrarse en los volúmenes facticios a los que ya nos hemos referido. Presentamos aquí el caso de una anotación que indica el tipo de obras que se contienen en un volumen.

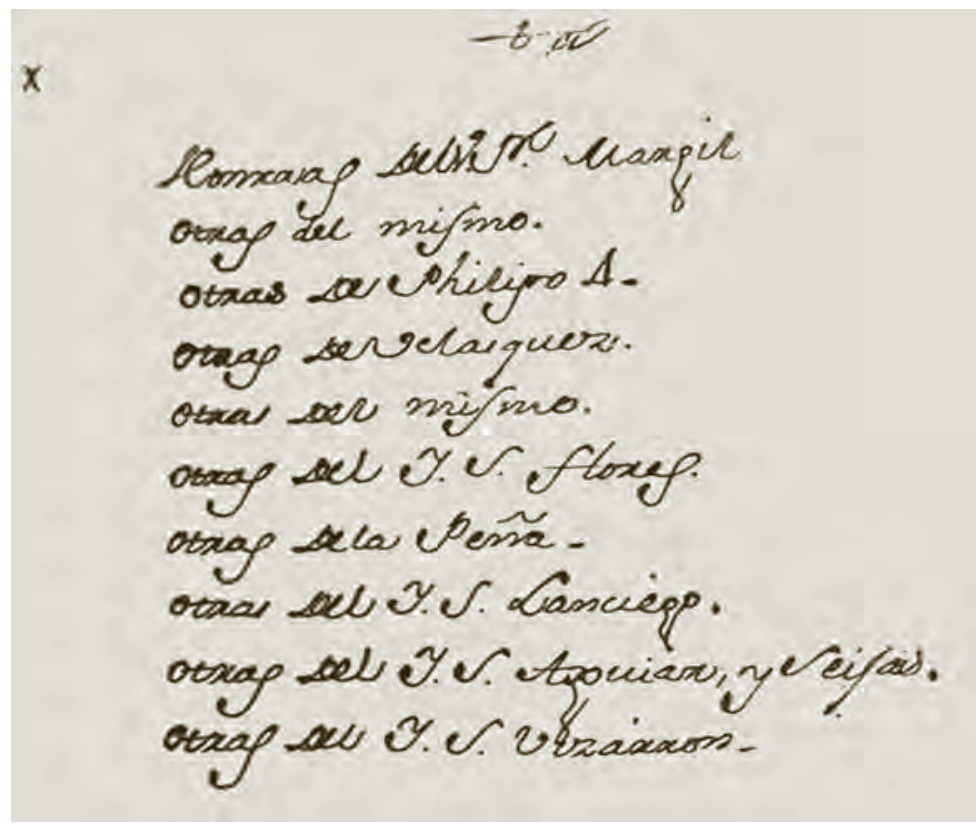

La casuística encontrada en esos volúmenes muestra que son dos las razones que parecen justificar este agrupamiento; la primera es derivada del interés de un bibliógrafo o coleccionista que reúne en un solo volumen las obras de un autor, las que comparten temática o que fueron impresas en un mismo periodo $;^{746}$ la segunda parece derivarse

746 En los casos analizados, algunas veces tenemos noticia del nombre bibliógrafo y su interés, en la mayoría la información se obtiene de la encuadernación. Actualmente estos volúmenes son mayormente apreciados ya que resguardan la producción de la oratoria novohispana que precisamente por su contenido religioso fue extraída de las colecciones donde se resguardaban. Son pocas las instituciones de custodia que todavía resguardan colecciones completas de sermones novohispanos. 
de una decisión institucional que buscó agrupar un tipo de documentos para resolver problemas de conservación u ordenación en la colección. De ahí que en los catálogos estos volúmenes suelen encontrarse registrados con el nombre de misceláneas. ${ }^{747}$

Por esta condición particular, creemos conveniente que se indique en las notas que el ejemplar descrito es parte de un volumen facticio porque es relevante para su ubicación dentro de una colección en algunas ediciones novohispanas. Cuando se realiza la descripción detallada de un volumen facticio, cada elemento constituye un registro diferente, pero el primero encuadernado debería indicarse con la nota "Encuadernado con" y la identificación breve de los otros impresos que conforman el volumen, mientras que los siguientes después del primero deberían llevar la nota "Encuadernado en", haciendo referencia a la primera obra encuadernada.

Finalmente debemos considerar que la mejor forma de organizar un fondo antiguo no es la moderna de las clasificaciones temáticas, sino que

debiéramos desterrar las concepciones metodológicas actuales para comprender el sentido y la estructura de las colecciones bibliográficas de esa época, acudiendo para ello a las fuentes existentes. ${ }^{748}$

Pueden observarse como ejemplo de interés los datos históricos reportados en los ejemplares registrados del Catálogo Colectivo del Patrimonio Bibliográfico Español, aun cuando el formulario de búsqueda no permita recuperar información por esos datos. Sin embargo, en esta base de datos se han reportado en algunos casos los elementos históricos

747 Desde una comparación meramente material, los volúmenes facticios suelen contener meramente impresos mientras que el volumen misceláneo suele contener varios tipos de materiales entremezclados como manuscritos, documentos y otros.

748 Manuel Sánchez Mariana. "Las clasificaciones bibliográficas: su estado a principios del siglo XVIII". El libro antiguo español III: el libro en palacio y otros estudios bibliográficos, al cuidado de María Luisa López Vidriero y Pedro M. Cátedra. Salamanca: Ediciones Universidad: Patrimonio Nacional: Sociedad Española de Historia del Libro, 1996. p. 279 
que conforman el valor patrimonial de un ejemplar incluyendo formas de organización antigua, como se observa en el siguiente ejemplo:

Huesca. Biblioteca Pública del Estado B-17-2720 -- Enc. perg., deteriorado el lomo y prácticamente suelta -- Ex-libris ms.: Aplicolo al Colegio de Huesca el P. Diego de Alastruey -- Sello: Instituto y Prova de Huesca, Biblioteca -- Deteriorada h. de guarda inicial y primer cuaderno, prácticamente desencuadernado -- Olim: B-17-1720 ; III$4037^{749}$

\section{o) Referencias bibliográficas y otros ejemplares}

La propuesta de descripción bibliográfica que hemos argumentado finaliza con la inclusión necesaria de las referencias, "cuando la noticia de un ejemplar se haya repetido en sucesivos o en multiplicados catálogos", ${ }^{750}$ por lo cual consideramos pertinente registrar cualquier bibliografía en la que se ha reportado anteriormente la existencia del libro que se describe. La forma más correcta de citar este dato es el autor, la edición (si fuese el caso), año, el número de registro y página correspondiente. ${ }^{751}$ Por ejemplo, si se trata de la obra de Palau, debe

749 Diego Luis San Vítores. El apostol de las Indias y nuevas gentes San Francisco Xavier de la Compañia de Iesus: epitome de sus apostolicos bechos, virtudes, enseñanças, y prodigios antiguos y nuevos ... Impresso en Mexico : en la imprenta de Agustin de Santistevan y Francisco Lupercio, 1661. Información extraída del Catálogo Colectivo del Patrimonio Bibliográfico Español, disponible en http://www.mcu.es/bibliotecas/MC/CCPB/index.html [Consultado: abril de 2006]

750 Julián Martín Abad (2003). Op. cit. p. 34

751 Standard citation forms for published bibliographies and catalogs used in rare books cataloguing, prepared by Peter $M$. VanWingen and Belinda D. Urquiza. 2nd ed. Washington: Library of Congress, 1996. p. xxv. Si se trata de impresos producidos en el siglo XVI, también pueden emplearse las recomendaciones de Julián Delgado Casado y Julián Martín Abad. Repertorios bibliográficos e impresos del siglo XVI (españoles, portugueses e iberoamericanos: con su fórmula abreviada de referencia. Madrid: Arco Libros, 1993. 
citarse "Palau y Dulcet"752 o si se trata de la obra de Toribio Medina, debe citarse "Medina, J.T. México, T. 1".

De igual forma, creemos que es conveniente indicar si se conocen otros ejemplares de la obra que se describe, para lo cual pueden citarse catálogos institucionales, impresos o automatizados, aun cuando no pueda precisarse con certeza absoluta que son ejemplares de la misma edición por las problemáticas que presentan los catálogos, a las que nos hemos referido.

Esta información puede ayudar a identificar una edición antigua ya registrada, pero que por diversas razones se ha comprendido y transmitido de forma diferente. El conocimiento preciso de un libro antiguo puede ayudar a identificar incluso los errores bibliográficos del pasado y rectificarlos, pero también ayuda a entender la historia misma de un material determinado. Este es uno de los puntos, donde cabe hacer mayor énfasis: determinar con plena certeza por qué un ejemplar registrado dentro de una colección determinada ha desaparecido o incluso nunca existió, porque simplemente el registro fue elaborado de manera errónea. ${ }^{753}$

752 Ibíd.p. 94

753 Esto es particularmente relevante cuando se trata de un libro antiguo que por sus características tipográficas se convierte en una rareza o por que su particular historia nos ha dejado pocos ejemplares supervivientes. Crf. Idalia García. "Narración de un equívoco bibliográfico: un ejemplar de la Psalmodia de Fray Bernardino de Sahagún”. [Inédito]. 



\title{
7. Propuesta para la descripción bibliográfica del libro antiguo
}

\author{
Un libro nunca es simplemente un objeto \\ extraordinario. Como todas las obras \\ tecnológicas, siempre es el producto de la \\ actuación humana en contextos complejos \\ y altamente volátiles que una investigación \\ cabal tiene que intentar recuperar si desea \\ entender mejor la creación y la comunicación \\ de significados como característica definitoria \\ de las sociedades humanas.
}

D.F. McKenzie (2005)

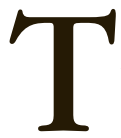
oda esta argumentación anterior, sin duda para muchos excesiva, ha pretendido demostrar que el conocimiento completo de un patrimonio cultural compuesto por libros antiguos ciertamente estará determinado por la utilización de un modelo bibliográfico compartido entre todas las instituciones que custodian materiales de esta naturaleza, el cual debe responder tanto a la identificación básica de un libro antiguo como al análisis bibliográfico histórico y textual del ejemplar que se describe. Esta es nuestra premisa en la medida en que reconocemos que el valor patrimonial de un libro se convierte en una responsabilidad tanto institucional como profesional, sin la cual la transmisión del objeto entre generaciones no sería posible.

La propuesta de descripción que presentamos está basada en trabajos anteriores e intenta combinar una parte de la tradición bibliográfica que reconocemos, así como las aportaciones metodológicas de la Bibliografía Material. En este sentido, consideramos necesario recuperar nuestra propia tradición bibliográfica para elaborar registros sobre objetos particulares o sobre colecciones determinadas. Esa forma 
tradicional posee peculiaridades compartidas que no han variado a lo largo del tiempo, y que todas las personas que la han utilizado repiten sistemáticamente. También es verdad modelos empleados por bibliógrafos del pasado requieren una modernización que sustancialmente se refiere a complementar información ya proporcionada.

Sin esta revisión y comprensión del problema para describir al libro antiguo, se dificulta enormemente establecer con precisión en un registro bibliográfico a la edición o sus variantes. De ahí que "comprender la interrelación forzosa de los fenómenos tipográficos", ${ }^{754} \mathrm{im}$ plica necesariamente reconocer la validez y viabilidad que representa un mayor detalle en la representación bibliográfica del libro antiguo; especialmente en lo que corresponde a los datos de la portada y a los que denotan la estructura material.

Es conveniente hacer aquí un comentario relacionado con el punto que tratamos y que nos preocupa. Pese a que la descripción bibliográfica detallada puede resultar una tarea enfadosa para quien no está interesado y que además es responsabilidad de las personas — bibliotecarios o no- que ejercen la custodia, creemos que también debería ser una labor que realiza por la investigación especializada. La razón de esta afirmación nos parece simple, ya que son los investigadores quienes encuentran en estas fuentes varios temas de estudio y, por tanto, son quienes más pueden ayudar a mejorar y corregir los registros ya realizados.

Por otra parte debemos considerar que la tarea del registro de bienes patrimoniales es una actividad social necesaria que requiere proyecciones a largo plazo; además, tenemos que reconocer nuestro problema concreto de falta de catálogos e inventarios como instrumentos de control y consulta de bienes bibliográficos. Por eso no tenemos duda de que la contribución de los investigadores fortalecería los trabajos de identificación de los libros antiguos conservados en nuestras bibliotecas, así como coadyuvaría en la toma de conciencia sobre el valor patrimonial que representan; una premisa que solamente sería posible si fomentamos y promulgamos que se trata de avanzar más allá de la mera descripción breve.

754 Emilio Torne. "La mirada del tipógrafo: el libro entendido como una máquina de lectura”. Litterae. Cuadernos sobre cultura escrita. No. 1 (2001). p. 156 
En efecto, esta descripción es útil e imprescindible en los trabajos académicos cuando la aportación de una investigación tiene mayores pretensiones que la mera constancia de la existencia de un libro antiguo (físico o documentado). Pero la misma descripción sin contexto patrimonial carece de una finalidad social concreta: aquella que nos permita conocer los objetos que heredamos para valorarlos culturalmente en su justa medida y así transmitirlos.

Ciertamente la descripción bibliográfica detallada implica una mayor inversión de tiempo, del que no siempre disponemos. Sin embargo a largo plazo posee mayores beneficios, tanto para el desarrollo de conocimiento como para el control patrimonial de las instituciones. Al igual que muchos, desearíamos contar de forma frecuente con este tipo de detalle bibliográfico en cualquier repertorio o en trabajos de investigación o, al menos, nos consolaría saber que la tarea se realiza con minuciosidad en las instituciones de custodia. Para éstas, contar con una descripción detallada, especialmente de aquellos ejemplares que son apreciados por un valor cultural superior a los otros, salvaría de los errores más comunes que se presentan en la mera identificación de los libros antiguos conservados.

Por eso creemos necesario recuperar el valor académico del catálogo y el inventario, particularmente en los procesos de formación. Lo hemos dicho en otras ocasiones: que los alumnos de las carreras humanísticas (o de otras interesadas) participen en la elaboración de esos instrumentos nos ayuda a todos. En primer lugar porque permite que éstos conozcan las fuentes originales y adquieran capacidades para su estudio; segundo, permite a la institución avanzar en el registro de los objetos en custodia y así mejorar las tareas de salvaguarda; tercero, aporta al conocimiento especializado la identificación de recursos de información disponibles, ${ }^{755}$ y finalmente, esta implicación garantiza a la sociedad la adecuada tutela de parte de su memoria bibliográfica.

Esencialmente se trata de implicar a los alumnos de universidades públicas. No olvidemos que son estas instituciones las que tienen más libros antiguos en custodia, y también las que cuentan con menos

755 Incluso de aquellos que se han reportado como desaparecidos o no existentes. 
recursos para el desarrollo de sus actividades. A este tenor también debemos recordar que la educación pública se financia con la participación de la sociedad, por lo que el compromiso de la universidad pública con la custodia del patrimonio cultural se transforma en una responsabilidad social ineludible.

Está visto que parte de los estudiosos del libro antiguo desearían que una descripción detallada fuera la predominante en los registros de las instituciones de custodia. Lo cierto es que la complejidad y la ardua tarea que implican estas descripciones han dado mayor fuerza a la interpretación catalográfica normalizada que al trabajo bibliográfico. Sin embargo, los resultados de esta catalogación no han logrado identificar puntualmente todas las peculiaridades de los ejemplares conservados, pese a que la norma reconoce que

el fin del bibliotecario al catalogar los libros antiguos no es únicamente describir un objeto antiguo sino, lo que es más importante, clarificar la transmisión del texto y los puntos que distinguen las ediciones. ${ }^{756}$

Sin que implique menospreciar el trabajo ya existente, las descripciones realizadas no parecen satisfacer plenamente a los interesados en este tipo de información, por lo que no es aventurado pensar que quizá lo más idóneo debió haber sido construir un modelo normalizado de descripción catalográfica más acorde a la naturaleza del libro antiguo, que intentar - como se ha hecho- que ese mismo libro se adaptara a las tendencias normativas de la catalogación desarrolladas para libros modernos.

Esta apreciación puede observarse en las notas preliminares de la propia ISBD (A), especialmente en sus definiciones. ${ }^{757}$ En lo particular resulta ingenuo pensar que con este mero instrumento cualquier catalogador, sin una formación específica previa, puede resolver las problemáticas de registro que toda institución requiere. Ciertamente, con un planteamiento así, parece fácil describir libros antiguos, pero no lo es, considerando la responsabilidad patrimonial implicada en tales descripciones y el tipo

756 ISBD (A). Op. cit. p. X

757 Ibíd. p. 1-28 
de información que los usuarios demandan para trabajar con esta clase de materiales, que puede ser pormenorizada en detalles textuales o históricos. La ingente bibliografía dedicada a esta problemática sobre la catalogación y descripción de libros antiguos es tan solo una muestra sintomática que debería llevarnos a una reflexión más puntual sobre la cuestión, especialmente ahora que esos libros han cobrado un renovado interés a nivel mundial.

Si en la catalogación del libro antiguo se consideraran simplemente la descripción de los datos íntegros de la portada con los criterios de la Bibliografía Material (sin traducciones, sin deshacer abreviaturas, marcando puntualmente altas, bajas, cursivas, y sin alteraciones de las formas ortográficas de época), el formato y las signaturas tipográficas, la descripción física y los elementos históricos que caracterizan a un ejemplar concreto, ${ }^{758}$ estaríamos posibilitando un diálogo entre dos disciplinas hermanas que si bien tienen finalidades distintas, confluyen y son corresponsables en la valoración patrimonial del libro antiguo.

Esta información, aparentemente básica, permitiría a los estudiosos del libro antiguo precisar con certeza que una institución posee la edición o variante de la misma que se está buscando, lo que finalmente es el espíritu conciliador y útil que inspira a las normas internacionales para toda descripción bibliográfica. Pero también tendríamos una representación más nítida de los valores textuales, históricos y de contenido que soportan el valor cultural que hoy apreciamos en el libro antiguo.

Estamos plenamente convencidos que ambas representaciones se pueden combinar consolidando un instrumento eficaz para la consulta (sea especializada o no) y para el control institucional (del Estado o la institución) de estos bienes patrimoniales de naturaleza bibliográfica. Pero esta responsabilidad requiere una inversión considerable de tiempo y esfuerzo, tanto en la formación como en la investigación, para facilitar la socialización de la riqueza cultural custodiada. Lo hemos dicho antes, no se trata solamente de un deber sino de una condición moral irrenunciable e impostergable; solamente así las generaciones

758 Cfr. E.W. Padwick. Op. cit. p. 143 
venideras podrán gozar del mismo privilegio patrimonial del que hoy disfrutamos con estos libros.

Finalmente, recordamos que la propuesta de modelo que presentamos está compuesta por los siguientes datos:

1. Descripción breve del ejemplar (encabezamiento),

2. Transcripción de los datos de la portada completos (de forma casi facsimilar),

3. Descripción física (formato, tamaño, colación, paginación o foliación, y tipo de letra),

4. Relación del contenido de la obra y,

5. Las notas correspondientes a cada ejemplar descrito. El orden que hemos preferido es el siguiente: a) Marca de fuego y/o Ex libris y/o Sellos; b) Anotación manuscrita (indicar de qué tipo, ubicación en hoja o folio exacto y transcribir si es relevante); c) Elementos de ilustración a distinguir (capitulares, grabados, viñetas, etc.) e indicar el folio o la hoja exacta de ubicación; d) Encuadernación (indicar tipo y características relevantes); e) Estado de conservación, EC (Indicar el tipo exacto de daño); f) Otras relevantes: errores de foliación, paginación, signatura; caja de texto (número de líneas), indicar si hay apostillas o glosas, también si el texto se encuentra en columnas; g) Ubicación del ejemplar descrito; h) Referencias bibliográficas y otros ejemplares localizados (se indica la biblioteca y el número de orden en la misma (inventario o clasificación).

La razón que ha inspirado estas líneas es contribuir a la consolidación del valor cultural de los libros antiguos impresos en México, debido a lo cual es que la mayoría de los ejemplos que aquí presentamos fueron seleccionados de los impresos en el mismo territorio. Sin embargo, también se encontrarán ejemplos de impresos europeos que se conservan en las bibliotecas del país, debido a que éstos igualmente son testimonio fiel de las redes culturales del escrito.

Es pertinente también aclarar que no hemos aplicado nuestra propuesta a los impresos mexicanos del siglo XVI, ya que consideramos que a éstos se les ha dado más protagonismo en la historia cultural del libro y la biblioteca en México. Además, porque 
el libro del diecisiete, inserto en la realidad política, histórica, social y económica [de su tiempo] refleja la etapa depresiva causada por la inestabilidad política, ${ }^{759}$

dando inicio a una época insegura donde florecerá el barroco como medio de expresión.

Es a partir de este momento que la producción de libros, especialmente la que se realiza en territorios coloniales, enfrentará duros tiempos en su transformación como actividad comercial para imprimir objetos que son algo más que meros producto del conocimiento. Frente a estas dificultades, como la baja calidad del papel o el empleo de tipos usados, a las que se añaden los efectos del control y la censura, la belleza tipográfica del libro antiguo es un muestrario de los intereses, virtudes, debilidades y aspiraciones de los hombres de una época. Las características de estos testimonios y la evidencia de su propia historia es lo que pretendemos representar en estas descripciones, que son ejemplos mínimos de una realidad cultural materializada.

\subsection{Modelos de descripción: Siglo XVII}

\section{ARNAYA, Nicolás de (S.I.)}

Conferencias espirituales, utiles y provechosas para todo genero $y$ estado de personas... Impresso en Sevilla: por Francisco de Lyra, 1617.

CONFERENCIAS / ESPIRITVALES, / vtiles, y prouechofas para / todo genero y eftado de / perfonas, / COMPVUESTAS POR EL PADRE / Nicolas de Arnaya de la Compañia de / IESVS. / TOMO SEGVNDO / A LA SERENISSIMA EMPERATRIZ / del Cielo, Madre de Dios, y Señora / nueftra. / [Emblema jesuita] / CON PRIVILEGIO, / Impreflo en Seuilla por Francifco de Lira. Año de 1617

8\%; (195 mm); []2, I4, A-Z8, Aa-Zz8, Aaa-Ccc8, Ddd3; [6], 398 fol. RC

759 Carmen Gómez-Senent Martínez. Catálogo de obras impresas en el siglo XVII de la Biblioteca Municipal de Valencia. Valencia: Ajuntament, 1996. p. 9 
Secretos del estante: elementos para la descripción bibliográfica...

\begin{tabular}{|l|l|}
\hline h1r. & Portada. \\
\hline h.1v. & En blanco. \\
\hline h.2r. & $\begin{array}{l}\text { [Suma de licencia y privilegio] Madrid, marzo de 1617. } \\
\text { Tassa, 4 maravedís cada pliego. Madrid, 22 de diciem- } \\
\text { bre1617. }\end{array}$ \\
\hline h.2v. & En blanco. \\
\hline h.3r.-6r. & Tabla de las conferencias y párrafos del libro. \\
\hline h.6v. & En blanco. \\
\hline Fol. 1r.-398v. & Texto de la obra. \\
\hline
\end{tabular}

Notas:

Sello de tinta en portada: "Instituto Científico de México, S.A. Biblioteca".

Ans. mss. en portada: "De la librería del Noviciado de Tepozotlan numero 80" y "Noviciado de Santa Ana en México", "1788ã.m:m”; en fol. 138r. "Laperulesa Samascoris la mas diligente", en fol. 398v. "Tepozotlan" (tres veces)

Encuadernación de pergamino con título gótico pintado en el lomo y cantos en rojo. Las tapas tienen documentos antiguos.

EC: Regular, lomo desprendido, con manchas de humedad y hojas oxidadas, algunas hojas ligeramente pegadas y rotas las numeradas con fol. 223, 224

Capitulares, viñetas de pie y cabecera a principio y fin de cada parte. Titulillo en recto y verso. Error de signatura, es y debe ser: I4-K4, coinciden reclamos y foliación. En foliatura, es y debe ser: 15-16, 35-32, 8191, 116-106, 142-149, 165-169, 166-170, 189-187 y nueva numeración a partir de 190; 187-197, 189-199, 100-200, 101-201, 102-202, 105-205, 106-206, 241-249, 260-259 y vuelve a numerar a partir del error; 269268 y vuelve a numerar a partir del error. El texto coincide.

Caja de texto: 40 líneas (42 con numeración y signaturas).

El ejemplar conservado en Sevilla (BGU A 011-065) tiene las hojas de la tabla encuadernadas al final del texto de la obra.

Ejemplar de la Biblioteca Eusebio Francisco Kino 017152

Referencias: Palau y Dulcet ( $2^{\mathrm{a}}$ ed.), 1, p. 117 (indica formato en $4^{\circ}$ ); 
Domínguez Guzmán, ${ }^{760}$ 1992: 388

Otros ejemplares: Sevilla (BGU); BNMx RFO 248 ARN.c. 1617; BNAH: Colección General, Convento de San Sebastián de la Ciudad de México, Ex Convento Grande de San Francisco (Querétaro), Convento de Santa Teresa (Querétaro), Museo Nacional del Virreinato; BPalafoxiana (14748 y 14749); BLafragua 15318-22010203, BNFr 330941, D-6282; CCPB CCPB000033092-2; ICCU BVEE $\backslash 047225$

\section{CASTRO, Francisco de.}

De arte rethorica... Cordubae: apud Francisco de Cea, 1611.

P. FRANCISCI / DE CASTRO / GRANATENSIS, / EX SOCIETATE IESV. / DE ARTE RHETORICA. DIALOGI QVATVOR / [filete] / [emblema jesuita] / [filete] / Cordubæ apud Franc. de Cea Anno. 1611 / Fran.Heylan Sculp.

$8^{\circ}$ : (151 mm); []1, $48, \mathrm{~A}-\mathrm{S} 8, \mathrm{~T} 4 ;$ [9], 225 p., [20]; RC.

\begin{tabular}{|l|l|}
\hline h.1r. & Portada enmarcada. \\
\hline h.1v. & En blanco. \\
\hline h.2r. & $\begin{array}{l}\text { Tassa. Miguel de Ordanza Zavala. Madrid, 12 de julio de } \\
\text { 1611. } \\
\text { Sic erratta corriges. Madrid: 17 de junio de 1611. }\end{array}$ \\
\hline h.2v. & $\begin{array}{l}\text { [Censura de Jacobo Martínez, jesuita, Catedrático del Cole- } \\
\text { gio de Hermenegildo] Córdoba, Prid.non.nou.an 1609. }\end{array}$ \\
\hline h.2v.-3r. & $\begin{array}{l}\text { [Aprobación de Martín de Roa, jesuita, Rector del Colegio } \\
\text { de Santa Catarina. Córdoba, 4 de noviembre de 1609. }\end{array}$ \\
\hline h.3r. & $\begin{array}{l}\text { Licencia del Provincial. Francisco de Quesada, Betica, 14 } \\
\text { de septiembre de 1610. }\end{array}$ \\
\hline h.3v. & $\begin{array}{l}\text { Censura de Francisco de San Villanova, Doctor en Sagrada } \\
\text { teología. Madrid, pridie ral. Octubre de 1610. }\end{array}$ \\
\hline h.4r.-4v. & Privilegio. San Lorenzo el Real, 16 de octubre de 1610. \\
\hline
\end{tabular}

760 Aurora Domínguez Guzmán. La imprenta en Sevilla en el siglo XVII: catálogo y análisis de su producción, 1601-1650. Sevilla: Universidad, 1992. 
Secretos del estante: elementos para la descripción bibliográfica...

\begin{tabular}{|l|l|}
\hline h.5r.-6r. & Dedicatoria del autor al Inca Garcilazo de la Vega. \\
\hline h.6v. & Epigrama al autor del P. Rodereci de Figueroa, jesuita. \\
\hline h.7r. & Epigrama de Pedro Manioni, jesuita. \\
\hline h.7v. & Epigrama al autor de Luis de Góngora y Argote. \\
\hline h.8r. & Soneto al autor de Luis de Góngora y Argote. \\
\hline h.8v. & $\begin{array}{l}\text { Texto laudatorio al autor de Francisco Fernández de Cór- } \\
\text { doba. }\end{array}$ \\
\hline h.9r. & Epigrama al autor de Luis Venegas de Figueroa. \\
\hline h.9v. & Texto laudatorio al autor de Juan Aquilarius. \\
\hline p. 1-7 & Autoris ad Lectores Proemium. \\
\hline p.8 & $\begin{array}{l}\text { D. Augustinus in Huis Artis Commendationem IV. De } \\
\text { Doct. Christ. }\end{array}$ \\
\hline p. 9-255 & Texto de la obra. \\
\hline h.1r.-20v. & Index Rerum et verborum. \\
\hline
\end{tabular}

Notas:

An. ms. en tapa anterior: "Est. CI"

Encuadernación de piel con evidencias de broches de cuero. Tejuelo en lomo de principios del s. XX.

EC: Regular, ataque de xilófagos en parte superior, manchas de humedad y hojas ligeramente oxidadas

Caja de texto: 24 líneas (26 con numeración y signaturas)

Titulillo en recto y verso

Ejemplar de la Biblioteca General Universitaria de Sevilla A 87-245

Referencias: Palau y Dulcet (2a ed.), 2, p. 103

Otros ejemplares: BNMx G 808 CAST.d.; CCPBE CCPB000038963-3

\section{CISNEROS, Luis de (O. de M.)}

Historia de el principio, y origen progresos venidas a México, y milagros de las Santa Imagen de Nuestra Señora de los Remedios... México: Emprenta del Bachiller Juan Blanco de Alcazar, 1621.

HISTORIA DE / EL PRINCIPIO, Y ORI- / GEN PROGRESSOS VENI- / das à Mexico, y milagros de la Santa Ymagen de / nueftra Señora de los Remedios, extramuros de Mexico. / I DIRIGIDA, AL INSIGNE CABILDO DE LA / nobilifsima Ciudad de Mexico, Patrona de fu Santa 
Hermita. / Por el Maestro Fray Luis de Ci/neros, de el orden de nue/tra Señora de la / Merced, Redempcion de captivos, Cathedratico de propiedad de Visperas, /de Theologia de la Real Universidad de Mexico. / [Grabado xil. con tacos a ambos lados] / I En Mexico, Impreffo con licencia, en la Emprenta del Bachiller Iuan / Blanco de Alcaçar, junto a la Inquificion, año de 1621

4 ; (199 mm); A-Z4, Aa-Rr4; [4], 156 fol., [1].; RC

\begin{tabular}{|l|l|}
\hline h.1r. & Portada enmarcada. \\
\hline h.1v.-2r. & $\begin{array}{l}\text { Licencia de impresión de Diego Fernández de Cór- } \\
\text { dova, Marques de Guadalcazar, Virrey de la Nueva } \\
\text { España. México, 9 de noviembre de 1620. }\end{array}$ \\
\hline h.2r. & $\begin{array}{l}\text { Licencia de impresión de Juan de la Serna, Arzo- } \\
\text { bispo de México. México, 30 de diciembre de 1620. }\end{array}$ \\
\hline h.2v. & $\begin{array}{l}\text { Aprobación de Fr. Pedro de Celis, Fr. Juan de Va- } \\
\text { lencia y Fr. Luis Vaca, mercedarios. Convento de } \\
\text { Nuestra Señora de la Merced de México, 21 de oc- } \\
\text { tubre de 1616. } \\
\text { Licencia del Provincial, Fr. Benito Martínez. Con- } \\
\text { vento de México., 21 de octubre de 1616. } \\
\text { Aprobación de Luis de Molina, jesuita. Casa Profe- } \\
\text { sa de la Compañía de Jesús. México, 8 de septiem- } \\
\text { bre de 1620. }\end{array}$ \\
\hline h.3r. & Dedicatoria del autor. \\
\hline h.3r.-4r. & Prólogo al lector. \\
\hline h.4v. & $\begin{array}{l}\text { Soneto al autor de Cosme de Medina, ex secretario } \\
\text { del Obispo de Tlaxcala, Don Alonso de la Mota. }\end{array}$ \\
\hline Fol. 1r.-156r. & Texto de la obra. \\
\hline Fol. 156r. & Colofón. \\
\hline Fol.156v.-[157v.] & Tabla del libro. \\
\hline
\end{tabular}

Notas:

Marca de Fuego en canto Superior del Seminario Conciliar de la Ciudad de México (Sala, p. 93; INAH, p. 89). Sellos de tinta en portada: "Asociación Histórica Americanista" y "Ex libris His. Mex. Coll. Mex. 
S.I. Prov. Mex. Merid.” El mismo en canto inferior.

Encuadernación de pergamino con título gótico (negro y rojo) pintado en el lomo, y restos de broches de cuero

EC: Lomo separado, deterioro ligero por xilófagos y hojas oxidadas.

Grabado de portada xilográfico: Escudo de la Ciudad de México con tacos a la izquierda y derecha. Grabado xilográfico en Fol. 79v. de la Virgen de los Remedios dentro de un recuadro formado por tacos (150 x $96 \mathrm{~mm}$ ). Capitulares al principio de cada parte.

Apostillas. Impreso titulillo en verso (parte de la obra) y en recto: Santa Ymagen de nuestra Señora de los Remedios.

Error en signatura es y debe ser: B3-D3; en foliatura: 43-33, 44-34, 4535, 46-36. Se repite el folio 107 dos veces.

Caja de texto: 31 líneas (33 con titulillo y reclamo).

Ejemplar de la Biblioteca Eusebio Francisco Kino 016179

Referencias: Palau y Dulcet (2a ed.), 2, p. 203 (Donde se indica que "El autor era mercedario y catedrático de la Universidad de México. Un ejemplar mediocre");

Otros ejemplares: CCILA 14492.

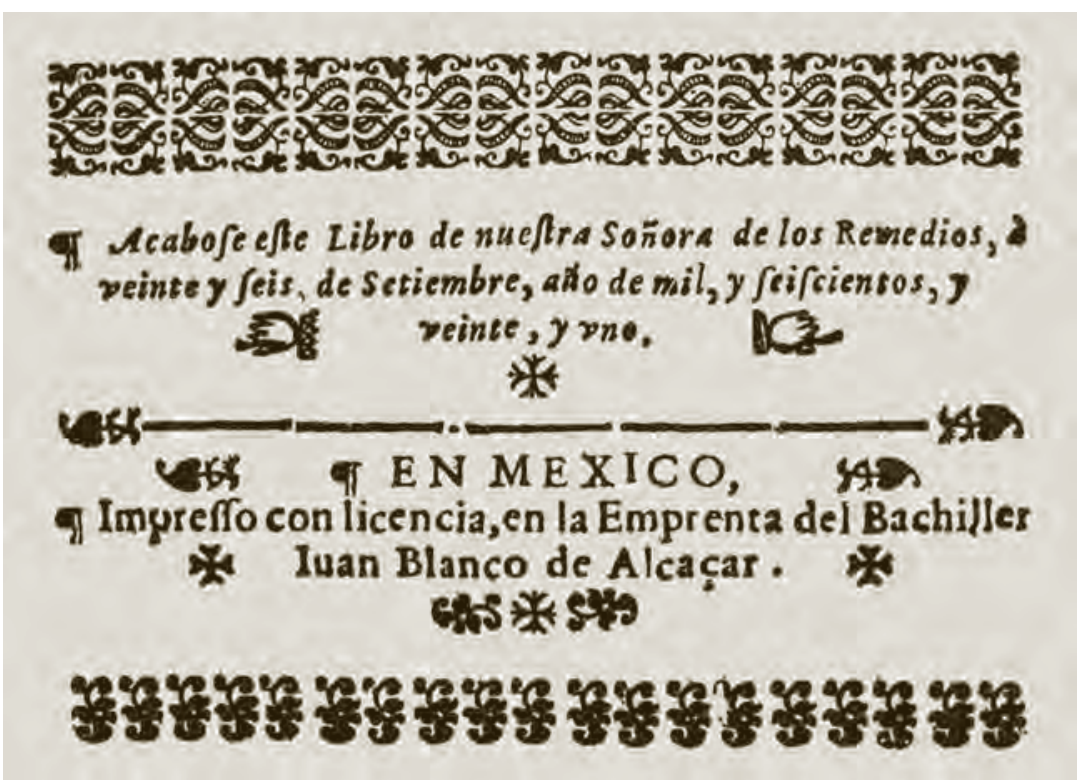




\section{CUBERO SEBASTIAN, Pedro.}

Peregrinación que ba becho de la mayor parte del mundo... En Zaragoza: por Pascual Bueno, 1688.

PEREGRINACION / QVE HA HECHO DE LA / MAYOR PARTE DEL / MUNDO / DON PEDRO CVBERO SEBASTIAN, / Predicador Apoftolico del Afsia, natural del Reyno / de Aragon; con las cofas mas fingulares que le han / fucedido, y vifto, entre tan Barbaras Naciones, fu Re- / ligion, Ritos, Ceremonias, y otras cofas memorables, y / curiofas, què ha podido inquirir; con el [falto] / por tierra, defde Efpaña, hafta las [falto: Indias] / Orientales. / E S C R I T A / POR EL MISMO DON PEDRO [falto: CUBERO] / Sebaftian / DEDICADO AL SS. CHRISTO DE LAS / Injurias, fita en la Igle Sia del Señor San Millan, / anexo de S. Iufto, y Paftor defta Coronada Villa / de Madrid / SEGVNDA IMPRESSION / [Filete] / EN ZARAGOZA, Por Pafqual Bueno, Impreffor del Reyno / de Aragon. / Año de 1688.

$8^{\circ} ;(200$ mm); §4, I4, A-S8; [8], 288 p.; RC

\begin{tabular}{|l|l|}
\hline h.1r. & Portada. \\
\hline h.1v. & En blanco. \\
\hline h.2r.-4v. & $\begin{array}{l}\text { Dedicatoria de Juan Fernández, Mayordomo de la Real } \\
\text { Congregación en la Iglesia de San Millán. }\end{array}$ \\
\hline h.5r. & $\begin{array}{l}\text { Licencia del Reino de Aragón. Zaragoza, 26 de agosto de } \\
1688 .\end{array}$ \\
\hline h.5v-6r. & $\begin{array}{l}\text { Censura de Félix Lucio de Espinosa y Malo, Cronista de } \\
\text { Castilla y León, y mayor de todos los reinos de Aragón. } \\
\text { Madrid, 28 de junio de 1680. }\end{array}$ \\
\hline h.6v. & $\begin{array}{l}\text { Soneto dedicado al autor, de Pedro Calderón de la Barca, } \\
\text { caballero del Orden de Santiago. }\end{array}$ \\
\hline h.7r. & $\begin{array}{l}\text { Soneto dedicado al autor de Juan de Matos, caballero del } \\
\text { Hábito de Cristo. }\end{array}$ \\
\hline h.7v. & Soneto de un amigo al autor. \\
\hline h.8r. & Décimas al autor de Joseph García de la Plaza. \\
\hline h.8v. & Prólogo al lector. \\
\hline p. 1-284 & Texto de la obra. \\
\hline
\end{tabular}


Secretos del estante: elementos para la descripción bibliográfica...

p. 284-286 Descripción de la monarquía de la Gran China.

p. 286-288 Índice de los capítulos.

Notas:

An. ms. en p. 246 “*Miguel Lopez de Legazpi, Adelantado de dichas Islas", en p. 255 “*Miguel Lopez de Legazpi”

Sello en tinta en h.2r.: "Biblioteca de la Sagrada Familia, Col. Roma. México, D.F."

Grabado interior xilográfico de un Cristo crucificado en la dedicatoria, h. 2 r. $(85 \times 56 \mathrm{~mm})$

Encuadernación holandesa con puntas, con tejuelo de piel rojo en el lomo.

EC. Regular con portada restaurada, hojas oxidadas y encuadernación desgastada por el uso.

Titulillo en el verso y el autor en el recto. Apostillas

Error en paginación, es y debe ser: 217-209, 200-220, 202-222, $203-$ $223,129-256$, se invierte 226 por 225 . Todos los reclamos y las signaturas coinciden. Cada cuadernillo numerado hasta la hoja 4.

Caja de texto: 40 líneas de texto (42 con numeración y reclamos). Algunas con 33 líneas sin romper la continuidad del texto.

Ejemplar de la Biblioteca Eusebio Francisco Kino 024013

Referencias: Palau y Dulcet ( $2^{\mathrm{a}}$ ed.), 2, p. 343 (indica formato en $4^{\circ}$ ); Mercado Libro Español, 1999: T. 1, 203 (1998: 180,000 pts).

Otros ejemplares: BNMx G 910.41 CUB.p.; BL 304.f.19.; BNFr G-5718, V9705; CCPBE 000039323-1; LC G460.C97

ESCALANTE, Thomas de (S.I.)

Breve noticia de la vida ejemplar y dichosa muerte del venerable padre Bartolomé Castaño de la Compañía de Jesús... con Licencia en Mexico: por Juan de Ribera, 1679.

BREVE / NOTICIA DE LA VIDA / EXEMPLAR Y DICHOSA MVERTE / DEL VENERABLE PADRE / BARTHOLOME/ CASTAÑO. / de la Compañía de JESVS, / QVE DIO A LOS SUPERIORES / de las Cafas, y Colegios defta Provincia de / Nueva-Efpaña el P. Francifco Ximenez fiendo / Prepofito de la Cafa Profeffa defta / Ciudad de Mexico 
en Carta / DISPVESTA / Por el P. Thomas de E/calante de la / misma Compañía / [tacos xil. en composición de triángulo lateral con [Emblema de la Compañía] [tacos xil. en composición de triángulo lateral con / CON LICENCIA, / En Mexico, por Juan de Ribera, en el Pedradillo, 1679.

$4^{\mathrm{o}}$; (206 mm); I] , [1], A-L ${ }^{4}, \mathrm{M}^{2}$; [7], 46 Fol.; RC

\begin{tabular}{|l|l|}
\hline h. 1r. & Portada con orla tipográfica. \\
\hline h. 1v. & En blanco. \\
\hline h. 2r.-5r. & $\begin{array}{l}\text { Censura de Fr. Andrés de Almazán, Ex prior del Con- } \\
\text { vento de San Agustín de México. [sin fecha] }\end{array}$ \\
\hline h. 5v. & $\begin{array}{l}\text { Licencia de impresión. Ciudad de México, 16 de sep- } \\
\text { tiembre de 1664. }\end{array}$ \\
\hline h. 6r. & $\begin{array}{l}\text { Licencia del P. Thomas Altamirano, Provincial de la } \\
\text { Compañía de Jesús. Colegio de San Pedro y San Pablo } \\
\text { de México, 26 de Agosto de 1679. }\end{array}$ \\
\hline h. 6v. & Protesta del autor, México, 12 de septiembre de 1679. \\
\hline h. 7r. & En blanco. \\
\hline h. 7v. & Grabado calcográfico. \\
\hline Fol. 1r.-26v. & Texto de la obra. \\
\hline Fol. 27r.-36r. & $\begin{array}{l}\text { Tratado de la virtud compuesto por Bartolomé Casta- } \\
\text { ño. }\end{array}$ \\
\hline Fol. 36v.-37r. & Continúa texto de la obra. \\
\hline Fol. 37v.-41r. & Tratado del acto de contrición del P. Castaño. \\
\hline Fol. 41v.-46v. & Termina texto de la obra. \\
\hline
\end{tabular}

Notas:

Sello de tinta en guarda anterior: "Ex libris Hist. Mex. Coll. Max. S.I. Prov. Mex. Merid."

Ans. mss. en guarda anterior: "Libros que he prestado / Al padre Joseph dias guerra Cortes de Inglaterra â Bernabé / Al Padre Miguel de San Esteban vida de Carlos V"; "De la librería del Noviciado de Tepotzotlan no. 924"; "Del Collegio y Casa de Privación / de Tepotzotlan Noviciado desta / Nueba España. Año de 1738"; "Vida y del venerable Pad"; en portada: "Del Collegio de Tepotzotlan"; y en h. 5v.: "Pertenece al Colegio 
de Tepotzotlan dela Compañia de dichos".

Encuadernación de pergamino con título gótico pintado en el lomo. Evidencias de broches de cuero.

EC: Bueno con poca oxidación, lomo desprendido y daño en tapa anterior.

Texto a doble columna (sólo la vida del autor), tacos xilográficos decorando el texto. Error en foliatura, es y debe ser: 26-36.

Retrato grabado del biografiado en h. 7v. (149 x $117 \mathrm{~mm})$.

Caja de texto: dos, la de biografía con 36 líneas (38 con titulillo y reclamos), y otra de textos con 28 líneas (30 con titulillo y reclamos).

Ejemplar de la Biblioteca Eusebio Francisco Kino 016192

Referencias: Palau y Dulcet (2a ed.), 3, p. 128.

Otros ejemplares: BNMx RSM 1679 M4ESC; BNAH Colección General; BPalafoxiana 21721; CCILA 15344; BL 4985.de.17. (Entrada de autor: Francisco Ximenez (S.I.);

Exercicios espirituales de San Ignacio acomodados a el estado y profesión religiosa de las señoras vírgenes, esposas de Cristo... Con licencia en México: por los Herederos de la Viuda de Bernardo Calderón, 1695.

EXERCICIOS / ESPIRITUALES / DE SAN IGNACIO / ACOMODADOS A EL ESTADO, Y / Profeffion Religiofa de las Señoras Virge- / [taco xil.] nes, Efposas de Christo; [taco xil.] / INSTRUIDO / Con un Diario, breve, pero fuficiente de todos / los exercicios cotidianos para que fe empiezen / à exercitar. / [taco xil. ] I Por el P. PREFECTO de la Congregacion de / la Puriffima fundada con Autoridad Apoftolica en / el Colegio Maximo de SAN PEDRO Y SAN PABLO / de la Compañia de IESUS de efta Corte. / † [taco xil. [Y) [taco xil. Señoras Religiofas Vírge- / nes E/pofas de Chrifto. / [floron] / [filete] / Con licencia en Mexico por los Herederos de la Viuda / de Bernardo Calderon Año de 1695.

8'; (151mm); I5, A-I4, J-Z8, Aa-Ee8, F.; [5], 196 fol. [2]; RC. 


\begin{tabular}{|l|l|}
\hline h.1r. & Portada. \\
\hline h.1v. & En blanco. \\
\hline h.2r.-3r. & $\begin{array}{l}\text { Dedicatoria de Pedro Arellano y Sosa para las es- } \\
\text { posas de Cristo. }\end{array}$ \\
\hline h.3v. & $\begin{array}{l}\text { Parecer del P. Francisco de Vera, jesuita. México, } \\
\text { Colegio Máximo de San Pedro y San Pablo de la } \\
\text { Compañía de Jesús, 4 de junio de 1694. } \\
\text { [Licencia de impresión]. Conde de Galve, Virrey de } \\
\text { la Nueva España. México, 9 de junio de 1694. }\end{array}$ \\
\hline h.4r. & $\begin{array}{l}\text { Parecer del P. Joaquín de Robles, jesuita. México, } \\
\text { Colegio Máximo de San Pedro y San Pablo de la } \\
\text { Compañía de Jesús, 29 de mayo de 1694. } \\
\text { [Licencia de impresión]. Francisco de Aguiar y } \\
\text { Seixas, Arzobispo de México. 28 de mayo de 1694. }\end{array}$ \\
\hline h.4v. & $\begin{array}{l}\text { [Licencia del Provincial]. Diego de Almonazir, je- } \\
\text { suita. México, 22 de Mayo de 1694. }\end{array}$ \\
\hline h.5r.-5v. & Erratas. \\
\hline Fol. 1r.-196r. & Texto de la obra. \\
\hline [fol. 196v.-198v.] & Tabla índice de las cosas que se contienen. \\
\hline
\end{tabular}

Notas:

Sellos de tinta en guarda anterior: "JHS Santa Brigida R." y "CE San Javier”, en portada: "JHS Santa Brigida R.”, “JHS Biblioteca Casa Iñigo", este también en fol. $24 \mathrm{v}$., dos no identificados, uno simbólico en forma triangular y circular.

An. ms. de propiedad cancelada en portada: "Pertenece al Br. Dn. José del Cardañada y Mendibuzu".

Encuadernación de piel, título en dorado y lomo decorado, cantos en rojo.

EC: Bueno con las hojas ligeramente oxidadas, tapa anterior desgastada en esquina inferior izquierda.

Error en foliación, es y debe ser: 94-93 y continúa la numeración a partir de $95,164-194$. Se repiten dos veces los folios 162 y 173 , sin afectar la numeración correspondiente. La hoja correspondiente a las erratas está impresa al revés: el verso por el recto.

Caja de texto 31 líneas (33 con foliatura y reclamo). 
Ejemplar de la Biblioteca Eusebio Francisco Kino 050623

Referencias: Palau y Dulcet ( $2^{\mathrm{a}}$ ed.), 6, p. 410.

Otros ejemplares: BNMx RSM 1695 M4NuaNE (Núñez de Miranda Antonio); BNAH Colección general; CCILA 15767

Explicación del Libro Quarto, conforme a las reglas del Arte de Antonio Nebrija... Impresso en México: En la imprenta de Francisco Rodríguez Lupercio, 1664.

EXPLICACION / DEL / LIBRO QVARTO, / CONFORME A LAS REGLAS / DEL ARTE DE ANTONIO / NEBRIJA / CON VN SUPLEMENTO / Singular à las Reglas generales / [Emblema de la

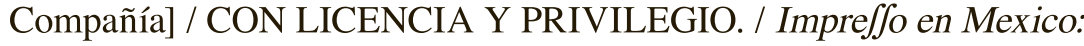
En la Imprenta de / Francifco Rodríguez Lupercio. 1664.

$8^{\circ}$; (149 mm); [ ]8, B-E8; [1], 38 fol. [1]; RC

\begin{tabular}{|l|l|}
\hline h.1r. & Portada. \\
\hline h.1v. & $\begin{array}{l}\text { Licencia y privilegio por Juan de Leyva y de la Cerda, } \\
\text { Capitán General de la Nueva España. }\end{array}$ \\
\hline Fol. 2r.-28r. & Texto de la obra. \\
\hline Fol. 28v. & Algunas reglas para empezar a construir. \\
\hline Fol. 29r.-38r. & Suplemento al libro quarto. \\
\hline Fol. 38v. & Colofón. \\
\hline h.1r. & Cita latina. \\
\hline
\end{tabular}

Notas:

Sello de tinta en portada y fol. 33r: "Asociación Histórica Americanista". An. ms. en portada: "Colegio de Tepozotlán"; en contraportada "Del Colegio de Tepozotlán"; en portada: "Año de 1664” y otras no legibles. También ans. ilegibles en última hoja.

Encuadernación de pergamino y conserva tejuelo en el lomo.

EC: Regular. Hojas sumamente oxidadas, separación del lomo y tapas maltratadas.

Titulillo en recto y verso.

Caja de texto: 28 líneas (30 con titulillo y reclamo) 
Biblioteca Eusebio Francisco Kino 016943

Referencias: Palau y Dulcet ( $2^{\mathrm{a}}$ ed.), 3, p. 293 (cita ediciones con autoría de Mateo Galindo, impresas en México en 1717 y 1722).

Otros ejemplares: BNMx: RFO 1664 M4GAL SN, RSM 1664M4GAL LC: PA2077. G34 (Entrada de autor: Mateo Galindo); CCILA 15083 (Entrada de autor: Antonio de Lebrija)

\section{EZCARAY, Antonio de (Propaganda FIDE)}

Voces del dolor, nacidas de la multitud de pecados que se cometen por los trajes profanos, afeytes, escotados y culpables ornatos... Con licencia en Sevilla: por Thomas López de Haro, 1691.

VOZES / DEL DOLOR / NACIDAS DE LA MVLTITUD / de pecados, que fe cometen por los trages / profanos, afeytes, efcotados, / y culpables ornatos, / Que en eftos miferables tiempos, y en los antecedentes ha / introducido el infernal Dragon para deftruir, y acabar / con las almas, que con fu preciofiffima Sangre / redimiò nueftro amantiffimo Jefus. / DABALAS / Fr. ANTONIO DE EZCARAY, PREDICADOR / de fu Mage/tad, y Apoftolico del Colegio, y Mifsion de / Propaganda Fide de las Indias Occidentales, / de la Ciudad de Santiago de Queretaro. / DEDICALAS AFECTVOSO, Y REVERENTE LAS CONSAGRA / Al iluftrisimo, y Reverendiffimo feñor, mi feñor, el feñor D. Antonio / de Venavides y Bazan, Patriarca de las Indias, Arçobilpo de Tiro, del / Confejo de su Mageftad, fu Capellan, y Limofnero mayor, / y Comiffario Apoftolico General de la / Santa Cruzada, \&c. / A expenfas de unos amigos, y hermanos efpirituales del Autor. / [florón] / [filete decorado] / CON LICENCIA, En Sevilla, por Thomas Lopez de Haro, / año de 1691.

4\% $(197 \mathrm{~mm}) ; *_{-} * * * * 4, * * * * * 2, \mathrm{~A}-\mathrm{Z} 4, \mathrm{Aa}-Y y 4, \mathrm{Zz2}$; [18], 354 p., [5]; $\mathrm{RC}$.

\begin{tabular}{|l|l|}
\hline h.1r. & Portada. \\
\hline h.1v. & En blanco. \\
\hline h.2r.-7r. & Dedicatoria del autor. \\
\hline
\end{tabular}




\begin{tabular}{|l|l|}
\hline h.7v.-10v. & $\begin{array}{l}\text { Parecer de Fr. Alonso Guerrero de Zúñiga, Cronista de la } \\
\text { Provincia de Michoacán. Querétaro, Convento de Santia- } \\
\text { go, 8 de noviembre de 1686. }\end{array}$ \\
\hline h.11r. & $\begin{array}{l}\text { Licencia de la Religión, Fr. Juan de Luzuriaga, francisca- } \\
\text { no. Convento de San José de Haximaloian, 31 de diciem- } \\
\text { bre de 1686. }\end{array}$ \\
\hline h.11v.-12v. & $\begin{array}{l}\text { Aprobación de Fr. Miguel de Mora, Guardián del Conven- } \\
\text { to de San Antonio de Padua de Sevilla, 6 de enero de 1691. }\end{array}$ \\
\hline h.13r. & $\begin{array}{l}\text { Licencia del Ordinario. Dr. Joseph Bayas, Provisor y Vica- } \\
\text { rio General de Sevilla. 9 de enero de 1691. }\end{array}$ \\
\hline h.13v. & Erratas. \\
\hline h.14r. & Suma de la Tassa. 6 maravedies cada pliego [Sin fecha] \\
\hline h.14v.-18r. & Al lector. \\
\hline h.18v. & En blanco. \\
\hline p. 1-354 & Texto de la obra. \\
\hline h.1r.-5v. & Índice compendioso de lo que se contiene en este libro. \\
\hline
\end{tabular}

Notas:

Ans. mss. de escritura y anotaciones de lectura relacionadas con fechas en recto y verso a lo largo de la obra como en h.14r. "Julio 11/66", p. 1 "Agosto 1", p. 19 [no se entiende], p. 27 “'Octubre 19”p. 321 "febrero 28”, o en p. 337 "Marzo 1". Encuadernación de pergamino con título redondo pintado en el lomo, evidencia de cantos en rojo.

EC: Regular, ejemplar incompleto con lomo desprendido y costuras rotas, medio cuerpo manchado de humedad y ataque de xilófagos.

Titulillo en recto y verso. Manitas. Faltan las páginas 67-70, 83-86, 123 126, 187-190.

Caja de texto: 28 líneas (30 con numeración y reclamos).

Testigo de pergamino con anotación ms. "Pida el de r. Agapito por que yo ya lo tengo liado".

Ejemplar de la Biblioteca Eusebio Francisco Kino 024012

Referencias: Palau y Dulcet ( $2^{\mathrm{a}}$ ed.), 3, p. 178.

Otros ejemplares: Las signaturas han sido contrastadas con el ejemplar conservado en Sevilla (BGU A 98-83); BNMx RFO26344, RFO 26349, RFO 93-34614, RFO 93-22017; BPalafoxiana 324, 16091, 16177; CCPBE 000049733-9; 
LEZAMIS, Joseph de.

Vida del apóstol Santiago el Mayor... En México: por Doña María de Benavides, 1699.

VIDA / DEL APOSTOL / SANTIAGO EL MAYOR / VNO DE LOS TRES MAS AMADOS, / Y FAMILIARES DE JESU-CHRISTO / vnico, y fingular Patron de Efpaña / con algunas antiguedades, y excelen- / cias de Efpaña, efpecialmente de Vifcaya / Efcrita por el Ldo. Jofeph de Lezamis, Cura / de la Santa Iglefia Cathedral de Mexico / y dada à la eftampa à cofta, y devocion / [ [taco xil. ] / [falto: Ded]icala al Venerable Dean, y Cabildo de / [falto: la S]anta Iglefia Cathedral Metropolitana, / y Apo/tolica de Santiago de Galicia. / [falto: a] quien en la Dedicatoria fe haze una breve relacion de la / [v]ida y muerte del $\mathrm{Ill}^{\mathrm{mo}}$. y $\mathrm{R}^{\mathrm{mo}}$. Señor Dr. D. Francifco / de Aguiar, y Seyxas, Arzobispo de Mexico, mi Señor. / [filete] / CON LICENCIA DE LOS SUPERIORES. / En Mexico, por Doña María Benavides. / [

4; (195 mm); A-O4, P6, A-Z4, Aa-Zz4, Aaa-Hhh4; [62], 426 p., [3]; RC.

\begin{tabular}{|l|l|}
\hline h.1r. & Portada con orla tipográfica. \\
\hline h.1v. & En blanco. \\
\hline h.2r.-56r. & $\begin{array}{l}\text { Dedicatoria del autor a Francisco de Aguiar y Seyxas, } \\
\text { Arzobispo de México, incluye breve relación de vida y } \\
\text { muerte de éste. }\end{array}$ \\
\hline h.56r. & Protesta del autor. \\
\hline h.56v.-58r. & $\begin{array}{l}\text { Carta para el autor de Fr. Joseph Sánchez, franciscano, } \\
\text { Calificador del Santo Oficio y Regente de los Estudios de } \\
\text { San Francisco de México. 9 de noviembre de 1698. }\end{array}$ \\
\hline h.58r.-58v. & $\begin{array}{l}\text { Aprobación de Juan de Narváez y Saavedra, Examinador } \\
\text { Sinodal del Arzobispado de México. 10 de noviembre de } \\
\text { 1698. }\end{array}$ \\
\hline h.58v.-60r. & $\begin{array}{l}\text { Aprobación de Lucas Verdiguel, cura de la parroquia de } \\
\text { San Miguel Arcángel de la Ciudad de México. 20 de no- } \\
\text { viembre de 1698. }\end{array}$ \\
\hline
\end{tabular}




\begin{tabular}{|l|l|}
\hline h.60v. & $\begin{array}{l}\text { Suma de las licencias. 12 de noviembre de 1698. } \\
\text { Licencia de impresión. Manuel de Escalante, Provisor } \\
\text { y Vicario General del Arzobispado de México. 9 de di- } \\
\text { ciembre de 1698. }\end{array}$ \\
\hline h.61r.-62v. & Prólogo al lector. \\
\hline p. 1-426 & Texto de la obra. \\
\hline h.1r-3v. & Tabla de los capítulos. \\
\hline
\end{tabular}

Notas:

Sellos de tinta en guarda anterior "Biblioteca Colegio de San Juan Saltillo 1906" [cancelado], y en canto inferior "Ex libris Hist. Mex. Coll. Max. S.I. Porv. Mex. Merid.” En portada y en h. 19r. de la “Asociación Histórica Americanista".

Encuadernación de pergamino con título gótico pintado en el lomo (Antiguedades de Vizcaya) y evidencia de broches de cuero.

EC: Bueno con portada y h.2 restauradas (injerto). Páginas rotas 15-16. Hojas oxidadas.

Con titulillo impreso en recto (altas y bajas) y en verso (altas). Viñetas, orlas y tacos xilográficos decorando texto.

Error de impresión: indica foliatura y es paginación. Error en primera signatura: es C2 y debe ser D2, en tercera H-Hhh, y en paginación 567267.

Caja de texto: 36 líneas (38 con titulillo y reclamo).

Biblioteca Eusebio Francisco Kino 016225

Referencias: Palau y Dulcet (2 ${ }^{\mathrm{a}}$ ed.), 4, p. 232.

Otros ejemplares: BNMx G225.92 SAN.1; BPalafoxiana 20760; BLafragua 32019-41030401, 32020-41030401; UIA BX4700.S2 L49.1699; BNFr 4-H277; MFICHE 4-H-277; CCILA 15894;

\section{LUZURIAGA, Juan de (O.F.M.).}

Paranympho Celeste historia de la mystica zarza, milagrosa imagen y prodigioso santuario de Aranzazu... Con licencia de los Superiores en México: por los Herederos de la Viuda de Bernardo Calderón, 1686. 
PARANYMPHO / CELESTE / HISTORIA / DE LA MYSTICA ZARZA, MILAGROSA / Imagen, y prodigiofo Santuario de / $\left[\begin{array}{c}{ }^{*} \\ { }_{*}\end{array}\right]$ Aranzazu [** ${ }_{*}^{*}$ / DE RELIGIOSOS OBSERVANTES DE N. / Seraphico Padre SAN FRANCISCO / EN LA PROVINCIA DE GVYPVZCOA / DE LA REGION DE [taco xil. CANTABRIA, [taco xil. / ESCRIBELA, Y CONSAGRALA A LA / Soberana Reyna de Angeles, y hombres / MARIA / SANTISSIMA SEÑORA NUESTRA / EL / M.R.P.Fr. JVAN DE LVZURIAGA, / Predicador apoftolico, Lectr Jubilado, Padre de las Santas / Provincias de Cantabria, y Valencia, y ComifJario General / de todas las de Nueva-E/paña de Nueftro Padre / SAN FRANCISCO. [ [filete decorado ] $/\left[\begin{array}{c}* \\ *\end{array}\right]$ CON LICENCIA DE LOS SUPERIORES: $\left[{ }^{*}{ }^{*}\right]$ / En Mexico, por los Herederos de la Viuda de Bernardo Calderon. Año de 1686.

$4^{\mathrm{o}}$; (284 mm); [1], a-d ${ }^{4}, \mathrm{e} 2, \mathrm{~A}-\mathrm{Z}^{4}, \mathrm{Aa}-\mathrm{Cc}^{4}, \mathrm{D}, \mathrm{A}-\mathrm{P}^{4}, \mathrm{Q}-\mathrm{R}^{2}$; [19], 114, 96, 112 p. [8]; RC

\begin{tabular}{|l|l|}
\hline h.1r. & Portada orlada. \\
\hline h.1v. & En blanco. \\
\hline h.2r. & Grabado calcográfico. \\
\hline h.2v. & En blanco. \\
\hline h3r.-6r. & Dedicatoria del autor a la Virgen de Aranzazu. \\
\hline h.6v.-8r. & $\begin{array}{l}\text { Censura del P. Martín de Rentería, jesuita, Catedrático del } \\
\text { Colegio de San Pedro y san Pablo de México y Califica- } \\
\text { dor del Santo Oficio. México, 4 de agosto de 1685. }\end{array}$ \\
\hline h.8v. & $\begin{array}{l}\text { Licencia de impresión. Conde de Paredes y Marques de } \\
\text { la Laguna, Virrey de Nueva España. México, 6 de agosto } \\
\text { de 1685. }\end{array}$ \\
\hline h.8v.-14r. & $\begin{array}{l}\text { Sentir de Manuel de Escalante y Mendoza, Catedrático de } \\
\text { Sagrados Cánones en la Real y Pontificia Universidad de } \\
\text { México. México, 24 de agosto de 1685. }\end{array}$ \\
\hline h.14r. & $\begin{array}{l}\text { Licencia de impresión. Francisco de Aguiar y Seixas, Ar- } \\
\text { zobispo. México, 26 de agosto 1685. }\end{array}$ \\
\hline h.14v. & Protesta del autor. \\
\hline h.15r.-16v. & Prólogo al lector. \\
\hline
\end{tabular}




\begin{tabular}{|l|l|}
\hline h.17r.-19v. & Índice de los libros y capítulos de esta historia. \\
\hline p. $1-114$ & Libro primero. \\
\hline p. $1-96$ & Libro segundo. \\
\hline p. $1-112$ & Libro tercero. \\
\hline h.1r. & Protesta del autor. \\
\hline h.1v. & Erratas. \\
\hline h.2r.-8v. & Índice de las cosas notables de esta historia. \\
\hline
\end{tabular}

Notas:

Marca de fuego en los cantos inferior y en superior muy borrosa. Identificada como de la Inquisición (Krausse, p. 91).

Sello de tinta en portada: "Ex libris Hist. Mex. Coll. Max. S. I. Prov. Mex. Merid." y "Asociación Histórica Americanista".

Encuadernación de pergamino con título gótico pintado en el lomo (negro y rojo), cantos en rojo y evidencia de broches de cuero.

EC: Bueno con hojas oxidadas, restaurado en el lomo y guarda anterior, ataque de xilófagos en parte inferior, cerca del lomo.

Grabado en h.2r. de la Virgen de Aranzazu (196 x 145 mm). "Gaspar Bouttats fecit". Capitular al principio de cada capítulo. Todo el texto fue impreso enmarcado. Capitulares y tacos xilográficos a lo largo de la obra.

Apostillas. Titulillo en recto y en verso. Las páginas 33-34 del Libro Segundo, están después de 35 y 36.

Caja de texto: 33 líneas (35 con paginación y reclamos).

Ejemplar de la Biblioteca Francisco Eusebio Kino 016307

Referencias: Palau y Dulcet ( $2^{\mathrm{a}}$ ed.), 4, p. 303 (indica edición In folio).

Otros ejemplares: BNMx RSM 1686 M4LUZ; BNAH Congregación del Oratorio de San Felipe Neri; BLafragua 43788-41090305, 4378941090305 c.2; BFUDLAP COCY/1857; CEHM 231.72.46 LUZ; UIA BT660.A67 L89.1686; CCILA 15537; CCPBE 000320248-8; BL: 4745.33.13; BNFr 


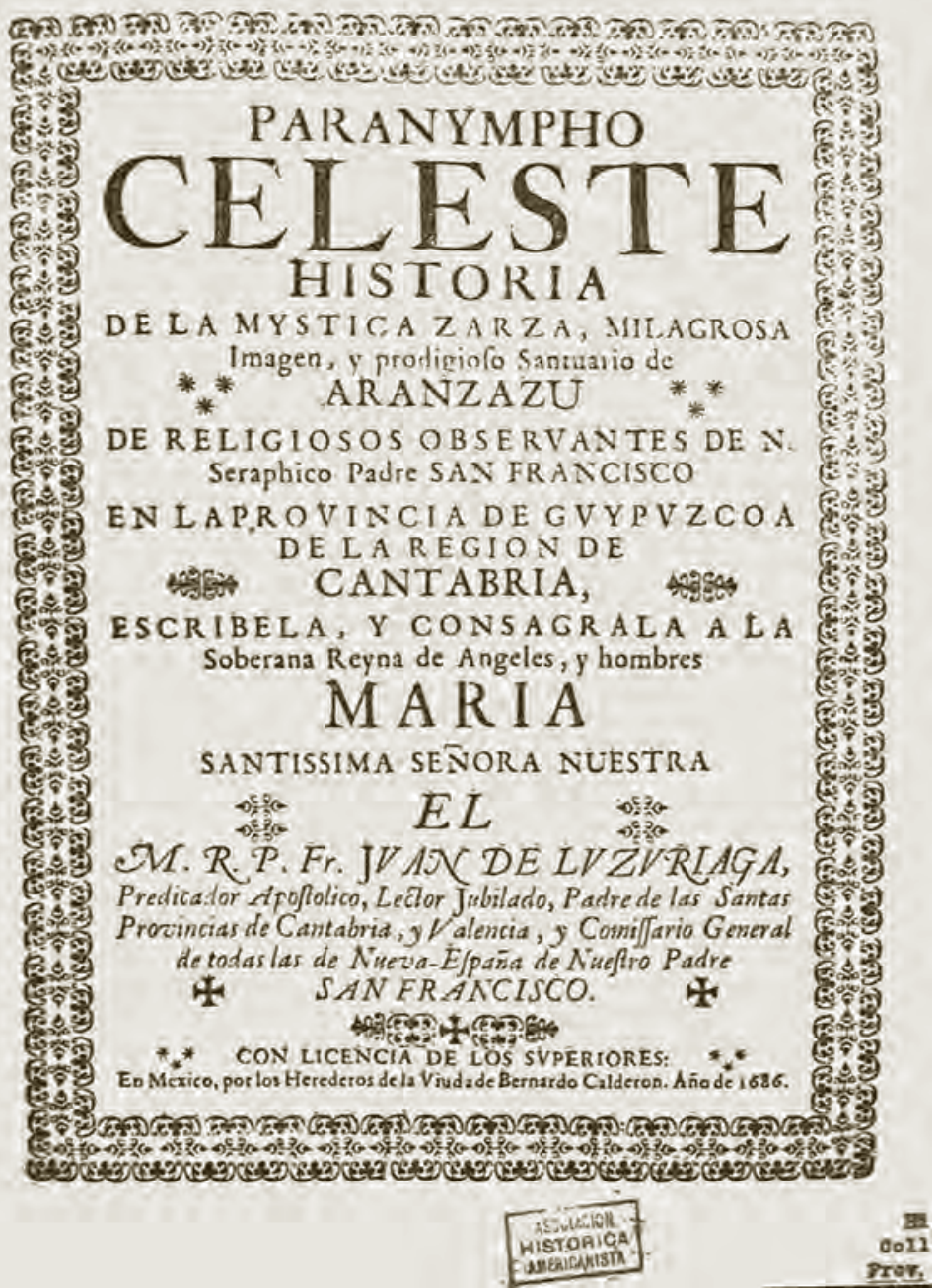

\subsection{Modelos de descripción: Siglo XVIII}

\section{AVILA, Francisco de (O.F.M.)}

Arte de la lengua mexicana... En México: por los Herederos de la Viuda de Miguel de Ribera Calderon, 1717. 
ARTE / DE LA LENGUA MEXICANA / Y BREVES PLATICAS DE LOS MYSTERIOS / de N. Santa Fee Catholica, y otras para exhortacion de / fu obligacion á los indios. / COMPUESTO / Por el P. F. FRANCISCO DE AVILA, / Predicador, Cura Miniftro por fu Mageftad / del Pueblo de la Milpan, y Lector del Idio- / ma Mexicano, del Orden de los Meno- / res de N.P. San Francifco. / DEDICALO / AL M. R. P.F. IOSEPH PEDRASA, / Predicador General Iubilado, Qualificador / del Santo Oficio de la Inquificion, Padre de / las Provincias de San Pedro, y San Pablo de / Michoacan, y Zacatecas, Ex Miniftro Pro- / vincial, y Padre mas digno de la de Xalisco; / y Vice Comiffario General de todas las / Provincias de Nueva E/paña, / e Iflas Philipinas \& c. / [filete decorado] CON LICENCIA DE LOS SUPERIORES: [filete decorado] / En Mexico, por los Herederos de la Viuda de Miguel / de Ribera Calderõ en el Empedradillo, Año de 1717.

4º (145 mm); [ ]4, IJ-IJ4, I, A8, B-H4, I.; [13], 36 fol., [1]; RC

\begin{tabular}{|l|l|}
\hline h.1.r. & Portada. \\
\hline h.1v. & En blanco. \\
\hline h.2r-3v. & Dedicatoria. \\
\hline h.4r-5r. & $\begin{array}{l}\text { Sentir de Fr. Manuel Pérez, Catedrático de lengua } \\
\text { mexicana en la Real Universidad de México. Cole- } \\
\text { gio Real de San Pablo de México, 6 de septiembre } \\
\text { de 1716. }\end{array}$ \\
\hline h.5v.-7r. & $\begin{array}{l}\text { Parecer de Fr. Joseph de Torres Pezellin, franciscano, } \\
\text { Vicario de las Religiosas de Santa Clara de México. } \\
\text { Santa Clara de México, 4 de noviembre de [17 6] [E1 } \\
\text { número no fue impreso] }\end{array}$ \\
\hline h.7v. & $\begin{array}{l}\text { Suma de licencias. [México], 19 de septiembre de } \\
\text { 1716 } \\
\text { [Licencia del Provisor y Vicario General del Arzobis- } \\
\text { pado], Doctor Carlos Bermúdez de Castro. [México], } \\
\text { 6 de noviembre de 1716. }\end{array}$ \\
\hline h.8r.-8v. & $\begin{array}{l}\text { Aprobación de Fr. Ignacio García de Figueroa, Cu- } \\
\text { ra Ministro de la Parroquia de San José de México. } \\
\text { México, 14 de agosto de 1716. }\end{array}$ \\
\hline
\end{tabular}




\begin{tabular}{|l|l|}
\hline h.9r.-9v. & $\begin{array}{l}\text { Licencia de la Religión. Convento de San Francisco } \\
\text { de México, 12 de agosto de 1717. }\end{array}$ \\
\hline h.10r.-12v. & Al pío lector. \\
\hline h.13r.-13v. & Fee de erratas. \\
\hline Fol. 1r.-27v. & Texto de la obra. \\
\hline Fol. 28r.-[37v.] & Pláticas explicativas para los indios. \\
\hline
\end{tabular}

Notas:

Sellos de tinta en portada y fol. 33r. "Asociación Histórica Americanista"; en portada "Ex libris Hist. Mex. Coll. Max. S.I. Prov. Mex. Merid" y en el verso de la portada "Ex libris Hist. Mex. Coll. Max. S.I. Prov. Mex."

An.ms. en portada con lápiz "150.-“y en tinta fol. 27r: "Alarcón”.

Encuadernación de pergamino con título redondo pintado en el lomo y evidencia de cantos salpicados en rojo.

EC: Bueno con hojas oxidadas.

Caja de texto: 29 líneas (31 con foliatura y signaturas).

Ejemplar de la Biblioteca Eusebio Francisco Kino 017852

Referencias: Palau y Dulcet ( $2^{\mathrm{a}}$ ed.), 1, p. 140 (indica formato en $8^{\circ}$, pero coincide información de hojas y folios).

Otros ejemplares: BNMx R497.4 AVI.a; BNAH Colección general; CEHM 497.47 AVI ; BL: 621.a.35.(1) ; UIA PM4063 A85.1717; CCILA 16635; CCPBE 000509559-X; BL 621.a.35.(1.); BNFr RES P-X-254; LC: PM4063. A8

\section{BORDA, Andrés de (O.F.M.)}

Practica de confesores de monjas... Con licencia en México: por Francisco de Ribera Calderon, 1708.

PRACTICA / DE CONFESSORES / DE MONjAS, / En que Je explican los quatro Vo- / tos de Obediencia, Pobreza Caf- / ftidad, y Claufura, por modo / de Dialogo. / DISPUESTA / Por el R.O.M.F. ANDRES DE BORDA / de la Regular Obfervancia de N.P. San / Francifco, Doctor en S. Teología, Lector / dos vezes jubilado por fu Religion, Pa / dre de la Provincia del S. Evangelio, / Catedrático de Scoto en efta Real / Vniverfidad. / DEDICALA A CHRISTO / CRUCIFICADO / Sale 
à luz, à folicitud de vn / Difcipulo del Autor. / [Filete decorado] / Con Licencia en MEXICO, por Francifco de / Ribera Calderon. Año de 1708 .

$8^{\circ}$; (145 mm); A-L8, M4; [12], 88 fol., [4]. RC

\begin{tabular}{|c|c|}
\hline h.1r. & Portada con orla tipográfica. \\
\hline h.1v. & En blanco. \\
\hline h. $2 \mathrm{r}$. & Citas latinas. \\
\hline h. $2 \mathrm{v}$. & $\begin{array}{l}\text { Licencia de Francisco Fernández de la Cueva Henrí- } \\
\text { quez, Virrey de la Nueva España. } 4 \text { de agosto de } 1708 .\end{array}$ \\
\hline h. 3r. $-4 v$. & $\begin{array}{l}\text { Aprobación del Dr. Rodrigo García Flores de Valdéz, } \\
\text { Examinador Sinodal del Arzobispado. México, } 16 \text { de ju- } \\
\text { lio de } 1706 .\end{array}$ \\
\hline h. $5 \mathrm{r}$. & $\begin{array}{l}\text { Licencia de impresión. Antonio Aunzibay Anaya, Juez } \\
\text { provisor y Vicario General de Arzobispado. México, } 10 \\
\text { de julio de } 1708 \text {. }\end{array}$ \\
\hline h. $5 \mathrm{v} .-9 \mathrm{v}$. & $\begin{array}{l}\text { Parecer de Fr. Isidro Alphonso de Castaneyra, francis- } \\
\text { cano, ex guardián del Convento Grande de Nuestro Pa- } \\
\text { dre San Francisco. Enfermería del N.P.S. Francisco de } \\
\text { México, } 27 \text { de agosto de } 1708 \text {. }\end{array}$ \\
\hline h.10r.-11r. & $\begin{array}{l}\text { Sentir de Fr. Francisco Navarro, franciscano, Califica- } \\
\text { dor del Santo Oficio. Convento Grande de Nuestro Padre } \\
\text { San Francisco, } 12 \text { de julio de } 1708 \text {. }\end{array}$ \\
\hline h.11v. & $\begin{array}{l}\text { Licencia de la Orden. Fr. Juan de la Cruz, franciscano, } \\
\text { Comisario General de todas las Provincias de la Nueva } \\
\text { España. Convento Grande de México, } 20 \text { de mayo de } \\
1708 .\end{array}$ \\
\hline h.12r. & Índice de los exámenes. \\
\hline h.12v. & Prólogo a los confesores de Religiosas. \\
\hline Fol. 1r.-88v. & Texto de la obra. \\
\hline h.1r.-4r. & Índice de las cosas notables. \\
\hline h.4v. & Nota. \\
\hline
\end{tabular}

Notas:

An. ms. de lectura en fol. 84 "luego también pero contra justicia". 
Encuadernación de pergamino con título redondo pintado en el lomo y cantos salpicados en rojo.

EC: Regular, hojas oxidadas y lomo maltrecho.

Apostillas.

Caja de texto: 26 líneas (28 con foliación y reclamo).

Ejemplar de la Biblioteca Eusebio Francisco Kino 021605

Referencias: Palau y Dulcet (2a ed.), 1, p. 250.

Otros ejemplares: BNMx G 248.89438 BOR.p. RSM 1708 M4BOR; BNAH Colección general, Museo Regional de Zacatecas. Ex Convento de Nuestra Señora de Guadalupe: BPalafoxiana 2982, 2983; BFUDLAP COCY/2970; CEHM 271.9 BOR; UIA BX 4210 B67.1708; CCILA 16326; BL: 4061.a.14.; LC: BX4210.B7

\section{CABRERA Y QUINTERO, Cayetano de.}

Hebdomadario trino, ejercicios devotos, y obsequiosos desagravios a la Santissima, amabilissima, y misericordiosissima Trinidad... Reimpresso en México: En la Imprenta del Lic. D. Joseph de Xauregui, 1769.

HEBDOMADARIO TRINO / EXERCICIOS DEVOTOS, / Y OBSEQUIOSOS DESAGRAVIOS A LA SANTISSIMA, / AMABILISSIMA, / Y MISERICORDIOSISSIMA / TRINIDAD / Por la execrable ingratitud, y grof- / fero olvido de los mortales en el / mas pronto obfequio, devocion, / y agradecimiento debido â tan / Soberano MYSTERIO. / DISPUESTOS Y REPARTIDOS / por las tres Semanas anteriores â la / Dominica de la Santiflima / TRINIDAD, / POR D. CAYETANO DE CABRERA, / Y QUINTERO, / Presbytero de efte Arzobispado. / [filete decorado] / Reimprefso en Mexico, en la Imprenta del / Lic. D. Joseph de Xauregui, en la Calle de / San Bernardo. Año de 1769.

$4^{\mathrm{o}}$; (143 mm); [ ]3, B-M4; [3], 87 p.; RC.

\begin{tabular}{|l|l|}
\hline h.1r. & Portada con orla tipográfica. \\
\hline h.1v. & En blanco. \\
\hline
\end{tabular}


Secretos del estante: elementos para la descripción bibliográfica...

\begin{tabular}{|l|l|}
\hline h.2r.-3v. & Prólogo a las almas devotas. \\
\hline p. $1-87$ & Texto de la obra. \\
\hline
\end{tabular}

Notas:

Evidencia de marca de fuego en canto superior no identificada "B".

Sello de tinta en h.1v. y en p. [88]: "Ex libris Hist. Mex. Coll. Max. S.I. Prov. Mex".

Encuadernación de pergamino con evidencia de cantos en rojo.

La última hoja de guarda es de otro impreso con fecha de 1773.

Error en paginación, es y debe ser: 6-36.

Caja de texto: 27 líneas (29 con numeración y reclamo).

EC: Bueno con hojas ligeramente oxidadas.

Ejemplar de la Biblioteca Eusebio Francisco Kino 017238

Referencias: Palau y Dulcet ( $2^{\mathrm{a}}$ ed.), 2, p. 11 (indica una edición de 1734 en $8^{\circ}$, impresa en México por José Bernardo de Hogal).

Otros ejemplares: BNMx RSM 1769 M4CAB

\section{EGUIARA Y EGUREN, Juan José de.}

Vida del venerable Padre Don Pedro de Arellano, y Sossa... México: En La Imprenta Real del Superior Gobierno y del nuevo Rezado, de Doña María de Rivera, 1735.

VIDA / DEL VENERABLE PADRE / DON PEDRO / DE ARELLANO, Y SOSSA, / SACERDOTE, Y PRIMER PREPOSITO / de la Congregacion del Oratorio de / Mexico. / POR EL DR. D. JUAN JOSEPH DE / Eguiara y Eguren, catedratico q fue de Phy- / lofophia, y actual Propietario de Vifperas de / Sagrada Theologia en la Real Univerfidad de / efta Corte y, Examinador Synodal de efte / Arzobifpado. I DEDICALA / A LA MISMA MUY ILUSTRE, Y / Exemplarifsima, Sagrada Congregación del / Oratorio de dicha Ciudad / [filete decorado] / CON LICENCIA: / En Mexico: En la Imprenta Real del Superior Gobier/ no, y del nuevo rezado, de Doña María de Rivera en / el Empedradillo. Año de 1735.

In folio; (203 mm); [ ]2, I-16I2, [1], A-Z2, Aa-Zz2, Aaa-Zzz2, Aaaa-

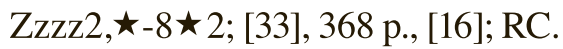




\begin{tabular}{|l|l|}
\hline h.1r. & Portada con orla tipográfica. \\
\hline h.1v. & En blanco. \\
\hline h.2r.-21v. & Dedicatoria. \\
\hline h.22r.-23v. & $\begin{array}{l}\text { Aprobación del Dr. Thomas Montaño, Arcediano de la } \\
\text { Santa Iglesia Catedral Metropolitana de México. México, } \\
8 \text { de agosto de } 1735 .\end{array}$ \\
\hline h.23v. & $\begin{array}{l}\text { Licencia del Superior Gobierno. México, 8 de agosto de } \\
1735 .\end{array}$ \\
\hline h.24r.-27v. & $\begin{array}{l}\text { Sentir de Fr. Juan Antonio de Mora, jesuita. Colegio } \\
\text { Máximo de San Pedro y San Pablo de la Compañía de } \\
\text { Jesús de México, } 1^{\circ} \text { de julio de 1735. }\end{array}$ \\
\hline h.27v. & Licencia de Impresión. México, 20 de junio de 1735. \\
\hline h.28r.-28v. & Al lector. \\
\hline h.29r. & Protesta del autor. \\
\hline h.29v. & Erratas. \\
\hline h.30r.-32r. & Índice de los libros y capítulos de esta historia. \\
\hline h.32v. & En blanco. \\
\hline h.33r. & Grabado calcográfico. \\
\hline h.33v. & En blanco. \\
\hline p. 1-368 & Texto de la obra. \\
\hline h.1r. & Protesta del autor. \\
\hline h.1vr.16r. & Índice de las cosas contenidas en esta historia. \\
\hline
\end{tabular}

Notas:

Ans. mss. de lectura en portada: "Canonigo Magistral de la Santa Iglesia Catedral y Obispo Electo de Merida Yucatan"; en h.22r.: "Y después Dean deella y también Obispo de Antequera Valle de Oaxaca donde murio", en p. 301 "Este año de 1750 y vivio hasta 31 de octubre de 1758 que murio", en p. 309 "y por muerte de este dicho que fue el Padre Don Julián, le sucedió el Padre Francisco Xavier Lazcano de la Compañía de Jesús". Número de p. 286 en manuscrito. En guarda posterior: "Este libro es para aprender ymildad y tenerse por nada / porque, todo lo quel mundo encierra es limitado / y pequeño, todo es polbo; todo sueño, todo viento / y todo tierra".

Sellos de tinta en portada de: "Santa Brigida" y "Ex libris Coll. Max. S.I. Prov. Mex. Merid.”, este también en h.1v. 
Encuadernación de pergamino con título gótico pintado en el lomo. Testigo (parte de un impreso: viñeta y tacos xil.) entre p. 270-271. EC: Bueno y ligeramente dañado en canto lateral.

Retrato grabado de Don Pedro de Arellano en h. 33r. (310 x 190 mm), tacos, viñetas y capitulares en el texto. Error en paginación, es y debe ser: 25-52. Sin imprimir los números de las páginas 286 y 287. Texto a dos columnas, titulillo en recto y verso, apostillas.

Caja de texto: 34 líneas (36 con numeración y signaturas).

Existe otro ejemplar (016152) encuadernado en volumen facticio, que solo tiene la portada y las hojas de la dedicatoria que corresponden a esta edición. Tiene ex libris de Andrés de Arce y Miranda en el verso de la portada. El volumen con Marca de Fuego en Canto Superior sumamente borrosa, aparentemente franciscana y un manuscrito "Índice o catálogo de los papeles que contiene este tomo de papeles varios". Ejemplar de la Biblioteca Eusebio Francisco Kino 016191 Referencias: Palau y Dulcet ( $2^{\mathrm{a}}$ ed.), 3, p. 104 (indica formato $4^{\circ}$ ). Otros ejemplares: BNMx G 922.272 ARE.e; BNAH, Museo regional de Zacatecas Ex Convento de Nuestra Señora de Guadalupe; CEHM 922. EGU; CCPBE 000547456-6; MORA 000041843; LC: BX4705. A67 E4

\section{LOPEZ EZQUERRA, José}

Lucerna mystica pro directoribus animarum... Cordubae: apud Viduam Sthepani de Cabrera, 1725

IOSEPHI LOPEZ EZQUERRA / PREBYTERI CANTABRI / ÆESOPOLENSIS. / LUCERNA MYSTICA / PRO DIRECTORIBVS ANIMARUM / QVÆ OMNIA PRORSVSDIFFICILIA, ET OBSVCV- / ra, quæ in dirigendis fpiritibus evenire folent, mira / dexteritate clarificat.

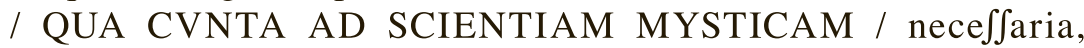
rerumque $\int$ upernaturalium quidditates, / vbicationes, cauææ, \& effectus, brevitèr, \& / compendiosè clarfcunt. / ET AD CALCEM IN GRATIAM DIRECTORVM / brevis manuductio paractica , iuxta huius volu- / minis doctrinam. / TYPIS MANDATA CAESARAVGVTAE ANNO / 1692 / SEGUNDA [grabado xil.] EDITIO. / CORDUBAE: Apud Uiduam Sthepani de cabrera Anno 1725. 
4 ; (195 mm); []2, IJJI-IJgJI4, A-Z4, Aa-Zz4, Aaa-Nnn4, Ooo3; [10], 471 p. ; RC.

\begin{tabular}{|l|l|}
\hline h.1r. & Portada. \\
\hline h.1v. & Citas latinas. \\
\hline h.2r. & Alabanza a la Virgen. \\
\hline h.2v. & $\begin{array}{l}\text { Summa del privilegio. Madrid, 12 de diciembre de 1724. } \\
\text { Summa de la tassa. Madrid, 13 de marzo de 1725. }\end{array}$ \\
\hline h.3r.-3v. & $\begin{array}{l}\text { Aprobación de Fr. Andres de Maya y Salaberria, Exami- } \\
\text { nador Sinodal del Arzobispado de Zaragoza. Colegio de } \\
\text { san Vicente Ferrer, 17 de diciembre de 1691. }\end{array}$ \\
\hline h.3v.-4v. & $\begin{array}{l}\text { Aprobación y censura de Fr. Felipe Aranda, jesuita, Califi- } \\
\text { cador Inquisitorial en Aragón. Colegio Jesuita de Zarago- } \\
\text { za, 18 de diciembre de 1691. }\end{array}$ \\
\hline h.4v.-5r. & $\begin{array}{l}\text { Aprobación de Fr. Jerónimo de Lorte y Escartín, Califica- } \\
\text { dor del Santo Oficio y Sinodal Examinador en la Provincia } \\
\text { de Aragón. Real Convento de San Francisco de Zaragoza, } \\
\text { 19 de diciembre de 1691. }\end{array}$ \\
\hline h.5r. & $\begin{array}{l}\text { Imprimatur. Bartolomé Sanz de Vera. Gobernador y Vi- } \\
\text { cario general. }\end{array}$ \\
\hline h.5r.-6v. & $\begin{array}{l}\text { Censura de Fr. Antonio Pérez, Calificador del Santo Ofi- } \\
\text { cio. Colegio de San Didaci, 3 de diciembre de 1691. }\end{array}$ \\
\hline h.6v. & Imprimatur. V. Blanco, Reg. \\
\hline h.6v.-8v. & Índice de tratados y capítulos. \\
\hline h.9r.-10r. & Prólogo del autor. \\
\hline h.10v. & $\begin{array}{l}\text { Fee de erratas. Benito de Rio Cao de Cordillo. Madrid, 5 } \\
\text { de Marzo de 1725. }\end{array}$ \\
\hline p.1-12 & Prolegomena. \\
\hline p. 13-471 & Texto de la obra. \\
\hline
\end{tabular}

Notas:

Ex libris en tapa anterior de José María Valdenebro y Cisneros (Catálogo de ex libris de Bibliotecas Españolas en la Biblioteca Nacional. p. 509 e ilustración 2315)

Sello de tinta en portada, h. 2r., 3r. y p. 150: "Biblioteca Universitaria Sevilla". 
Encuadernación de pergamino con título gótico pintado en el lomo y broches de cuero.

EC: Regular, lomo desprendido y tapas deterioradas, hojas oxidadas, ligeramente rotas en parte inferior: h. 6, p. 41-42, 47-48, 143-144, 173174, 189-190, 195-198, 243-244, 351, 411, 417, agujero en p. 415-416; y manchadas 237-242, 439-471.

Caja de texto: 41 líneas (43 con numeración y signaturas)

Grabado de portada: Virgen con el niño. Título y parte en recto y verso, texto a doble columna, apostillas.

Error en paginación, es y debe ser: 411-417, a partir de aquí numera hasta el final.

El Privilegio es de reimpresión y fue otorgado a Catalina de León, la primera edición fue realizada en Zaragoza por Pascual Bueno en 1691. Las citas latinas son de Mateo.

Ejemplar de la Biblioteca General Universitaria de Sevilla A027(a)-032

Referencias: Palau y Dulcet ( $2^{\mathrm{a}}$ ed.), 4, p. 264 (indica como segunda edición de la realizada en 1691).

Otros ejemplares: BNE 3/72175

\section{MENDO, Andres (S.I.).}

Crisis de la Compañía de Jesús, de su piedad, doctrina... México: En la Imprenta del Real y más Antiguo Colegio de San Ildefonso, 1765.

CRISIS / DE LA COMPAÑÍA DE JESUS / DE SU PIEDAD, DOCTRINA, / Y, multiplicado fruto, que hà cogido / en el vniverfo mundo. / ESCRITA EN LENGUA LATINA / Por el R.P. ANDRES MENDO de la / mifma Compañìa; / Y TRADUCIDA EN CASTELLANO / Por un Difcipulo afecto de efta Sagrada / Religion. / [taco xil. 8 estrellas formando un círculo] [Emblema de la Compañía de Jesús] [taco xil. 8 estrellas formando un círculo] / [Filete decorado] / CON LAS LICENCIAS NECESSARIAS: / En la Imprenta del Rl. y más antiguo Cole- / gio de S. Ildefonfo, año de 1765.

8; (149 mm); I8, A-S8; [8], 284 p., [2]; RC. 


\begin{tabular}{|l|l|}
\hline h.1r. & Portada. \\
\hline h.1v. & En blanco. \\
\hline h.2r.-5v. & Del traductor al lector. \\
\hline h.6r.-8r. & $\begin{array}{l}\text { Catálogo de los autores que en esta obra se citan a favor de } \\
\text { la Compañía de Jesús. }\end{array}$ \\
\hline h.8v. & Grabado interior xilográfico. \\
\hline p.1-284 & Texto de la obra. \\
\hline h.1r-2r. & Índice de los parágrafos que se contienen. \\
\hline
\end{tabular}

Notas:

Marca de Fuego en canto superior del Colegio de Misioneros de Propaganda Fide de Querétaro (Sala, p. 17). An. ms. en tapa posterior: "P. Bernal"

Encuadernación de pergamino con título redondo pintado en el lomo, tapas armadas con material manuscrito, con broches de cuero y evidencia de cantos salpicados en rojo.

EC: Bueno con manchas de humedad en parte de la obra, y el lomo ligeramente separado,

Grabado Emblema de la Compañía de Jesús, con dos ángeles a los lados en h.8v. (120 x $74 \mathrm{~mm})$.

Caja de texto: 24 líneas (26 con numeración y signaturas), Ejemplar de la Biblioteca Eusebio Francisco Kino 017855 Referencias: Palau y Dulcet ( $2^{\mathrm{a}}$ ed.), 5, p.151.

Otros ejemplares: BNMx RSM 1765 M4MEN; BPalafoxiana Número de localización 1279; CONDUMEX: 271.5 MEN; BNAH: Colección general, Museo Regional de Querétaro. Ex Convento Grande de san Francisco de la ciudad de Querétaro; LC: BX3702.A2 M4

\section{NUÑEZ, Antonio (S.I.)}

Distribución de las obras ordinarias y extraordinarias del dia... al Estado de las Señoras Religiosas... Con licencia de los superiores en México: por la Viuda de Miguel de Ribera Calderón, 1712.

DISTRIBUCION / DE LAS OBRAS ORDINARIAS, / y extraordinarias del día, / Para hazerlas perfectamente, conforme al / Eftado de las Señoras Religiosas. / INSTRUIDA / CON DOZE MAXIMAS / 
Subftanciales, para la vida Regular, y / Efpiritual, que deben feguir. / DISPUESTA / POR EL R. P. M. ANTONIO NUÑEZ, / de la Sagrada Compañía de Jesvs. Prefecto que / fuè de la Illustre Congregacion de la Puriffima. / SALE A LA LUZ / A solicitud, y expenfas de las Señoras Religiofas / del Convento Real de JESUS MARIA, / QUIENES LA DEDICAN / A / CHRISTO SEÑOR NRO. / SACRAMENTADO. / [filete decorado] / CON LICENCIA DE LOS SUPERIORES. / En Mexico: por la Viuda de Miguel de Ribera Calderon. / Año de 1712.

4; (205 mm); I4-IJ2, A-V4; [6], 160 p., [1]; RC.

\begin{tabular}{|l|l|}
\hline h.1r & Portada con orla tipográfica. \\
\hline h.1v. & En blanco. \\
\hline h.2r.-3v. & Dedicatoria. \\
\hline h.4r.-5r. & $\begin{array}{l}\text { Parecer de Fr. Juan de Torres, franciscano, Calificador del } \\
\text { Santo Oficio. Convento de Santa Isabel de México. 4 de ju- } \\
\text { lio de 1712. }\end{array}$ \\
\hline h.5r. & $\begin{array}{l}\text { [Licencia de Impresión] Fernando de Alencastre Noroña y } \\
\text { Sylva. Virrey de la Nueva España. 6 de julio de 1712 } \\
\text { [Licencia de impresión] Provisor y Vicario General del Ar- } \\
\text { zobispado de México. 4 de julio de 1712. }\end{array}$ \\
\hline h.5v.-6r. & $\begin{array}{l}\text { Aprobación del Bachiller Luis de la Peña, Predicador y } \\
\text { Confesor General. México, 2 de julio de 1712. }\end{array}$ \\
\hline h.6v. & $\begin{array}{l}\text { Prólogo dedicatorio del autor a dos niñas religiosas que se } \\
\text { criaron en el Convento de la Encarnación. }\end{array}$ \\
\hline p. 1-160 & Texto de la obra. \\
\hline h.1r. & Índice de máximas y capítulos. \\
\hline
\end{tabular}

Notas:

Sello de tinta en portada: "Asociación Histórica Americanista", y en h.1v.: "Ex. libris. Hist. Mex. Coll. Max. S.I. Prov. Mex."

Encuadernación de pergamino con título redondo pintado en el lomo, tejuelo, y evidencia de broches de cuero.

EC: Conservación regular, con daños importantes por humedad en la parte superior y final de la obra. Óxido en las hojas. Tapa anterior de la encuadernación restaurada con cartón sostenida por una tachuela. 
Indica foliatura y es paginación. Error en paginación: es 610 y debe ser 160. Caja de texto de 36 líneas (38 con paginación y reclamo) Ejemplar de la Biblioteca Eusebio Francisco Kino 017166 Referencias: Palau y Dulcet (2 ${ }^{\mathrm{a}}$ ed.), 5, p. 326.

Otros ejemplares: BNMx RSM 1712 M4NuäN, EPO 255.9 NuäN.d, RFO 93-17137, G 242.6943 NuäN.d.; BFUDLAP: Localización: COCY/0348; BPalafoxiana: Número de localización: 35380; CONDUMEX: 271.3 NUÑ; BNAH Colección general, Museo Regional de Querétaro. Ex Convento Grande de San Francisco, Ex Convento de Santa Mónica. Puebla; BL: 1225.18; LC: BX4213. N8

\section{PÉREZ DE VELASCO, Andrés Miguel.}

El ayudante de cura instruido... [Puebla]: Impresso en el Colegio Real de San Ignacio, 1766.

EL AYUDANTE / DE CURA / INSTRUIDO / EN EL PORTE A QUE LE OBLIGA / SU DIGNIDAD, / EN LOS DEBERES A QUE LE ESTRECHA / SU EMPLEO, / Y EN LA FRUCTUOSA PRACTICA DE / SU MINISTERIO / POR EL LICENCIADO / D. ANDRES MIGUEL PEREZ DE VELASCO / Colegial que fue de Opoficion en el Real de San Ignacio de / la Puebla, Cura Beneficiado, Vicario, y Juez Eclefiaftico de / la Parrochia de Santo Domingo Ytzocan, Comifario del Santo / Oficio de la Inquificion, y fu Revifor. / QUIEN LO IMPRIME / Para inftruccion de un Eclefiaftico, que fe la pide, y para / la de todos los que defearan exercitarfe con el empleo / DE AYUDANTES DE CURA / EN EL MINISTERIO / [Filete] / CON LICENCIA / Impreffo en el Colegio Real de San Ignacio de la Puebla. / Año de 1766.

4; (207 mm); ,I4, IJ5, A-O4, P3; [9], 106 p., [3]; RC.

\begin{tabular}{|l|l|}
\hline h.1r. & Portada a doble tinta. \\
\hline h.1v. & En blanco. \\
\hline h.2r.-2v. & $\begin{array}{l}\text { Parecer del Dr. Joseph Alphonso de Valladolid, Abogado } \\
\text { de la Real Audiencia y Canónigo Penitenciario de la Igle- } \\
\text { sia Metropolitana. México, 7 de septiembre de 1765. }\end{array}$ \\
\hline
\end{tabular}




\begin{tabular}{|l|l|}
\hline h.3r.-10r. & $\begin{array}{l}\text { Parecer del Dr. Andrés de Arze y Miranda, Examinador } \\
\text { Sinodal del Obispado de la Puebla de los Ángeles y Obispo } \\
\text { electo de la Iglesia de San Juan de Puerto Rico. [Casa de } \\
\text { Vuestra Señoría], 3 de junio de 1766. }\end{array}$ \\
\hline h.10v. & $\begin{array}{l}\text { Licencia del Superior Gobierno. Joaquín de Montserrat, } \\
\text { Virrey, Gobernador y Capitán General de la Nueva Espa- } \\
\text { ña. México, 22 de septiembre de 1765. } \\
\text { Licencia del Ordinario. Dr. Manuel Ignacio de Gorospe y } \\
\text { Padilla, Prebendado de la Iglesia [de Puebla], 17 de junio } \\
\text { de 1766. } \\
\text { Dos citas latinas sobre la tipografía }\end{array}$ \\
\hline h.11r.-13v. & Dedicatoria del autor a los señores eclesiásticos. \\
\hline p. 1-106 & Texto de la obra. \\
\hline h.1r.-3r. & Appendix. \\
\hline
\end{tabular}

Notas:

Sellos de tinta en portada, canto inferior y última hoja: "Ex libris Hist. Mex. Coll. Max. S.I. Prov. Mex. Merid.", y en portada “Asociación Histórica Americanista".

Ans. mss. en h.2r.: "Marcos Miguel Corona"; h.11r.: "De Don Marcos Miguel Corona"; p. 36: "Marcos Miguel Corona. Domiciliario del Obispado de la Puebla"; h.3r., final: "De Don Marcos Mig. uel Corona. Presbytero domiciliario del Obispado de la Puebla".

Encuadernación de pergamino con título redondo pintado en el lomo y evidencia de broches de cuero.

EC: Bueno con hojas oxidadas y ataque de xilófagos en la parte izquierda inferior de la obra y en margen exterior, más acusado en el centro.

La segunda hoja del cuadernillo de cada signatura en minúscula, salvo el cuadernillo $\mathrm{F}$.

Caja de texto: 33 líneas (35 con reclamos y signaturas).

Ejemplar de la Biblioteca Eusebio Francisco Kino 017824

Referencias: Palau y Dulcet (2a ed.), 6, p. 97.

Otros ejemplares: BNMx: RSM 1766 P6PER; BPalafoxiana 12356; BFUDLAP COCY/3040; CEHM 262 PER; LC: BX1912.P4 


\section{QUINTANA, Agustín de (O.P.)}

Confessonario en lengua mixe... Con licencia en la Puebla: por la Viuda de Miguel de Ortega, 1733.

CONFESSONARIO / EN LENGUA / MIXE $\star$ / Con vna Conftrucción de las Oraciones / de la Doctrina Chriftiana, y vn Compen- / dio de Voces Mixes, para enfeñarfe â pro- / nunciar la dicha Lengua. / ESCRITO TODO / POR EL P. FR. AUGUSTIN / de Quintana de la Orden de Predicado- / res, Cura q[con tilde] fuê de la Doctrina de S. Juan /

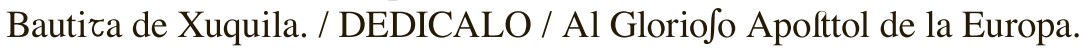
/ S. VICENTE FERRER / [taco xil. formando un rombo] [emblema de los predicadores] [taco xil. formando un rombo] / [filete decorado] / Con licencia: en la Puebla por la Viuda / de Miguel de Ortega. Año de 1733.

4; (200 mm); [ ]4, I4, A-S4, T2; [8], 146 p. [1]; RC.

\begin{tabular}{|l|l|}
\hline h.1r. & Portada con orla tipográfica. \\
\hline h.1v. & Grabado xilográfico. \\
\hline h.2r.-2v. & Dedicatoria del autor. \\
\hline h.3r.-3v. & $\begin{array}{l}\text { Parecer de Esteban de Rojas, predicador. San Miguel de } \\
\text { Talistaca, 15 de diciembre de 1732. } \\
\text { Licencia del Superior Gobierno. Juan de Acuña, Virrey } \\
\text { De Nueva España. [México], 19 de enero de 1733. }\end{array}$ \\
\hline h.4r.-5r. & $\begin{array}{l}\text { Parecer de Fr. Antonio Meneses, predicador. Parroquia } \\
\text { de San Pablo de Oaxaca, 10 de octubre de 1732. }\end{array}$ \\
\hline h.5v. & $\begin{array}{l}\text { Licencia del provisor], Lic. Geronymo Morales Sigala. } \\
\text { Antequera, Oaxaca, 11 de octubre de 1732. }\end{array}$ \\
\hline h.6r.-6v. & $\begin{array}{l}\text { Parecer de Fr. Antonio Valera, predicador, Presidente de } \\
\text { la casa de San Pablo Ayutla en la Nación Mixe. Ayutla, } \\
\text { 23 de septiembre de 1732. }\end{array}$ \\
\hline h.6v.-7r. & $\begin{array}{l}\text { Parecer de Fr. Nicolás Sánchez, predicador, Cura Mi- } \\
\text { nistro de la Doctrina de San Juan Bautista en la Nación } \\
\text { Mixe. Xuquila, 26 de septiembre de 1732. }\end{array}$ \\
\hline
\end{tabular}




\begin{tabular}{|l|l|}
\hline h.7v. & $\begin{array}{l}\text { Licencia de la Orden, Fr. Dionisio Levanto, predicador, } \\
\text { Provincial de San Hipólito Mártir de Oaxaca. Convento } \\
\text { de Santo Domingo de Oaxaca, 1 de octubre de 1732. }\end{array}$ \\
\hline h.8r.-8v. & Prólogo. \\
\hline p. $1-123$ & Texto de la obra. \\
\hline p. 124 & Grabado xilográfico. \\
\hline p.125-128 & Compendio de voces. \\
\hline p. $129-136$ & Vocablos. \\
\hline p. $137-138$ & De los diptongos y su necesidad. \\
\hline p. $139-143$ & De el modo de contar. \\
\hline p. $143-[147]$ & Nombre de todas las partes del cuerpo. \\
\hline p. $[148]$ & Grabado xilográfico. \\
\hline
\end{tabular}

Notas:

Sello de tinta en portada y en canto inferior de "Ex libris Hist. Mex. Coll. Max. S.I. Prov. Mex. Merid.” An. ms. en portada: “J.F.”, y en p. 59: "haihuijn".

Encuadernación de papel, con una tira de máquina de escribir pegada en el lomo con los datos del título y el autor.

EC: Regular, oxidado en numerosas partes, evidencia de restauración en la portada y al fin de la obra, con hojas rasgadas y rotas en: h.3-5 y p. 29, 61-66, algunas hojas desprendidas del lomo.

Grabado de San Vicente Ferrer en h.1v. (105 x 133 mm); emblema de la orden de predicadores en p. $124(92 \times 110 \mathrm{~mm})$ y viñeta de fin en p. 148 (103 x $95 \mathrm{~mm})$. Tacos xilográficos decorando todo el texto.

Parte del texto a doble columna: p. 2-13, 17-78 80-83, 84 129-136, 139147. La segunda hoja de cada cuaderno se numera con signatura " 3 ". Las pp. 49-50, se encuentran después de p. 54.

Caja de texto de 29 líneas (31 con reclamo y numeración). Ejemplar de la Biblioteca Eusebio Francisco Kino 017825 Referencias: Palau y Dulcet (2a ed.), 6, p. 194 (considera raro al libro) Otros ejemplares: BNMx RSM 1733 P6QUI; CEHM 497.43 QUI; CCPBE 000499533-3 


\section{SALQUERO, Pedro (O.S.A.)}

Vida del venerable padre y ejemplarisimo varón el maestro Fr. Diego Basalenque, provincial que fue de la provincia de San Nicolás de Mechoacan... En Roma: En la Imprenta de los Herederos de Barbielini, 1761.

VIDA / DEL VENERABLE PADRE, / Y EXEMPLARISSIMO VARON EL MAESTRO / FR. DIEGO BASALENQUE / Provincial que fue de la Provincia / DE SAN NICOLAS DE MECHOACAN / Del Orden de N. P. S. A. AGUSTIN / ESCRITA / POR EL R. P. M. FR. PEDRO SALGUERO / Diffinidor de la mi/ma Provincia, / Nuevamente imprefla con los Autos de fu Translacion al Convento / de Santa Maria de Gracia de la Ciudad de Valladolid / en la Nueva Efpaña, / POR EL P. LECTOR JUB. FR. LUCAS CENTENO / Procurador en la Corte Romana de dicha Provincia / Quien en nombre de ella la Dedica / al Reverendiffimo P. Maestrfo / FR. FRANCISCO XAVIER VAZQUEZ / DIGNISSIMO GENERAL DE TODO EL ORDEN AUGUSTINIANO. / [Florón] / CON LICENCIA / EN ROMA Año DE 1761. / [filete doble] / En la Imprenta de los Herederos de Barbielini.

$8^{\circ} ;(21 \mathrm{~cm}) ; \mathrm{a} 8,{\mathrm{~A}-\mathrm{M}^{8}}, \mathrm{~N} ;[8], 194$ p.; RC.

\begin{tabular}{|l|l|}
\hline h.1r. & Portada. \\
\hline h.1v. & En blanco. \\
\hline h.2r.-3v. & Dedicatoria de Lucas Centeno. Roma, 23 de mayo de 1761. \\
\hline h.4r.-5r. & Tabla de los libros y capítulos. \\
\hline h.5v. & $\begin{array}{l}\text { [Licencia de la orden] Fr. Francisco Xavier Vázquez, agusti- } \\
\text { no, Prior General. Convento de San Agustín de Urbe, 16 de } \\
\text { mayo de 1761. }\end{array}$ \\
\hline h.6r. & $\begin{array}{l}\text { [Aprobación] de Fr. Ludovicus Faura, predicador, Teólogo. } \\
\text { Roma, 9 de abril de 1761. }\end{array}$ \\
\hline h.6v. & Reimprimatur. \\
\hline h.7r.-8r. & Prólogo. \\
\hline h.8v. & Protesta. \\
\hline p. 1-194 & Texto de la obra. \\
\hline
\end{tabular}


Notas:

Sellos de tinta: "Ex libris Hist. Mex. Coll. Max. S. I. Prov. Mex”., "Asociación Histórica Americanista".

Encuadernación de pergamino con título gótico pintado en el lomo y canto moteado en rojo.

EC: Bueno con hojas oxidadas, y lomo deteriorado.

Caja de texto: 39 líneas (41 con titulillo y reclamo). Capitulares, viñetas y florones decorando el texto. Titulillo en recto y verso. Notas a pie de página.

Ejemplar de la Biblioteca Eusebio Francisco Kino 016198

Referencias: Palau y Dulcet ( $2^{\mathrm{a}}$ ed.), 6, p. 386 (la considera segunda edición, de la publicada en México por la Viuda de Calderón en 1664).

Otros ejemplares: Biblioteca Estatal de Baviera Biogr. 3242 z; BL 4985. de.18; LC BX4705.B2516 S24 1761; BNE 2/12829

\section{CATÁlogos de BIBliotecas CONSUlTAdos}

BNAH

Fondos Conventuales del Instituto Nacional de Antropología

e Historia

BNE

Biblioteca Nacional de España

BFUDLAP

Colecciones especiales de la Universidad de las Américas

Puebla

BL

British Library

BLafragua

Biblioteca José María Lafragua BUAP

$\mathrm{BNFr}$

Biblioteca Nacional de Francia 
BNMx

Biblioteca Nacional de México

BPalafoxiana

Biblioteca Palafoxiana

CCILA

Catálogo Colectivo de Impresos Latinoamericanos (Estados Unidos)

CCPBE

Catálogo Colectivo del Patrimonio Bibliográfico Español

CEHM

Centro de Estudios de Historia de México CARSO

ICCU

Istituto Centrale per il Catalogo Unico (Italia)

KVK

Karlsruhe Virtual Catalog (http://www.ubka.uni-karlsruhe. de/kvk.html)

LC

Library of Congress (Estados Unidos)

MORA

Biblioteca del Instituto Mora

UIA

Biblioteca de la Universidad Iberoamericana 
Los registros aquí presentados son tan sólo una diminuta parte de la casuística presente en los libros antiguos, pero sirven para representar la bondad del modelo propuesto. Es decir, nos permiten analizar las posibilidades del registro bibliográfico como forma de representación de un objeto. Sin embargo, como algunos modelos, el que aquí hemos presentado no está cerrado ni completo. Por el contrario, es necesario aplicar la metodología en la descripción para mejorar nuestra comprensión del libro como objeto material y resaltar el conjunto de elementos que lo convierten en un bien patrimonial. 


\title{
8. Interpretaciones de la Norma ISBD(A)
}

\author{
Cristina Herrero Pascual \\ Facultad de Comunicación y Documentación \\ Universidad de Murcia (España)
}

$\mathrm{L}$

a norma $\operatorname{ISBD}(\mathrm{A})$ se publica por primera vez en $1980^{1}$ como consecuencia de la necesidad de introducir en la $\operatorname{ISBD}(M)$ para monografías los aspectos relativos a las publicaciones antiguas que, si bien pueden utilizar la mayor parte de las normas generales, tienen unas características propias que es preciso reflejar en el catálogo. De esta manera, como una variedad de las normas para monografías modernas, las han asumido la mayoría de los códigos de catalogación incluidos el angloamericano y el español.

Pero la utilización de la ISBD(A) ha sido cuestionada por parte de autores que piensan que no es posible someter el libro antiguo a procesos normalizadores, debido a la dificultad que presenta conciliar la rigurosa técnica catalográfica con la variedad con que se presentan los distintos elementos en una edición antigua. Esta duda ha sido superada por la realidad, que ha demostrado que las publicaciones antiguas son

1 IFLA. ISBD(A): International Standard Bibliograpbic Description for Older Monograpbic Publications (Antiquarian). London: IFLA International Office for UBC, 1980. Aplicable a libros publicados entre 1501 y 1800. En su redacción trabajaron expertos de las más importantes bibliotecas europeas y americanas y a partir de esta edición se hicieron numerosas ediciones y traducciones. 
perfectamente normalizables, aunque para su catalogación se requiere una experiencia específica y conocimientos de la realidad de estos libros. La importancia de la normalización consiste no sólo en el hecho de que los catálogos son instrumentos de búsqueda para los estudiosos, sino también porque son fuentes de bibliografía general y especial, que se basan en los catálogos de bibliotecas sin recurrir a los ejemplares.

También se ha cuestionado la capacidad de la norma para identificar aspectos del libro antiguo que solo se aprecian con el examen directo de cada uno de los ejemplares de una obra, como es la diferenciación de emisiones y estados. En este caso, se olvida que la finalidad de un catálogo es la proporcionar una descripción del documento que permita su identificación, búsqueda y recuperación y se debe dejar para las bibliografías y tipobibliografías la individualización de cada uno de los ejemplares de la tirada. ${ }^{2}$

La generalización de los catálogos automáticos ha hecho imprescindible la utilización de la ISBD(A) para codificar la información mediante el formato MARC, aunque como toda norma tiene diversas interpretaciones.

En la transcripción de la portada se presenta el dilema de respetar la puntuación de ésta, actitud defendida por muchos bibliógrafos y estudiosos del libro, o utilizar la puntuación prescrita por la ISBD. ${ }^{3}$ Se ha optado por esta última solución pues se ha dado prioridad a la

2 B. Rodríguez Bravo, Problemática de la ISBD(A). Boletín de la Asociación Andaluza de Bibliotecarios, Sept. 1992, n.32, p.14.

3 La decisión de hacer la descripción de las publicaciones reflejando los datos igual que vienen en las portadas, o proceder a su normalización se ha planteado en reuniones de expertos a nivel internacional, y ha sido reflejada, entre otros, por: Dexeus, M. Y Agenjo, J. La catalogación cooperativa del libro antiguo en España. Boletín de ANABAD, 1990, 40, n. 4, pp. 75-84; y: Leoncini, C. Y Servello, R.M. (eds.) Libri antichi e catalogazione: metodologie e esperienze. Roma: Istituto Centrale per Il Catalogo Unico delle Biblioteche Italiane, 1984. En la mayoría de los casos se ha decidido, como en este trabajo, aceptar la normalización, para facilitar el intercambio de información, aunque con las precisiones necesarias para textos antiguos. En función de esto, las normas francesas han suprimido la puntuación prescrita para las áreas 1, título y mención de responsabilidad, y 2, edición, y han recogido los datos con la puntuación de la publicación. Véase: AFNOR. Catalogage des monographies anciennes: rédaction de la description bibliographique. Paris: AFNOR, 1986, pp. 6 y 12. 
normalización catalográfica, lo cual no merma la inteligibilidad de los datos por parte del usuario, ya que la $\operatorname{ISBD}(\mathrm{A})$ permite suprimir la puntuación prescrita en los casos que sea necesario para una clara interpretación de los datos de la publicación. Si se decide respetar la puntuación original de la obra se debe informar en el registro esta circunstancia.

La presencia de numerosas abreviaturas en títulos y otros datos bibliográficos es otro problema. Se puede resolver transcribiéndolas tal como vienen, lo que en muchos casos no es posible debido a los signos de puntuación utilizados y la necesidad de utilizar un formato en las letras que no permiten la mayoría de sistemas de catalogación, aunque para usuarios especializados es la mejor fórmula porque reproduce la tipografía del libro. La otra solución es desarrollar las abreviaturas encerrando entre corchetes las letras que no aparecen en el texto original. Se crean referencias más fáciles de interpretar pero hay que tener conocimientos mínimos de paleografía. En cuanto al uso de mayúsculas y minúsculas, se utiliza la ortografía normal de cada lengua, aunque en las portadas suelen venir todas las palabras en mayúscula. La transcripción de las letras capitales del alfabeto latino a sus equivalentes minúsculas se hace de la siguiente manera:

- U y V se transcriben como u, excepto cuando son la letra inicial de una palabra, que se pone $\mathrm{V}$.

- J e I se transcriben siempre como i.

- las letras minúsculas que no han pasado al alfabeto moderno (ese larga, r cuadrada o letras con nexo) se transcriben por sus equivalentes en el alfabeto actual: s, r, et, e, y.

- las minúsculas i y j, u y v, utilizadas en grafías antiguas indistintamente, se transcriben como vienen en la fuente.

Vamos a hacer una descripción de las áreas que establece la norma ISBD(A) identificadas por las etiquetas que utiliza el formato MARC. ${ }^{4}$

4 Para codificar loa registros se ha utilizado el formato MARC21, en la versión que aparece en www.absysnet.com . [Fecha de consulta: Enero de 2003]. 


\section{Área de título y mención de responsabilidad (Campo 245)}

El primer elemento de la descripción es el título propiamente dicho que es el título de la publicación, registrado como viene expresado en ésta.

En las obras en latín es frecuente que el elemento inicial del título sea el nombre del autor en genitivo, circunstancia que se debe respetar, aunque se pueden suprimir en la transcripción las palabras que expresan profesión o cargo del autor que no son necesarias para su identificación y siempre que no sean las primeras palabras del título. La supresión de alguna palabra del título se indica con el signo de omisión "...". Se considera, además, que la mención de responsabilidad va implícita en el título y no se repite a continuación de él.

24510 \$aReuerendi Patris Fratris Bartholomaei a Ledesma... De septem nouae legis sacramentum summarium...

Cuando el título de la publicación consta de dos partes separadas por las palabras $o$, esto es, es decir (o sus equivalentes en otros idiomas: seu, sive, id est, hoc est, etc.), la segunda parte se considera título alternativo, aunque puede ser también subtítulo o explicación de título).

24510 \$aRepetitio noua sive Commentaria rubricae...

Una publicación puede ofrecer en la portada varios títulos, lo que puede ser debido a circunstancias distintas:

a) Que la publicación sea una colección de obras individuales, agrupadas bajo un título colectivo y todos vienen en portada.

5 Se recomienda no abreviar el título salvo en los casos que sea muy largo. Si se hace, se debe procurar que no se pierda información esencial. Se abreviará por el centro o por el final, pero nunca las primeras palabras. Algunas normas publicadas establecen en seis el número de palabras del título previas a una omisión. LIBRARY OF CONGRESS. Descriptive cataloging of rare book. 2nd. edition. Washington: Cataloging Distribution Service, Library of Congress, 1991, p. 7 (Norma 1B7). 
En el campo 245 se pondrá el título colectivo, indicando la omisión de los títulos individuales con el signo de omisión "...", y los títulos individuales se recogerán como una nota de contenido en el campo 505. Excepcionalmente, cuando el título colectivo y los títulos individuales estén unidos gramaticalmente dentro de una frase, se indicarán todos en el área de título.

$24510 \$ a A r t e$ de lengua mexicana $\$$ c/ dispuesto... por el P. Fr. Augustin de Vetancurt...

505 0\# \$aContiene: Instruccion breve para la administracion de los Santos Sacramentos...; Catecismo mexicano

b) Que la publicación sea una colección de obras sin título colectivo. Los títulos se transcriben en el campo 245 en el mismo orden en que vienen en la portada, ${ }^{6}$ y con la puntuación prescrita según sean de un mismo autor, o de autores distintos, en cuyo caso, además, irán acompañados de sus respectivas menciones de responsabilidad. La puntuación se pondrá incluso cuando van unidos por palabras como eiusdem, item, quibus adiecimus, etc. Si alguno de los títulos no aparece en la portada común, se expresará entre corchetes.

24510 \$aAlgunos singulares, y extraordinarios sucessos del gouierno de don diego Pimentel Marques de Gelues Virrey desta nueua España por su excesiuo rigor ayudado desus [sic] consejeros \$b; La prission y destierro de don Iuan de la Serna Arçobispo de Mexico... La prission de la Real Audiencia por mandarlo boluer del destierro... El alboroto y tumulto de los muchachos, y indios y plebe que hizieron al Virrey salir huyendo del Real Palacio... \$c en relación por el licenciado Christoual Ruyz de Cabrera... (Varios títulos del mismo autor)

24500 \$aPor las Religiones de la Nueua-España y Reynos del

6 Las normas francesas establecen en cinco el número máximo de títulos a recoger en la descripción. Si hay más títulos, se pondrá el signo de omisión seguido de la abreviatura [et al.]. Véase AFNOR, Op. cit., p. 13. 
Pirù con los señores Fiscal y Arzobispos y Obispos e Iglesias Catedrales de los dichos Reynos. \$b. Sobre la recusación del señor don Francisco Manso Arzobispo de Mexico... (Varios títulos de distinto autor)

Cuando en una publicación la numeración de los volúmenes o partes se presenta formando parte del título, la numeración del último volumen se puede dar entre corchetes y detrás de un guión.

24510 \$aLibro tercero [- quarto] del proximo euangelico...\$c / compuesto por Don Iuan Dias de Arce... arçobispo y primado de la matropolitana de Santo Domingo en la Isla Española

En las publicaciones en que se desconoce el título, bien porque carezcan de portada, o porque ésta esté muy deteriorada, se puede tomar el título del inicio del texto, del colofón, si lo tienen, o de los preliminares. En estos casos, se pondrá entre corchetes y se hará mención del lugar de donde se ha tomado en el área de notas. ${ }^{7}$

$24510 \$ \mathbf{a}[$ Sucesos de las Islas Philipinas... \$c/ por el doctor Antonio de Morga]

500 \#\# \$aFalto de portada. - Título de inicio de texto.

- Título/s paralelo/s. Cuando la publicación presenta en la portada el título en dos o más idiomas, se transcriben en el mismo orden que vienen, separados por el código (\$b) y la puntuación (=) prescritos. Si los subtítulos y las menciones de responsabilidad están también en varios idiomas, se transcribirán junto al título que les corresponda, agrupados por idiomas y separados los de cada idioma por "=".

$24510 \$ \mathbf{a E \sigma v} \chi \operatorname{lov} \lambda \varepsilon \chi\llcorner\varkappa$ เ $\$ \mathbf{b}=$ Hesychii dictionarium

7 Es conveniente además, averiguar el título en un repertorio o catálogo e incluirlo como información complementaria en el área de notas o incluso fuera del registro bibliográfico, en nota a pie de página, si es un catálogo impreso. 
- Subtítulo o información complementaria del título. Son las palabras o frases que aparecen en la publicación como explicación o ampliación del título propiamente dicho. Puede estar constituido por la expresión desarrollada de las siglas o acrónimos que constituyen el título o hacer referencia a otros elementos o áreas, como mención de responsabilidad, edición, impresión, etc. En algunos casos, no es fácil distinguirlo de un título alternativo.

24510 \$a Discurso de don Iuan Ceuicos, thesorero de la S. Yglesia de la ciudad de Manila... sobre los priuilegios de las sagradas religiones de las Indias \$b: en el qual se ponen algunas dudas acerca de que los religiosos estienden los... priuilegios a mas de lo que pueden...

$24510 \$$ aSitio, naturaleza y propriedades de la ciudad de Mexico \$b: aguas y vientos a que esta sujeta, y tiempos del año: necesidad de su conocimiento para el exercicio de la medicina, su incertidumbre y difficultad sin el de la astrologia, assi para la curacion como para los prognosticos \$c por... Diego Cisneros...

Si la publicación contiene varios títulos y varios subtítulos, cada uno de estos irá a continuación del título correspondiente, salvo que haya un solo subtítulo común a todos ellos, en cuyo caso va a continuación del último título.

24510 \$aHieronymi Cardani Medici De sapientiae \$b: libri quinque ; eiusdem De consolatione libri tres : alias aediti sed nunc ab eodem authore recogniti ; eisdem De libris propiis liber unus...

Si un subtítulo aparece en la portada después de la mención de responsabilidad, se transcribirá en el orden que tiene en la publicación, pero siempre que sea un subtítulo y no unas palabras o frases escritas como invocación en cuyo caso irán en una nota de "Precede al título" (campo 500).

24510 \$a Ofrece este sermonario en lengua mexicana $\mathbf{\$} \mathbf{c}$ / su indigno sieruo Fr. Ioan Baptista de la Orden del Seraphico Padre Sanct Francisco 
...; primera parte.

24510 \$aPsalmodia Christiana, y Sermonario de los Sanctos del Año, en lengua Mexicana \$c/ compuesta por el muy R. Padre Fray Bernardino de Sahagun, de la orden de sant Francisco ; ordenada en cantares o Psalmos para que canten los Indios en los areytos, que hazen en las Iglesias

24510 \$aVerdadaera medicina, cirugía y astrología en tres libros dividida $\$ c /$ por el doctor Ihoan de Barrios...

500 \#\# \$aPrecede al tít.: "Iesus, Maria"

En otros casos, el subtítulo puede incluir la mención de responsabilidad, cuando ésta forma parte gramatical y linguísticamente del título y viene expresada como una explicación de él.

24510 \$aSummario breve delas utilidadaes que se siguen de las Misas dichas y oydas con deuoción \$b: según lo colige de diversos autores el... Padre F. Ioan de la Peña... : en un tratado que compuso el año de mil y cuatrocientos y noventa y ocho...

Un subtítulo que no aparezca en portada, pero esté en la publicación y se considere útil como aclaración del título, se puede incluir en esta campo, entre corchetes. Se hará constar, además, en nota, la fuente de donde se tomó.

24510 \$aCapreolus super tertio sententiarum \$b: [liber... defensionum theologie sancti \& gloriosi angelici doctoris Thome de Aquino] 500 \#\# \$aSubtítulo del colofón

- Título dependiente. Si varias publicaciones tienen una primera parte del título común, y otra que es distinta porque hace referencia a volúmenes o partes, niveles de comprensión, forma de presentación, etc., a esta segunda parte se llama título dependiente. En libros antiguos, sobre todo los del siglo XVI, se utiliza esta forma del título para describir obras en varios volúmenes o partes, ya que al estar en muchos casos cada volumen impreso en sitios distintos, no existe la concepción unitaria que tienen estas obras en la actualidad. 
24500 \$aBiblia sacra cum glossa interlineari... \$pTomus secundus $24510 \$$ aM. Tulli Ciceronis Opera \$p. Tomus septimus continens epistolas ad T. Pomponium Atticum

- Mención de responsabilidad: se considera como tal a todas las personas y/o entidades que tienen alguna responsabilidad intelectual o artística en el contenido de la publicación y así consta en cualquier parte de ella (portada, contraportada, colofón, preliminares, cubierta, etc.). No se consideran menciones de responsabilidad las relativas a lemas, dedicatorias, mecenazgo o financiación que se incluyen, si interesa, como notas (Campo 5XX).

Las menciones de responsabilidad se transcriben en el orden y forma en que vienen en la publicación. Se incluirán todas cuando se pueda, aunque se pueden omitir palabras e incluso nombres utilizando para ello el signo de omisión “...”. Si se considera necesario incluir alguna palabra de enlace que aclare la función que realiza una persona o entidad en la publicación, por que no quede claro en ésta, se hará siempre entre corchetes. En cuanto a la ortografía, se seguirán las normas españolas en cuanto a uso de mayúsculas y minúsculas, teniendo en cuenta dos excepciones:

a) se deben poner con mayúscula inicial las palabras que expresan el lugar de origen del autor, aunque éste tenga además un apellido.

\$cPaolo Gallucci Salodiano

\$cSedulii Scoti Hyberniensis

b) se pondrá igualmente con mayúscula inicial la primera palabra del título que aparece después del nombre del autor, cuando éste le precede .

24510 \$aErasmi Roterodami Opusculum cui titulus est...

La mención de responsabilidad se puede presentar de varias formas: 
a) Puede formar parte del título, bien al principio de éste o al final, y entonces no se utiliza el código correspondiente $(\mathbf{\$} \mathbf{c})$, a no ser que haya más menciones. Hay varias menciones de responsabilidad cuando varias personas o entidades desempeñan funciones distintas en la publicación: traductores, editores literarios, ilustradores, etc.

24510 \$aSermon que predico... fray Luis Barroso Regete del Conuento Real de S. Domingo de Mexico a las honrras que en el hizo el Santo Officio de la Inquisición de nueua España a... Philippe Tercero...

24500 \$aPoeticarum institutionum liber variis ethnicorum, christianorumque exemplis illustratus... $\$ \mathrm{c} /$ per Congregationem B.M.V. Anuntiatae in societatis Iesu Collegii Mexicani Coynnasiis Auctoritate Apostolica institutam ; collectore eiusdem Societatis... Antonio Rubio

b) Puede ir introducida por una palabra o partícula que exprese autoría: "compuesto por", "auctore", "a", "opera", etc.

24510 \$aVocabulario manual de las lenguas castellana y mexicana en que se contienen las palabras, preguntas, y respuestas mas comunes y ordinarias que se suelen ofrecer en el trato, y communicacion entre españoles e indios $\mathbf{\$} \mathbf{c} /$ compuesto por Pedro de Arenas

Las informaciones sobre apéndices, índices, etc., se transcriben según el orden que tengan en la portada. Si vienen a continuación del título y antes de la mención de responsabilidad, se transcriben como subtítulo. Si están a continuación de la mención de responsabilidad, irán como otra mención de responsabilidad. Cuando la mención de volumen o parte, o mención de un segundo título que se presenta como 
un apéndice y no como una segunda obra, o incluso un subtítulo aparezcan a continuación de la mención de responsabilidad, se incluye igualmente como otra mención de responsabilidad. ${ }^{8}$

24510 \$aLibro de la oración en que se ponen consideraciones sobre los Euangelios de todos los domingos del año... \$ $\mathbf{c} /$ compuesto por Fray Andres Capella... ; va al fin... una carta o colloquio interior de Christo nuestro redemptor al anima deuota compuesta por... Iuan Lanspergio

Las menciones de responsabilidad que preceden al título y no van unidas gramaticalmente a éste pueden registrarse en el \$c, siempre que el cambio de orden se registre en una nota:

500 \#\# \$aAutor precede al título.

Si una mención de responsabilidad no aparece en la portada de la publicación pero se considera necesario incluirla en la descripción, se registra entre corchetes y se redacta una nota indicando el lugar de donde se tomó la información .

24510 \$aUniversa loca in logicam Aristotelis in mathematicas disciplinas \$b: hoc novum opus declarat $\mathbf{\$} \mathbf{c} /$ [Petrus Cathena Venetus]

500 \#\# \$aAutor de licencia

Se consideran también menciones de responsabilidad las que no incluyen un nombre de persona y las que contienen información relativa a otros campos, siempre que en la publicación aparezcan como tales.

24510 \$a Relacion historiada de las exeqvias fvnerales de la Magestad del Rey D. Philippo II. nvestro Señor \$c/ Hechas por el Tribvnal del Sancto Officio de la Inquisicion desta Nueua España y sus prouincias, y yslas

IFLA. ISBD(A) Descripció biblogràfica normalitzada internacional per a publicacions monogràphiques antigues (Antiquària). Barcelona, Institut Català de Bibliografia, 1984, p. 23 (Norma 1.5.9). 
Philippinas...

24510 \$a Felicidad de Mexico en el principio, y milagroso origen, que tubo el Santuario de la Virgen María N. Señora de Guadalupe ... \$c/ sacada à luz, y añadida por ... Luis Bezerra Tanco para esta segunda impression que ha procurado ... Antonio de Gama

\section{Área de edición (Campo 250)}

En las monografías antiguas hay que identificar las distintas ediciones de una obra y las emisiones o estados 9 que se pueden producir en el proceso de producción de cada una de ellas, porque pueden dar lugar a descripciones independientes. Se puede considerar que lo prescrito para el área de edición incluye la información relativa a la emisión, impresión o estado que se describe. ${ }^{10}$

La mención de edición se registra como venga expresada en la publicación, que normalmente incluirá la palabra "edición" o "impresión", y sus correspondientes en otros idiomas, acompañado o no del número de edición.

250 \#\# \$a Agora nuevamente añadido

250 \#\# \$aEnmendado en esta ultima impression

250 \#\# \$aEditio postrema

Pero es preciso distinguir la figura del editor literario que aparece en el documento formando parte del título y se registra como mención de responsabilidad.

9 Para los conceptos de edición, emisión y estado véase el capítulo Incunables e impresos antiguos de Julián Martín Abad en la obra: Díez Carrera, C. (coord.). Los materiales especiales en las bibliotecas. Gijón: Trea, 1998, pp. 63-121. De manera resumida, podemos decir que una emisión es un conjunto de ejemplares que presenta diferencias intencionadas con el resto de la edición (portadas distintas en el caso de una coedición) y un estado son las variaciones no planeadas que presentan los ejemplares de una edición (corrección de erratas, nueva composición de pliegos, etc.).

10 IFLA. ISBD (A): Descripción bibliográfica internacional normalizada para publicaciones monográficas antiguas. $2^{\mathrm{a}}$ ed. rev. Madrid: ANABAD, 1993, p. 58. 
24510 \$a Mystico verano \$b: sermon panegyrico de la rosa : predicado en su celebridad que annual acostumbra hazer el Imperial Convento de Predicadores de esta ciudad, en concurrencia de la Invencion de la S.S. Cruz y de la ... Seraphica Madre Santa Catharina de Sena ... \$c/ por ... Fr. Ioseph de Armentia ...; sacalo a luz ... Alonso de Azinas Duque de Estrada.

Igualmente, términos como "nuevamente impresso en Mexico", pueden tener relación con el lugar de impresión y se expresarán en el campo 260 (área de publicación).

Se incluyen como mención de edición las palabras o frases que hagan mención a diferencias en el contenido de la publicación o en la forma de presentación entre las distintas ediciones, porque pueden contener información de que es una edición príncipe, que está corregida por el autor, que se han corregido errores de impresión anteriores o que se incluyen índices, comentarios o ilustraciones que las ediciones anteriores no tenían.

250 \#\# \$aNunc vero ad instantiam et ex sumptibus ... D.D. Ioannis de la Serna Archiep. Mexican. iussu regio editum ...

Cuando la mención de edición no viene en la portada y los datos se toman de otra parte de la publicación (colofón, preliminares), o incluso de fuentes externas a la publicación (repertorios, catálogos), se expresan, en el segundo caso, entre corchetes y, además, en un campo 5XX (notas bibliográficas) se indica la fuente de donde se ha tomado. En este caso la mención de edición se redactará en el idioma del centro catalogador, en la forma y con las abreviaturas prescritas.

250 \#\# $\$ \mathbf{a} 2^{\mathrm{a}}$ ed.

500 \#\# \$aEd. del colofón

250 \#\# \$a[Ed. príncipe]

500 \#\# \$aEd. de Palau (la información de que es la edición príncipe se ha tomado del Manual del Librero... de Palau)

Si la publicación es una colección sin título colectivo, las menciones de edición relativas a los títulos que la forman se redactarán a continuación de éstos, y no en el área de edición. 
24510 \$aAndrea Caesalpinii Aretini Quaestionum peripateticarum lib. $\mathrm{V}$; Daemonum inuestigatio peripatetica..., secunda editio ; Quaestionum medicarum libri II ; De medicament. facultatibus lib. II..., nunc primum editi

- Mención de responsabilidad de la edición. Se incluyen aquí los nombres de las personas y/o entidades que tienen una responsabilidad en la edición que se describe pero no en las demás ediciones de la obra. Pueden estar referidas a los apéndices, índices, ilustraciones, etc.

25022 \$a Saliò impressa en su tomo Despertador eucharistico, aora reimpressa aparte $\$ b /$ de orden del... señor don Antonio de Benavides y Bazan, Patriarca de las Indias, Arçobispo de Tyro...

- Mención de edición adicional. Se da este elemento cuando la publicación expresa claramente que es una edición dentro de otra edición o impresión, o cuando se advierte una variación dentro de una edición. Puede incluir una mención de responsabilidad propia, pero esto es normalmente raro.

250 \#\# \$aHaec editio post auctoris ipsius recognitionem...\$b, tertio nunc in lucem prodit

Área de publicación (Campo 260)

En los libros del siglo antiguos, sobre todo de los siglos XVI y XVII, no siempre está diferenciada la función de impresor, editor y librero, por eso se ha denominado a los elementos de esta área con el término general de "publicación". La mayoría de los impresores son también editores, por lo que no se les da el mismo tratamiento, aunque en la descripción se ha respetado la denominación de cada uno de ellos. Esto 
ha llevado a modificar la denominación de los elementos de este área en relación a la versión española de la $\operatorname{ISBD}(\mathrm{A}){ }^{11}$

La fuente de información para este área es la portada. Si no aparecen los datos en ésta se seguirá este orden: colofón, anteportada, otros preliminares y cualquier parte de la publicación. Cuando la publicación contenga estos datos en portada y colofón, se preferirá la portada y no se hará mención del colofón si los datos coinciden. Si los datos del colofón son distintos a los de portada, se expresarán después de los de publicación, en el mismo orden que éstos, pero entre paréntesis (como los datos de impresión en los libros modernos).

Cuando los datos de publicación se tomen en su totalidad de una fuente que no sea la portada, se hará constar la fuente en el área de notas. Si el área de publicación se redacta con datos procedentes de distintas fuentes, se hará constar en campos de notas la fuente de cada uno de ellos que no sea la portada.

- Lugar de publicación. Es el nombre de la ciudad donde se ha publicado el libro. Si aparece más de un lugar se escogerá el primero que venga citado o el que esté destacado tipográficamente. Se pueden incluir, si se considera conveniente, todos los nombres que vengan. Se transcriben tal como viene en la publicación, incluso precedido o acompañado de palabras que no hacen referencia a la mención de publicación. Se puede abreviar cuando resulte muy

11 Op. cit., p. 66. La modificación consiste en que los tres primeros elementos (\$a, $\$$ b y $\$ c)$ se refieren a los datos de publicación de la fuente principal de información, la portada, o de otras fuentes siempre que se indique cuales son. Los tres últimos elementos $(\$ \mathrm{~d}$, \$e y $\$ \mathrm{f})$, correspondientes en la versión española de las Reglas de catalogación los datos de impresión, se utilizarán sólo para los datos del colofón, cuando no coincidan con los de publicación. Esto se justifica en que, como se ha dicho, no es posible distinguir en el siglo XVI la figura del impresor, editor y, en menor medida, librero. Aunque hay denominaciones para cada oficio (impressum, impreso por, chez, apud, ex typographia, etc, se considera que se refieren a impresores; a costa de, excudebat, y otros, a editores), no siempre en las publicaciones se utilizan con rigurosidad. Sólo expresiones como bibliopolum, librero, vendese en casa de y mercader de libros, se refieren claramente a libreros. Esta modificación está avalada por las normas americanas (LIBRARY OF CONGRESS, Op. cit, p. 27) y las francesas (AFNOR, op. cit, p. 17). 
largo, utilizando el signo de omisión. Si se toma de una fuente distinta a la portada, se advertirá en un campo 5XX (notas bibliográficas).

260 \#\# \$aExcudebat Mexici

260 \#\# \$aEn Mexico

260 \#\# \$aEn la Puebla

26033 \$aPor su original en la Puebla

El lugar de publicación se registra entre corchetes en los siguientes casos:

- Cuando no viene como lugar de publicación, pero acompaña a los datos de identificación del editor, impresor o librero:

260\#\# \$a[Alcalá de Henares] : vendense en casa de Salzedo, librero en Alcala de Henares

- Cuando se utiliza el lugar donde habitualmente trabaja el impresor:

260 \#\# \$a[Mexico] \$b: en la emprenta de Diego Lopez Daualos

500 \#\# \$aEl impresor trabajó en México

- Cuando se desconozca el lugar de publicación, pero se pueda dar el de una región, estado o nación:

$$
260 \text { \#\# \$a[Italia] }
$$

- Cuando de toma de la licencia, privilegio u otros preliminares y en este caso irá acompañado del signo de interrogación: ${ }^{12}$

12 El lugar de licencia o privilegio no tiene que ser forzosamente el lugar de impresión o edición, aunque puede coincidir. 
260 \#\# \$a[Mexico] : por Francisco Rodriguez Lupercio, 1679

500 \#\# \$aLugar deducido del impresor y tomado de censura y licencias

Si no es posible averiguar ningún lugar, ni siquiera aproximado, se utiliza la abreviatura [S.1.].

- Mención de publicación. Incluye el nombre de todas las personas que aparecen en la publicación como impresores, editores, o libreros. Se transcriben como vienen en la fuente pero se pueden abreviar las direcciones y otras informaciones cuando no sean necesarias para completar la identificación de esta mención.

300 \#\# \$aEn Mexico \$b:en la emprenta del bachiller Iua[n] Blanco de Alcaçar\$c, 1621

500 \#\# \$aPié de imprenta tomado del colofón

300 \#\# \$aReimpreso en la Puebla de los Angeles \$b: en la oficina de Don Pedro de la Rosa...

300 \#\# \$aEn Mexico \$b: Por Doña Maria de Benavides, viuda de Juan de Ribera, En el Empedradillo

300 \#\# \$aEn Mexico : Por los Herederos de la Viuda de Bernardo Calderón

300 \#\# \$aEn la Puebla de los Angeles \$b: en la imprenta de Diego Fernandez de Leon \$b: hallarase este papel en la libreria de Diego Fernandez de Leon...\$c, 1690

Si la mención de publicación esté expresada por el lema o la dirección del editor o impresor pero se conoce el nombre, se añade éste entre corchetes:

250 \#\# \$aImpressa en México y agora en Valencia \$b: por Iuan Crisóstomo [Garriz]

250 \#\# \$aVenetia \$b: al segno delle Concordia [Pietro Dusinelli] 250 \#\# \$aIn Venetia \$b: presso il Muschio [Iacomo Vidali] 
La mención de publicación se pondrá entre corchetes en los casos siguientes:

- Cuando no aparece la publicación pero se deduce de la marca tipográfica. Se recomienda contrastar esta información en un repertorio, pues hay marcas que son utilizadas por varios impresores.

260 \#\# \$aVenetiis \$b: [Aldo Manuzio]

500 \#\# \$aImpresor de la marca tipográfica

- Cuando se utiliza el nombre del editor o impresor probable (p.e.: cuando hay varias obras publicadas en un volumen, una de ellas no tiene editor pero el papel y los tipos parecen iguales que los de las otras que sí lo tienen). Debe ir además acompañado del signo de interrogación.

260 \#\# \$a[Impressum Hispali \$b: arte e ingenio Iacobi Kronberger Alemani\$c, 1517]

500 \#\# \$aPublicación del colofón de la segunda obra

- Cuando el nombre del editor o impresor se toma de fuentes externas al documento, como repertorios y catálogos.

4250 \#\# \$a[Alcalá \$b: por Miguel de Eguía]\$c, 1526

500 \#\# \$aLugar e impresor del NUC y Palau ${ }^{13}$

- Fecha de publicación. Es la fecha de impresión o edición de la publicación que se describe. Se dará como aparece en la publicación, pero siempre en números árabes. Si no aparece en la portada se puede tomar del colofón, indicándolo en un campo de notas (5XX). Se puede suprimir la palabra "año" y su equivalente en otros idiomas.

13 Se hará de esta forma sólo cuando se tenga la seguridad de que la obra descrita es la misma que la citada en los repertorios. Para evitar errores, en un catálogo impreso esta información se puede poner en nota a pie de página. 
\$c,1540 (en la fuente: Anno M.D.XL.)

\$c,1543 (en la fuente: Anno nostrae salutis M.D.XLIII)

$\$ c, 1567$

500 \#\# \$aFecha del colof.

Si se sabe con certeza que la fecha es errónea, o el ejemplar está deteriorado afectando a la fecha o a parte de ella, se consignará la fecha real entre corchetes, aclarando esta circunstancia con las abreviaturas prescritas o en nota.

300 \#\# \$aMexico \$b: Por Iuan Rruiz [sic] ...\$c, [1658]

500 \#\# \$aFecha tomada de preliminares, en portada está guillotinada

Cuando se desconoce la fecha de publicación, se puede poner una aproximada que aparezca en la publicación (preliminares). Se expresará entre corchetes y con las abreviaturas normalizadas. Se hará constar en nota la procedencia de la fecha.

260 \#\# \$aEn Mexico \$b: por la viuda de Bernardo Calderon ...\$c, [s.a.]

500 \#\# \$alugar e imp. tomados de colofón

500 \#\# \$aLa producción de la viuda de Bernardo Calderón se fecha a partir de 1641

$260 \ldots$ \$c,[ca. 1598]

En la descripción de obras en varios volúmenes, se utilizará la fecha más antigua y la más moderna, que no tiene que coincidir forzosamente con las del primer y último volumen.

$\$ c, 1767-1770$

Los datos del colofón se indicarán sólo cuando son distintos de los datos de publicación. Van siempre en el mismo orden y con la misma puntuación que éstos pero con los códigos correspondientes del formato MARC. 
260 \#\# \$aMexico \$b: En el Conuento de Sanctiago Tlatilulco \$b: Por M. Ocharte\$c, 1600 \$dMexici \$e in Regio Collegio sancte Crucis, sancti Iacobi de Tlatilulco Ludouicus Ocharte Figueroa\$̦f, 1601

Área de descripción física (Campo 300)

La descripción de las características físicas es muy importante en los libros antiguos al no existir la uniformidad de ejemplares en cada edición o impresión que se da en los libros modernos.

- Extensión. Se expresa en número de columnas, páginas u hojas, según se presente la publicación. Las obras en varias unidades físicas se describen en volúmenes cuando la obra se considera como una unidad bibliográfica, pero en publicaciones antiguas es conveniente en muchos casos hacer una descripción para cada volumen. Se registran con números árabes o romanos, según vengan en la publicación, y con la cifra que venga en la última página, hoja o columna de cada secuencia.

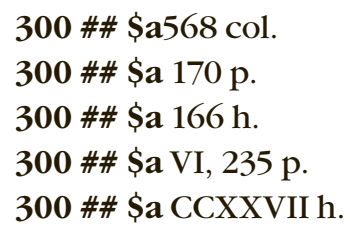

Si se detecta que el número de la última página, hoja o columna es erróneo, lo que puede ser frecuente, se indica con la abreviatura correspondiente. ${ }^{14}$

300 \#\# \$a 218 [i.e. 210]

14 Para no tener que repasar todas las páginas de cada libro, se pueden comprobar las signaturas y a través de éstas calcular las páginas. Si el número coincide con el del libro, no hay errores de paginación. Si no coincide, se buscarán los errores y se hará constar de la forma indicada. 
Cuando la publicación contenga secuencias de columnas y de páginas u hojas, pero la numeración sea correlativa, se expresa de la siguiente manera:

300 \#\# \$a 368 col., p. $369-500$

En las obras en varios volúmenes, si la numeración de ellos es consecutiva, se expresará de la siguiente manera:

300 \#\# \$aP. 237-268

Las secuencias de páginas u hojas no numeradas que aparecen en la mayoría de los libros, antes y después del texto, se cuentan y se registran entre corchetes, tanto si están impresas como si están en blanco. La denominación será de páginas u hojas, según sea la secuencia dominante de la publicación.

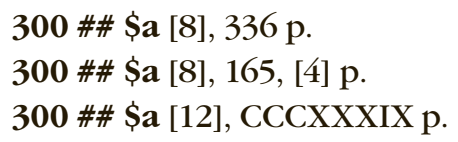

Pero si hay una secuencia sin numerar, que está incluida en el número final de páginas u hojas, se hará constar de la siguiente manera:

$$
\begin{aligned}
& 300 \# \text { \$a } 165 \text { p. } \\
& 500 \# \text { \$a P. } 1-15 \text { sin numerar } \\
& \text { (Las primeras } 15 \text { páginas están sin numerar, pero incluidas en } \\
& \text { la numeración final) }
\end{aligned}
$$

Si todas las páginas u hojas están sin numerar, se cuentan o se calculan por medio de las signaturas y se expresan entre corchetes.

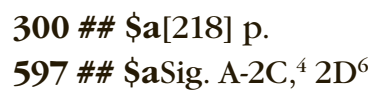


Cuando una publicación tiene varias secuencias de paginación, conviene darlas todas en el orden en que aparecen. ${ }^{15}$

300 \#\# \$a[16], 204, $178 \mathrm{~h}$.

300 \#\# \$a[16], 572, 425, [1] p.

El número de hojas o páginas de láminas no incluidas en la numeración del texto, se da a continuación de la última secuencia de paginación, tanto si las láminas van todas juntas como si están dispersas en la publicación, e incluso si sólo hay una.

300 \#\# \$a359 p. , 35 h. de lám.

300 \#\# \$a[12], 122 h., [1] h. de lám.

Si al ejemplar que se está describiendo le faltan páginas y hojas al principio o al final, esta circunstancia se expresa en nota de la manera siguiente:

300 \#\# \$a+6 p. (faltan páginas al principio)

300 \#\# \$a56+ p. (faltan páginas al final)

- Ilustraciones. Cuando una publicación tenga ilustraciones incluidas en la numeración de hojas o páginas, se pondrá la abreviatura "il." a continuación de las páginas. No se consideran ilustraciones las marcas tipográficas y las orlas, así como las viñetas y otros grabados que están al final de los capítulos. En los campos de notas (5XX) se debe indicar el tipo de grabado, xilográfico o calcográfico, utilizado para las ilustraciones, así como, cuando se pueda identificar, el contenido de éstas.

300 \#\# \$a [6], 234, [12] p. \$b: il.

15 La versión española de la ISBD(A) establece que hasta cinco secuencias de paginación se deben dar todas, y si hay más de cinco ofrece la alternativa de expresarlo por medio de sumarlas todas y dar el número resultante entre corchetes, o poner simplemente: 1 v. (paginación variada). $\operatorname{ISBD(A),~Op.~cit.,~p.~} 85$. 
300 \#\# \$a150 h. \$b: il., música

500 \#\# \$allustraciones son grabados xilográficos

500 \#\# \$aEn p. 2, grabado xilográfico, retrato del autor

- Formato y dimensiones. El formato bibliográfico de la publicación se expresa con las siguientes abreviaturas: Fol., $4^{\circ}, 8^{\circ}, 12^{\circ}$ y $16^{\circ}$, que reproducen las veces que se ha doblado el pliego de papel. ${ }^{16}$ A continuación se puede indicar la altura de la cubierta en centímetros. $^{17}$

300 \#\# \$a[4], 60 h. \$c; $4^{\circ}(12 \mathrm{~cm})$

300 \#\# \$a [2], 218, [6] h. \$c; Fol. (18 cm)

- Material anejo. Los libros antiguos no suelen llevar material anejo. En algunos casos puede aparecer un mapa o una ilustración que no forme parte físicamente de la obra pero que forme parte de ella en cuanto a contenido.

300 \#\# \$a 126 h. \$b: il. \$c; $4^{\circ}(16 \mathrm{~cm}) \$ \mathbf{e}+1$ mapa plegado

Área de serie (Campos 440, 490)

Este área se utiliza sólo cuando todas las partes de la publicación están publicadas en la misma serie o subserie. Es de poco uso en la catalogación de libros antiguos, solo se encuentra en publicaciones de

16 Para establecer el formato de una obra se puede utilizar el cuadro que aparece como Annexe 2: formats les plus frequents da les livres anciens, en: Dureau, J.M.; Merland, M.A. Catalogage des livres anciens. Villeurbanne: E.N.S.B., 1982, p. 98.

17 Según Giuseppina Zappella la mención del formato se debe dar en el área de descripción física, porque es la medida original de la publicación. Sin embargo, la medida en centímetros se debe dar en el área de notas, en las relativas al ejemplar, pues la dimensión puede cambiar de un ejemplar a otro. Es un argumento razonable que no está recogido en ninguna de las versiones de la ISBD(A). Zappella, G. Il formato nella descrizione del libro antico: valore bibliologico e suelte catalografiche. Biblioteche oggi, an. 11, n. 8 (Sept. 1993), p. 53. 
finales del siglo XVIII e inicios del XIX. ${ }^{18}$ Cuando una obra esté publicada dentro de una serie, se seguirán para su descripción las normas de esta área, que no difieren de las utilizadas en publicaciones modernas.

\section{Área de notas bibliográficas (Campos 5XX)}

Se utiliza para precisar y ampliar la descripción del documento con aquella información que completa la identificación y no está contemplada en las áreas anteriores. Hay notas relativas a las áreas de la ISBD y notas que no hacen relación a ningún área. Cualquiera de las notas previstas para un campo 5XX establecido en el formato MARC se puede registrar como nota general en el campo 500, ya que el MARC21 no contempla muchos de los campos que aparecen acompañando a los ejemplos que se exponen a continuación. Estos están ordenados por las etiquetas de los campos y no en el orden de las áreas, puesto que la práctica catalográfica lo hace más operativo.

\section{Nota general.}

500 \#\# \$aEdición tomada del colofón

500 \#\# \$aAnotación manuscrita: es la primera edición que se hizo en Madrid

500 \#\# \$aAnotación manuscrita en portada: $2^{\text {a }}$ edición, la $1^{\text {a }}$ en Valencia en 1556

500 \#\# \$a Portada marca tipográfica

500 \#\# \$a Colofón marca tipográfica

500 \#\# \$a Portada y colofón marca tipográfica

500 \#\# \$a Portada marca tipográfica (Vindel, 213) ${ }^{19}$

18 J. Martín Abad, Incunables e impresos antiguos. En: Díaz Carrera, C. (coord.). Los materiales especiales en las bibliotecas. Gijón: Trea, 1998, p. 108.

19 Se refiere a que la marca tipográfica que aparece en el libro que se está describiendo, aparece reseñada con ese número en la obra: Vindel, F. Escudos y marcas de impresores y libreros en España durante los siglos XV a XIX (14851850). Barcelona: Orbis, 1942. 
500 \#\# \$a Portada marca tipográfica? ${ }^{20}$

500 \#\# $\mathbf{\text { a Texto dos columnas }}$

500 \#\# \$a Portada dos tintas

500 \#\# \$a Letra gótica

500 \#\# \$a Portada orlada

500 \#\# \$a Dedicado a... ${ }^{21}$

Notas al contenido.

505 0\# \$aContiene: (Para colecciones con título colectivo)

Se puede hacer además la indicación del lugar donde viene la relación de títulos individuales:

505 0\# \$aContiene, en portada:

505 0\# \$aContiene, en contraportada:

505 0\# \$aContiene solamente la primera obra citada en el título.

505 0\# \$aSegunda obra con port., pág. y signaturas propias (cuando hay además una portada común y se ha becho la descripción como una colección sin título colectivo)

Nota de "Con" y "En". Cuando hay dos o más obras independientes en un solo volumen, se hace una descripción distinta para cada una de ellas, pero relacionándolas entre sí en el área de notas. En la primera obra que forme el volumen se pondrá una nota de "Con:" seguida de una breve referencia de las obras que le siguen. En las obras que no son la primera, se pondrá una nota de "En:" seguida de una breve referencia de la primera obra. ${ }^{22}$

20 Se ha puesto con interrogación porque se tiene duda de que lo sea. Aunque se deben comparar las marcas y contrastarlas en publicaciones especialidades, es posible que algunas no se puedan localizar.

21 Aunque en la transcripción de las portadas no se hace mención a las dedicatorias, en algunos casos es necesario incluirlas para ayudar a datar un libro que no tiene fecha. Se prefiere para ello el área de notas.

22 Se consideran obras independientes cuando cada una tiene portada, páginas y signaturas propias, y no vienen citadas en una portada común. La referencia de la obra relacionada se limita al nombre del autor y el número de registro. A través del número de registro se puede recomponer el orden de las obras en el volumen, al asignar a éste un número seguido de un guión y un número para cada obra según el orden que tienen dentro del volumen. 
Primera obra:

100 1\# \$aACCOLTI, Francesco

24510 \$aCastigatissima iuris responsa...

501 \#\# \$aCon: D’ANANIA, G., R. 1165-2

Segunda obra:

100 1\# \$aD'ANANIA, Giovanni

24510 \$aConsilia Iohannis de Anania...

501 \#\# \$aEn: ACCOLTI, F., R. 1165-1

- Referencias bibliográficas. Es importante en publicaciones antiguas indicar los repertorios, catálogos u otro tipo de publicaciones donde aparece citada la obra que se está describiendo. El nombre de los repertorios consultados se cita por medio de una abreviatura o sigla. ${ }^{23}$

Cuando el repertorio consultado no recoge la obra exacta que aparece en el Catálogo, pero la cita como anterior o posterior a otra, se expresa esta circunstancia por medio de "Citado en" seguido del nombre y página del repertorio.

510 0\# \$aRhodes, 8005.d.f.4

510 0\# \$aNUC, 128624

510 0\# \$aCitado en Palau 163461

- Notas al área de título y mención de responsabilidad. La mayor parte de ellas hacen referencia a la fuente de donde se ha tomado la información, cuando no es la prescrita.

594 \#\# \$aTítulo de inicio texto

594 \#\# \$aPrecede al título: CCCCCCCCCC

594 \#\# \$aTítulo de cubierta

594 \#\# \$aTítulo del lomo

594 \#\# \$aTítulo del colofón: (cuando sea distinto del de portada)

23 Para las citas de los repertorios véase: Delgado Casado, J.; Martín Abad, J. Repertorios bibliográficos de impresos del siglo XVI: (españoles, portugueses e iberoamericanos). Madrid: Arco-Libros, 1993. 
594 \#\# \$aAutor de contraportada

594 \#\# \$aAutor de inicio texto

- Notas al área de publicación. Son las más numerosas, debido a la poca uniformidad que ofrecen las publicaciones al presentar estos datos. Pueden agruparse de la siguiente manera:

- Hacen referencia a la fuente de donde se tomó la información:

596 \#\# \$aLugar del impresor

596 \#\# \$aLugar del colofón

596 \#\# \$aLugar del privilegio

596 \#\# \$aImpresor de la marca

596 \#\# \$aImpresor de la obra anterior

596 \#\# \$aImpresor del colofón

596 \#\# \$aFecha de dedicatoria

596 \#\# \$aFecha del privilegio

596 \#\# \$aFecha del colofón

596 \#\# \$aFecha de Palau

596 \#\# \$aPublicación del colofón (cuando todos los datos de publicación se han tomado del colofón)

- Correcciones de la fecha de la publicación cuando se tiene la certeza de que es errónea.

$260 \ldots$... $\mathbf{c}[1534]$

596 \#\# \$a Fecha del colofón

596 \#\# \$a Fecha de portada: Anno milesimo tricesimo quarto

- Composición de una fecha que en la publicación no se ve por estar deteriorada.

$260 \ldots \$ c[1567]$

500 \#\# \$aPortada deteriorada afectando a fecha

596 \#\# \$aFecha de Palau. 
- Notas a área de descripción física. Pueden estar referidas a la extensión (paginación) o a las ilustraciones.

597 \#\# \$aPág. 45-47 en blanco

597 \#\# \$aPág. 48-49 duplicadas

597 \#\# \$aErrores de numeración 24

599 \#\# \$all. grabados xilográficos

599 \#\# \$all. grabados calcográficos de "F.P. Bedel"

599 \#\# \$all. grabado xilográfico retrato autor

599 \#\# \$aEn a ${ }^{4}$ grabado xilográfico retrato autor

599 \#\# \$aPortada escudo xilográfico del arzobispo de Toledo

599 \#\# \$aPortada grabado calcográfico

599 \#\# \$aPortada y texto orla tipográfica

- Nota de las signaturas: se expresa aquí la numeración de las signaturas o numeración de los cuadernos que componen la publicación. Es un elemento opcional, pero se incluye siempre. ${ }^{25}$ Es muy importante la descripción exacta de las signaturas porque completan la identificación de una obra, diferenciándola de otra en la que el texto aparentemente es igual. Para establecer que han salido de la misma prensa, las signaturas tienen que ser también iguales. Además, sirven para controlar que la paginación del libro es correcta.

Si la suma de las hojas que dan las signaturas coincide con el número de hojas del libro, éste es correcto. En el caso de que la numeración del libro se exprese en número de páginas, hay que multiplicar por dos el número de las signaturas. Esto evita el tener

24 Se puede obviar esta nota en los registros de un catálogo del siglo Xvi ya que son muy frecuentes los errores de numeración en la paginación de los libros. Se debe comprobar si el número de páginas y hojas que ofrece la publicación es correcto a través del control y cómputo de las signaturas. Si se detecta un error de paginación, en el área de descripción física se corregirá de la manera prescrita.

25 Las normas francesas incluyen la mención de las signaturas en el área de descripción física, después de la extensión y antes de la mención de ilustraciones. Véase: AFNOR, Op. cit., p. 25. 
que pasar las páginas u hojas del libro una por una para comprobar si están correctamente numeradas. Para el cómputo de signaturas se pueden utilizar los Cuadros 1 y 2 que aparecen al final de este capítulo.

Las signaturas se pueden expresar de manera abreviada, agrupando varias secuencias cuando el tipo de letra o signo que las expresan son los mismos y las secuencias alfabéticas (a-z) están completas.

Si el registro completo de signaturas es: $+^{4}, 2++^{4}, 3+{ }^{4}, \mathrm{a}-\mathrm{z}^{8}, 2 \mathrm{a}-2 \mathrm{z}^{8}$, $3 \mathrm{a}-3 \mathrm{f}^{8}$

Se puede abreviar: 510 0\# \$a 597 \#\# \$aSig. $+-3+{ }^{4}$, a-3 $\mathrm{f}^{8}$

597 \#\# \$aSig. $+^{4}, \mathrm{a}^{\mathrm{f}} \mathrm{f}^{8}, \mathrm{~g}^{4}$

597 \#\# \$aSig. $\mathrm{a}^{8}, \mathrm{~A}-3 \mathrm{E}^{6}, 3 \mathrm{~F}^{8},{ }^{*}-4^{* 6}$

597 \#\# \$aSig. 2a-2 $\mathrm{Z}^{8}, 2 \mathrm{~A}-2 \mathrm{Y}^{8}$ (excep. $2 \mathrm{~V}^{6}$ ), $2 \mathrm{Z}^{6}$

597 \#\# \$aSig. a-t ${ }^{8}, v^{4}, 2 a-2 x^{8}, 2 y^{4}, 3 a-30^{8}, 3 p^{4}$

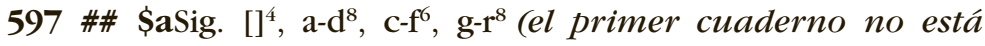
identificado por medio de letra o símbolo)

597 \#\# \$a Sig. a- $\mathrm{Z}^{8 / 6}, \mathrm{~A}-\mathrm{Z}^{8 / 6}$ (alternan los cuadernos en 8 y en 6)

Además se incluirán las notas referentes a las signaturas. Ej.:

597 \#\# \$aSig. alterna mayúsculas y minúsculas

- Notas relativas a ejemplar. Se refiere a notas que afectan sólo al ejemplar que se está describiendo y no al resto de la edición. Se registran en los campos correspondientes a la información que contienen.

500 \#\# \$aAnotación manuscrita: "lo dono el obispo Arias Gallego"

500 \#\# \$aEx-libris manuscrito Jesuitas de Murcia

500 \#\# \$aEx-libris de... 
500 \#\# \$aExpurgado en 1632 y $1707^{26}$

500 \#\# \$aEn portada firma autógrafa? del autor

$\mathbf{5 0 0}$ \#\# \$aSegunda parte con portada propia

597 \#\# \$aFalto de portada

597 \#\# \$aFaltan páginas al final

597 \#\# \$aEncuadernación plateresca

597 \#\# \$aFaltan páginas de grabados

\section{Área de identidad tipográfica (Fingerprint)}

Este área es opcional y equivale al número normalizado. Sirve para identificar duplicados con variantes en la impresión por tratarse de ejemplares pertenecientes a emisiones o estados distintos de una misma edición, y diferenciar unidades bibliográficas con una misma portada pero con textos distintos debido a falsificaciones o ediciones contrahechas. El formato MARC21 no contempla ningún campo específico para esta información, pero el formato IBERMARC lo registra en el campo $021 .^{27}$

Consiste en reseñar de cada ejemplar dieciséis caracteres correspondientes a la última y penúltima línea de cuatro páginas determinadas, a razón de un par de caracteres por línea. Este método, muy eficaz cuando los ejemplares están completos, falla si falta alguna de las páginas establecidas para sacar los caracteres, o está estropeada por las últimas líneas. Como ambos casos pueden ser frecuentes en libros antiguos, se ha preferido el sistema del cómputo de signaturas que, unido a una correcta descripción de las publicaciones puede suplir a la identidad tipográfica. Por otra parte, la determinación de emisiones y estados dentro de una misma edición, así como la comparación tipográfica de los libros, escapa del ámbito de la Descripción Bibliográfica y es más propio de la Tipobibliografía.

26 Hace referencia a que está expurgado según los Índices de libros prohibidos de esos años.

27 Formato IBERMARC para registros bibliográficos. Madrid: Biblioteca Nacional, 2001 


\section{Descripción de obras en varios volúmenes y tomos}

En primer lugar hay que hacer la distinción entre volumen y tomo. El volumen es una unidad física, compuesta de páginas y hojas encuadernadas con unas cubiertas comunes. Una obra, con un contenido unitario, puede estar distribuida en varios volúmenes por razones exclusivamente de extensión física. La mayoría de las veces cada volumen tiene una secuencia propia de paginación, pero puede darse el caso de que dos o más volúmenes tengan la numeración correlativa si constituyen una unidad de contenido inseparable. El tomo es la unidad de contenido, es decir la obra que comienza y termina según la intención del autor.

En los libros modernos un volumen coincide generalmente con un tomo, aunque haya obras en varios volúmenes. Estos están estructurados de manera que cada volumen coincide con una parte de la obra que constituye un tomo. Pero en los libros antiguos, especialmente los del XVI, no se da siempre esta coincidencia, por razones muchas veces económicas y de distribución de las publicaciones. Es muy frecuente encontrar dos o más obras independientes, que constituyen cada una de ellas un tomo, publicadas en un solo volumen. Puede tratarse de varias obras, no muy amplias, de un mismo autor con la intención de dar a conocer las que son menos solicitadas por los lectores. En otros casos, junto a obras de un autor muy conocido se publican otras de autores menores con la intención de darlos a conocer al amparo del más solicitado. Por último, muchas veces es una razón puramente económica. Los impresores/editores al reunir varias obras en un volumen simplifican los trámites de licencia, privilegio, tasa, etc., a la vez que los trabajos de encuadernación y distribución de la obra.

El tratamiento que se debe dar a cada obra está condicionado a su propia presentación, intentando individualizar cada una de ellas respetando la intención de la publicación, que es una de las premisas de la ISBD. Las formas de presentación son variadas, pero se pueden sistematizar, junto al tratamiento dado a cada una de ellas, de la siguiente manera:

a) Obras en varios volúmenes. Se debe hacer un registro individual para cada uno de los volúmenes. No se ha utilizado el 
sistema tradicional de la nota de contenido por razones anteriormente expuestas, ni la descripción a dos niveles porque no la contempla el formato MARC. Se dará un número de registro para toda la obra, seguido de un guión y el número del volumen en números romanos, respetando las lagunas que pudiera haber. Se ordenan en el catálogo por número de volúmenes y no por orden alfabético de los títulos.
R. 356-I
R. 356-II
R. 356-IV

b) Varias obras en un volumen, con portadas, paginación y signaturas distintas. Se hará un registro individual para cada una de ellas, relacionándolas en la descripción bibliográfica por medio de la nota de Con y En (Campo 510). Opcionalmente, se puede redactar una nota de: "3 tomos en 1 volumen". Se dará un número de registro al volumen, seguido de guión y el número de orden de cada obra dentro del volumen, expresado en números árabes. Cada obra va ordenada en el catálogo por su autor y/o título.
R. 564-3
R. 564-1
R. 564-2

c) Varias obras en un volumen, con portadas, paginación y signaturas distintas o no, pero citados todos los títulos en una portada común al principio del volumen. Cuando en la portada principal se anuncian distintas obras, aunque éstas tengan portadas propias, la obra se concibe y se describe como una unidad. Por tanto, se hará un registro único, incluyendo todos los títulos en el orden en que vienen en la portada común, como una colección sin título colectivo. Se redactará una nota explicando esta situación: "La $2^{\text {a }}$ obra con portada propia”. Si además de las obras citadas en la primera portada, 
hay alguna otra que no lo está, se pondrá la nota: "Contiene además, con portada propia:", seguido de una breve descripción. La recuperación de las obras que no vienen citadas en primer lugar se hace a través de índice de autores y colaboradores.

24510 \$aF. Dominici de Flandria ordinis praedicatorum... In D. Thomae Aquinatis commentaria super libris posteriorum analyticorum Aristotelis... \$b. Pauli quoque Soncinatis... Expositio in Porhyrii Isagogen \& Aristotelis...

Tienen paginación continuada, pero la segunda obra, además de venir citada en la portada común, tiene portada propia. Esto se expresa en nota:

500 \#\# \$aLa $2^{\text {a }}$ obra con portada propia

24510 \$aIoan. Baptista Bernardi patricii Veneti Seminarium totius philosophiae : opus sane admirabile...

505 0\# \$aContiene con portada propia: Ioan Baptistae Bernardi patricii Veneti Seminarii totius philosophiae appendix recens adiecta \& in lucem edita ( 34 h., sig. A- $\mathrm{G}^{4}, \mathrm{H}^{6}$ )

En este caso la segunda obra es un apéndice de la primera pero con portada, paginación y signaturas propias. No se ba considerado oportuno separarla de la primera obra.

d) Varios tomos de una misma obra en un volumen. Normalmente de un mismo autor y un mismo título, sólo varía la denominación de parte o volumen. Se hará un registro único para todas las partes, indicándolo en la descripción en el área de título. Se redactará una nota: "La 2 a obra con portada propia".

24510 \$aPrimera parte [-segunda parte] de la sylva spiritual de varias consideraciones para entretenimiento del alma christiana

500 \#\# \$aLa $2^{\text {a }}$ obra con portada propia

Si se da el caso de que siendo dos partes de una obra del mismo autor, con el mismo título, y formando un volumen, estén 
impresas en distinto sitio, se debe hacer un registro para cada una de las partes.

e) Varias obras publicadas en un volumen con un título colectivo y la mención de los títulos particulares, es decir una colección con título colectivo. Generalmente tienen una secuencia única de paginación, aunque puede haber varias. Al igual que en las obras modernas, se hará un registro para la colección, reseñando en el área de título el título colectivo, y los títulos individuales en nota de contenido. En esta nota, se ha hecho la diferenciación de si el contenido aparecía en la portada en la publicación o en contraportada, pues es frecuente en estos libros. La recuperación de las obras individuales, se hace por medio del índice de autores y colaboradores.

$5050 \#$ \$aContiene, en portada:

505 0\#Contiene, en contraportada:

Si alguna de las obras citadas en el título colectivo tiene además portada propia, se incluirá en nota: "Contiene, con portada propia:".

Elección y normalización de puntos de acceso.

El control de autoridades

Aunque la asignación de los puntos de acceso supera el ámbito de la descripción bibliográfica y, por tanto, de la norma ISBD, parece conveniente completar la interpretación de esta norma con unas notas sobre los puntos de acceso para poder completar el registro catalográfico.

Para la elección del punto de acceso principal se debe seguir la regla de asignarlo a la persona que tiene la responsabilidad intelectual del contenido de la publicación, esto es, el autor. En publicaciones antiguas es frecuente que las obras tengan una responsabilidad compartida pues abundan los comentarios, críticas, traducciones, anotaciones, etc., de un texto ya existente. En estos casos, siguiendo las Reglas de Catalogación, se ha elegido como punto de acceso principal al autor 
del texto y como puntos de acceso secundarios a los demás. Cuando el texto de la obra original es una pequeña parte de la obra nueva, y ésta se presenta como una edición crítica de la anterior, se ha dado preferencia al elegir el punto de acceso principal al comentarista, editor literario, etcétera.

En los casos que había duda, se ha elegido el autor original, además de consultar los repertorios existentes, aunque no siempre se ha coincidido con ellos. Todas las personas y entidades que aparecen en la descripción y que no constituyen el punto de acceso principal, se incluirán como puntos de acceso secundarios, con lo cual la obra se puede recuperar por cualquiera de ellos. El punto de acceso principal sólo tiene relevancia a la hora de ordenar el catálogo, pues la recuperación de información se puede hacer por todos los puntos de acceso y por cualquier campo de la descripción.

Las obras que no tienen autor, o éste no viene destacado en la publicación y la información se obtiene de los preliminares, texto o colofón, se tratan como anónimas, para respetar la intención de la publicación. Se debe incluir en la descripción y en los puntos de acceso secundarios cualquier nombre de persona o entidad que aparezca en las partes de la publicación, mencionadas anteriormente, que puedan ser un autor que quiere ocultar su nombre, una persona a la que se atribuye la obra o cualquier otra posibilidad.

De lo expuesto, se deduce que en los libros antiguos la elección de puntos de acceso no es especialmente problemática. Sí lo es, en cambio, la normalización de los puntos de acceso, sobre todo en los catálogos automatizados para garantizar la recuperación y el intercambio de información.

La complejidad del trabajo de normalización en la redacción y aplicación de los puntos de acceso, lo que se denomina el "control de autoridades", y la falta de una normativa clara para su redacción y aplicación ha sido una constante en el trabajo de las bibliotecas.

El trabajo de normalización en un catálogo de fondo antiguo presenta una gran dificultad debido a las distintas formas que presentan los términos de la descripción como autores, editores, impresores, y lugares de publicación. Pero actualmente contamos con ficheros de autoridades creados por grandes bibliotecas como la Library of Congress o la 
Biblioteca Nacional de España que proporcionan las formas autorizadas o "autoridades" que se utilizan para redactar los puntos de acceso en los catálogos.

Para los casos en que no se pueda contar con un fichero de autoridades o los nombres que hay que normalizar no aparezcan en ellos por su marcado carácter local, se pueden establecer las normas que se describen a continuación.

- La mayoría de los autores de las publicaciones del siglo XVI y parte del XVII presentan su nombre en latín, y no siempre en nominativo. Esto supone que el nombre, tal y como aparece en la descripción, en muy pocos casos se puede utilizar para los puntos de acceso, ya sea principal o secundario. Se precisa llevar a cabo un trabajo de normalización general basado en tres principios fundamentales:

- Se utiliza preferentemente la forma del nombre en la lengua original del autor, es decir sin traducir al latín ni al castellano. La traducción de apellidos y nombres al idioma del centro catalogador ha dado lugar a la aparición de autores fantasmas.

- En los casos en que no se sabe el origen del autor, se utiliza la forma latina en caso nominativo.

- Sólo se traducen al castellano los nombres de los autores griegos y latinos clásicos, y los encabezamientos de la Biblia, clásicos anónimos, Iglesia Católica, y en general todos los casos que las Reglas de Catalogación prescriben.

- La forma del encabezamiento de autor personal se hace, como es usual, posponiendo el nombre de pila al apellido o apellidos del autor. Pero los nombres de los autores hasta el siglo XVI no siempre están compuestos por el nombre de pila seguido del apellido familiar. Hay una gran variedad de formas del nombre en función del origen local de la persona o de la profesión, y, en muchos casos, nombres de los que sólo se conoce una parte porque son autores raros y los repertorios han completado con el origen local y la profesión. Las distintas formas de composición del nombre se pueden agrupar en: 
- Topónimos. El nombre está compuesto por el nombre de pila seguido del lugar de origen del autor, unido o no por la partícula "de". En estos casos el punto de acceso se redacta con el nombre en forma directa, es decir no se hace la inversión de apellidos y nombre.

100 0\# \$aAntonio de Nebrija

100 0\# \$aAlejandro de Afrodisias

- Nombres de religión. La Contrarreforma hizo aparecer una cantidad de escritos de religiosos en defensa de la Iglesia Católica y sus dogmas, aunque este fenómeno es en la segunda mitad del XVI y la proliferación de estas publicaciones se da fundamentalmente en el siglo XVII. Los religiosos publicaban sus obras con el nombre de religión, que no incluye el apellido y el nombre verdadero. Los nombres de religión se transcriben igualmente en orden directo, y acompañados, cuando se sepa, de las siglas de la congregación religiosa a la que pertenecen, que suele venir en las publicaciones como elemento identificador de la persona. La inclusión de las siglas evita confusiones entre dos nombres iguales que corresponden a distintas personas.

100 0\# \$aAgustín de la Magdalena \$c(O.C.D.)

100 0\# \$aTeresa de Jesús \$cSanta

100 0\# \$aAlonso de Ávila \$c(O.F.M.)

- Seudónimos. Algunos autores publican sus obras bajo un seudónimo, ya sea para eludir la censura, o porque normalmente son conocidos por él. En otros casos los seudónimos no son intencionados, sino que es como se conoce al autor aunque no sea su nombre. En ambos casos, si se puede averiguar el nombre verdadero, el punto de acceso se hará por él, con una indicación en el mismo encabezamiento o en el área de notas, y una referencia de la forma no utilizada a la utilizada. De esta manera habrá uniformidad en todos los 
catálogos y repertorios y se evitará considerarlo como dos autores distintos.

100 1\# \$aDuns, Joannes \$c"Scoto"

100 1\# \$aPernius, Ioannes

500 \#\# \$aIoannes Pernius es pseudónimo de Josep Cresswell

- Homónimos. Se puede dar el caso de que haya dos o más personas con el mismo nombre. Si son nombres de religión, se distinguirán por las siglas de la orden, como ya hemos visto. El sistema más seguro de diferenciar a dos personas de igual nombre es añadir a continuación de éste las fechas de nacimiento y muerte, $o$, si no se conocen, la fecha o fechas en que desarrolla su actividad. Pero no siempre es posible conocer las fechas, por lo que se suele recurrir a expresiones como "padre" e "hijo", "el joven" o "el viejo", y en otros casos la profesión, si se conoce.

100 1\# \$aManuzio, Aldo \$cel viejo

100 1\# \$aManuzio, Aldo \$cel joven

- Profesión o título nobilario como parte del nombre. Algunos autores utilizan el nombre de la profesión (Licenciado, Doctor, etc.) o el título nobilario como parte del nombre. Si se sabe la forma original del nombre, se utilizará ésta para completarlo, y se hará una referencia de la forma que aparece en la publicación. Cuando el título nobilario sea la única forma empleada en la publicación, se respeta la intención de ésta y el punto de acceso se constituye con el título.

100 1\# \$aSaravia de la Calle \$cDoctor

100 1\# \$aTixier, Jean, \$cSeñor de Ravisy

100 1\# \$aSástago, Artal de Alagón, \$cConde de

- Nombres incompletos o raros. Hay nombres de autores antiguos que constan sólo de un elemento porque son de origen 
raro o desconocido. En primer lugar hay que cerciorarse de que son nombres de autores o colaboradores, y después buscarlos en un fichero de autoridades y si, no aparecen, contrastarlos en un repertorio para darles una forma normalizada.

100 0\# \$aDeixippi \$cel Platonista

100 0\# \$aFilón \$cjudío

100 0\# \$aHermógenes \$cel retórico

100 0\# \$aArethas \$carzobispo de Cesarea en Capadocia

- Variaciones lingüísticas. El nombre de un autor puede adoptar distintas formas debido a variedades lingüísticas, relacionadas con el uso de determinadas letras, fundamentalmente "c" y " $\mathrm{z}$ ", "h" y "f". Se debe establecer una forma antes de realizar el catálogo para que haya uniformidad. Ej.:

Azevedo y Acevedo

Hernando y Fernando

- Es conveniente añadir al nombre de la persona la mención de profesión, cargo, o cualquier otra palabra (santo, beato...) que complete su identificación, aunque estas menciones no vengan en la publicación. Ej.:

100 1\# \$aBarcia y Zambrana, José de \$cObispo de Cádiz 100 0\# \$aAgustín, Antonio \$cArzobispo de Tarragona 100 0\# \$aAlonso de Orozco \$cBeato \$c(O.S.A.) 100 0\# \$aCarlo Borromeo \$cSanto 100 1\# \$a Contareno, Gaspar \$cCardenal

La normalización afecta también a los nombres de lugar de impresión o publicación ya que éste es un elemento de recuperación importante en publicaciones antiguas. Muchos estudios bibliográficos, fundamentalmente la Tipobibliografía, así como la Historia del Libro, están basados en los centros de producción bibliográfica y sus relaciones entre 
ellos. En la descripción bibliográfica se expresa el lugar de publicación tal como viene en los libros, pero en los puntos de acceso se normaliza utilizando la forma actual del nombre de cada ciudad para facilitar su localización.

Cuadro 1. Cómputo de hojas que componen una secuencia de signaturas (A-Z) en distintos formatos.

\begin{tabular}{|c|c|c|c|c|c|}
\hline \multirow[t]{2}{*}{ Cuadernos } & \multirow[t]{2}{*}{ Signaturas } & \multicolumn{4}{|c|}{ Hojas } \\
\hline & & $4^{0}$ & $6^{\circ}$ & $8^{\circ}$ & $12^{\circ}$ \\
\hline 1 & $A$ & 4 & 6 & 8 & 12 \\
\hline 2 & $B$ & 8 & 12 & 16 & 24 \\
\hline 3 & C & 12 & 18 & 24 & 36 \\
\hline 4 & $D$ & 16 & 24 & 32 & 48 \\
\hline 5 & $E$ & 20 & 30 & 40 & 60 \\
\hline 6 & $\mathrm{~F}$ & 24 & 36 & 48 & 72 \\
\hline 7 & $\mathrm{G}$ & 28 & 42 & 56 & 84 \\
\hline 8 & $\mathrm{H}$ & 32 & 48 & 64 & 96 \\
\hline 9 & 1 & 36 & 54 & 72 & 108 \\
\hline 10 & K & 40 & 60 & 80 & 120 \\
\hline 11 & $\mathrm{~L}$ & 44 & 66 & 88 & 132 \\
\hline 12 & $M$ & 48 & 72 & 96 & 144 \\
\hline 13 & $\mathrm{~N}$ & 52 & 78 & 104 & 156 \\
\hline 14 & 0 & 56 & 84 & 112 & 168 \\
\hline 15 & $P$ & 60 & 90 & 120 & 180 \\
\hline 16 & $Q$ & 64 & 96 & 128 & 192 \\
\hline 17 & $\mathrm{R}$ & 68 & 102 & 136 & 204 \\
\hline 18 & $S$ & 72 & 108 & 144 & 216 \\
\hline 19 & $\mathrm{~T}$ & 76 & 114 & 152 & 228 \\
\hline 20 & $V$ & 80 & 120 & 160 & 240 \\
\hline 21 & $X$ & 84 & 126 & 168 & 252 \\
\hline 22 & $Y$ & 88 & 132 & 176 & 264 \\
\hline 23 & $Z$ & 92 & 138 & 184 & 276 \\
\hline
\end{tabular}

(Fuente: DUREAU, J.M., Op. cit., p. 100) 
Cuadro 2. Cómputo de varias secuencias de signaturas según distintos formatos.

\begin{tabular}{|c|l|c|c|c|c|}
\hline \multicolumn{2}{|c|}{} & $1^{\text {a }}$ sec. & $2^{\text {a }}$ sec. & $3^{\text {a }}$ sec. & $4^{\text {a }}$ sec. \\
\hline \multirow{2}{*}{$A-Z^{4}$} & Hojas & 92 & 184 & 276 & 368 \\
\cline { 2 - 6 } & Páginas & 184 & 368 & 552 & 736 \\
\hline \multirow{2}{*}{$A-Z^{6}$} & Hojas & 138 & 276 & 414 & 552 \\
\cline { 2 - 6 } & Páginas & 276 & 552 & 828 & 1.104 \\
\hline \multirow{2}{*}{$A-Z^{8}$} & Hojas & 184 & 368 & 552 & \\
\cline { 2 - 6 } & Páginas & 368 & 736 & 1.104 & \\
\hline \multirow{2}{*}{$A-Z^{12}$} & Hojas & 276 & 552 & & \\
\cline { 2 - 6 } & Páginas & 552 & 1.104 & & \\
\hline
\end{tabular}

(Fuente: Herrero Pascual, C. "Metodología para un catálogo de libros el siglo XVI”. Revista General de Información y Documentación, Vol.6, n.2 (1996), p.36.

\subsection{Ejemplos}

Registros Completos:

\section{Aguilar Gordillo, Pedro de}

Alivio de mercaderes y todo genero de gente... / por Pedro de Aguilar Gordillo... -- Mexico : en la emprenta de Geronymo Balli, 1610

[4], 60 h. ; $4^{\circ}$

Sign.: $\mathrm{A}^{4}, \mathrm{~B}-\mathrm{H}^{8}, \mathrm{I}^{4}$

Port. con esc. xil.

\section{Agustín de la Magdalena (O.C.D.)}

Arte de la lengua tagala, sacada de diversas artes / por Fr. Augustin de la Magdalena, Religioso Descalço... -- [Mexico] : por Francisco Rodriguez Lupercio, 1679

[5], 71 h. ; $8^{\circ}$

Lugar deducido del impresor y tomado de censura y licencias

Sign.: A-I ${ }^{8}, \mathrm{~K}^{4}$

Port. con esc. 
Alemán, Mateo

Ortografia Castellana ... / por Mateo Aleman ... -- En Mexico : en la imprenta de Ieronimo Balli : por Cornelio Adriano Cesar, 1609

[7], 83 h., [1] h. de grab. ; $4^{0}$

Sign.: [ ] $]^{4}, \mathrm{~A}-\mathrm{X}^{4}, \mathrm{Y}^{3}$

Port. con orla tip.

La h. de grab. es xil., entre las h. [3] y [4]

\section{Alonso de Ávila (O.F.M.)}

Sagrada paremya, adagio, o comun proverbio No ay vida como la honrra, cumplido y christianado en el antithessis de las amistades entre llantos ... y consuelos de Maria ... al pie de la Cruz ... : sermon que en la fiesta de sus Dolores, en el convento de ... Santa Clara, de la villa de Carion, Valle de Atlixco el dia 28 de Marzo de ... 1692 / predico el Padre Fr. Alonso de Avila ... -- En la Puebla : en la Imprenta de Diego Fernandez de Leon : imprimese acosta de particulares bienhechores, q oyeron al Predicador esse dia, 1692

[8], 8, [4] h. ; $4^{\mathrm{o}}$

Medina, Puebla de los Ángeles, 148

Sign.: [ ] ${ }^{4}$, [calderón] ${ }^{4}$, A-C ${ }^{4}$

Port. con orla tip.

\section{Barcia y Zambrana, José de, Obispo de Cádiz (1695)}

[ Epístola 2 ]

Epistola exhortatoria en orden a que los predicadores... no priven de la doctrina... en los sermones de fiestas : escrita a un predicador / por... don Ioseph de Barcia y Zambrana... -- Saliò impressa en su tomo Despertador eucharistico, aora reimpressa aparte / de orden del... señor don Antonio de Benavides y Bazan, Patriarca de las Indias, Arçobispo de Tyro... -- Por su original en la Puebla : en la Impr ${ }^{-}$eta de Diego Fernandez de Leon, impressor y mercader de libros..., 1693

[6], 106 p. ; $4^{\mathrm{o}}$

Sign.: [ ] $]^{1}, 2$ [calderón] $]^{2},[]^{1}, \mathrm{~B}-\mathrm{C}^{4}, \mathrm{D}-\mathrm{Z}^{2}, 2 \mathrm{~A}^{2}$ 
La signaturización incluye cuadernillo J

Port. con orla tip.

\section{Barrios, Juan de}

Verdadera medicina, cirugía y astrologia en tres libros dividida / por el doctor Ihoan de Barrios... -- Ympreso en Mexico : por Fernando Balli, 1607

[10], 186, [1], 62, [1], 37, [1] h. : il. ; Fol.

Precede a tít. : "Iesus, Maria"

Colofón

Iniciales grab. xil.

\section{Barroso, Luis (O.P.)}

Sermon que predico ... fray Luis Barroso Regente del

Conuento Real de S. Domingo de Mexico, a las honrras, que en el hizo el Santo Officio de la Inquisicion de nueua España, à ... Philippe Tercero ... en diez y siete de Setiembre.

-- En Mexico : en la emprenta del bachiller Iuª Blanco de Alcaçar, 1621

[2], 20 h. ; $4^{\circ}$

Pie de imp. tomado de colofón

Sign.: A-E $\mathrm{E}^{4}, \mathrm{~F}^{2}$

Port. con esc. xil. real y orla tip.

\section{Betancourt, Alonso de}

Arte de lengua mexicana / dispuesto... por el P. Fr. Augustin de Vetancurt.... -- En Mexico : por Francisco Rodriguez Lupercio, 1673

[6], 49 [i.e. 50], [8] f. ; $4^{\circ}(21 \mathrm{~cm}$

En port.: “...San Antonio de Padua...”. Hay una variante citada per Palau 361210 en que aparece "S." en lugar de "San" Incluye: "Instruccion breve para la administracion de los Santos Sacramentos..." con testo en azteca y castellano y "Catecismo mexicano" en azteca en los [8] f. finales Palau 361209; Vindel (Manual) 3156; Gallardo 3188; CPBE(s.XVII) 2, 1728 
Sign. []4, A-P4, p. 14 duplicada

Parte del texto a 2 cols., reclamos

Port. enmarcada, grab. xil. de San Antonio de Padua con el Niño Jesús en los brazos

\section{Betancourt, Agustín de (O.F.M.) (1620-1700)}

Teatro mexicano : descripcion breve de los sucessos exemplares, historicos, politicos, militares y religiosos del nuevo mundo occidental de las Indias ... / dispuesto por ... Fr. Agustin de Vetancurt ... -- En Mexico : por doña Maria de Benavides viuda de Iuan de Ribera, 1698 [12], 66, 168, [2], 56 p. ; Fol. Contiene: Tratado de la ciudad de Mexico y las grandezas que la ilustran despues que la fundaron españoles, p. 1-45 (de las últimas 56 p.) ; Tratado de la ciudad de la Puebla de los Angeles y grandezas que la ilustran, p. 45-56 (de las últimas 56 p.) ; Catalogo de autores impressos y de instrumentos manuscriptos de que se ha compuesto la Historia del Teatro Mexicano segun el orden de los años de su imprenta, p.[9-12] Comprende las tres primeras partes; la cuarta parte sale con el tit. "Chronica de la Provincia del Santo Evangelio de Mexico"

Sign.: [ ] $]^{2}, 2$-3ף, A-3N², A-O ${ }^{2}$

Port. con orla tip.

Texto a dos col.

\section{Cabranes, Diego de}

Abito y armadura spiritual / compuesta por... Diego de Cabranes... -- Puebla de Guadalupe-Merida : por Francisco Diaz Romano, 1544 (1545)

[9], CCLXXXij h. ; Fol.

CCBE S. XVI, C, 4

Lugar imp. y $2^{\text {a }}$ fecha tomados de colofón en h. CCLXXXij:

“... Fue impressa la presente obra... enla $\mathrm{n}^{-}$obrada puebla de Guadalupe : por Francisco Diaz Romano. Acabose enla 
antigua ciudad de Merida : a diezinueve dias del Mes de Agosto. Año. de Mil. D.XXXXV."

Sign.: [cristus] ${ }^{6}, 2[\text { cristus }]^{3}, \mathrm{~A}-\mathrm{Z}^{8}, \mathrm{a}-\mathrm{-}^{8}, \mathrm{n}^{10}$

Texto enmarcado a dos col. con apostillas marginales

Letra gótica

Port. grab. xil. arquitectónico con texto a dos tintas

\section{Cisneros, Diego}

Sitio, naturaleza y propriedades de la ciudad de Mexico : aguas y vientos a que esta suieta, y tiempos del año :

necessidad de su conocimiento para el exercicio de la medicina, su incertidumbre y difficultad sin el de la astrologia, assi para la curacion como para los prognosticos / por ... Diego Cisneros ... -- Impresso en Mexico ... : en casa del bachiller Ioan Blanco de Alcaçar, 1618

[13], 148 [i.e. 149], [10] h., [1] h. de grab. ; $4^{\circ}$

Lugar e impresor tomados de colofón

Sign.: [ ] ${ }^{1},{ }^{*}-3^{* 4}, \mathrm{~A}-\mathrm{Z}^{4}, 2 \mathrm{~A}-2 \mathrm{P}^{4}, 2 \mathrm{P}^{4}[\mathrm{sic}], 2 \mathrm{R}^{4}$

Errores de fol. y de sign. : h.112 y $2 \mathrm{P}^{4}$ repetidas

Entre h. 117 y 118 va una portadilla con orla tip. y grab. xil.

Port. grab. calc. arquitectónica: "Samuel Estradan Anuerpiensis Sculp. Mexici"

La h. de grab. calc., retrato del autor, entre h. [13] y 1

\section{Congregación de Nuestra Señora de México}

Dudas acerca de las ceremonias Sanctas de la Missa / resueltas por los clerigos de la Congregacion de nuestra Señora, fundada... en el collegio de la Compañia de Iesus de Mexico. -- En Mexico : por Henrico Martinez, 1602 [16], 222, [2] p. $; 8^{\circ}$

Medina, Mexico, II, n. 206, encabeza esta obra por Juan Hernández Aragón, por una Carta a D. Juan de Cervantes, 28 de Julio de 1602, de los clérigos Juan Hernández Aragón y el bachiller lucas Antonio de Villena, en prelim.

Marca tip., copia de las que cita Vindel $n^{\circ} 235,286,343$ y 455 , en verso de última $h$. 
Sign.: [ $]^{8}, \mathrm{~A}-\mathrm{O}^{8}$

Port. con orla tip.

\section{Echave, Baltasar de}

Discursos de la antiguedad de la lengua cantabra bascongada / co[m]puestas por Balthasar de Echaue ... -- En Mexico : en la emprenta de Henrrico Martinez, 1607

[10], 84 h., [2] h. de grab. ; $4^{\circ}$

Sign.: [ ]3, [cristus] $4,{ }^{*} 5$, A-T4

Port. con orla tip.

Hs. de grab. son xil. una con escudo del conde de Lemos y

la otra con retrato del autor, situadas detrás de la portada

\section{Farfan, Agustín (O.S.A.)}

Tratado breue de medicina y de todas las enfermedades / hecho por ... Fray Agustin Farfan ... de la Orden de San Agustin ... -- Agora nueuamente añadido. -- En Mexico : en la emprenta de Geronymo Balli, por Cornelio Adriano Cesar, 1610

[3], 261, [5] h. ; $4^{\circ}$

Sign.: [ ]3, A-Z4, 2A-3T4, [ ]6

\section{Garcés, Garcia (S.I.)}

Relacion de la persecucion que huuo en la Iglesia de Iapon y de los insignes martyres que gloriosamente dieron sus vidas en defensa de nuestra Santa Fè, el año 1622 / por el Padre Garcia Garces de la Compañia de Iesus... -- Impressa en Mexicco y agora en Valencia : por Iuan Chrysostomo [Garriz], 1625

140 p. : il. ; $8^{\circ}$

Sign. : A-G ${ }^{8}, \mathrm{H}^{4}$

Portada con escudo xil. de la Compañía de Jesús

\section{García de Palacio, Diego}

Dialogos Militares, de la formacion, è informacion de Personas, Instrumentos, y cosas necessarias para el buen vso 
de la Guerra ... / compuesto por el doctor Diego Garcia de Palacio ... -- En Mexico : en casa de Pedro Ocharte, 1583

[4], 192 h. : il. ; $4^{\circ}$

CCBE S. XVI, G, 359

Sign.: [ ]4, A-Z8, \&8

Port. con esc. xil. heráldico

[Informe de los inconvenientes que tienen las ordenes religiosas contra sus estatutos, de la declaracion que los obispos de Nueva España dan a la cedula de 1624 y de la interpretacion que el marques de Cerralvo ha dado a otra cedula de 1628], Señor, los Procuradores generales de las Ordenes de Santo Domingo, San Francisco, San Agustin y la Compañia de Iesus de la Nueva España... -- [Nueva España? :

s.n., 16--?]

21 h. : il. ; Fol.

Sign.: A- $\mathrm{L}^{2}$

Las il. son grabs. xil. de los escs. de las 4 ordenes religiosas mencionadas en el tít.

\section{Losa, Francisco}

La vida que hizo el siervo de Dios Gregorio Lopez en algunos lugares de esta Nueua España y principalmente en el pueblo de Santa Fee, dos leguas de la ciudad de mexico... / por el licenciado Francisco Lossa... -- En Mexico : en la Emprenta de Iuan Ruyz, 1613

[8], 139, [4] h. [2] h. en bl. ; $8^{\circ}$

Sign. : []$^{8}, \mathrm{~A}-\mathrm{S}^{8}$.

Grab. de aguila en v. de [] ${ }^{1}$

\section{Morga, Antonio de}

Sucesos de las islas Philipinas... / por... Antonio de Morga...

-- [En Mexico? : en casa de Geronymo Balli. Por Cornelio Adriano Cesar?, 1609?]

[6], $172 \mathrm{~h} . ; 4^{\circ}$

Datos de pie de imprenta tomados de la ed. de Madrid : 
Victoriano Suárez, 1910 y de Gallardo, III, 3464

Sign. : [ $]^{1}, 3 \rrbracket^{1}, 4 \rrbracket^{3}, 2 \pi^{1}, \mathrm{~A}-\mathrm{Z}^{4}, 2 \mathrm{~A}-2 \mathrm{~V}^{4}$

Port. grab. calcográfica "Samuel Estradamus Antuerpiensis

faciebat. Mexici ad Indos, Anno 1609”

\section{Ruiz de Cabrera, Cristóbal}

Algunos singulares, y extraordinarios sucessos del gouierno de don Diego Pimentel Marques de Gelues Virrey desta Nueua España, por su excesiuo rigor, ayudado desus [sic] consejeros. La prission y destierro de don Iuan de la Serna Arçobispo de Mexico ... La prission de la Real Audiencia, por mandarlo boluer del destierro ... El alboroto, y tumulto de los muchachos, y indios, y plebe, que hizieron la Virrey salir huyendo del Real Palacio ... / en relacion por el licenciado Christoual Ruyz de Cabrera .. -- En Mexico : [s.n.], 1624

[2], 16 [i.e. 14] h. ; Fol.

Se ha respetado la puntuación original

Sign.: [ [ $]^{2}, \mathrm{~A}-\mathrm{G}^{2}$

Error de fol., de h. 13 pasa a 16

Port. con esc. xil. real

Dos emisiones de una misma obra:

Balbuena, Bernardo de, Obispo de Puerto Rico

Grandeza mexicana / del bachiller Bernardo de Balbuena ...

-- En Mexico : en la emprenta de Diego Lopez Daualos, 1604 [6], 140 [i.e. 132] h. ; $8^{\circ}$

Compendio apologetico en alabança de la poesia, h. 120

Existe emisión con pie de imp.: Mexico : por Melchor

Ocharte, 1604, con variente en prelim.

Sign.: [ ] $]^{2}$ [cristus $]^{8}, \mathrm{~A}^{4}, \mathrm{~B}-\mathrm{F}^{8}, \mathrm{G}^{4}, \mathrm{I}-\mathrm{S}^{8}$

Errores de fol., a partir de h. 40

Retrato xil. del autor, en [ $]_{2}$ V. y esc. xil., en [cristus $]_{1}$ 


\section{Balbuena, Bernardo de, Obispo de Puerto Rico}

Grandeza mexicana / del bachiller Bernardo de Balbuena ...

-- En Mexico : por Melchior Ocharte, 1604 140 [i.e. 132] h. : il. ; $8^{\circ}$

Compendio apologetico en alabança de la poesia, h. 120-140

Existe emisión con pie de imp.: Mexico : en la emprenta de

Diego Lopez Daualos, 1604, con variante en port. y prelim. Sign.: A-F ${ }^{8}, G^{4}, I-S^{8}$

Errores de fol., a partir de h. 40

Port. con orla tip.

Retrato xil. del autor, en h. 8, a toda plana

\section{Distintas impresiones de una misma obra}

\section{Arenas, Pedro de}

Vocabulario manual de las lenguas castellana y mexicana en que se contienen las palabras, preguntas, y respuestas mas comunes, y ordinarias que se suelen offrecer en el trato, y communicacion entre españoles é indios / compuesto por Pedro de Arenas. -- Impresso ... en Mexico : en la emprenta de Henrico Martinez, [s.a.]

[16], 160 p. ; $8^{\circ}$

Fecha de prelim., en p. [4], 1611

Sign.: $\mathbb{1}^{8}, \mathrm{~A}-\mathrm{K}^{8}$

\section{Arenas, Pedro de}

Vocabulario manual de las lenguas castellana, y mexicana en que se contienen las palabras, preguntas, y respuestas mas comunes, y ordinarias, que se suelen ofrecer en el trato comunicacion entre españoles e indios / compuesto por Pedro de Arenas. -- Enmendado en esta ultima impression. -Impresso en Mexico : en la imprenta de la viuda de Bernardo Calderon, 1683

$[8], 118,[2]$ p. $; 8^{\circ}$

Mención de ed. precede a la de responsabilidad

Sign.: []$^{4}, \mathrm{~A}-\mathrm{P}^{4}$ 


\section{Arenas, Pedro de}

Vocabulario manual de las lenguas castellana, y mexicana en que se contienen las palabras, preguntas, y respuestas mas communes, y ordinarias, que se suelen offrecer en el trato, y communicacion entre españoles è indios / compuesto por Pedro de Arenas. -- Impresso en Mexico : en la imprenta de Francisco de Rivera Calderon ..., [s.a.]

[12], 140 p. ; $8^{\circ}$

Probablemente impreso en el s. XVIII

Sign.: A-I ${ }^{8}, \mathrm{~K}^{4}$

Port. con orla tip.

\section{Arenas, Pedro de}

Vocabulario manual de las lenguas castellana, y mexicana en que se contienen las palabras, preguntas, y respuestas mas comunes, y ordinarias, que se suelen ofrecer en el trato, y comunicacion entre españoles é indios / compuesto por Pedro de Arenas. -- Reimpreso en la Puebla de los Angeles : en la oficina de Don Pedro de la Rosa ..., 1793

[12], 145 p. ; $8^{\circ}$

Sign.: []$^{8}, 1-8^{8}, 9^{7}$

Port. con orla tip.

\subsection{Bibliografía}

Afnor. Catalogage des monographies anciennes: rédaction de la description bibliographique. París: AFNOR, 1986.

Delgado Casado, J.; Martín Abad, J. Repertorios bibliográficos de impresos del siglo XVI: (españoles, portugueses e iberoamericanos). Madrid: Arco-Libros, 1993.

Dexeus, M.; Agenjo, J. La catalogación cooperativa del libro antiguo en España. Boletín de ANABAD, 40, n. 4 (1990), p. $75-$ 84. 
Díez Carrera, C. (coord.). Los materiales especiales en las bibliotecas. Gijón: Trea, 1998.

Dureau, J.M.; Merland, M.A. Catalogage des livres anciens. Villeurbanne: E.N.S.B., 1982.

Leoncini, C. Y Servello, R.M. (eds.) Libri antichi e catalogazione: metodologie e esperienze. Roma: Istituto Centrale per Il Catalogo Unico delle Biblioteche Italiane, 1984.

Formato MARC21. Www.absysnet.com . [Fecha de consulta: enero de 2003].

Herrero Pascual, C. Catalogación para formato IBERMARC. Monografías y publicaciones seriadas. $2^{\mathrm{a}}$ ed. Murcia: Universidad de Murcia, 2002.

Herrero Pascual, C. Metodología para un catálogo de libros del siglo XVI. Revista General de Información y Documentación. Vol. 6, n. 2 (1996), p. 11-50.

IFLA. ISBD(A): International Standard Bibliographic Description for Older Monographic Publications (Antiquarian). London: IFLA International Office for UBC, 1980.

IFLA. ISBD(A) Descripció biblogràfica normalitzada internacional per a publicacions monogràphiques antigues (Antiquària). Barcelona: Institut Català de Bibliografia, 1984.

IFLA. ISBD(A) : International Standard Bibliographic Description for Older Monographic Publications (Antiquarian). München: K.G. Saur, 1991.

Library Of Congress. Descriptive cataloging of rare book. 2nd. edition. Washington: Cataloging Distribution Service, Library of Congress, 1991. 
Secretos del estante: elementos para la descripción bibliográfica...

IFLA. ISBD (A): Descripción bibliográfica internacional normalizada para publicaciones monográficas antiguas. $2^{\mathrm{a}} \mathrm{ed}$. rev. Madrid: ANABAD, 1993.

Palau y Dulcet, T. Manual del librero hispanoamericano. $2^{\mathrm{a}}$ ed. Barcelona, 1948-1977.

Rodriguez Bravo, B. Problemática de la ISBD(A). Boletín de la Asociación Andaluza de Bibliotecarios, n. 32 (Sept. 1992), p. 11-18.

Vindel, F. Escudos y marcas de impresores y libreros en España durante los siglos XV a XIX (1485-1850). Barcelona: Orbis, 1942.

Zapella, G. Il formato nella descrizione del libro antico: valore bibliologico e suelte catalografiche. Biblioteche oggi, an. 11, n. 8 (Sept. 1993), p. 17-60. 


\section{Bibliografía}

4 siglos de imprenta en México: una muestra tipográfica mexicana. México: UNAM. Instituto de Investigaciones Bibliográficas, 1986.

ABIMEX. Antigua Bibliografía Mexicana. México: Fideicomiso para la Cultura México-Estados Unidos, 1996 [CD-ROM].

Alcalá, Ángel. Literatura y ciencia ante la Inquisición Española. Madrid: Laberinto, 2001.

Alegre Ávila Juan Manuel. Evolución y régimen jurídico del patrimonio bistórico. Madrid: Ministerio de Cultura, 1994. 2 tomos.

Alfaro Torres, Paloma. La imprenta en Cuenca, 1528-1679. Madrid: Arco Libros, 2002.

Álvarez Márquez, Carmen. "El escribano de letra de libros «versus» el cajista", en La memoria de los libros: estudios sobre la historia del escrito y de la lectura en Europa y América, bajo la dirección de Pedro M. Cátedra \& María Luisa López-Vidriero. Salamanca: Instituto de Historia del Libro y de la Lectura, 2004. T.1, pp. 87-176.

Antiquarian books, a companion for booksellers, librarians and collectors, compiled and edited by Philippa Bernard with Leo Bernard and Angus O’Neill. Philadelphia: University of Pensilvania Press, 1994.

Antón Melero, Pablo. Introducción a la restauración artesanal de libros, grabados y manuscritos. Madrid: Ollero \& Ramos, 1995. 
Arco y Garcia, Fernando del. Introducción a la Heráldica. Madrid: Ediciones. Iberoamericanas, 1996. (Perseverante Borgoña; 14)

Asencio, Eugenio. "Censura inquisitorial de libros en los siglos XVI y XVII. Fluctuaciones, decadencia", en El Libro Antiguo Español: Actas del primer Coloquio Internacional (Madrid, 18 al 20 de diciembre de 1986). Salamanca: Ediciones de la Universidad: Biblioteca Nacional de Madrid: Sociedad Española de Historia del Libro, 1993, pp. 21-36.

Association of College and Research Libraries. Descriptive Cataloging of Rare Materials (Books). Washington: Library of Congress, Cataloging Distribution Service, 2007.

- Examples to Accompany Descriptive Cataloging of Rare Books. Chicago: American Library Association, 1993.

Examples to Accompany Descriptive Cataloging of Rare Books. 2nd edition. Chicago: American Library Association, 1999.

Báez Macías, Eduardo, Jorge Guerra Ruiz y Judith Puente León. Libros $y$ grabados en el Fondo de Origen de la Biblioteca Nacional. México: UNAM. IIE, 1988.

Baldacchini, Lorenzo. Il libro antico. Roma: La Nuova Italia Scientifica, 1982.

\section{Editore, 2001}

Balsamo, Luigi. La bibliografía: historia de una tradición. Gijón: Trea, 1998.

Barbieri, Edoardo. "Bibliografia descrittiva e storia degli esemplari in Italia", en El libro antiguo español: de libros, librerías, imprentas y lectores, dirigido por Pedro M. Cátedra y Maria Luisa López Vidriero: Salamanca: Ediciones Universidad: Seminario de Estudios medievales y Renacentistas, 2002, pp. 37-52. 
Guida al libro antico: conoscere e descrivere il libro tipográfico. Firenze: Le Monnier Universitá, 2006.

Bas Martín, Nicolás."Muestrarios de letras de la imprenta valenciana del siglo XVIII", en La memoria de los libros: estudios sobre la bistoria del escrito y de la lectura en Europa y América, bajo la dirección de Pedro M. Cátedra \& María Luisa López-Vidriero. Salamanca: Instituto de Historia del Libro y de la Lectura, 2004. T.1, pp. 327-340.

Beal, Peter. A Dictionary of English Manuscript Terminology, 14502000. Great Britain: Oxford University Press, 2008.

Beaudiquez, Marcelle. Guide de bibliographie générale: méthodologie et pratique. Paris: Saur, 1989.

Becedas, Margarita. Tesoros de la Antigua librería de la Universidad de Salamanca. Salamanca: Ediciones Universidad de Salamanca, 2002.

Bello Fuentes, Yolanda Remedios, José Armando Vázquez Martínez y Miguel Ángel Venegas Elizalde. Libros raros en algunas bibliotecas del Distrito Federal: atributos para su identificación. México: los autores, 1998. (Tesis de Licenciatura en Bibliotecología. Facultad de Filosofía y Letras. UNAM).

Bello Urguellès, Carmen y Àngels Borrell Crehuet. El patrimonio bibliográfico y documental: claves para su conservación preventiva. Gijón: Trea, 2002.

Berger, Philippe. "La crisis de 1506-1509. Crónica de una quiebra anunciada", en La memoria de los libros: estudios sobre la historia del escrito y de la lectura en Europa y América, bajo la dirección de Pedro M. Cátedra \& María Luisa López-Vidriero. Salamanca: Instituto de Historia del Libro y de la Lectura, 2004. T.1, pp. 393-403. 
Secretos del estante: elementos para la descripción bibliográfica...

Beristáin De Souza, José Mariano. Biblioteca Hispano Americana Setentrional. $2^{a}$ ed. Amecameca: Tipografía del Colegio Católico, 1883. 3 tomos.

Bernart Vistarini, Antonio y John T. Cull. Enciclopedia de emblemas españoles ilustrados. Madrid: Akal, 1999.

Bibliographic Description of Rare Books. Washington: Library of Congress, 1981.

La bibliographie materièlle, Gilles Barber [...et. al.]; table ronde organiseé por le CNRS pars Jacques Petit. Paris: Éditions du Centre National de la Recherche Sientifique, 1983.

Binding terms: A Thesaurus for use in Rare Book and Special Collections Cataloging, prepared by the Committee of the Rare Books and Manuscripts Section. Chicago: Association of College and Research Libraries, 1988.

Bolaños, Joaquín Fr. La portentosa vida de la muerte, Emperatriz de los Sepulcros, Vengadora de los Agravios del Altísimo y muy Señora de la Humana Naturaleza (México, Joseph de Jáuregui, 1792), edición crítica, introducción y notas de Blanca López de Mariscal. México: COLMEX, 1992.

Bouza, Antonio L. El ex libris. Tratado general: su bistoria en la corona española. Madrid: Patrimonio Nacional, 1990.

Bouza Álvarez, Fernando J. Del escribano a la biblioteca: la civilización escrita europea en la Alta Edad Moderna (siglos XV-XVII). Madrid: Síntesis, 1992.

Corre manuscrito: una bistoria cultural del Siglo de Oro. Madrid: Marcial Pons, 2002.

Bowers, Fredson. "Bibliographical evidence from the Printer's Measure", en Studies in Bibliography. Vol. 2 (1949-1950), pp. 153-167. Texto disponible en http://etext.virginia.edu/bsuva/sb/ [Consulta: mayo de 2006]. 
- Principes of bibliographical description. Ann Arbor, Michigan: Princeton University Press, 1994 (Traducción al español: Principios de descripción bibliográfica. Madrid: Arco Libros, 2001).

Briquet, Charles Moïse. Les filigranes: dictionnaire historique des marques du papier dès leur apparition vers 1282 jusqúen 1600. Mansfield: Martino Publishing, 2000. 4 vol. (Facsimil de la edición original de 1923 publicada en Leipzig.)

Bravo Arriaga, María Dolores. "Dos dedicatorias de Nuñez de Miranda a Sor Filotea de la Cruz, indicios inéditos de una relación peligrosa", en La literatura novohispana: revisión crítica y propuestas metodológicas, editores José Pascual Buxo y Arnulfo Herrera. México: UNAM, 1994, pp. 231-239.

Brito, Sofía. "El libro antiguo, un mundo olvidado en nuestras bibliotecas: elementos indispensables para su catalogación descriptiva", en Organización bibliográfica y documental, compiladores Hugo Alberto Figueroa Alcántara y Cesar Augusto Ramírez Velázquez. México: UNAM. Facultad de Filosofía y Letras: Centro Universitario de Investigaciones Bibliotecológicas, 2004, pp. 253-262.

Brown, Michelle P. Understanding illuminated manuscripts: a guide to technical terms. London: The J. Paul Getty Museum: The British Library, 1994.

Brugalla, Emilio. Tres ensayos sobre el arte de la encuadernación. Madrid: Ollero \& Ramos, 2000.

Buxó, José Pascual. Impresos novohispanos en las bibliotecas públicas de los Estados Unidos de América, 1543-1800. México: UNAM. Instituto de Investigaciones Bibliográficas, 1994.

Cabello Martín, Mercedes. "Fuentes bibliográficas para el estudio del libro antiguo", en Documentos de Trabajo UCM. Biblioteca Histórica. Mayo 2004. 28 p. Texto disponible en http://eprints.ucm. es/5692/1/2004-1.pdf [Consulta: enero de 2011] 
Cabrera Nuñez De Guzmán, Melchor de. Discurso legal, bistórico y político en prueba del origen, progressos, utilidad, nobleza y excelencias del arte de la imprenta... Madrid: En la Oficina de Lucas Antonio Bedmar, 1675 (Edición facsimilar, Madrid: Singular, 1993).

Cadenas y López, Ampelio Alonso y Vicente de Cadenas y Vicent. Heraldario Español Europeo y Americano. Madrid: CSIC. Instituto Salazar y Castro: Hidalguía, 1991-2000. 6 tomos.

Cadenas y Vicent, Vicente de. Vademecum beráldico: aplicación de la ciencia del blasón, con especial referencia a la heráldica eclesiástica. Madrid. CSIC. Instituto Salazar y Castro: Hidalguía, 1984.

Calvo, Hortensia "The Politics of Print: The Historiography of the Book in Early Spanish America", en Book History. Vol. 6 (2003), pp. 277-305.

Caramuel, Juan. Syntagma de Arte Typographica, edición, traducción y glosa de Pablo Andrés Escapa. Salamanca: Instituto de Historia del Libro y de la Lectura, 2004.

Carmona Muela, Juan. Iconografía clásica: guía básica para estudiantes. Madrid: Istmo, 2000.

conografía cristiana: guía básica para estudiantes. Madrid: Istmo, 2001.

Carpallo Bautista, Antonio. Análisis documental de la Encuadernación española: repertorio bibliográfico, tesauro, ficha descriptiva. Madrid: Asociación para el Fomento de la Encuadernación de Arte, 2002.

- "La encuadernación y su descripción", en Boletín de la ANABAD. Vol. 49, núm. 1 (1999), pp. 227-236.

—. "Fuentes de información sobre encuadernación", en Pliegos de Bibliofilia. Núm. 17 (Primer trimestre 2002), pp. 55-68.

Carreño, Alberto María. Estudios bibliográficos: colección de obras diversas. México: Ediciones Victoria, 1962. Vol. XIII. 
Carreño Velázquez, Elvia. "Diego López Dávalos y la tipografía mexicana del siglo XVI". Texto disponible en http://www.adabi-ac.org/ investigacion_libro_ant/articulos/paginas/05art_ecv04.htm [Consulta: marzo de 2009]

- Fondo Conventual de la Biblioteca Nacional de Antropología e Historia: Catálogo de la Biblioteca del Convento Grande de San Francisco de la Ciudad de México, V. México: INAH, 2000.

Carrizo Sainero, Gloria. "La bibliografía", en Manual de fuentes de información, coordinadores Gloria Carrizo Sainero, Pilar IruetaGoyena Sánchez y Eugenio López de Quintana Sáenz. Zaragoza: Confederación Española de Gremios y Asociaciones de Libreros, 2000, pp. 261-286.

Carter, Harry. Orígenes de la tipografía: punzones, matrices y tipos de imprenta (siglos $X V$ y XVI) / edición y prólogo de Julián Martín Abad. Madrid: Ollero \& Ramos, 1999.

Carter, John. ABC for Book Collectors, Seventh Edition with Corrections, Additions, and an Introduction by Nicholas Barker. New Castle, Delaware: Oak Knoll Press, 1998.

Castañeda García, Carmen. "La imprenta en Guadalajara y su producción: 1793-1821", en Diccionario de Historia de la Educación en México, coord. Luz Elena Galván Lafarga. México: CIESAS: CONACYT, 2002. Texto disponible en http://biblioweb.dgsca.unam.mx/ diccionario/htm/articulos/sec_2.htm [Consulta: marzo de 2009]

Catálogo Biblioteca Conventual Museo Virreinal de Zinacantepec. México: Apoyo al Desarrollo de Archivos y Bibliotecas de México, A.C.: Fundación Alberto Harp Helú, 2005 [CD-ROM].

Catálogo Colectivo de Fondo Antiguo, siglos XV-XIX de la Asociación de Bibliotecas Nacionales de Iberoamérica. Madrid: Biblioteca Nacional de España: ABINIA, 1995 [CD-ROM]. 
Secretos del estante: elementos para la descripción bibliográfica...

Catálogo colonial bibliográfico de la Universidad Autónoma de Aguascalientes, integrado por Elvia Carreño Velázquez. Aguascalientes: Universidad Autónoma de Aguascalientes, 1999.

Catálogo de documentos antiguos: selección de impresos del siglo XVI al XIX. México: Cámara de Diputados. Comité de Biblioteca e Informática, 1994.

Catálogo de Ex libris de bibliotecas españolas en la Biblioteca Nacional, redactado por Consuelo Angulo Férnandez y María Luisa Molina Guerra. Madrid: Ministerio de Cultura. Dirección General del Libro y Bibliotecas, 1989.

Catálogo de la colección de Ex libris de Guillermo Tovar y de Tere$s a$. México: Universidad Iberoamericana, 2002.

Catálogo de la colección Manuel Arango Arias. México: Universidad Iberoamericana, 2000.

Catálogo de libros antiguos, Archivo Histórico del Estado de Tlaxcala, Tlaxcala, Coordinadora Elvia Carreño Velázquez. México: Apoyo al Desarrollo de Archivos y Bibliotecas de México, A.C., 2004.

Catálogo del fondo reservado de la Biblioteca de México: una selección. México: CONACUlTA. Dirección General de la Biblioteca de México, 1996.

Cave, Roderick. Rare books librarianship, Second revised edition. London: Clive Bingley, 1982.

Celestino Angulo, Sonsoles. "Una reflexión sobre bibliografía profesional", en De libros y bibliotecas: bomenaje a Rocío Caracuel. Sevilla: Universidad, 1994, pp. 95-106.

Charon, Annie y Magali Vène. Identification et description des livres anciens européens (XVe-XVIIIe siècle). Recurso electrónico de la École de Chartes. Texto disponible en http://theleme.enc.sorbonne.fr/sommaire234.html [Consulta: diciembre de 2007] 
Chartier, Roger. El mundo como representación. Estudios sobre bistoria cultural. $2^{\text {a }}$ ed. Barcelona: Gedisa, 1995.

Entre poder y placer: cultura escrita y literatura en la Edad Moderna. Madrid: Cátedra, 2000.

- y Daniel Roche. "El libro. Un cambio de perspectiva", en $\mathrm{Ha}$ cer la historia, dirección de Jacques Le Goff y Pierre Nora. Barcelona: Laia, 1980, pp. 119-140.

Checa Cremades, José Luis. La encuadernación renacentista en la Biblioteca del Monasterio de El Escorial: introducción al estudio de la decoración exterior del libro en la España de Felipe II. Madrid: Ollero \& Ramos, 1998.

2003.

_. El libro antiguo. Madrid: Acento Editorial, 1999.

Chocano Mena, Magdalena. La fortaleza docta: élite letrada y dominación social en México colonial (siglos XVI-XVII). Barcelona: Edicions Bellaterra, 2000.

"Imprenta e impresores de Nueva España 1539-1700: límites económicos y condiciones políticas en la tipografía colonial americana”, en Historia Social, núm. 23 (1995), pp. 3-19.

Cid Carmona, Víctor Julián. Antonio Ricardo: impresor de dos ciudades, México y la Ciudad de los Reyes. México: el autor, 2006 (Tesis de maestría. Maestro en Bibliotecología y Estudios de la Información. UNAM. UNAM. Facultad de Filosofía y Letras. División de Estudios de Posgrado).

[et. al.] "Compendio de impresos mexicanos que se conservan en la Biblioteca Daniel Cosío Villegas, siglo XVIII", en Boletín Editorial del Colegio de México. Núm. 126 (marzo-abril 2007), pp. 9-21. 
Secretos del estante: elementos para la descripción bibliográfica...

Repertorio de impresos mexicanos en la Biblioteca Nacional de España, siglos XVI-XVII. México: COLMEX, 2004.

Cien impresos coloniales poblanos. México: Instituto Mora, 1991.

Cisarova, Liduska. "Joaquín García Icazbalceta, iniciador de la bibliografía moderna en nuestro país", en Investigación Bibliotecológica. Vol. 18, núm. 36 (junio de 2004), pp. 28-41. Texto disponible en http://cuib.unam.mx/revistaCuib.html [Consulta: enero de 2011]

Clair, Colin. Historia de la imprenta en Europa. Madrid: Ollero \& Ramos, 1998.

Clavería, Carlos. Reconocimiento y descripción de encuadernaciones antiguas. Madrid: Arco Libros, 2006.

Cleary, John M. y Luis Crespo. El cuidado de libros y documentos: manual práctico de conservación y restauración. $2^{\mathrm{a}} \mathrm{ed}$. Madrid: Clan Editorial, 2001.

Clemente García, Enriqueta y Leonardo Blanco Lalinde. Los sellos municipales de tinta de la provincia de Teruel en el siglo XIX. Teruel: Instituto de Estudios Turolenses y Zaragoza Institución Fernando el Católico, 2002.

Clemente San Roman, Yolanda. "Las tipobibliografías como repertorios útiles para la investigación". Cuadernos de Documentación Multimedia. Núm. 10 (2000), pp. 39-48. Texto disponible en http://www.ucm.es/info/multidoc/multidoc/revista/num10/paginas/pdfs/yclemente.pdf [Consulta: enero de 2011]

Clair, Colin C. Historia de la imprenta en Europa. Madrid: Ollero \& Ramos, 1998.

Connaissances nécessaires à un bibliophile. $2 \mathrm{e}$ éd. rev., corr. et auge. Paris: Rouveyre, 1878. (FRBNF31260596). Texto disponible en http:// gallica.bnf.fr [consulta: febrero de 2006] 
Córdoba Barradas, Luis. "La imprenta de Felipe de Zúñiga y Ontiveros en la ciudad de México", en Boletín del Museo Nacional del Virreinato. Nueva época, núm. 16 (enero-febrero 1995), pp. 1-5, Texto disponible en http://mx.geocities.com/genealogiademexi$\mathrm{co} /$ [Consulta marzo de 2009]

Darnton, Robert. “Qué es la historia del libro?”. Historias. Núm. 44 (1999), pp. 3-24.

Deforneaux, Marcelin. Inquisición y censura de libros en la España del siglo XVIII, versión española de J. Ignacio Tellechea Idigoras. Madrid: Taurus, 1973.

Del autor al lector: I. Historia del libro en México, II. Historia del libro, coordinadora Carmen Castañeda con la colaboración de Myrna Cortés. México: CIESAS: CONACYT: Miguel Ángel Porrúa, 2002.

Delgado Casado, Juan. Introducción a la bibliografía: los repertorios bibliográficos y su elaboración. Madrid: Arco Libros, 2005.

1996.

Los ex libris españoles. Valencia: Vincent García Editores, 1996.

- y Julián Martín Abad. Repertorios bibliográficos e impresos del siglo XVI (españoles, portugueses e iberoamericanos: con su fórmula abreviada de referencia. Madrid: Arco Libros, 1993.

El depósito legal en México: órdenes y decretos expedidos de 1812 a 1991. México: Congreso de la Unión. Cámara de Diputados, 2001.

Descriptive Cataloging of rare books. 2nd ed. Washington: Library of Congress, 1991.

De sellos y blasones: sigiloheráldica para archiveros, María Carmona de los Santos... [et. al.]. Carmona: S \& C Ediciones, 1996.

Des livres rares depuis de l'invention de l'imprimerie, sous la direction d'Antoine Coron. Paris: Bibliothèque Nationale de France, 1998. 
Dexeus, Mercedes. "El tratamiento bibliográfico de los impresos producidos por la imprenta manual", en Homenaxe a Daria Vilariño. Snatigo de Compostela: Universidade, 1993, pp. 107-115.

Diego Erlés, Jesús Javier de y Esperanza Velasco de la Peña. "Recursos en Internet sobre el libro antiguo en Europa, en Scire: Representación y organización del conocimiento. Vol. 5, núm. 1, (1999), pp. 91-104.

Díez Méngues, Isabel Cristina. "Las bio-bibliografías: estado actual y metodología", en Primer Congreso Universitario de Ciencias de la Documentación. Texto disponible en http://www.ucm.es/info/multidoc/multidoc/revista/num10/paginas/pdfs/icdmenguez. pdf [Consulta: octubre 2006]

Domínguez Guzmán, Aurora. La imprenta en Sevilla en el siglo XVII: catálogo y análisis de su producción, 1601-1650. Sevilla: Universidad, 1992.

Dowding, Geoffrey. An introduction to the History of Printing Types: An Ilustrated Summary of the Main Stages in the Development of Type Design from 1440 up to the Present Day; an Aid to Type Face Identification. United Kingdom: The British Library \& Oak Knoll Press, 1998.

Duclas, Robert. Catálogo descriptivo de los libros impresos en la ciudad de Salamanca en el siglo XVI existentes en la Biblioteca Pública de Guadalajara. México: UnAM, 1961.

Dunkin, Paul Shaner. How to Catalog a Rare Book. 2nd edition revised. Chicago: American Library Association, 1979.

Eguiara y Eguren, Juan José de. Bibliotheca mexicana: Monumenta eguiarense, pról y vers. española Benjamín Fernández Valenzuela; estudio preliminar, notas, apéndices, índices y coord. gral. Ernesto de la Torre Villar; colab. Ramiro Navarro de Anda. México: UNAM. Coordinación de Humanidades, 1989. 
- Prólogos a la Biblioteca Mexicana, versión española anotada, con un estudio biográfico y la bibliografía del autor por Agustín Millares Carlo. México: FCE, 1944.

Eguízabal, José Eugenio. Apuntes para una bistoria de la legislación española sobre imprenta: desde el año 1480 al presente. Pamplona: Analecta Ediciones, 2003. (Facsímil de la edición de 1879).

Enciclopedia de la encuadernación. Madrid: Ollero \& Ramos, 1998.

Enciso Contreras, José. Antiguos libros jurídicos en dos bibliotecas de Zacatecas. Zacatecas: Tribunal Superior de Justicia del Estado de Zacatecas, 2003.

Enlightenment portaits, edited by Michel Vovelle. Chicago: The University of Chicago Press, 1997.

Escamilla, Gloria. Manual de metodología y técnica bibliográficas. México: UNAM, 1988.

España. Ley 16/1985 del Patrimonio Histórico Español. Texto disponible en http://www.mcu.es/patrimonio/index.html [Consulta: enero de 2011]

La estética del libro español: manuscritos e impresos españoles hasta finales del siglo XVI en la Biblioteca Lázaro Galdiano. Madrid: Fundación Lázaro Galdiano, 1997.

Esteve Botey, Francisco. Ex libris y exlibristas. Madrid: Aguilar, 1949.

- El grabado en la ilustración del libro: las gráficas artísticas y las fotomecánicas. Madrid: Ediciones Doce Calles, 1996. 2 tomos.

Ex libris: catálogo de la colección de Guillermo Tovar de Teresa, presentación de Perla Chinchilla Pawling y Rubén Lozano Herrera. México: Universidad Iberoamericana, 2002. 
Ex libris universitatis: el patrimonio de las bibliotecas universitarias españolas. Santiago de Compostela: CRUE: Ministerio de Educación Cultura y Deporte: Ministerio de Ciencia y Tecnología: REBIUN: Banco Santander Central Hispano, 2000.

Fahy, Connor. "Introduzione alla bibliografia testuale", en La Bibliofilia. Vol. 82, núm. 2 (1980), pp. 151-180.

- Saggi di bibliografia testuale. Padova: Editrice Antenore, 1988.

Febvre, Lucien y Henri-Jean Martin. La aparición del libro. $3^{\mathrm{a}}$ ed. México: CONACUlTa: FCE, 2005.

Fernández, Stella Maris y Graciela Maria Giunti. Planes de estudio de las escuelas de bibliotecología, archivonomía y museología de Iberoamérica. Buenos Aires: Sociedad de Investigaciones Bibliotecológicas, 1999.

Fernández De Córdoba, Joaquín. Tesoros bibliográficos de México en los Estados Unidos. México: Editorial Cultura, 1959.

Fernández De Zamora, Rosa María. "Hacia el catálogo colectivo nacional de fondos antiguos: patrimonio bibliográfico mexicano", en Actas de XXXIV Jornadas Mexicanas de Biblioteconomía (2003), pp. 151-156. Texto disponible en http://eprints.rclis.org/archive/00003458/01/ROSAMARIAFERNANDEZ.pdf [Consulta: agosto de 2005]

Los impresos mexicanos del siglo XVI: su presencia en el patrimonio cultural del nuevo siglo. México: La autora, 2006. (Tesis de doctorado. Doctor en Bibliotecología y Estudios de la Información. UNAM. Facultad de Filosofía y Letras. División de Estudios de Posgrado)

. "Sobre la bibliografía en México: reflexiones y comentarios, en Jornadas Mexicanas de Biblioteconomía: Memorias (12: 1981: San Luis Potosí). 
Fernández Valladares, Mercedes. "Los caminos de la búsqueda bibliográfica: rastros, indicios y hallazgos de raros impresos burgaleses del siglo XVI", en Pliegos de Bibliofilia. Núm. 6 (1999), pp. 5-18.

Fernández Vega, María del Mar. "Jerónima de Gales. Una impresora valenciana del siglo XVI", en La memoria de los libros: estudios sobre la historia del escrito y de la lectura en Europa y América, bajo la dirección de Pedro M. Cátedra \& María Luisa López-Vidriero. Salamanca: Instituto de Historia del Libro y de la Lectura, 2004. T.1, pp. 405-434.

Fondos del Tesoro. Colección de lenguas indígenas Biblioteca Pública del Estado de Jalisco "Juan José Arriola", coord. Marina Mantilla Trolle y Nora Jiménez Hernández. Guadalajara: Universidad de Guadalajara: El Colegio de Michoacán, 2007.

Fondos bibliográficos conventuales. México: INAH. Biblioteca Nacional de Antropología e Historia: Centro Nacional Editor de Discos Compactos, 1994 [CD-ROM].

Fuentes, Juan José. Las bibliotecas nacionales: un estado de la cuestión. Gijón: Trea, 2003.

Fuentes López, Silvia. "Estética y poder en el libro moderno", en Anexos de Signo. Núm. 4 (2001), pp. 93-113.

Gacetas de México, estudio introd. por Francisco González de Cossío. México: Conductores Mexicanos, Centro de Estudios de Historia de México, 1986.

García, Demetrio S. "La imprenta en América", en IV Centenario de la imprenta en México: conferencias sustentadas en su conmemoración. México: Asociación de Libreros de México, 1939, pp. 37-175. 
García Aguilar, Idalia. "Ese eterno desconocido del patrimonio cultural: el libro antiguo en México", en Primer coloquio internacional del patrimonio cultural tangible e intangible. Universidad Autónoma del Estado de Hidalgo, 2004. Texto disponible en http:// eprints.rclis.org/archive/00005858/01/Hidalgo2004.pdf [Consulta: marzo de 2006].

"El futuro incierto de una fuente histórica relevante: la situación de los fondos antiguos en México", en Revista General de Información y Documentación. Vol. 14, núm. 2 (2004), pp. 167188.

. "El legado bibliográfico en México: un aspecto inconcluso de la investigación bibliotecológica", en Memoria del XXI Coloquio de Investigación Bibliotecológica y de la Información: la Investigación bibliotecológica en la era de la información. México: UNAM. Centro Universitario de Investigaciones Bibliotecológicas, 2004, pp. 226-247.

Legislación sobre bienes culturales muebles: protección del libro antiguo. México: CUIB: BUAP, 2002.

- "Libros marcados con fuego", en Emblemata: Revista Aragonesa de Emblemática. Vol. 13 (2007), pp. 271-299. Texto disponible en http://ifc.dpz.es/recursos/publicaciones/27/25/7.Garcia. pdf [Consulta: abril de 2009]

. "Para empezar, hay que recordar: la formación profesional y la investigación del libro antiguo en México", en Revista Interamericana de Bibliotecología. Vol. 28, núm. 2 (julio-diciembre de 2005), pp. 157-175.

García Aguilar, Idalia y Miguel Ángel Rendón. "El fondo antiguo: su estructura conceptual", en Binaria. Revista de Comunicación, Cultura y Tecnología. Vol. 1 (diciembre 2001). Texto disponible en http://ru.ffyl.unam.mx/ [Consulta: abril de 2009] 
García Cuadrado, Amparo. "Aproximación a los criterios legales en materia de imprenta durante la edad moderna en España", en $R e$ vista General de Información y Documentación. Vol. 6, núm. 2 (1996), pp. 125-187.

. "Aproximación a la organización bibliotecaria española en el siglo XVIII", en Investigación Bibliotecológica. Vol. 11, núm. 23 (1997), pp 102-136.

García Ejarque, Luis. Diccionario del Archivero Bibliotecario. Gijón: Trea, 2000.

García Gómez, María Dolores. Memoria de unos libros: la Biblioteca de los Jesuitas expulsados del Colegio de Albacete. Albacete: Instituto de Estudios Albacete Don Juan Manuel de la Excma. Diputación de Albacete, 2001.

García Icazbalceta, Joaquín. Apuntes para un catálogo de escritores en lenguas indígenas de América. México, 1886.

- Bibliografía mexicana del siglo XVI: catálogo razonado de libros impresos en México. México: Librería de Andrade y Morales, Sucesores, 1886.

- Bibliografía mexicana del siglo XVI: catálogo razonado de libros impresos en México de 1539 a 1600. México: FCE, 1954.

García Vega, Blanca. El grabado del libro español, siglos XV, XVI y XVII: aportación a su estudio con los fondos de las bibliotecas de Valladolid. Valladolid: Diputación Provincial: Institución Cultural Simancas, 1984. 2 tomos.

Garone Gravier, Marina. Breve introducción al estudio de la tipografía en el libro antiguo: panorama bistórico y nociones básicas para su reconocimiento. México: AMBIFA, 2009

—. "Diseñadores de la lengua propia: calígrafos indígenas en la Nueva España" en Primer Coloquio Internacional de Lenguas y Culturas Coloniales (en prensa) 
- "Impresoras hispanoamericanas: un estado de la cuestión" en Boletín de la Real Academia de Buenas Letras de Barcelona, Vol. 51 (2008), pp. 451-471. Texto disponible en http://www.raco. cat/index.php/BoletinRABL/article/view/191317/270302 [Consulta: enero de 2011]

— "Mujeres y tipografía en la Nueva España", en Hibris: Revista de bibliofilia. Núm. 43 (2008), pp. 13-25.

- "Senderos de metal", en La Biblioteca Nacional: triunfo de la República. México: UNAM, 2006, .pp. 139-153.

"La tipografía en el libro antiguo, nociones generales para su estudio", en Un impreso encantador: conservación, protección y difusión del libro antiguo, compilación de Idalia García. [Edición en proceso México, CUIB, 2011]

Garza Merino, Sonia. "La cuenta del original", en Imprenta y crítica textual en el Siglo de Oro, estudios publicados bajo la dirección de Francisco Rico. Valladolid: Universidad. Centro para la Edición de los Clásicos Españoles, 2000, pp. 65-95.

Gaskell, Philip. "The Lay of Case", en Studies in Bibliography. Vol. 22 (1969), pp. 125-142. Texto disponible en http://etext.virginia.edu/ bsuva/sb/ [Consulta: abril de 2009]

. Nueva introducción a la bibliografía material. Gijón: Trea, 1999.

Geldner, Ferdinand. Manual de incunables. Madrid: Arco Libros, 1998.

Genre Terms: A Thesaurus for use in Rare Book and Special Collections Cataloging, prepared by the Committee of the Rare Books and Manuscripts Section. Chicago: Association of College and Research Libraries, 1991.

Gilmont, Jean-François. Le livre \& ses secrets. Gèneve: Université Catholique de Louvain: Librairie, 2003. 
Glaister, Geoffrey Ashall. Encyclopedia of the Book, with a new introduction by Donald Farren. 2nd. ed. London: Oak Knoll Press \& The British Library, c1999.

Gómez Álvarez, Cristina. "Libros y lectores en México, 1750-1850", en Boletín del AGN. 6a época, núm. 1 (agosto/octubre 2003), pp. 1129. Texto disponible en http://www.agn.gob.mx/menuprincipal/ cultural/publicaciones/boletines.html [Consulta: enero de 2011]

Gómez Álvarez, Cristina y Francisco Téllez Guerrero. Una biblioteca obispal. Antonio Bergosa y Jordán 1802. Puebla: BUAP. Instituto de Ciencias Sociales y Humanidades, 1997.

Un hombre de Estado y sus libros: el Obispo Campillo, 1740-1813. Puebla. BUAP. Instituto de Ciencias y Sociales y Humanidades, 1997.

Gómez Gómez, Margarita. "La bibliología como disciplina. Historia y tendencias actuales", en Conceptos: Actas del III Congreso de la Historia de la Cultura Escrita. Alcalá: Universidad, 1998, pp. 725 .

Gómez-Senent Martínez, Carmen. Catálogo de obras impresas en el siglo XVII de la Biblioteca Municipal de Valencia. Valencia: Ajuntament, 1996.

González De Amezúa y Mayo, Agustín. "Cómo se hacia un libro en nuestro Siglo de Oro”, en Opúsculos histórico-literarios. Madrid: CSIC, 1951. T. 1, pp. 331-373.

González de Cossío, Francisco. La imprenta en México 1594-1820: cien adiciones a la obra de don José Toribio Medina. México: Antigua Librería de Robredo de José Porrua e Hijos, 1947.

- La imprenta en México, 1553-1820: 510 adiciones a la obra de José Toribio Medina en homenaje al primer centenario de su nacimiento. México: Universidad Nacional de México, 1952. 
González Ordaz, Cintia Elizabeth. Catálogo de marcas de fuego del Fondo Antiguo y Colecciones Especiales de la Biblioteca Central de la Dirección General de Bibliotecas de la UNAM. México: la autora, 2006 (Tesis de licenciatura. Licenciado en Bibliotecología y Estudios de la Información. UNAM. Facultad de Filosofía y Letras).

El grabado: bistoria y trascendencia, Cristina Rodríguez...[et. al.] México: UAM-Xochimilco, 1989

Grañen Porrúa, Maria Isabel. "El ámbito sociolaboral de las imprentas novohispanas", en Anuario de Estudios Americanos, núm. 48 (1991), pp. 49-94.

_. "Francisca Flores y su imprenta". Texto disponible en http://www.adabi-ac.org/investigacion_libro_ant/articulos/ paginas/04art_igp01.htm [Consulta: marzo de 2009] . "Los orígenes de la imprenta en Oaxaca", en La Historia de la imprenta en Oaxaca. Oaxaca: Universidad Autónoma Benito Juárez de Oaxaca. Biblioteca Francisco de Burgoa, 1999.

Griffin, Clive. "La carrera del impresor en la Edad Moderna: Pierre Regnier, peripecias da un impresor en la Barcelona del siglo XVI", en La memoria de los libros: estudios sobre la historia del escrito y de la lectura en Europa y América, bajo la dirección de Pedro M. Cátedra \& María Luisa López-Vidriero. Salamanca: Instituto de Historia del Libro y de la Lectura, 2004. T.1, pp. 383-392.

Guerrero Alonso, Rosa Margarita. Los preliminares como versión de poder y de control en el impreso antiguo. Andrés de Arce y Miranda y Juan José de Eguiara y Eguren. Tesis en proceso. Programa de Posgrado en Bibliotecología y Estudios de la Información. Facultad de Filosofía y Letras/ CUIB, UNAM.

Haebler, Konrad. Introducción al estudio de los incunables. Madrid: Ollero \& Ramos, 1995.

Hampe Martínez, Teodoro. Bibliotecas privadas en el mundo colonial. Madrid: Iberoamericana: Vervuert, 1996. 
Harmon, Robert B. Elements of Bibliography: A Guide to Information Sources and Practical Applications. Maryland: The Scarecrow Press, 1998.

Hellinga, Lotte. Impresores, editores, correctores y cajistas. Salamanca: instituto de Historia del Libro y de la Lectura, 2006.

Henestrosa, Cristóbal. Espinosa: rescate de una tipografía novohispana. México: Designio, 2005.

Hernández De León Portilla, Ascensión. "Agustín Millares Carlo, polígrafo de España y de América”, en Cuadernos Americanos. Año. 8, vol. 5, núm. 47 (septiembre-octubre de 1994), pp. 76-100.

Herrejón Peredo, Carlos. "La oratoria en Nueva España", en Relaciones. Núm. 57 (1997), pp. 57-80. Texto disponible en http://www. colmich.edu.mx/relaciones/057/pdf/Carlos\%20Herrejon\%20Peredo.pdf [Consulta: noviembre de 2007]

Herrero Pascual, Cristina. "Metodología para un catálogo de libros del siglo XVI", en Revista General de Información y Documentación. Vol. 6, núm. 2 (1996), pp. 10-50. Texto disponible en http:// revistas.ucm.es/byd/11321873/articulos/RGID9696220011A.PDF [Consulta: enero de 2011]

Histoire de l'origine et des prémiers progres de l'imprimerie. A la Haye: Ches: La Vueuve Le Vier, et Pierre Paupie, 1740 (BGU de Sevilla, AFA 655 MAR).

Historia de la edición y de la lectura en España, 1472-1914, bajo la dirección de Víctor Infantes, François López y Jean-François Botrel. Madrid: Fundación Germán Sánchez Ruipérez, 2003.

Historia ilustrada del libro español. Madrid: Fundación Germán Sánchez Ruipérez: Pirámide, 1994.

Huarte Morton, Fernando. "La descripción de los libros raros", en Primeras Jornadas de Bibliografía. Madrid: Fundación Universitaria Española, 1977, pp. 65-69. 
Secretos del estante: elementos para la descripción bibliográfica...

Hunter, Dard. Papermaking: The History and Technique of an Ancient Craft. New York: Dover Publications, 1978.

Iguíniz, Juan B. La imprenta en la Nueva España. México: Porrúa Hermanos, 1938.

Léxico bibliográfico. México: UNAM. Instituto de Investigaciones Bibliográficas, 1987.

- El libro: epítome de bibliografía. México: Editorial Porrúa, 1946.

Impresos mexicanos del siglo XVI: los incunables. México: Centro de Estudios de Historia de México CONDUMEX, 1995.

Infantes, Víctor. "Letras con historia. Apuntes sobre las capitulares figuradas en la cultura tipográfica del Renacimiento Español (I)", en Pliegos de Bibliofilia. Núm. 3 (1998), pp. 35-55.

. "La memoria de la biblioteca: el inventario", en El libro antiguo español V: el escrito en el Siglo de Oro, prácticas y representaciones, dirigido por Pedro M. Cátedra, Agustín Redondo y Maria Luisa López Vidriero. Salamanca: Ediciones Universidad: Publications de la Sorbonne: Sociedad Española de Historia del Libro, 1998, pp. 163:170.

Imprentas, ediciones y grabados de México Barroco. México: Museo Amparo, 1995.

ISBD (A): descripción bibliográfica internacional normalizada para publicaciones monográficas antiguas, tr. al español realizada por Ana Baltar Gómez, Fabiola Labella Rivas, Luis Villén Rueda. $2^{\mathrm{a}}$ ed. rev. Madrid: Asociación Española de Archiveros, Bibliotecarios, Museólogos y Documentalistas, Arco Libros, 1995.

Joyas bibliográficas de la Biblioteca Pública del Estado de Jalisco. Universidad de Guadalajara. Guadalajara, Jalisco: Universidad: CIESAS, 1997. 
Las joyas bibliográficas de la Universidad Autónoma Benito Juárez de Oaxaca: la Biblioteca Francisco de Burgoa, María Isabel Grañen Porrúa... [et. al.]. México: Fomento Cultural Banamex, 1996.

Juan José de Eguiara y Eguren y la cultura mexicana, coordinación y presentación de Ernesto de la Torre Villar. México: UNAM. Coordinación de Humanidades, 1993.

Julve, Luis, Manuel José Pedraza y José Ángel Sánchez. "Dice, un auxiliar informático para la descripción de impresos antiguos aragoneses", en Apuntes CCUZ (Centro de Cálculo de la Universidad de Zaragoza) 8, (noviembre/diciembre 1995), pp. 26-32.

Knight, Stan. Historical Scripts: from classical times to the Renaissance. New Castle, Delaware: Oak Knoll Press, 1998.

Krausse Rodríguez, Carlos. Marcas de fuego: catálogo. México: INAH, 1989.

Labarre, Albert. Historia del libro. México: Siglo XXI, 2002.

Lafaye, Jacques. Albores de la imprenta: el libro en España y Portugal y sus posesiones de ultramar, siglos XV y XVI. México: FCE, 2002.

Lavender, Kenneth. Book repair. A How-To-Do-It Manual. 2nd edition. New York: Neal Shuman Publishers, 2001.

Lenz, Hans. Historia del papel en México y cosas relacionadas, 1525-1950. México: Miguel Ángel Porrúa, 1990.

León, Nicolás. "La bibliografía en México en el siglo XIX", en Boletín del Instituto Bibliográfico Mexicano. T. 3, (1902), pp. 58-59.

Bibliografía mexicana del siglo XVIII. México: Imprenta de la Viuda de Francisco Díaz de León, 1902-1908. 
- Ex libris de bibliófilos mexicanos. Colección formada por el Dr. Nicolás León y continuada e ilustrada con notas biográficas por Juan B. Iguíniz. México: Imprenta del Museo Nacional de Arqueología, Historia y Etnología, 1913.

El libro antiguo en las bibliotecas españolas, edición a cargo de Ramón Rodríguez Álvarez y Moisés Llorden Miñambres. Gijón: Universidad de Oviedo, 1998.

Le livre illustré italien au XVIe siècle: Texte-Image, sous la direction de Michel Plaisance. Paris: Klincksieck: Presses de la Sorbonne Nouvelle, 1999.

Loayza Valda Joaquín. "La Biblioteca Nacional de Bolivia: su misión y objetivos en la realidad nacional y en información", en Proceedings 2o. Congreso Internacional de Bibliotecología, Documentación y Archivística (CIBDA), La Paz (Bolivia, 2003). 6 p. Texto disponible en http://eprints.rclis.org/archive/00001104/01/lapaz25. pdf [Consultado: noviembre de 2007]

López Cervantes, Estela Beatriz. Dos transterrados intelectuales y su aportación a la cultura mexicana: el Dr. Agustín Millares Carlo y el Dr. José Ignacio Mantecón. México : la autora, 2003. (Tesis de Maestría. Maestro en Historia de México. UnAM. Facultad de Filosofía y Letras. División de Estudios de Posgrado).

López Cervantes, Gonzalo y Rosa García García. Ensayo bibliográfico del periodo colonial mexicano. México: INAH, 1989.

López-Huertas Pérez, Maria José. Bibliografía de impresos granadinos de los siglos XVII y XVIII. Granada : Universidad : Diputación provincial, 1997. 3 tomos.

López Vidriero, Maria Luisa. "El gabinete de un hombre de gusto. Manuales para la formación de bibliotecas en el siglo XVIII", en $\mathrm{El} \mathrm{li}$ bro antiguo español: coleccionismo y bibliotecas, siglos XV-XVIII, dirigido por María Luisa López- Vidriero y Pedro M. Cátedra. Salamanca: Ediciones Universidad: Patrimonio Nacional: Sociedad Española de Historia del Libro, 1998, pp. 447-460. 
López Yepes, José. "Introducción al concepto de bibliografía", en Fundamentos de información y documentación, comp. José López Yepes. Madrid: Ediciones de la Universidad Complutense, 1989, pp. 87-100.

Loring, Rosamond B. Decorated Book Papers: being an account of their designs and fashions. 4a ed. Cambridge: Houghton Library: Harvard College Library, 2007.

Lucía Megías, José Manuel. Imprenta y libros de caballerías. Madrid: Ollero \& Ramos, 2000.

. "Un ejército de soldados de plomo: la imprenta al servicio de las artes liberales y de la ciencia", en Península. Revista de Estudos Ibericos. Núm. 5 (2008), pp. 11-30. Texto disponible en http://ler.letras.up.pt/uploads/ficheiros/4703.pdf [Consulta: abril de 2008]

Lyell, James P. R. La ilustración del libro antiguo en España. Madrid: Ollero \& Ramos, 1997.

Malclés, Louise Nöelle. La bibliografía. Buenos Aires: EUDEBA, 1960.

Mantecón, José Ignacio. Índice de nombres latinos de ciudades con imprenta, 1448-1825. México: UNAM, 1973.

Marsá Vila, María. El fondo antiguo en la biblioteca. Gijón: Trea, 1999.

bros, 2002.

L La imprenta en los Siglos de Oro, 1520-1700. Madrid: Ediciones del Laberinto, 2001.

Martin, Henry-Jean. "Les débuts d'une révolution typographique", en Le livre et l'art: etudes offertes en hommage à Pierre Lelièvre, réunies par Thérèse Kleindienst. Italie: Somogy Éditions d'Art: ENSSIB, 2000, pp. 151-159. 
- La naissance du livre moderne: mise en page et mise en texte du livre français, XIVe-XVIIe siècles. Paris: ëditions du Cercle de la Librarie, 2000.

Martín Abad, Julián. "Del ejemplar, o de ciertas historias (casi) siempre pasadas por alto", en Actas I Jornadas sobre patrimonio bibliográfico en Castilla-La Mancha. Toledo: Junta de Comunidades Castilla-La Mancha, 2003, pp. 15-35.

- La imprenta en Alcalá de Henares, 1502-1600. Madrid: Arco Libros, 1991. 2 tomos.

- "Incunables, post-incunables y libros antiguos", en Exposición virtual Civitas Librorum. La ciudad de los libros. Alcalá de Henares: Centro Virtual Cisneros de la Universidad, 2002. Texto disponible en http://www.centrocisneros.uah.es/civitas/texto $4 . h t m$ [Consulta: abril de 2005]

_. "Incunables e impresos antiguos", en Los materiales especiales en las bibliotecas, coordinado y dirigido por Carmen Díez Carrera. Gijón: Trea, 1998, pp. 63-121.

—. Los libros impresos antiguos. Valladolid: Universidad, 2004.

- Los primeros tiempos de la imprenta en España: c. 14711520. Madrid: Ediciones del Laberinto, 2003.

. "La técnica impresora", en. Aquí se imprimen libros: la imprenta en la época del Quijote, José Manuel Lucía Mejías... [et. al.] Madrid: Imprenta Artesanal Ollero y Ramos, 2004, pp. 11-33.

_. "La tipobibliografía complutense del Siglo XVI: tareas y posibilidades", en El Libro Antiguo Español: Actas del primer Coloquio Internacional (Madrid, 18 al 20 de diciembre de 1986). Salamanca: Ediciones de la Universidad: Biblioteca Nacional de Madrid: Sociedad Española de Historia del Libro, 1993, pp. 273293. 
_. "La valoración del libro: el punto de vista del bibliotecario de fondo antiguo", en Ciclo de Conferencias sobre Bibliofilia y Mercado del Libro. Biblioteca Histórica Marques de Valdecilla. Texto disponible en http://www.ucm.es/BUCM/foa/Conferencias/conferencia2.pdf [Consulta: mayo de 2006]

Martínez, José Luis. El libro en Hispanoamérica: origen y desarrollo. $3^{\text {a }}$ ed. Madrid: Fundación Germán Sánchez Ruipérez, 1987.

Martínez, María de los Ángeles. Catálogo de la Biblioteca de la catedral de la Ciudad de México. México: UnAM; INAH, 1991.

Martínez de Sousa, José. Diccionario de bibliología y ciencias afines. $3^{\text {a }}$ ed. Gijón: Trea, 2004.

- Diccionario de edición, tipografía y artes gráficas. Gijón: Trea, 2001.

Mateo Ripoll, Verónica. El clero y los libros: catálogo de la biblioteca del Seminario de San Miguel de Oribuela, siglos XV-XVI. Alicante : Instituto Alicantino de Cultura Juan Gil-Albert, 2002.

Mathes, Valerie L. "Enrico Martínez of New Spain", en The Americas, Vol. 33, núm. 1 (July 1976), pp. 62-77.

Maza, Francisco de la. Enrico Martínez. Cosmógrafo e Impresor de Nueva España. México: UNAM, 1991.

McKenzie, D.F. La bibliographie et la sociologie des textes, préface de Roger Chartier. París: Éditions du Cercle de la Librairie, 1991.

- "Printers of the mind. Some Notes on Bibliographical Theories and Printing-House Practices", en Studies in Bibliography. T. 22 (1969), pp. 1-75. Texto disponible en http://etext.virginia.edu/bsuva/sb/ [Consulta: octubre de 2008]

McKerrow, Ronald. B. Introducción a la bibliografía material. Madrid: Arco Libros, 1998. 
Secretos del estante: elementos para la descripción bibliográfica...

McKitterick, David. Print, Manuscripts and the Search for Order, 1450-1830. United Kingdom: Cambridge University Press, 2004.

McMullin, B.J. "Signing by the page", en Studies in Bibliography. Vol. 48 (1995), pp. 259-268. Texto disponible en http://etext.virginia. edu/bsuva/sb/ [Consulta: mayo de 2006]

McMurtrie, Douglas C. The Book: the Story of Printing \& Bookmarking. New York: Oxford University Press, 1953.

- "The First Typefounding in Mexico", en The Library. Vol. s4VIII (1927), pp. 119-122.

Medina, José Toribio. La Imprenta en México, 1539-1821. México: UNAM, 1989. 8 tomos.

- La imprenta en la Puebla de los Ángeles (1640-1821). México: UNAM, Instituto de Investigaciones Bibliográficas, 1991.

La imprenta en Oaxaca, Guadalajara, Veracruz, Mérida $y$ varios lugares. (1720-1820). Santiago de Chile, Imprenta Elzeviriana, 1904 (Reimpresión en México, UNAM, 1991).

Mejía Ruiz, Jorge Alberto. Propuesta de una base de datos para el fondo antiguo de la biblioteca central de la Dirección General de Bibliotecas de la UNAM. México: El autor, 2003 (Informe académico e actividad profesional para la obtención del título de Licenciado en Bibliotecología. UNAM. Facultad de Filosofía y Letras)

Mena, Ramón. Filigranas o marcas transparentes en papeles de Nueva España, del siglo XVI. México: Secretaría de Relaciones Exteriores, 1925 (Monografías Bibliográficas Mexicanas; 5).

Mendoza Díaz-Maroto, Francisco. Introducción a la bibliofilia. Valencia: Vicent García Editores, 1995.

El mercado del libro antiguo español: una guía de precios. Madrid: Ollero \& Ramos, 1999. 
México. Ley Federal sobre Monumentos y Zonas Arqueológicos, Artísticos e Históricos. Publicada en Diario Oficial de la Federación de 6 de mayo de 1972. Diario Oficial de la Federación, 6 de mayo de 1972. Texto disponible en http://www.diputados.gob.mx/leyinfo/pdf/131.pdf [Consulta: Enero de 2006]

Middleton, Bernard C. Restauración de encuadernaciones en piel. Madrid: CLAN Editorial, 2001.

Miguel Alonso, Aurora. "Aproximación histórica al libro Antiguo", en Revista General de Documentación e Información. Vol. 5, num. 1 (1995), pp. 215-230. Texto disponible en http://revistas.ucm.es/ byd/11321873/articulos/RGID9595120215A.PDF [Consulta: enero de 2011]

Millares Carlo, Agustín. Introducción a la bistoria del libro y de las bibliotecas. México: FCE, 1975.

—. Don Juan José de Eguiara y Eguren (1675-1763) y su Biblioteca Mexicana. México: UNAM, 1957.

- Prontuario de bibliografía general. Caracas: Instituto de Investigaciones Históricas, 1973.

Millares Carlo, Agustín y Julián Calvo. Juan Pablos: primer impresor que a esta tierra vino. México: Librería de Manuel Porrúa, [1953].

Minguez, Víctor. "Imágenes para leer: función del grabado en el libro del Siglo de Oro", en Escribir y leer en el siglo de Cervantes, compilador Antonio Castillo Gómez. Barcelona: Gedisa, 1999, pp. 255283.

Moll Roqueta, Jaime. "La bibliografía en la investigación literaria", en Métodos de estudio de la obra literaria, ed. J.M. Díez Borque. Madrid: Taurus, 1985, pp. 145-182. 
—. "Las cursivas de Juan Mey, con algunas consideraciones previas sobre el estudio de las letrerías", en El Libro Antiguo Español: Actas del primer Coloquio Internacional (Madrid, 18 al 20 de diciembre de 1986). Salamanca: Ediciones de la Universidad: Biblioteca Nacional de Madrid: Sociedad Española de Historia del Libro, 1993, pp. 295-304.

- "La imprenta manual", en Imprenta y crítica textual en el Siglo de Oro, al cuidado de Pablo Andrés y Sonia Garza. Valladolid: Universidad. Centro para la Edición de los Clásicos Españoles, 2000, pp. 13-27.

. "El impresor y el librero en el Siglo de Oro", en $E l$ mundo del libro antiguo, dirigido por Francisco Asín Remírez de Esparza. Madrid: Editorial Complutense, 1996, pp. 27-41.

- "La justificación de las matrices y el estudio de las letrerías", en De la imprenta al lector: estudio sobre el libro español de los siglos XVI al XVIII. Madrid: Arco Libros, 1994, pp. 109-118.

. "Plantino, los Junta y el privilegio del Nuevo Rezado", en Simposio Internacional sobre Cristóbal Plantino, edición a cargo de Hans Tromp y Pedro Peira. Madrid: Universidad Complutense, 1990, pp. 9-23.

—. "Problemas bibliográficos del libro del Siglo de Oro", en Boletín de la Real Academia Española, Vol. 59 (1979), pp. 49-107.

Montaner Frutos, Alberto. Prontuario de bibliografía: pautas para la realización de descripciones, citas y repertorios. Gijón: Trea, 1999.

Morales, Elvia. "De nuestra biblioteca", en Todo es Historia: boletín de estudios históricos (julio-diciembre 2000). Puebla: UDLAP, pp. 58-61.

Moreiro González, José Antonio. Agustín Millares Carlo: el hombre y el sabio. Gobierno de Canarias: Viceconsejería de Cultura y Deportes, 1989. 
- "Don Agustín Millares Carlo: la profesión bibliográfica. Aportaciones a la historia de la bibliografía española", en Documentación de las Ciencias de la Información. Vol. 10, (1986), pp. 89-158. Texto disponible en http://www.ucm.es/BUCM/revistas/ inf/02104210/articulos/DCIN8686110089A.PDF [Consulta: enero de 2011]

Moreno, Roberto. Ensayos de bibliografía mexicana: autores, libros, imprenta, bibliotecas, primera serie. México: UNAM. Instituto de Investigaciones Bibliográficas, 1986.

-Un caso de censura de libros en el siglo XVIII novohispano: Jorge Mas Theóphoro. México: UNAM, 1978 (Suplementos al Boletín del Instituto de Investigaciones Bibliográficas; 4)

Moreno Jiménez Daniel. "La función del bibliotecólogo en el rescate de los testimonios bibliográficos históricos de nuestro país, siglos XVIXVIII", en Memorias de las XXV Jornadas Mexicanas de Biblioteconomía (Puerto Vallarta, 1994), pp. 90-94. Texto disponible en http://www.ambac.org.mx/publicaciones/memorias/25jornadas. pdf [Consulta: marzo de 2006]

Mortimer, Ruth. "Author's image: Italian Sixteenth-Century Printed Portraits", with an Introduction by G. Thomas Tanselle. Harvard Library Bulletin. Vol. 7, núm. 2 (summer 1996).

Moxon, Joseph. Mechanical Exercises or handy works. Applied to the Art of Printing. The second volume.... London: Printed for Joseph Moxon, 1683.

Moyano Andrés, Isabel. Toponomástica. Madrid: Arco Libros, 2006.

Muñoz Espinosa, María Estela. Una muestra iconográfica de las estampas que guardan las obras que llegaron a la Nueva España. México: INAH, 2000.

Norton, Frederick J. La imprenta en España, 1501-1520. Madrid: Ollero \& Ramos, 1997. 
O’Gorman, Edmundo. "Bibliotecas y librerías coloniales", en Boletín del Archivo General de la Nación, T. 10, núm. 4 (1939), pp. 6611001.

Osorio Romero, Ignacio. Historia de las bibliotecas novohispanas. México: SEP. Dirección General de Bibliotecas, 1986.

Padwick, E.W. Bibliographical method: an introductory survey. Cambridge: James Clarke \& Co., 1969.

Palau y Dulcet, Antonio. Manual del librero bispano-americano. Barcelona: Librería Anticuaria, 1923-1927. 7 tomos.

- Manual del librero bispano-americano: bibliografía general española e hispano-americana: desde la invención de la imprenta hasta nuestros tiempos, con el valor comercial de los impresos descritos. 2da ed. Barcelona, España: Librería Anticuaria de Palau, 1948-1977.

Manual del librero hispano-americano: inventario bibliográfico de la producción científica y literaria de España y de la América Latina desde la invención de la imprenta hasta nuestros días, con el valor comercial de todos los artículos descritos. Madrid: Julio Ollero Editor, 1990. 7 tomos.

Paper Terms: a Thesaurus for Use in Rare Books and Special Collections Cataloging, prepared by Bibliographic Standards Committee of the Rare Books and Manuscripts Section. Chicago: Association of College and Research Libraries, 1990.

Pardo Tomás, José. Ciencia y censura. La inquisición española y los libros científicos en los siglos XVI y XVIII. Madrid CSIC, 1991.

Paredes, Alonso Víctor de. Institución y origen del arte de la imprenta y reglas generales para los componedores, edición y prólogo de Jaime Moll. Madrid: El Crotalón, 1984. 
- Institución y origen del arte de la imprenta y reglas generales para los componedores, edición y prólogo de Jaime Moll; nueva noticia editorial de Víctor Infantes. Madrid: Calambur Editorial, 2002.

Parra, Jacinto de. Rosa Laureada entre los Santos... Madrid: Domingo García Morrás, 1670. (BGU de Sevilla 92 187).

Patrimoine écrit, patrimoine vivant: règles élémentaires pour la conservation et la valorisation des documents patrimoniaux. France: Fédération Française de Coopération entre Bibliothèques, 1999.

Paula Andrade, Vicente de. Ensayo bibliográfico mexicano del siglo XVII. $2^{\text {a }}$ ed. México: Imprenta del Museo Nacional, 1899.

Pearson, David. Provenance research in book history: a handbook. England: The British Library, 1994.

Pedraza Gracia, Manuel José. "La imprenta y el proceso de impresión", en Juan Párix: primer impresor en España. Segovia: Instituto castellano y Leonés de la Lengua: Caja Segovia, 2004, pp. 15-42.

- Lectores y lecturas en Zaragoza, 1501-1521. Zaragoza: Prensas Universitarias, 1998.

. "Lector, lecturas, bibliotecas...: el inventario como fuente para su investigación histórica, en Anales de Documentación, Vol. 2 (1999), pp. 137-158. Texto disponible en http://digitum.um.es/ jspui/bitstream/10201/3677/4/AD2\%20\%281999\%29\%20p\%20\%20137-158. pdf [Consulta: enero de 2011]

Yolanda Clemente y Fermín de los Reyes. El Libro Antiguo. Madrid: Síntesis, 2003.

Pensato, Rino. Curso de bibliografía: guía para la compilación y uso de repertorios bibliográficos. Gijón: Trea, 1994. 
Secretos del estante: elementos para la descripción bibliográfica...

Peña Díaz, Manuel. "El libro bajo sospecha (siglos XVI-XVII)", en La memoria de los libros: estudios sobre la bistoria del escrito y de la lectura en Europa y América, bajo la dirección de Pedro M. Cátedra \& María Luisa López-Vidriero. Salamanca: Instituto de Historia del Libro y de la Lectura, 2004. T.1, pp. 805-837.

_ "Libros y letras en tiempos de Isabel la Católica", en Domus Sapientae: fondos bibliográficos de la Universidad de Granada en la época de Isabel la Católica. Granada: Universidad 2004, pp. 13-47.

Peñarroya Cruz, Jaime. La probibición de las Indias: los libros perseguidos, 1492-1541. Barcelona: [s.n.], 1997. $2 \mathrm{v}$.

Perales Ojeda, Alicia. La cultura bibliográfica en México. México: UNAM. Instituto de Investigaciones Bibliográficas, 2002.

Pérez Salazar, Francisco. "Dos familias de impresores mexicanos del siglo XVI", en Memorias y Revista de la Sociedad Científica Antonio Alzate. T. 43, núm. 9-12 (1925), pp. 447-511.

Petroski, Henry. Mundo libro. Barcelona: Edhasa, 2002.

Pfeiffer, Heinrich. "IHS: el emblema de la Compañía de Jesús", en Jesuitas Anuario de la Compañía de Jesús, (2003), p. 12-14.

Pinto Crespo, Virgilio. Inquisición y control ideológico en la España del siglo XVI. Madrid: Taurus, 1983.

- "Institucionalización inquisitorial y censura de libros", en $L a$ Inquisición Española: nueva visión, nuevos horizontes. Madrid: Siglo XXI, 1980, pp. 513-536.

Portillo Muñoz, José Luis. La ilustración gráfica de los incunables sevillanos (1470-1500). Sevilla: Diputación Provincial, 1980. (Sección Arte, 1, 56)

Pouncey, L. "The fallacy of the ideal copy", en The Library. 5th. ser. Vol. 33, núm. 2 (1978), pp. 108-118. 
Printing and Publishing Evidence: Thesauri for use in Rare Book and Special Collections Cataloging, prepared by Standards Committee of the Rare Books and Manuscripts Section. Chicago: Association of College and Research Libraries, 1986.

Provenance Evidence: a thesaurus for use in Rare Books and Special Collections Cataloging, prepared by Standards Committee of the Rare Books and Manuscripts Section. Chicago: Association of College and Research Libraries, 1988.

Puzzles in paper. Concepts in historical watermarks: essays from International Conference on the History, Function and Study of Watermarks (Roanoke, Virginia), edited by Daniel W. Mosser, Michale Saffle y Ernest W. Sullivan II. Delaware: Oak Knoll Press: The British Library, 2000.

Quiñónez Melgoza, José. Catálogo de obras de autores latinos en servicio en la Biblioteca Nacional de México. México: UNAM, 1983.

Quondam, Amedeo. "Mercancía de honor, mercancía de utilidad: producción del libro y trabajo intelectual en Venecia en el siglo XVI", en Libros, Editores y Público en la Europa Moderna, comp.. Armando Petrucci. Valencia: Edicions Alfons el Manà, pp. 71-118.

Ramos, Roberto. "Estado actual de la bibliografía en México", en Boletín de la Biblioteca Nacional de México. T. 8, núm. 1 (eneromarzo de 1957), pp. 16-23.

Raubert, Cristian, Peter Tschudin, Sergei Startchik y Tierry Pum. "Archivage et recherche d'images de filigranes". Texto disponible en ftp://cui.unige.ch/pub/vision/papers/rauber/96.07.CNED96.pdf [Consulta: abril de 2006]

Readings in descriptive bibliography, edited and with a preface by John Bush Jones. USA: The Kent State University Press, 1974. 
Reglas de catalogación: edición refundida y revisada. Madrid: Ministerio de Cultura. Dirección General del Libro, Archivos y Bibliotecas, 2003.

Reyes, Alfonso. Letras de la Nueva España. México: FCE, 1948.

Reyes Gómez, Fermín de los. "Con privilegio: la exclusiva de edición del libro antiguo español", en Revista General de Información y Documentación. Vol. 11, núm. 2 (2001), pp. 163-200. Texto disponible en http://revistas.ucm.es/portal/abrir.php?url=http://revistas.ucm.es/byd/11321873/articulos/RGID0101220163A.PDF [Consulta: enero de 2011]

L La imprenta en Segovia, 1472-1900. Madrid: Arco Libros, 1997. 2 vol.

. "Los libros de Nuevo Rezado y al imprenta española en el siglo XVIII", en Revista General de Información y Documentación. Vol. 9, núm. 1 (1999), pp 117-158. Texto disponible en http://revistas.ucm.es/portal/abrir.php?url=http://revistas.ucm.es/byd/113218

73/articulos/RGID9999120117A.PDF [Consulta: enero de 2011]

El libro en España y América. Legislación y censura (siglos $X V$-XVIII). Madrid: Arco Libros, 2000. 2 vol.

"Licencia y privilegio en el libro español antiguo: breves notas y aclaraciones", en Pliegos de Bibliofilia. Núm. 15 (2001), pp. 77-78.

.La tasa en el libro español antiguo", en Pliegos de Bibliofilia. Núm. 4 (1998), pp. 35-52.

Rico y Sinobas, Manuel. El arte del libro en España, prólogo Francisco Hueso Rolland. Madrid: Editorial Escelicer, 1941.

Riesco Terrero, Ángel. Vocabulario científico técnico de paleografía, diplomática y ciencias afines, colaboradores José María de Francisco Olmos y Manuel Barrero y Acedo. Madrid: Barrero \& Acedo, 2003. 
Rivas Mata, Emma. Bibliografías novohispanas o bistoria de varones eruditos. México: INAH, 2000.

Robinson, A.M. Lewin. Introducción a la bibliografía: guía práctica para trabajos de descripción y compilación. $4^{\mathrm{a}}$ ed. Madrid: Fundación Germán Sánchez Ruipérez: Pirámide, 1992.

Rodríguez Bravo, Blanca. "Problemática de la ISBD (A)", en Boletín de la Asociación Andaluza de Bibliotecarios. Núm. 32 (1993), pp. 11-16.

Rodríguez De Romo, Ana Cecilia, Arnulfo Irigoyen y María Teresa Hernández Sánchez. Tesoros de la Biblioteca Histórica Doctor Nicolás León: libros de medicina de los siglos XVI, XVII y XVIII. México: UNAM, Facultad de Medicina. Departamento de Historia y Filosofía de la Medicina, 1996.

Rodríguez Díaz, Fernando. El mundo del libro en México. México: Diana, 1992.

Romero De Terreros, Manuel. Encuadernaciones artísticas mexicanas. $2^{\text {a }}$ ed. México: Biblioteca de la II Feria del Libro y Exposición Nacional del Periodismo, 1943.

Ronco López, María Milagros. Los documentalistas españoles: nuevas contribuciones a la vida y la obra de Agustín Millares Carlo, 1893-1980. Madrid, 2001.

- Nuevas aportaciones biobibliográficas y documentales en torno a la figura de Millares Carlo: la imprenta en Barcelona durante el periodo renacentista (1590-1600). [s.1.] : Universidad del País Vasco, 2001.

Ros, Vicente. "La máquina de prensar uvas", en Infodiversidad. Num. 10 (2006), pp. 101-112. Texto disponible http://redalyc.uaemex. $\mathrm{mx} /$ redalyc/pdf/277/27701005.pdf [Consulta: diciembre de 2007]

Rosenberg, Margot y Bern Marcowitz. The care and Feeding of Books Old and New: a Simple Repair Manual for Book Lovers. New York: Thomas Dunne Books: St. Martin’s Press, 2002. 
Secretos del estante: elementos para la descripción bibliográfica...

Rueda Ramírez, Pedro. "La circulación de menudencias impresas en las redes atlánticas (siglos XVI-XVII)", en Cultura escrita \& sociedad. Núm. 2 (2006), pp. 53-76.

Ruiz, Elisa. Manual de codicología. Madrid: Fundación Germán Sánchez Ruipérez, 1988.

Ruiz Fidalgo, Lorenzo. La Imprenta en Salamanca, 1501-1600. Madrid: Arco Libros, 1994.

Ruiz Rivera, Leticia. Catálogo de sermones de la Biblioteca Eusebio F. Kino de la provincia mexicana de la Compañía de Jesús. Madrid: Fundación MAPFRE, 2006.

Rusell, Beth M. "Description and Access in Rare Books Cataloging: A Historical Survey", en Cataloging and Classification Quarterly. Vol. 35, núm. 3/4 (2003), pp. 491-523. Texto disponible en https://kb.osu.edu/ dspace/bitstream/1811/46643/4/RussellB_CatalogingClassificationQuarterly_2003_p491-523_AG.pdf [Consulta: enero de 2011]

Saavedra Vega, David. Marcas de fuego de la Biblioteca Conventual del Museo Regional de Querétaro del Instituto Nacional de Antropología e Historia, 1994.

Sala, Rafael. Marcas de fuego de las antiguas bibliotecas mexicanas. México: Secretaría de Relaciones Exteriores, 1925.

Saladino García, Alberto. Libros científicos del siglo XVIII Latinoamericano. México: Universidad Autónoma del Estado de México, 1998.

Salazar Ibargüen, Columba. Una biblioteca virreinal de Puebla, siglo XVIII: Fondo Andrés de Arze y Miranda. Puebla: BUAP. Instituto de Ciencias Sociales y Humanidades, 2001.

Salomón Salazar, Mercedes Isabel y Andrew Green. "Las marcas de fuego: propuesta de una metodología para su identificación", en Leer en tiempos de la Colonia: imprenta, bibliotecas y lectores en la Nueva España, comp. Idalia García y Pedro Rueda, México: CUIB, 2010, pp. 341-367. 
Salony, Mary F. "The History of Bibliographic Instruction: Changing Trends for Books to the Electronic Books". Library Instructions Revisited. 1995. Texto disponible en http://libsnap.dom.edu/Reserves/Removed\%20Reserves/LIS764Cason/LIS764Cason_History. pdf [Consulta: noviembre de 2007]

Sánchez Bueno De Bonfil, María Cristina. El papel del papel en la Nueva España. México: INAH, 1993.

Sánchez Mariana, Manuel. "Las clasificaciones bibliográficas: su estado a principios del siglo XVIII", en El libro antiguo español III: el libro en palacio y otros estudios bibliográficos, al cuidado de María Luisa López Vidriero y Pedro M. Cátedra. Salamanca: Ediciones Universidad: Patrimonio Nacional: Sociedad Española de Historia del Libro, 1996, pp. 279-284.

Sánchez Fernández, Juan Manuel. Bibliografía zaragozana del siglo XV. Madrid: Imprenta Alemana, 1908 (Edición facsímil Herstellung: Prof. GMBH \& Co.).

Santiago, Ramón. "Imprenta y ortografía en torno a Guillermo Foquel y Alonso Victor de Paredes", en La memoria de los libros: estudios sobre la bistoria del escrito y de la lectura en Europa y América, bajo la dirección de Pedro M. Cátedra \& María Luisa López-Vidriero. Salamanca: Instituto de Historia del Libro y de la Lectura, 2004. T.1, pp. 539-561.

Santos, María Carmona de los. Manual de sigilografía. Madrid: Ministerio de Cultura. Subdirección General de Archivos Estatales, 1996.

Santos Quer, Maria Ángeles. La ilustración en los libros de la imprenta de Alcalá en el siglo XVI: introducción y catálogo. Madrid: Fundación Universitaria Española, 2003.

Schneider, Georg. Theory and history of bibliography, translated by R.R. Shaw. New York: Columbia University, 1934 (University Microfilms International 1987). 
Segura Martínez, Salvia y Alejandro Flores Barrón. Catálogo de las bibliotecas de San Agustín de Puebla y del Colegio de San Pablo de México. México: INAH, 1988.

Shaw, D.J. "A Sampling Theory for Bibliographical Research", en The Library. T. 27, núm. 4 (1972). p. 310-319.

Sigüenza y Vera, Juan Joseph. Mecanismo del arte de la imprenta para facilidad de los operarios que le exerzan. Madrid: Imprenta de la Compañía, 1811 (Edición facsímil, Madrid: Tipus Almarabu, 1992).

Simón Diáz José. La bibliografía: conceptos y aplicaciones. Barcelona: Planeta, 1971.

. "El libro en Madrid durante el Siglo de Oro", en El mundo del libro antiguo, dirigido por Francisco Asín Remírez de Esparza. Madrid: Editorial Complutense, 1996, pp. 43-54.

. El libro español antiguo: análisis de su estructura. Madrid: Ollero \& Ramos, 2000.

Smith, Margaret S. The title page: its early development 1460-1510. London: The British Library: Oak Knoll Press, 2000.

Soberón Mora, Arturo. "Felipe de Zuñiga y Ontiveros, un impresor ilustrado en la Nueva España", en Tempus. Revista de Historia de la Facultad de Filosofía y Letras UNAM. Núm. 1 (otoño de 1993), pp. 51-75.

Soler I Fabregat, Ramón. El libro de arte en España durante la edad moderna. Gijón: Trea, 2000.

Standard citation forms for published bibliographies and catalogs used in rare books cataloging, prepared by Peter M. Van Wingen and Belinda D. Urquiza. 2nd ed. Washington: Library of Congress, 1996. 
Steinberg, Sigfrid Henry. Five hundred years of printing, new edition revised by John Trevitt. New Castle: Oak Noll Press: The British Library, 1996.

Stoddard, Roger S. A library-keeper's bussines: essays, selected and edited by Carol Z. Rothkopf. New castle, Delaware: Oak Knoll Press, 2002.

Stokes, Roy. A bibliographical companion. Metuche, New Jersey: The Scarecrow Press, 1989.

- "Descriptive Bibliography: its definitions and function", en Papers of the Bibliographical Society of Canada. Vol. 18 (1979), pp. 19-25.

. Esdaile's Manual of Bibliography. Fifth revised edition. United States of America: The Scarecrow Press, 1981.

Stols, Alexandre A.M. Antonio de Espinosa: el segundo impresor mexicano. México: UNAM. Instituto de Investigaciones Bibliográficas, 1989.

- Pedro Ocharte: el tercer impresor mexicano. México: UNAM. Instituto de Investigaciones Bibliográficas, 1990.

Suárez De Figueroa, Cristóbal. Plaza Universal de todas las cosas... Perpiñan: Luis Roure, 1629. (BGU de Sevilla 5537 ).

Suárez Rivera, Manuel. Felipe y Mariano de Zuñiga y Ontiveros: impresores ilustrados y empresarios culturales (1761-1825). México: el autor, 2005. (Tesis Licenciatura en Historia. UNAM, Facultad de Filosofía y Letras).

Taffarelli, Jean-Louis. "Mélanges; pour une redefinition de la bibliographie, en Bulletin des Bibliothèques de France. T. 25, núm. 7 (1980), pp. 347-348.

Tagle De Cuenca, Matilde. Notas sobre historia del libro. Córdoba, Argentina: Ediciones del copista, 1997. 
Tamayo, Alberto. Archivística, diplomática y sigilografía. Madrid: Cátedra, 1996.

Tanselle, G.T. "The concept of format", en Studies in bibliography, Vol. 53 (2003), pp. 67-116. Texto disponible en http://etext.virginia.edu/bsuva/sb/ [Consulta: mayo de 2006]

- "The concept of ideal copy", en Studies in bibliography, Vol. 33 (1980), pp. 18-53. Texto disponible en http://etext.virginia. edu/bsuva/sb/ [Consulta: mayo de 2006]

- "Descriptive Bibliography and Library Cataloging", en Studies in Bibliography. Vol. 30 (1977), pp. 1-56. Texto disponible en http://etext.lib.virginia.edu/bsuva/sb/ [Consulta Enero de 2005]

. "Printing history and other History", en Studies in Bibliography. Vol. 48 (1995), pp. 269-289. Texto disponible en http:// etext.virginia.edu/bsuva/sb/ [Consulta: mayo de 2006]

. "Title-Page Transcription and Signature Collation Reconsidered", en Studies in Bibliography. Vol. 38 (1985), pp. 45-81 Texto disponible en http://etext.lib.virginia.edu/bsuva/sb/ [Consulta: Enero de 2005]

Teixidor, Felipe. Ex libris y bibliotecas de México. México: Secretaría de Relaciones Exteriores, 1931 (Monografías Bibliográficas mexicanas; 20).

Terán Elizondo, María Isabel. Los recursos de la persuasión: la portentosa vida de la Muerte de fray Joaquín Bolaños. Michoacán: El Colegio de Michoacán: Universidad Autónoma de Zacatecas, 1997.

Tesoros bibliográficos mexicanos. México: primera imprenta de América, investigación, selección de material y textos Margarita Bosque Lastra; catalogación bibliográfica Aurora Serrano Cruz. México: UNAM, 1995. 
Torne, Emilio. "La mirada del tipógrafo: el libro entendido como una máquina de lectura", en Litterae. Cuadernos sobre cultura escrita. Núm. 1 (2001), pp. 145-177.

- Tesauro de la cultura escrita en la Edad Moderna. Madrid: Calambur, 2005 (Biblioteca Litterae; 9).

Torner Morales, Lucía. "El estudio material del libro antiguo: El análisis de guardas, cantos y planos decorados", en XVIII Encuentro de Investigadores. Del pensamiento novobispano. Noviembre de 2005.

Identificación de pigmentos en cantos, guardas y planos decorados: 12 libros novohispanos y mexicanos de los siglos XVIII Y XIX. México: La autora, 2005. (Tesis de Licenciatura en Restauración de Bienes Muebles. Escuela Nacional de Conservación, Restauración y Museografía "Manuel del Castillo Negrete". INAH).

Torre Viilar, Ernesto de la. "Autógrafos desconocidos de Sor Juana Inés de la Cruz en un libro más de su biblioteca", en Les cultures ibériques en devenir: essais publiés en hommage à la mémoire de Marcel Bataillon, 1895-1977. Paris: Fondation Singer-Pollinac, 1977, pp. 503-512.

- "El barroco en los libros mexicanos", en Boletín del Instituto de Investigaciones Bibliográficas, segunda época, núm. 5 (1991), pp. 9-30.

- Breve historia del libro en México. México: UNAM. Dirección General de Publicaciones y Fomento Editorial, 1999.

. Ex libris y marcas de fuego. $2^{\mathrm{a}} \mathrm{ed}$. México: UnAM, 2000.

- "Los ex libris y las marcas de fuego", en Nueva Gaceta Bibliográfica, Año 3, vol. 11, núm. 5 (julio-septiembre 2000), pp. 1516. 
—. "Juan José de Eguiara y Eguren, hombre de Iglesia y gran bibliógrafo americano", en Hispania Sacra. Vol. 41 (1989), pp. 491527.

—. "El trabajo bibliográfico en México", en Nueva Gaceta Bibliográfica. Vol. 6, núm. 23-24 (julio-diciembre 2003), pp. 10-16.

Tovar De Teresa, Guillermo. Bibliografía novobispana de arte. Primera parte: impresos mexicanos relativos al arte de los siglos XVI y XVIII / prólogo de José Pascual Buxó. México: FCE, 1988.

- Bibliografía novohispana de arte. Segunda parte: impresos mexicanos relativos al arte del siglo XVIII. México: FCE, 1988.

Type evidence: a thesaurus for use in Rare Books and Special Collections Cataloging, prepared by Bibliographic Standards Committee of the Rare Books and Manuscripts Section. Chicago: Association of College and Research Libraries, 1990

Twyman, Michael. The British Library Guide to Printing: History and Techniques. London: The British Library, 1998.

Urso, Tomaso. Toponomastica bibliográfica: guida ai nomi dei luoghi di stampa fino al 1799. Firenze: Leo S. Olschki Editore, 1990.

Valton, Emilio. "Algunas particularidades tipográficas de los impresos mexicanos del siglo XVI", en IV Centenario de la Imprenta en México: conferencias sustentadas en su conmemoración. México: Asociación de Libreros de México, 1939, pp. 239-277.

Impresos mexicanos del siglo XVI (incunables americanos) en la Biblioteca Nacional de México, el Museo Nacional y el Archivo General de la Nación. México: UNAM, 1935.

Vargas Alquicira, Silvia. Catálogo de obras latinas impresas en México durante el siglo XVI. México: UNAM. Instituto de Investigaciones Filológicas, 1986. 
Varia bibliographica: homenaje a José Simón Díaz. Kassel: Reichenberger, 1988.

Vergara Peris, José. Conservación y restauración de material cultural en archivos y bibliotecas. Valencia: Biblioteca Valenciana, 2002.

Vilagran, Martin Gelaberto. La palabra del predicador. Contrarreforma y superstición en Cataluña (siglos XVII y XVIII). Barcelona: El autor, 2003 (Tesis de doctorado en Historia moderna y Contemporánea. Universidad de Barcelona). Texto disponible en http:// www.tesisenxarxa.net/TESIS_UAB/AVAILABLE/TDX-0621104-164655// mgv1de1.pdf [Consulta: Noviembre de 2007]

Villagrán Reyes, Manuel. Marcas de fuego de las librerías conventuales en la Biblioteca "Elías Amador" de Zacatecas. Zacatecas: Museo Pedro Coronel, 1992.

Villarroya, Joseph. Disertación sobre el origen del nobilísimo arte tipográfico, y su introducción y uso en la ciudad de Valencia de los edetanos... En Valencia: y Oficina de D. Benito Monfort, 1786 (Edición facsímile: Madrid: Tipus Almarabu, 1992)

Wagner, Enrique W. Nueva bibliografía mexicana del siglo XVI: suplemento a las bibliografías de Don Joaquín García Icazbalceta, Don José Toribio Medina y Don Nicolás León. México: Editorial Polis, 1940.

Weruaga Prieto, Ángel. Libros y lectura en Salamanca: del Barroco a la Ilustración, 1650-1725. Salamanca: Junta de Castilla y León, Conserjería de Cultura y Turismo, 1993.

Whittaker, Martha Ellen. Jesuit Printing in Bourbon Mexico City. The Press of Colegio de San Ildefonso, 1748-1767. (Dissertation for degree Doctor of Philosophy in Library and Information Studies. University of California. Berkeley)

Yhmoff Cabrera, Jesús. Catálogo de Incunables de la Biblioteca Nacional de México. $2^{\text {a }}$ ed. México: UnAM, 1987. 
Catalogo de los impresos europeos del siglo XVI que custodia la Biblioteca Nacional de México. México: UNAM, 1996. 3 tomos.

L Los impresos mexicanos del siglo XVI en la Biblioteca Nacional de México. México: UnAM, 1990.

Zappella, Giuseppina. Il libro antico a stampa: struttura, tecniche, tipologie, evoluzione. Parte prima. Milano: Editrice Bibliografica, 2001 (I Manuali della Biblioteca; 3/1).

- Il ritrato nel libro italiano del Cinquecento. Milano: Editrice Bibliográfica, 1988.

Zulaica Gárate, Román. Los franciscanos y la imprenta en México en el siglo XVI. México: UNAM. Instituto de Investigaciones Bibliográficas, 1991. (Edición facsimilar de la original 1939).

Zboray, Ronald J. y Mary Saracino Zboray. A Handbook for the Study of Book History in the United States. Washington: Library of Congress. Center of the Book, 2000.

Ziga, Francisco y Susano Espinosa. Adiciones a la imprenta en México de José Toribio Medina: Puebla, Oaxaca, Guadalajara, Veracruz y de la Insurgencia, 1706-1821. México: UNAM. Instituto de Investigaciones Bibliográficas, 1997. 


\title{
10. Figuras e ilustraciones ${ }^{1}$
}

\author{
Capítulo 4
}

Modelo1

p. 83 (Millares)

Eguiara Y Eguren, Juan José de. Prólogos a la Biblioteca Mexicana, versión española anotada, con un estudio biográfico y la bibliografía del autor por Agustín Millares Carlo. México: FCE, 1944, p. 245.

Modelo2

p. 86 (Guadalajara1)

Duclas, Robert. Catálogo descriptivo de los libros impresos en la ciudad de Salamanca en el siglo XVI existentes en la Biblioteca Pública de Guadalajara. México, UNAM: 1961, p. 61.

Modelo3

p. 88 (quinones1)

Quiñónez Melgoza, José. Catálogo de obras de autores latinos en servicio en la Biblioteca Nacional de México. México: UNAM, 1983, p. 19.

1 Las imágenes de libros antiguos, se corresponden con ejemplares conservados en la Biblioteca Eusebio Francisco Kino de la Compañía de Jesús en México, por tal razón sólo se indicará entre paréntesis el número de localización de los materiales en este repositorio. Las imágenes se reproducen con el permiso de la institución. 
Modelo4

p. 91 (Vargas2)

Vargas Alquicira, Silvia. Catálogo de obras latinas impresas en México durante el siglo XVI. México: UNAM. Instituto de Investigaciones Filológicas, 1986, p. 81.

Modelo5

p. 92 (Grabados1)

Báez Macías, Eduardo, Jorge Guerra Ruiz y Judith Puente León. Libros y grabados en el Fondo de Origen de la Biblioteca Nacional. México: UNAM. IIE, 1988, p. 31.

Modelo6

p. 95 (Segura1)

Segura Martínez, Salvia y Alejandro Flores Barrón. Catálogo de las bibliotecas de San Agustín de Puebla y del Colegio de San Pablo de México. México: INAH, 1988. p. 19.

Modelo7

p. 97 (Tovar1)

Tovar De Teresa, Guillermo. Bibliografía novohispana de arte. Primera parte: impresos mexicanos relativos al arte de los siglos XVI y XVIII, prólogo de José Pascual Buxó. México: FCE, 1988, p. 171.

Modelo8

p. 102 (Poblanos2)

p. 102 (Poblanos3)

Cien impresos coloniales poblanos. México: Instituto Mora, 1991, pp. 99-100.

Modelo9

p. 104 (CatedralinaH)

Martínez, María de los Ángeles. Catálogo de la Biblioteca de la catedral de la Ciudad de México. México: UNAM: INAH, 1991, p.19. 
Modelo10

p. 106 (Portentosa2)

p. 107 (Portentosa3)

p. 108 (Portentosa4)

Bolaños, Joaquín Fr. La portentosa vida de la muerte, Emperatriz de los Sepulcros, Vengadora de los Agravios del Altísimo y muy Señora de la Humana Naturaleza (México, Joseph de Jáuregui, 1792), edición crítica, introducción y notas de Blanca López de Mariscal. México: Colmex, 1992, pp. 61-64.

\section{Modelo11}

p. 111 (Congreso1)

Catálogo de documentos antiguos: selección de impresos del siglo XVI al XIX. México: Cámara de Diputados. Comité de Biblioteca e Informática, 1994. Vol. 1, p. 26.

Modelo12

p. 112 (Amparo2)

Imprentas, ediciones y grabados de México Barroco. México: Museo Amparo, 1995, p. 140.

Modelo13

p. 115 (Impresosmx)

Impresos mexicanos del siglo XVI: los incunables. México: Centro de Estudios de Historia de México CONDUMEX, 1995, p. 44.

\section{Modelo14}

p. 117 (Tesoros1)

Tesoros bibliográficos mexicanos. México: primera imprenta de América, investigación, selección de material y textos Margarita Bosque Lastra; catalogación bibliográfica Aurora Serrano Cruz. México: UNAM, 1995, p. 102.

\section{Modelo15}

p. 123 (Joyas1)

Las joyas bibliográficas de la Universidad Autónoma Benito Juárez de Oaxaca: la Biblioteca Francisco de Burgoa, María Isabel Grañén Porrúa... [et. al.]. México: Fomento Cultural Banamex, 1996, p. 27. 
Modelo16

p. 129 (YhmoffEU1)

Yhmoff Cabrera, Jesús. Catálogo de los impresos europeos del siglo XVI que custodia la Biblioteca Nacional. México: UNAM, 1996, t. 1, p. 70.

Modelo 17

p. 131 (BibliotoBIP)

Gómez Álvarez, Cristina y Francisco Téllez Guerrero. Una biblioteca obispal Antonio Bergosa Jordán 1802. Puebla: BUAP. Instituto de Ciencias y Sociales y Humanidades, 1997, p. 59.

Modelo 18

p. 131 (ObispcampilLo)

- - -. Un hombre de Estado y sus libros: el Obispo Campillo, 1740-1813. Puebla. BUAP. Instituto de Ciencias y Sociales y Humanidades, 1997, p. 92.

Modelo19

p. 133 (AdicionesZiga1)

Ziga, Francisco y Susano Espinosa. Adiciones a la Imprenta en México de José Toribio Medina, Puebla, Oaxaca, Guadalajara, Veracruz y de la Insurgencia, 1706-1801. México: UNAM. Instituto de Investigaciones Bibliográficas, 1997, p. 3.

Modelo20

p. 138 (Fconv1)

Carreño Velázquez, Elvia. Fondo Conventual de la Biblioteca Nacional de Antropología e Historia: Catálogo de la Biblioteca del Convento Grande de San Francisco de la Ciudad de México, V. México: INAH, 2000, p. 13.

\section{Modelo21}

p. 141 (UDLA)

Morales, Elvia. "De nuestra biblioteca", en Todo es Historia: boletín de estudios históricos (julio-diciembre 2000). Puebla: UDLAP, p. 59 . 


\section{Modelo22}

p. 143 (Columba1)

Salazar Ibargüen, Columba. Una biblioteca virreinal de Puebla, siglo XVIII: Fondo Andrés de Arze y Miranda. Puebla: BUAP. Instituto de Ciencias Sociales y Humanidades, 2001, p. 56.

\section{Modelo23}

p. 145 (Lafragua2001)

Tecocoatzi Hernández, María Estela Graciela. Impresos de la colección Lafragua 1680-1873 (Folletería) legada al Colegio del Estado de Puebla, boy BUAP. México: la autora, 2001 (Tesis de Licenciatura en Historia. Facultad de Filosofía y Letras. UNAM), p. 106.

Modelo24

p. 147 (Enciso1)

Enciso Contreras, José. Antiguos libros jurídicos en dos bibliotecas de Zacatecas. Zacatecas: Tribunal Superior de Justicia del Estado de Zacatecas, 2003, p. 156.

Modelo25

p. 150 (CidCarmona1)

Cid Carmona, Víctor Julián. Repertorio de impresos mexicanos en la Biblioteca Nacional de España, siglos XVI-XVII. México: COLMEX, 2004, p. 37.

Modelo 26

p. 152 (Tlaxcala1)

Catálogo de libros antiguos Archivo Histórico del Estado de Tlaxcala, Tlaxcala, coordinadora Elvia Carreño Velázquez. México: Apoyo al Desarrollo de Archivos y Bibliotecas de México, A.C., 2004 , p. 37.

Modelo 27

p. 157 (CidCarmona2006)

Cid Carmona, Víctor Julián. Antonio Ricardo: impresor de dos ciudades, México y la Ciudad de los Reyes. México: el autor, 2006. (Tesis de Maestría en Bibliotecología y Estudios de la Información. Facultad de Filosofía y Letras. UNAM), pp. 93-94. 
Modelo28

p. 160 (Sermones2006)

Ruiz Rivera, Leticia. Catálogo de sermones de la Biblioteca Eusebio F. Kino de la provincia mexicana de la Compañía de Jesús. Madrid: Fundación MAPFRE, 2006, p. 35.

Modelo29

p. 162 (CidCarmona2007)

Cid Carmona, Víctor... [et. al.] "Compendio de impresos mexicanos que se conservan en la Biblioteca Daniel Cosío Villegas, siglo XVIII", en Boletín Editorial del Colegio de México. Núm. 126 (marzo-abril 2007), pp. 12 y 13.

Modelo30

p. 164 (Vizcaínas)

Fondos bibliográficos del Archivo Histórico "José María Basagoiti" del Colegio de San Ignacio de Loyola, Vizcaínas. México: Apoyo al Desarrollo de Archivos y Bibliotecas de México, A.C., 2007, p. 45.

Modelo31

p. 166 (Indígenas)

Fondos del Tesoro. Colección de lenguas indígenas Biblioteca Pública del Estado de Jalisco "Juan José Arriola", coord. Marina Mantilla Trolle y Nora Jiménez Hernández. Guadalajara: Universidad de Guadalajara: El Colegio de Michoacán, 2007, p. 256.

\section{Capítulo 5}

p. 179 Imagen 01: tipo

Versión gráfica de Mario Ocampo de la letra de imprenta incluida en José Martínez de Sousa. Diccionario de bibliología y ciencias afines. $3^{\text {a }}$ ed. Gijón: Trea, 2004, p. 553. 
p. 182 Imagen02: TiposEnciclopedia

L' Encyclopédie. [29], Imprimerie, reliure: Recueil de planches sur les sciences, les artes libéraux, et les artes mechaniques, avec leur explications. Paris: Inter-livres, 1989, plate I. Disponible en http://gallica.bnf.fr

Imagen 03 y 04 :

p. 183 Pliego impreso1

p. 183 Pliego impreso2

Dibujo a mano de Idalia García

p. 184 Imagen 05: cuadernillo

Dibujo a mano de Idalia García

p. 188 Imagen 06: prensa

Versión gráfica de Mario Ocampo. Joseph Moxon. Mechanical Exercises or Handy Works. Applied to the e Art of Printing. The second volume... London: Printed for Joseph Moxon, 1683. Plate 3 .

p. 190 Imagen 07: secado

Versión gráfica de Mario Ocampo. Joseph Moxon. Mechanical Exercises or Handy Works. Applied to the e Art of Printing. The second volume... London: Printed for Joseph Moxon, 1683. Plate 32.

p. 205 Imagen 08: Edicion1724

Velasco, Alonso Alberto de.

Exaltación de la divina misericordia en la milagrosa renovación de la soberana imagen de Christo señor nuestro crucificado... México: por los Herederos de Miguel de Ribera, 1724 (16257).

p. 206 Imagen 09: Edicion1790

Velasco, Alonso Alberto de.

Exaltación de la divina misericordia en la milagrosa renovación de la soberana imagen de Christo señor nuestro crucificado... Reimpreso en México: en la oficina de los Herederos del Lic. D. Joseph de Jáuregui, 1790 (016155). 
Secretos del estante: elementos para la descripción bibliográfica...

\section{Capítulo 6}

p. 221 Imagen LicenciaP

Licencia de publicar y vender en $h .2 r$.

Nieremberg, Juan Eusebio de (S.I.)

Practica del catecismo romano y doctrina cristiana... en Madrid: en la Imprenta Real de la Gaceta, 1763 (021975).

p. 223 Imagen Romanos

Impresión de fecha

Natalis, Alexandri (O.P.)

Historia Ecclesiastica veteris novique testamenti... tomus primus. Parisiis: apud Silvanum de Grasortis, 1740 (019892).

p. 225 Imagen Tacos

Tacos xilográficos en h. $14 \mathrm{r}$.

Segura, Jacinto

Norte critico con las reglas mas ciertas para la discreción en la bistoria... en Valencia: en la imprenta de Joseph García, 1733 (023895).

p. 226 Imagen EscudoA

Escudo de Arzobispo en h.1r.

Blosio Ludovico

Obras de Ludovico Blosio... traducidas de latín en romance... Madrid: en la Imprenta de Juan de la Cuesta, 1608. (024082).

p. 228 Imagen Florón

Florón de final de Indice en h. 12v.

Segura, Nicolas de (S.I.)

Exhortaciones domesticas o la perfeccion de su Instituto dichas a los... padres... de la Compañía de Jesús. En Madrid: en la Imprenta de Joseph Gonçalez, [s.a.] (016452). 
p. 233 Imagen PortadaS

Portada simple

Rodriguez, Joseph Manuel (O.F.M.)

Vida prodigiosa del V. Siervo de Dios Fray Sebastian de Aparicio... En Mexico: En la Imprenta de D. Phelipe de Zuñiga y Ontiveros, 1769 (16190).

p. 234 Imagen PortadaDT

Portada a dos tintas

Oviedo, Juan Antonio de (S.I.)

El devoto de la Santissima Trinidad, instruido en muchos motivos eficaces para amarla... Con licencia de los Superiores en Mexico: por Joseph Bernardo de Hogal, 1736 (17854)

p. 235 Imagen PortadaO

Portada orlada

Jesús, María de (Sor).

Mystica Ciudad de Dios... Historia divina y vida de la Virgen, Madre de Dios Reyna y señora nuestra... tercera parte. Con privilegio en Madrid: En la Imprenta de la Causa de la V. Madre, 1744 (020928).

p. 236 Imagen PortadaOT2

Portada con orla tipográfica

Centeno de Vera, Gerónimo.

Sermón Panegyrico que en el plausible anual novenario, que en glorias de la Concepcion Inmaculada de Maria Santissima celebra la Noble Ciudad de Teztcoco... En Mexico: con licencia de los Superiores, por la Viuda de Miguel de Ribera, [1712 $\left.{ }^{2}\right]$ (19158).

p. 237 Imagen PortadaEN

Portada enmarcada

Palma, Luis de la (S.I.)

Camino espiritual de la manera que lo enseña el bienaventvrado Padre San Ignacio... Parte Primera... En Alcala: en casa de Iuan de Orduña, 1626. (024533).

2 Fecha tomada de los preliminares. 
Secretos del estante: elementos para la descripción bibliográfica...

p. 238 Imagen PortadaGR

Portada grabada

Atlas Moderne ou collection de cartes sur toules des partier $d u$ globe terrestre. Paris: chez Laurè Graveur et Jean Thomas, [1762] (017009).

p. 240 Imagen PortadaFR

Portada arquitectónica ${ }^{3}$

Puente, Luis de la (S.I.)

Vida maravillosa de la Veneravle Virgen Doña Marina de Escobar, natural de Valladolid... Madrid: Francisco Nieto, 1665 (16283).

p. 241 Imagen MarcaTIPO

Marca tipográfica en portada

Valboa Magraue, Ioanne de.

Lectiones Salmanticenses... Salmanticae: Ex Tipographia Antoniae Ramírez, 1629 (017860).

p. 242 Imagen MarcaTIPO2

Marca tipográfica en portada

Cobarrubias Orozco, Sebastian.

Parte segunda del tesoro de la lengva castellana o española... Con Privilegio en Madrid: Por Melchor Sánchez, 1673 (016868).

p. 243 Imagen MarcaTIPO3

Marca de impresor al finalizar el Index en $\mathrm{h}$ 5r. posterior Lipsi, Iusti.

Diva Virgo Hallensis... Antverpiae: Ex Officina Plantiniana, Apud Ioannem Moretum, 1605 (017128).

p. 246 Imagen Genaro

Formato dibujado a mano por Genaro Lamarca Langa.

3 "Marcus Orozco delineavit" 
p. 251 Imagen Calderón

Signatura en h.4r.

Santo Thomas, Francisco de

Medula Mystica sacada de los divinas letras de los santos padres... Segunda impresión. En Madrid: en la Imprenta de Manuel Ruiz de Murga, 1702 (022000).

p. 255 Imagen Paginación

Inicio de paginación de la obra

Señeri, Pablo (S.I.)

Mana del alma, o exercicio fácil y provechoso... En Madrid: por los herederos de Antonio Roman, 1701 (024527).

p. 258 Imagen Caja

Camberos de Yegros, Fernando.

El béroe seráfico San Pedro de Alcantara glorioso timbre de la familia descalza de el Gran Patriarca San Francisco de Assis... Impresso en Salamanca: en la Imprenta de Francisco García Onorato y San Miguel, 1723 (24502).

p. 260 Imagen Reclamo

Reclamo en p. 472

Fernández, Alonso (O.S.A.)

Historia eclesiastica de nvestros tiempos, que es compendio de los excelentes frvtos que en ellos el Estado Eclesiastico y sagradas Religiones ban becho y bazen, en la conversión de idolatras y reducción de hereges... Con privilegio en Toledo: por la Viuda de Pedro Rodríguez, 1611 (16575).

p. 262 Imagen GrabadocAL

Grabado calcográfico en p. 23

Palafox y Mendoza, Juan de

Obras del Ilustrísimo y venerable... excelencias de San Pedro, príncipe de los Apóstoles... En Madrid: en la imprenta de Don Gabriel Ramírez, 1762 (016850). 
Secretos del estante: elementos para la descripción bibliográfica...

p. 264 Imagen GrabadoPOR

Grabado de portada

Nolarci, Virgilio.

Vita del patriarca Sant Ignatio di Loiola... quarta editione...

Venetia: Presto Combi e la Noù, 1687 (016315).

p. 265 Imagen RetratoGROviedo127

Retrato grabado del padre Juan Antonio de Oviedo en h. 7r.

Vida ejemplar y virtudes heroicas del venerable Padre Juan Antonio de Oviedo de la Compañía de Jesús... Con licencia en México: en la Imprenta del Real, y mas Antiguo Colegio de San Ildefonso, 1760 (16187).

p. 267 Imagen Capitular

Capitular en h. 2r. 37L x 33A

Cruz, Felipe de la (OSBas).

Tesoro de la Iglesia enque se trata de indulgencias: iubileos: purgatorio: bula de difuntos, vltimas voluntades, cuarta funeral... Con Privilegio en Madrid: Por Diego Flamenco, 1631 (021607).

p. 267 Imagen OrlatiPO

Orla tipográfica en folio $1 r^{4}$

Gómez de la Parra, Joseph

Fundación y primero siglo del muy religioso convento de Sr. S. Joseph de Religiosos Carmelitas Descalzos de la Ciudad de la Puebla de los Ángeles... En la Puebla de los Ángeles: por la viuda de Miguel de Ortega, 1732 (017995).

p. 268 Imagen ViñetaCAB

Viñeta de cabecera en h. 2r.

Escobar a Corra, Joanne

Tractus bipartitus de puritate et nobilitate probanda... Lugduni: sumptibus laurentii Arnaud, Petri Barde Joannis, \& Petri Arnaud, 1678 (016323).

4 En esta obra indica foliatura pero se trata de paginación. 
p. 269 Imagen ViñetaPIE

Viñeta de pie al final de la obra

Eguiara y Eguren, Juan Joseph de

El santo mas semejante... panegírico del glorioso principe $S$. Miguel Arcángel... En México: en la Imprenta Real del Superior Gobierno, 1751 (018629).

p. 270 Imagen GrabadoINT

Grabado calcográfico interior T.II. p. 202 (entre p. 202 y 203) $^{5}$

Solis, Antonio de.

Historia de la conquista de Mexico, población y progresos... Tomo II. En Madrid: En la Imprenta de Antonio de Sancha, 1784 (016596).

p. 272 Imagen LicenciasuP

Licencia del Superior Gobierno h.15v.

Rodríguez, Joseph Manuel

El protector del estado religioso... en la fiesta que anualmente celebra la Tercera Orden de N. P: S. Francisco... a S. Luis Rey de Francia... [México]: Imprenta del Real y más antiguo Colegio de San Ildefonso de México, 1766 (018075).

p. 274 Imagen Protesta

Protesta de fe en 19v.

Mora, Juan Antonio de (S.I.)

Vida y virtudes heroicas de el exemplar y fervoroso hermano Juan Nicolas... En México: por Joseph Bernardo de Hogal, 1726 (016220).

p. 277 Imagen LicenciaProv

Licencia del provincial en h.6r.

Escalante, Thomas de

Breve noticia de la vida exemplar y dichosa muerte del venerable Padre Bartholome Castaño... en México: por Juan de Rivera, 1679 (016192).

5 "Moreno Tejada sc.t" 
Secretos del estante: elementos para la descripción bibliográfica...

p. 279 Imagen Aprobación

Aprobación en h.13r.

Bermúdez de Castro, Diego Antonio

Parentacion funeral... notorias letras, justos meritos y singulares virtudes de... Don Carlos Bermúdez de Castro... En la Puebla: por la Viuda de Miguel de Ortega, 1711 (019067 encuadernado en 016152).

p. 281 Imagen CensuraMemorias

Censura p. 382-383.

Vidal, Joseph (S.I.)

Memorias tiernas, dispertador afectuoso y devociones practicas con los Dolores de la Santissima Virgen... En Amberez: por Henrico y Cornelio Verdussen, 1695 (21651).

p. 288 ImagenColofón

Cifuentes, Luis (O.P.)

Oracion engrandecida con la asistencia de los Ex. ${ }^{\text {mos }}$ Señores Dvques de Albvrqverqve, Vir-Reyes desta Nveva España: en el SegVndo dia de la dedicación del sumptuoso y magnifico templo, que el Capitan Simon de Haro consagro a la Purissima Concepcion de Nuestra Señora... Con licencia en México: en la Imprenta de la Viuda de Bernardo Calderón, 1656 (18456 encuadernado en 16092).

p. 289 Imagen Regestrum

Regestrum

Morales, Ambrosio de

La coronica general de España... en Alcalá de Henares: por Iuan Iñiguez de Lequerica, 1574 (016697).

p. 293 Imagen Tejuelo

Tejuelo en guarda coloreada y en h.1v.

Dechales Cambieriensis, Milliet Francisci (S.I.)

R. P. Francisci Millier Dechales Cambieriensis e Societatu Jesu Cursus seu mundus mathematicus Tomus quartus... Lugduni: apud Anissonios, Joan Posuel \& Claud. Rigaud, 1690 (017569). 
p. 295 Imagen Siguenza

Firma de Siguenza en portada

Fernandez, Alonso (O.P.)

Historia eclesiastica de nvestros tiempos, que es compendio de los excelentes frvtos qve en ellos el estado... Con Privilegio en Toledo: Por la Viuda de Pedro Rodriguez, 1611 (016575).

p. 297 Imagen MarcafuE

Marca de Fuego desconocida

Sylveira, Joao da (O.C.)

Commentariorum in Apocalypsim B. Ioannis Apostoli Tomus Primus... Lugduni: Sumptibus Anissoniorum, Joannis Possuel \& Claudij Rigaud, 1600 (24296, t.2).

p. 298 Imagen MarcaTiN

Marca de tinta en canto

Sanchez Cordvbensis, Thomae (S.I.)

Consilia sev opuscula moralia... opus posthumum... Lugduni: sumptibus Iacobi Prost, 1636 (023810).

p. 301 Imagen ExLibirsS

Ex libris de Sancha en portada Sierra, Joseph Martín de la (S.I.)

Mapa de arcanos y verdades de Ntra. Católica Religión... Tomo segundo... En Madrid: En la Imprenta de Gabriel del Barrio, 1721 (20286).

p. 303 Imagen ExLibrisA

Ex libris heráldico en tapa anterior de Antonio Álvarez de Abreu Montemayor y Córdoba de Cuenca, Juan Francisco de Svmarios de las cedvlas, ordenes, y provisiones reales... Con licencia en México: En la Imprenta de la Viuda de Bernardo Calderón, 1678 (016493).

p. 304 Imagen ExDono

Ex dono de Andrés de Arce y Miranda en h.2v.

Las memorias de Felipe de Commes señor de Argenton... tr. Juan Vitrion. Amberes: En la Imprenta de Juan Mevrsio, 1643 (016320). 
p. 306 Imagen SelloMH

Sello de matriz hueca

Saabedra Faxardo, Diego.

Idea de un principe politico christiano... Tomo II. Con licencia del Real Consejo: En Valencia: En la Imprenta de Salvador Fauli, 1786 (022032).

p. 307 Imagen SelloTIN

Sello de tinta en portada

Possevini, Antonii (S.I.)

Ivdicium de nuae militis Galli Bodini, Philippi Marnaci, \& Nicolau Machiauelli... Lugduni: Apud Ioannem Baptistam Bvysso, 1593 (021665).

p. 309 Imagen AnotaciónMSP

Anotación manuscrita de propiedad institucional en guarda anterior Santo Thomas, Francisco de.

Medula mystica sacada de los divinas letras de los Santos Padres... Segunda impresión. En Madrid: en la Imprenta de Manuel Ruiz de Murga, 1702 (022000).

p. 310 Imagen AnotaciónMSL

Anotación manuscrita de lectura en guarda anterior Florez, Henrique (O.S.A.).

Clave historial, con que se abre la puerta a la bistoria eclesial y politica... Con Privilegio en Madrid: por Antonio Marin, 1749 (020361).

p. 311 Imagen AnotacionmSE

Revisión del Santo Oficio en h.1v.

Jesús, María de (Sor)

Mystica ciudad de Dios milagro de su omnipotencia, y abismo de la gracia, historia divina y vida de la Virgen Madre de Dios... Tercera parte... Lisboa con las licencias necessarias: En la Emprenta de Miguel Manescal, 1684 (023840). 
p. 314 Imagen Encuader

Encuadernación holandesa común

Serpi Calaritano, Dimas (O.F.M.)

Tratado de pvurgatorio contra Lvthero y otros hereges... Con licencia y privilegios en Barcelona: Ebn la Emprenta de Jayme Cetidrar, 1604 (

p. 316 Imagen EncBroMetal

Encuadernación con broches en Biblioteca Kino

p. 320 Imagen Conserva

Estado de conservación 6

Genovesi y Tomay, Joseph María Ignacio (S.I.)

La soledad christiana que en la luz del cielo se consideran las eternas verdades... Tomo primero... Puebla de los Angeles: Reimpressa en la Imprenta de Pedro de la Roca, 1791 (23578).

p. 324 Imagen Composicion

Composición p. 23

Balcarcel y Formento, Domingo y Feliz Venancio Malo.

Lagrymas de la paz, vertidas en la exequias del Señor Don Fernando de Borbon... Con las licencias necessarias en México: en la Imprenta del Real y más Antiguo Colegio de San Ildelfonso, 1762 (16157).

p. 326 Imagen VolFacticio

Anotaciones de contenido en guarda anterior de volumen facticio

Harizon, Antonio de (O.F.M.). Vozes que bizieron eco en la religiosa pyra que en las honras del V.P. Fray Antonio Margil de Jesús...Con licencia de los Superiores en México: Por Joseph Bernardo de Hogal, [1726] ${ }^{7}$ (16004).

6 El daño del libro se presenta principalmente en la parte posterior a la portada y hasta más de la mitad de la obra

7 Fecha tomada de la Licencia del Superior Gobierno 
Secretos del estante: elementos para la descripción bibliográfica...

\section{Capítulo 7}

p. 342 Imagen 2088

Colofón de la edición descrita

p. 355 Imagen1769

Portada de la edición descrita 
Secretos del estante: elementos para la descripción bibliográfica del libro antiguo. La edición consta de 300 ejemplares. Cuidado de la edición, Zindy Elizabeth Rodríguez Tamayo. Formación editorial, Mario Ocampo Chávez. Revisión especializada, Martha Castro. Centro Universitario de Investigaciones Bibliotecológicas. Fue impreso en papel cultural ahuesado de 90 gr. en Producciones Editoriales Nueva Visión, ubicados en Juan A. Mateos número 20, Col. Obrera, México D.F. Se terminó de imprimir en el mes de junio de 2011. 
